[p. 117]

\title{
GABRIELE PALEOTTI
}

\section{DISCORSO INTORNO ALLE IMAGINI SACRE E PROFANE}

DIVISO IN CINQUE LIBRI, DOVE SI SCUOPRONO VARII ABUSI LORO E SI DICHIARA IL VERO MODO CHE CRISTIANAMENTE SI DOVERIA OSSERVARE NEL PORLE NELLE CHIESE, NELLE CASE ET IN OGNI ALTRO LUOGO. RACCOLTO E POSTO INSIEME AD UTILE DELLE ANIME PER COMMISSIONE DI MONSIGNORE ILLUSTRISSIMO E REVERENDISSIMO CARD. PALEOTTI VESCOVO DI BOLOGNA.

Al POPOLO DELLA CiTTÀ E DIOCESE SUA. 
[p. 118]

Omnis superstitio in imaginum sacro usu tollatur; omnis turpis quaestus eliminetur, omnis denique lascivia vitetur, ita ut procaci venustate imagines nec pingantur nec ornentur.

Concil. Trid., sess. XXV (Surius, IV, p. 983).

Postremo tanta circa haec diligentia et cura ab Episcopis adhibeatur, ut nihil inordinatum, aut praepostere aut tumultuarie accommodatum, nihil prophanum, nihilque inhonestum appareat, cum domum Dei deceat sanctitudo.

Ibid. 
[p. 119]

\section{PROEMIO}

Tra molte cose utilissime e santissime decretate dal sacro Concilio Tridentino per introdurre nel mondo la vera disciplina del cristiano, anzi per restituirla all'antica sua forma e dignità, una è, nella quale hanno premuto assai i padri del Concilio, ch'è stato intorno alla materia delle imagini, nella quale due principali astuzie del Demonio e mancamenti degli uomini, se bene l'uno più grave dell'altro, oggi si scorgono. Il primo è degli eretici et iconomachi, che, togliendo affatto alle imagini la debita venerazione, hanno cercato di esterminarle da tutti i luoghi; l'altro è de' catolici, i quali, ritenendo l'uso delle imagini, hanno nondimeno in varii modi corretta e difformata la dignità loro. Onde il sacro Concilio, avendo prima dannata la perfidia et empietà degli eretici, ha cercato poi di rimediare agli abusi de' catolici, caricando con molta veemenza et ardore le conscienze de' Vescovi, accioché ciascuno nella sua diocese provegga con ogni diligenza alla religione, onestà e convenevolezza di quelle.

Perciò, ricordevole dell'ufficio e debito suo, monsignore illustrissimo e reverendissimo Cardinale Paleotti, vescovo di Bologna, considerando che nel popolo suo, Dio grazia, non è necessaria provisione alcuna intorno alla prima parte, come quello che è fondato nell'antica e sincera religione e vive lontano da ogni eretica macchia, ha giudicato esser bene far opra con alcuni rimedi di rintegrare l'altra, come molto trascorsa per la longhezza de' tempi, et assai dalla corrottela del mondo contaminata. Per che ha procurato, col mezzo e giudizio di persone eccellenti in bontà, dottrina, prudenza e pratica delle cose ecclesiastiche, che fossero messe insieme quelle cose che, per essecuzione del Concilio, più potessero servire alla gloria di Dio et utilità del popolo suo. Il che sendosi elle forzato di fare con ogni diligenza e sincerità, dopo lo avere insieme conferito e discorso lungamente il tutto, l'hanno [p. 120] ultimamente, come meglio si è potuto, ridotto e steso in iscritto, come nella presente operetta si contiene.

Nel che in vero parve, alle volte, che si scoprissero così ardue difficoltà, che più ch'altro dissuadessero il mettere mano ad impresa tanto difficile, della quale non si potesse sperare il desiderato frutto. E mostrando la ragione che, per curare una grave infermità, è necessario andare a trovare l'origine di quella, per applicarle poi i rimedi; entratosi ad investigare le cagioni di tanti abusi e così notabili difetti che tutto 'l giorno si scorgono in questa professione di formare le imagini, pareva che tra molte cause due principalmente vi si scoprissero.

L'una perché, sì come degli oratori è stato scritto che, per riuscire grandi et eccellenti, debbono essere versati in ogni facoltà e scienza, poi che di tutte le cose può occorrere loro di dover ragionare e persuadere il popolo; così pareva si potesse dire della pittura, la qual essendo, come un libro popolare, capace d'ogni materia, sia di cielo o di terra, di animali o di piante, o d'azzioni umane di qualunque sorte, richiedesse insieme che il pittore, al quale appartiene il rappresentare queste cose, fosse di ciascuna, se non compitamente erudito, almeno mediocremente instrutto o non affatto imperito; come degli architetti ancora anticamente fu lasciato scritto. Si vede nondimeno oggi per lo più avvenir il contrario ne' professori di quest'arte; poiché, riservata la laude dovuta in ciò ad alcuni, gli altri, o per la necessità del vivere, che li fa trascurare i principii et ornamenti necessarii a l'arte, o per lo sconcerto grande e quasi universale di tutte le cose del mondo, che non si fanno co' metodi suoi, ma come a caso, restano i pittori nella cognizione dell'altre discipline affatto rozzi et inesperti.

L'altra è che, ricercandosi nelle imagini, quanto alle sacre, che muovano i cuori de' riguardanti alla divozione e vero culto di Dio, i pittori, per non essere communemente meglio disciplinati degli altri nella cognizione di Dio, né essercitati nello spirito e pietade, non possono rappresentare, nelle 
figure che fanno, quella maniera di divozione ch'essi non hanno né sentono dentro di sé; onde si vede per isperienza che poche imagini oggi si dipingono, che produchino questo effetto.

Giudicandosi donque queste essere le più alte radici de' nostri mali, si credeva ancora che, per curare queste due piaghe così profonde et invecchiate, più alta mano si ricercasse di quella di [p. 121] persone, se ben scelte, umane però, avendo ciò bisogno di particolare soccorso dal cielo e di un singolarissimo et estraordinario favore divino. Non parve, con tutto ciò, che, per qual si voglia causa, fosse da abbandonare l'impresa, non solo per l'ubidienza che si deve agli ordini del sacro Concilio, ma ancora perché, se bene non possiamo in questa vita essequire le cose perfettamente, ricerca però Iddio da noi quello che la debole industria nostra, appoggiata alla grandezza della sua potenza, può produrre, la quale di piccioli semi moltiplicati spesse volte fa riuscire grande e copiosa messe; e di quello che le presenti età non possono intieramente godere fa che ne riceva il frutto la posterità, con riconoscimento perpetuo di chi ne fu autore. Per che, preso animo da questa viva speranza e fondati nel favore divino, non hanno cessato quei, a chi fu commesso questo carico, di abbracciare con ogni diligenza e raccorre insieme tutto quello che loro è parso più a proposito in questi cinque libretti, che serviranno almeno ad aprire la strada agli altri, che con più ampio et ordinato trattato potranno supplire a' difetti di questo.

Ora quel che più importa saria che le persone, avvedutesi degli errori in che fin qui sono state involte, cominciassero ad applicarvi bene la considerazione e mettere in pratica quello che nel presente discorso si è compreso. Imperoché non è dubbio che, con la instruzzione sola di quello che in esso si contiene, già si principiarebbe a rendere in buona parte il vero onore e dignità a' sacri tempii. Di qui cominciarebbono ad imparare i pittori e scoltori come potessero con l'arte loro giovare più che mediocremente all'anime cristiane; di qui scoprirebbono quali siano i veri fini delle imagini; di qui intenderiano et intendendo potriano correggere gran parte degli abusi delle opere loro. Vi saria di più, che ciascun uomo o donna commodamente potria conoscere quali imagini convengano e quali siano disdicevoli alle cristiane case. Ma Dio voglia che la malizia degli uomini non avanzi ogni discorso e poco aggradisca tanto bene. I curati almeno, in ogni caso, caveranno di qua varie cose che in questa materia devranno ricordare a' popoli loro, e, conosciuta l'importanza del tutto, svegliare spesso gli altri a scriverne più diffusamente. Il che quando riesca, assai frutto si sarà di questa fatica raccolto; poiché in un modo o in un altro, purché si serva alla gloria di Dio, si viene ad essequire quello che è stato scopo e fine nostro. 
[p. 122]

\section{ALCUNI AVVERTIMENTI A CHI LEGGERÀ IL PRESENTE DISCORSO}

Desiderandosi di provedere quanto si può agli abusi delle imagini secondo il decreto del sacro Concilio Tridentino, e considerandosi ciò essere non tanto errore degli artefici che le formano, quanto de' patroni che le commandano, o più tosto che tralasciano di commandarle come si doverebbe, essendo essi come i principali agenti, e gli artefici essecutori della loro volontà; però si è avuta considerazione in questo trattato di ragionare non solo con li pittori e scoltori, ma principalmente con li curati e con li nobili e persone onorate, che sogliono abbellire le chiese e le loro abitazioni con simili ornamenti. Imperoché, capaci che siano fatti essi di quello che si conviene, non è dubbio che sarà quasi in tutto facilitato questo negozio. Di qui è adunque che in molti capi si è proceduto alquanto scientificamente e con concetti di dottrina, avendosi riguardo ai nobili ingegni, per meglio stabilirli nella verità. A questo fine ancora ci si sono inserite molte autorità latine senza tradurle altrimenti, presupponendosi che quelle abbiano a servire a persone letterate; non essendosi però lasciato, quando si tratta di cose pertinenti all'uso degli artefici, di voltare in lingua popolare i luoghi necessarii, et esplicare il tutto più pienamente che si è potuto.

Ricordiamo ancora che questo trattato, per ordine di monsignore illustrissimo nostro Vescovo, è stato composto per uso del popolo della città e diocese sua; onde, sì come egli non può prescrivere legge agli altri luoghi, così non intende manco di tassare i costumi loro o fare il censore delle usanze, che essi servano differenti da queste. Anzi non è sua intenzione ancora di ascrivere a peccato mortale del suo popolo ogni cosa che sarà stata in questo libro ripresa; ma lasciare il tutto sotto le medesime [p. 123] proibizioni e sotto le medesime pene di peccato o mortale o veniale, o di semplice imperfezzione, a che i sacri canoni l'hanno sottoposto: sapendosi che, come si danno i gradi degli errori negli uomini, essendone alcuni più gravi et altri più leggieri, così nella pittura $\mathrm{e}$ scoltura si ritrova quella varietà di maggiore e minore difetto.

Si dice, di più, che, essendo uffizio di buon vescovo il ridurre a perfezzione quanto più può il gregge a sé commesso, né potendosi ciò fare se prima non si scacciano dagli occhi le tenebre degli errori, o grandi o piccioli che siano, che non lasciano discernere la chiara luce: però si sono toccate varie cose, che ad alcuni potriano parere forse troppo diligenti e severe. Ma chi considererà che a ciascuno conviene il fare tutte le cose con la debita ragione e che molti si scusano, ora con gli essempi degli altri, ora dicendo non essergli stata mostrata la strada: giudicherà insieme essere stata a punto impresa pastorale, di dare alcuna luce al suo popolo, per farli sapere il modo più ragionevole e cristiano che si dovria tenere in fare le imagini nelle chiese, nelle case, nelle ville et in ogni altro luogo, acciò per l'avenire, scorgendo ciascuno il bersaglio, possa cercare di toccarlo, o almeno accostarseli più che può; il che ha giudicato Sua Signoria Illustrissima tanto più convenire a questo popolo, quanto che, nominandosi la città di Bologna maestra degli studii, desidereria ancora che fosse regola a' forestieri del bene operare in ogni cosa.

Ora aggiongiamo che, nel trattare quest'opera, si è cercato non solo di abbracciare tutte le cose che si sono giudicate necessarie in questo soggetto di sapersi da ciascuno, per liberarsi a fatto da tutti gli abusi et errori delle pitture; ma ancora di compartirle in modo che apportino ogni chiarezza e facilità possibile al lettore. E però si è diviso il tutto nei cinque presenti libretti.

Il primo libro consta di tre parti principali, perché primamente si discorrono varie cose in generale delle imagini, come fondamento al resto dell'edificio, e, dopo l'essersi fatto sapere quale sia lo scopo che si ha in questo trattato et in che senso noi pigliamo le imagini, si dichiarano le cause et origini loro, mostrando insieme la dignità et eccellenza di esse, e le arti che principalmente versano nel formarle, paragonando con questa occasione la pittura e scoltura insieme; il che fatto, si 
viene alla seconda parte, nella quale si divide tutta la materia delle imagini [p. 124] in dui capi principali, cioè profane e sacre; e qui, lasciando a dietro le sacre, come quelle nelle quali principalmente ha da versare il trattato, che ricerca più disteso ragionamento, si tocca delle profane quanto è parso necessario per cognizione della origine e qualità loro, congiongendoli la materia degli idoli, molto frequente nei libri degli antichi, come ognuno sa; poi segue la terza parte, che è delle imagini sacre, nella quale, dopo' l'essersi dimostrata l'antichità et origine loro, si dichiara copiosamente l'officio, fine et effetto che producono, mostrandosi quanto siano necessarie nel popolo cristiano, e si gettano finalmente a terra tutte le machine e sforzi del Demonio, fatti per levare l'uso di esse, essendosi giudicato necessario di stabilire bene questo punto prima che si tratti degli abusi, poiché senza questo fondamento dell'uso necessario delle imagini vano serìa stato tutto il resto del trattato.

Nel secondo libro, volendosi ragionare degli abusi principali che sogliono spesse volte trovarsi nelle imagini, si è continovata la divisione già cominciata nel primo libro fra le pitture sacre e le profane; e però si è partito questo libro anch'esso in tre membri principali: il primo parla degli abusi intorno alle imagini sacre; il secondo degli abusi delle imagini profane; il terzo degli abusi che possono essere communi all'une e l'altre.

Nel terzo poi, perché tra tutte le sorti degli abusi uno ve n'è che, sì come è riputato il più ingannevole e fallace, così stende più largamente i suoi rami quasi in tutti i luoghi della cristianità, il qual è delle imagini lascive e disoneste; però si è giudicato necessario farne particolare trattato e ragionare di questa parte più diffusamente, col mostrare con varii essempi, ragioni et autorità quanto sia dannoso e da essere fuggito tal abuso: rinchiudendosi in esso tutto il trattato di questa materia sola, come molto principale al proposito nostro et alla necessità dei moderni tempi.

Nel quarto libro parimente, considerandosi che, quanto più si viene al particolare delle cose, più si giova alla vera pratica di quelle, e che i discorsi universali non fanno tanta impressione nella mente di ciascuno quanto si ricerca; però si è in questo libro minutamente trattato capo per capo di ciascuna di quelle imagini che sogliono essere più frequenti nella nostra città e diocese, e, come si crede, ancora negli altri luoghi catolici della cristianità, avendo noi cominciato dal modo del dipingersi Dio [p. 125] Padre, Dio Figliuolo, Dio Spirito Santo, con tutti i loro misteri principali, e così della gloriosa Vergine, degli angioli, de' patriarchi, degli apostoli e degli altri, seguitando l'ordine commune delle Litanie della santa Chiesa, e dando varii avvertimenti nelle pitture di ciascheduno, e riducendo i decreti generali del sacro Concilio, più che si è potuto, alle occorrenze dei casi, non altrimenti che sogliono i medici applicare anch'essi le teoriche generali et aforismi alle complessioni et infermità de' soggetti.

Nel quinto et ultimo libro si abbracciano varie altre cose per ammaestramento dei curati, dei padri di famiglia e degli stessi pittori, acciò veggano come cristianamente possono essercitare l'arte sua; con la conclusione del modo da osservarsi per lo avenire nella città e diocese nostra intorno alle pitture.

E se bene a [sic] principale intenzione nostra è stata di provedere agli abusi delle imagini sacre, non si è però tralasciata quella delle imagini profane, come annessa a questa e piena anch'essa di gravi abusi, e che nei costumi e disciplina del popolo suole causare gran corruzzione, come dal progresso del discorso si potrà comprendere.

Si era dipoi pensato di mettere in disegno l'istesse cose che nel discorso si sono approvate et inserirle stampate nel libro, acciò, accompagnandosi con le ragioni addotte in esse i lineamenti ancora e l'effigie delle cose, tanto più chiaro apparesse ai lettori et agli artefici quale sarebbe la intenzione e desiderio nostro; ma per giuste cause si è ora sopraseduto, riservandosi ad altro tempo (se piacerà a Dio) di supplire più opportunamente. 
Resta ora che, sì come noi sottomettiamo il tutto al giudizio e correzzione della santa Sede Apostolica, così le persone di questa città e diocese, a chi è indrizzata quest'opera, vogliano leggerla consideratamente e con pia intenzione di mettere in pratica le cose che giudicheranno essere buone e ragionevolmente convenirsi a chiunque fa professione della legge cristiana. Il che si degni il signore Dio di concederli per la sua infinita misericordia.

[p. 127]

\section{LIBRO PRIMO}

CAP. I.

Qual sia la principale intenzione nel presente trattato intorno agli abusi delle imagini, e dell'ordine da servarsi in questo primo libro diviso in tre parti.

Narrano le Sacre Lettere che, avendo Iddio signor nostro formato l'uomo ad imagine e similitudine sua, facendolo capace di tutti i beni che la natura di lui era atta a ricevere et alla divina liberalità si conveniva di donarle, egli usando male le celesti grazie, cadde in sì miserabile stato che, reflettendosi sopra di lui la propria disobedienza, le potenze dell'anima, che innanzi erano regolatissime, venute in sconcerto si fecero rubelle al bene suo. Piacque nondimeno alla divina misericordia di conservarli un picciolo raggio della eterna luce, col quale fosse atto a conoscere che ci era Dio et un Dio solo, patrone dell'universo ${ }^{1}$. Con questo, altramente chiamato lume naturale, tanto più si stabilì nel conoscere che ci fosse un principio di tutte le cose, quanto che per vari accidenti umani s'avvidero gli uomini d'essere inabili per supplire alle loro necessità: onde conclusero $^{2}$ che ci fosse una podestà superiore a ciascuno, alla quale si dovesse stare soggetto et a quella nei bisogni ricorrere e prestarle supremo onore e riverenza. Di che, oltre la divina Scrittura, testimonio ne rendono anco i gentili autori, avendo scritto uno di loro ${ }^{3}$ : [p. 128] Nulla gens est, neque tam immansueta neque tam fera, quae non, etiam si ignoret qualem habere Deum deceat, tamen habendum sciat. E narrano quei che hanno descritte le nuove navigazioni, che in molti paesi, se bene remotissimi dagli altri et incultissimi, trovansi popoli senza lettere, senza arti, senza leggi e senza magistrati; ma non però senza qualche sorte di religione.

A che appartiene quello che hanno scritto alcuni ${ }^{4}$, che la religione è più propria dell'uomo che la ragione; perciò che in molti animali bruti appare alcuna specie o apparenza di ragione, ma vestigio nessuno di religione, per essere ella sola degli uomini e peculiarmente prodotta nella loro natura. Onde fu scritto saviamente ${ }^{5}$ : Ex tot generibus nullum est animal, praeter hominem, quod habeat notitiam aliquam Dei. Per la qual cosa, se mai in tempo alcuno si sono veduti uomini che dicano non vi essere Dio, questi sono stati più tosto riputati mostri o animali irragionevoli, che uomini, poiché tanto si sono allontanati dal discorso e dalla cognizione propria dell'uomo.

Quindi donque cominciarono le persone in ogni età non solo interiormente, ma ancora con segni

${ }^{1}$ S. Agostino, De lib. arbitr., II, 3 ss.

${ }^{2}$ S. Tommaso, Sum. theol, II II, q. 85, a. 1.

${ }^{3}$ Cicerone, De leg., I, 8.

${ }^{4}$ Lattanzio, Div. instit., III, 20; De ira Dei, 7.

${ }^{5}$ Cicerone, De leg., I, 8. 
estrinseci, di venerare questa altissima causa e con varii culti protestare la soggezzione che le dovevano $^{6}$. E tutto questo fu nominato religione, perché ligava (come dissero alcuni ${ }^{7}$ ) gli uomini con Dio e gli ordinava a lui.

Ma perché questo lume naturale, onde scaturisce la religione, se bene in tutti fu impresso, non però da tutti fu egualmente essercitato, quindi ebbero origine le false religioni e la ignoranza del vero Dio. Imperò che, essendo per lo peccato del primo padre quel lume restato assai indebolito, ebbe bisogno dagli uomini di diligente cultura, come terra che bene espurgata e custodita produce felice messe, ma inculta [p. 129] e derelitta non rende altro che ortiche e spine. Però quegli che, con la guida di questo lume, si diedero alla essercitazione della giustizia, innocenza, pietà et altre virtù, ebbero, aiutati dalla divina grazia, la notizia del sommo Dio e la protezzione di quello ${ }^{8}$. Ma quegli che, dati in preda ai sensi, volsero seguire la legge de' suoi pravi appetiti, offuscarono maggiormente sempre il lume naturale, e quindi incorsero in perniciosissimi errori, adorando per Iddio quello che non era et involgendosi in essecrabili superstizioni. Da che nacque che, sendo molti gli atti estrinseci della religione ${ }^{9}$ - come oblazioni, vittime, incenso, statue, imagini, altari e sacrifizii -, quegli che con pura mente e candidi costumi riverivano Dio, si servirono ancora santamente dei sopradetti riti, e particolarmente dell'uso delle imagini. Ma gli altri, corrotti da' vizii et in preda delle libidini et abominazioni, convertirono le imagini in onore de' demonii, adoperandole come idoli e venerando quella materia di legno, o quello che in essa era rappresentato, come vero Dio. Et in ciò ancora varia fu la osservanza loro e diversi i gradi de' suoi errori, secondo che più e meno si allontanarono dal lume naturale e disciplina de' buoni costumi. Onde sono stati autori $^{10}$ che tutte queste religioni della antichità divisero in cinque sette, delle quali alcune ammessero le imagini, altre le esclusero, altre variamente in ciò si adoperarono. Ma perché noi abbiamo l'occhio alla utilità de' nostri tempi, non è intenzione nostra di ragionare intorno ai riti di questi popoli, se non quanto l'occasione ricercherà talora per aprire maggiormente la strada al corso nostro; disegnando noi di trattare, quanto all'uso delle imagini, quello che ai tempi nostri causa maggiore difficoltà e che ha più bisogno di presentaneo rimedio.

Onde, discendendo al tempo di Cristo signore nostro, vero fondatore et illustratore delle religioni, diciamo che una [p. 130] sola si trova la vera e perfetta religione da lui instituita, che si chiama de' cristiani e fedeli. Cristiani, perché adorano Cristo Dio et omo, salvatore e redentore dell'umana generazione. Fedeli, perché credono alla verità rivelatali da Dio, contenuta nelle Scritture sacre et esplicata dal consenso universale di santa Chiesa, alla quale ubidiscono; e però ammettono et adorano le imagini sacre, secondo il culto e rito che da essa è stato ordinato. A questa si trovano opposte tre sette principali, che con nome commune si chiamano d'infedeli, et una de' perfidi cristiani, i quali tutti nell'osservazione dell'imagini sono differenti dall'uso de' veri cristiani ${ }^{11}$. Infedeli sono i Giudei, Gentili e Maumetani.

I Giudei adorano un Dio solo, ma non credono nella Trinità, Padre, Figliuolo e Spirito Santo, né che Cristo sia stato il vero Messia; et ostinati nella superficie della lettera della legge antica, male da essi interpretata, non venerano le imagini, riputandole idoli ${ }^{12}$.

\footnotetext{
${ }^{6}$ S. Tommaso, Sum. theol., II-II, q. 84, a. 1, ad 1.

${ }^{7}$ S. Tommaso, Sum. theol., II-II, q. 81, a. 1.

${ }^{8}$ Alessandro di Hales, Summa, III, q. 6, m. 2, a. 3.

${ }^{9}$ S. Tommaso, Sum. theol., II-II, q. 81, a. 7.

${ }^{10}$ S. Epifanio, Haer., I-XX; Anacephal., 1 ss.

11 Alessandro di Hales, Summa, II, q. 158 (in princ.).

${ }^{12}$ Paolo di Burgos, Addit. 2 in Exod. 20.
} 
I Gentili, altrimenti detti Pagani, adorano gli idoli, cioè le statue e le imagini o d'uomini, o d'animali, o del sole, luna e stelle, o d'altre loro imaginazioni, tenute da essi per veri dèi, o che almeno rappresentino la divinità, come di sotto si dirà; e però sono chiamati idolatri.

I Maumetani dicono di adorare uno sol Iddio invisibile, ma con nuovi riti lasciatili da Maumeto loro ingannatore; e questi non accettano né venerano alcuna imagine di Dio, né de' santi.

Restano i Cristiani, come rose tra le spine, quelli però che si chiamano catolici, che, seguendo la legge di Cristo N. S., si sottopongono alla ubidienza et ammaestramento di santa Chiesa guidata dallo Spirito Santo; poiché altri Cristiani si chiamano eretici o scismatici, e questi noi diciamo perfidi Cristiani, perché, segregatisi dal grembo di santa Chiesa e rotta la fede promessa nel santo battesimo, vivono con pro [p. 131] prie elezzioni di dottrina, costumi et instituti; e questi sono di varie sette e la maggior parte d'essi ributtano le imagini e le fanno aperta guerra.

Dunque, raccogliendo tutte queste diversità insieme, diciamo che si scorgono in esse dui estremi et un mezzo: il primo estremo è del pagano, che tribuisce più alle imagini che non deve, adorandole come Dio; l'altro estremo è dello eretico, e simili, che le levano più che non si deve, discacciandole affatto; il mezzo è del catolico cristiano, che non bandisce le imagini, né anco le adora come cosa divina, ma avendo in quelle l'occhio al suo prototipo et assimigliato, modera la venerazione secondo si conviene et è prescritto dai sacri canoni e concilii.

Ma perché in questo culto del catolico nella longhezza del tempo sono incorsi varii abusi, la intenzione nostra in questo trattato è di riformare il catolico e non di oppugnare direttamente il pagano o l'eretico, se non dove si giudichi esser espediente per maggior chiarezza di quello che pretendiamo di mostrare.

$\mathrm{E}$, per trattare il tutto più commodamente, si è seguito l'ordine che è parso più convenire alla utilità di questa materia, che da noi si tratta non magistralmente, né con metodo di dottrina, ma solo per correggere gli abusi. I quali perché tutti cadono in due sorti d'imagini, cioè profane o sacre, perciò si è atteso nel primo libro, come introduttivo agli altri, a parlare di questa materia in universale, dividendolo però in tre parti per più chiarezza: nella prima si ragiona delle imagini in generale; nella seconda delle profane; nella terza delle sacre, con quelle considerazioni che si sono poste di sopra negli avvertimenti al lettore, dove parimente si rende ragione dell'ordine servatosi anco negli altri libri; al quale luogo rimettiamo ciascuno per fuggire la longhezza et inutile repetizione.

[p. 132]

\section{CAP. II}

Che cosa noi intendiamo per questa voce 'imagine'.

Per giungere dunque più ispeditamente e con maggior chiarezza al fine proposto, comincieremo da alcuni principii generali e necessarii da intendersi, pigliando per capo il dichiarare che cosa sia imagine e quello che noi per questo nome intendiamo. Intorno a che non vogliamo già obligarci a perfetta definizione, ma più tosto pensamo ponere certa generale descrizzione, per levare ogni equivocazione che nel discorso potesse occorrere e per più chiara cognizione delle cose che si averanno da trattare.

Laonde diciamo che per imagine noi pigliamo ogni figura materiale prodotta dall'arte chiamata il dissegno e dedotta da un'altra forma per assomigliarla. 
Abbiamo detto 'ogni figura', per abbracciare tutte le forme delle $\operatorname{cose}^{13}$, o razionali o irrazionali, delle quali si possono formare i ritratti; e non sono di un punto, né di una linea, ma di più insieme: come di uomo, di elefante, d'uccello, di pesce, d'arbore, di sasso e d'ogni altra cosa, non solo naturale, ma ancora artifiziata, come di chiesa, di calice, di vestimento, di libro o altro simile. E diciamo più presto 'figura' che 'vestigio', perché quello significa propriamente la impressione del piede e quel segno che nello andare si lascia nella polvere o nel terren molle, se bene si stende poi per certa similitudine ad altre cose ancora ${ }^{14}$; ma non abbraccia però se non cose irrazionali et imperfette, mostrando anzi il segno et effetto di un'altra cosa che la sua figura vera: sì come, vestigio viso (dice S. Agostino ${ }^{15}$ ), transisse animal, cuius vestigium est, cogitamus. [p. 133]

Diciamo 'materiale', a differenza delle imagini astratte et incorporee, che si comprendono solo con l'intelletto; sì come, per essempio, attribuiscono i sacri teologi nelle persone divine il nome di imagine al Figliuolo ${ }^{16}$ e dicono la mente dell'uomo essere fatta alla imagine di Dio, e talora fatta ad imagine della Trinità ${ }^{17}$. E di più hanno detto che nell'intelletto umano si formano varie imagini per li vari fantasmi e concetti che se gli imprimono ${ }^{18}$; di che bella comparazione diede S. Basilio ${ }^{19}$, tratta in parte dagli antichi filosofi ${ }^{20}$, che fa molto al proposito nostro, paragonando la mente dell'uomo ad una tavola d'un pittore, dove alla giornata va disegnando, aggiungendo e mutando or una cosa et or un'altra, tenendola intratanto coperta con la cortina finché del tutto sia finita: così, dice questo santo, nella mente nostra, che è come una tavola polita, ogni giorno disegnansi vari pensieri, i quali si scopriranno quando si leverà dall' anima questo velo del corpo nostro. E da questa varietà d'imagini, che interiormente concepisce l'uomo, hanno detto molti essere stata chiamata imaginativa quella facoltà animale del senso interiore, che dalle cose sensibili esteriori, e talora da cose che non sono né possono essere, compone dentro di sé certe forme che chiamano fantasmi, et in altri modi ancora che non appartengono al nostro proposito.

Diciamo dipoi 'prodotta dall'arte', per escludere le imagini fatte dalla natura, sì come sono quelle che si vedono negli specchi e nell'acqua chiara et altri corpi lucidi, overo ancora che si scorgono nei figliuoli generati dai padri (leggendosi nella Scrittura ${ }^{21}$; Et genuit Adam Seth secundum imaginem suam), o in altri modi, di che tratta S. Agostino ${ }^{22}$. [p. 134]

V'aggiungiamo 'chiamata il dissegno', per essere questo nome commune e che dà principio a tutte l'arti che formano imagini, pigliando esse il loro cominciamento dal dissegno, o siano fatte con linee pure, o con un colore solo, o con più, o con scalpello, o con qualonque altro instrumento, o di rilievo, o in piano, o in qual si voglia materia, d'oro, argento, marmo, legno, terra, stucco et altre cose somiglianti.

Diciamo 'dedotta da un'altra forma', imperò che possono bene essere due cose simili insieme, come due uomini della medesima faccia, due leoni e due aquile; ma uno non si dirà imagine

\footnotetext{
${ }^{13}$ S. Agostino, De quantit. animae, 7.

${ }^{14}$ S. Tommaso, Sum. theol., I, q. 93, a. 6; q. 45, a. 7.

${ }^{15}$ S. Agostino, De doctr. Christ., II, 1.

${ }^{16}$ S. Tommaso, Sum. theol., I, q. 35, a. 2.

${ }^{17}$ Ibid., I, q. 93, a. 6.

${ }^{18}$ Ibid., I, q. 93, a. 7. 8.

${ }^{19}$ De virginitate.

${ }^{20}$ Platone, Phil., 39 b; Aristotele, De anima, III, 4.

21 Gen., 5, 3.

${ }^{22}$ De decem chordis, 8.
} 
dell'altro, non essendo fatto per rappresentare quello, come afferma S. Agostino ${ }^{23}$ dicendo: Si alter ex altero natus non est, nullus eorum imago alterius dici potest; imago enim tunc est, cum de altero exprimitur etc. E sempre la imagine presuppone un' altra cosa anteriore, dicendo Platone ${ }^{24}$ in questo proposito: In quacunque re tria, considerantur: idea rei, res et imago rei; ut idea lecti, lectus et imago lecti. Idea est in Deo ante rem; res a natura aut ab arte, post ideam; imago a pictore vel alio artifice, post rem.

Diciamo 'per assomigliarla', imperoché questo è lo scopo et il fine della imagine, di rappresentare la similitudine d'un' altra spezie; il che è tanto proprio della imagine, che spesso piglia il nome dal suo esemplare, dicendo il medesimo S. Agostino ${ }^{25}$ : Adeo sunt similes imagines rebus, quarum sunt imagines, ut plerunque earum etiam nomina sortiantur; sic hominem pictum, hominem appellamus, et intuentes tabulam aut parietem dicimus: ille Cicero est, ille Salustius. E dice il Nazianzeno $^{26}$ : Haec est natura imaginis, ut imitatione id exprimat, a quo primum deducitur et cuius imago dicitur. Onde hanno voluto alcuni, che per certa somiglianza di voce sia stata chiamata imago, quasi imitago.

Le quali cose vengono confirmate da quel che scrive [p. 135] S. Agostino, seguitato da S. Tomaso, dove dimostra che altro è imagine, altro è similitudine, altro è equalità; e, per usare le parole sue, dice egli: Aliud est imago, aliud aequalitas, aliud similitudo. Ubi imago, ibi continuo similitudo, non continuo aequalitas; ubi aequalitas, continuo similitudo, non continuo imago; ubi similitudo, non continuo imago, non continuo aequalitas ${ }^{27}$; volendo inferire ch'alla imagine, tra l'altre cose, principalmente si ricerca che sia espressa da un'altra specie e che con similitudine rappresenti quella. È vero che tal volta si considera essa imagine e come similitudine e come misterio che figura un'altra cosa dissimile; sì come anticamente il serpente fabricato per commandamento di Dio da Moisè ${ }^{28}$, in quanto assomigliava i serpenti velenosi del deserto, era vera imagine e similitudine; ma in quanto figurava la passione del Salvatore nostro, non era in luogo di imagine, ma di misterio.

Per lo che, restando chiaro in che senso noi pigliamo questo nome d'imagine, non ci stenderemo in riferire altri sensi degli autori, che secondo la varietà delle loro professioni si sono serviti diversamente dell'uso di questo nome, altramente pigliandolo talora i retori ${ }^{29}$, altramente gli astrologi $^{30}$, altramente i iurisconsulti ${ }^{31}$ et altramente, per certa metafora, la sacra Scrittura, quando dice: Verumtamen in imagine pertransit homo ${ }^{32}$; et altramente i dottori sacri, come S. Ambrosio ${ }^{33}$, che fa differenza inter umbram, imaginem et veritatem, dicendo: Umbra in lege, imago in evangelio, veritas in caelo; et altrimente alcuni altri teologi ${ }^{34}$, che distinguono inter signum, formam

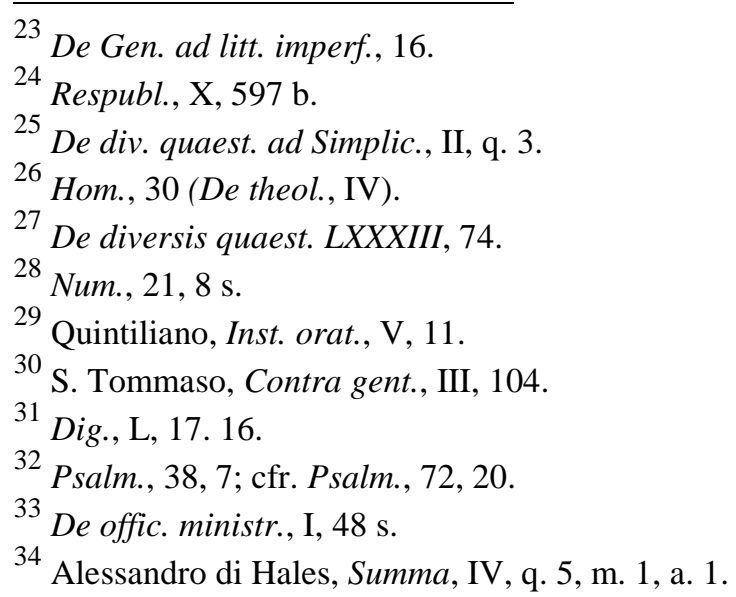


et imaginem, et altrimente il Damasceno ${ }^{35}$, [p. 136] che pone varie significazioni del nome d'imagine, oltre quello che da' dottori scolastici in ciò è stato avertito ${ }^{36}$. Le quai cose, perché non appartengono al nostro proposito, per ora tralasciaremo.

\section{CAP. III.}

Delle cose che in ciascuna imagine concorrono da considerarsi.

Pigliandosi il nome d'imagine nel significato detto di sopra, vengono ora in considerazione varie cose, che tutte concorrono al formare un'imagine.

Prima vi è l'autore o artefice; dipoi vi è la materia di ch'è composta la imagine; appresso l'instrumento o mezzo con che si è formata la imagine; di più il corpo tutto della imagine e la forma che le dà il nome; ultimamente il fine per lo quale ella è stata fabricata.

Quanto all'artefice, che si chiama causa efficiente, molte sono le parti che si ricercano nella persona sua per corrispondere a questo ufficio, delle quali ci riserviamo a parlarne al luogo suo distesamente, essendo capo molto importante. Ora ricordiamo sol due cose: l'una, che deve essere perito l'artefice di quello che vuol fare, dicendo il proverbio antico: Quam quisque norit artem, in ea se exerceat; l'altra, che non basta solo esser buono artefice, ma, oltre l'eccellenza dell'arte, essendo egli di nome e di professione cristiano, ricercano da lui l'imagini ch'egli farà, un animo et affetto cristiano, essendo questa qualità inseparabile dalla persona sua, e tale ch'egli è ubligato di mostrarla ovunque fia bisogno. Il che conseguirà facilmente, seguendo gli avvertimenti che si diranno nel presente discorso.

Della materia onde si compongono le imagini e degli [p. 137] istrumenti con che si possono formare non intendiamo noi di parlar altramente, essendo cose proprie dell'arte e disciplina de' maestri, alla quale non è diritto il ragionamento nostro. Solo ricorderemo che, sì come in alcuni sacramenti hanno detto i sacri teologi ${ }^{37}$ che, per essere di somma necessità, è stata ancora instituita la materia loro tale che sia commune e pronta al bisogno di ciascuno: onde al battesimo serve l'acqua pura et alla Eucaristia il formento, che si trovano ordinariamente in tutti i luoghi; così, per lo bisogno universale delle imagini, pare ch'ogni materia loro sia applicata, formandosi elle non solo di tutte le sorti di legni, di terra o di pietre e di metalli, ma ancora d'infinite altre cose, e naturali et artificiali: come di cera, di fiori, piume d'uccelli, radici d'erbe, foglie d'arbori, di lana, lino, seta, carta, bambagia, di gomme d'arbori e di mill'altre cose, come, oltre quello che vediamo ogni giorno con gli occhi secondo l'uso di santa Chiesa, leggiamo ancora esser stato avertito nella seconda Sinodo Nicena, detta la settima ${ }^{38}$, dove Teodosio vescovo d'Amorio dice così: Probo quae a primordio receptae traduntur imagines, sive ex auro, sive ex argento, sive colorum ductibus, sive quacunque materia exprimantur. E di S. Giovanni Crisostomo si legge ${ }^{39}$ che egli si compiaceva molto d'una imagine di cera formata divotamente, dicendo: Ego et ex cera fusilem picturam pietate plenam amavi. E questa varietà si è osservata anco nella maniera del farle, formandosene alcune grandi, alcune picciole, et alcune di rilievo, altre piane, altre colorite, altre semplici, e con diversissimi istromenti, qual col penello o col scarpello, qual col carbone, col gesso o con la penna

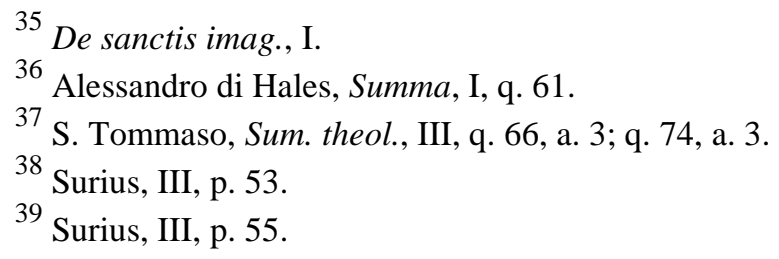


et inchiostro; taluna tessendosi, alcuna conglutinandosi, et altre improntandosi o delineandosi, et ora in ricamo o in mosaico, ora in tarsia o in piano, e talora in superfizie; così nelle chiese, come nelle case, nelle piazze e nelle ville, nei libri, nei vasi e nelle vestimenta; [p. 138] di che ne resta memoria anco nell'istessa Sinodo settima ${ }^{40}$, dove si legge: Diffinimus sanctas imagines e coloribus et tessellis, aut alia quavis materia commode paratas, dedicandas et in templis Dei collocandas, habendasque tum in sacris vasis et vestibus, tum in parietibus et tabulis, in aedibus privatis et in viis publicis. Et in somma non è quasi materia alcuna, come ciascuno sa, né luoco, né tempo, che non sia capace dell'imagini, con mille maniere et istrumenti, come ampiissimo testimonio ne rendono quei santi Padri, nella sinodo di sopra, aggiungendo queste parole dove parlano della istoria della passione di Cristo signor nostro ${ }^{41}$ : Nos passim in ecclesiis, in domibus et foro, in picturis, in sindonibus, in promptuarii vestibus, omnibus denique in locis, hanc figuram ponimus, quo continuo contemplantibus nobis haec in mentem veniant, et non obliviscamur.

Quanto alla forma, chiaro è che, sendo l'imagine cosa che rappresenta una specie già prodotta $\mathrm{o}$ dalla natura o dall' arte, conseguentemente può ricevere tutte le forme delle cose che sono e che si vedono con gli occhi; anzi, di quelle ancora che non si veggono, purché si possano imaginare con la mente, nascendo la forma dal concetto interiore dell'autore, espresso di poi col dissegno esteriore. E di qui si dice quella essere imagine d'un monte, d'un fiume, d'una casa, d'un re, d'un santo e d'altro, che il dissegno dell'autore rappresenta alla vista.

Intorno alla causa finale, diciamo ciascuna imagine ordinariamente essere fatta per imitare un'altra cosa, che è il fine principale, come di sopra abbiamo detto; da quello poi ne derivano molti altri particolari e quasi vari effetti, secondo le varie cause che hanno mosso il pittore a formare l'imagine. Onde alcuni gli hanno ridotti tutti a tre capi, che è onesto, utile e dilettevole; altri alle tre potenzie dell'anima, memoria, intelletto e volontà; altri altrimente, come ai suoi luoghi si tratterà.

[p. 139]

\section{CAP. IIII.}

Della origine delle imagini in universale.

Conosciuta la qualità delle imagini di che siamo per trattare, ora intendiamo di toccare alcune cose in generale della origine loro, riservandoci ai suoi luoghi di ragionare più distintamente, secondo le varie sorti di esse, de' diversi principii et introduzzioni che hanno avute. Diciamo dunque che tra le grazie meravigliose et eccellenti, di che piacque all'eterna previdenza d'Iddio signor nostro adornare l'uomo sopra tutte l'altre creature, una ve ne fu singolarmente privileggiata, che egli solo con l'arte et industria potesse imitare e rappresentare l'istesse opere che Dio con le sue mani avea fabricato.

$\mathrm{Fu}$ questo dono tanto segnalato per varie ragioni a lui conceduto, ma, quanto appartiene al proposito nostro, per due, che principalmente si sogliono considerare. L'una fu, perché avesse l'uomo più largo campo di palesare i suoi concetti; imperò che, avendo egli solo tre maniere et istrumenti da far questo - la voce, $\mathrm{i}$ cenni et i sogni -, la voce è cosa personale, che non si può separare dalla persona che l'usa, e perciò serve a pochi luoghi, a pochi tempi et a poche cose; i cenni, facendosi col gesto o con l'armonia, col ritmo o con altri modi dell'arte mimica, manco

\footnotetext{
${ }^{40}$ Surius, III, p. 183.

${ }^{41}$ Surius, III, p. 103.
} 
possono sodisfare a tutti, per essere congionti anch'essi con la persona di chi li fa ${ }^{42}$, e ristretti dal termine della vista di quelli che gli hanno da intendere; i segni, che è il terzo istrumento, sono di due sorti, o naturali, come è il fumo che esce dal fuoco e l'orma del piede, e questi ancora poco si stendono, overo sono artificiati, [p. 140] accettati dal consenso degli uomini, che si chiamano signa data $^{43}$, e questi sono o caratteri di lettere, note, linee, ziffere o cose simili, le quali non da tutti sono intese, né si sanno da chi non le impara, e l'imparare è di pochi.

Dunque, per sodisfare più universalmente a questo desiderio e necessità commune di significare a ciascuno i concetti altrui, fu ritrovata l'arte del formare le imagini, che, vedute, subito si riconoscono indifferentemente e servono per favella commune a tutte le nazioni. Laonde nel tabernacolo e nel tempio della Legge antica, fatti per ordine d'Iddio, non leggiamo che vi fossero scritte parole alcune, ma sì bene figurate le palme, i pomi granati, i gigli, i cherubini et altre cose che poteano servire universalmente a tutti per intelligenza di quello che significavano; perciò che, quando non siano gli uomini nati nel medesimo paese, né intendano il medesimo linguaggio, sono in certo modo tra di loro come mutoli, dicendo Plinio ${ }^{44}$ : Tanta est loquendi varietas, ut externus alieno non sit hominis vice. E niuno istromento è più atto ad isprimere acconciamente gli occulti concetti, che questo delle imagini e pitture, e perciò dicono ${ }^{45}$ che, essendo Quinto Pedio Romano, che fu dato per coerede ad Augusto, per natura muto, fu consigliato da Messala Oratore, parente suo, ad imparare l'arte della pittura, con la quale potesse emendare il difetto della natura et in qualche parte isprimere i concetti suoi. Di modo che fino nel firmamento del cielo hanno voluto alcuni che si scorghino forme di vari animali e varie figure d'altre cose, perché siano più alla natura nostra conoscibili.

L'altra causa principale dicono essere stata per aiutare con questo mezzo il desiderio di sapere, naturalmente impresso a tutti gli uomini; imperò che, avendo la cognizione nostra origine dai sensi, né potendo questi per apprendere le cose valersi se non degli oggetti presenti, veniva a restare la facoltà del conoscere molto ristretta e debole. E però piacque [p. 141] alla divina sapienza di fare l'uomo capace di questa disciplina, col mezzo della quale potesse rappresentare davanti agli occhi di ciascuno tutte le cose materiali, così naturali come artificiate, non dico le presenti, ma le lontane ancora e quelle che già sono passate o spente. Sì che questa facoltà, chiamata il dissegno, con la quale si formano le imagini di tutte le cose con mirabile espressione, fu riputata sopra tutte l'altre opportuna per sodisfare a questa commune necessità, accostandosi ella molto alla forma di tutte le cose e mettendocele dinanzi agli occhi in qualonque parte elle si trovino.

E però, raccogliendo amendue le ragioni insieme, poi che l'una è conseguente all'altra, diciamo l'origine dell'imagini essersi trovata a fine che potessimo rappresentare la similitudine delle cose e con essa supplire al difetto della lontananza ${ }^{46}$; non perché non possano servire le imagini ancora per le cose presenti e che abbiamo inanzi agli occhi, ma perciò che principalmente vengono elle a ristorare il danno che si patisce per le cose lontane e separate da noi ${ }^{47}$; perciò che, se si potessero vedere tutte a nostra commodità e sempre guardarle a voglia nostra, non saria stato punto necessario il rappresentarle. Il che da Lattanzio fu in parte significato con queste parole ${ }^{48}$ : Nam omnino

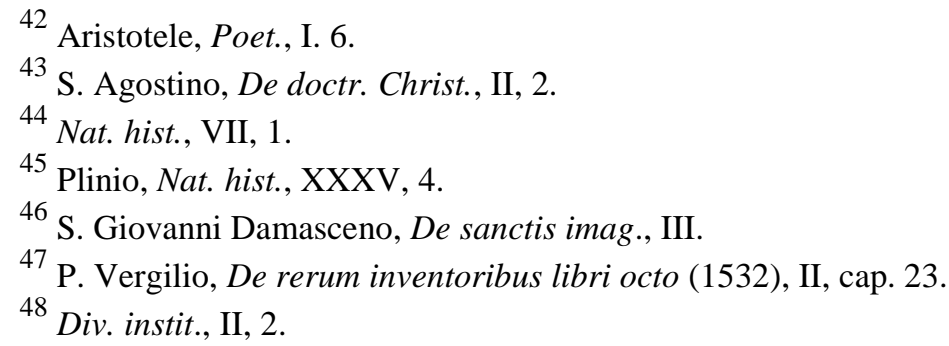


fingendarum similitudinum ratio idcirco ab hominibus inventa est, ut posset eorum memoria retineri, qui vel morte subtracti, vel absentia fuerant separati etc.; e dipoi: Etenim hominis imago necessaria tum videtur, cum procul abest, supervacua futura cum praesto est. Dicasi di grazia, chi è tanto curioso che, se potesse con gli occhi propri veder a sua posta la faccia vera di Cristo benedetto, della beata Vergine o degli apostoli, o le meravigliose loro azzioni, volentieri faticasse in leggerle scritte o in mirarle dipinte? Ma perché quello non si può e la natura non lo concede, però [p. 142] ci vagliamo di questo rimedio delle imagini per supplire a tale necessità.

E se alcuno dicesse che, anzi, le imagini furono trovate per diletto, o per onorare i prencipi e re, o per instinto di religione, o per molt'altri rispetti; rispondiamo che ciò non contradice alla opinione nostra, poi che queste sono più tosto cause secondarie et effetti particolari, che nascono da quella causa principale che fu la loro origine, sì come dai primi principii universali nelle scienze si formano poi varie conclusioni distinte. E noi sappiamo bene che, sendo diverse le sorti delle imagini, come sacre, profane, e di esse molte specie, le quali poi si racconteranno, hanno ancora diversi fini e possono dirsi introdotte per diversi rispetti. Ma noi ora intendiamo della causa principale et origine loro, la quale concorre con quest'altre cause prossime e sottoordinate, delle quali noi tratteremo ai suoi luoghi secondo l'opportunità.

\section{CAP. V.}

Se la introduzzione delle imagini sia stata anteriore ai libri, e che convenienza abbia con essi.

Trattandosi ora della origine delle imagini, ci pare opportuno di considerare insieme alcune cose della conformità che tengono coi libri, poi che veggiamo che gli autori sacri et i gentili, parlando delle imagini, non solo le accoppiano spesse volte coi libri, assomigliandoli insieme, ma ancor il nome dato da' Greci allo scrittore, che è $\gamma \rho \alpha \varphi \varepsilon u ́ s$, l'hanno attribuito parimente al pittore, et il nome

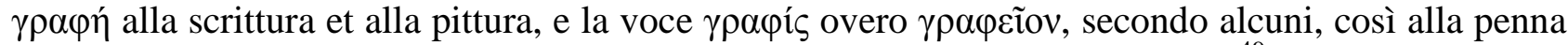
o altro istrumento con che si scrive, come al pennello con che si dipinge ${ }^{49}$ : talché sono state chiamate le ima [p. 143] gini stesse ora libri mutoli, ora scrittura popolare, dicendo S. Basilio ${ }^{50}$ : Quae sermo historiae per auditum exhibet, ea pictura tacens per imitationem ostendit; et il Damasceno $^{51}$ : Quia non omnes literas norunt, neque lectioni incumbunt, patres nostri consenserunt haec in imaginibus repraesentari; e S. Gregorio ${ }^{52}$ : Quod legentibus scriptura, hoc et idiotis praestat pictura; quia in ipsa ignorantes vident quid sequi debeant, in ipsa legunt qui literas nesciunt.

Richiedono nondimeno queste cose, che per l'uso commune son vere, varie considerazioni, e però per maggior chiarezza le divideremo in tre parti. La prima serà dell'origine cambievole delle imagini e de' libri; la seconda del fine; la terza de' mezzi ch'usano l'une e gli altri.

Quanto alla origine, non intendiamo già di voler trattare sottilmente quali di queste due cose siano state prima vedute al mondo, cioè le imagini o i libri, non solo perché simili questioni della precedenza de' tempi nelle cose sogliono apportare spesso molte difficultà e poco frutto, ma ancora perché talora una cosa sarà stata cominciata in un tempo, e poi in un altro ridotta a più perfetta forma, un'altra sarà stata antichissimamente trovata, di poi per longhi secoli andata in oblivione, e finalmente di nuovo tra i popoli suscitata: talché, secondo diversi rispetti, amendue si potranno

\footnotetext{
${ }^{49}$ Polluce, Onomast., VII.

${ }^{50}$ Hom., 19 (In quadrag. mart.).

${ }^{51}$ De orthod. fide, IV, 17.

${ }^{52}$ Epist., IX, 9; c. 27, D. III de cons.
} 
nominar ora anteriori, ora posteriori a qualcun'altra nel tempo di mezzo apparsa in luce. Sarà un'altra venuta a notizia solamente d'un picciol paese o nazione, che rispetto all'università del mondo è come picciol rio a paragone del mare. Onde nel caso nostro, se bene si provasse per autorità delli scrittori che in qualche luogo per alcun tempo prima fossero stati conosciuti libri che le imagini, qual argomento potremmo noi pigliare da questo, che necessariamente provasse che così fossero stati conosciuti nelle altre età dal resto degli uomini? [p. 144]

Sì che, lasciate le dispute da banda e discorrendo noi più tosto probabilmente, giudicheremo che si potesse dire che la introduzzione delle imagini, fatte almeno rozzamente e con poco artificio, sia stata anteriore ai libri, percioché sappemo che quelle cose più facilmente s'introducono che da minor travaglio e fatica sono accompagnate; laonde, vedendosi che per formare i caratteri delle lettere e di essi comporne libri è stata necessaria una esquisita industria e perizia, per essere $\mathrm{i}$ caratteri molto diversi dalle cose naturali, e che nel delineare una semplice imagine molto minore diligenza si richiede, poi che a questa pare che la natura faccia la strada, come si vede ne' specchi e corpi lucidi: perciò si può assai verisimilmente pensare che in quei primi tempi, ne' quali erano inculti gli ingegni e poco essercitati nella disciplina delle cose, più facilmente si appigliassero o si dessero le persone a quelle arti ch'aveano minore difficoltà, e così prima attendessero a rappresentare con figure le cose ch'avevano inanzi gli occhi, che ad imaginarsi segni e caratteri artificiati, che non hanno conformità alcuna con le cose create. Anzi, in una medesima arte, che può essercitarsi in vari modi, è verisimile che prima cominciassero da quella maniera che fosse più facile, sì come della pittura stessa dicono gli autori ${ }^{53}$, che prima fu cominciata dal dissegnare con linee semplici, poi con un colore solo, poi con diversi, conducendola tuttavia a maggiore perfezzione. Il che è stato scritto ancora dell'arte detta da' Greci plastice ${ }^{54}$, che prima fu in uso forse per l'istesso rispetto che quella del fare le statue.

E chi volesse con più fondamento onorare le imagini di questa prerogativa del tempo, potrebbe forse dire, che per quelle si rappresentano direttamente i concetti nostri senza mezzo d'altra cosa, ma che le lettere significano solamente le voci, le quali sono segni dei concetti interiori, dicendo Aristotele $^{55}$ : quod voces sunt signa eorum quae sunt in anima, et [p. 145] ea quae scribuntur sunt signa eorum quae sunt in voce. E però da questo si verria a concludere che le imagini fossero anteriori alle lettere, perché di due cose significanti un'altra cosa, quella che immediatamente significa è prima di quella che mediatamente la mostra, come sanno i dotti. Il che dipoi si verria maggiormente a confirmare da vari essempii di diversi popoli che, per significare i loro concetti, prima cominciarono a servirsi dell'uso dell'imagini che de' caratteri, come di sotto più a pieno si dirà ${ }^{56}$.

Ma sopra tutto stimiamo d'importanza quello che si cava dalle Lettere Sacre, vero fondamento delle cose, perché, essendo commune consenso de' dottori santi, che il primo autore de' libri ch’oggi si trovano al mondo sia stato il profeta Moisè, superiore a tutti gli altri scrittori gentili di gran spazio di tempo ${ }^{57}$, chiaro è che molto inanzi a lui si trova essere stato l'uso delle imagini, sì come di sotto a' suoi luoghi si mostrerà. Né ci move quello che pare che in contrario si legga di Seth e di Enoch, che, essendo stati quasi all'origine del mondo, lasciorono nei suoi tempi scritte

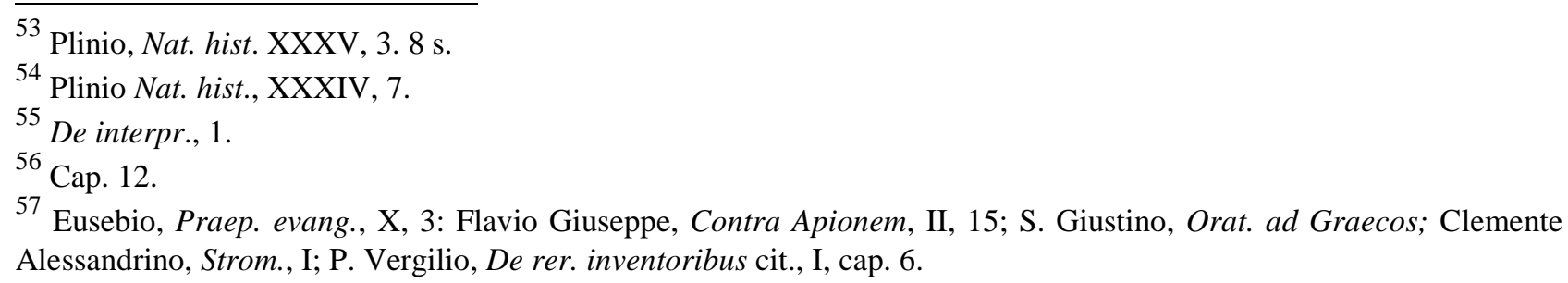


varie $\operatorname{cose}^{58}$; overo quel che dice Plinio ${ }^{59}$ degli Assiri, literas semper Assyrias fuisse et aeternum illarum usum: perché già abbiamo detto che noi parliamo quanto all'universale, non negando che può essere accaduto in alcuna parte del mondo, che prima gli uomini si siano serviti delle lettere che dell'imagini per qualche particolare causa appropriata ad essi, sì come puoté avenire agli Ebrei, che, per essere stato il popolo di Dio et il primo tra tutte le genti del mondo creato dalla mano sua e disciplinato da esso, fu degno ancora di questo particolar dono, di essere come esemplare di molte arti e scienzie a tutte l'altre nazioni, e però ebbe la cognizione dei caratteri delle lettere e del [p. 146] formare l'imagini, servendosi di mano in mano di quello che più li tornava a proposito.

E però, quanto al luogo di Plinio allegato di sopra, si vede dalle parole sue stesse ciò non aver fondamento, volend'egli che sia stato eterno l'uso delle lettere, che viene a negare la creazione del mondo e principio delle cose, sì come il medesimo Plinio in un altro luogo ${ }^{60}$, parlando della origine della magia, tien per vana l'opinione di quelli che volsero ch'avesse principio da Azonace, innanzi la guerra Troiana per spazio di cinque millia anni. Dice egli: Mirum hoc in primis, durasse memoriam artemque tam longo aevo, comentariis non intercidentibus, praeterea nec claris nec continuis successionibus custoditam; e molte altre ragioni aggionge, che servono assai a questo proposito. Ma noi ancora più chiaramente rispondemo secondo che Eusebio espone, dicendo che la Giudea era in Siria, e spesso participa di quel nome, e però quello che è narrato in molte cose degli Assiri deve attribuirsi agli Ebrei; onde scrive ${ }^{61}$ : Multi Syros literas primos comperisse asserunt; Syrii autem Hebraei sunt, nam Iudaea in Syria semper a scriptoribus habita fuit, et Phoeniciam etiam apud priscos appellari constat, temporibus autem nostris Palaestinam Syriae appellant.

Ma, lasciando gli Ebrei e tornando al proposito nostro, dicemo che, se bene per via di discorso ragionevole ci pare che le imagini siano state di tempo anteriori alle lettere, concedemo però che siano state infinite cose prima narrate nei libri che poste in pittura; onde rispetto a queste si potria dire i libri essere anteriori, parte perché gli artefici delle imagini hanno appresso imitato e rappresentato quello che ne' libri hanno ritrovato, parte perché sono restate nei libri molte cose che fino a ora non si sono potute esprimere col pennello, non essendo atto il dissegno a rappresentare ogni cosa, come ognuno sa: e però resta in questa parte assai più povera e sterile la pittura che la scrittura. [p. 147]

Venendo ora alla seconda parte, che è del fine, e considerando in ciò la somiglianza che gli autori scoprono tra queste due facoltà, dicemo che, sì come ogni libro ordinariamente ha per fine di fare capace colui che legge e persuaderlo a qualche cosa, così si può dire che le pitture vadano anch'elle all'istesso fine con quelli che le mirano, sì come lasciò scritto Plutarco con queste parole $^{62}$ : Dixit Simonides picturam esse poesim tacentem, poesim picturam loquentem. Nam quas res tamquam si coram agerentur pictores repraesentant, hae ut praeteritae oratione narrantur; ac cum pictores idem coloribus et figuris exprimant, quod scriptores verbis et dictionibus, materia quidem et modo imitationis differunt, utrisque tamen idem est finis propositus. Itaque optimus historiae scriptor habetur, qui narrationem personis animoque movendo aptatis figuris ita conformat, ut picturam referat. E S. Basilio in una omilia disse ${ }^{63}$ : Res in bello fortiter gestas, tum

\footnotetext{
58 Flavio Giuseppe, Ant. Iud., I, 2; Giorgio Cedreno, Compend. hist., in princ.; S Agostino, De civ. Dei, XV, 22; Tertulliano, De cultu feminarum, II.

${ }^{59}$ Nat. hist., VII, 56.

${ }^{60}$ Plinio, Nat. hist., XXX, 1.

${ }^{61}$ Eusebio, Praep. evang., X, 2.

${ }^{62}$ De gloria Athen., 3, p. 346 f - 347 a; De aud. poet., 3, p. 18 a.

${ }^{63}$ Hom., 19.
} 
eloquentes homines saepe numero, tum pictores exprimunt, illi sermone ornantes, hi tabulis delineantes, et utrique multos ad fortitudinem excitarunt.

Soggiungemo nondimeno noi che, se bene il fine pare il medesimo d'amendue, l'effetto però, che da tal fine esce, si scuopre molto più ampio e con più fecondità si diffonde nelle pitture che nei libri, quando però le pitture possono esprimere quello che i libri contengono; perciò che i libri sono letti solo dagl'intelligenti, che sono pochi, ma le pitture abbracciano universalmente tutte le sorti di persone. Al che serve molto a proposito quel che scrisse S. Giovanni Crisostomo ${ }^{64}$, ricercando la cagione perché la sacra Scrittura fosse publicata così tardi, come fu doppo la creazione del mondo almeno 2370 anni; ove egli risponde che ne' primi tempi volse Iddio ammaestrare gli uomini per l'istesse opere sue e cose create, che potessero essere universalmente apprese da [p. 148] tutti, allegando il detto del salmo: Caeli enarrant gloriam Dei et opera manuum eius annunciat firmamentum $^{65}$. Il che, dice egli, non poteva egualmente riuscire per mezzo de' libri, che sono intesi da pochi, e soggionge: Si per libros nos Deus docuisset, illos tantum peritus didicisset, non imperitus; et dives emisset librum, sed non pauper; et deinde illum librum intellexisset tantum noscens illam linguam, sed non Scytha, Barbarus, Indus et Aegyptius. Verum ex aspectu rerum creatarum, qui liber est communis, fructum capit idiota, pauper, dives et quicunque alius etc. E si serve a questo proposito del versicolo del salmo detto di sopra: Non sunt loquelae neque sermones quorum non audiantur voces eorum, intendendo egli che voglia dire: Non ci è gente o lingua o condizione di persone, che non possa intendere bene quelle voci tacite ch'escono dall'opere create d'Iddio, le quali rappresentano la grandezza e maestà sua, come scrisse ancora il Nazianzeno ${ }^{66}$; la quale ragione ciascun vede quanto ben faccia al proposito delle imagini che rappresentano l'istesse creature di Dio nella loro forma, e conseguentemente si fanno conoscere et intendere da tutti: il che così non possono fare i libri. Oltre che ci sono ancora molti altri effetti notabili propri e particolari delle imagini, di che al suo luogo parlaremo ${ }^{67}$.

Resta la terza parte, che è dei mezzi ch'usano i libri al persuadere. Intorno a che dicemo che, solendosi nell'arte oratoria assignare tre principali, che sono il dilettare, l'insegnare et il commovere $^{68}$, non è dubbio che i medesimi cadono ancor notabilmente nella pittura. E perché altrove diffusamente se ne tratterà $^{69}$, per ora basterà ricordare che le pitture tanto più sono atte ad essercitare e servirsi di ciascuno di questi mezzi, quanto che possono essere da tutti apprese indifferentemente, il che non aviene così de' libri; oltre che [p. 149] S. Basilio in una sua omilia ${ }^{70}, o$ lo dicesse per modestia o per verità, pare che attribuisca molto più all'arte della pittura che alla sua facoltà dello scrivere, dicendo così: Exurgite nunc, o splendidi egregiorum factorum athleticorum pictores, imperatoris imaginem mutilatam vestris artibus magnificate, coronatum athletam obscurius a me depictum vestrae sapientiae coloribus illustrate. Discedo fortium martyris factorum pictura a vobis superatus, gaudeo tali vestrae fortitudinis victoria hodie victus, video manus ad ignem, luctam exactius a vobis depictam, video luctatorem in vestra imagine illustrius a vobis depictum. Né in questo ci restringemo più a' libri degli istorici che degli oratori o de' poeti o d'altri, poi che la pittura, in alcuna cosa più all'uno et in alcun'altra più all'altro accostandosi, diffonde in

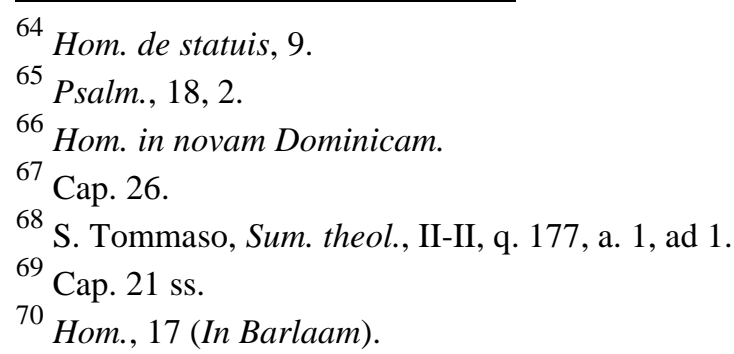


tutti i soggetti la sua grandezza, communicandosi a tutte le materie, a tutti i luoghi et a tutte le persone, quasi imitando in ciò la divina natura et eccellenza. Il che potrà servire in tanto per memoria de' cristiani pittori, acciò, ricordandosi essi che sono quelli che compongono i libri per lo popolo, da leggersi publicamente per salute universale, tanto più si ingegnino e sforzino di formare le imagini che rispondine a questo fine così alto e glorioso.

\section{CAP. VI.}

Se l'arte di formare le imagini si ha da numerare tra le nobili o ignobili.

Non ostanti le cose dette nei capi precedenti, suole dubitarsi da molti se quest'arte di formare imagini debba essere posta tra le nobili o ignobili. Intorno a che ritroviamo non solo opinioni per una e per l'altra parte, ma altri ancora pareri di mezzo, che cercano, secondo vari casi, difendere questa e quella opinione. [p. 150]

Quegli che dicono che queste sono arti ignobili e mecaniche, pare che tra l'altre ragioni si muovano, che, sì come negli uomini si trovano alcuni per natura servi, quali vagliono solamente nella forza del corpo, et altri per natura liberi, che per altezza, d'intelletto sono atti a comandare agli altri; così quell' arti c'hanno bisogno di fatica corporale e consistono in facitura di mano, dicono non poter essere se non servili et ignobili, avilendo e bruttando il corpo nel loro essercizio, sì come scrisse Aristotele $^{71}$; Sordidissimi sunt, in quibus corpora inquinantur, maxime illiberales, qui usu plurimo corporis egent. E di questo parere leggiamo essere stato Seneca chiaramente, che in una epistola sua a Lucilio ${ }^{72}$ dice queste parole: Non facile adducor ut in numerum liberalium artium pictores recipiam, non magis quam statuarios aut marmorarios aut caeteros luxuriae ministros; e Vulpiano iureconsulto, scrivendo delle opere fabrili, numera tra esse quelle dei pittori ${ }^{73}$, e similmente Valerio Massimo, parlando di Q. Fabio Pittore, dice ${ }^{74}$ : Caeterum sordido studio deditum ingenium, qualemcunque illum laborem suum silentio obliterari noluit.

Dall'altra parte veggiamo che presso i re e popoli antichi fu grandemente stimata e riputata la nobiltà sua, dicendo Plinio di essa ${ }^{75}$ : Arte quondam nobili tunc cum expeteretur a regibus populisque, et illos nobilitante, quos esset dignata posteris tradere. E presso i Romani Quinto Fabio prese il cognome con la casata sua dalla pittura, dicendo l'istesso Plinio ${ }^{76}$ : Apud Romanos quoque honos huic arti mature contigit, siquidem cognomina ex ea Pictorum traxerunt Fabii clarissimae gentis, princepsque eius cognominis ipse aedem Salutis pinxit. Et in molti altri luoghi ${ }^{77}$ fa testimonio amplissimo della nobiltà sua e tra gli altri dice de' Greci $^{78}$ : Effectum est Sicyone primum, deinde et in tota Graecia, ut pueri ingenui ante omnia diagra [p. 151] phicen, hoc est picturam in buxo, docerentur, recipereturque ars ea in primum gradum liberalium. Semper quidem honos ei fuit, ut ingenui eam exercerent, mox ut honesti, perpetuo interdicto ne servitia docerentur.

\footnotetext{
${ }^{71}$ Polit., I, 7; VIII, 2.

72 Epist., 89.

${ }^{73}$ Dig., XII, 6, 26, 12.

${ }^{74}$ VIII, 14, 6.

${ }^{75}$ Nat. hist., XXXV, 1.

${ }^{76}$ Ibid., 4.

${ }^{77}$ Ibid., $2.8 \mathrm{~s}$.

78 Ibid., 10.
} 
Et Aristotele nella Politica ${ }^{79}$, numerando le arti in che deono ammaestrarsi i giovani, dopo che ha nominata tra quelle la pittura soggiunge che questa arte si deve imparare non solo per la utilità, sed quia reddit hominem contemplatorem pulchritudinis, quae in corporibus versatur. Quaerere enim omnibus in rebus utilitatem minime convenit viris magnanimis atque ingenuis. Onde e gli imperatori Teodosio e Valentiniano nelle sue leggi congiunsero i professori delle arti liberali con quei della pittura, dandoli privilegio che fossero liberi et essenti dal carico d'alloggiare soldati ${ }^{80}$.

Ma sopra gli altri Filone Ebreo, tanto commendato da S. Ieronimo, così scrive in laude della pittura $^{81}$ : Quidam picturandi artem adeo neglectam vilemque existimant, ut eam ad textores relegent; ego vero etiam nomen eius admiror, praesertim quando terrae segmenta, caelestes circulos, animalium stirpiumque differentias et hunc mundi multiformem contextum aspicio. Quae admiratio cogit me credere, huius opificem invenisse artem variegandi, atque ita et inventorem veneror et inventum eius honoro, operis vero ipsius spectaculo stupeo.

Tra queste contrarietà altri si sono appigliati ad un temperamento, che talora concede a quest'arti la nobiltà, e talora la leva loro. Hanno detto che, quando elle si fanno a richiesta d'altri e per puro guadagno e mercede, che allora tengono del servile, perché si fanno quasi per commandamento et il proprio dei servi è fare a modo d'altri ${ }^{82}$; onde scrisse Cicerone ${ }^{83}$ : Illiberales et sordidi sunt quaestus mercenariorum [p. 152] omnium, quorum operae, non quorum artes emuntur. Est enim in illis ipsa merces authoramentum servitutis. Ma quando si facessero per proprio fine et elezzione nostra, o sia diporto o alcuno onesto essercizio o qualche altra lodevole occasione, come scrive Plutarco ${ }^{84}$ di Polignoto, pittore famosissimo; allora dicono che ritengono il grado tra le liberali, perché proprio dei liberi è il reggersi da sé stessi. E questa distinzione hanno cercato d'autenticare con l'essempio di molti altri essercizii admessi per servizio publico, i quali diversamente sono considerati quando sono fatti per premio o liberalmente ${ }^{85}$. Ma questa differenza patisce molte difficultà: prima, perché non è essenziale dell'arte, ma più tosto accidentale, et appartiene alla persona dell'artefice. Dipoi, perché si vedono molti altri essercitare le professioni loro con premii e stipendii, né perciò patiscono nella riputazione detrimento alcuno, come sono i lettori publici nelle università, gli avvocati, medici et altri molti ${ }^{86}$; et ultimamente, perché la mercede et il premio non altera ordinariamente la condizione dell' azzione, se non nelle cose meramente spirituali, come è sentenza de' teologi e canonisti ${ }^{87}$.

Altri $^{88}$ pare che abbiano voluto sentire in questo, come nella mercanzia, della quale fu già risposto che, se era di cose minute e vili, ella ancora si rendeva umile et abietta, ma se di cose grandi e preziose, venia riputata allora magnifica, come scrisse Marco Tullio, dicendo: Mercatura, si tenuis est, sordida putanda est, sin magna et copiosa, multa undique apportans, multisque sine

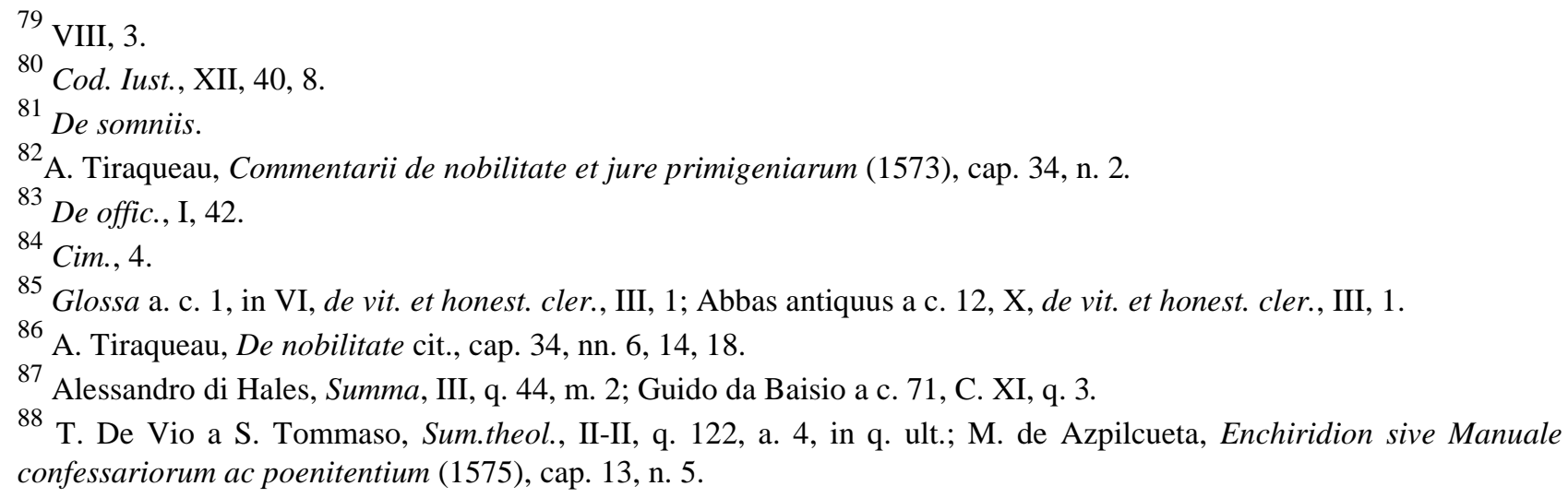


vanitate impertiens, non [p. 153] est admodum vituperanda ${ }^{89}$. Onde nella pittura ancora hanno detto che ella seguita i soggetti suoi e che dipende dalla qualità delle cose in che si essercita; le quali se saranno di pregio e magnifiche, come figure et imagini con esquisito dissegno, ella ancora si innalza; ma se di cose picciole et oscure, come fatte a stampa, che dimandono essi di scudaria e senza molta speculazione, ella parimente si avilisce.

Ma né anco questo pare che stia a martello, non dipendendo la vera nobiltà di queste arti del formare le imagini né dalla materia, né dal luogo, né dai colori, né d'altra simile circostanza, ma principalmente dalla somiglianza rappresentata col suo decoro, sì come altrove si è detto.

Per venire dunque a qualche risoluzione, dicemo essere necessario affermare prima il punto della controversia e chiarire bene come s'intenda la nobiltà d'una cosa et in che sia posta. Ma questo sappiamo essere un campo larghissimo, sendone stato scritto diffusamente da molti e trovandosi in ciò diverse opinioni: altre secondo i termini de' iuresconsulti, altre secondo i filosofi et altre secondo altri pareri.

Ma noi, che incidentemente siamo scorsi in quella materia, non per disputarla sottilmente, ma solo per levar alcune difficultà che potriano nel progresso del trattato nostro ingombrare l'animo del lettore, tocheremo solo due opinioni, le più universali e che più servono al proposito nostro: l'una è secondo i dotti e savii del mondo, l'altra secondo la disciplina cristiana; acciò che dall'una e l'altra resti tanto più chiaro il vero onore e pregio di quest'arte.

Dicono i primi, che la nobiltà di una cosa si può considerare in due modi: l'uno, che sta nel parere degli uomini e dipende più tosto dal giudizio d'altri che dalla eccellenza stessa della cosa e però si chiama nobiltà estrinseca e per accidente; l'altra consiste nella natura propria e perfezzione della cosa, la quale dimandano nobiltà intrinseca, perché nasce da sé stessa e partecipa della filosofia, o almeno può in qualche modo appartenere a quella. [p. 154]

Noi dunque giudichiamo che amendue queste nobiltà ragionevolmente si possano attribuire all'arte di che parliamo; perché, quanto alla prima, nascendo tale nobiltà da una chiara notizia che si ha della qualità delle cose, certo è ch'ella non ha la sua propria fermezza e stabilità perpetua nelle dette cose, ma piglia la dignità sua dalla stima e riputazione in che sono tenute elle da altri. La quale, perché varia spesse volte secondo i luoghi, costumi et ordini de' popoli, però l'hanno chiamata nobiltà accidentale, vedendosi in un luogo alcune cose o persone essere pregiate et in un altro avilite. Laonde i iureconsulti ${ }^{90}$, dopo l'avere longamente trattato e disputato di questa nobiltà, ch'addimandano civile, si risolsero a dire che nobile si avea a dimandare colui che era per tale avuto e riputato nel luogo. E di qui volsero inferire ch'un'istessa cosa potesse essere nobile et ignobile, secondo il concetto e credito ch'avea presso le persone dei luoghi.

Per la qual cosa, venendosi al particolare di quest'arte di formare l'imagini, crederessimo che allora si potesse riputare nobile e degna, quando in alcun luogo fosse per tale dal popolo ricevuta, il quale se bene di poi mutasse parere, cominciando ad averla per vile, non resterebbe però ella di non aversi goduta dianzi quella nobiltà, la quale per questo si chiama accidentale, per essere incerta e variabile. E se ad alcuno paresse strano e disdicevole che sia fatto il popolo censore della dignità d'un'arte, della quale ne fa talora giudicio molto alla cieca, si risponde che in questo si conosce la differenza tra la nobiltà intrinseca, di che poi parleremo, e l'estrinseca, della quale ora dicemo: poi che quella sta appoggiata al saldo fondamento di sé stessa e questa dipende tutta dal parere altrui. A che soggiongemo che neanco questa è totalmente incerta e mutabile, anzi per lo più giusta $\mathrm{e}$

\footnotetext{
${ }^{89}$ Cicerone, De off. I, 42.

90 Bartolo e Iohannes de Platea a Cod. Iust., XII, I, 1; A. Alciati a Dig., L, 16, 207; B. de Chasseneux. Catalogus gloriae mundi (1576), VIII, n. 16; A. Tiraqueau, De nobilitate cit., cap. 10.
} 
regolata, imperò che, parlandosi in queste maniere per quello che [p. 155] per lo più suol accadere, veggiamo noi per isperienza che questa varietà dell'essere riputata la pittura in un luogo molto pregiata e degna, et in altro di assai minor pregio, non nasce principalmente da ignoranza o volubilità de' popoli, presso i quali non dureriano gli eccellenti artefici poco pregiati, ma nasce dalla qualità di quei che l'essercitano e dalle cose in che si adoperano. Perché, sì come il resto delle arti, scienzie e discipline, quando sono trattate da soggetti di gran perizia et eccellenza, sono grandemente stimate, e per lo contrario, dove siano maneggiate da autori deboli et imperiti, restano molto abiette e vili; così aviene a' pittori et altri simili, i quali ordinariamente sogliono essere stimati più o meno, secondo l'eccellenza loro e l'openione che n'hanno i popoli, presso i quali non le arti, ma i professori dell'arti sono quelli che danno il tratto alla billancia. Sì come si legge dell'agricoltura, che nel principio della republica romana, quando fu da persone gravi essercitata e per le mani loro coltivata, fu anco tenuta nobilissima, ma quando poi, corrotta l'antica republica, rimase quell'arte presso di persone più volgari, fu ella insieme riputata vile ${ }^{91}$.

Da che possiamo inferire che dalla qualità degli artefici riceverà parimente quest'arte della pittura e scoltura il suo maggiore e minore ornamento, trovandosi tra essi gran differenza, non solo quanto all'ingegno e sufficienza, ma ancora quanto all'invenzione e soggetti in che si occupano: perché è raccontato ${ }^{92}$ che tra gli antichi alcuni imitavano sempre le cose più eccellenti, altri le cose più basse, altri le cose communi e volgari, sì come da Plinio ${ }^{93}$ è nominato un pittore che non pingeva se non tonstrinas, sutrinas, asellos, obsonia ac similia et ob id cognominatus rhyparographus. Onde appresso Tebani scrive Eliano ${ }^{94}$ che vi era legge che i pittori e scultori

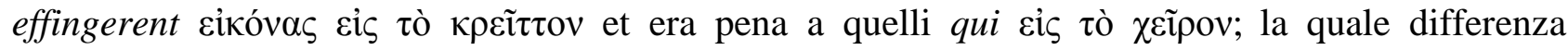
sappiamo nelle nostre età [p. 156] essere spesse volte accaduta e tuttavia vedersi. Sì che, quanto appartiene all'eccellenza dell'arte, leggiamo ch'ella è stata talmente molte volte in pregio, che ancora gli imperatori, filosofi o poeti grandi l'hanno abbracciata; secondo che si legge d'Adriano imperatore, di Marco Antonino filosofo et imperatore, d'Alessandro Severo parimente imperatore, di Socrate, di Platone, di Eschine, d'Euripide e di Metrodoro, di che scrive Plinio ${ }^{95}$ quod erat pictor idemque philosophus, magnae in utraque scientia authoritatis; et è narrato nelle croniche ${ }^{96}$ che Costantino VIII imperatore, nell'anno 918 cacciato dall'imperio, sostentò la vita con l'arte della pittura, essercitata da lui egreggiamente. Anzi, di quei ancora che fanno imagine e lavori di terra cotta o di gesso o di cose simili, detti da' latini figuli, scrive Plinio multas gentes, oppida, nationes hac arte nobilitatas fuisse, videlicet etc. E di Numa Pompilio, sapientissimo re, si scrive che in Roma septimum collegium figulorum istituit ${ }^{97}$; oltre molt'altri, che in quest'arte del formare imagini sono stati dagli autori con grandissima lode et onore del nome loro celebrati ${ }^{98}$.

Quanto all'altra nobiltà, che si chiama intrinseca, dicemo che essa ancora molto bene conviene a quest'arte, perché, essendo la pittura assomigliata alla poesia e che in un certo modo piglia regola

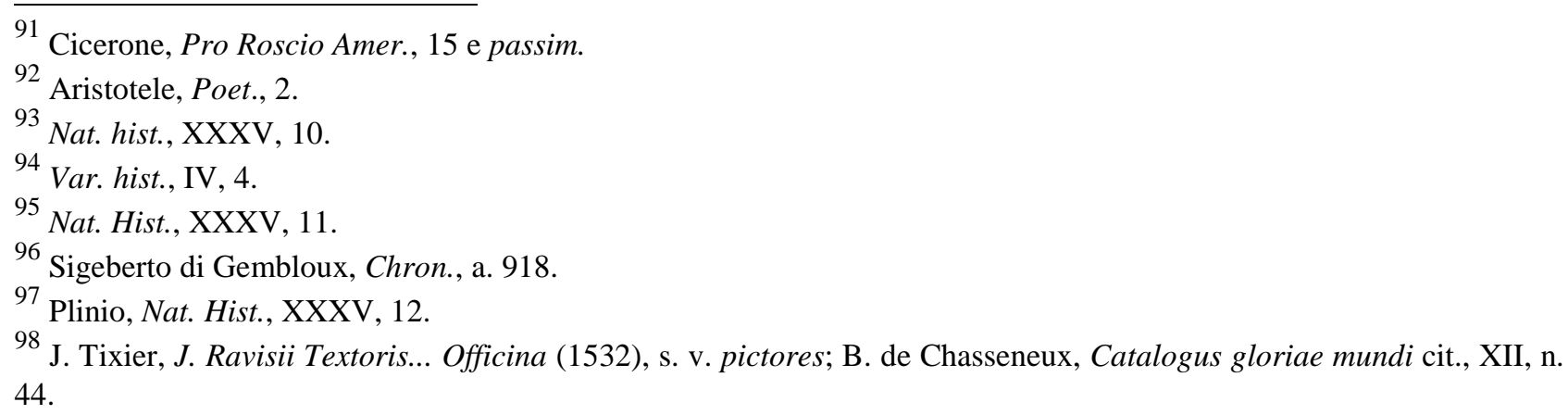


da essa, dicendo Aristotele ${ }^{99}$ che gli eccellenti pittori deono imitare gli eccellenti poeti; però dicemo che, sì come la poesia è posta tra le arti nobili, così deve essere tra quelle collocata la pittura, poi che la poesia, conforme a quello che narrano i gesti onorati d'uomini e di donne, vien a dare agli altri essempii del viver bene, il che è officio di arte nobile, detta morale; così la pittura, rappresentandoci avanti gli occhi quelli che in alcuna virtù sono [p. 157] stati eccellenti, conseguentemente viene ad ammaestrare et eccitare gli uomini ad imitarli. Oltre che, sì come tutte le professioni degli studii e scienzie sono onoratissime, così questa dell'imagini, che serve per dottrina aperta al popolo, deve anch'ella secondo il grado suo essere tenuta per molto nobile e degna; tanto più che è noto a ciascuno, che quell'arti che servono per sé alla filosofia attiva e contemplativa, dove secondo il giudicio degli antichi era posta la felicità umana, sono state sempre tenute ingenue e liberali, perciò che s'insegnavano a' liberi et ingenui e non a' servi: come sono le sette arti chiamate liberali, a ciascuna de [sic] quali, e massime alla geometrica e sue parti, servendo, per dire così, la pittura, come quella che con dissegni le va imitando e rappresentando agli altri, in conseguenza si può dire che si riferisce in certo modo alla filosofia e perciò sia ancor essa arte ingenua e liberale.

E se alcuno s'opponesse, dicendo che, per maneggiare queste arti colori stemperati, carboni, terra, sassi, scarpelli, cera e materie immonde, non possono chiamarsi se non sordide e mecaniche; si risponde che, per essere quest'istrumenti necessarii all' arte, non le levano il pregio, sì come né lo inchiostro all'advocato per iscrivere consegli, o al teologo per comporre omelie o sermoni, leva la molta eccellenza della professione; né toglie riputazione al matematico o all'astrologo il trovarsi sempre con sesti, tavole, compassi, astrolabii e misure in mano, imperò che tutte le facoltà hanno bisogno d'alcuni istrumenti materiali.

E però hanno gli autori ${ }^{100}$ dimandate mecaniche solo quelle arti, nelle quali con la fatica principale del corpo non solo si snervano i membri, ma si rendono ancora languidi gli spiriti della mente, avendo scritto Aristotele ${ }^{101}$ : Artes illae, quaecunque deterius disponunt corpus et cuncta mercenaria exercitia, sordida nuncupamus: mentem enim occupatam et vilem reddunt; [p. 158] nel qual numero non è compresa questa delle imagini, sì come scrive Galeno ${ }^{102}$, il quale, avendo divise dall'arti servili le oneste e liberali, soggiunge queste parole: Istis adde, si placet, plasticen et picturam; nam etsi utraque opificis manu tractatur, neutra tamen viribus iuvenilis corporis eget.

Sì che, restringendo ora l'una e l'altra nobiltà insieme, dicemo che, se il prezzo d'una cosa, la difficultà di farla, il pregio in che si ha dopo' che è fatta è l'utile che apporta, l'onore che gli è attribuito dalle persone grandi, l'eccitamento che indi nasce alla virtù e la disciplina che può causare nei popoli sono atte a rendere un' arte o un artefice veramente nobile; non ha dubbio che, potendo tutte concorrere in queste di che parliamo, resteranno adornate di sommo pregio, dignità e splendore, oltre gli altri privilegii di che nel capitolo seguente si ragionerà.

\section{CAP. VII.}

Che l'arte del formare le imagini, cristianamente essercitata, riesce nobilissima.

Oltra le due nobiltà politiche dette di sopra, resta la cristiana, tanto più sublime et onorata delle

\footnotetext{
99 Poet., 2.

100 Senofonte, Oecon., 4.

101 Polit., VIII, 2.

102 Protrept. ad artes, in fine.
} 
altre, quanto la legge evangelica, portata al mondo dal Salvatore nostro, avanza di perfezzione tutte l'altre di gran lunga che siano state giamai nei secoli adietro ${ }^{103}$. La qual nobiltà affirmiamo noi che giustamente viene ancor essa attribuita all'arte di che parliamo.

Né ci movemo a dir questo, perché tal arte sia stata ordinata dal grande Dio, sì come altrove si dimostrerà; perciò che questo concluderebbe, che tutte le cose del mondo, sen [p. 159] sibili et insensibili, fossero indifferentemente nobili, poi che escono tutte da un fonte e da un autore istesso. Ma dicemo che, quantonque Iddio sia autore commune di tutte le cose, ha però creata ciascuna nei suoi gradi, altre superiori, altre inferiori, altre più et altre meno perfette, altre picciole, altre grandi, accioché l'une servissero all'altre. E parimente ha instituito diversi ordini di persone, d'ufficii maggiori e minori, che così è stato conveniente alla bellezza, alla necessità et alla perfezzione dell'universo ${ }^{104}$; sì come veggiamo che tra i membri del corpo nostro, che pure tutti sono fattura delle mani sue, alcuni sono più ignobili degli altri, che così li chiama $\mathrm{S}$. Paolo ${ }^{105}$, che v'aggionge ${ }^{106}$ : Non omnis caro eadem caro, sed alia hominum, alia pecorum, alia volucrum, alia piscium; et corpora caelestia, et corpora terrestria, sed alia quidem caelestium gloria, alia autem terrestrium, alia claritas solis, alia claritas lunae et alia claritas stellarum.

Ma noi ci movemo per lo privilegio della legge cristiana, la qual con modo meraviglioso e supremo nobilita et illustra le cose sue; e questo in due modi: l'uno, ch'è generale a tutte le cose cristianamente da noi operate; l'altro è particolare e proprio di questa arte e di alcune altre sorti di operazioni. Et amendue questi modi giudichiamo noi che egreggiamente convengano al proposito nostro.

Onde, per miglior intelligenza del primo, è da sapere che tutte quelle cose, le quali possono essere communi anco a gentili et infedeli, come sono i beni dimandati di natura, o quei chiamati esterni, o quelli che sono azzioni puramente morali, non sono presso la religione cristiana stimate cose di molto pregio, poi che con quelle non si acquista il regno del cielo, al quale siamo nati. E però quella nobiltà civile che si è detta di sopra, o intrinseca o estrinseca, se non è accompagnata da spirito cristiano et usata a gloria di Dio, [p. 160] riesce molto vana e frustatoria; di che spesse volte ci avertiscono i sacri dottori ${ }^{107}$, acciò non ci fondiamo et inganniamo nei titoli di questa fallace nobiltà e lasciamo quella che veramente essalta gli uomini: sì come tra gli altri scrive S. Girolamo $^{108}$ in una epistola, dicendo: Nescit religio nostra personas accipere, nec conditiones hominum, sed animos suscipit singulorum: servum et nobilem de manibus pronuntiat: sola apud Deum libertas est, non servire peccatis; summa nobilitas apud Deum est, clarum esse virtutibus. Quid apud Deum in viris nobilius Petro, qui piscator et pauper fuit? Quid in faeminis beata Maria illustrius, quae sponsa fabri describitur? Sed illi piscatori et pauperi coelestis regni a Christo creduntur claves; haec sponsa fabri meruit esse mater illius, a quo ipsae claves datae sunt. Elegit enim Deus ignobilia et contemptibilia huius mundi, ut potentes ac nobiles ad humilitatem facilius adduceret.

Da che si vede che la religione cristiana altrimente misura le cose di quello che facciano l'altre leggi, imperoché non si contenta della forma loro esteriore, né anco della qualità intrinseca o d'altre

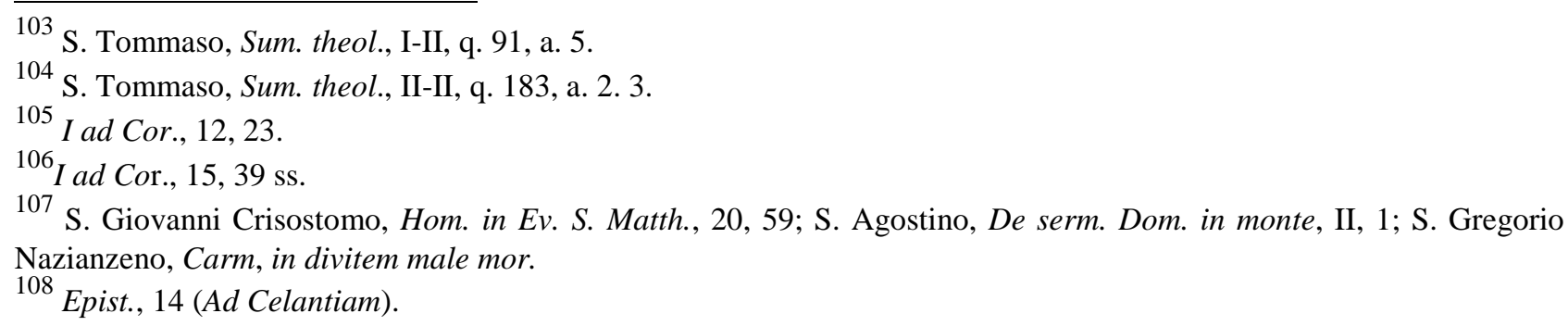


circonstanzie con che siano state fatte, se non sono state accompagnate da pura intenzione di servire a Dio, e che a lui siano state offerte come sacrificio delle mani nostre; perché, quando a questo fine sono dirizzate, egli subito le adorna e le imprime il carattere della celeste nobiltà, come supremo artefice che dà perfezzione a tutte le cose indirizzate a lui. Il che hanno voluto alcuni che si cavi da quelle parole del Salvatore, quando dice ${ }^{109}$ : Cum exaltatus fuero, omnia traham ad me ipsum. E per lo contrario tutte le altre cose, se bene a noi paiono grandi et illustri, se bene da personaggi eccelsi vengono fatte, et anco con debiti modi essequite, quando però dalla superna sua grazia non siano accettate, tutte riescono vili, tutte ignobili [p. 161] e di niun momento, come egli stesso significò dicendo ${ }^{110}$ : Si quis in me non manserit, mittetur foras sicut palmes, et arescet, et in ignem mittent, et ardet. La qual differenza molto bene notò S. Agostino, quando scrisse ${ }^{111}$ : Et si usus quarundam rerum similis videtur nobis esse cum gentibus, sicuti cibi et potus, tectorum, vestimentorum et lavacrorun; longe tamen aliter hisce rebus utitur qui ad alium finem usum earum refert, et aliter qui ex his Deo gratias agit.

Dalle quai cose vogliamo inferire che, potendosi per questa strada nobilitare tutte le cose, ancor che picciole e basse, anzi, per questa ragione non ritrovandosi, come bene dice S. Agostino ${ }^{112}$, cosa alcuna che secondo la regola della disciplina cristiana assolutamente si possa chiamare picciola o leggiera, tanto più si applicherà questa nobiltà alle arti di che parliamo, quanto più seranno con la regola cristiana essercitate; talché si potrà dire con verità che molto più nobilmente et altamente oggi può un pittore cristiano fare le opere sue, di quello che facesse mai Apelle o Fidia o Protogene, o qualonque altro de' più famosi pittori o scultori della antichità.

Ma perché questa nobiltà può essere commune ancor a tutte le arti, quantunque meccaniche $\mathrm{e}$ vili, noi ora aggiungiamo un'altra nobiltà propria e peculiare a quest'arte, la quale si scuopre manifestamente dal formare che ella fa e rappresentare dinanzi agli occhi persone cumulatissime de meriti e che per la loro essemplare vita, piena d'ogni virtù, sono state sopra modo grate a Dio. Il che viene meravigliosamente ad illustrare e la fatica e l'arte e l'industria e tutto il corpo dell'opera accuratamente fatta a questo fine, non potendosi l'ingegno umano occupare in cosa più degna et onorata, che in essaltare dopo' il grande Dio quelli che sono stati partecipi della divina eccellenza. Al che s'aggionge un'altra ragione principalissima, cavata dal fine altissimo che si pretende di queste cristiane pitture: perché, essendo tutte le [p. 162] azzioni proprie di quella virtù, al fine della quale esse sono ordinate, e non avendo altra mira insomma tutte le sacre imagini, mediante gli atti religiosi che rappresentano, che di unire gli uomini con Dio, che è il fine della carità: ne segue manifestamente che l'essercizio del formare imagini si ridurrà alla carità, e perciò diverrà virtù dignissima e nobilissima.

E se alcuno dicesse che, anzi, per questo non doveria da cristiani tal arte essere tenuta in molta stima, percioché, avendo essi il vero lume delle cose e conoscendo quanto queste nostre artificiose sono inferiori alle vere, non doveriano abbassarsi a queste, ma stare sollevati alla contemplazione del sommo artefice del tutto, sì come scrisse quell' autore ${ }^{113}$, dicendo: Tu, quem haec ficta et fucis inanibus adumbrata usque adeo delectant, attolle oculos ad illum, qui os humanum sensibus, animam intellectu, coelum astris, floribus terram pinxit, et spernes quos mirabaris artifices, quos

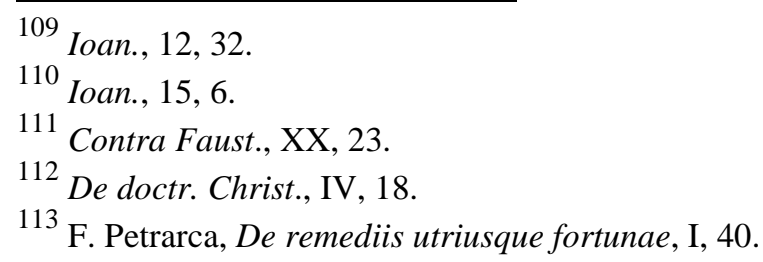


vulgus errorum princeps invexit; e dipoi ${ }^{114}$ : Profecto si illum aspicies, qui solidam terram, fretum mobile, coelum volubile fecit, quique non fictos, sed veros vivosque homines et quadrupedes terrae, coelo volucres dedit, puto ut Protogenem atque Apellem, sic etiam Polycratum spernes et Phidiam; noi rispondemo che, poi che la imbecillità nostra ordinariamente non comporta che possiamo salire alla contemplazione delle cose sublimi senza l'appoggio di queste inferiori, però è commendata questa arte come mezzo et istrumento per ascendere più alto e quindi ritiene giustamente la sua dignità, sì come alcune virtù, se bene sono mezzane paragonate ad altre virtù maggiori, restano nondimeno nel coro delle virtù e sono per la necessità et importanza loro da tutti pregiate et onorate; oltra molti altri effetti degni di meraviglia, causati dalle imagini, che al suo luogo si diranno.

Ora per tutte queste cose crediamo che debba essere chiaro, quanta sia la dignità, grandezza et eccellenza di que [p. 163] sta arte, poi che viene adornata di quatro titoli di rara e singolare nobiltà, due secondo il consenso de' savii del mondo, e due secondo la verità nostra evangelica; il che per più chiarezza con varii essempi ancora si mostrerà.

\section{CAP. VIII.}

Essempii d'alcuni pittori, scultori et altri formatori de imagini, che sono stati nel numero de' santi e beati, o riputati di buonissima et essemplare vita.

Alle ragioni dette di sopra, per corroborare tanto più la dignità di quest'arte, aggiungeremo ora la memoria d'alcuni che, cristianamente essercitandosi in essa, hanno stabilita la chiarezza della nobiltà sua con eterna gloria. Imperò che, oltre i due nominati nel Testamento Vecchio ${ }^{115}$ Bezeleel et Ooliab, ch'ebbero la scienzia infusa da Dio, come dice la Scrittura, nell'arte del formare di oro, d'argento, di bronzo, di marmo e d'altre materie ogni sorte di lavoro; et oltre l'evangelista S. Luca, chiaro et illustre nel dipingere, di che noi in altro luogo parleremo ${ }^{116}$ : recita l'istoria ecclesiastica che cinque scultori, osservanti dell'onore d'Iddio, sotto Diocleziano imperatore prima volsero sostenere l'accerbissimo martirio, che fabricare idoli o altramente con la loro arte fare ignominia al culto del suo Signore; i nomi de' quali furono Claudio, Nicostrato, Sinfroniano, Castorio e Simplicio, de' quali la santa Chiesa fa menzione nel martirologio l'ottavo giorno di novembre ${ }^{117}$. E nella vita loro si legge ${ }^{118}$, quod fuerunt artifices insignissimi et marmorum caesores probatissimi, et artem suam Crucis signo muniebant. [p. 164]

È narrato da S. Atanasio ${ }^{119}$, e nella Sinodo Nicena seconda, e da altri, che San Nicodemo fece con le proprie mani l'imagine del Salvatore, che fu poi portata a Berito, dalla quale venne poi quel miracolo famoso del sangue che ognuno sa.

Di un altro pittore, detto Eucrazio, scrivesi nella vita di San Cornelio Centurione ${ }^{120}$ che, sendo stato ricercato di dipingere l'imagine di questo santo et avendo egli mostrato di farlo poco volentieri, cadde in una grave malattia; ma di poi, sendoli apparso il detto santo e mostratali la vera effigie sua, il pittore, accortosi dell'errore e mutato pensiero, riconoscendo il fallo, con gran

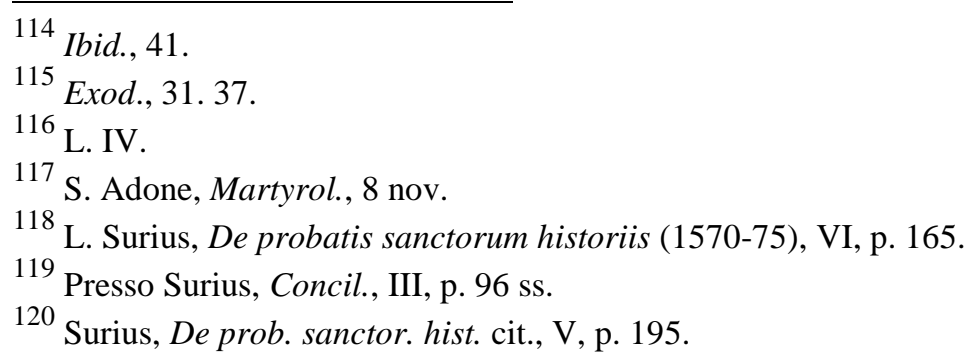


pentimento e molta pietà si mosse a ritrarlo, il che gli successe felicemente, e ne fu liberato.

Scrive il Metafraste nella vita di S. Eutichio, patriarca Constantinopolitano ${ }^{121}$, che, avendo un giovine, perito nella pittura, cancellata da un muro la imagine di Venere per mettervi alcune imagini de' santi, il Demonio, che custodiva quella imagine di Venere, s'aventò alla mano del pittore, che subito enfiataseli et impiagatasi, gli minacciava pericolo della vita; ma che il pittore, tutto zelante di devozione, fu col divino aiuto per mezzo di quel santo liberato, il quale egli per gratitudine del beneficio volse lasciare nell' istesso luogo ritratto; e dice: Quo in loco pictor vulnus acceperat, in eo memoriae et grati animi declarandi causa sancti viri depinxit imaginem, ut manus, quae curationis benefitium acceperat, medicum suum secundum Deum testaretur.

Il detto Metafraste nella vita di S. Anastasio ${ }^{122}$ martire persa racconta di uno, il quale facea l'arte di getto d'argento et anco era incantatore, che, avendolo S. Anastasio menato nelle chiese, dove si vedevano dipinti nei muri i miracoli e gloriosi trionfi dei martiri, si convertì a Cristo signor nostro. [p. 165]

Si narra ancora nella vita di S. Gregorio papa ${ }^{123}$ d'un monaco pittore, detto Saturnino, che tra l'altre virtù sue sendo divoto di S. Gregorio, dipinse la imagine sua posta nel mezzo degli apostoli S. Pietro e S. Paolo; e piacque a Dio tanto questa sua divozione, che volse privilegiare notabilmente quella imagine, in modo che alcune volte le si trovava innanzi una candela ardente, senza che alcuno gliel'avesse accesa.

A questi si aggiunge un monaco chiamato Lazaro, pittore segnalatissimo, come narra il Zonara $^{124}$, che avendolo Teofilo imperatore con rabbioso furore perseguitato, perché si dilettava di dipingere l'imagini sacre, et avendolo doppo molte crudeli battiture e cruciati rinchiuso in carcere, rinovando egli la sua attrocità contra la persona del monaco, causò il miracolo che narra con queste parole: Pictor cum ex plagis illis recreatus iterum manus sacrarum imaginum picturae admoveret, ignitas laminas tyrannus eius manibus admoveri iussit, ne labores manuum eius pii adorare possent. Fertur enim confessor ille post ea tormenta carcere eiectus, plagas adhuc in manibus gestans, divina adiuvante gratia, venerandas imagines depinxisse, ac post tyranni interitum Salvatoris imaginem in carcere pinxisse, ac qualis nunc cernitur restituisse, cum prius imago iam olim erasa fuisset.

Bello essempio narra il Cedreno ${ }^{125}$ d'un servo di Dio, monaco e parimente pittore, chiamato Metodio, che con l'artifizio suo del dipingere, accommodandolo a' concetti cristiani e documenti del fine nostro, fu causa ch'el principe de' Bulgari, gentile, si riducesse alla fede nostra, poiché li fece vedere ritratto l'orrendo spettacolo del giorno del giudizio estremo. Il che egli narra con queste parole: Bogoris, Bulgarorum dux, cum novam domum aedificasset, monachum Methodium, Roma oriundum pingendique artificem, historiis eam to [p. 166] tam exornare iussit; divinoque instinctu factum est, ut non diceret nominatim quae animalia depingi vellet, sed pingere suo arbitratu, modo terribilis esset pictura, iuberet. Monachus secundum Christi adventum depinxit, quod nihil eo terribilius sciret. Princeps ab hac parte videns iustorum coetum expressum, ab altera impiorum supplicia perpetientium, edoctusque a pictore quid sibi ista vellent, illico suam eiuravit superstitionem, institutusque, ut diximus, a S. Episcopo divinis arcanis, intempesta nocte baptizatus est. Contra eum proceres Bulgarorum ac populus insurrexerunt et interficere conati sunt, quos ille

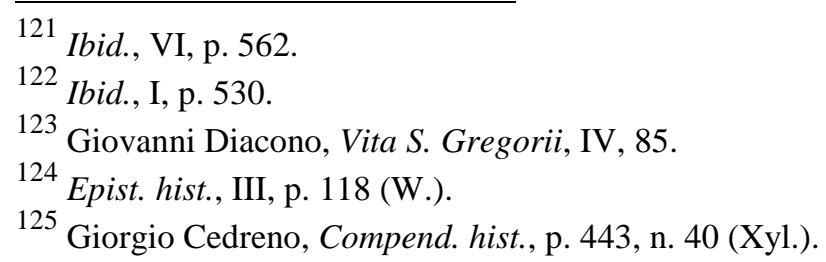


parva suorum manu, crucis signo praelato, fudit reque inopinata territos ad fidem Christi perduxit.

Di S. Eligio è narrato ${ }^{126}$ quod multas sanctorum ex auro, argento atque gemmis fabricavit thecas sive tumbas, et mausoleum sancti martyris Dionisii, e molt'altri lavori suoi notabili sono raccontati da S. Audoeno, vescovo Rotomagense, nella vita sua.

Si trova scritto ${ }^{127}$, per venire ad altri essempi più prossimi a' tempi nostri, d'un pittore romano chiamato Pietro Cavallini, che, oltre la eccellenza dell'arte, fu divotissimo et amicissimo de' poveri, e che, crescendo in lui l'età matura, si diede con tanto spirito alla religione, facendo vita veramente essemplare, che fu tenuto come santo. E si legge che di sua mano fu fatto il Crocifisso ch'ancor oggi si trova nella chiesa di S. Paolo fuori di Roma, il quale si dice che parlò a S. Brigida circa l'anno 1370, e che dipinse altre imagini sante, che hanno fatto miracoli notabili.

Aggiungesi il venerando fra' Giovanni da Fiesole ${ }^{128}$ dell'ordine de' predicatori, pittore segnalatissimo e celebre in tutta Europa. Questo fu chiamato padre veramente angelico e di singolar umiltà e simplicità cristiana. Fece molte degne pitture, non volendo però mai adoprarsi in altro che nelle [p. 167] imagini de' santi; e dicono che egli non metteva mai mano al penello, se prima non avea fatta orazione, e che non fece mai Crocifisso, che non si bagnasse le guancie di lagrime, e che le sue figure tutte aveano certa particolar aria di santo.

Nelle Croniche de' Padri dell'ordine de' Servi si narra che un pittore nell' anno 1252, trovandosi involto ne' peccati, più volte si mise per dipingere la faccia della veneranda Nonziata di Firenze, né mai puoté farlo; onde, dubitando ciò accaderli per le sue colpe, si risolse col sacramento della confessione di purgarsi. Il che fatto et avendo preparato tutti gli strumenti per finire l'opera, ecco (cosa maravigliosa!) che, accostandosele, ritrova il capo venerando et il resto della imagine così felicemente compita, che fu giudicato ciò essere stato fatto per ministerio degli angeli celesti e vi concorse tutto il popolo a vederla ${ }^{129}$.

Si legge ancora di fra' Bartolomeo ${ }^{130}$ dell'ordine dominicano, il quale, essendo eccellente pittore, entrò nella religione, dove attese compitamente all'osservanza della regola, et insieme fece varie pitture degne di memoria, che mostravano nella faccia non so che di celeste.

Di Alberto Durero, pittore e geometra germano, è reso nella vita sua chiaro testimonio, quanto egli nelle opere sue fosse osservante della santità et onestà, leggendosi fuisse illum sanctimoniae et pudoris diligentissimum custodem, et nullam spurcitiem, nullum dedecus in ipsius operibus extitisse, refugientibus scilicet talia omnia castissimis animi cogitationibus.

Sono stati, oltra questi, altri molti di varie nazioni et ordini di religiosi, che con la eccellenza della pittura, scultura o architettura ebbero congiunta una signalata pietà, divozione bontà cristiana, la quale lasciarono espressa nelle loro opere che sono rimase al mondo. Tra i quali potressimo nominar ancora alcuni bolognesi; ma perché non è stato nostra intenzione di tessere catalogo di pittori, ma solamente [p. 168] con alcuni essempii più celebri lasciare viva memoria ai lettori, quanto sia il valore e dignità di quest'arte, quando sia piamente essercitata, però, non volendo stenderci più oltre in questo, passeremo al contesto del soggetto nostro.

${ }^{126}$ L. Surius, De prob. sanctor. hist. cit., VI, Vita S. Eligii, cap. 32.

${ }_{127}$ G. Vasari, Vite de' più eccellenti pittori, scultori e architettori (1568).

128 S. Razzi, Vite dei Santi e Beati, così huomini come donne, del Sacro Ordine de' Frati Predicatori (1577).

${ }^{129}$ M. Poccianti, Chronicon Ordinis Servorum (1557), p. 14.

${ }^{130}$ G. Vasari, Vite cit. 


\section{CAP. IX.}

Della pittura e scoltura et altre arti che versano nel far imagini.

Trovandosi introdotte le imagini per servizio publico del mondo, et accompagnate da tanta dignità et ornamento come si è detto, non è meraviglia che cominciassero ancora con varie maniere gli ingegni ad adoperarsi per isprimerle, ora in materia d'oro, argento, metallo, marmo, legno, terra e simili, ora con lineamenti, ombre, colori et altri modi, servendosi ciascuno di quell'artificio ch'a lui tornava meglio e che aggradiva maggiormente al popolo. E perché tutte queste varie maniere di formare l'imagini pare che si riduchino a due arti principali, l'una chiamata pittura, l'altra scoltura, però di qui cominciò a nascere quella onorata contenzione, che ancora dura nel mondo, della precedenza loro; né sono mancati chi per l'una e chi per l'altra parte abbiano addotte varie ragioni et argomenti, anteponendo questa a quella.

Ma noi ora non intendiamo di farci giudici tra di loro, anzi, riconoscendole come care sorelle, nate di padre commune, chiamato il dissegno, abbiamo pensato, a guisa di quelli arbitri che, in vece di dare la vittoria ad alcuna delle parti, cercano, col concedere qualche cosa ad ognuna di esse, d'accordarle, così dover far noi e dire che, secondo diversi rispetti, ciascuna di loro talora sopravanzi l'altra, e che, quando ambe unite si ritrovano in un istesso soggetto, vi apportino scambievolmente grandissimo ornamento e lume.

Nell'una e l'altra chiara cosa è, col testimonio degli an [p. 169] tichi scrittori, che i lavori et opere fatte per mano di eccellenti artefici sono sempre stati di molto pregio nel mondo, et i loro autori grandissimamente stimati, e di essi conservatasi onoratissima memoria. E se dal prezzo delle opere si conosce la riputazione dell'arte, questo solo ancora può evidentemente dimostrare quanta sia stata la stima et eccellenza loro, leggendosi che alcune imagini sono state spesse volte con così smisurati prezzi comperate, che il narrarlo solo rende meraviglia ${ }^{131}$. Onde tra gli altri si narra d'un famoso pittore ne' suoi tempi, che, doppo lo avere con alcune opere sue adunato grandissimo tesoro, si risolse a donare ciò che faceva, e fu giudicato prudentissimo che egli donasse le cose alle quali nessuna sorte di prezzo poteva essere uguale ${ }^{132}$.

Leggemo parimente diversi re et imperatori grandissimi avere talmente stimato e presa la protezzione delle opere di questi eccellenti artefici, che averanno difese le città dal furore de' nemici e sacheggiamenti de' soldati solo per tema che insieme non si abbrusciasse qualche notabile opera di quest' arte, come avenne nel tempo di Demetrio re verso la città di Rodi ${ }^{133}$.

Et in somma, chi bene considera, non è sorte alcuna di merce che sia mai stata in tanta stima, in quanta sono state in tutti i tempi le ben fatte imagini, poi che non ci sono gioie, che con cura maggiore si conservino e che con maggiore noia e dolore si perdano, di quelle ${ }^{134}$. E ben a ragione, poiché, se quelle cose hanno ad essere tenute più care, che maggiore industria ricercano e più di rado riescono compitamente, chi considererà bene, ritroverà l'uno e l'altro avenire nelle belle e ben proporzionate imagini. La circonscrizzione del luogo ove sono; la superficie dei corpi; il componimento delle parti in una imagine sola; l'affetto overo accommodamento dell'istoria; il colorire con grazia; il com [p. 170] partire della luce e dell'ombra; il modo della prospettiva; le proporzioni; le distribuzioni; le discrezzioni; il dare grazia e dolcezza ad un sasso, e svolgere in maniera la figura che non paia di molti pezzi, et altre cose simil assai, fanno difficilissime queste

\footnotetext{
131 Strabone, XIV, 19.

132 Plinio, Nat. hist., XXXV, 9.

133 Plutarco, Demetr., 22.

${ }^{134}$ Plinio, Nat. hist., VII, 38; XXXIV, 7 s.; XXXV, 4. 8 s.; XXXVI, 5.
} 
arti del formare imagini, che siano, come si deve, riguardevoli et eccellenti. E però non è maraviglia se rarissime riescono bene, e quelle poche che riescono in grandissimo pregio e riputazione sono tenute da tutti.

Dalle quali cose, toccate da noi ora in brevità, potrà molto bene chi è dotato di giudicio comprendere quello che pretendiamo del valore e dignità dell'una e l'altra di queste arti.

\section{CAP. X.}

Che tutte le imagini si riducono a due capi principali: che sono o sacre o profane.

Si ricerca ora, che vediamo in quante maniere si possono formare le imagini, e che differenza sia tra loro. In che, se vorremo risguardare quello che si è detto di sopra, cioè che le imagini sono atte a rappresentare tutte le forme delle cose create o propriamente, come le sensibili, o largamente, come le intellettuali mediante le sensibili, si potrà dire che tante siano le differenze loro, quanto sono diverse le specie delle cose che si figurano.

Ma perché ciò potrebbe moltiplicare troppo le divisioni, alcuni, mirando la materia di che si fanno e l'artificio con che sono composte, hanno di qui preso a dare diversi e proprii nomi a l'imagini: chiamando quelle dove entrano colori e lineamenti, pitture; dove entra l'intaglio, scolture; dove è il getto o forma fatta con le mani, plastice col nome greco, e col latino ars figulina; e così de l'altre. Ma in vero questo modo ancora si stende troppo difusamente, essendo, per essempio, molto diversa la materia e l'artificio delle imagini [p. 171] che si fanno con l'ago da quelle che ricercano lo scarpello, e di quelle ove intervengono i colori liquidi da quelle che si fanno col fiato e col fuoco, come ne' vetri, e di quelle che si fanno col tessere da quelle che si formano col mosaico o che si fanno con veli per le mura; et il medesimo aviene in altre maniere quasi innumerabili e di che si è detto di sopra. Però, lasciando noi tutte queste divisioni da banda, che poco servono al caso nostro, riduciamo la materia delle imagini a due capi principali: l'uno chiamando imagini sacre, l'altro imagini profane; nel che seguitiamo l'ordine della Legge vecchia, che così avea distinto Moisè ai sacerdoti, comandandoli che avessero scienza di discernere tra le cose sante e profane ${ }^{135}$, onde Ezechiele profeta si querelava dicendo ${ }^{136}$ : Sacerdotes inter sanctum et profanum non habuerunt distantiam; inter pollutum et mundum non intellexerunt.

Sotto questi dui capi dunque abbracciamo tutto il discorso nostro, mostrando ai suoi luoghi la vera differenza tra esse imagini, e gli abusi che in ciascuna specie occorrerà d'avertirne il lettore, acciò siano fuggiti. E perché alcune cose sono proprie delle sacre, altre delle profane, altre communi ad ambedue, noi cercheremo di trattare di ciascuna più separatamente che si potrà, pigliando il principio talora dalle sacre, altrove dalle profane, e tal volta congiongendole insieme, sì come la opportunità ci persuaderà.

Vogliamo però ora avertire il lettore, che queste differenze dette, delle imagini sacre e profane, si possono considerare in due modi: l'uno quanto alla figura per sé stessa, l'altro quanto alla persona che le riguarda; perché potrà essere che una imagine di sua natura e secondo la sua forma debba giustamente essere riposta tra le sacre, e nientedimeno chi la mira la collocherà in altro ordine. Questo aviene perché lo spettatore averà concetto molto diverso nella imaginazione sua da quello che l'artefice ha avuto, come anticamente il serpente di metallo fatto da Moisè per ordine di Dio ${ }^{137}$

\footnotetext{
135 Levit., 10, 10.

136 Ezech., 22, 26.

${ }^{137}$ Num., 21, 8 s.
} 
[p. 172] ad alcuni era in loco di cosa sacra e misteriosa, ad altri in vece d'idolo. Così, in queste imagini, potrà alcuna di esse, quanto alla superficie esteriore, essere tenuta da qualcuno per religiosa e sacra, la quale da altri perversi et empii si terrà per idolo, e da altri sciochi come pittura profana, che serva solo per passatempo; sì come dai santi Padri nella settima Sinodo ${ }^{138}$ già fu avertito, dicendo: Quemadmodum in Babylone Ismaelitae organa et citharam et alia quaedam sicuti ipsi Babylonii habebant, et illi quidem ad laudem Dei, ii vero in ministerio daemonum; sic de imaginibus gentilium et christianorum censendum est: si quidem gentes ad cultum Diaboli, nos vero ad gloriam et recordationem Dei illas servamus. Di modo che la medesima imagine partorirà più differenze, secondo i varii concetti che di essa piglieranno i riguardanti, conforme assai a quel detto delle scuole, se bene in altro proposito: quod omne receptum habet se per modum recipientis et non recepti. Onde noi veggiamo che ancor del succo de' fiori nati alla campagna le api ne fanno soave mele e le aragni ne cavano mortifero veneno. Il che accade similmente in molte altre cose, come ognuno può comprendere.

Noi donque, se bene principalmente intendiamo in questo trattato di parlare delle imagini sacre, nondimeno cominciaremo ora dalle profane, dovendocene espedire brevemente quanto spetta al proposito presente; e seguiremo poi le sacre senza interrozzione fino al fine di questo libro. Ma non si tralascierà però nei seguenti libri di ripigliare tutto quello che serà necessario, e nelle profane e nelle sacre, secondo che la materia richiederà.

[p. 173]

\section{CAP. XI}

Quali si chiamino imagini profane.

Questo nome di profano presso gli autori si suole largamente pigliare in varii modi. Ma, quanto appartiene all'intendimento nostro, pare che in tre modi, per lo più, se ne soglia addurre essempi. L'uno a differenza delle cose sacre, perché piacque anticamente alli santi Padri nostri, affinché nel popolo cristiano fosse riconosciuto meglio l'ufficio di ciascuno, dividerlo tutto come in due schiere: l'una chiamorno de' laici, cioè popolari, percioché ritenevano la condizione conceduta da principio a ciascuno del popolo, che è di potere pigliare moglie e servire a tutti gli usi necessari della città; l'altra de' chierici, che, scelti dal popolo, erano particolarmente ascritti al culto divino, come ne rende testimonio S. Ieronimo, dicendo ${ }^{139}$ : Duo sunt genera christianorum: unum genus divino mancipatum officio, qui clerici vocantur; alterum laicorum, quibus licei uxorem ducere etc. Parimente divisero tutte le altre cose in due ordini: l'une chiamando profane, che vale il medesimo che laico e secolare, e l'altre sacre, intendendo per profane quelle che persistevano nel suo nativo stato di potere servire ad uso commune del popolo, e sacre quelle che erano levate da quella communanza e per maggiore privilegio applicate al culto divino et a cose di religione ${ }^{140}$; abbracciando sotto questi due nomi non solo tutte le persone, ma ancora i tempi, i luoghi, le azzioni et universalmente tutte le cose, volendo che fossero divise in sacre e profane. E però commandò la Legge vec [p. 174] chia a' sacerdoti, ut haberent scientiam discernendi inter sacrum et prophanum $^{141}$.

\footnotetext{
138 Surius, III, 105.

${ }^{139}$ Ad quendam suum Levitam (= c. 7, C. XII, q. 1).

${ }^{140}$ S. Tommaso, Sum. theol., II-II, q. 81, a. 8; C. Jannsen, Concordia evangelica (1558), cap. 60, e. 466 e.

${ }^{141}$ Levit., 10, 10.
} 
Dunque, conosciuti che siano i modi con li quali si faccia questa differenza o, per dir meglio, con quai si constituisce una cosa sacra, ne seguirà che le imagini d'altra forma resteranno nel genere delle profane.

L'altro senso, nel quale si suole pigliare una cosa profana, è quando ella prima era fatta sacra mediante il modo ordinato da' canoni, ma dipoi, per qualche delitto et accidente, è stata violata o altramente imbrattata quella santità; talché, essendo già ascesa al grado di essere sacra, ora ritorna indietro e cade di quello per la machia supervenutale, e diviene impura, che è il contrario della santità $^{142}$, la quale presuppone cosa netta e monda e segregata dalla terra, come il nome greco ö $\gamma 10 \varsigma$ dimostra. Quel adunque ripiglia il nome di profano, sì come volgarmente si chiama chiesa profanata, cemiterio profanato, o cosa simile, nel qual senso pare che s'intenda il detto del salmo ${ }^{143}$ : Prophanasti in terra sanctuarium eius, etc.; et Ezechielle ${ }^{144}$ : Sabbatha mea prophanaverunt; e nei Macabei ${ }^{145}$ : Altare prophanatum et portas exustas etc., Et Iudas vehementer instabat puniens prophanos.

E questo senso è differente dal primo detto di sopra, ché in quello, sotto nome di profano, non si intende opera che significhi delitto; ma in questo altro s'intende cosa alterata e come degradata dal suo primo stato.

Nel terzo modo si piglia per certa similitudine questo nome, stendendosi a quelle cose che, se bene non sono mai state né sacre né violate, sono nondimeno per modo sconvenevoli, che sono come contrarie e repugnanti alle sacre. Onde si dice in mala parte 'un uomo profano' et 'un parlare profano', leggendosi in Ezechielle ${ }^{146}:$ Tu autem, prophane, impie dux Israel, e S. Paolo ${ }^{147}$ : Devitans prophanas vocum no [p. 175] vitates. Secondo il quale senso si chiamano da alcuni profane certe pitture licenziose e che hanno quasi dello scandoloso; de quali al suo luogo si dirà.

\section{CAP. XII.}

Delle cause perché s’introducessero le imagini profane.

Oltre le cose altre volte da noi discorse della invenzione delle imagini in universale, chi vuole più diligentemente investigare $\mathrm{i}$ primi principii della introduzzione di quelle che si chiamano profane, ritroverà che da quattro principali cause elle sono derivate. L'una è stata necessità, l'altra utilità, la terza dilettazione e la quarta virtù; le quali possono ancor parimente convenire alle sacre per altri rispetti, ma di quelle parleremo poi al luogo suo.

La necessità si mostra perché, essendo l'uomo di natura, come dicono, conversevole, e che per la debolezza sua ha bisogno continuamente di vari aiuti, si trova essere forzato a significare i bisogni suoi ad altri. Onde, non potendo ciò fare con le parole sole, perché non possono essere intese se non da chi l'ode e da quegli che hanno cognizione della medesima favella, perciò fu necessario che si provedesse di qualche istrumento che supplisse all'uno et all'altro diffetto: che fu il formare le imagini profane delle cose create, ora d'animali, ora di piante, ora d'artificii, e talora di varie parti del corpo umano, con che gli antichi padri nostri rapresentavano meglio che poteano i concetti suoi,

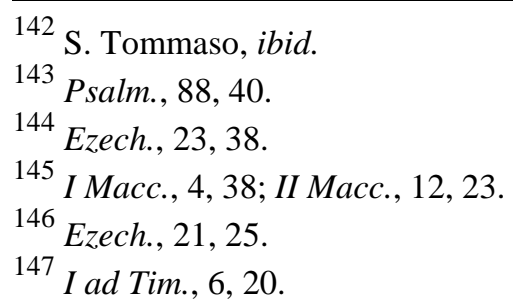


non essendo fino allora da essi conosciuti i caratteri delle lettere, né trovata la maniera dello scrivere. Di questo rendono testimonio molti gravissimi autori, che, parlando di diversi popoli, ci fanno fede ch'eglino di tali figure si serveano in luogo di [p. 176] lettere. Così narra Diodoro degli Etiopi $^{148}$, quali vuole egli che fossero i primi uomini nati al mondo, e dice: Sunt Aethiopum literae variis animantibus extremitatibusque hominum atque instrumentis, sed praecipue artificum persimiles; non enim syllabarum compositione aut literis verba eorum exprimuntur, sed imaginum forma, earum significatione usu memoriae hominum tradita. Il medesimo dice Filone delli Egizzii, scrivendo ${ }^{149}$ : Aegyptii occultam philosophiam describunt literis, ut vocant, hieroglyphicis, hoc est notis animalium, quae ipsi venerantur etiam pro numinibus. E Cornelio Tacito, parlando delli istessi popoli, lasciò scritto ${ }^{150}$ : Primi Aegyptii per figuras animalium sensus mentis effingebant et antiquissima monumenta memoriae hominum impressa saxis cernuntur; e Plinio ${ }^{151}$ medemamente: Sculpturae illae effigiesque, quas videmus, Aegyptiae sunt literae; di che sono ancora stati scritti libri da diversi ${ }^{152}$. Ma di più, nella età nostra narrano quegli c'hanno osservate le cose del Mondo Nuovo, che si sono trovati per longhissimo spacio di paesi popoli in gran numero, i quali non aveano cognizione alcuna né di lettere, né dello scrivere, ma in vece loro si servivano delle figure e ritratti delle cose; ma che, sendo poi venuti quei luoghi in potestà de' cristiani, dicono c'hanno appresa l'arte dei caratteri et oggi la essercitano ancora felicemente ${ }^{153}$. Di modo che, se bene gli Ebrei, ch'ebbero antichissima la notizia delle lettere, non furono così astretti da questa necessità dell'uso delle imagini, come altre volte abbiamo detto ${ }^{154}$; non segue però che il rimanente della università degli uomini in quella prima fanciullezza del mondo non potesse avere bisogno di simile ri [p. 177] medio, e se ne servisse ancor assai commodamente, per essere la natura umana molto atta et inclinata alla imitazione delle cose.

La seconda causa dello introdurre le imagini profane, che s'attribuisse alla utilità, chiaramente si può comprendere da ciascuno che vada tra sé discorrendo i giovamenti ch'ancor oggi queste arti di far figure o imagini apportano al mondo, or col rinovare le cose vecchie, coprire le diformi, far parer ricche le povere, illustrare le abiette e fare con poca spesa per via del pennello quel che non si potrebbe fare anco con le gran masse d'oro. A che s'aggiongono tutte quelle utilità che si cavano nella guerra e nella pace dal rappresentare i siti, le regioni, le provincie, i regni e mondi, e mettere in dissegno e come inanzi agli occhi in opera tutte le cose che cerchiamo di condurre a fine; e, quello che importa oltre modo, il cavare ammaestramento mirabile per mezzo di quest'arte nella cognizione delle cose naturali, che, figurate e colorite al vivo, ci danno la vera notizia di arbori, piante, ucelli, pesci, quadrupedi, serpenti, insetti, marmi e d'altre specie peregrine, senza la quale spesso si sta in molte difficultà e tenebre di varie cose, come ogni giorno esperimentiamo. Da che potiamo dire che non è arte o facoltà o scienza, che dalle imagini non riceva grandissimo commodo et utilità. Il che, conosciuto parimente dagli antichi, non è dubbio che non gli incitasse grandemente ad abbracciare simile arte et essercitarla diligentemente, oltre molt'altri suoi frutti che in altro proposito si diranno ${ }^{155}$.

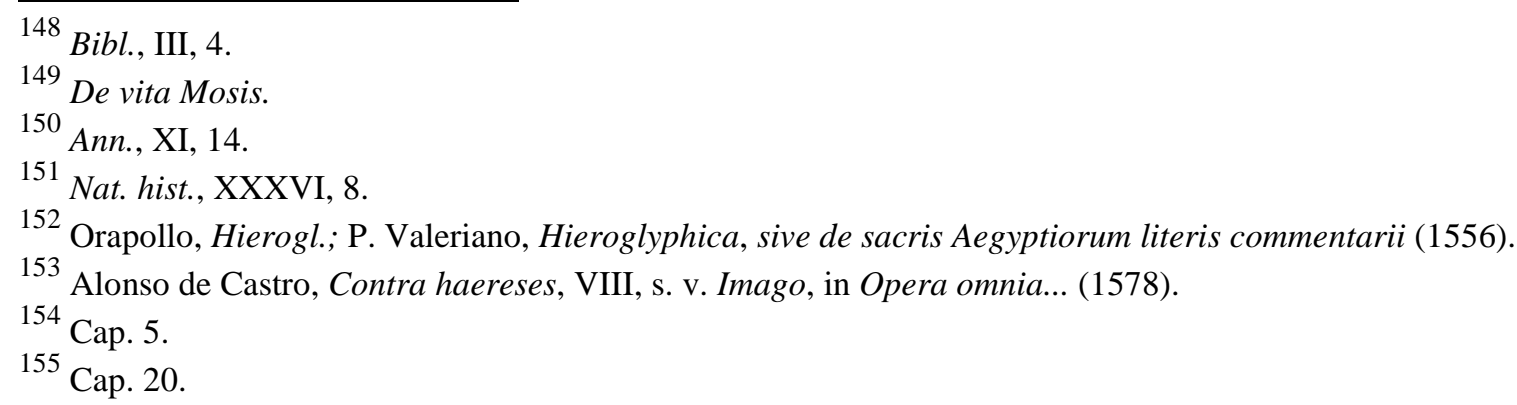


Ma che diremo noi della dilettazione, la quale abbiamo posta per terza causa? Anzi, che non diremo noi, potendosi dire di essa cose infinite? Non è dubbio alcuno che quella dilettazione, della quale tanto sogliono compiacersi gli occhi nostri nelle dipinte imagini, sì per l'imitazione, sì per la vaghezza e varietà de' colori, come anco per molt'altri meravigliosi trattenimenti che indi nascono, fu che mosse gran [p. 178] demente gli antichi ad abbracciare quest'arte, massimamente invitandoli a ciò et ammaestrandoli la natura stessa, che, senza aiuto alcuno degli uomini, forma da per sé le imagini di tutte le cose create nei corpi lucidi e le rappresenta agli occhi nostri con tutti i loro colori e movimenti, come si vede nelli specchi, ne' cristalli e nell'acque. Il che, porgendo all'aspetto nostro infinito diletto e trattenimento, ci dà a credere che di questo invaghiti et incaminati o invitati, gli uomini cominciassero con l'arte del dissegno ad imitare or questa or quella cosa; della quale dilettazione più diffusamente si ragionerà ancor altrove ${ }^{156}$.

Resta, per conclusione di questo capitolo, l'ultima causa a che s'attribuisce l'origine di queste imagini, la quale si giudica che nascesse da virtù e desiderio onorato, perciò che avviene spesse volte che gli uomini, o per benefici ricevuti, o per desiderio di conseguire cose importanti, o per la stima grande che fanno della virtù e meriti d'altri, sentono dentro di sé una voglia accesa di fare conoscere ancor essi questi loro giusti e nobili pensieri; onde non si contentano di ciò fare solo con le parole, ma desiderano d'aggiongervi altri segni più gloriosi e più durevoli. Però di qui cominciarono molti, mossi da rispetti grandi et al parer loro degni di memoria, a formare le imagini e statue in onore d'altri, partorendo a certo modo quello che l'animo loro avea conceputo. Oltre di ciò conobbero anco quanto per mezzo di queste imagini potessero gli altri, come da libri, ammaestrarsi nella cognizione delle cose, e però tanto più cercarono di figurare varietà d'istorie, descrizzioni di fatti meravigliosi degni di memoria, di guerre, di vittorie, di legazioni, ritratti di personaggi grandi, figure d'animali e d'istrumenti, che prima a molti erano ignoti e oscuri, acciò che, venendone per questa via in cognizione, tanto più s'accendessero gli uomini ad avere care le imagini e moltiplicarle nei suoi popoli.

Potressimo qui soggiongere altri rispetti di virtù, sopra [p. 179] tutti nobilissimi, che diedero occasione all'imagini, come fu di onorare col mezzo di quelle maggiormente il sommo Dio con la sua ierarchia celeste et illustrare tutta la Chiesa sua santa; ma perché questo appartiene alle imagini sacre, lo riserviamo al suo proprio luoco.

\section{CAP. XIII.}

Che cosa siano idoli, simulacri, sculptili et altri simili nomi.

Tra le imagini profane ci è parso di parlare particolarmente degl'idoli, per essere molto nominati nei libri antichi et avere con la loro apparenza ingannato longamente il mondo. Idoli donque si chiamano quelle imagini che, con falsa somiglianza figurando cose di religione, ricevono dagli uomini culto che non si deve; perché, sì come nelle cose naturali et artificiali altre sono vere, altre false (come parti veri e parti soppositizii, oro vero et oro adulterino, gioie vere e gioie false), così nelle cose morali e nelle virtù si trova la medesima differenza, essendo una giustizia vera et una falsa, una carità vera et una finta: di che parla l'Apostolo ${ }^{157}$. L'istesso dunque accade ancora nelle imagini, poi che altre sono veramente sacre e religiose, altre adombrate di religione e finte, che si chiamano idoli, simulacri, sculptili, conflatili, similitudini et altri nomi; de' quali volendone cercare

\footnotetext{
156 Cap. 22.

157 Ad Rom., 12, 6 ss.; II ad Cor., 6, 4 ss.
} 
la vera etimologia, come dicono, e differenza tra loro, entraremmo facilmente in troppo longo e minuto ragionanento, né punto convenevole all'intenzione.

Diremo sol questo, che alcuni hanno voluto distinguere questi nomi tra di loro et assignare certe proprietà a ciascuno, e quanto alla materia e quanto alla forma ${ }^{158} \cdot[$. 180]

Altri hanno voluto che idolum, parola greca, sia quella che nella tradozzione volgata si legge theraphim, di che si fa menzione nei libri dei Iudici e di Osea profeta; sopra di che i sacri interpreti e rabini hanno dette varie cose ${ }^{159}$.

Altri gli hanno confusi insieme e presi come sinonimi, non solo tra sé stessi, ma ancora col nome d'imagine; onde scrive S. Ieronimo ${ }^{160}$ che, dove noi nella Scrittura sacra troviamo idola, Aquila ha interpretato figuras vel imagines. Et appresso Cicerone ${ }^{161}$ si legge: Imagines, quae idola nominantur. E Platone ${ }^{162}$ : Idola vocamus imagines, quae et in aquis et in speculis sunt, et quae picta sunt, et quae typis seu figuris expressa, atque alia huiusmodi. E medesimamente il nome di simulacro latino hanno preso per lo medesimo che idolo greco, sendo che, dove nella tradozzione latina del salmo si dice simulacra gentium, argentum et aurum, nel greco dice $\tau \dot{\alpha} \varepsilon \Uparrow \delta \omega \lambda \alpha \tau \tilde{\omega} v$ $\dot{\varepsilon} \theta v \tilde{\omega} v^{163}$.

Ma noi, lasciando tutte quelle differenze e proprietà che fossero nelle voci secondo gli idiomi loro, seguiteremo l'uso commune, vero maestro delle lingue e del parlare, dicendo che nelle Sacre Lettere e presso i dottori sacri il nome d'imagine si piglia nel senso dichiarato di sopra da noi ${ }^{164}$, che, secondo la proprietà della voce, conviene così ad una figura buona e santa, come ad una empia e diabolica, ma il più frequente e commune uso è che si pigli in buona parte, dicendo Moisè nel principio de' suoi libri ${ }^{165}$ per bocca di Iddio: Faciamus hominem ad imaginem et similitudinem nostram, et in altri luoghi assai medesimamente. Ma il nome di idolo e simulacro e sculptile e conflatile ordinariamente si piglia in cattiva parte, come di cosa reprovata dalle leggi ${ }^{166}$; e [p. 181] questo in due modi: overo perché rappresenta cosa che non è né mai è stata, overo perché la rappresenta con altra ragione da quello che è stata. Nel primo modo si figura una Sfinge o Tritone, o uomini con la faccia di cane, o altre cose che mai non si sono vedute. Onde S. Paolo disse ${ }^{167}$, quod idolum nihil est in mundo; e Teodoreto ${ }^{168}$ lo dichiarò, dicendo: Idolum nullam habet subsistentiam; et quoniam gentiles ea, quae nusquam forent, effingebant, ut Sphinges, Tritones et Centauros, Aegyptii vero homines sub effigie canina et bovina, ea Sacrae Literae idola solent appellare; dalla

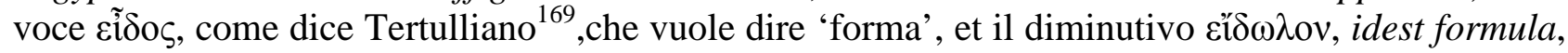
che significa la forma di una cosa apparente, ma che manca di subsistenza e verità, ancor che altri

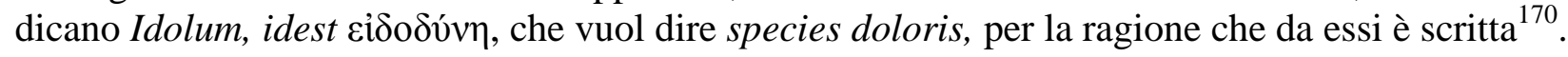

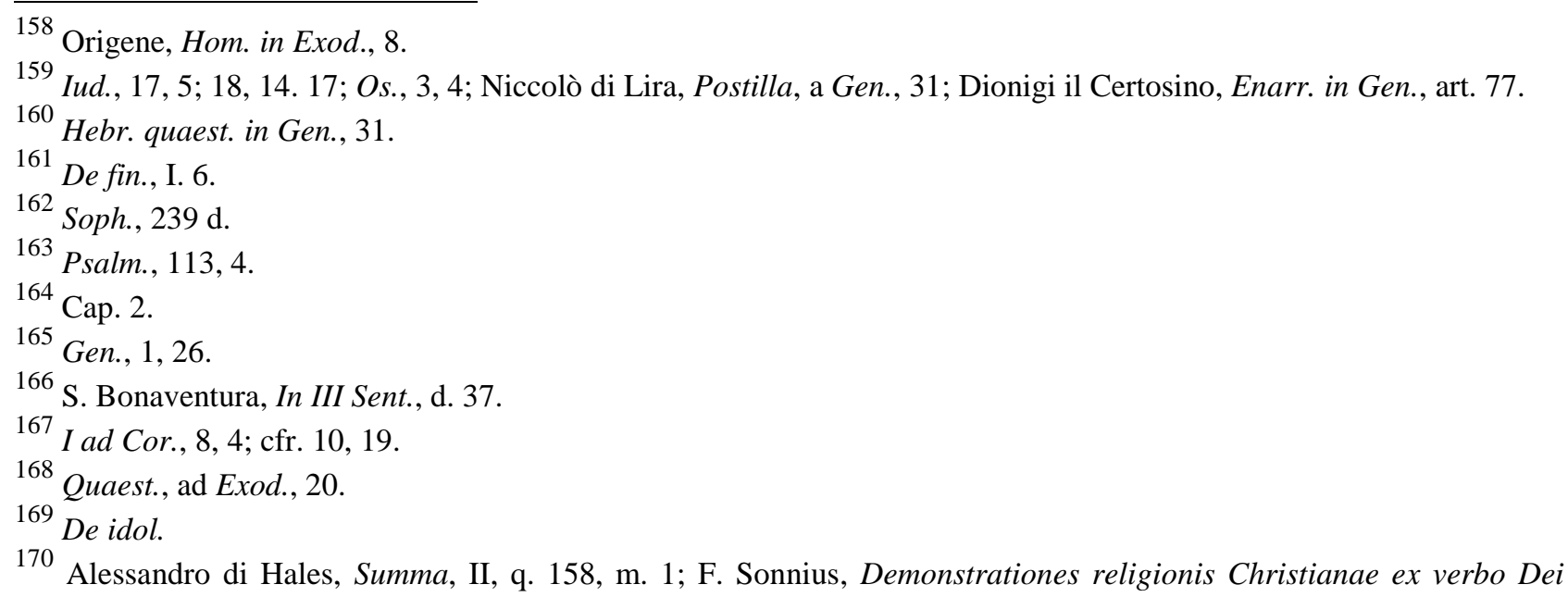


Nel secondo modo si figura la effigie di qualche uomo, o di alcun animale, o del sole, o delle stelle, perché abbiano da essere adorate, e però cadono sotto nome d'idolo; perché, se bene esse quanto alla sostanza e forma loro sono state vere, il fine però a che ora si formano è molto diverso dalla condizione di esse. Onde S. Agostino ${ }^{171}$ disse: Pagani ea colunt quae sunt, sed pro Diis colenda non sunt. E queste tali cose Teodoreto le comprende sotto il vocabolo di similitudine ${ }^{172}$, qual nome anticamente la Legge proibiva, dicendo: Non facies tibi sculptile, neque omnem similitudinem $^{173}$; il che si intendeva ad effetto di adorarle, perché dice: $u$ t adores e $a^{174}$, sì come dai dottori santi è stato dichiarato ${ }^{175}$.

Et a questi significati parimente si riferiscono l'altre parole dette di sopra di 'simulacro, sculptile, conflatile', che sono [p. 182] frequenti nella Scrittura Vecchia ${ }^{176}$; e tutti si pigliano in mala parte, come cose dannate da Dio e proibite dalla legge sua santa. Onde disse S. Ambrosio: Simulacrum vere nihil est, quia imago videtur rei mortuae, sed sub tegmine simulacrorum Diabolus colitur ${ }^{177}$. A che appartengono ancora altri titoli con che nominavano i loro idoli, tutti biasimati nelle divine Lettere, come Molocho, Astaroth, Baal, Chamos, Melchon, Rempha, et altri assai ${ }^{178}$.

Ora vogliamo avertire i lettori dello inganno fallacissimo degli eretici nemici della catolica pietà, i quali, vedendo che la scrittura sacra per lo più piglia il nome d'idolo e simulacro, et altri detti di sopra, in mala parte, essi, per levare l'uso delle sacre imagini dal popolo cristiano, hanno cercato, ovunque gli è accaduto fare menzione d'imagine, di riporvi la parola d'idolo, o d'altre delle sopranominate, affinché, essendo la voce d'idolo per sé stessa odiosa, essi col suono di questo nome mettessero in orrore al popolo ogni imagine, chiamandola con vocabolo abominevole alle leggi. Il che hanno machinato ancora nelle traslazioni di greco in latino: dove, in luogo della parola greca

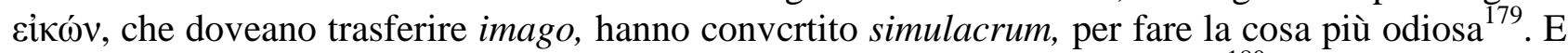
però nel Concilio Niceno ragionevolmente furono anatematizzati questi tali ${ }^{180}$, che con sì empie cautele vogliono confondere questi nomi, dicendo il Concilio: Qui sacras imagines idola vocant, anathema; qui ex Scriptura sententias contra idola dictas in sanctas imagines torquent, anathema; qui dicere audent sanctam catholicam Ecclesiam idola unquam accepisse, anathema; il che fu ancora replicato nel Concilio Constantinopolitano, sotto Adriano II ${ }^{181}$.

[p. 183]

CAP. XIIII.

Della origine delli idoli e simolacri.

(1564), cap. 5; Fulgenzio, Mytholog., I, 2.

171 Contra Faust., XX, 5.

172 Quaest., ad Exod., 20.

173 Exod., 20, 4.

174 Levit., 26, 1.

175 S. Tommaso, Sum. theol., I-II, q. 100, a. 4.

176 I Reg., 19, 13; Psalm., 96, 7; Iud., 17, 1 ss.; II Paral., 33, 7.

177 S. Ambrogio, In I ad. Cor., 10.

178 Levit., 20, 2 ss.; Iud., 2, 13; 10, 6; I Reg., 7, 3 s.; Num., 21, 29; Ierem., 49. 1; Amos., 5, 26; IV Reg., 23,4 ss.

179 N. Sanders, De typica et honoraria imaginum adoratione (1569), I, cap. 10; J. van der Meulen, De picturis et imaginibus sacris (1570), cap. 87.

180 Surius, III, p. 64 ss., 122, 138, 187.

181 Surius, III, p. 533. 
Questa materia degli idoli e simolacri sanno i dotti et intelligenti che si trova ampiamente trattata dagli autori cristiani, e greci e latini, i quali però principalmente si diedero a riprendere la vanità loro et a scoprire gli inganni e le fallacie con che erano aggirate le persone in quei tempi. Ma noi, che, Dio grazia, lontani da quelle tenebre, godiamo la vera luce, tralasciando tutta questa parte come non necessaria, intendiamo di parlare solo della origine et introduzzione nel mondo di questi idoli; il che per più chiarezza distinguiamo in due parti: l'una è, considerando il puro loro principio, in che tempo e da che persone siano usciti; l'altra sarà di investigare la causa che movesse quegli antichi a ricevergli e dargli luoco nei loro paesi.

Quanto al primo capo, ritroviamo varie essere state le opinioni degli autori, non solo gentili, ma ancor cristiani ${ }^{182}$. De' gentili non accade in questo parlar molto, non solo perché, mancando del puro lume, non poteron ben discernere il vero dal falso; ma ancora perché non ebbero la intiera cognizione dell'antichità, onde non gionsero nei suoi monumenti a gran parte dei secoli che erano già preceduti. Dei cristiani, non è cosa da turbarli molto, benché sia stato tra loro qualche disparere, non essendo ciò cosa dogmatica, ma più tosto istorica, che pende dalla diligenza e testimonio di chi ha riferito le cose antiche.

In questo però pare che convenga l'una e l'altra classe insieme: che in progresso di tempo fosse grandemente occu [p. 184] pata la terra e ripiena di varietà di questi mostri, avendo scritto Esiodo, come anco riferisce Eusebio ${ }^{183}$, che in quei tempi ne erano più di trentamila; e da quello che scrisse Varrone, come narra S. Agostino ${ }^{184}$, si vede che i gentili a ciascuna operazione umana aveano applicato un dio falso col suo nome.

Noi donque, per non essere stata questa materia così partitamente descritta come forse serìa stato bisogno, andremo ora più tosto narrando le opinioni degli altri, sì come le abbiamo ritrovate, che determinandole; lasciando il giudicio al lettore di sciegliere quella che ritroverà migliore.

Hanno voluto alcuni che la idolatria et adorazione de' falsi dèi sia stata anteriore alla vera religione, parendo ad essi che la perfetta cognizione e culto del sommo Iddio abbia avuto bisogno, negli uomini, di più soda radice, quanto alla pietà, di quella che da prima fosse concessa a quella rozza e nascente etade. Il qual errore fu significato e ripreso da Lattanzio, così scrivendo ${ }^{185}$ : Errant qui deorum cultus, ab exordio rerum fuisse contendunt, et priorem esse gentilitatem quam Dei religionem, quam putant posterius inventam, quia fontem atque originem veritatis ignorant.

Altri hanno voluto che il vero e falso culto di Iddio nel mondo abbia avuto origine dai primi due fratelli Abel e Caino, e che da Abel sia derivata la vera chiesa e religione, e da Caino la perfida e diabolica $^{186}$; il che si raccoglie da S. Augustino ${ }^{187}$ in simile senso, dicendo: A principio mundi processerunt duae civitates, una Dei, altera Diaboli, una caelestis, altera terrestris; caelestem aedificat Abel, terrenam vero Cain; et in un altro luoco dice: Haec civitas initium habet ab ipso Abel, sicut mala a Cain $^{188}$. [p. 185]

Sono stati altri che hanno detto che la idolatria non cominciò se non doppo il diluvio, nella

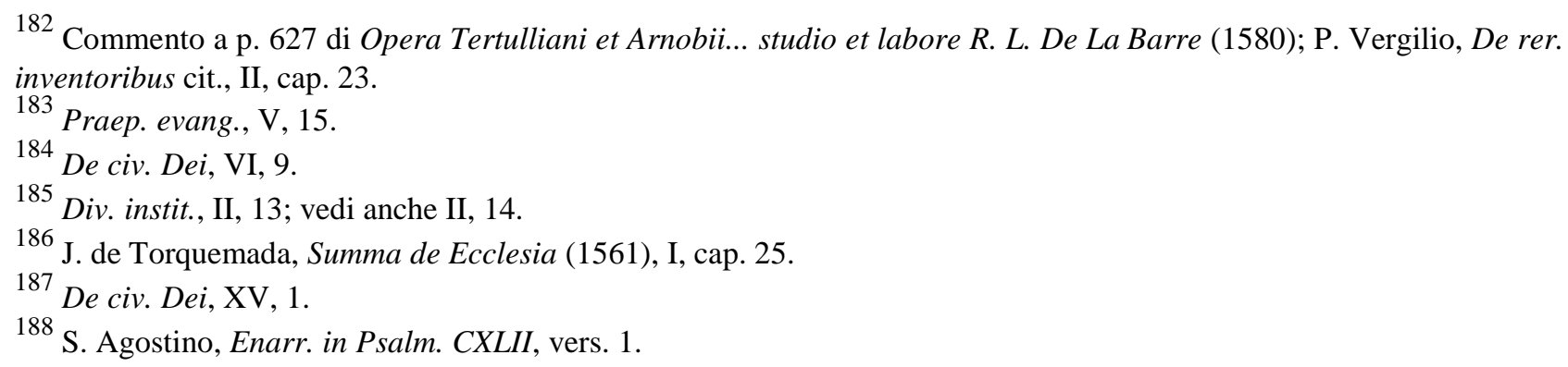


decima quarta generazione, che ebbe origine da Cham, che fu maladetto da Noè suo padre; il che scrive S. Clemente papa ${ }^{189}$ con queste parole: Quartadecima generatione ex maledicta progenie quidam propter artem magicam primus aram statuit daemonibus. Il che parimente fu scritto da Lattanzio in un luoco ${ }^{190}$ dicendo: Unus ex filiis Noe, cui nomen fuit Cham, non texit patris nuditatem, e poco doppo: Ideo ab eo expulsus consedit in eius terrae parte, quae nunc Arabia et de nomine suo Canaan dicta est. Haec fuit prima gens quae Deum ignoravit, quoniam princeps eius et conditor cultum Dei a patre non accepit, maledictus ab eo; itaque ignorantiam divinitatis minoribus suis reliquit; il che è da S. Ireneo ${ }^{191}$, da S. Cirillo ${ }^{192}$ e da altri confirmato.

S. Iustino ${ }^{193}$ scrive che Orfeo fu l'inventore e maestro de' falsi dèi, dicendo: Orpheus

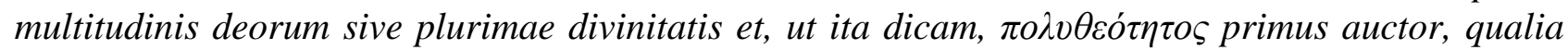
posterius ad filium suum Musaeum praedicaverit etc. Il che conferma ancora Atenagora nella sua Legazione ${ }^{194}$.

Lattanzio Firmiano ${ }^{195}$, parlando dell' arte del formare i simolacri e statue e confutando l'opinione de' poeti, che aveano detto che Prometeo era stato il primo autore e protoplaste degli uomini, dice in varii luoghi questa sentenzia: Poetae hominem de luto a Prometheo factum esse dixerunt; res eos non fefellit, sed nomen artificis, nam Deus ipse hominem figuravit ex limo terrae, unde homo nuncupatus est, quod sit factus ex humo. Prometheus autem primus omnium simulacrum hominis formavit de pingui et molli luto, ab eoque nata primo ars et statuas et simulacra fingendi; sic veritas fucata mendacio est, nam fictio veri ac vivi hominis e limo, Dei est.

Epifanio $^{196}$ pare che faccia differenzia tra le imagini di [p. 186] pinte fatte con colori e le statue e simolacri fatti con scoltura di pietre, legni e metalli, volendo che l'idololatria che nasce dalla pittura fosse anteriore e cominciasse da Seruch, come ancor ha di poi scritto il Damasceno ${ }^{197}$, ma quella delle statue solide avesse principio da Thare, padre d'Abraham, scrivendo queste parole: $A$ temporibus Seruch simulacra coeperunt, per colores quidem ab initio depingentibus hominibus ac repraesentantibus eos, qui olim apud ipsos in honore fuerunt. Deinde vero, a temporibus Thare patris Abraham, etiam per statuas idolatriae error inductus. Et il medesimo autore nel principio delle sue opere contra gli eretici ${ }^{198}$, dopo che ha narrato la istessa sentenzia, soggionge che per questa causa volse Dio che Aram, figliuolo di Thare, moresse prima di suo padre per castigo del delitto del padre, ch'avea eretto gli idoli, essendo che fino a quel tempo nissun figliuolo era mai morto di morte naturale prima del padre. E questa origine de' simolacri, ch'avesse principio da Seruch e da Thare, è riferita parimente da Suida ${ }^{199}$, se bene alquanto diversamente.

S. Cirillo Alessandrino ${ }^{200}$ pone per autore della idololatria Arbelo re degli Assirii, dicendo: In sacris literis nullum omnino invenimus qui ante diluvium idolatriae crimine fuerit implicitus; e

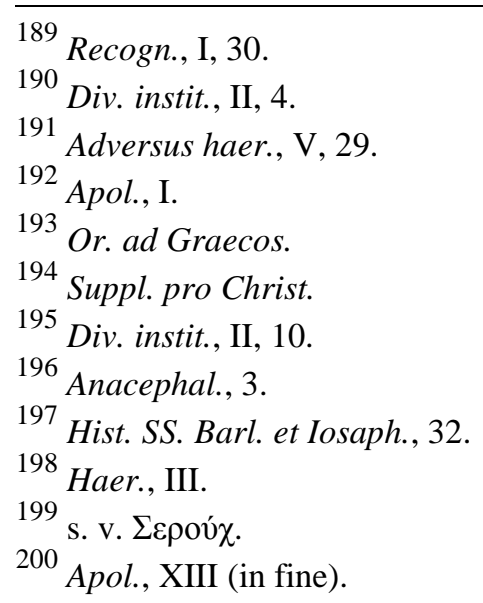


dipoi: Primus regnavit in Assyriorum terra vir superbus et arrogans Arbelus, qui et primus hominum dicitur a subditis nomen deitatis accepisse; inde perseverarunt Assyrii et finitimae illis gentes sacriftcantes ei et adorantes. Postea fuit Ninus Arbeli filius, cuius tempore vixit divinus Abraham.

Alessandro de Ales scrive ${ }^{201}$ che la idolatria fu prima in uso appresso li gentili che appresso i Giudei, e che non fu conosciuta se non nella seconda età.

S. Tomaso ${ }^{202}$ dice anch'esso essere stata opinione d'alcuni che la idolatria fosse ritrovata nella seconda età, o da Nembroth, che sforzava gli uomini ad adorare il fuoco, o da [p. 187] Nino, che fece adorare l'imagine di Belo suo padre ${ }^{203}$, dal quale dicono che molti nomi d'idoli derivarono, come Baal, Belzebub, Beelfegor, et altri simili ${ }^{204}$; al qual Belo parimente Semiramis moglie di Nino eresse statue di smisurata grandezza come scrive Diodoro ${ }^{205}$, ancor che altri hanno voluto che Baal fosse il nome del dio degli Assirii, e da quello poi denominato Belo.

Sono stati narrati da altri ${ }^{206}$ varii altri principii e diverse sette produtrici delle superstizioni, che riferisce Epifanio ${ }^{207}$ essere stati cinque: Barbari, Sciti, Greci, Iudei, Samaritani. Ma altri autori gentili $^{208}$ però pare che le riduchino tutte a due principali, l'una addimandando de' Barbari, l'altra de' Greci. Dimandorono Barbari, quanto a questo proposito, quegli che adoravano animali, arbori, piante, nel quale numero e principali furono gli Egizzii, o vero che adoravano il sole, la luna, le stelle, come furono i Caldei ${ }^{209}$. Dimandaro poi Greci quelli che adorarono Giove, Appoline, Venere, Cerere et altri simili dèi; talché i Romani, come scrive Dionisio Alicarnaseo ${ }^{210}$, accettorono la religione e riti de' Greci e non de' Barbari, adorando anco essi non le piante né gli animali, ma Giove, Marte et altri, ai quali aggionsero una particolare e segnalata superstizione, che fu in deificare ancora le virtù et $\mathrm{i}$ vizii, dando titoli divini a molte operazioni degli uomini buone et a molte cattive; di che fa menzione Lattanzio ${ }^{211}$, dicendo: Apud eos ipsa etiam vitia religiosa sunt, eaque non modo vitantur, verum etiam coluntur, e ne racconta varii nomi et essempii S. Agostino $^{212}$. [p. 188]

Gli Ebrei distinsero il popolo suo da tutte le altre nazioni, chiamando Gentili tutti quelli che non aveano notizia del vero et invisibile Dio, usando questo nome commune di 'gente', quasi che iure gentium et non Dei legibus viverent, come hanno voluto alcuni, o per altre ragioni che ora non è necessario di addurle; onde Lattanzio così scrisse ${ }^{213}$ : Caeteri qui per terram dispersi fuerunt, admirantes elementa mundi, caelum, solem, terram, mare sine ullis imaginibus ac templis venerabantur et his sacrificia in aperto celebrabant, donec processu temporum potentissimis regibus templa et simulacra, fecerunt, eaque victimis et odoribus colere instituerunt. Sic aberrantes

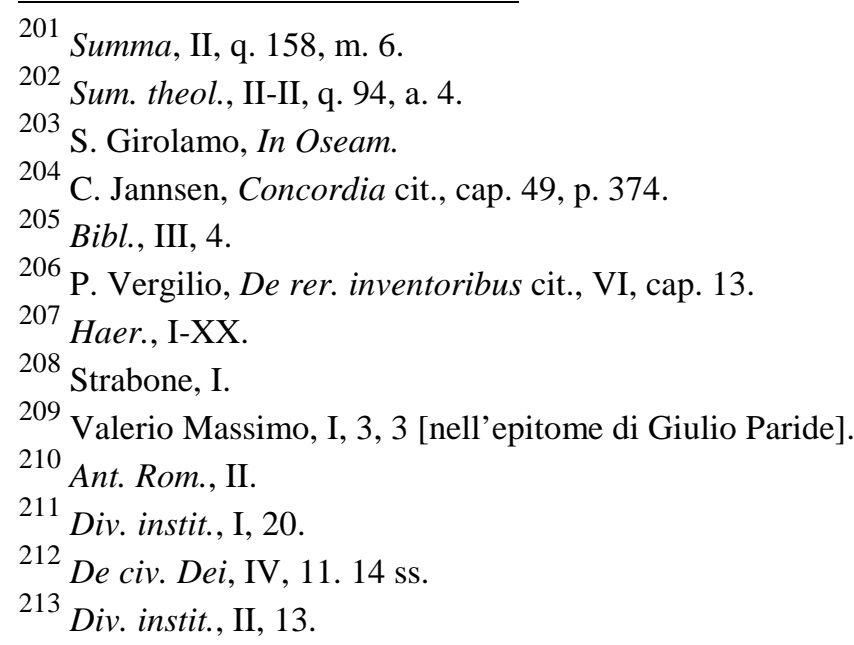


a notitia Dei, gentes esse coeperunt.

Sono state ancora altre opinioni d'alcuni Ebrei, che dissero, come riferisce S. Tomaso ${ }^{214}$, che Ismaele fu il primo che fece i simolacri di terra; et altri Ebrei e rabbini scrissero altrimente, per non raccontare ogni particolarità ${ }^{215}$.

Ma quelli che più sodamente hanno voluto appoggiarsi alle parole della Scrittura, hanno detto che la prima menzione propria e particolare, che si faccia nella Scrittura, degli idoli è stata quella di Rachele nel Genesi ${ }^{216}$, quando si dice, quod Rachel furata est idola patris sui etc., e di poi, illa festinans abscondit idola. È vero che vogliono alcuni che questo non sia stato attribuito ad alcuna impietà di Rachele, che era donna timorata di Dio, ma che ella così fece per liberare Laban suo padre dal culto di detti idoli, del che ci rimettiamo alli sacri espositori, bastando a noi di avere significato ai lettori le opinioni principali intorno a questo capo ${ }^{217}$.

[p. 189]

\section{CAP. XV.}

Con che occasione si introducessero da principio nel mondo gli idoli e simolacri.

Resta l'altra parte proposta da trattarsi, della occasione con che da principio furono introdotti gli idoli nel mondo. E per dichiararla meglio, ricordiamo primamente che è stato sempre nelle Sacre Lettere e dagli autori santi riputato il peccato della idolatria gravissimo et impiissimo ${ }^{218}$, perché, sì come nei regni terreni resta più offeso il prencipe da un suddito suo, quando cerca di cacciare lui dal regno e mettere un altro in luogo suo, che quando solamente recusa di prestargli la debita ubidienza; così la idolatria, quanto è in lei, scaccia Dio dal regno ${ }^{219}$ e pone un suo nimico capitale in seggio e giurali fedeltà: che è atto nefando e però dalle leggi è sempre stato con pene severissime castigato $^{220}$. Onde al quesito di sopra, con che occasione da principio la idolatria nel mondo si introducesse, rispondono i sacri dottori ${ }^{221}$ che fu causata dalla prava disposizione degli uomini, aggiontavi la soggestione et incitamento dell'antico serpente e fallacissimo Demonio; sì come scrivono S. Clemente ${ }^{222}$, S. Iustino ${ }^{223}$, S. Ambrosio ${ }^{224}$ e molti altri, che ne fanno autore il Prencipe delle tenebre. Dunque è da vedere ora primieramente che causa spingesse il Demonio a procurare questo; dipoi che sorte di mezzi o inganni egli abbia tenuto per sedurre et instigare gli uomini a così biasimevole errore. [p. 190]

La causa che mosse il nemico nostro è assai nota in varii luoghi della Scrittura: perché, non essendo riuscito a Lucifero et a' seguaci suoi di porre il seggio suo sopra gli altri et essere adorato in cielo, ha di poi sempre machinato d'essere almeno da' suoi ministri adorato in terra; oltre che,

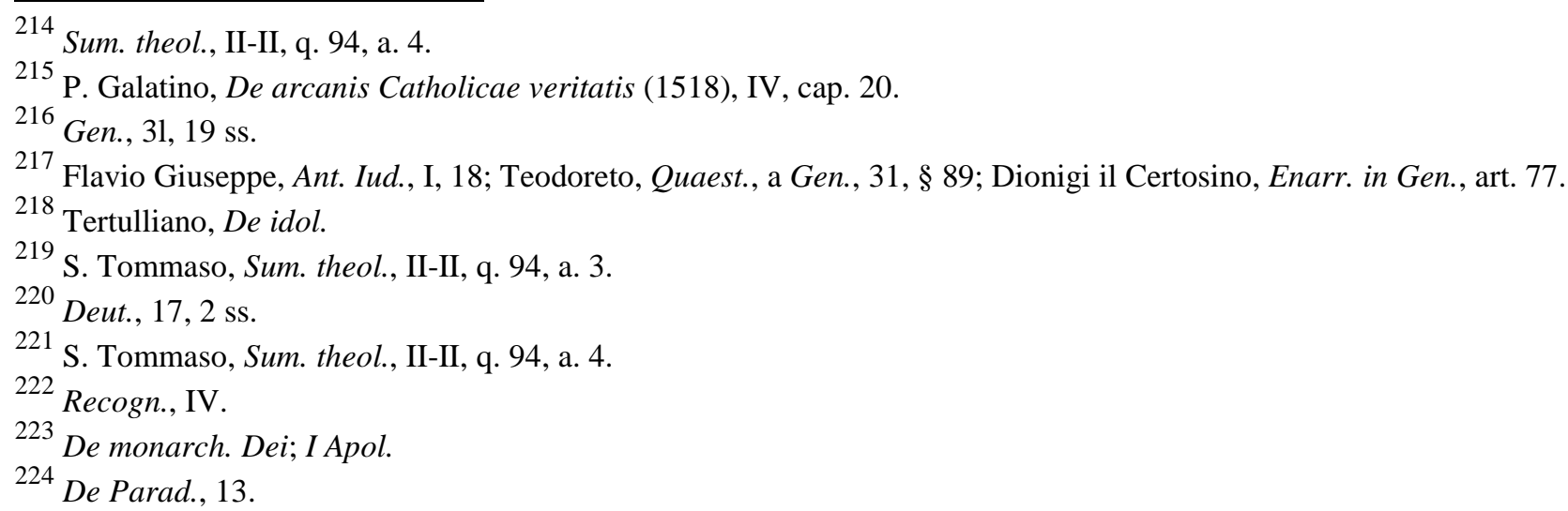


per la invidia sua implacabile et odio inveterato, che porta a Dio et agli uomini come creature sue, pensò di trovare modo che in un tempo medesimo oltraggiasse la divina maestà, facendo adorare in luogo di Iddio un pezzo di legno o marmo, et insieme schernisse gli uomini, che, in vece di onorare Dio, dessero il culto al nemico suo, che era egli stesso angelo delle tenebre ${ }^{225}$.

Lo mosse oltre di questo un'altra ragione, cioè il sapere che il Salvatore del mondo doveva discendere di cielo in terra per vestirsi di carne umana et essere adorato dagli uomini per vero et eterno Dio $^{226}$, dicendo lo Apostolo ${ }^{227}$ : Cum introducit Deus primogenitum suum in orbem terrae, dicit: Et adorent cum omnes angeli Dei etc.; onde pensò l'insidiosissimo adversario di fare che varii uomini et altri animali fossero in statue adorati come dèi, accioché, venuto Cristo, non paresse egli solo e supremo Dio in terra ${ }^{228}$.

I mezzi dipoi e maniere tenute da lui per indurre a ciò gli uomini sono stati di varie sorti ${ }^{229}$, osservando egli le male disposizioni delle persone, e secondo la varietà de' soggetti et opportunità de luoghi e tempi tessendo lacci diversi più atti ad ispugnare la debolezza di ciascuno, a guisa d'un capitano d'essercito, il quale dirizza l'artiglieria a quella parte della muraglia che conosce essere più debole e per la quale più facilmente possa entrare con le sue squadre ad occupar la rocca.

Alcuni dunque indusse a credere che nei simolacri fosse [p. 191] la vera divinità, fingendo alle volte in essi alcune voci sensibili che davano risposte a certi tempi e con parole ambigue, parendo che predicessero le cose avvenire ${ }^{230}$; talora con incanti e col risanare apparentemente certe malattie causate da loro stessi ${ }^{231}$; alcuna volta con porre sotto gli altari nascosamente persone che mangiassero le vittime che si offerivano all'idolo, persuadendo in quella maniera che l'idolo era cosa vivente e che si nodriva, come fu scoperto da Daniele profeta nella statua di Belo e del dracone $^{232}$; e talora con suono o stridore artifizioso facendo credere che quelle statue fossero animate, cioè che con quella materia corporale fossero congionti spiriti invisibili atti a giovare o nuocere: la quale fu opinione di Trimegisto, ributtata gagliardamente da S. Agostino ${ }^{233}$, e tale inganno ebbe alle volte tanta forza, che indusse gli uomini a sacrificare agli idoli fino i proprii figliuoli, come vittime che li fussero più accette, come scrive S. Crisostomo ${ }^{234}$ : Daemones, ludificantes homines, eos impulerunt, ut sacrificiis filios mactarent, quasi gratiores essent hae victimae Deo, novam immanitatem excogitantes; e David profeta $^{235}$ : Immolaverunt filios et filias suas daemoniis.

Ma non solamente nei legni o marmi effigiati e composti come di sopra fece credere che vi fosse ascosa la vera divinità; ma ancora in alcuni animali o piante, o altre cose più segnalate, vi fosse il medesimo, e ciò col mezzo d'un falso instinto di natura, quale, inclinando l'uomo interiormente al culto di Dio come causa sua, né trovando bene in che luogo fosse posto questo Iddio, come quello che con gli occhi del corpo non si scorge, fu occasione al demonio di indurre

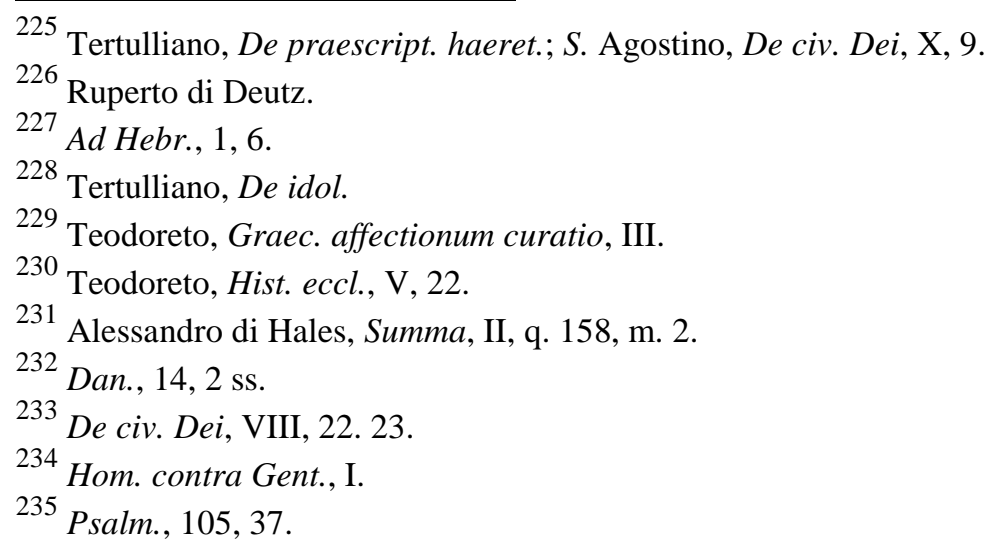


quei tali che cercavano Dio e non lo trovavano, a pigliare per Dio quelle cose che erano loro poste innanzi, o più belle $o\left[p\right.$. 192] più giovevoli o più mirabili delle altre ${ }^{236}$. $E$ così da questa cieca ignoranza e perversità cominciarono adorare, senza altri simolacri, chi il sole, chi la luna, chi il fuoco, chi i buovi, i montoni, e fino i crocodilli e serpenti, e gli agli e le cipolle che nascono negli orti $^{237}$. E l'uno e l'altro di tali culti, che si tribuivano a queste creature o artificiose o naturali, come ripiene di divinità, significò S. Paolo ${ }^{238}$ quando scrisse ai Romani: Et mutaverunt gloriam incorruptibilis Dei in similitudinem imaginis corruptibilis hominis et volucrum et quadrupedum et serpentium; sì come da $\mathrm{S}$. Tomaso ${ }^{239}$ è stato dichiarato.

Altri dipoi per altra strada più ingannevole indusse ad adorare i simolacri: non perché in quelli fosse la divinità, ma perché rappresentavano creature, le quali erano state trasferite in cielo et ora godevano la divinità. La quale deificazione cercò egli di persuadere con varii mezzi: imperoché alcuni indusse con titolo di virtù e meriti a porre in cielo quegli che avevano benificate le persone, come scrive Cicerone ${ }^{240}$ : Suscepit autem vita hominum consuetudoque communis, ut beneficiis excellentes viros in caelum fama et voluntate tollerent: hinc Hercules, hinc Castor et Pollux, hinc Esculapius, hinc Liber.

Altri poi sollevò con più facile e fallace strada, che fu il mezzo della adulazione verso i re e tiranni, inducendo gli uomini a tenere essi per dèi e tribuirli perpetua immortalità con dedicarli statue e sacrificargli, scrivendo S. Cipriano ${ }^{241}$ : Reges olim fuerunt, qui ob regalem memoriam coli apud suos etiam post mortem coeperunt: inde illis instituta templa; inde ad defunctorum vultus per imaginem detinendos expressa simulacra, quibus et immolabant hostias; e Lattanzio Firmiano ${ }^{242}$ : Daemones, [p. 193] ut hominum mentes a vero Dei cultu averterent, et fictos regum mortuorum vultus et ornatos exquisita pulchritudine statui consecrarique fecerunt, hincque imagines et simulacra fingere docuerunt; S. Crisostomo ${ }^{243}$ : Idolatria principium coepit, cum homines nimiae supra meritum haberentur admirationi; hanc siquidem invenit Diabolus, ut cum mors naturam convinceret mortalem, ipse per assentationem post mortem in impietatem multos perduceret.

Altri indusse, per lo troppo affetto che portavano alli figliuoli o ad altre persone care che gli erano levate di vita, a fingersi nell'animo che fossero andate in cielo e che però venerassero i loro simolacri come numi celesti ${ }^{244}$, sì come Salomone ne fa chiara menzione, dicendo ${ }^{245}$ : Acerbo luctu dolens pater cito sibi rapti filii fecit imaginem, et illum, qui tunc quasi homo mortuus fuerat, nunc tanquam Deum colere coepit; et haec fuit vitae humanae deceptio, quoniam aut affectui aut regibus deservientes homines incommunicabile nomen lapidibus et lignis imposuerunt.

Altri mosse (e questi furono gran parte de' gentili), con la licenza di potere più liberamente continuare ne' vizii in che erano involti, o di ambizione o di libidine o di avarizia o d'altro, a formare alcune imagini di persone che erano state in quelle sorti di sporcizie sceleratissime; le quali chiamarono dei, accioché, tenendo essi la medesima sordidezza di vita, paressero di fare cose

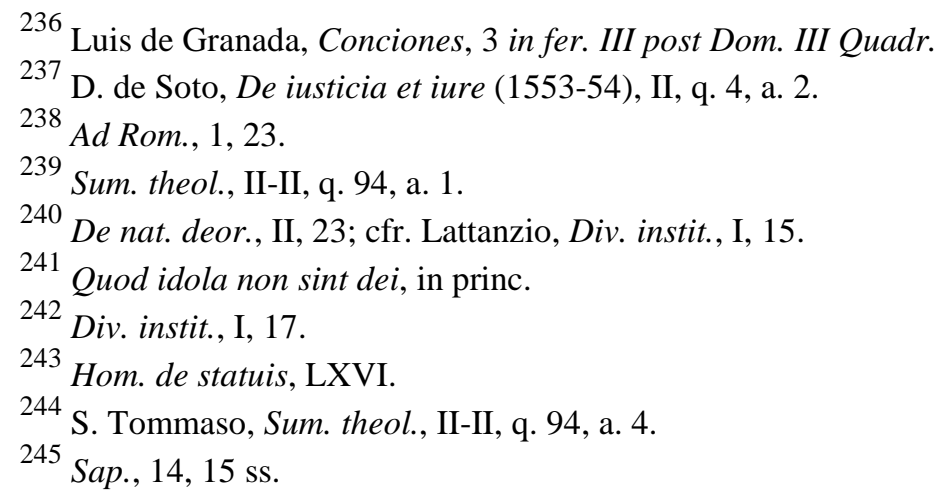


lodevoli seguendo l'essempio di quello dio che essi nominavano o Giove o Venere o Bacco o Marte, secondo la qualità del vizio in che avea superato gli altri ${ }^{246}$; sopra di che scrive S. Crisostomo $^{247}$ : Gentiles hoc [p. 194] nomine execrabiles sunt, quod hominum affectus deos effecerunt concupiscentiam appellaverunt Venerem et iram Martem et ebrietatem Bacchum etc.; et in altro luogo ${ }^{248}$ : Daemon docet per aspectum statuarum eas res imitari, quarum sunt figurae, et hinc allicit ad stupra, adulteria et vitia innumera; et altrove ${ }^{249}$ : Huius cultus causae hae existunt, crapulae, commessationes, et quod liberum est, omnia turpia proferre et perficere etc.; et il Crisologo dice ${ }^{250}$ : Denique et ipsi gentiles ob hoc simulacra finxerunt, ut in ipsis erroribus oculis cernerent quod colebant; e di Adriano imperatore narra S. Atanasio ${ }^{251}$ : Hoc tempore Antinous, Adriani imperatoris amasius, cum Adrianus in Aegyptum profugus esset, ibique ille defunctus esset, edicto publico statuii, ut eum sacrificiis colerent.

Altri prese con la esca della dilettazione, che naturalmente si piglia di cosa con leggiadria et artificio fatta, che ne rappresenti al vivo un'altra, apportando questa somiglianza non solo piacere, ma ancora ammirazione; e per questa via indusse gli uomini più rozzi e semplici a venerare le imagini come cose mandate dal cielo e che eccedessero la facoltà delle forze umane ${ }^{252}$, come ne rende testimonio Salomone ${ }^{253}$ : Si quis artifex faber de sylva lignum rectum secuerit, et scientia suae artis figuret illud, et assimilet illud imagini hominis, de substantia sua et filiis, nuptiis votum faciens inquirit etc.

Levò altri di strada con falso e sciochissimo inganno, persuadendoli che Iddio non vedesse le cose sotterranee e però li fosse lecito a loro piacere di fabricare gli idoli nei luoghi occulti et oscuri, et a quegli servire e dare ubidienza, come racconta Ezechiele profeta ${ }^{254}$, che in una facciata di muro erano dipinte simili mostruosità e, tra l'altre, settanta de' più vecchi d'Israele con i turiboli in mano, che davano incenso a varie sorti d'animali con grande abominazione, di [p. 195] cendo che Dio non li vedeva, e soggionge: Dixit ad me: Certe vides, fili hominis, quae seniores domus Israel faciunt in tenebris unusquisque, in abscondito cubilis sui; dicunt enim: Non videt Dominus nos, dereliquit Dominus terram etc.

Altri prese con altri inganni et irrisioni o scherni diabolichi ${ }^{255}$, sì come della pazzia e false ragioni loro scrisse una divina epistola Ieremia profeta al popolo giudaico ${ }^{256}$; et ampiissimamente di poi i santi Padri nostri, e greci e latini ${ }^{257}$ nei suoi libri si sono stesi in fare chiarissima a ciascuno la vanità degli idoli e dei bugiardi loro, come presso d'essi si legge, e delle varie sette loro intorno a ciò. La quale vanità tanto più restò convinta palesemente e confusa, quanto che si vidde che alla

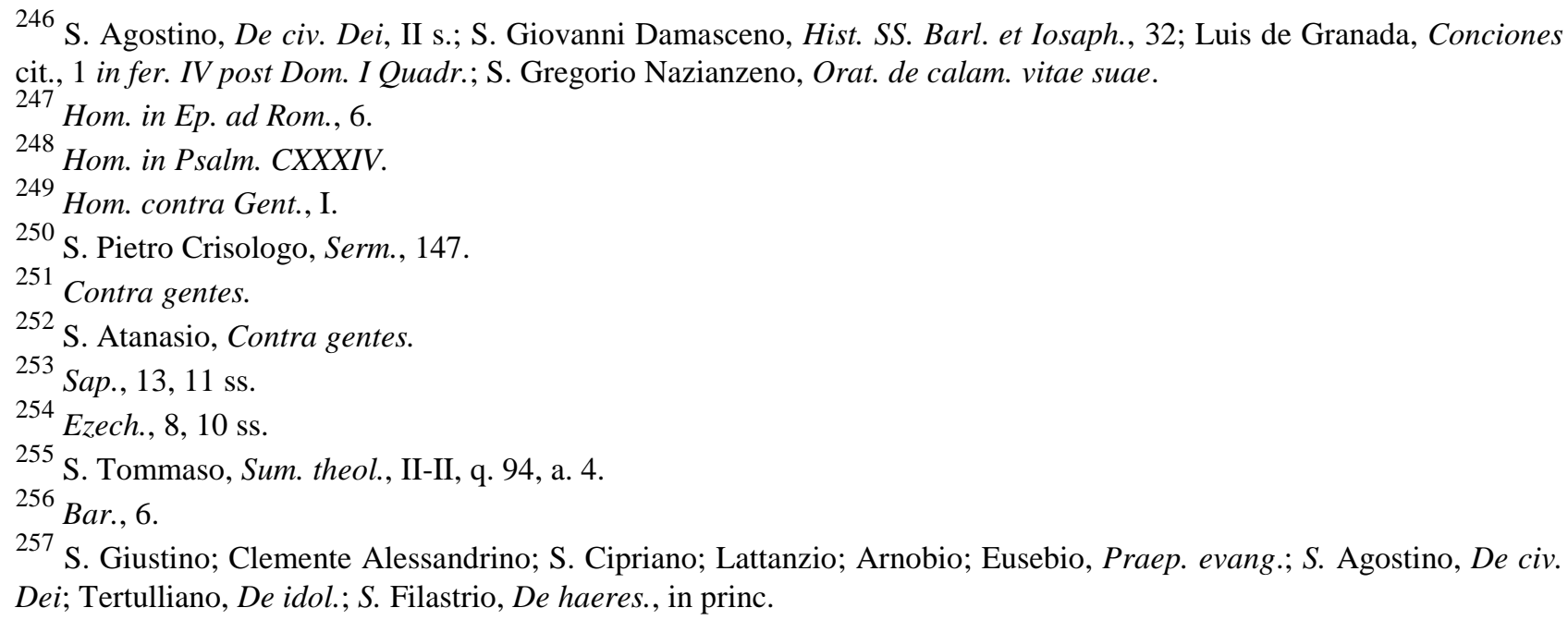


venuta del Salvatore nostro in terra restarono muti subito tutti i simolacri, né più diedero risposte; di che Plutarco ${ }^{258}$ ne rende testimonio, se bene lo attribuisce ad altra causa, come da Eusebio si trova scritto $^{259}$.

Laonde, per terminare ormai questa materia, vogliamo lasciare al lettore uno avertimento: che non tutti di un popolo osservavano il medesimo culto intrinsecamente di questi dèi, imperoché con altro concetto si movevano gli idioti, con altro i più giudiziosi e con altro gli eruditi e sapienti ${ }^{260}$. Onde Seneca, come racconta S. Agostino ${ }^{261}$, parlando delli Dei Capitolini dice: Haec sapiens servabit, tanquam legibus iussa, non tanquam Diis grata; e di poi: Sic, inquit, adorabimus, ut meminerimus cultum eius magis ad morem, quam ad rem pertinere.

E questo è quello di che gli autori cristiani spesso anticamente si querelavano, che, trovandosi tra' gentili persone di [p. 196] giudizio e dottrina, che conoscevano benissimo la vanità e sciocchezza de quei suoi finti dèi, nondimeno sì leggiermente e timidamente seguissero il commune errore; onde Lattanzio tra gli altri così scrisse ${ }^{262}$ : Quid attinet imperitos arguere, cum videamus etiam doctos et prudentes viros, cum religionum intelligant vanitatem, nihilominus tamen in iis ipsis, quae damnant colendis nescio qua pravitate perstare? Intelligebat Cicero falsa esse quae homines adorarent; nam cum multa dixisset, quae ad eversionem religionum valerent, ait tamen non esse illa vulgo disputanda, ne susceptas publice religiones disputatio talis extinguat; et il medesimo poco di poi soggionge ${ }^{263}$ : Summa rei haec est: imperiti et insipientes falsas religiones pro veris habent, quia neque veram sciunt, neque falsam intelligunt; prudentiores vero, quia veram nesciunt, aut in iis, quas falsas esse intelligunt, perseverant, ut aliquid tenere videantur, aut omnino nihil colunt, ne incidant in errorem, cum idipsum maximi sit erroris, vitam pecudum sub figura hominis imitari.

E però veggiamo alcuna volta questi tali, che aveano più cognizione e perizia degli altri, esser usciti in parole che mostravano chiaramente aversi da loro per cosa da burla tutti quei simolacri de' dèi, come scrisse Cicerone ${ }^{264}$, dicendo: An tu haec portenta inferorum esse credis? E così leggiamo essere stato opinione di Socrate e d'altri filosofi ancora; onde gran cagione ebbe Lattanzio ${ }^{265}$ di meravigliarsi che Cicerone, sì grande oratore e filosofo, nel libro De consolatione facesse professione, se imaginem filiae eodem modo consecraturum, quo dei a veteribus sunt consecrati.

Aggiungemo di più, che alcuni non per paura de' magistrati, ma per altri suoi disegni si lasciarono indurre ad adorare quelli che nel concetto suo sapevano non essere dei; sì come scrive $\mathrm{S}$. Agostino $^{266}$ essere accaduto a Salomone, che adorò gli idoli non perché errasse nel credergli, sendo sapien [p. 197] tissimo, ma per gratificarsi le sue concubine. Sì che varii sono sempre stati gli errori et inganni degli uomini intorno a questo.

\section{CAP. XVI.}

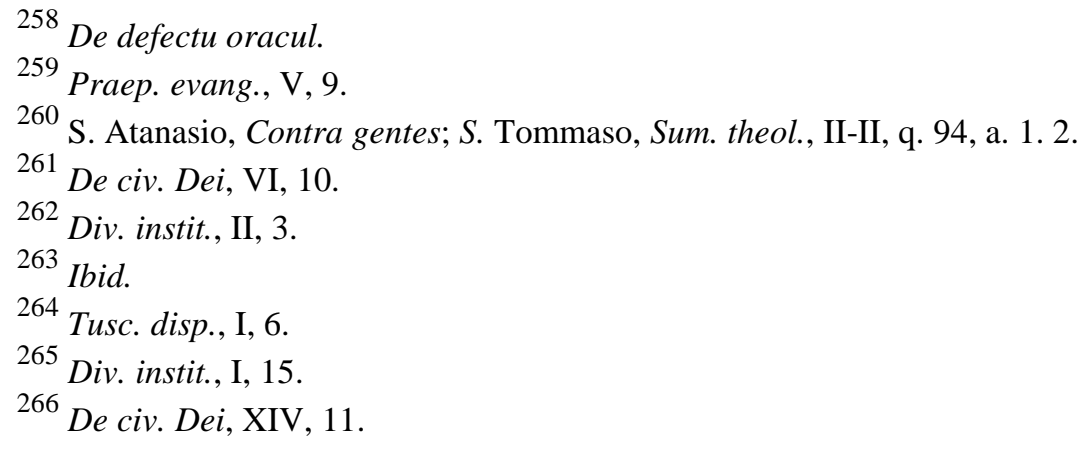


Quali si chiamino imagini sacre.

Ora entriamo a ragionare delle imagini sacre, che è la principale materia nostra. E però dichiareremo primamente varii modi, secondo i quali si suole chiamare una imagine sacra, acciò meglio si conosca l'intenzione nostra, lasciando la distinzione c'hanno fatta i iureconsulti tra le cose sacre, religiose e sante, la quale non conviene al proposito nostro.

Racordiamo prima, che questo nome di sacro si piglia a differenza di profano, come di sopra abbiamo dichiarato, dimostrando che una cosa si dice sacra, che è levata dal commune uso del popolo et applicata al culto di religione. E però ora abbiamo a vedere in quanti modi si soglia causare questo e conseguentemente in che maniera una imagine si possa domandare sacra.

Si dice prima una imagine sacra, per essere stata commandata da Dio, sì come avenne de' due cherubini formati da Beseleel et Ooliab per ordine di Dio, e parimente nelle altre cose di pittura e scoltura che fece fabricare nel tempio Salomone, overo nel serpente di metallo inalzato da Moisè per parola di $\mathrm{Dio}^{267}$.

Secondo, si dirà sacra, perché abbia toccato il corpo o la faccia o altro del Signor nostro o d'alcuno de' suoi santi e da quel solo tatto li sia remasa impressa la figura del corpo o di quella parte ch'averà toccata, sì come si chiama il Volto [p. 198] Santo lasciatoci da santa Veronica, che in Roma si conserva overo il sacro linteo dove fu involto il beatissimo corpo del Salvatore nostro dopo la morte, ch'oggi ancora mantiene la imagine di quello et è custodito con molta venerazione nel dominio del signor duca di Savoia; overo s'altra figura si trovasse, che si sapesse essere stata con simile modo dipinta o figurata.

Terzo, si domanderà santa una imagine, per essere stata fatta da persona santa, come sono quelle fatte da S. Luca, o altre che si trovassero fatte da altri santi.

Quarto, perché sia stata fatta miracolosamente, come si dice della imagine del Salvatore in

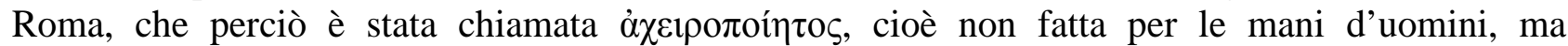
invisibilmente per opera divina, overo di qualch' altra simile ${ }^{268}$.

Quinto, perché Iddio abbia operato manifestamente segni e miracoli in tale imagine, come sappiamo essere accaduto in quella della casa santa di Loreto, trasportandola di così lontano paese et operando di poi tanti miracoli col mezzo di essa, quanti ogni giorno si veggono; il che similmente si dirà delle altre, che si ritrovano in varii luoghi, le quali per opera divina si serano vedute talora con la faccia risplendente, talora gittare vive lagrime dagli occhi o gocciole di sangue, overo fare qualche movimento della persona, come fossero vive, o pure perché in esse si sarà evidentemente riconosciuta la bontà divina, che col mezzo loro avrà risanato in un momento infermi, resa la luce a ciechi e liberato altri da diversi pericoli.

Sesto, si dimandavano sacre anticamente, quando, secondo il costume vecchio de' padri, si ungevano col sacro crisma; di che fa menzione Adriano papa I, scrivendo a Carlo Magno con queste parole: Fideliter et veraciter dicimus et probamus, [p. 199] qui usus sanctae et catholicae et apostolicae Romanae Ecclesiae fui et est, quando sacrae imagines vel historiae pinguntur, prius sacro chrismate inunguntur, et tunc a fidelibus venerantur ${ }^{269}$. Il che pare che avesse origine da l'uso del Testamento Vechio, introdotto per ordine di Dio a Moisè, quando gli disse: Facies unctionis oleum sanctum unguentum compositum opere unguentarii et unges ex eo tabernaculum testimonii et

\footnotetext{
${ }^{267}$ Exod., 31, 1 ss.; 37, 7 ss.; III Reg., 6, 23 ss.; II Paral., 3, 5. 10 ss.; Num., 21, 8 s.

268 Breviarium Romanum, 9 nov.; Liber Pontificalis, Stefano II; C. Sigonio, Historiarum de regno Italiae libri quindecim (1574), III, a. 753; Paolo Diacono, De gestis Romanorum, XVIII, Heraclius.

${ }^{269}$ Surius, III, p. 209; J. van der Meulen, De picturis cit, cap. 40.
} 
arcam testamenti mensamque cum vasis suis etc.; et altrove dice: Assumpto unctionis oleo, unges tabernaculum cum vasis suis, ut sanctificentur etc. ${ }^{270}$. E se ne fa spesse volte menzione nella Scrittura $^{271}$; onde Innocenzio III, commendando il costume ecclesiastico di ungere non solo i sacerdoti, ma tutti i cristiani e varie altre cose per servigio delle chiese e del sacrificio santo, disse: Unctio visibilis et exterior signum est interioris et invisibilis unctionis ${ }^{272}$.

Settimo, si chiamano sacre, quando sono benedette nel modo e con l'orazioni che ancor oggi serva la santa Chiesa, sì come si legge nel Pontificale, dove sono le proprie orazioni e benedizzioni delle imagini, della nuova croce, del crucifisso, della gloriosa Vergine e d'altri santi ${ }^{273}$; il che ancora si legge nel Sacerdotale ordinario.

Ottavo, si piglia ancora più largamente per ogni pittura che rappresenti alcuna cosa di religione $\mathrm{e}$ sia fatta a questo effetto: però che e per lo soggetto che contiene, che è cosa sacra, e per la fede di chi l'ha formata, e per lo fine a che è stata destinata, subito acquista una certa santificazione e separazione dalle altre cose meramente profane, sì come aviene alle chiese, oratorii e capelle fabricate per lo culto di Dio, che, se bene ancora non sono dai vescovi solennemente consecrate, pure si chiamano sacre per la rappresentazione e fine a che sono ordinate o fabricate, imperoché l'imagini per sé [p. 200] stesse non sono cose, ma segni di cose, onde pigliano la sua condizione da quello che rappresentano, sì come tutti i segni si considerano secondo le cose che significano; di che testimonio rende S. Epifanio nella settima Sinodo ${ }^{274}$, dicendo: Multa quae inter nos sacrata sunt, sacram precationem non accipiunt, cum a seipso et nomine suo plena sint sanctificatione et gratia; quapropter et veneranda et sancta honoramus et amplectimur. Ipse itaque typus salutiferae crucis sive sacrata precatione, sive dedicatione apud nos honorabilis existit; satisfacit enim nobis figura, quae tum sanctificationem accipit, cum a nobis fuerit adorata; et Adriano papa nella stessa Sinodo $^{275}$, narrando l'autorità del beato Stefano vescovo Bostrense, dice: Omnis imago, sive angelorum, sive prophetarum aut martyrum, in nomine Dei facta, sancta est: non enim ipsum lignum adoratur, sed ipsum illud, quod in ligno datur contemplandum.

Dalle quali parole resta sbattuta e convinta la protervia degli eretici, che ardivano di persuadere non potersi chiamare le imagini nostre sante per alcuna ragione, né per la materia, né per li colori, né per l'artificio, né per opera alcuna di mano d'uomini. Ora dalle dette considerazioni resta chiaro che una cosa molto bene si può chiamare santa per la forma sola e misterio che rappresenta, sì come da papa Nicolao fu scritto ${ }^{276}$, dicendo: Ipsa crucis imago, antequam suscipiat eius formae figuram, lignum commune omnibus est; suscepta autem veneranda similitudine, sacra est et daemonibus terribilis, propterea quod in ea figuratus est Christus. Laonde S. Paolo ${ }^{277}$ nominò le Lettere sacre e si dicono sacri i libri degli Evangelii che oggi si stampano, perché contengono e significano cosa santa, se bene né la carta, né l'inchiostro, né la penna, né la mano dello scrittore è stata santa; et il giorno si chiama santo nell'Essodo ${ }^{278}$, dove dice: dies prima erit sancta, non per sua natura, ma perché significava cosa santa [p. 201] fatta in quel giorno; e parimente il luogo santo, che disse Dio

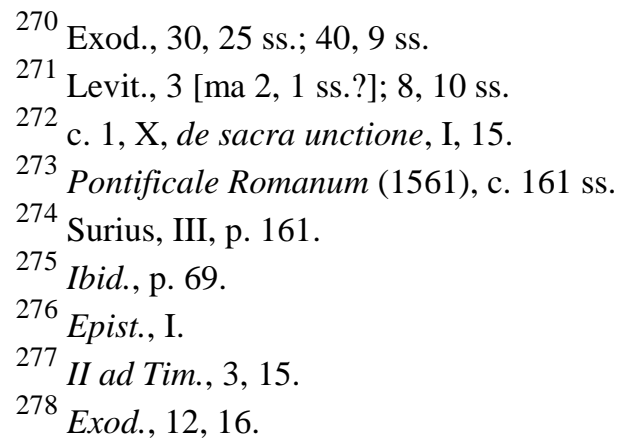


a Moisè ${ }^{279}$ : Solve calceamentum de pedibus tuis; locus enim in quo stas terra sancta est etc. Sopra di che, per esserne stato a' moderni molto bene e dottamente scritto contra gli eretici, noi non ci stenderemo al presente più oltre ${ }^{280}$.

\section{CAP. XVII.}

Della antichità et origine delle imagini sacre.

Quanto si siano ingannati quelli autori che, scrivendo della invenzione et instituto delle imagini, hanno attribuito il principio loro alli Egizzii o Fenici o Sicioni o Corinti o altri simili, ancor che in buona parte si possa comprendere da quello che altre volte abbiamo discorso della origine delle imagini et introduzzione loro, nondimeno ora meglio anco si potrà conoscere dalla memoria antichissima delle imagini sacre, di che fanno testimonio ne' suoi sacratissimi volumi Moisè et $i$ Profeti, dei quali chiara cosa è che non abbiamo scrittura alcuna o più lontana da questi secoli, o più autentica di quella ${ }^{281}$.

Cominciando noi dunque dalla prima origine loro, non tralascieremo quello che da alcuni è stato scritto $^{282}$, che Iddio stesso ne fu autore nella propria sua persona, fino al principio che creò questa machina del mondo; imperoché dicono che subito egli si adombrò d'imagine umana, ne la quale parlò con Adamo, con Eva e col serpente: il che cercano provare con varie ragioni. [p. 202]

Altri probabilmente vanno discorrendo che, sì come cominciarono fino da principio col lume interiore sapere gli uomini pascere gli animali, coltivare la terra, cogliere i frutti, edificare le città, governare le famiglie e poco dipoi essercitare anco l'arte fabrile et altre opere piene d'industria (come di Lamecho dice la Scrittura ${ }^{283}$, il quale ebbe due figliuoli, l'uno detto Iubal, qui fuit pater canentium cithara et organo etc., e l'altro Tubalcain, qui fuit malleator et faber in cuncta opera aeris et ferri); così dicono parere molto verisimile che, adoperandosi già l'arte fabrile col martello et altri istrumenti necessarii, si servissero gli uomini ancora d'essa a formare le imagini tanto necessarie a diversi bisogni et instituti della vita umana, come altrove si mostrerà: massime facendosi da Moisè frattanto menzione di questa parola 'imagine e similitudine' ${ }^{284}$ e seguendo dipoi la narrazione di quella fabrica stupenda, con sì meraviglioso artificio et industria composta per commandamento d'Iddio, chiamata l'arca di Noè ${ }^{285}$, che altro non fu che una imagine e picciolo modello della università della terra, conceduta per stanza et abitazione a tutti gli animali.

Altri hanno detto che il fare imagini per lo culto d'Iddio sia nato da un occulto lume, impresso nella natura nostra, di onorare e riverire quella potenza superiore, alla quale ciascuno si sente essere soggetto, chiamata communemente da tutti Dio, se bene non egualmente da tutti conosciuta. Perché, sì come l'offerire sacrificio a Dio si dice essere per legge di natura commune a tutte le genti, che, conoscendosi col lume interiore impotenti per supplire a tutti i loro bisogni, ricorrono per uno

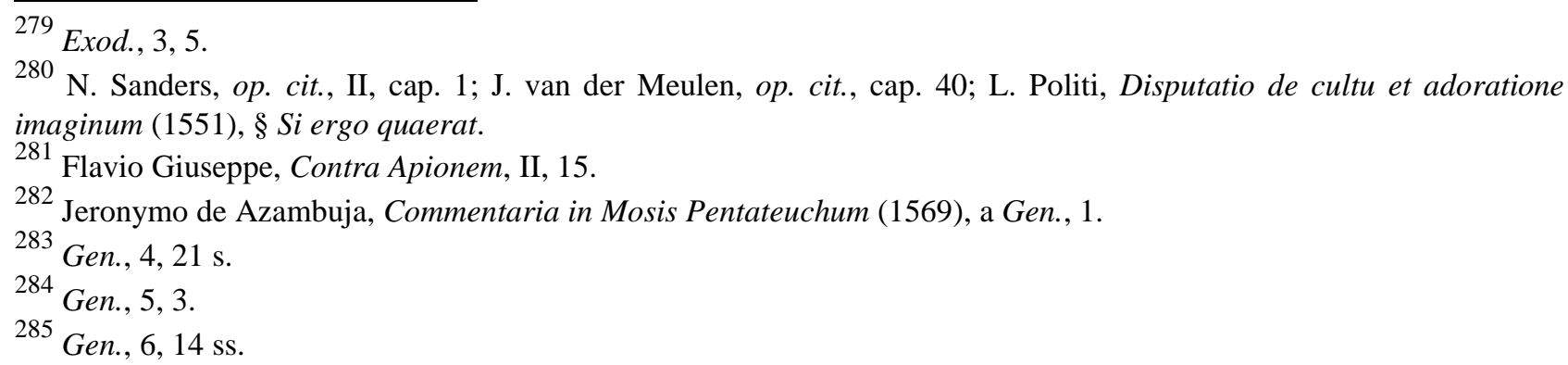


occulto instinto a una natura maggiore di sé286, facendole con atti esteriori, or di sacrificii, or d'oblazioni, or d'altri riti, segno della soggezzione sua e dello aiuto che [p. 203] da quella aspettano $^{287}$; così per lo medesimo instinto si mossero formare alcune imagini o simolacri, che, rappresentando, come ad essi parve meglio, quella deità superiore, conservasse loro più viva nella mente la memoria della grandezza sua et egli si rendesse più propizio alle necessità loro.

Ma, per venire più al particolare di queste imagini di che parliamo, fatte per lo culto d'Iddio, hanno voluto alcuni che fino al tempo di Abraham fossero in uso, quando egli, per commandamento di Dio venuto nella terra di Canaan fin al luogo detto Sichen, edificò ivi un altare al Signore, come si legge nella Scrittura ${ }^{288}$ : Apparuit Dominus Abraham et dixit ei: Semini tuo dabo terram hanc; qui aedificavit ibi altare Domino, qui apparuerat ei, et invocavit ibi nomen eius; dicendo essi non essere altro, questo altare ch'egli drizzò, che un ritratto et imagine di quella stanza e patria celeste, dove regna il sommo creatore del mondo.

Si legge poi ${ }^{289}$ che il patriarca Giacob, veduta quella scala che da terra arrivava fino al cielo, tulit lapidem, quem supposuerat capiti suo, et erexit in titulum, fundens oleum super summitatem eius, et appellavit nomen loci Bethel, idest domum Dei; le quali parole, quando dice 'erexit lapidem in titulum', vogliono gli Ebrei che s'intenda che fosse eretta in statua ${ }^{290}$; e così Sante Pagnino ${ }^{291}$ et altri periti delle cose ebraiche, in luogo di quelle parole 'erexit in titulum', essi leggono 'erexit statuam'. Et Eustazio, autore greco, dice ${ }^{292}$ : Lapidem ceu columellam erexit visionis monumentum, exprimens pro viribus imaginem eius personae, quae sibi apparuerat; e perché si conosca che fu cosa sacra, dice che vi fu aggiunta la unzione santa et il nome religioso, chiamandola domus Dei, cioè casa [p. 204] di Dio; onde S. Agostino ${ }^{293}$ scrisse: Ille lapis, quem Iacob sibi ad caput posuerat, et illud pecus, quod pro filio immolavit Abraham, ita sunt res, ut aliarum etiam sint signa rerum: peroché fu figura del tabernacolo di Moisè, come è stato scritto ${ }^{294}$.

Di più leggiamo nell'Essodo che Iddio di sua bocca dice chiaramente d'avere ordinato due persone nell'arte di fabro, di legnaiuolo e di disegno perfette, che furono Beseleel et Ooliab, perché fossero sufficienti a formare il tabernacolo, il propiziatorio, l'arca, la mensa, l'altare, la imagine di due cherubini e molte altre cose di pittura, scoltura e simili arti; e sono le parole sue ${ }^{295}$ : Ecce vocavi Beseleel, et implevi eum spiritu Dei et scientia in omni opere ad excogitandum quidquid fabre fieri potest ex auro et argento et aere, marmore et gemmis, et diversitate lignorum, dedique ei socium Ooliab, ut faciant tabernaculum foederis, arcam, propitiatorium etc., e seguita di poi ${ }^{296}$ : Fecit Beseleel duos Cherubim ex auro ductili, quos posuit ex utraque parte propitiatorii, extendentes alas et tegentes propitiatorium, seque mutuo et illud respicientes; fecit et candelabrum ductile de auro

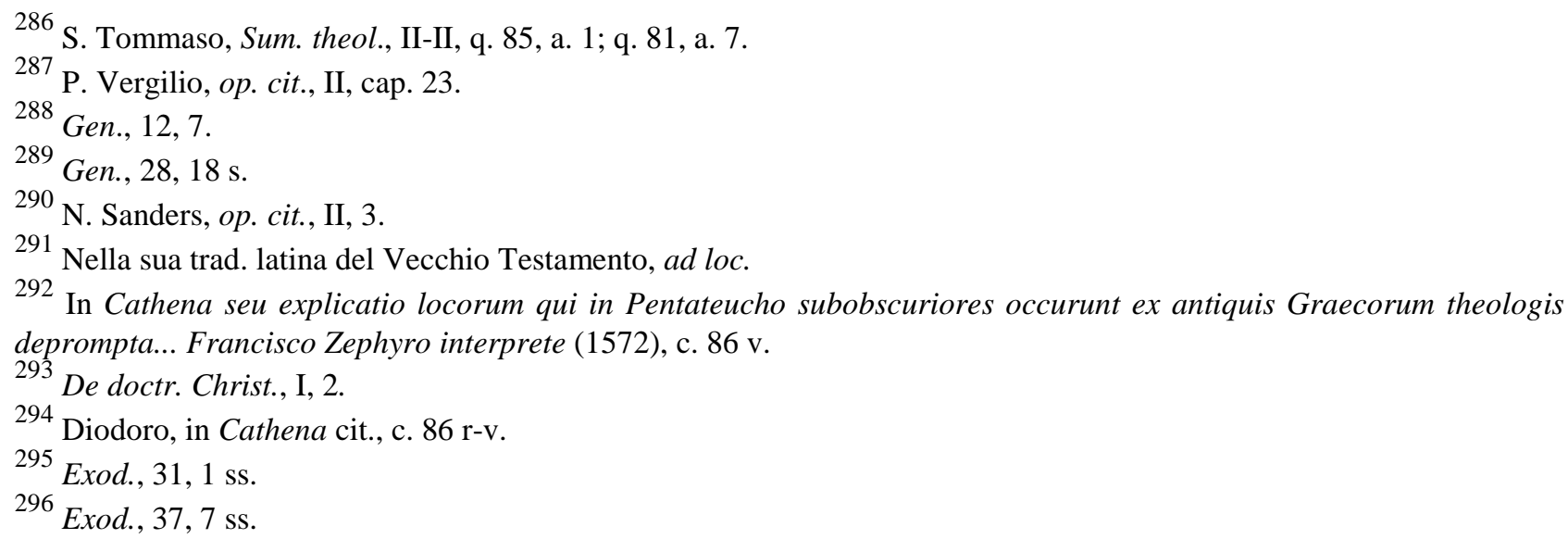


mundissimo; fecit etc. Sopra le quali cose scrivendo S. Ieronimo ${ }^{297}$ e volendo mostrare la importanza di quelle imagini dei cherubini et altre cose, così disse: Venerabantur quondam Iudaei Sancta sanctorum, quia ibi erant Cherubin et propitiatorium et arca etc..

Si fa oltre di ciò menzione in molti luoghi della Scrittura di quel tempio tanto famoso di Salomone, ornato di pitture, scolture et altre opere, leggendosi in essa ${ }^{298}$ : Omnes parietes templi per circuitum sculpsit variis caelaturis et torno; et fecit in eis Cherubim et palmas et picturas varias quasi prominentes de pariete et egredientes; e nel Paralipomenon dice di Salomone ${ }^{299}$ : Fecit in domo Sancti sanctorum Cherubim duos opere statuario et texit eos auro; alae autem utriusque Cherubim [p. 205] expansae erant et extendebantur per cubitos viginti; ipsi autem stabant erectis pedibus et facies eorum erant versae ad exteriorem domum etc.; et è nominato Hiram, qui novit operari in auro et argento et aere et ferro et marmore et lignis, in purpura quoque et hyacintho et bysso coccino, et caelare omnem sculpturam, et adinvenire prudenter [etc. ${ }^{300}$.

Oltre di ciò ritroviamo che Iddio commandò a Moisè che facesse un serpente di metallo e lo levasse in alto, accioché quegli che lo guardassero fossero liberati dal morso de' serpenti venenosi; come si legge nei Numeri ${ }^{301}$ : Fecit Moyses serpentem aeneum, et posuit eum pro signo, quem cum percussi aspicerent, sanabantur. Il che significava il misterio sacratissimo della redenzione nostra, sì come il Salvatore nostro dichiarò a Nicodemo ${ }^{302}$.

Si legge ancora ${ }^{303}$ dei figliuoli di Ruben e di Gad che, entrando nella terra di Canaam, aedificaverunt iuxta Iordanem altare infinitae magnitudinis, dicentes: Extruamus nobis altare, non in holocausta, neque ad victimas offerendas, sed in testimonium inter nos et vos, ut serviamus Domino. Et vocaverunt altare illud Testimonium nostrum, quod Dominus ipse sit Deus.

È parimente scritto che Iddio onnipotente si mostrò in varie figure alcune volte ai profeti, e particolarmente a Daniele, in forma antiqui dierum sedentis in throno eum vestimento candido sicut nix, et capillis tanquam lana munda ${ }^{304}$. Per lo che, sì come da' profeti fu descritta la figura sua in quella maniera, non è da credere che anco gli artefici non la potessero rappresentare o non la rappresentassero allora al popolo nell'istesso modo.

Ci sono dopo questi le autorità et essempii della Legge nuova, quali nel trattato si narreranno ai luoghi suoi ${ }^{305}$, bastando per ora questo, quanto alla origine delle sacre imagini negli antichi secoli.

[p. 206]

\section{CAP. XVIII.}

Perché siano state introdotte le imagini sacre nel popolo cristiano.

Intesa la origine delle imagini sacre, comincieremo ora a narrare la causa perché già s'introducessero tra' fedeli, e di poi dei meravigliosi frutti che sono atte a partorire.

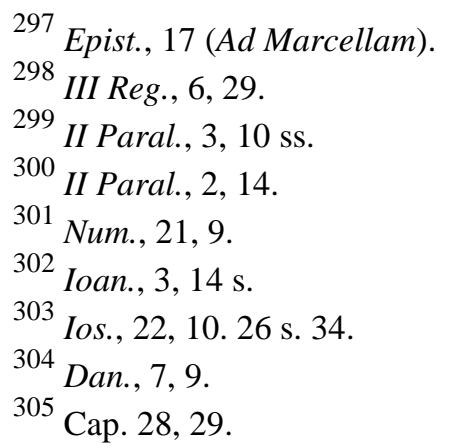


È cosa manifesta che, sendo stati gli uomini creati da Dio alla felicità eterna e gloria del cielo, gli ha ancora ordinati i mezzi convenienti per conseguire tal loro fine. Questi mezzi sono posti nel conoscere Iddio, amarlo et obedirlo sopra tutte le cose; il che si acquista col mezzo delle tre virtù chiamate teologali, Fede, Speranza e Carità ${ }^{306}$. Ora, se bene doveria ciascuno, e per la bellezza di queste virtù, che hanno per oggetto il sommo Iddio, e per la grandezza del premio, occuparsi continuamente in esse, nondimeno tanta è la corruttella della natura e sì grave il peso di questa carne, che, se ognora non è levata la mente nostra in alto, subito cade e giace in terra; onde l'eterna providenza di Dio, mossa a compassione delle miserie nostre, sino al tempo degli antichi padri nostri, per la infinita bontà sua, oltre varii aiuti con che di continuo cercò d'incaminarli al diritto sentiero, oltre li patriarchi e profeti che mandava loro, i tanti benificii per allettarli al bene, i castighi per ritirarli dal male, le minaccie per mantenerli nella ubidienza, i prodigii che mostravano la vendetta, la Legge scritta et i documenti con che gli ammaestrava, et oltre il tempio, i sacrificii, il tabernacolo, le imagini del serpente eneo, de' cherubini et altre cose dette di sopra, che tutte misteriosamente adombravano la redenzione loro; volse che il popolo suo col segno della circoncisione portasse ancora ne' vestimenti esteriori certi freggi e fascie di colore [p. 207] iacintino, affinché, quando si vedessero tali imprese e segni nei loro abiti, da quelle, come da simboli, intendessero che erano del popolo di Dio e se gli risvegliasse la memoria de' suoi commandamenti, come è scritto nei Numeri ${ }^{307}$ con queste parole: Loquere filiis Israel, et dices ad eos, ut faciant sibi fimbrias per angulos palliorum, ponentes in eis vittas hyacinthinas, quas cum viderint, recordentur omnium mandatorum Domini; le quali parole ci dimostrano che questi vestimenti li servivano per segni e figure di quello che Dio voleva da loro.

Sopravenne dipoi il tempo della grazia, nel quale, avendo il grande Iddio aperte in abbondanza le viscere della misericordia sua verso di noi, mandandoci l'unigenito suo figliuolo per redenzione nostra, volse più copiosamente usare tutte le maniere, con che la mente nostra si rendesse capace e la volontà si affezzionasse e la memoria si stabilisse a pieno nel servigio suo santo. Onde, ancor che con gli essempii meravigliosi delle operazioni sue ci ammaestrasse, con la legge d'amore ci invitasse, con la dottrina evangelica, da seminarsi per li discepoli et apostoli suoi nel popolo cristiano, ci illuminasse; veduto nondimeno che molti seriano tra' fedeli non così capaci delle cose sacre, né atti ad intendere quello che fosse scritto; molti a chi le parole non fariano sufficiente impressione nella mente, e molti che per la lubricità de' pensieri umani facilmente lo manderiano in oblivione: che rimedio trovò lo Spirito Santo a tanta varietà, imbecillità e bisogno della umana natura? Niuno veramente più facile, più ispedito e più proporzionato universalmente a tutti, che l'uso delle sacre imagini ${ }^{308}$, non più sotto velo né in figura, ma chiare e spiegate, come si legge nel Concilio Niceno, ove dice: Sicut olim fimbriae assuebantur vestibus ad memoriam mandatorum Dei, multo magis ex scripturis egressum gloriosae ca [p. 208] tastrophes videre licet ${ }^{309}$; onde servono per aiuto delle tre potenze dell'anima nostra, intelletto, volontà e memoria ${ }^{310}$.

Imperoché, quanto allo intelletto, chi non vede com'elle lo instruiscono e li servono per libri popolari, come di sotto diremo? atteso che il popolo minuto le cose che i dotti leggono sui libri, egli le intende dalla pittura, o almeno dalle pitture piglia occasione di domandarne i più savii et intenderle da loro, come disse il vescovo Germano Constantinopolitano nella settima Sinodo:

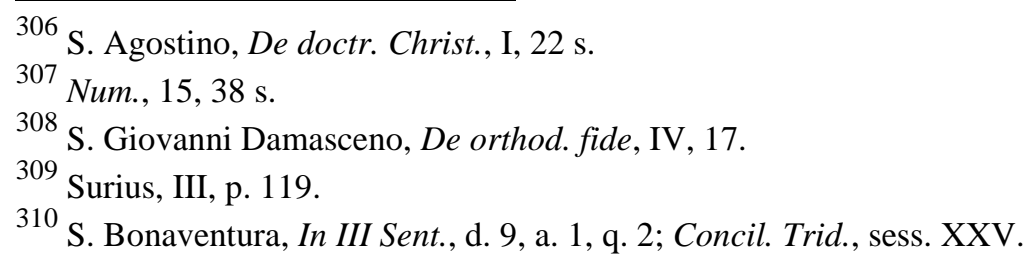


Imagines causam saltem inquirendi et pervestigandi ab aliis praebent. ${ }^{311}$

Quanto alla volontà, non è dubbio che il vedere le imagini piamente fatte accresce i desiderii buoni, fa abborrire il peccato, eccitando in noi pietosa voglia d'imitare la vita di quei gloriosi santi che veggiamo rappresentati.

Della memoria che diremo? sapendo noi che quella chiamata artificiosa sta la maggior parte posta nell'uso delle imagini; onde non è meraviglia che queste sacre, di che parliamo, tanto più la tenghino rinfrescata, ut contemplatione picturae, si legge nel detto concilio ${ }^{312}$, in memoriam reducant, quinam germane Dea servierunt; e S. Gregorio ${ }^{313}$ : Dum nobis ipsa pictura quasi scriptura ad memoriam filium Dei reducit, animum nostrum aut de resurrectione laetificat, aut de passione demulcet. La qual cosa già talmente fu da alcuni appresa, ch'a questo effetto solo, per rimembranza dei santi, volsero che le imagini fossero accettate; il che però dall'istesso concilio fu reietto con queste parole: Qui dicunt usum imaginum sufficere ad memoriam solum et non ad venerationem, semiprobi sunt, nam partim verum dicunt, partim negant. Ma dei meravigliosi frutti delle imagini più estesamente si dirà nei capitoli seguenti.

[p. 209]

\section{CAP. XIX.}

Del fine proprio e particolare delle imagini cristiane.

Altre volte abbiamo detto che il fine universale e commune a tutte le imagini non è altro che il rappresentare qualche altra specie et assomigliarla. Dal qual fine si causano poi altri fini particolari e come effetti o frutti di quella prima radice; perché, sì come il fine del parlare, dato da Dio agli uomini, non è altro anch'esso in universale che il rappresentare fuora i concetti che s'hanno dentro nell'animo, con quelle espressioni che si chiamano signa data, e da questi concetti poi derivano altri diversi fini loro particolari, che sono come effetti corrispondenti alle cause che hanno indotto a muoversi la lingua nostra in questo o in quel modo; così l'imagini, oltre l'essere formate a questo fine di assomigliare un'altra cosa, riguardano ancora altri fini loro proprii e particolari, de' quali ora disegniamo di ragionare. Il che servirà eziandio al pittore per regola dell'arte sua, con ciò sia che dalla natura del fine si pigliano i mezzi proporzionati ad esso; et anco potrà giovare al lettore di questo discorso per più chiara intelligenza del tutto.

Parlando noi adunque delle imagini cristiane e già concedendosi che ogni imagine si faccia per rappresentare et esprimere un'altra cosa creata, ora soggiungiamo che questa rappresentazione anch'essa deve essere dirizzata a qualche fine, e che lo investigare qual sia proprio questo fine ha bisogno di varie considerazioni, imperoché altro è il parlare del pittore come puro artefice, altro del pittore come artefice cristiano.

Nel primo capo, quando si considera come puro artefice, è necessario valersi d'una divisione assai usata da' dottori, che serve molto alla chiarezza di questo che si tratta. Dicono [p. 210] essi che altro è il fine dell'opera, altro è il fine dell'operante ${ }^{314}$; e così noi diremo che altro è il fine del pittore et altro il fine di essa pittura. Il fine del pittore, come artefice, serà col mezzo di quella arte fare guadagno, o acquistarsi laude o credito, o fare servigio altrui, overo lavorare per suo

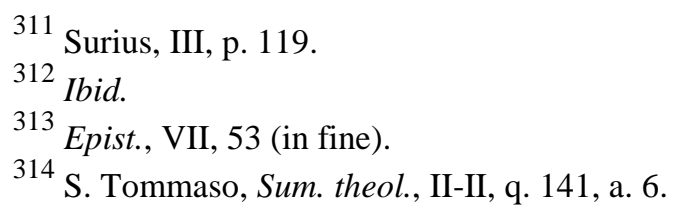


passatempo o per simili altre cause.

Il fine della pittura serà l'assomigliare la cosa rappresentata, che alcuni chiamano l'anima della pittura, perché tutte l'altre cose, come la vaghezza, varietà de' colori et altri ornamenti, sono accessorie ad essa; onde disse Aristotele nella Poetica ${ }^{315}$ che, di due pitture, quella che serà piena di bei colori, ma non assomiglierà, serà stimata inferiore a quella che serà formata di semplici linee et assomiglierà; e la ragione è, perché quella contiene uno accidente della pittura e questa abbraccia quello che è il fondamento e nervo di essa, che consiste nello esprimere bene quello che vogliamo imitare.

Nel secondo capo, quando parliamo del pittore cristiano, come proprio è l'intenzione nostra, allora è molto più differente il fine del pittore dal fine della pittura. Quanto al fine del pittore, egli può cristianamente avere due oggetti o fini: l'uno principale, l'altro secondario, o vogliamo dire in consequenza. Questo fine in consequenza serà di essercitare l'arte sua per ritrarne guadagno, o per acquistarne onore, o per altre cause dette di sopra, quando però siano tutte regolate con le debite circonstanze - della persona, del luogo, del tempo, del modo e del resto che si richiede -, talché da niun lato si possa dire che egli biasimevolmente esserciti questa arte et in niun modo s'adopri contra il fine supremo. Il fine principale serà, col mezzo della fatica et arte sua acquistarsi la grazia divina; imperoché il cristiano, nato a cose sublimi, non si contenta nelle operazioni sue avere mira così bassa e riguardare solamente alla mercé degli uomini e commodi temporali, ma, levando gli occhi in alto, si propone [p. 211] un altro fine molto maggiore e più eccellente, che sta riposto nelle cose eterne: e questo è quello di che spesse volte avvertiva S. Paolo i servidori e gli altri operarii, acciò, servendo i loro padroni, si ricordassero di servire principalmente al sommo Iddio universale, signore di tutti, dicendo ${ }^{316}$ : Servi, obedite dominis vestris carnalibus, non ad oculum servientes, sed ut servi Christi, scientes quod unusquisque, quodcunque fecerit hoc recipiet a Domino etc., et altrove ${ }^{317}$; Quodcunque facitis, ex animo operamini sicut Domino, et non hominibus, scientes quod a Domino accipietis retributionem.

Del fine poi di essa pittura diciamo che, sì come, quando ella si considera come pura arte, il fine suo è solamente di assomigliare, come già s'è detto; così ora, essercitandosi come operazione di uomo cristiano, acquista insieme un'altra più nobile forma e perciò passa nell'ordine delle più nobili virtù. E questo privilegio nasce dalla grandezza della legge cristiana, col mezzo della quale tutte le azzioni che per altro seriano stimate mecaniche o vili, fatte con deliberazione e dirizzate con debita ragione al fine eterno, crescono subito di grado e si vestono de' meriti di virtù; né però distruggono o contradicono al prossimo fine, che era dell'arte sola, ma lo inalzano, lo aggrandiscono e gli danno perfezzione. Sì che, quanto al proposito nostro, la pittura, che prima aveva per fine solo di assomigliare, ora, come atto di virtù, piglia nuova sopraveste, et oltre l'assomigliare si inalza ad un fine maggiore, mirando la eterna gloria e procurando di richiamare gli uomini dal vizio et indurli al vero culto di Dio.

Il che volendo noi dichiarare meglio e più distintamente, sendo cosa d'importanza, lo rimettiamo al capitolo seguente.

[p. 212]

\section{CAP. XX.}

\footnotetext{
315 Poet., 6.

316 Ad Ephes., 6, 5 ss.

${ }^{317}$ Ad Coloss., 3, 23 s.
} 
Che le imagini cristiane hanno riguardo a Dio, a noi stessi et al prossimo.

Non è dubbio che, tra tutte le operazioni virtuose, quelle che possono servire congiuntamente alla gloria di Dio, alla disciplina di noi stessi et alla edificazione del prossimo tanto più debbono essere stimate et inalzate, quanto più abbracciano questi tre ufficii, ne' quali veramente sta posta la somma della giustizia cristiana. Onde, potendosi da noi in questo ordine ragionevolmente annoverare quelle delle sacrate imagini, da questo ancora resterà tanto più chiara la grandezza del pregio loro et in che modo si riduchino nella schiera delle virtù più nobili; imperoché, cominciandosi dal primo capo, più volte già si è detto che una delle cause principali perché anticamente si introducessero le imagini, fu per onorare quegli a chi elle si dedicavano: così la sciocca gentilità, volendo celebrare Giove o Minerva o Nettuno, nissuna strada giudicò migliore o più atta, che di fabricarli statue e dirizzare i loro idoli e simolacri, più numerosi che poteva. Tennero questo medesimo stile i Greci, Romani et altri popoli per magnificare i loro imperadori o altri personaggi degni di onore. Il medesimo hanno fatto, si può dire, tutte le genti per certo instinto di natura, che, volendo far segno di riverenza e grande osservanza verso alcuno, gli hanno poste le statue in publico. Dunque non è meraviglia se la legge cristiana, valendosi del medesimo mezzo a fine perfetto e sacrosanto, anch'essa abbia ricevute le imagini per onorare il vero Dio e suoi santi, e con questo mezzo palesare più la infinita potenza, misericordia, giustizia e sapienza sua, e diffondere in tutti i confini della terra la gloria del regno suo.

Dicemo dipoi che servono anco a noi stessi, perché, dovendo il sommo Iddio essere adorato da ciascuno col culto [p. 213] interiore et esteriore, vengono le imagini, come cosa del culto esteriore, a protestare l'interiore nostro affetto, dedicandole noi a Dio come oblazioni e specie di sacrificio, col quale facciamo testimonio degli oblighi, della soggezzione, della ubidienza e della speranza eterna che abbiamo riposta nella sua celeste grazia; et il piacere smisurato che abbiamo di vedere la maestà sua, rappresentataci avanti gli occhi a tutte l'ore come padre, signore e Dio nostro.

Ma sopra tutto giovano meravigliosamente esse alla utilità et edificazione del prossimo, imperoché, se vogliamo noi mirare quelle tre sorti di beni poste dai savii, che contengono universalmente ogni bene, cioè il dilettevole, l'utile e l'onesto ${ }^{318}$, chiaro è che ciascuno di essi largamente conseguiamo col mezzo delle imagini, vedendosi per isperienza che, quanto al diletto, nissuna cosa forsi è che, communemente parlando, aggradisca così gli occhi nostri e gli apporti una soavissima ricreazione, quanto le cose ben fatte di pittura, come di sotto si dirà più pienamente.

Quanto all'utile, lasciando la commodità infinita che apporta questa arte per coprire la deformità delle cose, pascendo meravigliosamente i sensi; lasciando lo splendore e bellezza che riceve ogni luoco da' suoi ornamenti, e che non è così basso o vil tugurio che, adornato di esse, non riesca degno et onorato; lasciando da parte la conservazione della antichità in molte cose che sariano già smarrite et ogni giorno più si smarrirebbono senza il loro aiuto; lasciando l'utile universale che apportano al popolo, servendoli per libri senza molta spesa; e finalmente lasciando molti altri giovamenti che, per essere più nobili et eccellenti, passano nella classe dei beni onesti, de' quali ora trattaremo: dicemo che, quanto a questo dello onesto e della virtù, non si può pienamente isprimere il frutto che da esse si riceve, ammaestrando elle l'intelletto, movendo la volontà e rifrescando la memoria delle cose divine, con produrre insieme negli animi nostri quei maggiori [p. 214] e più efficaci effetti che si possono sentire d'alcuna altra cosa al mondo, rappresentandoci inanzi agli occhi et insieme imprimendo nei nostri cuori atti eroici e magnanimi, or di pazienza, or di giustizia et or di castità, di mansuetudine, di dispreggio del mondo, di misericordia e d'altri simili. Talché in

\footnotetext{
318 Aristotele, Eth. Nic., VIII, 2.
} 
uno instante causa in noi e desiderio della virtù et orrore del vizio, che sono le strade prencipali et aperte per condurci al vero onore et alla perpetuità della gloria, come nei seguenti capitoli più largamente si mostrerà.

\section{CAP. XXI.}

Dell'officio e fine del pittore cristiano, a similitudine degli oratori.

Oltre le cose dette di sopra, vi è un altro effetto che deriva dalle cristiane pitture, molto notabile e prencipale, il qual a guisa degli oratori è dirizzato al persuadere il popolo e tirarlo col mezzo della pittura ad abbracciare alcuna cosa pertinente alla religione. Intorno a che, oltre quello che di sopra $^{319}$ toccassimo in altro proposito, della conformità c'hanno le pitture coi libri, ora che il luogo lo ricerca dicemo per maggior chiarezza che, secondo i dotti che dell'arte oratoria hanno scritto, si ha da fare differenzia tra l'officio et il fine d'un autore. Chiamiamo officio tutti quei mezzi che s'adoprano per conseguire il fine; e chiamiamo fine quello che è prencipale et ultima intenzione; sì come officio dell'oratore dicono essere di parlare acconciamente per persuadere ${ }^{320}$, il fine poi essere il persuadere. Il quale fine non è in podestà dell'autore, ma sì bene l'ufficio e lo usare i mezzi proporzionati al fine; sì come neanco nel medico è posto il risanare l'infermo, che è il fine della medicina, ma sì bene il curare l'infirmità ca [p. 215] nonicamente, che è l'ufficio del medico. Parimente dunque nel pittore, quanto al proposito in che conviene con lo scrittore si dirà che l'ufficio suo sarà di formare la pittura in modo che sia atta a partorire il fine che dalle sacre imagini si aspetta.

E questo fine, se bene sempre è uno, che è di persuadere, nondimeno, secondo varii soggetti che si hanno alle mani, può riguardare diverse cose; sì come l'oratore, se bene ha per iscopo di persuadere gli auditori e tirarli nella opinione sua, questa persuasione però sarà dirizzata ora alla guerra, ora alla pace, ora al punire o all'assolvere o al premiare alcuno, o a cose simili. Per lo che il fine ancora del pittore, quanto a questo rispetto, potrà essere vario, secondo la diversità delle cose che figurerà; ma noi al presente, parlando delle imagini cristiane, dicemo che il fine di esse prencipale sarà di persuadere le persone alla pietà et ordinarle a Dio; perché, essendo queste imagini sacre cose di religione e richiedendo la virtù della religione che si renda il debito culto a Dio ${ }^{321}$, ne segue che lo scopo di queste imagini sarà di movere gli uomini alla debita obedienza e soggezzione a Dio, se bene possono con questo ancora concorrere altri fini particolari e più prossimi, come è d'indurre gli uomini alla penitenza, o al patire volentieri, o alla carità, o allo sprezzo del mondo, o altre simili virtù, che sono nondimeno tutte come istrumenti per unire gli uomini con Dio, che è il fine vero e prencipale che si pretende in queste imagini.

Quello poi che abbiamo detto chiamarsi ufficio del pittore, che è il mezzo per conseguire questo fine, pare a noi che da nissun altro luogo meglio si possa cogliere, che dalla stessa comparazione degli scrittori, a' quali per ufficio dell'arte è imposto che debbano dilettare, insegnare e movere. Parimente dunque ufficio del pittore sarà usare li stessi mezzi nella sua opera, faticandosi per formarla di maniera, che ella sia atta a dare diletto, ad insegnare e movere l'affetto di chi la guar [p. 216] derà. E se bene tutti questi tre mezzi sono importanti e necessarii per sodisfare a quello che si deve, nientedimeno non si può negare che tra essi non siano i suoi gradi et alcuno più eccellente

\footnotetext{
319 Cap. 5.

${ }^{320}$ Cicerone, De invent., I, 5.

${ }^{321}$ S. Tommaso, Sum. theol., II-II, q. 81, a. 1 ss.
} 
dell'altro, come disse quel gran Padre ${ }^{322}$, parlando dell'ufficio dell'oratore: Delectare est suavitatis, docere necessitatis, flectere victoriae; per il che e le pitture ancora più e meno si giudicheranno perfette in questo proposito, secondo che più e meno abbraccieranno questi mezzi, e tra essi quelli che più si accosteranno al fine.

\section{CAP. XXII.}

Della dilettazione che apportano le imagini cristiane.

Ora, per esponere meglio ciascuna delle tre parti che debbono concorrere in ogni cristiana imagine, cominciamo prima dal diletto, del quale forse ad alcuno potria parere essere superfluo il ragionarne, poiché non è alcuno tanto stupido e così privo di senso, che non senta dalle belle pitture grandissimo piacere. Ma noi non abbiamo per fine di provare questo, ma più tosto di spiegare la grandezza di questo diletto e farlo conoscere molto maggiore che forse non suole essere communemente stimato.

Laonde dicemo che ogni piacere, che si piglia d'una cosa, presuppone sempre che preceda la notizia di essa; perché di quello che non si conosce non si sente piacere né dispiacere. Questa cognizione negli uomini è di tre sorti ${ }^{323}$ : l'una animale, che si ha per via dei sensi, gustando, odorando, toccando etc.; l'altra è razionale, che, se bene ha principio anch' ella dal senso, passa però per via della ragione e discorso [p. 217] a grado più alto e giudica le cose universali astratte da ogni materia; la terza è sopranaturale, nascendo da un lume divino infusoci mediante la fede, per mezzo della quale crediamo e conosciamo cose che eccedono non solo la capacità de' sensi, ma ancora ogni discorso umano et intelligenza razionale: la quale ancora si chiama cognizione spirituale, donata agli animi mondi et innocenti dalla singolare grazia di Dio.

A ciascuna dunque di queste cognizioni sono congiunti ancora e conseguenti certi affetti, largamente parlando, come sono amare, odiare, attristarsi, dilettarsi e simili cose ${ }^{324}$. E però dalla prima cognizione, che si ha per mezzo de' sensi quando l'oggetto è conveniente e proporzionato a quelli, ne nasce una dilettazione che si chiama animale overo sensuale, non pigliandosi però in questo luogo in mala parte; dall'altra ne nasce una dilettazione chiamata razionale; e dalla terza l'altra dilettazione chiamata spirituale. Di modo che una cosa istessa, sì come può essere da noi conosciuta in tutte queste tre maniere diverse, così ci può apportare tre sorti diverse di dilettazione, corrispondenti a ciascuna delle cognizioni: come, per essempio, chi guarda il cielo stellato piglia la prima dilettazione, vedendolo di sì bel colore e che, oltre il cerchio figurato della luna, è compartito di sì numerosa schiera di stelle, a guisa di varii lumi posti da lontano, alcuni maggiori, altri che scintillano, altri che si movono, altri che stanno fissi; dalla quale varietà e bellezza sente il senso grandissimo piacere.

Comincia dipoi il medesimo a discorrere con la ragione intorno alla grandezza di ciascuna stella, e la volubilità de' cieli, il corso de' pianeti e l'ordine costantissimo di ciascuno, e gli effetti che nelle piante, negli animali et in molte altre cose elementari derivano da quelli; onde ne gode grandemente l'intelletto e si rallegra.

Oltre di questo ne siegue la terza cognizione, imperò che, [p. 218] considerando l'uomo la rara et ammirabile bellezza di questo cielo, pensa tra sé stesso, illuminato da Dio, quanto più eccellente sia

\footnotetext{
322 S. Agostino, De doctr. Christ., IV, 12.

323 S. Tommaso, Sum. theol., I-II, q. 1, a. 4.

${ }^{324}$ A. de Sbarroya, Purificador de la conciencia (1546).
} 
quello che l'ha fabricato, e con quanta previdenza e sapienza abbia voluto, per mezzo di queste cose create, fare scala agli uomini per penetrare le eterne et eccitarli desiderio dei beni celesti; onde sente allora l'anima un godimento dentro di sé, tanto maggiore degli altri due detti di sopra, quanto che questo nasce da causa molto più eccelsa e più perfetta. Per lo che disse David: Renuit consolari anima mea; memor fui Dei et delectatus sum ${ }^{325}$.

E perché la legge cristiana non vieta alcuna sorte di queste dilettazioni, purché siano adoperate col debito modo, perciò che non distrugge le cose della natura, ma le dà perfezzione, servendosi di esse come di gradi e mezzi per giungere al fine alto della beatitudine eterna; però dalle imagini sacre, di che parliamo, può parimente un cristiano godere di ciascuna di queste tre sorti di dilettazioni, del senso, della ragione e dello spirito.

Quanto al senso, è cosa manifestissima a tutti che, essendo il senso del vedere più nobile degli altri, riceve dalle pitture per la varietà de' colori, per l'ombre, per le figure, per gli ornamenti e per le cose diverse che si rappresentano, come monti, fiumi, giardini, città, paesi et altre cose, meraviglioso piacere e ricreazione.

Del diletto razionale dicemo che, oltre il particolare gusto che può ciascuno pigliare dalla qualità delle cose figurate, una ve ne è, che universalmente serve a tutte quelle che col disegno si rappresentano, che è l'imitazione: essendo detto de' savii ${ }^{326}$ che, sì come l'uomo fra tutti gli altri animali nasce attissimo ad imitare, così egli per naturale instinto sente grandissimo diletto e gusto della imitazione; il che forse nasce perché la virtù propria dell'uomo, per la quale apprende le cose et apprendendole si trasforma in esse in certo modo, non è altro che una virtù imitatrice di quelle con perfetto giudizio. [p. 219] La qual cosa, essendo naturale, seguita che ancora sia di piacere.

E questa imitazione, che nella pittura si scorge così evidentemente, tanto maggiormente suole recare diletto, quanto pare che subito renda le cose presenti agli uomini, se bene sono lontane, et a guisa della omnipotente mano di Dio e della natura sua ministra pare che in un momento faccia nascere e produca uomini, animali, piante, fiumi, palazzi, chiese e tutte l'istesse opere che si veggono in questa gran machina del mondo; overo, che le medesime cose già create da Dio e distribuite in varii luoghi e disperse in tutti i lati della terra ella con meravigliosa maniera in un momento le apporta dinanzi agli occhi, quasi avantaggiando e soprafacendo alla natura, che avendoli determinata la sua sede propria et i suoi confini certi in questa o in quella parte, con la pittura si mutano le loro stanze, e di lontane si fanno presenti, e di grandi picciole, e di brutte spesse volte belle, con infinito piacere e meraviglia. E tanta è la dilettazione che porta così fatta imitazione, che le cose che di sua natura sogliono recare agli occhi fastidio et orrore, come il vedere un mostro o un cadavero o una talpa, fanno contrario effetto quando sono bene imitate, e dilettano mirabilmente, come oltre Aristotele disse Plutarco ${ }^{327}$ con queste parole: Delectat picta lacerta, aut simia, aut Thersitae facies, non pulchritudinis, sed similitudinis causa; nam quod turpe est suapte natura, nec potest fieri pulchrum, imitatio tamen exprimens similitudinem sive pulchrae, sive turpis rei laudatur.

E se bene, come dicono i filosofi ${ }^{328}$, niuna arte si trova la quale non imiti la natura, imitatrici nondimeno chiamiamo quelle per eccellenza, le quali non solo con la proporzione imitano, ma con la somiglianza ancora; tra le quali sono numerate la poesia e la pittura, che hanno però tra di loro grandissima conformità; e chi scrisse dei precetti del poetare, gli andò illustrando quasi tutti con gli

\footnotetext{
325 Psalm., 76, 3 s.

${ }^{326}$ Aristotele, Poet., 4.

327 De aud. poet., 3, p. 18 a.

328 Aristotele, Polit., VIII, 5.
} 
essempi tolti dal dipin [p. 220] gere $^{329}$. Laonde Platone disse ${ }^{330}$ che la imitazione propriamente si adattava solo al senso del vedere e de l'udito, intendendo per il vedere la pittura e scultura e per l'odire la poesia, e la ragione è perché amendue attendono prencipalmente ad imitare; onde quelle pitture che più imitano il vivo e vero, per modo che ingannano gli animali e tal volta gli uomini, come racconta Plinio $^{331}$ di Zeusi e di Parasio, tanto più sempre sono state degne di commendazione e maggiormente hanno dilettato i riguardanti.

Resta la terza dilettazione, che nasce dalla cognizione spirituale, la quale non è dubbio che, sì come ha oggetto più desiderabile et è causata da virtù più prestante e durevole e che più è rimossa dall'alterazione e travaglio, tanto maggiore e più perfetta dilettazione apporta ${ }^{332}$; il che significò David dicendo: Eloquia Domini dulciora super mel et favum $^{333}$ mostrando che le dilettazioni spirituali trapassano di gran longa tutte le altre che derivano dalle cose materiali; e però, sì come la dilettazione dell'intelletto eccede quella del puro senso, così quelle dello spirito sono superiori a tutte le altre ${ }^{334}$.

Da che vogliamo concludere che, oltre le due precedenti, che si sogliono da ciascuno facilmente prendere, seguita questa terza ancora, la quale, quanto è più dell'altre eccellente, tanto più suole svegliarsi negli animi nobili per mezzo delle pie imagini, dicendo un autore ${ }^{335}$ : Pictae tabulae delectatio, si consilio regeremur, ad amorem caelestem erigere et originis nos deberent admonere; nam quis unquam, rivi appetens, fontem odit? E però chi con occhio purgato guarderà le cristiane pitture, non dubitiamo che non sia per participare di tutte queste dilettazioni.

[p. 221]

\section{CAP. XXIII.}

Che le imagini cristiane servono grandemente per ammaestrare il popolo al ben vivere.

Il fondamento posto di sopra della similitudine degli oratori e dei libri, per provare il diletto che ci apportano le cristiane imagini, serve ancora al capitolo presente per dimostrare la mirabile loro facoltà ad instruire gli uomini nella disciplina cristiana. La quale è tale e tanta, che in varie cose, secondo la loro proporzione, avanza la industria dei libri; imperoché, se vorremo guardare la commodità, la facilità, la brevità, la stabilità et altre circostanze non picciole che rendono un'opera lodevole, troveremo che nelle imagini ne concorrono molte, che sogliono nei libri essere disiderate.

È certo gran meraviglia che, per volere intendere qualche libro, vi sono necessarie sì difficili cose, come la cognizione della lingua, il maestro, l'ingegno capace e la commodità d'imparare, tal che la cognizione loro si ristringe solo in pochi, che si chiamano dotti et intelligenti; dove che le pitture servono come libro aperto alla capacità d'ogniuno, per essere composte di linguaggio commune a tutte le sorti di persone, uomini, donne, piccioli, grandi, dotti, ignoranti, e però si lasciano intendere, quando il pittore non le voglia stroppiare, da tutte le nazioni e da tutti gli intelletti, senza altro pedagogo o interprete. Si aggiunge che, con brevità grandissima, anzi in un

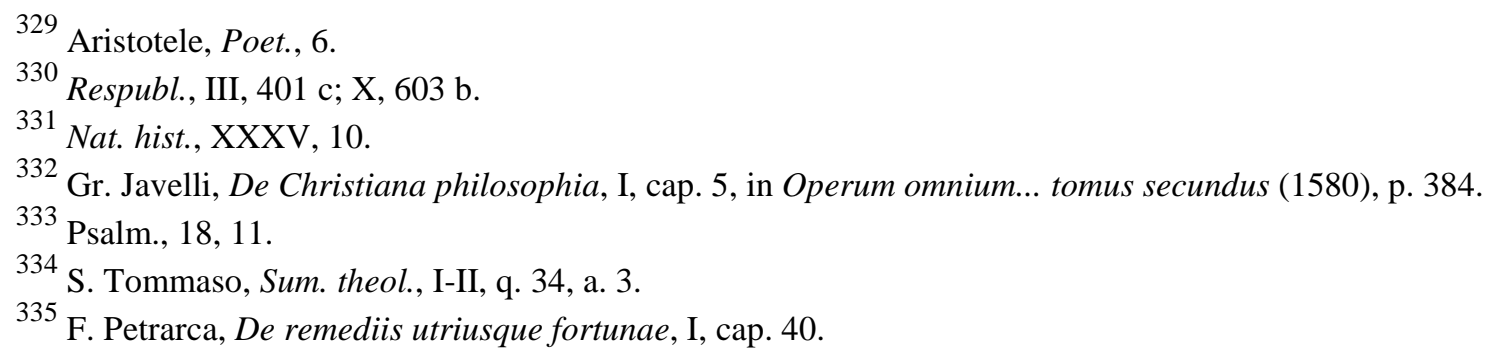


momento, o più tosto in uno sguardo, fanno capaci subito le persone ${ }^{336}$; dove nei libri provano gli eruditi quanto tempo et oglio vi si consuma per intenderli. E quel che più importa è che, non acquistandosi le lettere, o scienze de' libri, se non con gran fatica, travaglio e spesa, dalle imagini siamo ammaestrati con grandissima dolcezza e ricreazione. Et [p. 222] oltre ciò spesso dei libri avviene che quello che con gran difficoltà si è imparato, con gran facilità si scorda; dove le imagini quello che insegnano lo scolpiscono nelle tavole della memoria sì saldamente, che vi resta impresso per molti anni. E di più, le imagini in poco spazio, senza voltare volumi o fogli, abbracciano ampiissimi e gravissimi concetti, come si può vedere nel misterio della annunziazione della gloriosa Vergine, o della crocifissione del Redentore nostro, o della venuta dello Spirito Santo, o d'altri simili, che, ritratti ciascuno d'essi in qualche tavola, se ben picciola, bastano per molti volumi, insieme scoprendo in un punto la grandezza della potenza, sapienza, giustizia e misericordia di Dio, e la somma di tutte le virtù celesti.

Vi s'aggiunge che, sendo tenuti noi di palesare la legge nostra, secondo quel detto volgare di San Paolo: Corde creditur ad iustitiam, ore confessio fit ad salutem ${ }^{337}$, e secondo la opportunità persuaderla ancor ad altri et imprimerglila nel cuore ${ }^{338}$; qual maniera possiamo trovare noi più spedita o più chiara e giovevole, di questa delle sacre imagini? che non solo, come stendardi inarborati e bandiere spiegate, la manifestano a tutte le sorti di persone in qualonque luogo, ma ancora, come trombe perpetue, la vanno gridando et inculcando ne' sensi di ciascuno: talmente che, quello che l'uomo per via dell'udito, mediante la fede, nella mente sua ha conceputo, ora, con gli occhi mirandolo, viene mirabilmente a confermarlo e stabilirlo nel cuore suo. Onde col profeta può dire: Quemadmodum audivimus, ita vidimus ${ }^{339}$.

Ma dove lasciamo noi quello che è capo prencipale per insegnare una cosa? Che è l'autorità del maestro, essendo scritto: Oportet discentem credere, onde nacque quel motto antico celebrato in onore di Pitagora presso i suoi auditori, che dicendosi: Ipse dixit, non si cercava più alto ${ }^{340}$. Dunque, se [p. 223] presso quegli che hanno da essere ammaestrati sono di tanto peso le parole de' suoi precettori, per essere elle come instrumento adoprato dallo artefice, con che imprime la forma che vuole nelle cose; quanto maggiormente doveranno persuadere le sacre imagini, essendo di esse autore et institutore l'altissimo Dio, quale per mezzo di esse vuole scolpire nei cuori nostri la grandezza dei misterii suoi santi? Veggiamo nella legge antica, quando voleva Moisè che alcuna cosa fosse maggiormente riverita et osservata dal popolo, gli ricordava che il grande Iddio ne era stato l'autore e che il tralasciarla era offesa sua, dicendo: Non contra nos est murmur vestrum, sed contra Dominum $^{341}$; e l'apostolo S. Paolo per muovere più i Corinti diceva: Praecipio non ego, sed Dominus $^{342}$. Parimente per sapere noi che le nostre imagini sono publicate dalla celeste sapienza, canonizzate per tradizione degli apostoli et autenticate dalla santa Chiesa, come di sotto si mostrerà $^{343}$, debbono ragionevolmente tanto più acquistarsi e l'animo e la riverenza di ciascuno.

Non vogliamo stenderci più in raccontare altri suoi meravigliosi giovamenti intorno a questo ${ }^{344}$,

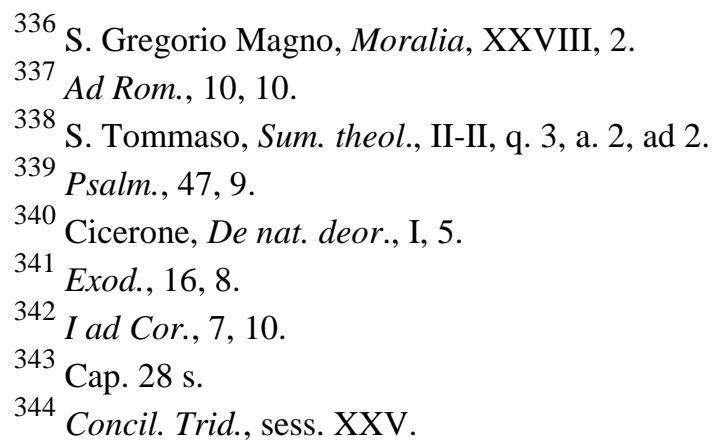


poi che possiamo in sostanza concludere che da esse, con grande facilità e brevità, non solo conseguiamo la teorica di tutto quello che è necessario alla salute, ma insieme ancora la prattica di tutte le virtù e la vera instituzione della vita nostra, rappresentataci con lo essempio di persone sante, che per servire a Dio hanno scacciato da sé i vizii, avuto in orrore le iniquità e superato tutte le difficoltà del mondo, abbracciando la pietà, la carità, la pudicizia, la giustizia e la vera ubidienza della legge di Dio; e questo con tanto ardore e zelo, che, per non stare pure un momento fuori della grazia sua, sono andati con grandissima prontezza alli rasori, alle croci, alle fiamme ardenti et ad ogni sorte d'acerbissimi supplicii. Sì che, conse [p. 224] guendo noi per mezzo delle cristiane imagini tutti questi e molti altri frutti, non possiamo se non concludere che questo loro mezzo serva ottimamente al fine di che già parlato abbiamo.

\section{CAP. XXIIII.}

Altre ragioni per dimostrare il giovamento che si cava dalle cristiane imagini per instruzzione del popolo.

Essendo assai manifesto, e per sé stesso e per le ragioni dette di sopra, di quanta importanza siano le imagini cristiane per ammaestramento del popolo, non ci saressimo noi stesi più oltre intorno a ciò, per fuggire la superfluità, se non ci spignesse la proterva importunità degli eretici, che con tutto ciò ardiscono pure di biasimarle, sforzandosi di bandirle da ogni luoco, come nocive alla salute degli uomini.

Alla quale impietà se bene si cercherà di farsi incontro al luogo suo, nientedimeno ora, con la occasione di quello che si tratta, che è di mostrare l'utile grande che ne riceve il popolo per sua disciplina, non possiamo lasciare di ricordare che il levarle dall'uso degli uomini serìa come essercitare una ingiustizia estrema verso infinite persone, e forse la maggior parte del popolo cristiano: non solo perché si verria a privarli di quel modo dalla natura concesso a ciascuno, che mediante il senso si possa venire in cognizione delle cose necessarie; ma ancora perché, sendo ognuno obligato, secondo i teologi e sommisti ${ }^{345}$, per la salute propria, di sapere esplicatamente gli articoli della fede, e, non sapendoli, non possono avere l'assoluzione sacramentale, come inabili alla grazia; saria bisogno che quelli, che aborriscono le imagini, insegnassero in che modo si dovrà provedere alla salute d'infiniti [p. 225] poverelli, che non sanno leggere, né meno con parole si possono fare capaci de' misterii necessarii alla salute.

E certo è che per via di queste pitture communemente usa la santa Chiesa in tutti i luoghi della cristianità di soccorrere alla infirmità loro ${ }^{346}$, perché, dichiarati che li siano almeno rozzamente gli articoli della fede, per mezzo poi delle pitture più facilmente li capiscono e li conservano a memoria; altrimenti resteriano privi del mezzo di godere dei santi sacramenti, onde giustissima causa avriano sempre di dolersi che, non essendo proibito l'uso dei libri in qualonque lingua a chi vuole imparare, sia greca, ebraica, arabica, schiavona o indiana, ad essi solo fosse vietato il linguaggio che possono intendere, cioè le pitture, che a loro servono per libri.

Ma di più anco: se è lecito di predicare il misterio della passione o la vita d'un santo, perché non sarà permesso parimente il poterla con figure rappresentare? E se è lecito l'ascoltare con le orecchie la Passione, perché non con gli occhi a mirarla? E se è lecito a leggerla in un libro approvato,

\footnotetext{
345 S. Tommaso, Sum. theol., II-II, q. 2, a. 5; F. Silvestri, In libros S. Thomae Aquinatis contra Gentiles commentaria (1524), s. v. fides, §6.

${ }^{346}$ G. de Loarte, Instructio sacerdotum et confessariorum, II, cap. 30.
} 
perché non di guardarla in una tavola fedelmente e divotamente compartita? Se nell'indice de' libri sono esclusi solo i libri perniciosi e gli altri ammessi, perché non si ha da servare nelle pitture la medesima regola e distinzione? perché si hanno generalmente da bandire tutte? Leggiamo che nella veste del sacerdote chiamata poderis, totus erat orbis terrarum ${ }^{347}$, perché rappresentava certa figura di tutte le cose celesti e terrestri ${ }^{348}$; e similmente il propiziatorio e tabernacolo tutto era di varii misterii adornato ${ }^{349}$; perché dunque non potremo noi per instruzzione nostra valerci delle imagini che ci rappresentano cose buone, sante e salutari? Altrimenti si averanno ancora a distruggere tutte le chiese, i monasteri, gli altari, i tabernacoli et i reliquiari, che sono [p. 226] certa sorte d'imagini sode, che ci insegnano e rappresentano altre cose maggiori e più eccellenti ${ }^{350}$.

$\mathrm{E}$ però veggiamo che $\mathrm{S}$. Gregorio ${ }^{351}$ così risentitamente si querelò contra quel vescovo Massiliense, che, avendo proibito al suo popolo le imagini, gli avesse ancora in esse levato il mezzo di potersi instruire delle cose ecclesiastiche, dicendo: Picturae imaginum ad aedificationem imperiti populi fuerunt factae, ut nescientes literas, ipsam historiam attendentes, discerent quid actum sit; et in una altra epistola dice ${ }^{352}$ : Imagines quas rogasti, tibi dirigendas misimus, unde valde nobis tua postulatio placuit; quia ab re non facimus, si per visibilia invisibilia demonstramus.

Dalle quali cose si può conoscere quanto a torto et iniquamente si siano mossi questi nemici della salute a volerci privare di tanto bene e commodo; la perversità de' quali tanto più si fa palese, quanto che si vede che essi non aborriscono di sua natura le imagini, leggendosi ${ }^{353}$ che si compiacciono grandemente nelle loro proprie et in quelle delli eresiarchi, come di Wicleffo, di Martino, di Melanctone, di Calvino et altri, ma solo servano la rabbia e furore suo contro quelle del sommo Iddio e de' suoi santi, perché sono approvate dalla santa Chiesa catolica et apostolica. Il che però, a chi ben considera, non deve porgere molta meraviglia, poi che, vedendo essi le loro imagini abbruggiarsi dal Santo Officio, né potendosi vindicare contro di lui, rivolgono l'ira contro il cielo, né si accorgono i meschini che fino negli antichi tempi degli imperatori Arcadio, Onorio, Teodosio, Valentiniano et altri giustamente fu ordinato che il nome degli eretici si cancellasse dai luoghi e la memoria loro si spegnesse $\mathrm{s}^{354}$.

[p. 227]

\section{CAP. XXV.}

Che le imagini cristiane servono molto a movere gli affetti delle persone.

Resta la terza parte, non solo propria, ma prencipale delle pitture, che è di movere gli animi de' riguardanti, il che tanto maggior laude le apporta, quanto che l'effetto in sé è nobilissimo et esse a ciò sono molto atte et efficaci. Ché se nelli oratori il saper volgere con la facoltà del dire gli affetti altrui in questa o in quella parte è stata riputata laude sopra le altre eggregia et eccellente, chi dubita

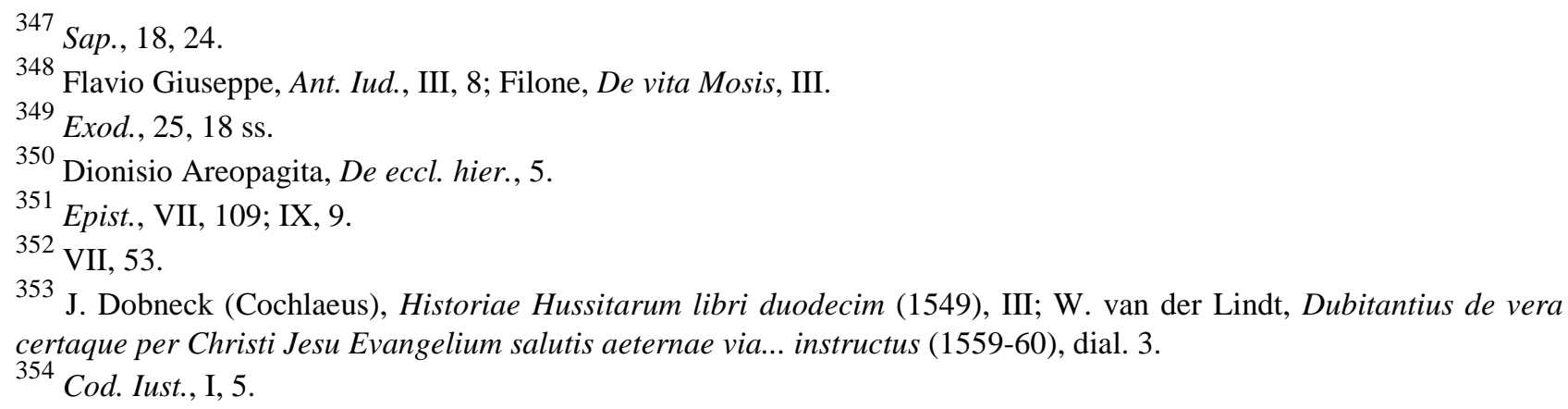

353 J. Dobneck (Cochlaeus), Historiae Hussitarum libri duodecim (1549), III; W. van der Lindt, Dubitantius de vera certaque per Christi Jesu Evangelium salutis aeternae via... instructus (1559-60), dial. 3.

${ }^{354}$ Cod. Iust., I, 5. 
che le pitture cristiane, da bellezza spirituale accompagnate, tanto più efficacemente e nobilmente potranno effettuare questo, quanto che di natura sua, rispetto alla moltitudine universalmente rozza, a ciò sono più atte, et il fine a che caminano, come di già dicemmo, è molto più sublime e glorioso?

È noto et approvato da tutti quello che disse il poeta lirico ${ }^{355}$ : Segnius irritant animum demissa per aures, quam quae sunt oculis subiecta fidelibus; onde possiamo ancor noi dire che in proporzione pare risponda la pittura alle cose vedute nel modo proprio ch'avennero, come la

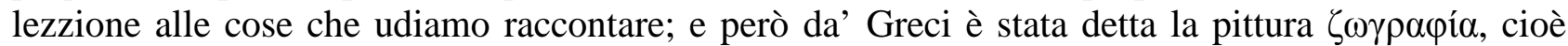
viva scrittura, come dicono gli autori ${ }^{356}$. Di modo che, se leggiamo varii essempi di persone che, avendo letto un solo libro, ancor che a caso, sùbito da quella lettura hanno mutato in tutto parere; perché non vogliamo persuaderci che tanto più efficacemente debba ciò riuscire da una imagine sacra divotamente fatta?

Narra Pontiziano in S. Agostino ${ }^{357}$ ch'alcuni soldati di Valentiniano imperatore, avendo letta la vita di S. Antonio tro [p. 228] vata in una casetta di villa, presero subito nuova deliberazione della vita loro, per servire a Dio; e di sé stesso narra il medesimo S. Agostino ${ }^{358}$ ch'avendo letto l'Ortensio di Cicerone, tutto si mutò, scrivendo così: Ille liber mutavit affectum meum, et ad te ipsum, Domine, mutavit preces meas, et vota ac desideria mea fecit alia, Viluit mihi repente omnis vana spes etc. Onde, se tanta efficacia hanno le parole, che si odono o leggono, di tramutare i sensi nostri, con molta maggiore violenza penetreranno dentro di noi quelle figure, dalle quali si vedrà spirare pietà, modestia, santità e divozione, dicendo S. Gregorio: Dum exteriorum rerum intrinsecus species attrahuntur, quasi in corde depingitur quicquid fictis imaginibus deliberando cogitatur.

Il sentire narrare il martirio d'un santo, il zelo e costanza d'una vergine, la passione dello stesso Cristo, sono cose che toccano dentro di vero; ma l'esserci con vivi colori qua posto sotto gli occhi il santo martirizzato, colà la vergine combattuta e nell'altro lato Cristo inchiodato, egli è pur vero che tanto accresce la divozione e compunge le viscere, che chi non lo conosce è di legno o di marmo. Onde S. Basilio scrive ${ }^{359}$; In ecclesia ad spectandum me alliciunt picturae flores, contemplor fortitudinem martyris, coronarum proemia considero, et tanquam igne incendor aemulandi cupiditate, atque prostratus et supplex per martyrem Deum adoro, salutemque percipio; et il Metafraste nella vita di S. Tarasio ${ }^{360}$, defensore zelante delle sante imagini contro la rabbia degli iconomachi, dice: Quis videns coloribus eum expressum qui decertat, ac flagellorum nubes et ignem despicit, creatori suo confidens, non lacrymis circunfunditur? Quis eum videns, qui pro Christo se tradidit lictoribus, et fortiter in suppliciis persistit, non admiratur patientiam, invictamque excelsi animi virtutem? Quis alium spectans, qui ne aliquod verbum emitteret indignum pietate, su [p. 229] stinensque in lateribus et dorso laniari, non emollescit miseratione? Quis eum aspiciens, qui leonibus devorandus et dentibus eorum molendus traditur, non spiritualis illius particeps fit convivii? Quis haec non solum in masculis, sed etiam in feminis contemplans, non muliebrem abjiciat timiditatem et fiducia in Deum muniatur? Quis etc.

Sì che non crediamo che sia alcuno così insensato e stupido, che non conosca dai proprii sensi la convenienza grande e simpatia che la natura umana ha con queste imagini, quando sono

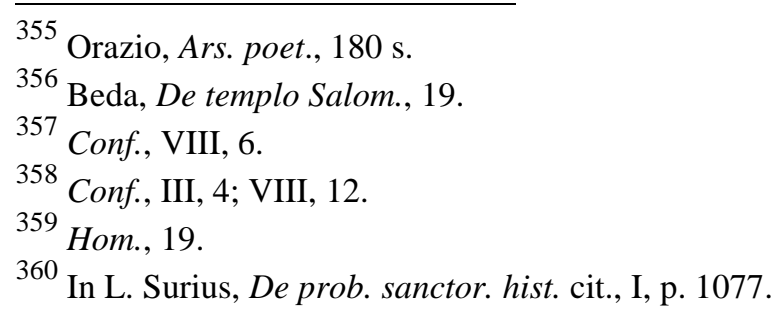


spiritosamente e vivamente espresse. Onde scrive S. Agostino nel libro Del visitare gli infermi ${ }^{361}$, che, oltre la fede che se li debbe ricordare in quell'atto, sunt quaedam extraria signa pigritantis etiam fidei aliquando excitatoria, et quasi quandam compunctionem penetralibus suis figentia, quae et christianitatis religio vult servari, et amicorum ad infirmos convenientium devotio gaudet adimpleri; e seguita dicendo della imagine del Crocifisso, quanto a ciò giovi; et il Beda ${ }^{362}$ pur dice: Imaginum aspectus multum compunctionis solet praestare contuentibus, et eis qui literas ignorant, quasi vivam dominicae historiae pandere lectionem. Intorno a che molte altre cose si potriano aggiongere, se fosse necessario.

\section{CAP. XXVI.}

Dei varii effetti notabili causati dalle imagini pie e divote.

Desideriamo ora di far chiaro a tutti che gli effetti corrispondono alle ragioni già dette, e dalla isperienza stessa rendere manifeste le meravigliose operazioni che per via di tali imagini si sono vedute. Né in ciò vogliamo servirci degli essempi, che sariano infiniti, de' miracoli che continoatamente [p. 230] nella santa Chiesa per mezzo di esse si sono scoperti, per li quali manifestamente si vede quanto la divina potenza si compiace di elle in cose meravigliose e stupende: sì come nel dare la sanità a chi s'è a Dio davanti esse raccomandato, nel liberare altri da' pericoli inevitabili, nel conservare intatte dette figure in mezzo delle fiamme ardenti, nel difendere $\mathrm{i}$ luoghi e le città oppresse da' nemici, et in molt'altri modi tutti miracolosi; imperò che, sendo questi effetti sopranaturali et argomenti infallibili della virtù celeste, reserviamo noi in altro luogo di trattarne, et intendiamo ora solamente di ragionare di quelli effetti che possono chiamarsi naturali, aiutati però dalla superna grazia.

Per dimostrar questo, potressimo cominciare da quello che viene affirmato da' filosofi e medici, dicendo che, secondo i varii concetti che apprende la nostra fantasia dalle forme delle cose, si fanno in essa così salde impressioni, che da quelle ne derivano alterazioni e segni notabili nei corpi; di che chiaro testimonio ci rende l'esperienza stessa, mettendoci ogni giorno inanzi agli occhi diversi parti notabilmente signati da macchie o figure, ora di vino, ora di frutti, ora di membri di animali e d'altro $^{363}$; onde scrisse Plinio: Plures in homine quam in caeteris animalibus differentiae, quoniam velocitas cogitationum, animique celeritas et ingenii varietas multiformes notas imprimit, cum caeteris animalibus immobiles sint animi ${ }^{364}$.

Essendo donque la imaginativa nostra così atta a ricevere tali impressioni, non è dubbio non ci essere istrumento più forte o più efficace a ciò delle imagini fatte al vivo, che quasi violentano $\mathrm{i}$ sensi incauti; il che da varii essempii si può conoscere, raccontati dagli autori, tra' quali non è da tralasciare quello che scrisse un oratore greco in una sua declamazione fatta per difesa d'una donna, accusata di adulterio per aver partorito uno figliuolo moro, molto dissimile dal padre; il quale prese per fondamento della difesa sua l'aver ella nella [p. 231] stanza una simile imagine: il che viene ancor confirmato da Plutarco ${ }^{365}$, che lasciò scritto: mulieres simulacra saepe et statuas in delitiis habuisse, similesque partus enixas. È appresso narrato d'uno padre che, desideroso d'aver bella

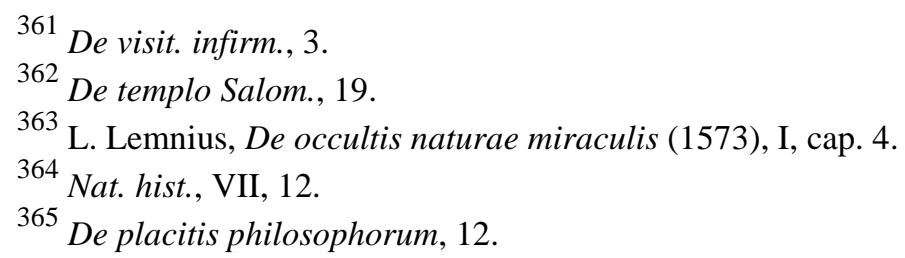


successione, donò alla moglie sua uno ritratto d'un picciol fanciullino, bello e gentile, accioché nell'immaginazione le s'imprimesse la figura di quello; per lo che scrisse Plinio ${ }^{366}$ : Similitudinum quidem in mente reputatio est, et in qua credantur multa fortuita pollere, visus, auditus, memoria, haustaeque imagines sub ipso concepiti. Fa a questo proposito quello che è scritto della imagine di Giulio Cesare ${ }^{367}$, quod eius imago occisi in cera expressa mox populi animos ad caedis ultionem excitavit; e quello che racconta Quintiliano ${ }^{368}$, che solevano da alcuni prodursi nei giudizii al conspetto de' magistrati le imagini di quelli per li quali giudicavano le parti doversi tanto più commovere l'animo del giudice: onde leggiamo che quelli antichi senatori romani solevano dire: cum maiorum imagines intuerentur, vehementius sibi animum ad virtutem accendi ${ }^{369}$. Intorno ai quali essempi, e quanta impressione si faccia per la semplice vista, basti per ora quello che narra la Scrittura ${ }^{370}$ delle pecore di Iacob, quando fece scorzare le verghe a questo effetto solo, perché dalle imagini varie di quei ramuscelli riuscissero anco i parti del gregge di color vario e di belle macchie.

E perché dissegnamo noi al suo luogo raccontare altri molti essempi degli effetti causati dalle imagini profane, per ora staremo solo in quegli delle pitture sacre e morali, ricordando prima che scrive S. Gregorio Nisseno, allegato più volte nella settima Sinodo, che l'istoria d'Abraham, quando volse immolare il figliuolo suo Isaac, era stata così vivamente e pietosamente da un pittore ritratta, che, ogni volta che la mirava, si mutava talmente tutto, che non potea [p. 232] ritenere le lagrime ${ }^{371}$ : Vidi, inquit, saepius inscriptionis imaginem et sine lacrymis transire non potui, cum tam efficaciter pictura ob oculos poneret historiam; e soggiungono quei padri nel concilio: Si tanto doctori peperit utilitatem et lacrymas, quanto magis rudibus hominibus utilis erit? Narra nella detta sinodo S. Asterio $^{372}$, vescovo di Amasea, d'una pittura fatta del martirio di S. Eufemia, ove era così bene espressa l'acerbità della passione e la grandezza della fortezza sua, che facea muover le lagrime: Lacrymas, inquit, fundo, nam tam exacte sanguinis guttas pictor defluentes depinxerat, ut iuraveris a labiis profluere.

Nella vita di S. Maria Egizziaca $^{373}$ si legge che, vedendo ella un giorno il popolo, che numerosissimo entrava nel tempio, dal quale pareva si fosse ritirata, ricordatasi della vita sua disonesta alzò gli occhi là dove era una imagine della $\mathrm{S}$. Croce et un'altra della gloriosa Vergine, e sùbito le parve che da quella imagine uscissero dardi che le penetrassero il core; e queste sono le parole: Me igitur horror animique extasis invasit, totaque contremiscere et conturbari coepi; presso che ne seguì quella meravigliosa conversione et inusitata penitenza che si legge.

Scrive parimente S. Gregorio Nazianzeno ne' suoi versi, che una donna meretrice, sendo stata chiamata a casa d'uno sfrenato giovine, tosto che gionse alla porta di quello, alzati gli occhi alla imagine di Polemone, che era stato persona costumatissima e di ottima vita, mutò l'animo suo cattivo e, tornata indietro, lasciò totalmente il pensiero di peccare; onde dice:

Scortum intemperans aliquis ad se vocarat iuvenis.

Illa vero, ubi prope limen pervenisset,

\footnotetext{
366 Nat. hist., VII, 12.

367 Appiano, Bell. civ., II, 147.

368 Inst. orat., VI, 1.

369 Sallustio, Iug., 4.

${ }^{370}$ Gen., 30, 37 ss.

371 Surius, III, p. 92.

372 Surius, III, p. 94.

373 Surius, III, p. 112.
} 
[p. 233]
De quo in imagine Polemon prospiciebat,
Inspecta illa, erat autem veneranda,
Spectaculo victa, mox recessit,
Ut vivum reverita pictum ${ }^{374}$.

Narra l'abbate Teodoro ${ }^{375}$ che, avendo uno gran divozione ad una imagine della madre d'Iddio che aveva il figliuolo in braccio, il Demonio non cessò di fargli tutti gl'insulti, perché si levasse di casa quella imagine, e racconta cose meravigliose, che da quella occasione successero.

Si legge di S. Bernardo la divozione grande e l'ardore dello spirito, che egli spesse volte concepì dentro di sé inanzi le imagini del Crucifisso. Di S. Francesco parimente si legge che guardando con forte ammirazione le sacre piaghe del Salvatore, ne ritrasse egli le sante stigmate nel corpo suo, et a noi ha riferito un padre dominicano degno di fede che, trovandosi in Milano, conobbe un signore che, avendo fatta ferma deliberazione di ammazzare un suo nimico, entrato in chiesa e riguardata la imagine d'un Crucifisso, sentì subito tutto commoversi, et ingenocchiatosi cangiò affatto quel malvagio pensiero; e crediamo che simili accidenti siano anco a molti altri per Dio grazia avvenuti. Dalle quali cose, per non stenderci maggiormente, potrà il pittore facilmente giudicare la importante e segnalata occasione che se gli appresenta ogni volta che ha da fare una imagine sacra, confidandosi nel divino aiuto che col mezzo di quella potrà imprimere nel popolo il vero culto di Dio e la grandezza delle cose eterne, e convertire come ministro celeste i cuori delle nazioni intiere, e cangiarli in altra forma, e seco rapirli in cielo; di che abbiamo narrato di sopra ${ }^{376}$ varii essempi, che potranno servire ancor al presente capo.

\section{CAP. XXVII.}

Quanta forza abbia usato il Demonio per levare le sacre imagini dal popolo cristiano.

Di quello che finora si è discorso dei varii e notabili frutti che dalle cristiane pitture derivano al mondo, se per [p. 234] caso non si appagasse a pieno l'animo di qualcuno, crediamo che ora resterà intieramente sodisfatto, intendendo quanto si sia affatticato il Demonio in tutti i tempi per levare l'uso delle imagini dalla chiesa d'Iddio. È, come sa ognuno, perpetuo nemico della salute nostra il Diavolo, né può soffrire che debbiamo arrivare a quelle felici sedie noi, dalle quali egli per la superbia sua fu discacciato; e però egli si oppone a tutte quelle azzioni nostre, dalle quali può imaginarsi che noi caviamo utile e profitto. Per questo oppugna le orazioni, cerca di dissuader i digiuni, interrompe i peregrinaggi, disturba le elemosine, e per questo prencipalmente, dal nascimento di Cristo benedetto in qua, pare che si abbia pigliato per impresa di estinguere con ogni suo potere le imagini dal popolo cristiano.

Laonde non è meraviglia ch'abbia tentato già longo tempo ogni strada per conseguire questo suo dissegno, servendosi di varii pretesti e ragioni apparenti, ora della Scrittura sacra, or de' concilii, e quando del mezzo di personaggi grandi, imperatori, patriarchi, vescovi et altri, per ingannare più facilmente $\mathrm{i}$ popoli imperiti. $\grave{\mathrm{E}}$ questo antico costume del prencipe delle tenebre, e conscguentemente de' seguaci suoi, sì come fu notato da $\mathrm{S}$. Agostino ${ }^{377}$, di seguitar sempre gli

\footnotetext{
${ }^{374}$ Presso Surius, III, p. 93 s.

375 Surius, III, p. 136.

376 Cap. 8.

${ }^{377}$ De fide et operibus, 4.
} 
estremi, ne' quali ordinariamente sta riposto il vizio, e di fuggire il mezzo, dove tiene il suo seggio la virtù. Così ha fatto egli nel proposito delle imagini, perché persuase i gentili e spesse volte il popolo ebreo di adorarle come veri dèi, acciò incorressero nella idolatria, e per quella via cercò tirarli al precipizio ${ }^{378}$; con altri poi ha preso l'altro estremo, con indurli a scacciarle affatto e bandirle come nimiche della salute. Ma la santa legge cristiana, vero albergo di tutte le virtù, fuggendo i dui estremi, come altre volte abbiamo detto, se ne sta nel mezzo e non adora le imagini come cosa divina, né manco le abor [p. 235] risce o le scaccia come cosa sacrilega et immonda, ma si serve dell'uso loro moderatamente per ammaestrare, svegliare e rinovare la memoria de' fedeli alle cose salutifere del cielo et al fine che di sopra si è detto.

E però replichiamo non essere meraviglia che molti eretici, ministri di lui, per abbattere l'uso delle imagini si siano serviti di varii luochi della scrittura, torti all'intento loro; sapendo noi questa essere ordinaria malizia del Serpente antico, con l'apparenza delle parole divine male interpretate coprir il veleno, onde scrisse S. Ilario ${ }^{379}$ : De intelligentia haeresis est, non de scriptura, sensus non sermo fit crimen. E però sappiamo con queste armi essere stato da lui assalito nel deserto il Salvatore nostro, e che gli stessi Ebrei spesso avevano in bocca: Scrutamini Scripturas ${ }^{380}$. Ma ben dice $\mathrm{S}$. Ireneo ${ }^{381}$ che, sì come alle volte di varie gemme e pietre preziose formerà alcuno una figura di serpe e di scorpione, così dice egli delle parole della Scrittura, che sono come gemme, solere gli eretici servirsi per saette mortali e venenose. Ma noi con l'istesso scorpione ci facciamo medicina, e con la istessa spada ammazziamo Golia, mostrando che i medemi luoghi della Scrittura, bene intesi e secondo il commune senso de' santi Padri, fortificano tanto più l'uso delle imagini sacre, come nei sacri concilii e da' santi Padri è stato dichiarato.

Non è meraviglia ancora che talora abbia il medesimo Satanasso messo in campo persone prencipali e fatto conciliaboli, et alcuna volta esserciti di genti sotto imperatori, per venire all'ultima destruzzione di queste imagini; perché, sì come fu scritto da $\mathrm{S}$. Crisostomo ${ }^{382}$, ha ancor egli in questo mondo la sua republica et i suoi ministri in tutti i gradi e professioni di questa vita, de' quali, come de istromenti, si serve in procurare le maligne opere sue. A che basti per esempio quello che disse il Salvatore nostro, parlando de' [p. 236] suoi apostoli: Nonne duodecim ego vos elegi et unus ex vobis diabolus est ? $^{383}$ Sì che nel corso de' secoli del mondo, e nelle tenebre di questa vita, non ha da parere cosa nuova o non verisimile, che e tra gl'imperatori, patriarchi, vescovi et altri spesse volte ve ne siano stati alcuni suoi stipendiati e nimici delle buone leggi, i quali però non ha permesso la divina providenzia che regnino, e che al fine non siano stati negli ecumenici concilii abbattuti, e che non siano rimase superiori di gran longa sempre le ragioni vive et efficaci de' santi Padri, col consenso universale di santa Chiesa, che ha perpetuamente abbracciate e riverite le sacre imagini, come dai seguenti capi si conoscerà.

\section{CAP. XXVIII.}

Autorità della scrittura santa e de' sommi pontefici e de' concilii,

\footnotetext{
${ }^{378}$ Valafrido, De exordiis et incrementis quarundam in rebus ecclesiasticis rerum, 8.

${ }^{379}$ De Trin., II.

${ }^{380}$ Ioan., 5, 39; 7, 52.

381 Contra haereses, I, 1.

382 De sacerdotio, IV.

383 Ioan., 6, 71 .
} 
che provano l'uso delle sacre imagini.

Ancor che nostro intendimento non sia di volere dogmaticamente trattare delle sacre imagini, né disputare contro la ostinazione degli eretici, parendoci che ad un animo pio debba essere bastevole il generale assenso di santa Chiesa; nondimeno, perché essi vanno insidiosamente spargendo molto obbrobrio contra di quelle, abbiamo pensato, per levare ogni equivocazione che potesse con falsa apparenza ingombrare la debol mente di qualcuno, soggiongere ora alcuni prencipali fondamenti e verità catoliche, alle quali possa stare ciascuno sicuramente appoggiato; il che tanto più ci è parso necessario, che, dovendo noi parlare degli abusi di esse per sradicarli, che sono com'accidenti, indarno avressimo preso questa fatica, se la sostanza loro fosse vile o infetta. Dunque, per stabilire tanto più nella mente dei lettori l'onore e vero pre [p. 237] gio che a quelle si deve, affine che con maggiore prontezza siano abbracciati li avvertimenti che nel discorso si diranno, comincieremo in questo capitolo dal testimonio degli autori, il quale perché sia più certo e senza contradizzione, adduremo solo quelli la cui autorità ci è in luogo di legge et induce necessità all'osservanza, come dei libri sacri, de' sommi pontefici e de' concilii, lasciando per ora il cumulo di molti altri santi e gravissimi autori, per fuggire il tedio della longhezza, non essendo questo prencipale intento nostro.

Troviamo fino nell' antica legge, che Iddio molte volte commandò che si formassero le imagini. Di sua propria bocca si può dire che egli ne insegnasse e commandasse molte: i leoni, i buoi, le palme, le scolture del candelabro, i cherubini del propiziatorio, tutti furono segni datici da Dio istesso $^{384}$; Dio fu che disse: Fac tibi Cherubin $^{385}$; Dio che disse: Fac tibi serpentem aeneum ${ }^{386}$; Dio che commandò le scolture dei pomi granati e di molt'altre imagini. E se da Dio non viene mai comandata cosa che non sia di giovamento e di utile, chi potrà negare che l'uso delle imagini, commandato da lui in tanti luoghi, non debba essere utilissimo e giovevolissimo?

Essendo di poi venuto al mondo il Salvatore nostro, predicando la sua evangelica dottrina, e dopo' lui i suoi santi apostoli e discepoli, et essendo già in essere l'uso delle sacre imagini, fu per l'avvenire continuata sempre la osservanza loro, come appare dal canone del Concilio degli Apostoli Antiocheno ${ }^{387}$ e la tradizione ecclesiastica dimostra, la quale a noi è in luogo di legge certissima, sì come ne rende ampio testimonio il Concilio Niceno secondo ${ }^{388}$ con queste parole: Fatemur unanimiter nos ecclesiasticas traditiones, sive scripto sive consuetudine valentes et decretas, retinere velle, [p. 238] quarum de numero est imaginum effiguratio; e nella medesima sinodo dice Eutimio vescovo Sardense, seguitato da altri vescovi, de' quali ivi si fa menzione: Ego sanctas imagines toto corde suscipio, non velut novum dogma nuper inventum, sed clare cognoscens ex apostolica traditione, sanctorumque doctorum in Ecclesia iussu, per manum nobis traditum fuisse; et in altro luogo S. Epifanio dice ${ }^{389}:$ Non est imaginum structura pictorum inventio, sed Ecclesiae catholicae probata legislatio et traditio; pictoris enim sola ars est, verum ordinatio sanctorum patrum. E l'istesso da S. Basilio, dal Damasceno e communemente dalli sacri nostri dottori vien confirmato ${ }^{390}$; talché non fu necessario publicare altra legge universale per quelle. Ma

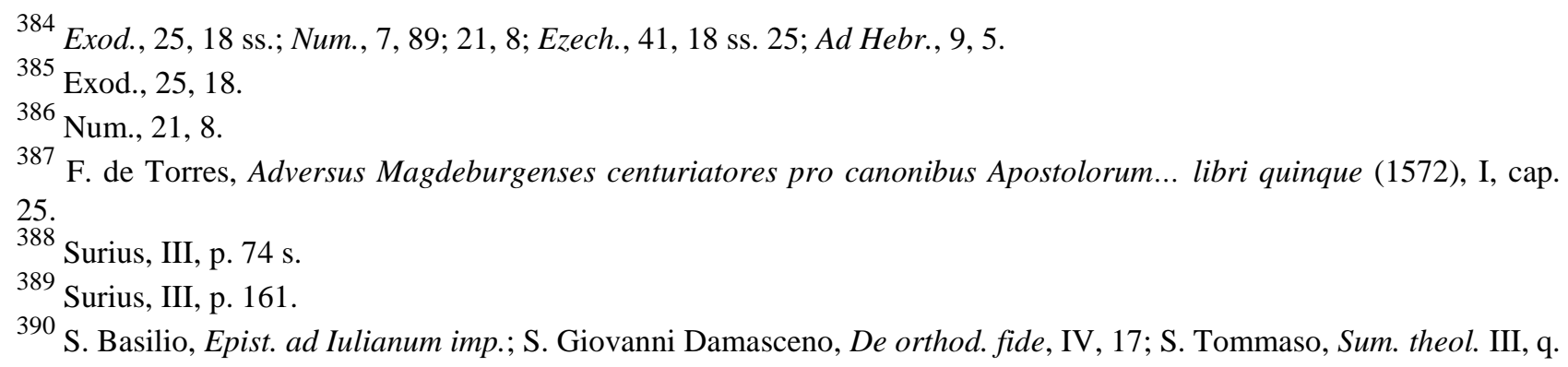


se in alcun tempo pullularono alcune piante di perfidia, furono dalle autorità de' pontefici e santi Padri di quei tempi subito succise, come si legge in varie epistole di S. Gregorio ${ }^{391}$, et appresso altri autori se ne fa menzione ${ }^{392}$; ma quando cominciarono poi a scoprirsi i sacrilegi eretici, apertamente favoriti ancor talora da scelerati prencipi ${ }^{393}$ di quei tempi per distruggerle totalmente, non tardarono varii pontefici santissimi di subito congregare sinodi generali per opporsi a tanta impietà, scomunicando gli impugnatori delle sacre imagini e confirmando e canonizzando l'uso di quelle. Onde narra Paolo Diacono ${ }^{394}$ che papa Costantino fece già varie provisioni per le sante imagini, che erano state da Filippico, eretico imperatore, offese. Successe di poi papa Gregorio II, del quale è rifferito da Adriano papa ${ }^{395}$, eo in concilio 79 episcoporum praesidente, ante confessionem beati Petri et in eorum concilio, multorum sanctorum patrum testimoniis allatis, fuisse sancitum [p. 239] venerandas et adorandas esse sacras imagines; et altre cose intorno a questo sono di lui narrate da Anastasio bibliotecario ${ }^{396}$ e da Nicefforo ${ }^{397}$ e da Zonara ${ }^{398}$ e da altri.

A papa Gregorio II successe Gregorio III e dopo lui molt'altri santissimi pontefici, Zacaria, Steffano II, Steffano III, Paolo I che, come appare nella stessa sinodo ${ }^{399}$, tutti in favore delle sante imagini procurorono varie cose. Dopo i quali papa Adriano I celebrò quella famosa e notabile sinodo, chiamata Nicena II et ecumenica settima, nell'anno $789^{400}$, nella quale, oltre moltissimi decreti intorno a ciò, si leggono queste parole: Ex legali, prophetica, apostolica patrumque traditione instructi sumus hanc esse veritatem pietatemque, ut in sacris ecclesiis venerandae imagines colantur; e questa sentenzia così efficacemente e con tanta vivacità fu da quella santa sinodo accettata, che tra gli altri padri quel greco Pelusiota lasciò scritto quel detto notabile ${ }^{401}$ vaoṽ

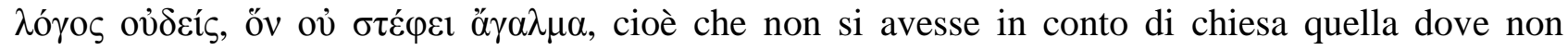
fossero imagini, come sono le sinagoghe degli Ebrei, le moschee de' Turchi e le scole moderne degli eretici, nude di ogni pittura, che più tosto paiono stanze private che chiese. Anzi, tra le acclamazioni che si fanno fornita la sinodo, leggonsi queste parole ${ }^{402}$ : Omnes sic credimus, omnes idem sapimus, omnes approbantes subscripsimus; haec est fides apostolorum, haec est fides patrum, haec est fides orthodoxorum; haec fides orbem terrarum confirmavit. Dopo la quale sinodo, sotto il medesimo Adriano, fu poi celebrata la Francfordiense, con detestazione pure degli iconomachi ${ }^{403}$.

Alla pietà di questo pontefice aggionse poi Leone III circa l'anno 800, con lo aiuto di Carolo Magno imperatore, molte [p. 240] altre cose, acciò restasse tanto più stabilito questo dogma nella

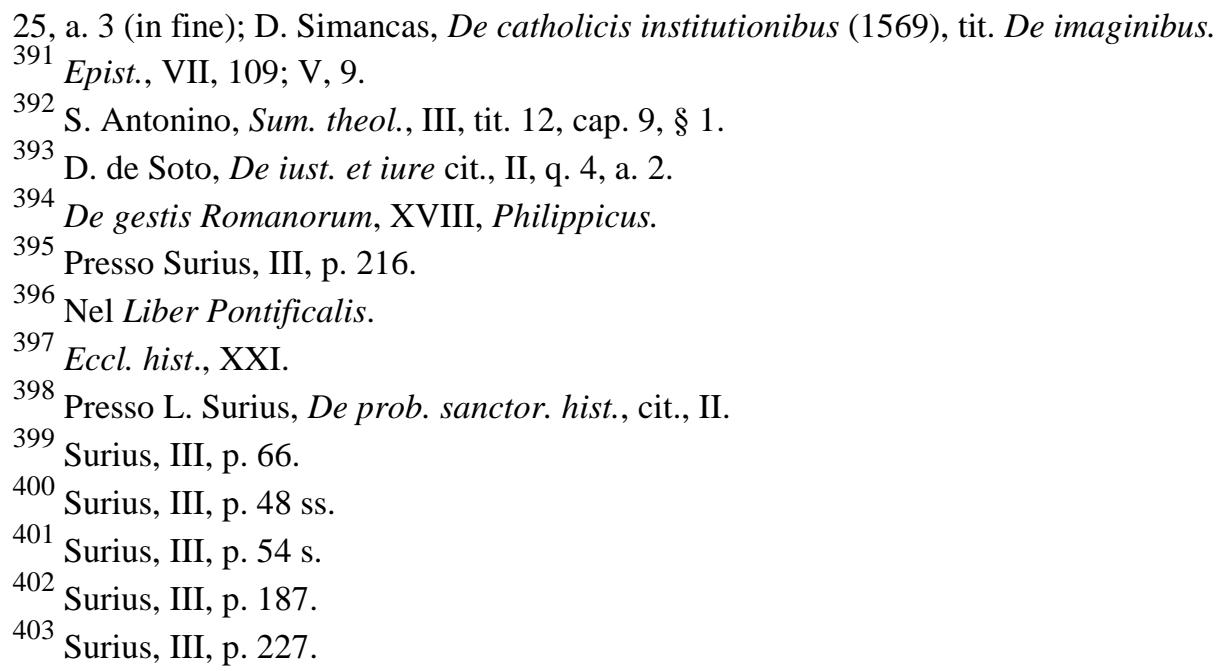


Chiesa catolica. Doppo lui papa Nicolao I scrisse, tra le altre, due epistole ${ }^{404}$ a Michele imperatore de' Greci, dicendo nella prima: Pristinam sanctorum patrum traditionem quam a praedecessoribus nostris, qui post beatum Petrum in eius apostolica sede resederunt, nobis observandam suscepimus et hactenus immutilatam sancta catholica et apostolica defendit Ecclesia. Oportet ergo venerandas Christi domini nostri et sanctissimae suae genitricis et beatorum apostolorum atque omnium sanctorum imagines venerari et colere etc.; e nella epistola VII pure conferma il medesimo; onde i suoi decreti furono per ciò commendati molto da Leone Nono, come nelle epistole sue dimostra ${ }^{405}$. E dopo esso Adriano II, che congregò l'ottava generale Sinodo, volse anch'egli dell'istessa materia publicare alcuni canoni, tra i quali si legge ${ }^{406}$ : Sacram imaginem D. N. Iesu Christi et omnium salvatoris aequo honore cum libro sanctorum evangeliorum adorari decernimus: nam per colorum imaginariam operationem et sapientes et idiotae cuncti, ex eo quod in promptu est perfruuntur utilitate; et in un altro canone ${ }^{407}$ parla pure dell'istesso. E di poi nella Sinodo universale Fiorentina fu decretato con queste parole ${ }^{408}$ : Impii homines, nullam inter pietatem impietatemque differentiam facientes, Domini ac sanctorum eius imagines idolorum ac diabolorum signa esse credunt. Nos, cum Deum unum in Trinitate adoremus, necesse est etiam venerandas eius imagines excolamus; qui vero non ita sentiunt, sint anathema et ab ecclesia expellantur; et ultimamente nel Concilio Tridentino è stato pure approbato e ratificato il medesimo, con mirabile assenso de tutti i Padri, dicendosi, tra le altre cose, ex omnibus sacris imaginibus magnum fructum percipi; non solum quia admonetur populus beneficiorum et munerum quae a Christo sibi collata [p. 241] sunt, sed etiam quia Dei per sanctos miracula et salutaria exempla oculis fidelium subiiciuntur, ut pro iis Deo gratias agant, ad sanctorumque imitationem vitam moresque suos componant, excitenturque ad adorandum et diligendum Deum et pietatem colendam ${ }^{409}$.

E per conclusione riferiremo la orazione stessa che la santa Chiesa anticamente ha osservata nella benedizzione delle sacre imagini ${ }^{410}$, dicendo: Omnipotens sempiterne Deus, qui sanctorum tuorum imagines seu effigies sculpi aut pingi non reprobas, ut quoties illas oculis corporeis intuemur, toties eorum actus et sanctitatem ad imitandum memoriae oculis meditemur, hanc quaesumus imaginem in honorem ac memoriam beati N. etc.

Dalle quali autorità pensiamo che chiarissimamente si pruovi, quanto appartiene al proposito nostro, qual sia sempre stato il sentimento et ordinazione della santa Chiesa catolica nel ricevere e venerare le sacre imagini; lasciando innumerabili altri testimonii d'autori santi greci e latini, dai quali si prova il medesimo, et anco de' moderni, da' quali diffusamente n'è stato scritto ${ }^{411}$.

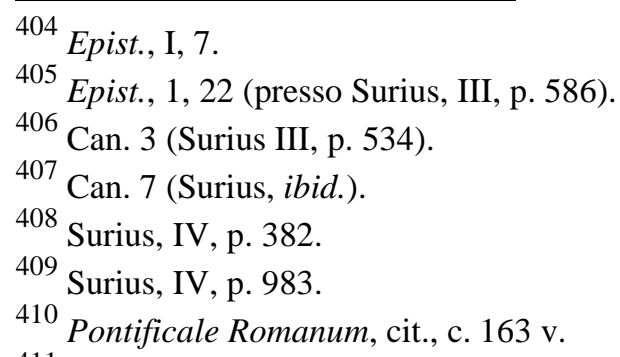

411 S. Atanasio, Doctr. ad Antioch., 16, 38; S. Gregorio Nisseno, In S. Theodorum; Beda, De templo Salom., 19; Valafrido, De exordiis et incrementis, 8; L. Politi, Disp. de cultu et adorat. imaginum cit.; N. Sanders, op. cit.; F. de Torres, Dogmatici characteres verbi Dei adversus novos Evangelicos (1561), IV; [N. Harpsfield], Dialogi sex contra Summi Pontificatus... oppugnatores... ab Alano Copo editi (1566), IV, cap. 5 ss.; W. van der Lindt, Panoplia Evangelica (1559-60), III, cap. 23. 


\section{CAP. XXIX.}

Essempi antichi, riferiti da varii autori greci o latini, che provano l'uso delle imagini.

Alle autorità dette di sopra ora aggiungiamo varii essempi dell'uso delle imagini fino a quei primi tempi del Salvatore nostro e de' suoi santi discepoli e martiri, acciò tanto più [p. 242] chiaro resti che questa osservanza ha origine non solo antichissima, ma ancora santissima et autentichissima. A che doveria bastare certo l'essempio solo di Cristo signore nostro, al quale essendo mostrato da' discepoli de' Farisei il denaro con la imagine di Cesare, non solo egli l'approvò, ma insieme vi aggiunse quel memorabile documento che si legge Reddite quae sunt Caesaris Cesari, et quae sunt Dei Deo ${ }^{412}$; talché, se fu da lui approvata la imagine che si suole fare per onoranza e segno di superiorità a uno prencipe terreno, come dice il Beda ${ }^{413}$, quanto maggiormente si doverà ciò affirmare in quelle che si pongono per ricognizione et ubidienza del vero Iddio e santi suoi, ch'oggi sono trionfatori del mondo e regnanti in cielo? Quare - scrisse Nicolao papa ${ }^{414}$ - animarum sanctorum, quae in corpore aliquando fuerunt, execremur effigies, per quos agnovimus fidei veritatem? E se nel castigare i scelerati ci serviamo delle loro imagini per ignominia, perché nell'esaltare i buoni non potremmo adoprarle per loro onore?

Ma di più, scrive Eusebio nella sua istoria ${ }^{415}$ che in Cesarea vi era la statua della donna emoroissa, che già fu risanata dal Salvatore, fatta in forma di donna che, gettatasi in terra alle ginocchia di quello, prega con le mani giunte, et insieme una altra statua in abito d'uomo vestito di stola longa, che porge la man destra alla donna; e vuole egli che questa imagine fosse quella del Salvatore nostro, dicendo: Hanc statuam ad similitudinem vultus Iesu formatam tradebant, quae permansit ad nostra usque tempera, sicut ipsi oculis nostris inspeximus; et il Damasceno ${ }^{416}$ riferisce la supplica stessa presentata ad Erode dalla medesima donna per potere drizzare tale statua. Narra di poi Sozomeno ${ }^{417}$ che Iuliano Apo [p. 243] stata levò quella statua, e riposta nel medesimo luogo la sua propria, scese una saetta dal cielo, che l'aperse per mezzo, et una parte di quella restò fissa e sepolta in terra, l'altra dirizzata dura ancora per memoria ai posteri di tanta impietà; e che la imagine prima del Salvatore fu dai cristiani raccolta e riposta nella chiesa, dove ancora si conservava.

Il medesimo narra Eusebio ${ }^{418}$, che al suo tempo si trovavano le imagini del Salvatore e di S. Pietro e di S. Paolo dagli antichi conservate, dicendo così: Videmus etiam nunc apostolorum Petri et Pauli et ipsius Salvatoris imagines designari, tabulasque depingi; sed et antiquas ipsorum imagines a quibusdam conservatas nos vidimus.

Scrive Niceforo ${ }^{419}$ che Abagaro re di Edessa mandò uno pittore per ritrare il volto del Signore nostro, e vedendo egli questo pio desiderio, impresse da sé stesso la sua imagine in uno panno e mandogliela a donare. La qual cosa, se bene da molti è tenuta, come dicono, per apocrifa, è però narrata da varii autori, come da Evagrio $^{420}$, Procopio ${ }^{421}$, Stefano Bibliotecario nella settima

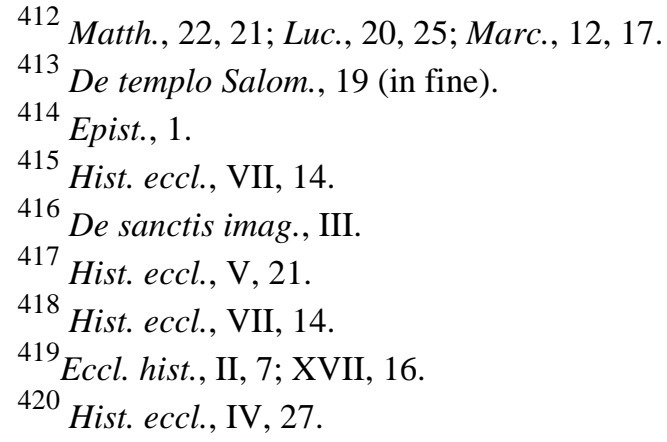


Sinodo $^{422}$, dal Damasceno ${ }^{423}$, da Constantino Porfirogenito ${ }^{424}$, che scrive distesamente questa istoria coi miracoli seguiti, et anco Eusebio ne tocca parte ${ }^{425}$.

Ma che più? Nel sudario, nel quale fu involto il corpo preziosissimo di Cristo, operò Dio che rimanesse impressa la imagine sua, ch'ancor oggi si vede.

Di S. Luca scrive il Metafraste, Teodoro Lettore, et è cosa notissima, che egli dipinse di sua mano varie imagini di Nostra Signora, delle quali oggi ancora se ne conservano molte con gran venerazione.

Delle imagini di S. Pietro e Paolo, oltre quello che scrive [p. 244] Eusebio e molti altri, rende testimonio il venerabile Beda ${ }^{426}$ che nella chiesa ierosolimitana si servava un lenzuolo fatto molto acconciamente, ove erano impresse le imagini degli Apostoli fatte al tempo loro.

Racconta S. Atanasio ${ }^{427}$ che Nicodemo con le proprie mani formò la icona così detta da' Greci del Salvator nostro, la quale morendo diede a Gamaliele e Gamaliele a S. Giacomo e S. Giacomo a Simone, e così per successione fu sempre conservata, fino a quel tempo che poi fece quel stupendo miracolo di spargere così copioso sangue, onde si convertirono infiniti Ebrei. Il che parimente è narrato nella settima Sinodo.

È riferito uno canone degli apostoli nel Concilio Antiocheno, dove, vietando l'uso degli idoli, ordinano che si drizzino le imagini del Salvator nostro e dei suoi santi servi ${ }^{428}$.

Restano infiniti altri luoghi d'autori gravissimi, de' quali sono pieni i libri e l'istorie ecclesiastiche. E si vede fino al tempo di S. Silvestro e di Costantino imperatore, ch'essi non solo adornarono e pubicamente mostrarono il sacratissimo segno della croce e le sacre imagini, ma che ornarono le chiese di meravigliosa grandezza e magnificenza con varie istorie de' santi, e di opere di mosaico et altri artificii eccellenti. E nella vita del glorioso nostro S. Petronio ${ }^{429}$, vescovo e protettore di questa città, si legge ch'egli procurò che nelle nostre chiese fossero formate le sacre imagini a somiglianza dei luoghi di Gerusaleme. E narra S. Agostino ${ }^{430}$ che la immolazione d'Isaac fatta da Abraamo si trovava dipinta in tanti luoghi e celebrata da tante voci, ut et aures et oculos dissimulantes feriret; e Teodoreto ${ }^{431}$ afferma il medesimo della imagine di Simeone Stilita, che si trovava in tutte le piazze, contrade e boteghe d'artefici. Et è cosa no [p. 245] tissima che nel popolo fedele sempre si sono conservate queste imagini, e le vestimenta, i letti, gli scabelli et altre suppellettili de' santi, a memoria loro sempiterna; oltre gli stupendi miracoli accaduti avanti quelle effigie, raccontati da S. Ambrosio, S. Agostino et altri ${ }^{432}$, che da noi al suo luogo più copiosamente si diranno.

Chi vuol saperne molti altri pur anticamente fatti e col testimonio di dignissimi autori, legga la

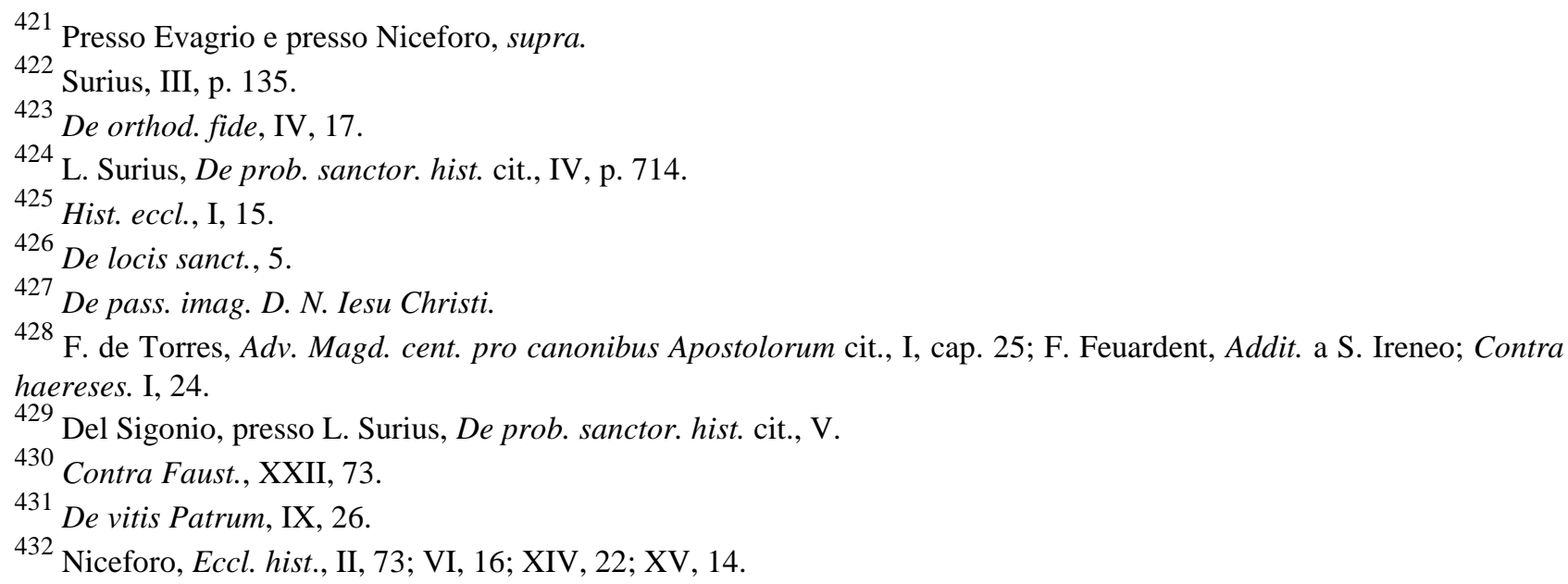


settima Sinodo, che resterà pienamente sodisfatto, e varii moderni che in ciò si sono adoperati ${ }^{433}$; onde noi non ci stendiamo più oltre in ciò, massimamente che nel quarto libro ci accaderà farne spesso menzione et altrove commemorarne ancora degli altri.

Solo per conclusione ora vogliamo dir quello che è raccontato da Paolo Diacono ${ }^{434}$, il quale dà particolare lode alla nazione italiana nei tempi travagliosi, quando erano le sedizioni degli eretici contro le imagini, d'essersi ella sempre gagliardamente a quelli opposta; onde, parlando di Leone imperatore sacrilego, loro oppugnatore, dice: Cognita ergo imperatoris nequitia, omnis Italia consilium iniit, ut sibi eligerent imperatorem et ducerent Constantinopolim; sed compescuit tale consilium pontifex, sperans conversionem principis etc.; et in un altro luogo ${ }^{435}$ dice: Omnis Ravennensis exercitus et Venetiarum Leonis iussis uno animo resistere; et nisi potitifex prohibuisset, imperatorem super se constituere aggressi fuissent.

E questo poco basti per ora in questo proposito, tra infiniti essempi che di ciò si potriano addurre; il che non ci pare necessario.

[p. 246]

\section{CAP. XXX.}

Qual sia il vero modo di venerare cristianamente le sacre imagini, e del culto che le si deve.

Ora soggiongeremo alcune dichiarazioni o distinzioni lasciateci dai sacri dottori come fondamento prencipale di questo edificio delle sacre imagini; e per farlo meglio, tocheremo prima alcune ragioni prencipali, che sogliono turbare la mente dei deboli nell'uso delle imagini.

La prima è, che pare pazzia espressa il volere dipingere il grande Iddio o gli angeli o ancor i santi; i quali, essendo spiriti beati e senza corpo sensibile, pare che con ripugnanza assai della ragione siano ridotti in cosa soggietta ai sensi, scrivendo massimamente il Damasceno ${ }^{436}$ : Invisibilis, incorporei, incircumscriptibilis et infigurabilis Dei, quis posset conficere imitationem? Extremae igitur insipientiae et impietatis est figurare Deum.

Ma noi diciamo che in due modi, cioè con due intenzioni, si possono formare le imagini degli spiriti beati e sostanze celesti ${ }^{437}$ : l'una per isprimere la divinità come è in sé stessa, e questa saria pazzia, non essendo capace materia alcuna di simile espressione, né sendo la divinità cosa che si possa ritrarre; l'altra è per figurare quelle cose ne le forme che ritroviamo nella sacra Scrittura o che dai santi nostri Padri a noi sono state lasciate, come serìa il dipingere lo Spirito Santo in forma di colomba, et Iddio Padre con faccia di vecchio, e gli angeli giovini et alati col diadema o altri misteri che se li convengono.

E di questa maniera è stato sempre dalla antichità giudicato che si possano e si debbano con tali somiglianze, pro [p. 247] porzionate a' sensi nostri per la debolezza di quelli, rappresentare le cose celesti $^{438}$, acciocché dalla significazione et imitazione di queste cose visibili, a noi note, ascendessimo alla meditazione delle invisibili.

E perché di questa materia ne abbiamo a trattare più minutamente nel quarto libro, ci rimettiamo

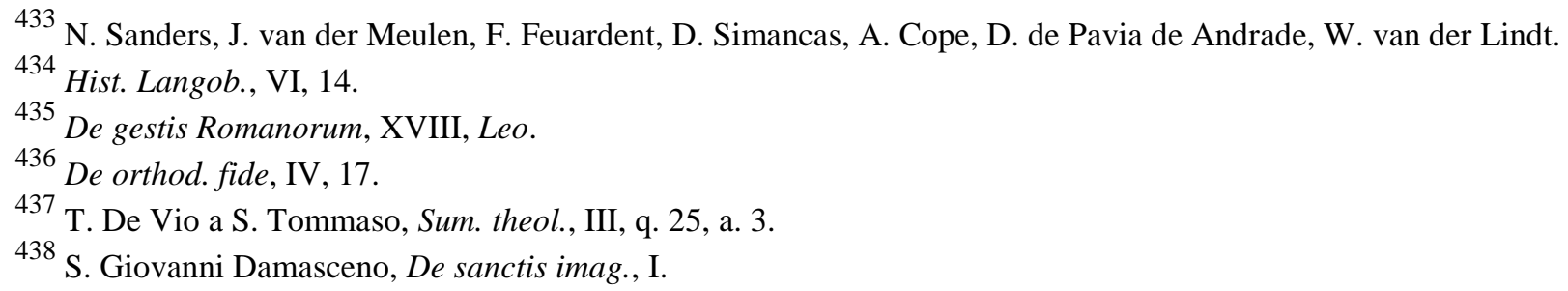


a quel luogo.

L'altra prencipale dubitazione suol essere, che è parso ad alcuni che, nel venerare le nostre imagini, noi non facciamo differenza dal grande e sommo Iddio dagli altri santi suoi, ma che egualmente onoriamo questi e quello. A che per rispondere più chiaramente, è necessario di ricordare che, essendo proprio degli effetti il corrispondere alle sue cause e convertirsi a quelle secondo il modo a ciascuno conveniente ${ }^{439}$, et essendo Iddio creatore, conservatore e amministratore dell'universo, richiede, come suprema causa et origine del tutto, che l'uomo, eccellente sopra tutte le sue creature, prencipalmente si converta a lui e gli renda il debito onore e riverenza; il che si chiama adorazione. E perché l'uomo è composto di due sostanze, anima e corpo, l'una spirituale, l'altra materiale ${ }^{440}$, richiede parimente che a lui si inchini l'una e l'altra parte, e che con l'anima interiormente, col corpo esteriormente, gli si presti obedienza e si riconosca per superiore.

Ma di più, perché quella immensa bontà celeste va sempre communicando alcuni de' suoi doni e grazie a varie creature sue, vuole ancora che a quelle, come membri suoi vivi e partecipi della sua bontà et eccellenza, noi diamo onore e culto, non già di pare dignità e prerogativa a quello che alla maestà sua si deve, ma con alcuni gradi inferiori, che pigliano insieme diversi nomi, chiamandosi il primo latrìa, il secondo iperdulìa, il terzo dulìa.

La latrìa si deve a Dio solo, Padre, Figliuolo e Spirito Santo, et a' misterii loro, perché, non essendo altro l'adorare, [p. 248] come già s'è detto, che uno esibire la debita riverenza ad alcuna cosa per la sua eccellenza, e potendosi considerare questa eccellenza o di perfezzione assoluta, che sta raccolta in sé stessa né dipende da altro, o di perfezzione partecipata che deriva da altra et è molto inferiore alla prima ${ }^{441}$, mostra il nome di latrìa propriamente il culto che si deve all'eccellenza di perfezzione assoluta, la quale si trova solo nel primo principio di tutte le creature, che è il grande Iddio, autore, fabricatore e governatore de l'universo.

L'altra specie di onore, che si deve alle creature per la loro perfezzione partecipata, che è quando il sommo bene gli ha communicato alcuni doni della grandezza e dignità sua, suole essere di due sorti: l'una maggiore, chiamata iperdulìa ${ }^{442}$, con che si inchina e riverisse la immacolata Vergine madre di Dio, la quale, per essere stata tanto singolarmente privilegiata e ripiena di grazie con favori indicibili dalla eterna sapienza, ha meritato ancora dal popolo cristiano, come advocata sua, di essere da quello onorata e riverita di grado maggiore di quello che si esibisca communemente agli altri santi ${ }^{443}$.

La terza specie, che si chiama dulìa, è una venerazione e segno di riverenza che si mostra verso li santi, nei quali si è manifestata la divina eccellenza partecipata ${ }^{444}$; onde noi riveriamo le loro imagini non come cose per sé stesse onorabili, essendo materiali, né meno per quella sola causa generale ch'elle ci inalzino alla contemplazione delle cose celesti (perché questo può avvenire ancora nella figura del cielo, del sole, degli animali, delle piante e di tutte le cose create; onde disse David profeta $^{445}$ : Coeli enarrant gloriam Dei et opera manuum eius annunciat firmamentum). Ma noi prenci [p. 249] palmente veneriamo queste imagini, perché la intenzione de' fedeli è dirizzata ad

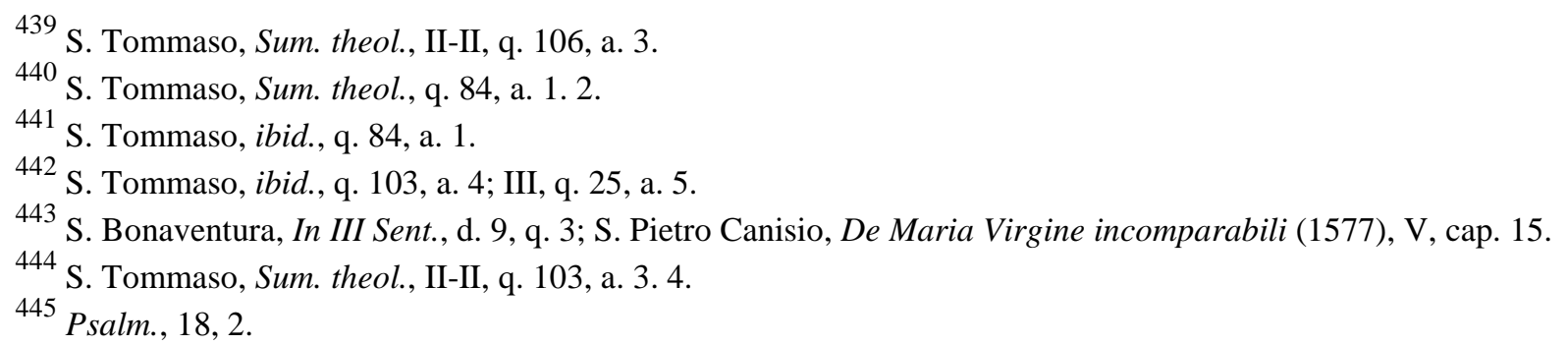


onorare la memoria de' $\operatorname{santi}^{446}$, rappresentataci allora e concetta da noi nel grado e forma che si conviene. E di qui è che vi si tengono accesi lumi e lampade, se bene alcuno non vi sta presente, ch'allora si commova per l'aspetto di quella figura ${ }^{447}$; perché noi abbiamo in animo prencipalmente di riverire con quel segno esteriore la gloria di quelli che sono stati tabernacoli in terra dello spirito celeste e vasi puri della grazia divina. Et in conseguenza poi ne vengono tutti gli altri effetti meravigliosi, che altre volte sono stati detti; onde veggiamo che anco Platone, se bene non era gionto alla luce chiara, ebbe però qualche simile opinione, quando scrisse ${ }^{448}$ : Deos non videmus quidem, sed eorum imagines fabricamus, easque licet inanimes dum honoramus, deos ipsos viventes existimamus ob id nobis maxime gratos et propitios fare. E per non stenderci più, basti la ragione addotta da papa Adriano nella settima Sinodo ${ }^{449}$, dove dice: Omnes principes, etiam si pessimi sint peccatores, adoramus et reverenter salutamus. Quid vetat igitur, quominus non liceat et sanctos Dei ministros venerari, et in memoriam eorum imagines statuere et erigere?

E se pure alcuno replicasse che, anzi, non si scorge in noi alcuno segno di differenza tra la latrìa, iperdulìa e dulìa, poi che pare che indifferentemente ci inginocchiamo al santissimo Sacramento, all'imagine della gloriosa Vergine et a quelle dei santi; si risponde che questi nostri segni esteriori, quanto in sé, sono equivoci, onde non tanto ad essi, quanto alla intenzione con che si fanno si ha da riguardare. E però vedremo talora, secondo i costumi delle persone, alcuno inchinarsi ad una imagine, altro abbracciarla, altro bacciarla, altro toccarla solo col dito, come si legge degli Armeni, qui sacras imagines honorant quidem, sed non osculantur, at digito [p. 250] tantum eas contingentes, huic postea osculum figunt ${ }^{450}$; e nondimeno, con tutta questa diversità esteriore, potrà essere un solo il culto interiore. All'incontro serà talor uniformità nell'esteriore e molta diversità nell'interiore, che è la radice del tutto, sì come ci caviamo la beretta a uno re et anco ad uno gentiluomo, ma con altra intenzione salutiamo il re che il gentiluomo. Così ancora, se bene accendiamo i cerei o pieghiamo le ginocchia alla sacratissima Eucaristia et anco alle figure de' santi $^{451}$, con altra intenzione però si fa questo da quello, sì come nella settima Sinodo con varii essempi è stato dichiarato, di cui riferiremo le parole seguenti, per essere molto a proposito ${ }^{452}$ : Nunquid saepe uxoris aut filiorum mortuorum vestem osculatus es, et lacrymis rigasti, neque tamen damnandus es? Non enim vestes ut Deum honorasti, sed amorem tuum erga illum, qui eis induebatur, per oscula declarasti; sic filios etiam peccatores deosculamur, non tamen ut Deos complectimur, sed naturalem amorem ostendimus; nam in omni salutatione et adoratione intentio ipsa spectatur; e di poi: Tu qui criminaris christianum, quod lignum crucis ut Deum adoret, cur non damnas Iacob adorantem in summitate baculi Ioseph? cur non Abraham, qui impios illos viros adoravit? cur non Iacob, qui Pharaonem benedixit et coram Esau adoravit? Nempe quia non ut Deos adorarunt, nam et tu uxorem tuam plerunque oscularis et salutas, nec tamen es idolatra. Dalle quali cose si vede manifestamente che la diversità del culto si ha da giudicare prencipalmente dalla intrinseca nostra intenzione.

\footnotetext{
446 Concil. Trid., sess. XXV, tit. 2, § illud (Surius, IV, p. 983).

447 S. Girolamo, Contra Vigilantium.

448 Platone, Leg., XI, 930 e - 931 a.

449 Surius, III, p. 69.

${ }^{450}$ G. Dupréau, De vitis, sectis et dogmatibus omnium haereticorum... elenchus alphabeticus (1569), s. v. Armeni.

451 J. Viguier, Institutiones ad naturalem et Christianam philosophiam (1571), cap. 5, § 4, vers. 12.

452 Surius, III, p. 104.
} 
[p. 251]

\section{CAP. XXXI.}

Della differenza tra cristiani e gentili nello adorare le imagini.

Un'altra dubitazione maggiore vien mossa contro le nostre imagini, che in questo modo dicono non esser noi differenti da' gentili, che adoravano anch'essi l'opere delle mani loro. Ma noi rispondiamo che la adorazione si può essercitare da noi in tre modi: l'uno, credendo che la cosa adorata sia divina o assolutamente o per participazione, come di sopra; l'altro, credendo che essa contenga cosa divina; il terzo, credendo che essa almeno rappresenti cosa divina.

Nel primo, non crediamo noi che alcuna imagine sia cosa divina, o per sé o per participazione, essendo la imagine ordinariamente cosa artificiata, fatta per rappresentarne un'altra vera; eccetto se non avesse acquistata qualche santità in alcuno delli modi da noi narrati altre volte ${ }^{453}$, i quali però non appartengono alla sostanza loro, essendo materiale.

Nel secondo, teniamo noi che 'l tabernacolo del Sacramento non sia già Dio, ma che vi sia riposto Dio; e parimente i reliquiarii, dove sono reliquie di santi certe et approvate, contengono anch'essi cose divine per participazione.

Nel terzo, diciamo che la imagine figurata del Padre o Figliuolo o Spirito Santo non sia già Dio, né abbia in sé Dio, ma rappresenti Dio, sì come anco le imagini della gloriosa Vergine e dei santi del cielo rappresentano i loro autori. È vero però che tra queste è differenza nel modo di rappresentare, perché quella dello Spirito Santo non figura Dio immediatamente o propriamente, ma secondo quelle forme nelle quali piacque a lui di manifestarsi a noi; ma queste de' santi esprimono ciascuno di essi vivamente e realmente, come sono già stati. Et a questo modo di venerazione, che si chiama [p. 252] con parola greca 'tipico', cioè figurativo, si riporta tutto il culto delle nostre imagini $^{454}$, venerandole noi non per sé stesse, ma per quello che rappresentano, di qualonque materia elle siano formate ${ }^{455}$, poiché la nobiltà loro non si considera quanto alla materia di che sono fatte, ma quanto a quello che rappresentano; la quale hanno chiamata nobiltà di significazione, sì come nella settima Sinodo ampiamente è stato dimostrato ${ }^{456}$, ove spesse volte ne è fatta menzione, e da quei santi Padri del concilio è approvato il detto di S. Basilio, quod imago refertur ad prototypum, e tra varie ragioni che vi si adducono, si leggono le seguenti parole: Quemadmodum qui mandatum imperatoris suscepit illius sigillum osculando, non ipsam ceram aut characterem aut plumbum veneratur, verum imperatori ipsi adorationem et cultum exhibet; ita quoque christianorum filii typum crucis adorantes, non naturam ligni adoramus, sed aspicientes sigillum et anulum et characterem, et per hoc Christum ipsum, qui in illo crucifixus est, salutamus et adoramus. E di poi: Quemadmodum genuini filii, peregrinante longo tempore patre, ex ingenti amore, quicquid in illius domo viderint, sive baculum, sive sedem, sive clamydem, haec omnia cum lacrymis amplexantur, non illa adorantes, sed padrem adorantes et venerantes; sic nos fideles omnes crucem Christi tanquam virgam adoramus, sepulcrum vero ter sanctum, ut sedem et cubile illius, praesepe autem ut domum, inde apostolos eius et martyres veluti amicos eiusdem colimus, et sic reliqua illius loca et habitacula, non ipsam regionem aut lapidem venerantes, sed illum qui in illis conversatus est, et nos ab erroribus liberavit, Christum dominum Deum nostrum.

E per non raccontare molte altre bellissime cose dette da quei santi Padri in quel concilio,

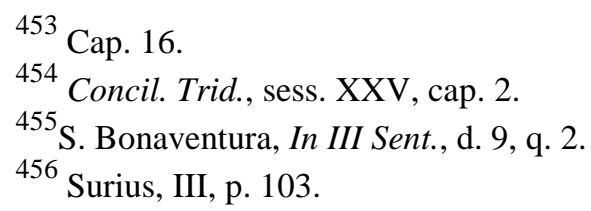


basteranno ora per brevità i due versi che in esso furono canonizzati et oggi sono assai volgari in questa materia, cioè:

[p. 253]

Nam Deus est quod imago docet, sed non Deus ipsa.

Hanc videas, sed mente colas quod cernis in ipsa.

Le quali cose tutte si conformano con quello che hanno parimente scritto i dottori santi della Chiesa, dicendo S. Ambrosio ${ }^{457}$ : Qui coronat imaginem imperatoris, utique illum adorat, cuius imaginem coronavit; e S. Agostino ${ }^{458}$ : Qui veneratur utile signum divinitus institutum, cuius vim atque significationem intelligit, non hoc veneratur quod videtur et transit, sed illud potius ad quod cuncta referenda sunt, et in altro luogo ${ }^{459}$ dice: Naturaliter ea regula plurimum valet, ut auditis signis ad res significatas feratur intentio; et Eutimio ${ }^{460}$ dottore greco dice: Quemadmodum in speculo persona quodammodo describitur et manet a materia separata, et ipso recedente simili etiam avolat imago, quando a speculi materia ipsa persona separatur; eadem ratione qui imaginem sanctorum osculatur, licet materiae inhaereat, imaginem non materiam osculatur; e S. Gregorio in epistola ad Secundinum ${ }^{461}$ : Scio quod imaginem Salvatoris nostri non ideo petis, ut quasi Deum colas, sed ob recordationem filii Dei, ut in eius amore recalescas, cuius te imaginem videre desideras. Et il medesimo è stato dal Damasceno, da $\mathrm{S}$. Tomaso e da altri dottori affirmato ${ }^{462}$.

Dalle quali ragioni et autorità chiaramente si scuopre quanto noi in ciò siamo differenti dai gentili, de' quali alcuni adoravano i simolacri credendo che fossero veri dèi, altri gli adoravano credendo che almeno contenessero in sé Dio, et altri in altre maniere; ma noi nelle nostre imagini nessuna di queste cose crediamo $^{463}$, ma solo abbiamo in concetto che [p. 254] elle ci rappresentino l'oggetto della adorazione nostra, sì come di sopra si è mostrato.

E se ad alcuno paresse che ancor molti de' gentili abbiano avuto questo animo, che nell'idolo si rappresentasse solamente l'oggetto della adorazione, dicemo che presero un oggetto falso, come un Giove, un Bacco, una Venere; onde poco importa che s'ingannassero nel mezzo o nel fine ${ }^{464}$. Ma noi, prendendo veri e santi oggetti et i mezzi interamente proporzionati, mostriamo insieme quanto dalle loro adorazioni siamo lontani, dirizzando noi il culto nostro al fine vero e perfetto; al che serve quello che scrive S. Agostino ${ }^{465}$ in altro proposito con queste parole: Et si usus quarundam rerum similis videtur nobis esse cum gentibus, sicuti cibi et potus, tectorum et vestimentorum; tamen longe aliter his rebus utitur qui ad alium finem usum earum refert, et aliter qui ex his Deo gratias agit, de quo prava et falsa non credit. Resta ora un'altra difficoltà da sciogliere, la quale riserviamo nel capitolo seguente.

\footnotetext{
457 Exp. in Psalm. CXVIII, 10.

${ }^{458}$ De doctr. Christ., III, 9.

${ }^{459}$ De magistro, 8.

${ }^{460}$ Panoplia, II, 19.

461 Epist., VII, 53. 3; Alonso de Castro, Contra haereses cit., II, s. v. adoratio.

${ }^{463}$ S. Tommaso, Sum. theol., II-II, q. 94, a. 1.

464 S. Agostino, Enarr. in Psalm. CXIII, serm. 2.

${ }^{465}$ Contra Faust., XX, 23.
}

462 S. Giovanni Damasceno, De orthod. fide, IV, 17; S. Tommaso, Sum. theol., II-II, q. 81, a. 3 (in fine); S. Bonaventura, In III Sent., d. 9; S. Antonino, Sum. theol., III, tit. 12, cap. 9; Alessandro di Hales, Summa, II, q. 158, m. 


\section{CAP. XXXII.}

Se il medesimo culto si deve ad una sacra imagine, che si conviene al suo prototipo o imaginato; e se è uno atto solo, o come.

Abbiamo ora a levare una difficoltà che tra' dottori è grandemente agitata et intricata; la quale è, come piamente possiamo rendere alle sacre imagini il debito onore, e se è un atto solo che si defferisce alla imagine et imaginato, o come. Intorno a che, lasciando le questioni scolastiche da parte, diciamo che nelle imagini si possono considerare tre cose: l'una è la materia della quale elle son fatte, come sarebbe a dire [p. 255] l'oro l'argento, l'avorio e cose tali; la seconda è la forma data dall'autore a tal materia con disegni, lineamenti et ombre etc.; la terza è ciò che risulta dalla materia e figura insieme, ch'è quella cosa che chiamiamo imagine, rappresentante un'altra cosa, della quale essa è similitudine. E di qui nasce che nel mirarla possono cadere in noi varii pensieri: l'uno dirizzato alla materia, come pregiata, ricca e vaga di colori; l'altro, come a cosa disegnata con grande arteficio, e con molta diligenza figurata; il terzo, come ad imagine, cioè in quanto fa lo effetto di rappresentare un'altra cosa, nel qual modo non attendiamo più all'opera come materia $o$ figura, ma alla cosa rappresentata, che è in lei per modo di rappresentazione, et in questa fissiamo il pensier nostro.

Nei primi due modi non diamo noi sorte alcuna d'onore o riverenza a questa opera, se bene sia d'oro o di perle e con stupendo artificio sottilissimamente lavorata, percioché l'onore si conviene a cose maggiori e più eccellenti, ma queste tutte sono di gran longa inferiori alla natura dell'uomo, che è ragionevole e supera tutte le altre di questo mondo.

Nel terzo modo prendiamo noi esse imagini non come semplici figure, ma sotto questo atto di rappresentare; il che vuol dire che, riguardando noi con gli occhi corporali nella imagine, la mente si fissa nella cosa rappresentata e contenuta in essa per modo di rappresentazione, e di qui nasce che quell'onore che si conviene alla cosa rappresentata si potrà ancora misteriosamente tribuire alla imagine, secondo i gradi di latrìa, iperdulìa e dulìa, di sopra da noi dichiarati. Né saranno questi due atti diversi, che mirino due termini distinti, ma è un istesso atto, portato in un medesimo oggetto, ancorché sotto modo diverso tra la imagine e l'imaginato; percioché, per essempio, quando si adora Cristo senza imagine, l'adoriamo secondo il suo proprio modo di essere, e quando l'adoriamo nella imagine, l'adoriamo nell'essere rappresentativo et imaginato, sì come, quando si contempla un uomo o una pietra, veramente contempliamo la natura dell'uomo o della pietra, non che esso uomo o essa pietra [p. 256] siano realmente nel nostro intelletto secondo il loro essere reale, ma rappresentativa e figurativamente; in modo che sì come l'uomo e la pietra non sono perciò nel suo essere diversi da quello che sono nello intelletto compresi, né possiamo dire che siano due uomini o due pietre, ma un uomo solo et una pietra sola; così, quando si adora la imagine di Cristo, si adora veramente Cristo, e Cristo è nella imagine non secondo l'essere reale, ma secondo l'essere figurativo o rappresentativo. Talché la differenza non è dalla parte di Cristo, che sempre è il medesimo, ma dal modo dell'essere percioché il medesimo Cristo è nella imagine et è in sé, ma l'essere è diverso, perché in sé ha l'essere reale, e nella imagine ha l'essere rappresentato; il che ci insegnò S. Atanasio ${ }^{466}$ dicendo: In imagine regis forma et species est, in rege vero ea, quae est in imagine, forma existit; impermutabilis autem est in imagine regis similitudo, ita ut qui imaginem inspexerit, ipsum quoque regem simul inspiciat, rursus qui regem conspicit, novit eum esse, quem in

${ }^{466}$ Contra Arianos, IV. 
imagine conspexerat; e S. Basilio nel sermone contra Sabellianos ${ }^{467}$ dice: Qui in foro oculos intendit in imaginem regiam et dicit regem esse eum, qui in tabula, non confitetur duos reges, et imaginem et eum cuius est imago; neque si, demonstrans eum qui est pictus in tabula, dicat 'Hic est rex', privavit prototypum appellatione regis, sed magis ei honorem confirmavit huius confessione. Si enim imago rex, multo magis rationabile est esse regem eum, qui praebet imagini causam; e S. Ambrosio, scrivendo della incarnazione del Signore ${ }^{468}$ : Num quando in eo et divinam imaginem adoramus et crucem, ipsum partimur? e S. Crisostomo ${ }^{469}$ dice: Cum regiae imagines et figurae in civitatem adferuntur, magistratus et populus gratulabundus non tabulas veneratur, neque ex cera fusilem imaginem, sed regiam figuram; sic et creatio non terrestrem formam, sed caelestem characterem veneratur; et il Damasceno ${ }^{470}$ pur dice: Regis imago rex dicitur, non duo reges; [p. 257] neque enim imperium scinditur, nec dividitur gloria, nam, sicut potestas quae nobis imperat una est, sic et honor quem nos praestamus unus est et non multi. Nello adorare dunque le sacre imagini di Cristo, della Vergine e de' santi, adoriamo Cristo, la Vergine et i santi rappresentati nelle imagini; e quando ci inginocchiamo davanti le loro imagini, è quanto ci inginocchiassimo davanti essi, misurando questo atto interamente dal prototipo; sì come et onoriamo i legati et ambasciadori in quanto rappresentano i loro prencipi, e che la persona dei signori a un certo modo si truova nella persona dei loro nunzii. Onde concludiamo che il culto che si deve all'imaginato, proporzionatamente debbiamo darlo ad esse imagini ${ }^{471}$.

E se alcuno opponesse che, se fosse vero che la propria ragione del venerare le imagini nascesse da questa intrinseca rappresentazione che si trova già inseparabilmente congionta con la imagine, seguirebbe che non saria più lecito né rompere, né cancellare o abbruggiare alcuna immagine (il che però piamente spesso si permette, per ristoro e maggior ornamento de' luoghi); si risponde che questi atti esteriori, come altrove abbiamo detto, sono equivoci, et il vero loro effetto nasce dalla causa interiore. Imperoché quando i catolici cancellano alcuna imagine, non la apprendono interiormente come cosa rappresentante, ma solo materialmente, servendosi di quella cosa come di materia ad altro uso per alcuna giusta causa, come al suo luogo dichiareremo più pienamente ${ }^{472}$.

E se altri dicesse che non è vero che l'istesso culto et effetto di venerazione si tribuisca ad una imagine semplice della gloriosa Vergine, che si farrebbe alla stessa madre di Dio, se fosse qui presenzialmente in terra, sì come maggiormente ci muoviamo verso la persona del re nel suo trono reale, che non facciamo verso il suo ambasciadore; si risponde questa differenza, quanto alle sacre imagini, non nasce [p. 258] dalla disparità delle cose, ma dalla condizione dei sensi, che più efficacemente sono mossi dagli oggetti che sono sensibili. Imperoché, non potendo noi apprendere in questa vita le cose celesti, che non si veggono, se non mediante lo intelletto mosso dalla fede, questa, perché in noi si trova molto debole, muove ancora languidamente l'intelletto e però non produce quegli effetti così palesi, come si sogliono scoprire nell'apprensioni delle cose materiali presenti; che se in noi avesse così alte radici la viva fede, come doverebbe, non è dubbio che, senza altri oggetti presenti, si riempirebbe mirabilmente lo spirito nostro, come è accaduto ai santi infiammati di zelo e carità. Et a questo si potria aggiugnere che ad un ambasciadore non si dà a pieno quella preeminenza che si farrebbe al suo prencipe, poiché egli non rappresenta interamente

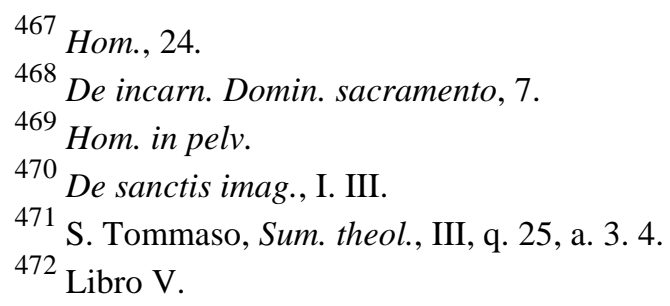


in tutte le cose, né meno ne la piena podestà, il suo signore, ma solo in quella parte di cose che li sono state commesse. La qual ragione cessa nella venerazione e culto di che noi parliamo, comprendendo la mente nostra Iddio o i santi suoi con quella suprema autorità e gloria che essi fruiscono in cielo, quanto però è lecito ad un viandante di capire le cose superne.

Per ultimo aggiongiamo che il culto che diciamo doversi alle sacre imagini per rispetto della rappresentazione non esclude quello che per sé stesso se gli deve, quando siano santificate nei modi che di sopra sono stati da noi dichiarati ${ }^{473}$.

\section{CAP. XXXIII.}

Che oggi nello adorare le sacre imagini non vi è pericolo alcuno probabile, tra' cristiani, di incorrere nella idolatria.

Per conclusione di questa materia e del presente libro, ci resta da rispondere ad una obiezzione, della quale, perché [p. 259] vi premono molto i nemici della religione santa e con questa vanno persuadendo i popoli alla distruzzione delle chiese e delle imagini, bisogna parlar alquanto più largamente.

Dicono essi che con l'uso di queste nostre imagini si induce il popolo nella idolatria, per non essere egli capace delle distinzioni narrate di sopra, né sapere discernere tra la figura et il figurato, o tra la imagine e l'oggetto; onde per la sua simplicità, come dicono, incorre in errore e resta ingannato, adorando quello che vede e lasciando quello che non vede.

Questo istesso dicono essere accaduto anticamente al popolo ebreo e che per questa causa fece Ezechia levar via il serpente di metallo ${ }^{474}$, se bene era stato fatto prima per comandamento di Dio; anzi, che di qui ebbe origine già longo tempo la setta degli Antropomorfiti, che, vedendo nella Scrittura sacra tribuirsi a Dio gli occhi, le mani, la faccia et il petto, e vedendolo ancora figurato con lineamenti umani, si pensarono che fosse composto essenzialmente di membri e corporatura umana; onde ne nacque quella setta di eretici molto scandalosa ${ }^{475}$.

Noi, rispondendo, diciamo che, se bene tra' gentili, a' quali era ascosa la vera luce della verità, furono varie sorti di culti et adorazioni, perciò che con un concetto si movevano gli imperiti e sciochi, con altro i più fondati e dotti, e con diverso da tutti questi, quelli che erano stimati sapienti sopra gli altri, per sopra nome detti filosofi ${ }^{476}$; nientedimeno presso di noi, da che fu il lume dello evangelio santo illustrato, non è persona sì rozza che non sappia che altra è una figura di marmo di S. Gio. Evangelista et altro è il santo che è in cielo. E questo è che già fu predetto dagli antichi profeti, che verria il tempo quando niuno saria più ingannato dalla superstizione degli idoli e che fino il più picciolo conosceria [p. 260] il vero, dicendo Ieremia ${ }^{477}:$ Ego ero eis in Deum et ipsi erunt mihi in populum; et omnes scient me a minore usque ad maiorem; et Osea ${ }^{478}$ : Et auferam nomina Baalim de ore eius et non recordabitur ultra nominis eorum; e Zaccheria ${ }^{479}$ : In die illa disperdam

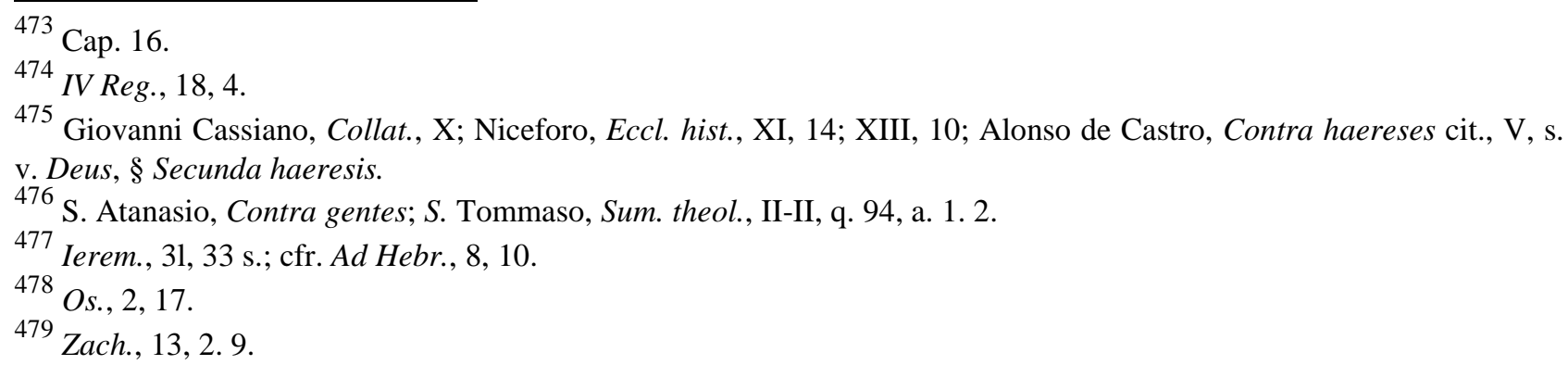


nomina idolorum de terra et non memorabuntur ultra etc. Ipse invocabit nomen meum et ego exaudiam eum; et dicam: Populus meus es, et ipse dicet: Dominus meus; e per questo ancora fu detto da Isaia: Erunt omnes docibiles $D e{ }^{480}$ cioè 'tutti i fedeli di santa Chiesa seranno instrutti et ammaestrati dallo Spirito Santo, ${ }^{481}$.

Onde oggi, Dio grazia, nel popolo cristiano ordinariamente non è alcuno, ch'abbia l'uso della ragione, che si inganni in credere ch'una statua di pietra sia un vero santo ${ }^{482}$, e chi vuole avere questo concetto tratta gli uomini da bestie; sì come scrive $\mathrm{S}$. Basilio ${ }^{483}$ accadere alle pantere, che, sendole messo innanzi certe imagini di carta con faccia di uomo per burlarle, esse, che portano naturale odio agli uomini, ingannate da quella figura, si muovono con impeto a farli violenzia, come se fossero veri uomini; e come anco vediamo usarsi dagli uomini di villa con gli uccelli per ispaventarli e tenerli lontani da' frutti, i quali fingono certe larve et ispauracchi, che da quegli animali sciocchissimi sono tenuti per uomini veri. E certo sciocchissimi sono, poiché gli altri un poco più accorti, ben che siano uccelli, non solo non ne fuggono, ma vanno ancora ad abitarvi e vi fanno i nidi fra di loro. [p. 261]

Donque non è verisimile ch'oggi un cristiano, oltre il lume della ragione nodrito del latte di santa Chiesa, si lasci abbagliare da cose a che pure non credono molti animali. Altrimenti si potria ancora dubitare che, nelle comedie, quelli che sono vestiti da re siano veri re, o che i mascherati nel carnevale siano quelli stessi che agli abiti dimostrano; il che è cosa da fanciullo.

A questo proposito serve molto quello che nella settima Sinodo ${ }^{484}$ un santo vescovo argomenta contra l'Ebreo, dicendo: Sicut tu, adorans librum legis, non naturam membranarum aut atramentum adoras, sed verba Dei quae in ilio continentur, sic et ego, imaginem Christi adorans, non lignorum aut colorum naturam adoro, sed inanimatum characterem Christi etc.; e di poi: Quemadmodum Iacob, accipiens a filiis suis vestem Ioseph, sanguine conspersam, cum lacrymis eam osculatus est suisque oculis circumposuit, non ipsam vestem diligendo aut honorando, sed per eam arbitratus est Ioseph osculari et in manibus habere; sic et christiani omnes, imaginem Christi aut apostoli aut martyris tenentes eamque osculantes, videmur nobis ipsum Christum aut martyrem amplecti.

E da queste ragioni si può conoscere quanto fosse lontana dal vero la obiezzione di Varrone, toccata da S. Agostino ${ }^{485}$, il quale biasima quei che prima aveano erette le statue di dei nelle città, dicendo che avevano insieme levato da' popoli il timore e la riverenza che si deve a Dio, poiché, accortosi che quegli erano simolacri di pietra o di legno, facilmente si erano indotti a non farne conto; percioché diciamo noi, oltre la risposta data da S. Agostino, che questa considerazione oggi poco può muovere niuno che non sia leggierissimo o stolto totalmente, per le ragioni dette di sopra $^{486}$.

Diciamo parimente che il fatto di Ezechia, che tolse via il serpente di metallo, fu allora

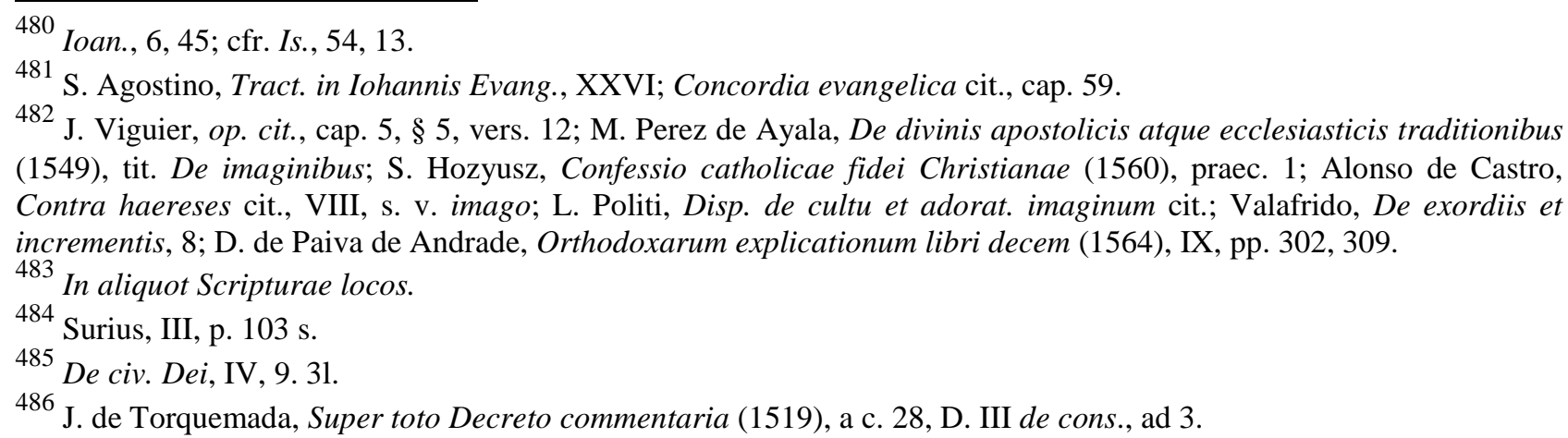


necessario per la grande in [p. 262] clinazione che regnava nel popolo ebreo all'idolatria ${ }^{487}$; il quale non potendo in quel tempo essere fatto capace che il serpente, che era stato posto, non come imagine, ma come misterio, figurasse il vero Messia venturo e Cristo redentore nostro, fu bisogno che quel santo re lo gettasse a terra, poiché il popolo l'adorava come puro serpente e simolacro di idolo; che così anco scrive il Damasceno ${ }^{488}$ dicendo: Sicut medicus non semper idem medicinae genus adhibet omnibus, sed pro varietate temporis, morbi et aetatis ratione diverse se habet et aliud hieme, aliud vere aut aestate praebet; sic Deus ipse Iudaeorum populo nunc prohibuit figuram Dei, nunc permisit sacrificia, nunc serpentem adorandum tradidit, nunc sustulit, ut salubrius esse censuit. E così la proibizione antica della Legge: Non facies tibi sculptile, neque omnem similitudinem $^{489}$, tutta mirava a questo fine, Ne adores ea, peccandosi in quel tempo in ciò assai, come dichiarano i sacri dottori ${ }^{490}$; ma tale ignoranza crassa cessa, Dio grazia, oggi nel popolo fedele, che può masticare cibo più sodo, essendo già uscito della fanciullezza della legge e disciplina del pedagogo, come scrive S. Paolo ${ }^{491}$, e però negli Atti delli Apostoli, parlando agli Ateniesi, disse ${ }^{492}$; Genus cum simus Dei, non debemus aestimare auro et argento, aut lapidi sculpturae artis et cogitationis hominis, divinum esse simile. Et tempora quidem huius ignorantiae despiciens Deus, nunc annunciat hominibus; e nella settima Sinodo ${ }^{493}$ dice Epifanio, quod veri adoratores, qui Deum colunt in spiritu et veritate, non cessabunt ab imaginibus, quas erigunt in historiam tantum et recaordationem, et has venerantur [p. 263] iuxta modum Dea placitum; onde S. Gregorio $^{494}$ per questo riprese tanto l'indiscreto zelo de quel vescovo ch'avea spezzate e tolte via le imagini delle chiese per vana dubitazione che altri non si ingannasse, dicendo: Pervenit ad nos quod fraternitas vestra ecclesiae imagines fregit atque proiecit; et quidem zelum vos, ne quid manufactum adorari possit, habuisse laudavimus, sed frangere easdem imagines non debuisse iudicamus. Idcirco enim pictura in ecclesiis adhibetur, ut hi, qui literas nesciunt, saltem in parietibus videndo legant, quae legere in codicibus non valent.

Per le quali cose concludiamo che, quando pure qualche errore potesse in ciò occorrere in alcuni, questo pericolo non è tale che, per fuggirlo, si abbiano a proibire le imagini ${ }^{495}$; imperò che, quando una cosa per sé stessa è buona, o anco indifferente, non deve ella essere vietata, se bene alcuni di quella si servissero male: perché, in questa maniera, si averia da vietare il vino, che a molti causa ebrietà, e l'uso delle armi, perché ne vengono spesse volte omicidii ingiusti, e l'uso dell'oro e dell'argento, perché induce gli uomini alla avarizia. Anzi, la lezzione dei libri sacri e dottrina evangelica per questo porteria pericolo di essere proibita, perché, per lo abuso di molti, da quella tutto dì veggiamo nascere nuove eresie; la qual cosa che altro saria che eradicare il grano, perché non vi nascesse zizzania, contro il precetto del Salvatore? ${ }^{496}$.

Si devono donque levare gli abusi e gli accidenti cattivi, lasciando sana et intera la sostanza; e

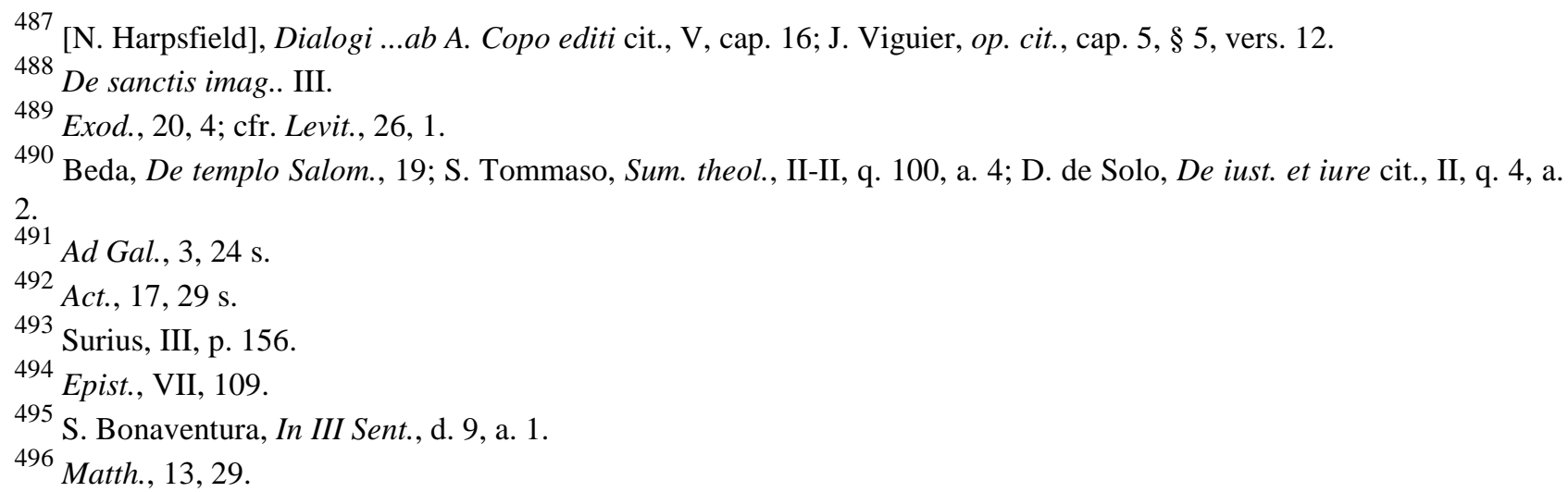


perciò quelli che dubitassero hanno da essere instrutti et ammaestrati nella vera cognizione delle cose, acciò non errino; il che è facilissimo e sicurissimo a ciascuno, volendo seguire, come deve, la norma antica della santa Chiesa ${ }^{497}$. Onde, se bene noi, che parliamo con popolo confirmatissimo nella religione catolica [p. 264] et apostolica romana, avressimo potuto tralasciare molte delle cose dette in questo proposito, nientedimeno ci è parso non essere anco superfluo il ricordare al lettore le dichiarazioni dette di sopra, cavate dalla ortodossa dottrina de' Padri santi, perché non resti in parte alcuna ingombrata o perplessa la mente di chi si sia, lasciando tuttavia maggior campo nel resto a' dottori scolastici et altri eruditi di rispondere più pienamente a tutte le opposizioni che in contrario si possono fare.

Con che poniamo fine a questa materia et al presente libro.

\section{IL FINE DEL PRIMO LIBRO}

${ }^{497}$ D. Simancas, De catholicis institutionibus cit., tit. De imaginibus, n. 11. 
[p. 265]

\section{LIBRO SECONDO}

CAP. I.

Che non potendo il Demonio levare l'uso delle imagini, cerca di riempirle di abusi.

Sì come ad una veste ricca e preziosa pare che ciascuno porti ragionevole rispetto di non macchiare la sua bellezza in parte alcuna; così, essendosi dimostrata la dignità, importanza et utilità delle sacre imagini, avria devuto bastare questa loro eccellenza per acquietare affatto ogni pensiero di non procurarle mai obbrobrio alcuno. Ma è così perversa et inveterata la malizia del Demonio, nemico d'ogni virtù, che, dove non può totalmente levare uno uso lodevole e santo, almeno procura di farcelo abusare e di rendercelo inutile. Cerca levarci la spada di mano, e quando con ogni sua arte vede di non poterlo fare, almeno si sforza di levarle il filo e torle la punta, o di farcela adoperare in modo che a noi stessi noccia e non al nemico. Vede che le orazioni ci giovano assai, studia di distorcene e, quando non può, almeno si adopera che le facciamo per ostentazione e per fine mondano, acciò tanto ci nocciano quanto era ragione che elle ci giovassero; vede che le limosine ci aiutano, e però cerca di stringerci la mano e, quando non può, almeno procura che la allarghiamo in publico, acciò che, concependo quivi l'aura popolare, empiamo le azzioni nostre di vana gloria e le rendiamo frustatorie et inutili. Così l'arte del formare le imagini sacre vede che è introdotta per utile delle anime e che con le figure si può [p. 266] apportare molto giovamento al mondo; per questo ha cercato di levarci l'uso loro e, non potendo, vi ha introdotto dentro tanti abusi, che ormai la scoltura e la pittura, che deveriano essere di giovamento a chi le essercita et agli altri, poco ci resta che non siano fatte ad essi et a noi perniziose e dannevoli.

Leggiamo, per essempio, che quel crudel capitano Oloferne, volendo assediare la città di Betulia e non potendo seccare il fonte che dava l'acqua alla terra, fece tagliare gli acquedotti e divertirgli altrove $^{498}$; così il Demonio cerca di divertire il proprio e vero uso delle imagini in altre vie storte et illecite, e però opera che un pittore, in vece di formare uno Cristo, formi uno Apolline, e lo scultore, in loco di comporre la statua di uno martire, compona una trasformazione favolosa; fa opra che le figure si dipingano ignude per lo più e molto lascivamente. Entra fino nei santi, e se la beata Maddalena o san Giovanni evangelista o un angelo si dipinge, fa che siano ornati et addobbati peggio che meretrici o istrioni; overo sotto coperta di una santa fa fare il ritratto della concubina; et in somma si adopera di modo, che ormai in molti luoghi la pittura e la scoltura poco servono per edificio delle anime ad onore di Dio, ma sì bene per molto incitamento alla propria dannazione, in gloria di Satana. Così soleva dire un dottor grave, che il Diavolo, ove non può vincere come leone, si muta subito in dragone o serpente ${ }^{499}$; cioè che, dove con la forza non prevale, adopera subito gli stratagemi, e dove non può levarci le armi, almeno, come si è detto, ne le rintuzza o ne le ritorce contra. Vorrebbe il Diavolo torci il cibo e farne morir di fame; ma ove non può, almeno mescola il veleno e, non potendo fare che le imagini non vi siano, almeno vi interpone tanti abusi, che ormai più male che bene possono fare le imagini, se non vi si provede. Le cittadi più facilmente si perdono per trattato che per assalto; [p. 267] perciò il Demonio, lasciando l'assalto, col quale voleva rapire le figure, attende al trattato di farcele corrompere et abusare. Onde, sì come i ladri balnearii più si punivano perché più commodamente poteano nuocere ${ }^{500}$; così non poco minore cura deve prendersi

\footnotetext{
498 Iudith, 7, 6.

499 Ruperto di Deutz, In Gen., III, 3.

500 Dig., XLVII, 17, 1.
} 
per levare gli abusi delle imagini, quasi di quello che si prende per levar l'eresie d'intorno ad esse, come quelli che, sendo veleni ascosi, facilmente penetrano a darci la morte. Piaccia pure a Dio che nascano in ogni parte iconomachi, ma santi, i quali così gridino contro le imagini abusate e disoneste che si introducono ogni giorno, come gridavano quegli antichi ingratamente e sceleratamente contro le figure sante; e voglia Dio che, raveduti i pittori e gli scultori cristiani de' loro errori, a quella purità ritornino le loro arti, per la quale sono state introdotte. E si ricordino quanto insino ai gentili siano dispiacciuti quelli formatori di imagini, che, abusando l'arte, hanno con le loro opere dato occasione, ai giovani principalmente et a tutti gli altri, di fomentare affetti lascivi e di accrescere sempre maggiore la corruttela de' costumi loro; sì come nel terzo libro se ne ragionerà più diffusamente.

CAP. II.

Delle cose che si possono o non possono dipingere, e dell'ordine da seguirsi nel presente libro.

Ora, per cominciare a discorrere intorno a questi abusi, acciò, scoperte le sordidezze che tengono diformata la bellezza delle imagini, più facilmente si possa reintegrare la purità loro, ci pare necessario pigliare principio da questo capo generale, delle cose che si possono o non possono dipingere.

$\mathrm{Al}$ che si potrebbe con una regola generale sodisfare assai commodamente: dicendosi che quelle cose, che possono essere [p. 268] soggetto idoneo ad uno autore per metterle in iscritto e farne libri, possono egualmente servire per materia ad un pittore o altro simile artefice per rappresentarle con figure; et allo incontro, quello che dalle leggi è proibito che non si ponga in scrittura, parimente non sarà lecito ad essere espresso da uno pittore; poiché, come più volte di sopra abbiamo detto secondo l'autorità de' santi dottori, non è altro la pittura, che certa sorte di libro muto e taciturno.

E però, sì come le parole, quasi messaggiere, portano per le orecchie i concetti nostri ad altri, così la pittura rappresenta per gli occhi le cose da noi significate alla mente altrui; per lo che da' Greci il medesimo nome è attribuito communemeute allo scrittore et al pittore. Dunque, essendosi dal sacro Concilio Tridentino con l'indice dei libri data buona regola per discernere quali siano i libri permessi e quali i proibiti, potrà la istessa servire per norma al conoscere quali siano le pitture da essere seguite o fuggite dal cristiano.

Ma perché diverse sono le classi et ordini dei libri, né tutti li non proibiti debbono però essere egualmente abbracciati, essendovene alcuni di materie inutili, altre puerili, altre favolose, altre confuse e male ordinate, e molte totalmente superflue, nelle quali un giudizioso non si metterà ad occupare lo ingegno e tempo suo, se bene non vi è pena posta dalla legge; però, potendo accadere questo similmente nella pittura, abbiamo giudicato ispediente, per utilità commune, di ponere dinnanzi agli occhi di tutti alcuni capi principali che di sotto si numeraranno, ne' quali più frequentemente sogliono versare le pitture, parte dannati dalle leggi, parte, se bene tolerati, non però lodati, e tra essi altri con maggiore, altri con minore biasimo; accioché, conosciuta la differenza e pregio di ciascuno, possa a chi appartenerà, lasciati li più vili et inutili soggetti, appigliarsi alli più degni, più giovevoli et onorati.

A questo potressimo aggiongere un'altra regola, dicendo che tutto quello che cade sotto l'arte del formare imagini o sono cose, o sono operazioni. Pigliamo per cose ogni sostanza [p. 269] e specie visibile in sé stessa, non considerando altro, di lei, non quello essere; per operazione pigliamo ogni sorte di azzione di qual si voglia cosa; perciò che, se bene pare che le cose permanenti solamente cadano sotto l'arte del pittore, e non le successive, che si causano dai moti, può nondimeno il pittore 
dipingere le cose permanenti in apparenza tale, che, chi le vede, distinguerà le loro azzioni: come, dipingendo molte navi nel mare in atto di somergersi, se bene le cose dipinte, che sono le navi, sono permanenti, nondimeno dagli atti loro impariamo la azzione successiva, cioè il naufragio. E potiamo per essempio servirci in questo di quel verso di Virgilio tenuto per cosa singolare, quando parla dello scuto di Enea, dove era scolpita la lupa che con la lingua lecava or Romulo or Remo, con queste parole:

\section{Mulcere alternos et corpora fingere lingua ${ }^{501}$.}

Sì che potressimo dire che può il pittore dipingere persone e cose, come la benedetta Vergine, la sacra Croce, il Volto Santo e simili; overo operazioni, come il Battesimo del Signore, la Nunziazione della Madonna, con altre somiglianti. Ma perché questo pertiene più tosto all' arte del pittore, noi, che non intendiamo entrare in questa parte nel discorso nostro, se non talora per occasione, attenderemo, con quella più facile e chiara strada che potremo, di scoprire $\mathrm{i}$ varii scogli che rendono questa navigazione pericolosa, acciò che più cautamente possano essere da ciascuno fuggiti, dividendo il presente libro in tre parti: l'una, che tratterà degli abusi delle imagini sacre; l'altra, di quegli delle imagini profane; la terza, di altri molti che sono communi ad amendue, sì come dal progresso del libro si conoscerà.

[p. 270]

CAP. III.

Delle pitture sacre che peccano in materia di fede, e prima, delle pitture dette temerarie.

Inteso che si è in universale quali siano i soggetti capaci delle pitture, discendiamo ora alle cose particolari e pigliamo il principio da quegli abusi che pertengono a materia di fede o disciplina ecclesiastica; il che perché può accadere in diversi modi, noi, seguitando l'uso più commune de' teologi, che ne fanno cinque gradi, chiamandone alcune asserzioni temerarie, altre scandalose, altre erronee, altre sospette et altre eretiche formali, tratteremo, ad imitazione loro, di ciascuna di esse, non ci astringendo però così essattamente ai termini loro e descrizzioni, perché ora non siamo sul speculare le proposizioni dogmatiche, ma solo per mostrare come si debba mettere in prattica l'ufficio delle imagini. Onde cercheremo noi di accomodare gli essempii alla capacità delle pitture, come meglio giudicheremo convenirsi.

Chiamano proposizione temeraria, quando una cosa che è possibile, ma non ha ragione certa più per una che per altra parte, alcuno si muove ad affirmarla sicuramente in favore di una parte ${ }^{502}$; sì come serìa, chi facesse una pittura con qualche motto che significasse che il mondo debba finirsi tra cinquanta anni, certo tal pittura serìa temeraria, perché, se bene può ciò avenire, è però arroganzia e temerità grande il volerlo assicurare, non ci essendo ragione efficace per provare questo ${ }^{503}$.

Chi pingesse il giudicio estremo in modo che mostrasse dovere essere maggiore il numero delle donne che si salvino, che degli uomini, o più de' preti che de' monachi, o più de' contadini che de' cittadini, o più degli artefici che de' cortegiani: tutte queste seriano pitture temerarie. [p. 271]

Chi rappresentasse per certe alcune cose che la santa Chiesa non ha voluto determinare, come

\footnotetext{
501 Virgilio, Aen., VIII, 634.

502 S. Antonino, Sum. theol., II, tit. 12, cap. 5 (in princ.).

${ }^{503}$ S. Tommaso, Sum. theol., II-II, q. 53, a. 3.
} 
della concezzione della gloriosa Vergine, o che Salomone sia in gloria o nello inferno, o quanto sia il numero delli angelici spiriti, o altre simili materie sinora non resolute, incorreria nel medemo errore $^{504}$

Il dipingere, come alcuni hanno voluto, Enoch trasferito in cielo, et esprimere il luoco dove ora si trova et il modo di vivere che egli fa e l'abito di che va vestito, non serìa fuori di temerità, non avendo voluto la sacra Scrittura ${ }^{505}$ significare a noi se non quello che era necessario, quod fuit translatus, ut non videret mortem, sì come è stato annotato da S. Giovanni Crisostomo ${ }^{506}$.

Similmente il dipingere S. Gio. Battista, che in cielo tenga il luogo stesso e la sedia che già avea Lucifero, come vogliono alcuni, overo dipingere quali apostoli in cielo precedano gli altri e, tra li santi, chi sia di maggiore merito e più favorito nella corte celeste, tutte sono cose che, volendole il pittore co' suoi dissegni e figure rappresentare, facilmente incorreria nel vizio di temeritade.

E generalmente, le cose che non ha voluto la santa Chiesa per degni rispetti determinare, se alcuno volesse col suo sapere diffinirle e con parole ad altri persuadere, sì come non è dubbio che di temerità serìa notato; così chi cercasse ciò con pittura esprimere, tanto maggiormente pare che serìa riprensibile, quanto che, essendo la pittura agli occhi di ciascuno esposta, viene a manifestare publicamente lo stolto ardire suo, non con parole fugaci, ma con l'opera permanente, quasi volendo rendere certo et indubitato testimonio di quello che presso a tutti è incerto e così farsi autore di nuove opinioni, levando le passate. [p. 272]

È però d'avvertire che non ogni cosa incerta, narrata nondimeno o dipinta come certa, rende subito lo autore di essa temerario; perché ciò non ha luogo quando quello che si narra o dipinge è accompagnato da molta probabilità et insieme è atto a movere il cuore et eccitare divozione ${ }^{507}$; sì come veggiamo che sogliono le persone contemplative e predicatori nella passione di Nostro Signore narrare molte cose che non si trovano scritte negli Evangelii: come dei lamenti della Madonna, dei prieghi lunghi fatti da N. S. nella orazione nell'orto, della acerbità de' flagelli, delle parole obbrobriose usateli da' Giudei, e simili altre cose che raccontano per muovere più l'affetto et intenerire il cuore. Le quali narrazioni o pitture, se saranno congionte con giudicio e verisimilitudine, scuseranno il predicatore o pittore dalla temerità; ma se saranno cose solamente imaginate per far piangere e destare fervore di devozione, non avendosi riguardo alcuno al decoro della persona o alla probabilità e verisimilitudine del fatto, certo che ciò non difenderà l'autore dalla temerità. Il che ci è parso di avvertire grandemente, però che molti, mossi da zelo indiscreto, errano facilmente in questo, non vi usando la debita prudenza.

CAP. IIII.

Delle pitture scandalose.

Altre sono pitture dette scandalose, a similitudine delle asserzioni in materia del Santo Officio; imperoché sì come quelle suonano male et offendono le orecchie de' buoni, così queste offendono gli occhi pii delle persone e danno occasione di ruina spirituale ${ }^{508}$. [p. 273]

\footnotetext{
504 Concil. Trid., sess. V.; F. Feuardent, in Alonso de Castro, Opera omnia... Accessit Appendix ad libros contra haereses... authore F. Francisco Feuardentio (1578), p. 1047.

505 Gen., 5, 24; Ad Hebr., 11, 5.

506 Hom. in Ep. ad Hebr., 22.

507 Alonso de Castro, De iusta haereticorum punitione, I, cap. 3.

${ }^{508}$ A. Albertinus, Tractatus solemnis... de agnoscendis assertionibus catholicis et haereticis (1571), q. 6, n. 10.
} 
Gli essempii sogliono darsi di varie maniere, ma non tutti capiscono bene nella pittura, perché alcuni sono di cose pertinenti all'intelletto, che, quanto al suono delle parole, sono offensive della religione. Altri sono scandalosi quanto alli costumi, e perché questi meglio si accommodano al dissegno, però de tali parleremo.

Sogliono gli eretici, a similitudine degli avoltori, che, lasciando i cibi buoni e sani, si nutriscono solo di cadaveri fetidi e carogne ${ }^{509}$; così essi, non volendo vedere le molte e segnalatissime virtù che si trovano nei catolici, vanno investigando solo i difetti. E se talora ne scoprono alcuno, come avviene in questa umana fragilità, subito a quello si appigliano; anzi, non lo trovando, se lo fingono con somma falsità e maledicenzia, talché, a guisa de' fanciulli che, non sapendo adoperare la spada, si voltano ai morsi co' denti et alle strida con la voce, parimente essi, non potendo prevalere in alcuna parte contra i dogmi fondatissimi della religione nostra, studiano di lacerarla con la mordacità, disseminando non solo con parole cose obbrobriose della vita e costumi delli ecclesiastici, ma dipingendole ancor per le osterie et altri luoghi publici e privati, accioché entri questo veneno nelle menti de' popolari, facili a credere il male altrui. E per questa strada li tengono lontani dallo stendardo di santa Chiesa.

Ora di simili invenzioni ragioniamo, che scoprono in fronte la sua malignità, sì come saria chi dipingesse una monaca che si facesse i ricci e s'imbellettasse la faccia, o chi pingesse un sacerdote con la concubina a tavola, o uno religioso che si trovasse in danza con le dame, o veramente chi dipingesse i prelati di santa Chiesa starsene giocando, o invitarsi a bere ne' banchetti, o simili altre cose: tutte sariano scandalose, perché, oltre che spesso non sono vere, non conviene, anco quando ben fossero, di scoprire in publico i difetti altrui. Si viene ancora con tale essempio, che serà accaduto in pochi, [p. 274] a diffamare il resto di quell'ordine, che non ne ha colpa; il che ripugna alla prudenza, che dà i suoi gradi a tutte le cose né per mancamento de alcuni si mette a dannare tutto lo stato; ripugna alla giustizia, che non condanna mai uno per un altro, né dà sentenzia contra alcuno senza avere udite le sue ragioni; e ripugna alla carità, che sempre si veste de' panni d'altri e tutte le azzioni prima riflette in sé stessa, considerando se le piaceria che altri ragionassero in quella maniera della persona sua o d'altri suoi cari. La qual cosa quanto dispiaccia a Dio essempio ce ne porge la Scrittura parlando di Cham, figlio di Noè, il quale, avendo scoperto a' suoi fratelli le vergognose parti del padre, fu da Noè giustamente maledetto e gli altri fratelli, che lo copersero, furono benedetti ${ }^{510}$; il che figurava misticamente, secondo alcuni, che quegli che riveriscono il sacerdozio, significato per Noè, hanno da Dio la benedizzione, ma quegli che ardiscono di sprezzarlo meritano la maledizzione, presumendo fuori dell'officio loro ingerirsi nel santuario di Dio e con arrogante temerità conculcare quelli che egli ha admessi al servizio e ministerio suo santo.

Quelle pitture, dunque, che trapasseranno questi termini doveranno meritamente come scandalose essere ributtate, non si potendo cavare altro da tale spettacolo, se non che sia stato fatto in ingiuria e scherno di alcun ordine, o religioso o clericale, o anco secolare, per porlo in vilipendio, overo per invitare gli altri a simile indignità e, facendoli come la strada al precipizio, dare occasione ad altri di ruina, che è l'effetto dello scandalo ${ }^{511}$.

\section{[p. 275]}

\footnotetext{
509 S. Basilio, Hom., II (De invidia).

${ }^{510}$ Gen., 9, 22 ss.

511 S. Tommaso, Sum. theol., II-II, q. 43, a. 1 ss.
} 
CAP. V.

Delle pitture erronee.

Seguitano le erronee, il cui nome di sua natura è generale a tutte le specie di falsità che occorrono in qualunque materia o scienza che sia, dicendo S. Agostino ${ }^{512}$ : Error est falsi pro vero approbatio; et altrove: Errare est approdare falsa pro veris, aut improbare vera pro falsis, aut habere incerta pro certis, aut certa pro incertis; e di nuovo: Dicitur ille errare, qui aestimat se scire quod nescit. Ma perché, sì come le infirmità del corpo, nascendo da intemperanza de umori, pigliano il nome da quella parte del corpo che più averanno oppressa: onde, prevalendo il male negli occhi, si chiamerà oftalmia, nelle mani chiragra, nei piedi podagra, nel costato pleuritide, e così negli altri membri ${ }^{513}$; medesimamente gli errori delle pitture, diffondendosi in tutti i soggetti per varii modi, pigliano la denominazione loro da quella specie ove si sono stesi, e però si chiamano talora pitture vane, altre pitture mostruose, altre inette o apocrife o superstiziose, o con altri nomi che in questi nostri capitoli si vanno compartendo: che tutti non inferiscono altro che errori varii e difetti delle pitture. Resta però questo nome generale di erronee ad alcune, che peccano in materia di fede o di costumi, Ma non giungono al grado delle eretiche, e di queste ora parliamo ad imitazione di quelle del Santo Ufficio. E perché non si accordano bene i dottori, in che cosa propriamente queste siano distinte dalle altre e che condizione particolare li convenga ${ }^{514}$, noi per ora seguitiamo il parere di quegli ${ }^{515}$ [p. 276] che hanno chiamate erronee quelle che pigliano errore in quella sorte di materia, la quale non solo è creduta da noi per essere misterio della santa fede, ma perché si può ancora provare col lume naturale della ragione ${ }^{516}$ : come saria, per essempio, il dubitare se Iddio sia, e se sia uno o più, è cosa che la fede ce lo insegna e la ragione ancora necessariamente ce lo persuade; parimente, che Iddio abbia potestà e providenza sopra le cose create, questa, secondo alcuni, è asserzione commune alli dogmi della fede et alla dimostrazione naturale ${ }^{517}$; altro essempio in contrario saria affermare che il corpo di Cristo, salvatore nostro, sia stato veramente uomo nei tre giorni della morte sua, overo che l'anima di uno uomo sia prodotta da seme umano come l'anima di un animal bruto, perché a queste, oltre alla verità della fede, ripugna ancora la ragione naturale.

L'ingannarsi dunque in alcuna di simili materie vogliono che appartenga propriamente alle proposizioni erronee; il che medesimamente potrà servire per dar essempio delle pitture erronee, quando queste o altre simili si potessero ridurre acconciamente in disegno et in pittura che si lasciasse intendere.

CAP. VI.

Delle pitture sospette.

Lasciando ora la contesa tra dottori, quali propriamente si chiamino asserzioni sospette, volendo

\footnotetext{
512 Contra Academ., I, 4; Enchiridion, 17 (cfr. c. 11, D. XXXVIII).

513 Giovanni Cassiano, Collat., XXIV, 15.

514 J. de Torquemada, Summa de Ecclesia cit., IV, pt. $2^{\text {a }}$, cap. 11.

${ }^{515}$ N. Eymerich, Directorium inquisitorum (1503), schol. 22.

516 Alonso de Castro, De iusta haereticorum punitione, I, cap. 3; S. Tommaso, Sum. theol., I, q. 11, a. 3; q. 12, a. 12; q. 32 , a. 1 ; II-II, q. 2 , a. 1 ss.

${ }^{517}$ S. Tommaso, Sum. theol., I, q. 2, a. 3; M. Cano, De locis theologicis (1563), XII, cap. 4, p. 700.
} 
alcuni che siano quelle che propongono alcuno fatto o azzione di cosa commendata da qualche setta riprovata; altri che siano quelle che rappresentano una azzione che sia cattiva di natura sua, né possa [p. 277] verisimilmente essere causata da pravo affetto alcuno, come di libidine o di avarizia o di ambizione o di simile altra passione, ma solo da errore d'intelletto, occulto però e non manifesto; altri quelle che esteriormente nelle parole suonano cosa di eresia, se bene, piamente intese, possono admettere intrinsecamente sano intelletto (del che ne danno varii essempi, facendo ancora tre gradi di tale sospizione, cioè leggiera, veemente e violenta) ${ }^{518}$ : noi, che non trattiamo ora di cose dogmatiche e ci serviamo solo de questi nomi per più chiarezza e distinzione de' difetti che cadono nelle pitture, non intendiamo ancora di astringerci ad alcuna di queste dichiarazioni, ma più tosto valerci degli essempi di ciascuna, secondo che meglio convengono alle pitture, pigliando per sospette tutte quelle che, non essendo così chiare e certe della loro eresia, lasciano però molta perplessità e sospizione nell'animo di chi le riguarda. Come, per essempio, chi dipingesse Constantino imperatore il magno col Demonio a canto che lo consigliasse, pareria che favorisse l'opinione di Giovanni Wicleff, condennata nel Concilio Costanziense ${ }^{519}$, che ardiva dire che quello santissimo imperatore fosse stato con false illusioni dal Demonio sedutto a dotare de' beni temporali la Chiesa santa.

Simile essempio saria quello che è scritto da $\mathrm{S}$. Antonino ${ }^{520}$, quando si dipinge il misterio della Annunziazione della Madonna con li raggi dal cielo dello Spirito Santo, e tra essi un corpicciuolo picciolo in forma di bambino, che discende verso il ventre della gloriosa Vergine; peroché questo dà sospetto della opinione di Valentino eretico o degli Eutichiani, che volsero che Cristo signor nostro avesse portato il corpo suo etereo dal cielo e non fosse stato formato del sangue purissimo della madre $^{521}$. [p. 278]

Parimente chi la dipingesse nel parto del figliuolo aiutata dalle ostetrici, e dopo il parto starsene nel letto per alcun tempo pallida come afflitta da' dolori, e che vada ristorandosi con cibi delicati e vini di sostanza, pareria che favorisse l'errore di Elvidio e d'altri, riprovato da san Ieronimo, che scrisse $^{522}$ : Nulla obstetrix, nulla muliercularum sedulitas intercessit, ipsa et obstetrix et mater fuit, et è avvertito ancora nella sesta Sinodo ${ }^{523}$.

Un altro saria chi dipingesse uno demonio in abito di sacerdote che battezzasse, perché si potria sospettare che sentisse che 'l battesimo ministrato da un sacerdote peccatore non fosse buono; o chi pingesse due imagini nel cielo, che disonestamente si abbracciassero; o chi rappresentasse le anime uscite dal corpo andare tutte in un giardino ameno et ivi tratenersi: queste dariano sospizione delle eresie che tennero alcuni, che in cielo si godesse di queste delizie carnali e che le anime si riposassero nel paradiso terrestre fino al giorno del giudizio.

Un altro pure non mancheria di sospizione, che si vede in alcune chiese, se bene forse senza malizia (ma pure è bene avvertirlo), che è il rappresentare Melchisedech il quale, avendo il pane et il vino in mano, non a Dio l'offerisce, ma lo dona ad Abraham; intorno a che, se bene si può credere che 'l pittore non abbia avuta mala intenzione, nondimeno noi per li detti di san Paolo e di David,

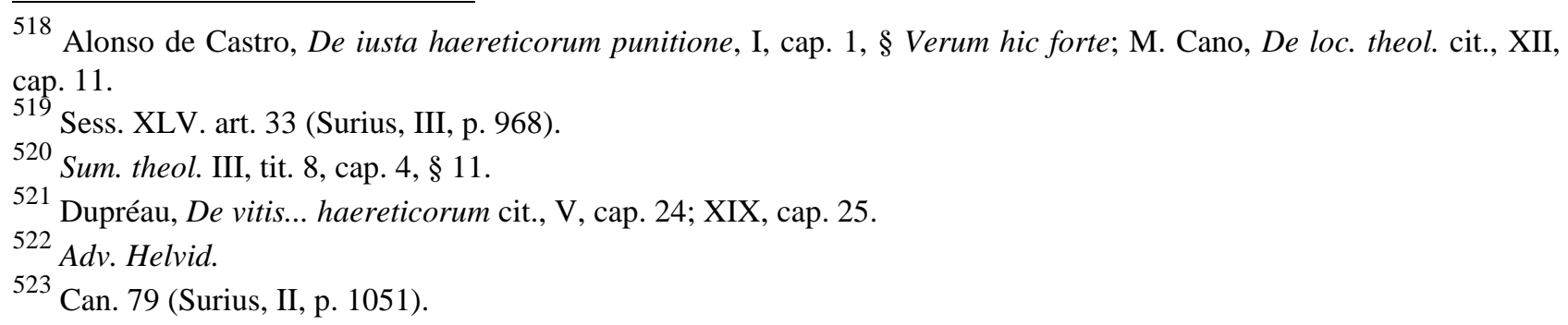


che domandano Cristo signore nostro sacerdote secondo l'ordine di Melchisedech ${ }^{524}$, affermiamo che Cristo così dovette sotto le specie del pane e del vino instituire un sacrificio, come pane e vino offerì a Dio Melchisedech; il che ce lo negano gli eretici e dicono che non a Dio, ma ad Abraham diede egli il pane, quasi che non si veggia espresso il contrario, soggiognendosi subito: Erat enim sacerdos Dei altissimi ${ }^{525}$. Il pittore dunque in quel caso favorisce l'opinione eretica, e potrebbono di qui a cento anni, [p. 279] se vi fossero gli eretici, allegare nello sciocco filo delle loro tradizioni, che a questo tempo così si credeva, perché così si dipingeva. E se il pittore dirà che egli, come non dotto, non sa ove siano questi scogli e come debbano fuggirsi, si risponde che non è gran cosa il consigliarsi con uomini savii, quando hanno da farsi opere tali; anzi, sarebbe bene il non porsi mai a dipingere istoria alcuna sacra, che prima non si conferisse il disegno con alcuni di quegli che intendano, perché questo ci farebbe schifare molti inconvenienti che ogni giorno si scorgono nelle pitture, causati forse per la sola inavvertenza.

\section{CAP. VII.}

Delle pitture eretiche.

Potria forse alcuno dubitare che difficilmente si possa formare pittura, alla quale propriamente convenga il nome di eretica, peroché, concorrendo alla eresia due cose congiuntamente, l'una dalla parte dello intelletto che pigli errore nelle cose della fede, l'altra dalla parte della volontà che pertinacemente aderisca a tale errore ${ }^{526}$, non pare che in una pittura si possa interamente discernere l'uno e l'altro ${ }^{527}$. Nientedimeno chi considera bene troverà il contrario essere vero; il che per dichiarare meglio, parleremo prima della pittura in sé stessa, poi rispetto alla persona che la possiede.

Quanto al primo, sì come chiamano un libro eretico, quando dalla lettura di esso si mostrano dogmi eretici, se bene non è chiaro con che intenzione sia stato scritto, così diremo una pittura essere eretica, che rappresenta cose di eresia, non essendo necessario in ciò investigare a che fine sia stata fatta, [p. 280] poi che non si tratta ora della persona o dell'autore di essa, ma solamente di quel puro disegno e materiale lavoro che si vede, il quale, dalla fronte scoprendo il vizio suo, viene senz'altro a condennare sé stesso; oltra che, secondo la regola ancora de' iuresconsulti, ogni cosa cattiva si presume fatta con cattiva intenzione, e, secondo il proverbio antico, ab impiis progredietur impietas $^{528}$. Sì che, alla similitudine de' libri, ne' quali, subito che si scuopre errore d'eresia, si intendono riprovati et interdetti, così e maggiormente diciamo d'una pittura che rappresenti cosa contraria alla verità cattolica, e non solo perché ancor questa è una sorte di libri popolari, come più volte si è detto, ma perché efficacemente imprime nei sensi altrui il veleno, più che non fanno i libri. Sì come, per essempio, parlando delle cose de' moderni eretici, pittura eretica si dirà chi dipingesse un prete o frate che publicamente prenda moglie; overo un secolare che dia gli ordini sacri; overo una donna che celebri la messa; overo un altro che conculchi le reliquie sacre e per dispregio violi il santissimo Sacramento; overo che isporchi con impietà la veneranda Croce; overo che battezzi e ribattezzi più volte il popolo: et in somma ogni pittura che, a guisa di libro,

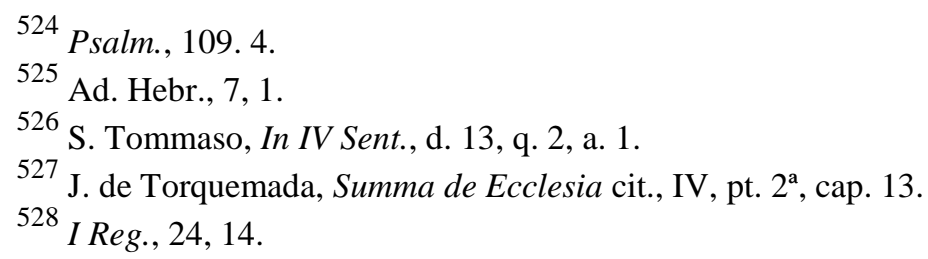


rappresenti cosa che direttamente o indirettamente sia vietata dalla Chiesa catolica ${ }^{529}$.

Scrive Tertulliano ${ }^{530}$ che anticamente gli infedeli, per fare scherno a' cristiani, dipingevano un uomo togato con un libro in mano e con le orecchie asinine et un piede guernito di onghia, con una inscrizzione: Deus christianorum ononychites. Così oggi talora in Germania e Francia, con gran dolore de' catolici, si dipingono animali bruttissimi e vilissimi, apparati con vesti ecclesiastiche, in guisa che ad uno altare essercitino ufficii santissimi; volend'essi con tai figure sbeffare o schernire il sacerdozio e negargli l'autorità. Onde tutte queste [p. 281] imagini, dal cui primiero aspetto appare il mostro della eresia, doveranno come eretiche essere ributtate.

Ora parliamo del pittore che averà fatta cotale pittura, del quale non potendosi presumere se non molto sinistramente, ci rimettiamo al Santo Ufficio nel determinare in che pena egli incorra e che compassione gli si possa avere, quando per qualche ignoranza fosse scorso. Bene avvertiamo i nostri pittori, non perché crediamo che sia necessario, essendo essi, Dio grazia, catolici, i quali per nessuno rispetto giamai doveranno ardire di porre mano in simile lavoro; ma solo per modo di ricordo che, quando per alcuna via capitasse alle mani loro alcuna simile pittura eretica, vogliano ad ogni modo levarsela subito di casa e dinunziarla a chi si deve, non attendendo all'artificio, per molto che vi fosse, ma al veleno pestifero che sotto vi sta ascoso.

Ma de' padroni che si troveranno in casa tali pitture, che diremo? Noi, oltre la similitudine di quei che tengono libri proibiti, che secondo varie circostanze possono essere rei di varie pene ${ }^{531}$, vi aggiungiamo che tanto più paiono questi colpevoli, quanto che, col tenere simili pitture, pare che non solamente appruovino gli errori di esse, ma ancora che gli tribuiscano certo onore e riputazione, che dalle imagini suole derivarsi ${ }^{532}$. Anzi, di più, chiamandosi eretici manifesti quegli che pubblicamente predicano o fanno professione di cosa contraria alla fede catolica, sì come fu già da papa Innocenzio III dichiarato ${ }^{533}$, pare che quelli, che tenessero tali pitture in prospetto degli altri, si potessero numerare tra i manifesti, come quegli che con tali imagini, di che si compiacciono, vengono a protestare palesemente la fede loro interiore, che da simili segni esteriori si suole comprendere $^{534}$, o almeno non si potrà negare che non si mostrino difensori e fautori [p. 282] di tali errori e conseguentemente peggiori assai di quegli che favoriscono solamente le persone degli eretici $^{535}$.

Si debbono però tutte queste cose intendere, quando non si conoscesse chiaramente che tali pitture fossero fatte in biasimo e dispregio di quella impietà, con alcune dimostrazioni di castigo notabile che li fosse dalla divina giustizia o da' suoi magistrati imposta, sì come più a basso si dirà nel capitolo de' ritratti degli eretici ${ }^{536}$; perché ora parliamo non delle persone eretiche, ma degli errori e perversità in che stanno implicati.

\footnotetext{
${ }^{529}$ S. Tommaso, Sum. theol., II-II, q. 11, a. 2.

530 Apol., 16.

531 D. Simancas, De catholicis institutionibus cit., tit. De libris, n. 24; N. Eymerich, Directorium inquisitorum cit., II, schol. 1, c. 30.

532 Dig., XLVII, 10, 27; 10, 13, 2.

533 c. $26, \mathrm{X}$, de verb. signif., V, 40.

534 N. Eymerich, op. cit., III, De signis, c. 293; III, c. 141, schol. 31.

535 D. Simancas, op. cit., tit. De haereticis, n. 14 s.; N. Eymerich, op. cit., II, c. 256 ss.

536 Cap. 33.
} 


\section{CAP. VIII.}

Delle pitture superstiziose.

Contrarie alle pitture dette di sopra sogliono essere stimate quelle che si chiamano superstiziose; intorno alle quali per più chiara loro cognizione diciamo che, essendo la religione prencipale tra tutte le virtù morali, la quale consiste nel dare il debito culto a $\mathrm{Dio}^{537}$, conseguentemente sta posta nel mezzo tra due estremi viziosi: l'uno de' quali pecca in difetto del meno, che si chiama impietà o irreverenza e negletto di Dio, l'altro in eccesso del troppo, il quale è dimandato superstizione; non perché si possa adorare Dio maggiormente di quello che si conviene, ma perché non si adora nel modo che si deve o con i mezzi proporzionati al debito fine ${ }^{538}$. Talché il nome di superstizione abbraccia ogni indebito culto di divinità; la quale, quanto spetta al proposito nostro delle pitture, si può considerare in tre maniere: o quanto al modo [p. 283] di dipingerle, o quanto alle cose che si dipingono, overo quanto all'usare e servirsi delle pitture già fatte; e però dice il Concilio Tridentino ${ }^{539}$ : Omnis superstìtio in imaginum sacro usu tollatur.

Quanto al primo, non è dubbio che, sì come nell'altre operazioni di questa vita vi può cadere superstizione, con l'osservare sotto titolo di religione certi luoghi o tempi o modi superflui e non corrispondenti a quello che si pretende; così può cadere questo errore in un pittore che, mosso da sciocco zelo o falso inganno del Demonio, osserva nello essercizio dell'arte sua alcune cose non pertinenti a quella facoltade e non appropriate naturalmente a fare quegli effetti, che però da' teologi sono giudicate non come cause, ma come segni e tacite convenzioni col Demonio ${ }^{540}$ : sì come sarà il non volere dipingere l'imagine di S. Pietro fin che non si ode cantare il gallo, overo non volere dipingere l'imagine della Madonna se non in tela ordita per mano di vergine, overo volere che i colori siano stemperati in tal giorno a tale ora, overo che il pennello sia fatto a numero determinato di sete, o altre simili stultizie.

Quanto poi alle cose che si dipingono, vi può occorrere in molti modi la superstizione, col rappresentare o atto di idolatria, o di divinazione, o falsa osservazione: sì come, quanto alla idolatria, saria formare persone che adorassero l'idoli, o facessero sacrificio secondo la gentilità, o offerissero incenso a falsi dèi, o in altri modi, del che si leggono varii essempii nel popolo iudaico e tra gli altri quello che narra Ezechiele con queste parole ${ }^{541}$ : Dixit Dominus: Ingredere et vide abominationes pessimas, quas isti faciunt. Et ingressus vidi, et ecce omnis similitudo reptilium et animalium, abominatio et universa idola, domus Israel depicta erant in pariete in circuitu per totum, et septuaginta viri de senioribus domus Israel, et [p. 284] unusquisque habebat thuribulum in manu sua et vapor nebulae de thure consurgebat. E se bene in simili materie si potesse scusare il pittore, non avendo intenzione di dipingere quelle cose se non come false, nientedimeno, significandosi la falsità tanto con li fatti quanto con le voci, potrà essere talora ciò interpretato superstizione per quella parte che significa cose false: onde è bene astenersene; e così ancora nel rappresentare atti di divinazione, come di negromanzia, augurii, sortilegii et altri simili, o, quanto all'osservazione, nel figurare arti magiche ${ }^{542}$, incantazioni, immagini con caratteri incogniti, ligature di erbe, ossa de' morti, capegli intrecciati e simili osservazioni reprovate dai canoni, sì come narra il

\footnotetext{
${ }^{537}$ S. Tommaso, Sum. theol., II-II, q. 81, a. 6. 4.

538 Ibid., q. 93, a. 2.

539 Sess. XXV, tit. 2, § illud.

${ }^{540}$ S. Tommaso, Sum. theol., II-II, q. 96, a. $1 \mathrm{s.}$

${ }^{541}$ Ezech., 8, 9 ss.

542 S. Agostino, De doctr. Christ., 19 s.
} 
Turonense $^{543}$ di uno chiamato Desiderio, che con l'imagine della croce santa et una ampolla, che egli diceva essere di oleo santo, fu scoperto ch'avea una sacoccia piena di radici d'erbe, insieme con denti di talpa et ossa di sorgi et unghie e grasso d'orso, con molt'altre imposture, le quali perché possono essere come infinite ${ }^{544}$, basterà al presente avere toccato queste, rimettendoci nel resto al libretto che di ordine di monsignore illustrissimo Vescovo si publicherà dei varii avvertimenti per li curati e confessori intorno alle superstizioni.

L'altro capo è dell'uso superstizioso delle imagini, il quale può cadere anch'esso in varii modi: o con l'adorarle in altra maniera e con altro sentimento che la religione cristiana non comporta, come si legge degli eretici detti Colliridiani, che offerivano certa focaccia all'imagine della beata Vergine, come scrisse Epifanio $^{545}$ (il che appartiene all'idolatria ${ }^{546}$ ), di che altre volte abbiamo ragionato); overo col servirsi di queste imagini ad altro uso di quello a che sono state instituite, sì come in alcuni luoghi si legge che nel giorno della conversione di S. Paolo, se avverrà che sia pioggia o tempestoso [p. 285] tempo dal cielo, buttano la imagine sua nel fiume corrente di quel luogo; altri portano in certi giorni le imagini d'alcuni santi per le campagne e seminati, con gran grido e strepito tumultuoso de' lavoratori, persuadendosi che, quanto maggiore sarà stato il ribombo delle voci e strida loro, sia per riuscire tanto più abbondante quell'anno la ricolta; altri se ne servono ad incantazioni, maleficii et altre loro diaboliche menzogne, dalle leggi severamente punite. A che aggiungono altri una somma e biasimevole irreverenza, che, nel tempo degli interdetti permessi da' canoni per la contumacia de' rei, essi, per aggravarli maggiormente, gittano in terra l'imagine santa della croce e della beata Vergine Maria e degli altri santi, coprendola di ortiche e spine; il quale abuso, per la sua enorme irreligiosità, fu condennato da Gregorio X nel Concilio Lugdunense, come oggi ancora si legge ${ }^{547}$.

\section{CAP. IX.}

Delle pitture apocrife.

Questo nome di apocrifo presso gli autori ecclesiastici, se bene suole attribuirsi a materia de' libri e scritture, è però preso non uniformemente da tutti ${ }^{548}$. Ma quello in che più communemente pare che essi convengano è che di tutti i libri pertinenti alle cose della religione ve ne siano tre ordini: l'uno, che chiamano libri canonici; il secondo, libri agiografi; il terzo, libri apocrifi ${ }^{549}$. Li primi hanno autorità e necessità, perché ci astringono a credergli nelle cose della fede, e questi sono i libri della Scrittura sacra, scritti non dagli uomini, da Dio per mano degli uomini. I secondi non hanno per [p. 286] l'ordinario necessità, ma autorità, onde si leggono publicamente ad edificazione de' fedeli. I terzi non hanno né autorità né necessità, ma però non sono con pena alcuna reprovati, onde non si possono leggere publicamente, ma sì bene in privato con debita cautela; il che può essere nato o perché non si sappia l'autore certo di essi, o perché abbiano meschiate cose false con vere, o perché le cose che narrano non paiano così ben fondate come si doveria, o per qualonque

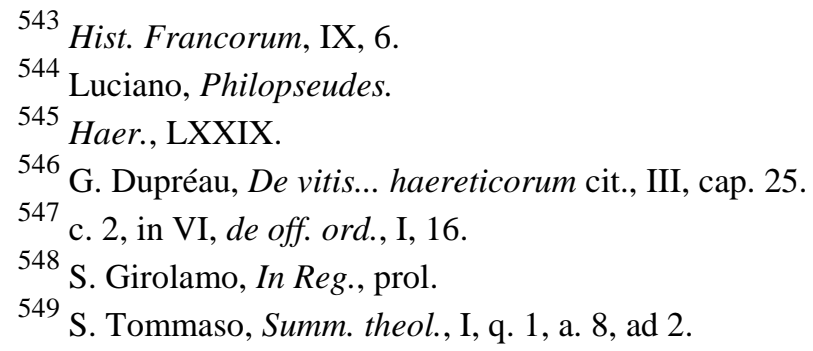


altra causa: basta che la condizione loro è tale, che passa come in occulto e sconosciuta tra gli uomini, sì come sono le cose scritte nel terzo e quarto libro di Esdra, il libro della Fanciullezza del Salvatore, l'Evangelio di Nicodemo, e molti altri autori che recita papa Gelasio nel suo decreto ${ }^{550}$. Nel che però si ha d'avvertire che talora sarà tenuta per un tempo una scrittura apocrifa, che di poi si scuopre manifestamente bugiarda, onde, non essendo più incerta, non resta più nel numero delle apocrife, ma passa nel regno della bugia da essere da noi scacciata, sì come afferma $\mathrm{S}$. Ieronimo ${ }^{551}$ essere accaduto al suo tempo di quello che si narrava De periodis Pauli et Theclae et de Leone baptizato, che poi l'autore istesso confessò di aversi fabricata questa invenzione per lo troppo amore che portava a $\mathrm{S}$. Paolo, desiderando aggrandire più il nome suo. Così potrà avenire ancora alle vere, che per un tempo saranno tenute per apocrife, poi piacerà a Dio, o con miracoli o con altre evidentissime ragioni, mostrare al mondo che sono cose autentiche et indubitate, sì come avvenne per alcuno tempo nei cinque libri che, non essendo posti dagli Ebrei nel canone, non furono da

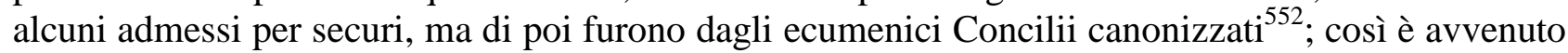
ancora in alcune istorie e narrazioni di cose, che per un tempo seranno state ributtate, come degli antipodi $^{553}$ et [p. 287] abitatori sotto la zona torrida, che di poi l'esperienza ha mostrato esser vero. Donque, quanto spetta alle pitture, che in gran parte si regolano dai libri, come più volte s'è detto, chiamaremo apocrife quelle che contengono cose di religione non autenticate dalla santa Chiesa, ma né anco dannate, e della cui verità si dubita, né si può dare certo iudicio; dalle quali bene faranno i pittori ad astenersi, per non ingannare massime i semplici, credendosi che siano cose vere, et anco per non occupare sé stessi et il tempo in cose non necessarie, quando potriano essercitarlo in altre opere più fruttuose.

Ora, nel conoscere quali siano queste apocrife, ricordiamo che è necessario e di giudicio e di cognizione non poca, e consiglio buono di persone intelligenti, percioché, sì come nei libri non tutto quello che non si trova espresso nel sacro testo subito si dice essere bugiardo e reprovato - peroché vi sono le tradizioni antiche de' santi padri e della catolica Chiesa, le quali da noi sono accettate con eguale pietà, secondo che dice il Concilio Tridentino ${ }^{554}$, che sono l'altre fondate nelle parole stesse della Scrittura (onde diceva S. Basilio ${ }^{555}$ : Si conemur non scriptas consuetudines quasi non magnam vim habentes rejicere, eo deveniemus ut praecipuas evangelii partes labefactemus) -, così possiamo dire delle pitture, che, se bene non si troveranno tutte conformi alle parole sacre, non però si averanno a chiamare apocrife, purché siano conformi alla autorità de' santi Padri et uso universale della Chiesa, et in somma abbiano le condizioni che disse il Lirinense ricercarsi alle cose ecclesiastiche: cioè, quod probatae fuerint semper, ubique et apud omnes ${ }^{556}$. Sì come, per essempio, non ci è evangelista che dica che, quando nostro Signore fu crocifisso, gli fossero coperte le parte pudende di alcun panno o velo, e nientedimeno è cosa tanto ragionevole e tanto frequentata già da tutti i secoli nella cristianità, che il volere mettere in [p. 288] dubbio questo pareria quasi una impietà. Nella nonziazione della gloriosa Vergine, quando l'arcangelo Gabriele la salutò, non dice la Scrittura quello che allora facesse la Madonna, se caminava o sedeva o cusciva o operava altro;

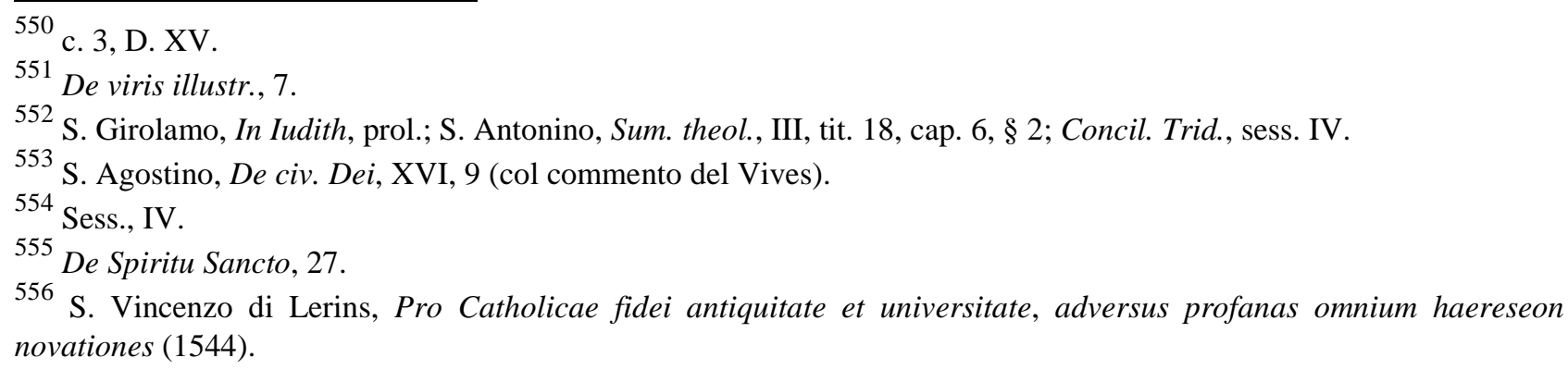


nientedimeno tutti i pittori sempre hanno concordato che ella fosse genuflessa intenta all'orazione, e così ci abbiamo a persuadere che fosse. Non dice lo Evangelio, quando il Salvator nostro fanciullo con la madre e S. Gioseppe fuggì in Egitto, se andassero a piedi o a cavallo o come; nientedimeno communemente dipingono i pittori la Madonna sopra l'asinello col figliuolino in braccio, che è così ragionevole che fosse, essendo la beata Vergine ancora tenera, e dovendo fare viaggio così longo, et essendo usanza che le altre donne andassero in quel modo, sì come la Scrittura nominatamente fa menzione della moglie di Moisè e suoi figliuoli, dicendo: Tulit ergo Moyses uxorem suam et filios suos, et imposuit eos super asinum, reversusque est in Aegyptum ${ }^{557}$. Nella conversione di san Paolo dipingono un cavallo feroce, dal quale egli cadesse in terra, e nientedimeno non dice san Luca che fosse più a piedi che a cavallo; ma perché è più verisimile che, essercitando l'ufficio commessoli dai prencipi de' sacerdoti e facendo viaggio in Damasco, fosse a cavallo, come sogliono usare simili personaggi, però in tal modo e giudiciosamente si suole ritrarre: il che in altri simili molti essempi può eziandio occorrere.

Ma qui di nuovo è d'avvertire primieramente, che non basta che li pittori si accordino insieme a dipingere una cosa, se ella non è fondata nella ragione e verisimilitudine grande e communemente dai dotti accettata; perché alle volte essi dipingono quello che trovano fatto da altri, senza alcuna considerazione se sia bene o male, come disse san Basilio $^{558}$ : Dum pictores ex imaginibus imagines depingunt, saepe deficiunt ab archetypo. Di più, non basta ancora che tal pittura sia narrata da alcun dottore di autorità, né bisogna così fidarsi di [p. 289] ciascuno in tutti i particolari, se quell'istesso non corrisponde al sentimento degli altri e dalla santa Chiesa non viene approvato; nel che è bisogno di molto iudicio et intelligenzia, come, parlando dei libri e scritture apocrife, disse Gelasio papa $^{559}$, servendosi delle parole di san Paolo: Omnia probate, quod bonum est tenete ${ }^{560}$, e da noi nel quarto libro se ne parlerà più a pieno.

\section{CAP. X.}

Delle pitture di Giove, di Apolline, Mercurio, Giunone, Cerere et altri falsi dèi.

Dalle cose dette altre volte nel primo libro se bene assai si può comprendere quello che sentiamo delle pitture de' falsi dèi, nientedimanco, perché questo abuso di tenere la loro memoria è tanto più pericoloso e biasimevole, quanto che, sotto nome di studio di antichità o di polite lettere e di ornamento di librarie, penetra spesso nelle persone grandi, e con fatica, sollecitudine e spesa non poca tiene occupato l'animo nobile di quelle, ci è parso necessario di discorrere alcune cose in particolare. Imperoché, lasciando il risentimento che il grande Iddio per Moisè et i suoi profeti tante volte ne ha fatto nella Scrittura sacra ${ }^{561}$ e particolarmente per Zaccheria, dicendo: Disperdam nomina idolorum de terra et non memorabuntur ultra ${ }^{562}$, e per Ieremia, che ne scrive una epistola così longa e così efficace della vanità loro ${ }^{563}$; lasciando che fino $\mathrm{i}$ gentili se ne siano burlati così

\footnotetext{
557 Exod., 4, 20.

558 Hom., 18 (In Gordium mart.).

559 c. 3, D. XV.

560 I ad Thess., 5, 21.

561 Deut., 7, 5; Levit., 26, 1.

562 Zach., 13, 2.

563 Bar., 6.
} 
apertamente $^{564}$, come si narra di Agesilao re de' Lacedemoni, al quale avendo li Tasii edificato un tempio per adorarlo come dio e mandatoli ambasciatori per significarli questo, egli dimandò agli ambasciadori se la loro patria avea potestà di fare di uomini dèi, [p. 290] et avendola, che doveano prima fare sé stessi dèi, che allora averia creduto che potessero fare anco lui ${ }^{565}$; lasciando da parte che tanti santi Padri greci e latini con sì maravigliosa facondia e dottrina hanno mostrata la pazzia, et illusione sciochissima di questi dèi, come ne estano volumi loro amplissimi; lasciando ancor varii essempi narrati nelle istorie ecclesiastiche, che tutti condannano questo abuso e tra gli altri quello che si scrive del vescovo Teofilo Alessandrino, che pieno di zelo, avendo distrutto tutti gli idoli alessandrini e convertito quella materia in varii usi di chiese e de' poveri, al fine volse che un solo simolacro di una simia restasse in piedi e publicamente eretto, affine che i pagani nei tempi avvenire non potessero negare di avere adorati tali dèi e si confondessero da sé stessi ${ }^{566}$ : che diremo che, avendo Cristo nostro signore sparso il suo sangue per spegnere totalmente la memoria loro, pare che molti tra' cristiani, in vece di dipingere quel Cristo, il quale con la croce santa ha abbattuto i Giovi e le Giunoni, attendano a rinovare le memorie di quelli con lo scalpello e pennello? Onde ben disse san Crisostomo ${ }^{567}$ di quegli che portavano una imagine d'oro di Alessandro Magno nel capello: Dic mihi, haene sunt expectationes nostrae, ut, post crucem et mortem dominicam, in gentilis regis imagine spem ponas?

Certo si può credere che, mentre un pittore o un scultore esprime un falso dio, si sdegnino gli apostoli, i quali con le proprie vite attesero a distruggere le memorie de tali dèi ${ }^{568}$; si sdegnino tanti santi, che per questo hanno sostenuto il martirio; si sdegni così nobil schiera d'autori greci e latini, che ne' suoi libri hanno mostrato la vanità loro; e finalmente si sdegni Dio stesso, il quale, avendo predetto che con la venuta del figlio si doveano cacciare i sciocchi dèi, pare che sia fatto bugiardo per la temerità di questi artefici, i quali [p. 291] continuamente attendono a rinovare le memorie dei Bacchi e delle Veneri. In India, quando si atterravano gli idoli, dicono le istorie che i diavoli uscivano mormorando di venire in Europa, e si può credere che volessero accennare che, dove in quelle parti tanto lontane si spezzavano gli idoli, eglino sarebbono venuti nell'Europa stessa, ove è il fondamento della fede, et averebbono con le loro arti fatto che, ove in India si rompevano, qui non solo tutti i pittori e tutti gli scoltori attendessero a rifarne, ma che in fino sotto terra si andassero cercando le reliquie degli idoli antichi. E questo è quello che dà campo maggiore agli eretici di nominarci idolatri; ché, se noi avessimo le sole imagini de' santi, non resterebbe forsi luogo al loro inganno, ma sendo fra noi tante statue de' falsi dèi e facendosene tante ogni giorno, non è meraviglia se con questo pretesto ci dimandano tutti idolatri e prendono occasione d'ingannare $\mathrm{i}$ popoli. Quando ci battezziamo facciamo giuramento di rinonziare alle invenzioni del Diavolo; ma quale invenzione è più diabolica di quella de' falsi dèi? Di questo ride il Diavolo e, vedendo alcuna volta anco nei tempii appese l'arme e le invenzioni sue, ne gode fra sé stesso e ne trionfa. E pure la santa Chiesa, per levare infino i nomi stessi dalla bocca de' cristiani, mutò le denominazioni dei giorni, et ove si diceva 'di Luna', 'di Marte', 'di Mercurio' cominciò a nominare 'feria II, III e IIII', sì come, oltre quello che si legge nella vita di S. Silvestro ${ }^{569}$, ne fa menzione sant'Agostino ${ }^{570}$,

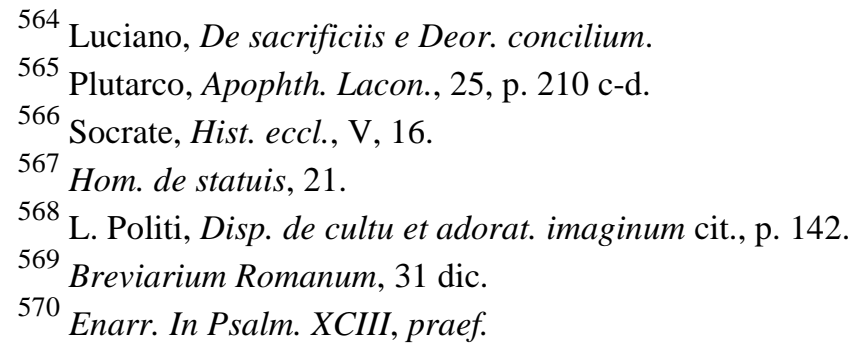


dicendo: Dies Lunae, dies Martis et dies Mercurii dicitur a paganis et a multis christianis, sed nolumus ut dicant, atque utinam corrigantur ut non dicant; melius enim de ore christiano ritus loquendi ecclesiasticus procedit; e un altro santo, accomodando quel verso di Virgilio Sic pater ipse Deus faveat, sic altus Apollo, disse: Sic pater ipse Deus faveat, sic magnus Iesus, riputandosi cosa indegna di nominare Apollo; e S. Agostino si ritrattò che avesse nominata la Fortuna e le [p. 292] Muse, scrivendo ${ }^{571}$ : Displicet mihi saepe interpositum Fortunae vocabulum et quod Musas quasi aliquas deas quamvis iocando commemoraverim; $e \mathrm{~S}$. Gregorio ${ }^{572}$ riprese gravemente un vescovo, che si tratenesse con i libri che parlano di Giove, dicendo, quod in uno se ore cum Iovis laudibus Christi laudes non capiunt; e più distesamente Clemente Alessandrino ${ }^{573}$, padre gravissimo e vicino al tempo degli apostoli, dannando simili abusi tra l'altre cose dice: Deorum itaque nuptias et liberorum procreationes, et puerperia et adulteria quae canuntur, et convivia quae a comicis recitantur, et risus qui in potu inducuntur, incitant me ut vociferer etiam si velim tacere. $O$ impietatem, scaenam caelum fecistis et Deus vobis factus est actus! et quod sanctum est, daemoniorum personis in comoedia ludificati estis, verum Dei cultum ac religionem daemonum superstitione libidinose inquinantes.

Ma non curano tali cose molti pittori, anzi non pare loro che cosa alcuna sia per riuscire leggiadra, ove non sia Venere o Giove; anzi vi aggiungono et i sacrificii et i sacerdoti, con altre loro impietà. E se dirai che queste imagini si tengono solo per passatempo, sapendo benissimo ognuno quod idolum nihil est in mundo ${ }^{574}$, diciamo che il pigliarsi dilettazione di una imagine non solamente vana, ma falsa e che per sì longhi secoli ha ingannati tanti nel mondo, non pare cosa degna della pietà e prudenzia cristiana, scrivendo Clemente Alessandrino ${ }^{575}$ : Non sunt idolorum imprimendae facies, quibus vel solum attendere prohibitum est, sicut nec ensis vel arcus iis, qui pacem persequuntur, nec pocula iis, qui sunt moderati ac temperantes.

Se dirai che sono prezzate queste imagini non per quello che rappresentano, ma per lo artificio e maniera ingegnosa con che sono state fatte, overo per servizio de' letterati, o per cognizione dell'antichità, o per altri onesti rispetti che possono ritrovarsi, sì come si leggono i libri de' gentili e le [p. 293] favole de' poeti, che sono piene delle cose di questi dèi, non essendo alcuno sì sciocco nel popolo cristiano, che le legga o le riguardi per venerarle, o che per loro causa sia mai incorso in idolatria; noi, per replica di queste et altre simili obiezzioni, rimettiamo per maggiore brevità il lettore a quello che si discorrerà al suo $\operatorname{luogo}{ }^{576}$, concludendo che noi biasimiamo principalmente l'abuso del tenere queste cose in prospettiva e come per ornamento dei luoghi, perché da questo non si può negare che insieme non se gli attribuisca certo onore e dignità, che non gli si deve, anzi, che grandemente offende gli occhi pii de' cristiani. Onde che, se alcuno per causa di studio delle lettere solamente si dilettasse di avere presso di sé queste imagini, doveria almeno secondo la prudenzia cristiana tenerle in luoghi tanto remoti, che si conoscesse che fa gran differenza tra queste e quelle di persone cristiane et onorate. Il che principalmente dovria esser osservato dalle persone ecclesiastiche, massimamente avendosi l'essempio di S. Gregorio papa, come si trova scritto ${ }^{577}$, e di molti altri santi, che tutte queste imagini de' falsi dèi come monstri si levarono d'attorno. Onde,

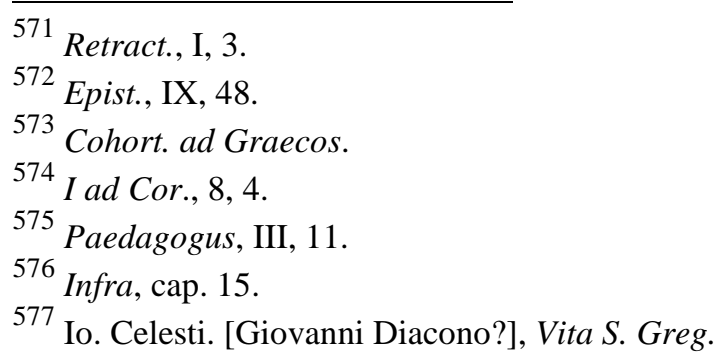


quando bene si trovassero altri che le avessero usate, nientedimeno pare a noi che molto difficilmente si possa un cristiano scusare, ch'avendo inanzi agli occhi gli essempii di persone chiaramente sante, c'hanno biasimate et abborrite tali imagini, et altri di persone non canonizzate e forsi reprovate, che le hanno abbracciate, voglia egli postporre quelle a queste e, lasciando il sentiero sicuro, attenersi all'incerto e pericoloso, contra quello che conviene al giudicio, alla prudenza et al buon governo che deve avere ciascuno dell'anima sua.

[p. 294]

\section{CAP. XI.}

Delle pitture de' santi e sante, o di altre cose di religione.

Il presente capitolo servirà più tosto per accennare alcuni abusi principali che sogliono diformare le imagini religiose, che per abbracciare quanto serìa bisogno in questa parte; imperò che, essendo gli errori o difetti, che nelle sacre figure spesso si scorgono, quasi infiniti, chi potrà già mai materia sì larga restringere in uno o due fogli, et acque sì copiose rinchiudere in così picciol vaso? Sopra di che, acciò che niuno pensi che si parli iperbolicamente, pregamo caramente il lettore che cominci tra sé stesso a discorrere quanta differenza si trovi in queste imagini sacre, non solo quanto alla forma et effigie loro, ma ancor quanto all' apparato che se gli ricerca attorno; onde verrà facilmente in cognizione che tal materia non si può risolvere con regole generali, ma è necessario il dilatarsi assai e penetrare al profondo delle piaghe, per espurgarle pienamente e ridurle alla intiera sanità.

E per venire più al particolare, si consideri quanta diversità si trovi in ciascun ordine de' beati nella celeste corte, per rappresentarli: come saria tra la pittura di un angelo e quella di un patriarca; tra l'imagine di un martire e di un confessore; tra quella di un vescovo e di una verginella. Di più, nell'istesso ordine vedasi quanta dissimilitudine spesso si scorga tra persona e persona: come, nella schiera degli apostoli, tra S. Pietro e S. Bartolomeo; in quella de' martiri, tra S. Stefano e S. Vincenzo; in quella de' vescovi, tra S. Atanasio e S. Martino; in quella degli abbati, tra S. Antonio e S. Bononio. Poi, quanto agli accidenti congionti con le persone loro, quanta varietà possa concorrere nei movimenti et atti del corpo; quanta nelle azzioni che si esprimono, o sole, o che hanno corrispondenza con altre; ma maggiormente quanta [p. 295] differenza occorra negli accidenti separati, come nei vestimenti, insegne, ornamenti, abitazioni, luoghi et altre simili particolarità. Quanta diversità, di più, si trovi nell'altre cose ancora che pertengono ad atti di religione, come nel rappresentare croci, reliquiarii, lampadi, tabernacoli, turiboli, mitre, altari, monasterii, chiese et altre cose, le quali quanto più sono numerose, tanto più sono atte a moltiplicare le sorti degli abusi che possono intervenirvi, causandosi l'abuso tuttavolta che si altera il vero modo di esprimere la sostanza o alcuna sua circonstanza, secondo il detto di S. Dionisio ${ }^{578}$ communemente accettato da' teologi ${ }^{579}$, quod bonum consistit ex integra causa, malum autem ex singularibus defectibus.

Dunque, non si potendo sodisfare a tanta varietà de mali se non con diversità de remedii, penseremo noi di potere più facilmente provedere a' bisogni con l'accomodare i ragionamenti nostri alla opportunità delle materie che occorreranno, trattando prima in universale nel presente libro quelle sorti di abusi, che di sua natura possono cadere non solo in ogni imagine sacra, ma ancor profana. Poi perché, quanto alle sacre, uno de' principali disordini e più frequenti, che in esse si

\footnotetext{
578 De div. nominibus, 4.

${ }^{579}$ S. Tommaso, Sum. theol., I-II, q 19, a. 6, ad 1.
} 
scuoprono, si è la poca onestà e molta lascivia, che molte di loro non hanno quasi cosa di santo né in quelle si osserva, figurandole in maniera che spirano punto di divozione, anzi si veggono fatte con modi e faccie et ornamenti totalmente alieni dal rigore della vita e mortificazione che hanno sempre osservato quei santi che sono figurati; però a questo errore molto notabile, e che si diffonde in ogni parte, si è pensato di assignare un libro intiero, che serà il seguente, per eradicare, se Dio ne concederà grazia, costume così irreligioso dalle religiose pitture. Oltre di ciò, mostrando la esperienza che, quanto si viene più agli individui, tanto più si fa frutto, però nel IIII libro si ricchiuderanno poi tutte quelle cose che a particolari santi seranno giudicate essere necessarie; et ultima [p. 296] mente non tralascieremo, nel V libro et altrove ancora, di inserire varii altri antidoti per remedio di altri abusi, secondo che i luoghi e le cose ricchiederanno. Il che quantunque di sopra da noi negli avvertimenti al lettore sia stato significato, nientedimeno, perché ciò fu per altro rispetto, ci è parso al presente che l'occasione della materia che abbiamo per le mani ragionevolmente ricercasse questo brieve conto che ora si è dato. Il che servirà ancora per maggiore chiarezza di tutta la intenzione nostra nel restante del presente trattato.

\section{CAP. XII.}

Abusi delle pitture profane, e se elle cristianamente debbono essere admesse.

Sono molti che giudicano alla vera professione di cristiano non convenirsi altra cognizione o cura che di cose religiose e sante, e conseguentemente nelle pitture non vogliono admetterne alcuna che non sia di quella classe, escludendo in questo modo non solo tutte le cose de' gentili, ma ancora tutte l'altre che oggi chiamiamo profane e secolari. Però, avanti che passiamo più oltre, abbiamo pensato che sia necessario l'essaminare più consideratamente questo passo, acciò nissuno resti ingannato. Il che per far meglio, presupponiamo, come principio notissimo, che la infinita providenza di Dio signor nostro non solo volse creare tutte le cose di questo mondo buone, ma ancora diede i mezzi agli uomini per apprenderle e conseguirle parimente buoni, purché da essi fossero bene essercitati; ma molti, deviando spesso dal diritto sentiero, incorrono per loro cagione in lacci e danni gravissimi, come scrisse Salomone: Creaturae Dei factae sunt in tentationem et in muscipulam pedibus insipientium $^{580}$. Laonde il pericolo che [p. 297] noi corriamo mentre siamo in questo mondo non nasce dalle cose, ma dall'uso o abuso nostro; imperoché, essendo elle state disposte tutte con mirabile ordine tra sé, acciò l'una servisse all'altra e le più ignobili alle più degne, doveva la industria umana, fatta da Dio capace dei misterii suoi, essercitarsi principalmente in questo, di conoscere la dignità loro, quali servano per mezzo alle altre, et il fine a che tutte sono dirizzate. Ma spesse volte, tralasciandosi questo dagli uomini, anzi pervertendosi questo bello ordine e pigliandosi per fine quello che è stato dato per mezzo, nasce gran parte della confusione in tutte le cose del mondo, e nelle scienze e nelle arti e nelle virtù e nell'altre operazioni; di che bello essempio ci lasciò scritto $\mathrm{S}$. Agostino ${ }^{581}$ di una nave, che essendo stata trovata per condurre gli uomini da un luogo a un altro, se avvenisse che alcuno pellegrino, entrato in nave, si invaghisse tanto di quella commodità, che non si curasse più di uscire di nave né di giungere alla patria destinata, certo che questo saria come prendere il mezzo per fine e farsi conoscere di giudicio molto storto e debole. Così avviene nelle altre cose ancora, che essendo tutte sottoordinate l'una a l'altra, se alcuno, non sapendo o non volendo servare $\mathrm{i}$ loro gradi, se ne serve a suo capriccio, viene a

\footnotetext{
580 Sap., 14, 11.

${ }^{581}$ De doctr. Christ., I, 4.
} 
sconcertare le ruote e i contrapesi di questo orologio, che perciò non caminerà né batterà più l'ore a misura.

E se alcuno desiderasse sapere con qual distinzione siano state create le cose del mondo et in che maniera noi debbiamo servircene per non errare, abbiamo la dottrina di S. Agostino, seguitata communemente da tutti i teologi ${ }^{582}$, che con due parole abbracciò il tutto, che sono frui et uti, dicendo che altre sono le cose che abbiamo da fruire, altre che abbiamo da usare. In quelle che abbiamo da fruire sta posto il fine, perché si cercano per sé stesse e non per altro: e [p. 298] questo è Dio benedetto, Padre, Figliuolo e Spirito Santo; le altre tutte di questo mondo sono date per usarle et acciò ci servano come mezzo per condurci al fine che si ha da fruire: onde dice: Utendum est hoc mundo, non fruendum, ut invisibilia Dei per ea quae facta sunt intellecta conspiciantur; hoc est ut de corporalibus temporalibusque rebus aeterna et spiritualia capiamus. Res igitur quibus fruendum est, Pater et Filius et Spiritus sanctus est ${ }^{583}$.

Laonde per regola generale si può affermare che tutte le cose, di qualonque sorte, che non contradicono a questo fine del regno del cielo, tutte possono essere, secondo il modo suo, materia o istrumento, perché ce ne serviamo utilmente. Da che segue che quelle sole affermaremo contradire, che ripugnano alla legge d'Iddio et alla debita ragione, come sono tutte quelle che sono infettate da vizio, che, per essere contrarie alla virtù, ci sviano dal sommo bene; e quelle ancora che, se bene non ripugnano al fine direttamente, non però sono atte per farci strada di giungere là, né fanno per la impresa che abbiamo alle mani, che è di ascendere in cielo, sì come in altri luoghi abbiamo trattato.

Presupposto tutto questo, ne segue che, potendo tutte le scienze, le arti et operazioni umane servire in qualche modo alla vera sapienza, quando non siano con vizii, superstizioni o altri errori accompagnate, non veggiamo perché da un cristiano debbano essere ricusate secondo la convenienza loro; riconoscendole però per ancelle e mezzane alle cose maggiori e come sottoordinate alle spirituali e sacre, le quali, per essere più prossime al fine che si pretende, conseguentemente sono più nobili delle altre e più eccellenti. Altrimenti saria come, dice san Paolo $^{584}$, se il capo dicesse ai piedi di non volergli in sua compagnia, perché sono inferiori a lui. Non potest, dice egli, oculus dicere manui: Opera tua non indigeo; aut iterum caput pedibus: Non estis mihi necessarii; ma il piede [p. 299] ha da fare l'ufficio del piede, e la mano della mano, e l'occhio dell'occhio, tutti però a servizio del corpo.

E di qui si risponde alle ragioni fallaci, che anticamente mossero i nemici della religione nostra a proibire a' cristiani lo studio delle arti liberali; che torna a proposito nostro per la convenienza c'hanno i libri con le pitture. Imperoché si legge in varii luoghi ${ }^{585}$ nelle istorie ecclesiastiche di Giuliano imperatore, detto Apostata, che con publico editto interdisse ai cristiani, che non dessero opera a simili studii, acciò restassero più imperiti et inabili a sciogliere i sofismi de' gentili et a convincere le fallacie loro. Il che parimente dagli eretici de' nostri tempi è stato suscitato, cercando essi con questo mezzo di distruggere l'academie publiche e d'estinguere la cognizione di tutte le scienze che ci fanno scala alle cose divine ${ }^{586}$. Il quale errore, oltre alle ragioni sopradette, si convince chiaramente con quello che è scritto di Salomone nella Sapienza ${ }^{587}$ con queste parole:

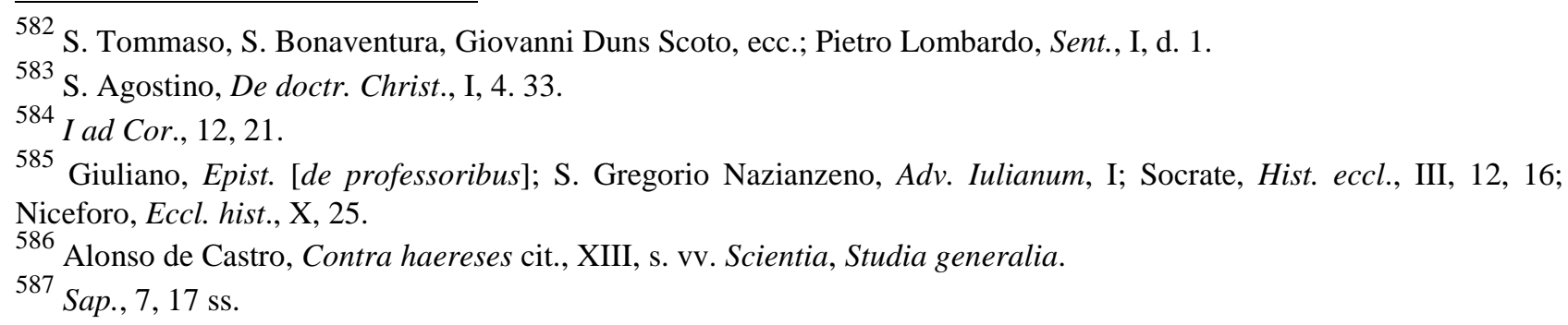


Dedit illi Deus horum, quae sunt, scientiam veram, ut sciret dispositionem orbis terrarum et virtutes elementorum, divisiones temporum, stellarum dispositiones, naturas animalium, vim ventorum, djfferentias virgultorum; perché, se Iddio è quello che insegna le cose utili, come dice Isaia ${ }^{588}$ : Ego dominus Deus tuus docens te utilia, non si può negare che la cognizione di queste cose, come data da Dio, non debba riuscire giovevole.

Ma si vede, di più, che la sacra Scrittura in molti luoghi fa menzione del sole, delle stelle, dei venti, d'animali, d'arbori, de' pesci, di margarite, de' medici, de' soldati, de' mercanti, d'agricoltori e simili altre cose; onde saria molto sconvenevole che non potesse un cristiano imparare la scienzia di queste cose tanto nominate e frequentate in tutti i libri [p. 300] sacri, massime vedendosi gli antichi santi Padri, greci e latini, non solo essere stati eruditissimi in tutte queste discipline, ma ancora avere particolarmente trattato e difeso con vive ragioni questo articolo di che parliamo, mostrando di quanto giovamento siano ad un cristiano queste facoltà: sì come si legge presso Clemente Alessandrino, S. Basilio, S. Gregorio Nazianzeno, S. Ieronimo et altri ${ }^{589}$. Onde scrivono gli autori della istoria ecclesiastica ${ }^{590}$, che anticamente molti sono stati per questo commendatissimi, perciò che hanno saputo valersi a proposito delle cose de' gentili in servizio della legge cristiana, come è scritto di Origene ${ }^{591}$, qui graecorum divitias omnes ad christianum dogma locupletandum convertit; il che da S. Agostino ${ }^{52}$ fu mirabilmente confirmato, dicendo che uno ecclesiastico deve essere ad ogni modo di queste scienzie ornato, et quod a philosophis et gentilibus tanquam iniustis possessoribus in usum nostrum sunt vindicanda, quae ipsi de quibusdam quasi metallis divinae providentiae, quae ubique infusa est, eruerunt et perverse ad obsequia daemonum abusi sunt: ad essempio del popolo israelitico ${ }^{53}$, che, spogliando gli Egizii dell'oro e dell'argento e vasi preziosi, lasciò loro gl'idoli e falsi dèi, portandosene le cose migliori alla terra di promissione, per convertirle in uso buono et offerirle al vero Iddio nostro, sì come scrive $\mathrm{S}$. Ieronimo ${ }^{594}$ di quella donna straniera che, rasosi i crini e ributtate le cose superflue, passava al popolo di Dio ${ }^{595}$, figurando che dagli autori, se bene gentili, si potevano sciegliere cose buone al culto divino e risecare l'altre disutili e dannevoli. [p. 301]

Da queste cose adunque dette dei libri dei gentili noi per medesime ragioni argomentiamo che le pitture profane, potendo apportare a noi varii giovamenti, non devono essere subito ributtate, ma misurate bene con sano giudicio, acciocché a guisa de api che da varii fiori colgono il mele, sappiamo valerci di queste pitture ad uso di pietà, essendo che la grazia non distrugge, ma fa perfetta la natura, e la natura non aborrisce la grazia, ma la riceve ${ }^{596}$.

Non intendiamo però d'inalzare tanto questa parte, che si abbia da incorrere in uno altro estremo abbracciato oggi, come si vede, da molti, i quali, totalmente dati alle scienze, arti e trafichi mondani, non si servono d'altri libri o pitture et ornamenti, che non siano di cose de' gentili; et

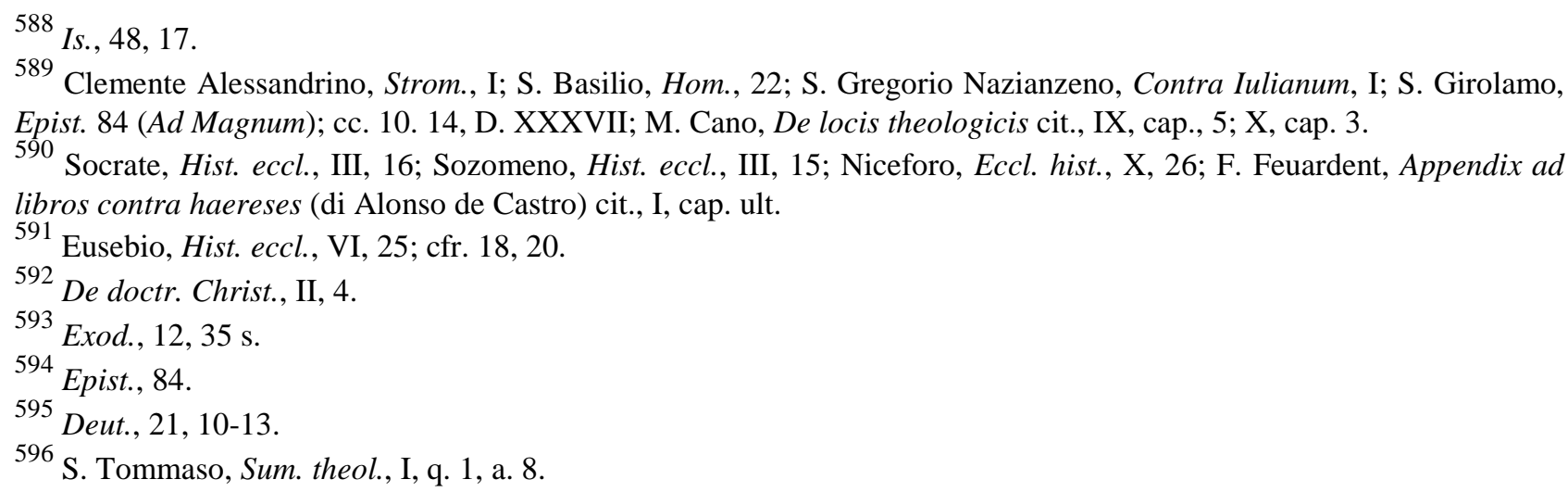


avendo ripieni i loro studii di moltitudine di libri secolari et adornate le sale e loggie di varie pitture terrene, non vi se ne scorge né tra i libri alcuno sacro, né tra gli ornamenti alcuno che abbia del pio e religioso; cosa che fa spesso stupire gli uomini di maturo giudicio e cristiana prudenza, vedendo le schiere di persone di dottrina, d'autorità e di riputazione nel popolo tutte involte, nei desiderii e nei ragionamenti e nelle azzioni, in queste cose profane, senza partecipazione alcuna che si vegga, o segno che apparisca in essi di lume cristiano. E nientedimeno è pur certo, sì come di sopra si è detto, che tutte queste cose hanno da servire per mezzi et istrumenti di arrivare più oltre; e chi si ferma in esse resta a mezzo il corso senza toccar mai la meta, onde viene escluso dalla vittoria.

Per la qual cosa ricercando questa materia gran circospezzione e molto temperamento, conforme allo stato e professione nella quale ciascuno si trova, però si averanno da Considerare varii avvertimenti, affinché noi non restiamo ingannati e gli altri male edificati, dicendo quel savio ${ }^{597}$ : Prophanae imagines etsi interdum moveant, atque erigant ad vir [p. 302] tutem, amandae tamen aut colendae aequo amplius non sunt, ne aut stultitiae testes, aut avaritiae ministrae, aut fidei sint rebelles. Per il che soggiungeremo ora alcune cose più principali, degne di essere avvertite da chi desidera servirsene cristianamente et usarle con frutto.

\section{CAP. XIII.}

Che nelle chiese non si convengono pitture profane.

Primieramente diciamo che nelle chiese, dove ogni cosa deve essere sacra e misteriosa, non si doveria ammettere alcuna imagine di cose profane, dicendo il Concilio Tridentino ${ }^{598}$ : Tanta $a b$ episcopis cura adhibeatur, ut nihil prophanum, nihilque inhonestum appareat, cum domum Dei deceat sanctitudo. Al che serve l'essempio di Nilo vescovo, narrato da noi altrove, che non volse che nei muri del tempio vi fossero dipinte né cacciagioni, né uccelli, né altre cose simili, irnperoché questo uso di dipingere nei tempii indifferentemente le cose è stato di persone lontanissime dalla vera religione e buoni costumi, come racconta Virgilio ${ }^{599}$ di Didone, che avea fatta dipingere nel tempio tutta la guerra troiana. Anzi, dai medesimi gentili che hanno avuto più cognizione si può prendere per altra strada argomento, quanto a noi cristiani ripugni il mettere nelle chiese simili cose del secolo, poiché essi, come scrive Vitruvio ${ }^{600}$, altro dissegno usavano in fare tempii ad Ercole, altri a Giunone et altri a Giove, volendo che alla deità che essi fingevano di ciascuno fosse proporzionato ancora l'ordine e l'architettura. Onde tanto maggiormente conviene a noi cristiani di servare l'intero decoro col nostro vero et infallibile Dio; e tanto più che non manca copia di [p. 303] cose ecclesiastiche, per supplire e variare ogni sorte d'ornato se vorrà il pittore investigare bene e consigliarsi ancora con persone versate nella Scrittura et istorie sacre. Si trova nelle epistole di S. Paolino a Sulpizio Severo ${ }^{601}$ che egli lo biasima perché avea dipinta appresso la imagine di S. Martino in una chiesa la figura di esso Paolino, dicendoli: Nonne tu lactis et fellis poculum miscuisti? Quae societas lumini et tenebris? lupis et agnis? serpentibus et columbis? E li manda insieme alcuni versi, che escusino questa pittura, dicendo:

\footnotetext{
${ }^{597}$ F. Petrarca, De remediis utriusque fortunae, I, cap. 41.

598 Sess. XXV.

599 Aen., I, 456 ss.

${ }^{600}$ De archit., I, 2.

${ }^{601}$ Epist. ad Sever., 12.
} 


\section{Martinum veneranda viri testatur imago. \\ Altera Paulinum forma refert humilem. \\ Hunc, peccatores, illum spectate, beati. \\ Exemplar sanctis ille sit, iste reis.}

E questo uso veggiamo dagli antichi essere stato molto religiosamente osservato, ché non solo nei tempii, ma ancora nei portici fuori di chiesa volsero si dipingessero solo cose ecclesiastiche; sì come di papa Giovanni si scrive ${ }^{602}$ che nella chiesa del Salvatore in Roma dall'una parte fece dipingere l'istoria del Vecchio e dall'altra del Nuovo Testamento, accioché dall'un canto le persone vedessero Adam exeuntem paradiso, e dall'altro latronem ingredientem paradisum. Di Costantino papa pur si legge ${ }^{603}$ che nel portico di S. Pietro in Roma fece fare pitture che contenevano gli atti de' concilii. E di S. Felice Nolano scrive S. Paolino ${ }^{604}$, parlando della chiesa fabricata da S. Felice:

\section{Sanctasque feramur in aulas, Miremurque sacras veterum monumenta figuras Et tribus in spatiis duo testamenta legamus.}

\section{[p. 304]}

Anzi, questo buon instituto, che nelle chiese non siano altre che imagini sacre o cose significanti misterii sacri, doveria talmente osservarsi, che ancora gli ornamenti intorno alle porte delle chiese, alle finestre, agli architravi, alli fregi, alle ancone, alle volte del tetto, al pavimento et ad ogni altro luogo doveriano avere tutti qualche buona convenienza con le cose di chiesa, et essere composti di materie ecclesiastiche, e proporzionati a' tempii sacri, sì come sappiamo che in alcune chiese della cristianità si serva questo uso religioso, che sino i panni di razzo e spaliere per addobbare la chiesa reppresentino la vita del santo titolare o altre cose misteriose. Il che desideraressimo noi grandemente che dai superiori delle chiese in questa città e diocese, che possono farlo, fosse imitato, introducendo simili ornamenti nelle loro chiese; perché è pure stravagante cosa quando, sentendosi ragionare un predicatore del perdonare a' nemici, si considera che egli ha apparato il pergamo con uno panno di razzo, nel quale è tessuta la imagine di Turno che chiede la vita in dono, e quella di Enea che non vuole concederla e l'uccide; overo quando, andandosi in una chiesa per pregare da Dio pace, e che infonda negli animi umiltà e castità, si vedono tutte le pareti di quella addobbate de' razzi di Fiandra, pieni di battaglie antiche, de trionfi romani o di danze e balli molto licenziosi.

Sì che, volendosi osservare la debita ragione delle cose, non si avriano, nelle chiese e negli altri luoghi ancora dove fossero poste figure de santi, da mettere tra loro né accompagnare insieme imagini di quelli che non sono santi, potendo parere questa livrea troppo sproporzionata et indegna, anzi, che potrebbe dare suspizione che non gli si tribuisse la intiera venerazione che si deve a quelle de' santi, sì come anticamente leggiamo che gli eretici chiamati Carpocraziani e Gnostici con l'imagine del Salvatore nostro e di S. Paolo accompagnavano le figure de' filosofi, come di Pitagora, Platone, Aristotele e d'altri, communicando ad essi il culto che [p. 305] a Dio solo si deve $^{605}$. E parimente di Alessandro Severo imperatore si narra ${ }^{606}$ che teneva nel suo larario con le

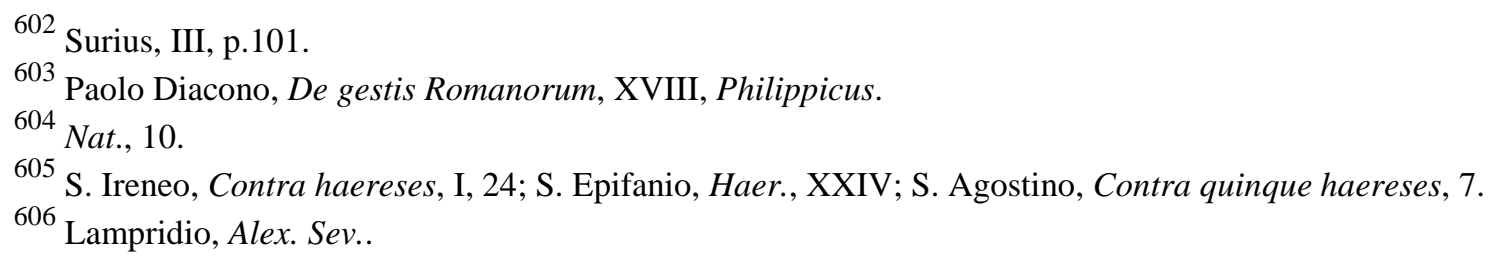


figure di Cristo nostro signore quelle di Abraham et insieme di Orfeo, di Apolonio e d'alcuni imperatori più stimati, i quali onorava come dèi; la quale impietà fu maggiormente abbracciata da Giuliano Apostata ${ }^{607}$, che accompagnava nelle publiche imagini la sua propria con quelle di Giove, di Mercurio e di Marte. Et hoc agebat, dice Paolo Diacono ${ }^{608}$, imaginibus, ut sub occasione imperii latenter adorarentur dii, et hoc modo subiecti clanculo fallerentur.

Concludiamo adunque, che nelle chiese non si hanno da comportare se non cose ecclesiastiche; il che parimente appartiene a tutti gli apparati sacri, come de processioni, de rappresentazioni et altri simili, de' quali il fine è di cose di religione, non escludendosi però quelle cose c'hanno significato e si fanno per misterio, come anticamente nel tempio di Salomone erano le palme, i pomi granati, e fuori i buovi, leoni et altre cose ${ }^{609}$; et in molte chiese antiche della cristianità si vedono dipinte per misterio pecore, agnelli, cervi, il gallo, aquila, colombe, cicogne, pellicano, sole, luna, stelle, e simili cose ${ }^{610}$.

Né anco si escludono quelle a che la necessità dell'istoria sacra ne costringesse per rappresentare meglio tutta l'azzione: sì come né escludiamo parimente quelle persone che fossero figurate in atto di adorazione e di raccomandarsi a Dio genuflessi e con segni di umiliazione, essendo le chiese ordinate principalmente per questo, acciò che ivi s'adori Iddio e se gli chiegga perdono; pur che s'avvertisca in questi [p. 306] che si fanno dipingere genuflessi, che si fugga ogni vanitade e che la intenzione non sia diversa da quell'atto che si figura, sì come di sotto più pienamente si dirà nella materia dei ritratti. Aggiongendo per fine, che sotto queste regole non intendiamo includere gli onori che si fanno a' santissimi pontefici per la suprema et apostolica dignità loro, né meno abbracciamo le cose che per causa di voto e di religione si offeriscono nelle chiese, come al suo luogo si esplicarà ${ }^{611}$.

\section{CAP. XIIII.}

Delle imagini de imperatori gentili, o tiranni o altri persecutori del nome cristiano.

Essendosi concluso che nelle chiese non deve darsi luogo a pitture profane, resta ora di vedere se fuori delle chiese possono ammettersi indifferentemente. E perché questa è materia assai ampia, noi per maggiore chiarezza pensiamo di distinguerla in due membri principali: l'uno sarà di quelle che rappresentano persone, l'altro di quelle che figurano altre cose, come sono città, paesi, animali, piante; overo sono miste di persone e di altre cose insieme.

Quanto alle persone, pigliamo principio dalle imagini degli imperatori gentili o d'altri personaggi che non sono stati cristiani; de' quali volendo noi sapere s'è conveniente il conservare le loro statue o ritratti, poneremo per fondamento generale di tutta questa materia che, sendo le imagini tra $\mathrm{i}$ cristiani principalmente ordinate per giovamento della vita umana, debbiamo sempre star con l'occhio aperto ch'elle corrispondano a questo fine, e che nella casa nostra, sì come non debbono alloggiare se non persone oneste e di buona fama, così non siano vedute se non imagini tali. [p. 307]

Onde, per discendere al quesito proposto, diciamo che, se questi sono stati nemici del nome cristiano e nel numero di quegli che hanno perseguitata la santa religione nostra (sì come

\footnotetext{
${ }^{607}$ S. Gregorio Nazianzeno, Adv. Iulianum, I.

${ }^{608}$ De gestis Romanorum, XI.

${ }^{609}$ III Reg., 6, 29; 7, 18 ss.; P. Valeriane, Hieroglyphica cit., I.

${ }^{610}$ G. Durand, Rationale divinorum officiorum, I, cap. 3.

${ }^{611}$ L. V, cap. [5].
} 
anticamente sono stati molti imperatori romani, et altri saraceni, mori, vandali, goti et oggi turchi e maumetani pieni di rabbia e sdegno contro di Cristo e della sua sacra legge), non veggiamo come un prudente cristiano possa comportare avanti agli occhi suoi l'effigie di quelli, che sono stati soldati stipendiarii di Satana e rabiosissimi contro il vero Dio Signore nostro.

E questo tanto maggiormente affermiamo in quelli che, oltra l'essere stati persecutori della santa legge, hanno accompagnata la vita loro con molti nefandi vizii e sceleragini; in che certo è da essere deplorato grandemente l'abuso, che così gagliardamente corre per li palazzi, per le sale, per le loggie, per le librarie e per gli studii di molti, che con isquisita diligenzia vanno raccogliendo le imagini de' dodeci imperatori, et a gara l'uno dell'altro cercano averli chi in medaglie d'oro o d'argento, chi in pitture magnifiche, e chi in statue superbe, facendone publico spettacolo; né si accorgono che con queste vengono a macchiare e disonorare più tosto il resto che è di buono in quelle abitazioni, poiché questi, oltre l'essere stati odiosissimi al sangue cristiano, i medesimi autori gentili c'hanno scritta la loro vita ci hanno lasciata memoria d'essi vituperosa et infame. Talmente che, se venisse qualcuno dai paesi nuovi, mosso dalla fama della religione cristiana, et entrato in tal luogo vedesse con tanta pompa, tanta sollecitudine e tanta spesa conservarsi il nome di quelli che sono stati colmi d'ogni vizio et ignominia, e conseguentemente tanto abborriti dalla legge nostra, non si vede come potesse fare di non stupirsi del giudizio, discorso et intelletto nostro.

$\mathrm{Ci}$ sovviene quel che narra Plutarco ${ }^{612}$ essere accaduto il consiglio de' Lacedemonii, che, trattandosi un maneggio [p. 308] di cosa molto importante e stando tuttavia sospesi gli animi loro nella deliberazione, per non trovare strada che giudicassero bene sicura, al fine gli fu riferito il parere d'uno, che non si potea negare che non fosse più a proposito di quanti altri s'erano fino allora sentiti; ma perché l'autore di esso era persona di mala fama e pravi costumi, non volsero accettarlo, dicendo che da un cattivo vase non poteva uscire buon vino; e di poi, essendo detta la medema sentenzia da un altro di buon nome, subito l'approvarono, tanto stimavano doversi considerare la qualità della vita e professione della persona. Onde tanto più diciamo noi doversi nel proposito nostro avere grandissima avvertenza di non favorire quelli che non meritano, percioché, ricercando la vita cristiana, della quale facciamo professione, che assiduamente ci essercitiamo in atti virtuosi per giongere al cielo, nel quale non capisce se non somma perfezzione, non è dubbio che tutte le cose che possono deviarci da questo camino e mirare ad altro segno debbono essere da noi sùbito fuggite; nel qual numero sono in vero queste imagini, che, sendo di persone viziose, spirano a un certo modo il lor veleno nei sensi nostri. Ma perché nascono varie dubitazioni in contrario, le quali, se non siano bene sradicate, potriano tenere sospeso assai il giudicio de molti; però abbiamo pensato essere ispediente di essaminarle separatamente ad una ad una, perché serviranno insieme a sciogliere le difficultà che possono occorrere in molti altri capitoli.

\section{CAP. XV.}

Risposte a varie obiezzioni intorno al tenere le imagini degli imperadori gentili e d'altri simili.

Quegli che vogliono difendere simili sorti de imagini profane, siano pitture o statue o medaglie o altre, sogliono coprirsi con vari scudi, e principalmente dire che queste sono [p. 309] cose indifferenti e che il tutto in esse dipende dalla intenzione dal fine che l'uomo vi ha: potendosene una persona da bene e perita valere a molte cose utili alla vita secondo $i$ varii disegni suoi.

A questo si risponde che una statua o imagine, per sé stessa considerata, non è cosa puramente

612 Praec. ger. republ., p. 801 c. 
indifferente, ma dimostra insieme certo onore che s'attribuisce alla persona rappresentata mediante quella imagine ${ }^{613}$; imperoché una delle principali cause perché già si ordinarono le imagini fu, come altre volte dicemmo, per onorare con tal segno quelli che si figuravano, sì come a prencipi e signori si suol fare, non si leggendo mai che sia stata eretta statua ad alcuno infame e vizioso, se non da persone parimente scelerate e protettori delle iniquità. Laonde, essendo la propria natura della imagine di rappresentare la persona con onore, se alcun talora vuole farlo per ignominia e dispregio, suole accompagnarla con altri atti o indicii che lo dimostrino: e così si dipingono i traditori appiccati per un piede, i rei castigati col laccio o col ferro dalla giustizia, i demonii e dannati nelle fiamme dello inferno. Da che inferiamo che, se si vederà una statua di Sardanapalo o di Faraone o di Maometo o d'altro simile posta in una sala o in un altro luogo riguardevole, come si suol fare, senza altra compagnia di castigo, ma più tosto con oro et ornamenti di prezio attorno, si potrà giudicare che questa statua renda onore a questi tali, contra ogni debito e convenevolezza.

E se alcuno replicasse che questa ragione serve ad uno concetto universale che si può avere delle imagini, che siano fatte per onore; nientedimeno, se uno saprà che quella imagine è di Nabuchodonosore, di Erode o di Nerone, e parimente saprà che essi sono stati scelerati, non le terrà per onorarle, sapendo che sono degne di biasimo, ma per altri fini particolari e buoni che si possono avere, onde non gli deve essere vietato il tenerle come a chi piacciono, poi che [p. 310] non si inganna punto in esse: a questo si risponde che tali imagini non servono solo ai padroni di esse, ma ancora a ciascuno che le mira; e perché la casa ha alcuni luoghi come publici et altri privati, potrassi più facilmente concedere ad una persona letterata e di giudicio di poterle tenere ad uso buono in luoghi privati per sua commodità, che nei luoghi publici, come nelle loggie, sale e cortili delle case, dove capitano altre persone, le quali non avendo il concetto che ha il padrone, ma giudicando essi secondo l'ordinaria condizione delle imagini, che siano fatte per onorare, possono insieme restare offesi che l'onore e dignità sia attribuita a persone indegne et infami.

Altri dicono che quello che si può scrivere deve ancora potersi dipingere; ond'essendo non solo nominate, ma scritte ancora le vite degli idolatri e degli imperatori infedeli, e le loro azzioni fino nelle istorie sacre per bocca dello Spirito Santo, come si legge degli esserciti degli Assirii, de' Babilonii, e di Salmanasaro e di Senacheribbe e di tali altri nemici di Dio, pare che similmente si possano mettere in pittura le loro persone et i loro fatti, come ancora si scrive di Pilato, di Caifa e di Giuda.

Si risponde che gli scritti o libri che fanno menzione di quelle persone narrano insieme i loro fatti viziosi e li fanno conoscere, a chi legge, per quelli che in effetto erano, e causano nel lettore stomaco e biasimo di tali persone nemiche di ogni virtù; ma la imagine fa in ciò contrario effetto, perché, non rappresentando se non nudamente quella persona, induce con tale ritratto almeno gli imperiti, che sono la maggiore parte, a credere che quello sia stata persona virtuosa, o almeno dimostra che il padrone lo ha per tale; poiché non solo non lo accompagna con alcun atto che denoti l'impietà sua, ma più tosto lo presenta in capo di una loggia, in luogo eminente, posto in uno trono regale et in seggio di maestà, sì come ordinariamente veggiamo figurarsi questi imperatori.

Altri dicono che servono queste imagini agli studiosi dell'antichità et a' letterati per intendere meglio la istoria de' [p. 311] tempi e varii sensi d'autori greci e latini, e per cognizione di molte altre cose oneste, vedendosi per isperienza che, medianti i sassi, i bronzi, le medaglie, archi, statue e simili altre memorie si è venuto in gran luce di molte cose dell'antichità intorno agli abiti, vestimenti, sacrificii, trionfi, spettacoli, magistrati e cose simili.

A ciò si risponde, seguendo quello che si è già detto, che questi rispetti, quando pure siano così,

${ }^{613}$ Dig., XLVII, 10, 13, 2. 
servono a pochi e possono scandaleggiare molti; onde, per servire agli uni et agli altri, si averiano da conservare queste imagini nelle camere private e luoghi appartati, sì come certe sorti d'armi che, per essere pericolose, non si lasciano maneggiare ad ogni uomo, ma servono solo a chi è ben perito et essercitato in esse. Così noi biasimiamo principalmente lo abuso di tenere queste cose in prospettiva e come per ornamento dei luoghi, dal che ne viene in conseguenza una demostrazione de dignità, che pare se le attribuisca.

Altri dicono che queste servono per la nobiltà dello artificio, per la eccellenza del disegno e maniera meravigliosa con che sono state espresse, di dove si cava grande utilità dai professori dell'arte. Si risponde che questo non basta per difenderle, sì come non si ammette un libro di soggetto cattivo, quantunque sia graziosamente miniato o scritto con ben formati caratteri, et ornato ancora con eleganza di parole, né le leggi tolerano le false monete, ancor che ben coniate, né manco le chiavi contraffatte, se bene con sommo artificio fabricate; peroché, quando è cattiva la sostanza, nessuno accidente la può salvare, e chiamasi quella cosa veramente buona, che ha la corrispondenza di bontà in tutte le parti. Oltraché non mancano, Dio grazia, altri soggetti et artificii sicuri per opere esquisite, che possono senza intoppo alcuno vedersi da tutti et imitarsi.

Altri dicono che si veggono essempii di uomini illustri et onorati nella antica età, e forse in quella di oggi, che hanno ripiene le loro case, stanze e ville di simili pitture e scolture; e che troppa censura è il volere sindicare quello che per [p. 312] tanti secoli non è stato biasimato, né anco al presente è tenuto in conto di cosa pregiudiciosa al retto et onesto, anzi più tosto di cosa nobile e giudiciosa.

Noi, per rispondere meglio a questo, che abbraccia luoghi, tempi e persone, diciamo, quanto ai luoghi, che il nostro fine è di parlare con quegli del popolo di questa città e diocese, i quali speriamo, per la bontà loro, non debbano avere a male che gli sia ricordato quello che si giudica più ispediente alla salute loro. Quanto al tempo, già in altro proposito fu detto che le cose debbono misurarsi dalla natura loro, se sono buone o cattive, e non dalla antichità o novità del tempo; e chi volesse pure stare in questo, di anteporre la antichità, potria considerare che noi in questo discorso non trattamo d'introdurre novità alcuna, ma più tosto restituire la vera disciplina e dignità delle imagini al suo possesso antico, di che si trovano spogliate e se ne querelano e ne domandano ragione. Et a questo effetto il sacro Concilio Tridentino ${ }^{614}$ ha dato il carico ai vescovi di conoscere la loro causa e di restituirli quello che le si deve.

Quanto alle persone, non intendiamo di dannare quegli che sinora hanno fatto altramente, mossi forse per alcun buono fine, come si deve credere, se bene a noi occulto, e sono degni almeno di grandissima escusazione; poiché, vedendo essi correre questo commune uso publicamente quasi in tutte le città principali della Italia e della cristianità, essi non hanno pensato errare in quello che universalmente si è avuto per onore e grandezza, sì come veggiamo alla giornata in molte altre cose, che prima communemente parevano lodevoli, o almeno non erano notate per male, et ora il farle apporteria appresso di ognuno non picciol biasimo. Dunque e nel proposito nostro vogliamo sperare che le persone, dopo che il sacro Concilio e le riforme de' santissimi pontifici ci hanno aperti gli occhi, cedendo ormai alle vere ra [p. 313] gioni conosceranno che, senza biasimo de' predecessori nostri, si deve servare molta moderazione in tali imagini di gentilità, acciò non più siano da noi, a guisa de'gentili istessi, magnificate et essaltate.

Ad altri suole parere grave di privarsi di tali imagini, poi che con molta fatica e spesa sua o de' maggiori sono state raccolte; ma noi diciamo che tanto sarà maggiore la virtù, quanto maggiore serà il contrasto, che si averà, di spogliarsene o almeno di porle in luogo sequestrato. Sì come quando

614 Sess. XXV. 
dalle leggi sono vietate alcune sorti d'armi o vestimenti non si reputa gravezza un animo nobile e virtuoso di lasciarle e non usarle, se bene siano dorate e ricamate, anzi se ne rallegra, poi che con questa contesa che fa al senso, fa più risplendere la virtù et induce gli altri con lo essempio suo a non caricarsi di cose inutili.

Non vogliamo già negare che questi, che facessero di nuovo dipingere per le case, alla villa et alla città, in vece di martirio de' santi, qualche trionfo di Caligola, de Eliogabalo o simili, overo ne cavassero copie dalli già fatti, non fossero degni di molto maggior colpa che quei che tenessero le medeme medaglie o statue o pitture di essi, già fatte sino al tempo de' gentili. Ma con tutto ciò in queste ancora giudicamo necessaria la discrezione detta di sopra.

Altri dicono che, per la differenza degli stati, molte cose si concedono al laico che non si concedono all'ecclesiastico, e molto ad un chierico che non ad un monaco, e molte ad un monaco che non ad un eremita; e che questa sia una che si possa proibire allo ecclesiastico, ma troppo rigoroso sarebbe proibirla ad un laico.

A questo si risponde che la differenza tra gli ecclesiastici et i laici consiste nei mezzi e non nel fine; perché il fine, che è di rendersi degni della beatitudine eterna, conviene indifferentemente a tutti, ma dei mezzi di conseguire questa eccellenza altri sono necessarii negli ecclesiastici, altri possono convenire a' secolari, pur che questi istessi non repugnino mai al fine dove si camina, cioè che sempre siano [p. 314] accompagnati dalla ragione e dall'ufficio onesto ${ }^{615}$. Laonde, essendo le imagini di questi gentili di che parliamo più tosto contrarie al debito fine per le ragioni sopradette, non doveranno essere buone ordinariamente né per lo ecclesiastico né per lo secolare. È ben vero che tanto più doverà ciò essere biasimato nello ecclesiastico, come quello che è posto in questo mondo perché sia lume e specchio agli altri di religione, di sapienza e disciplina cristiana.

\section{CAP. XVI.}

Delle imagini de' filosofi, oratori, poeti, capitani o altri gentili, quali debbiano essere admesse.

Passiamo ora ad altre imagini de' gentili molto diverse dalle precedenti; peroché, se bene furono somiglianti agli altri in questo, che mancarono anch'essi del vero lume della salute, è chiara cosa nondimeno che, quanto alla vita civile et uso morale della ragione, se ne trovarono alcuni dagli altri molto differenti, conciosia che non solo non si mostrarono apertamente contaminati da' vizii di sopra espressi, ma più tosto ornati di costumi o di scienzia o di nobiltà d'ingegno: sì come sono stati molti prencipi, senatori, filosofi, oratori, istorici, poeti, capitani et altri, i quali, ancor che fossero gentili, hanno lasciati nondimeno essempii e documenti molto utili al mondo per la vita umana.

Di questi non neghiamo noi che non si possa conservare degna memoria, ad imitazione della saggia antichità, che de tali imagini di persone onorate si valea per uno sprone al bene operare, dicendo in un luogo Salustio ${ }^{616}$ : Audivi ego Quintum Maximum, Publium Scipionem, praeterea civitatis no [p. 315] strae praeclaros viros solitos ita dicere, cum maiorum imagines intuerentur, vehementissime animum sibi ad virtutem accendi, ac memoria rerum gestarum eam famam egregiis viris in pectore crescere.

E di qui si può credere che nascesse lo instituto presso a' Romani di conservare le imagini de' suoi maggiori negli atrii de' palazzi o negli armarii, scrivendo Valerio Massimo ${ }^{617}$ : Prudentissimo

\footnotetext{
615 S. Tommaso, Sum. theol., II-II, q. 184, a. 3.

616 Iug., 4.

${ }^{617} \mathrm{~V}, 8,3$.
} 
viro succurrebat effigies maiorum cum titulis suis, idcirco in prima aedis parte poni solere, ut eorum virtutes posteri non solum legerent, sed etiam imitarentur; e Plinio ${ }^{618}$ scrive: Apud maiores in atriis imagines erant, quae spectarentur; expressi cera vultus singulis disponebantur armariis, ut essent imagines, quae comitarentur gentilitia funera.

Sì che di queste imagini si vede che si servivano gli antichi, per monumenti della virtù et antica nobiltà loro ${ }^{619}$, non solo negli atrii et armarii detti di sopra, ma ancora nei funerali, come narrano Polibio $^{620}$, Cornelio Tacito ${ }^{621}$ et altri ${ }^{622}$; e talora nei giudicii de' magistrati, avanti ai quali si producevano per commoverli maggiormente: di che fa menzione Quintiliano ${ }^{623}$. Et alcuni ancora li scolpivano negli anelli, dicendo Valerio Massimo ${ }^{624}$, e manu Scipionis, ignobilis filii Africani, propinquos anulum detraxisse, in quo caput Africani sculptum erat; de' quali si valevano in luogo di sigillo, come scrive Macrobio ${ }^{625}$ : Veteres non ornatus, sed signandi causa anulum secum circumferebant. E perché siamo entrati in questa materia, non resteremo di dire che, tra le imagini delle famiglie, quelle erano prezzate molto che si chiamavano affumicate, perché, scolorite et adombrate dal fumo per la [p. 316] longhezza del tempo, rendevano con quella oscurità testimonio di longa antichità e discendenza; onde scrisse Cicerone ${ }^{626}$ : Obrepsisti ad honores errore hominum, commendatione fumosarum imaginum, quarum simile habes nihil, praeter colorem; e Seneca ${ }^{627}$ : Non facit nobilem atrium plenum fumosis imaginibus. E queste hanno voluto alcuni ${ }^{628}$ che ancora si chiamassero stemmata, o perché fossero disegnate in foggia d'arbori con li rami delle discendenze, overo per le corone che si soleano donare ai benemeriti e di che si ornavano simili imagini, o per altri rispetti, di che ora non trattiamo.

Vedendosi dunque che dagli antichi erano conservate queste memorie per indicio di nobiltà et eccitamento de' posteri alla virtù de' suoi maggiori, non intendiamo noi ora di dannarle, potendo elle apportare servigio al vivere bene, ma solo vogliamo avvertire questo popolo, che, sì come nelle monete si dà il suo grado a ciascuna, né tutte ascendono ad egual valore, così vorressimo che di queste niuno si invaghisse più di quello che si conviene; poiché questi tali, se bene sono stati uomini famosi di lettere et eccellenti per valore dell'armi o del governo de' popoli, o in altre virtù morali, nientedimeno, se alcuno di essi non sia stato specialmente aiutato dalla grazia divina, essendo essi stati infedeli, sono conseguentemente condennati alle perpetue tenebre. E però il frutto principale che pareria a noi dovesse cavare il cristiano da quelle, serìa il considerare che, se questi, senza particolare aiuto e celeste favore, ma solo con quelle forze naturali et industria che Iddio sparse nella natura umana, hanno potuto così egreggiamente resistere ai contrasti del senso et ai fieri impeti dell'alterezza, della cupidigia e delizie carnali ${ }^{629}$, molto maggior testimonio de' meriti e di

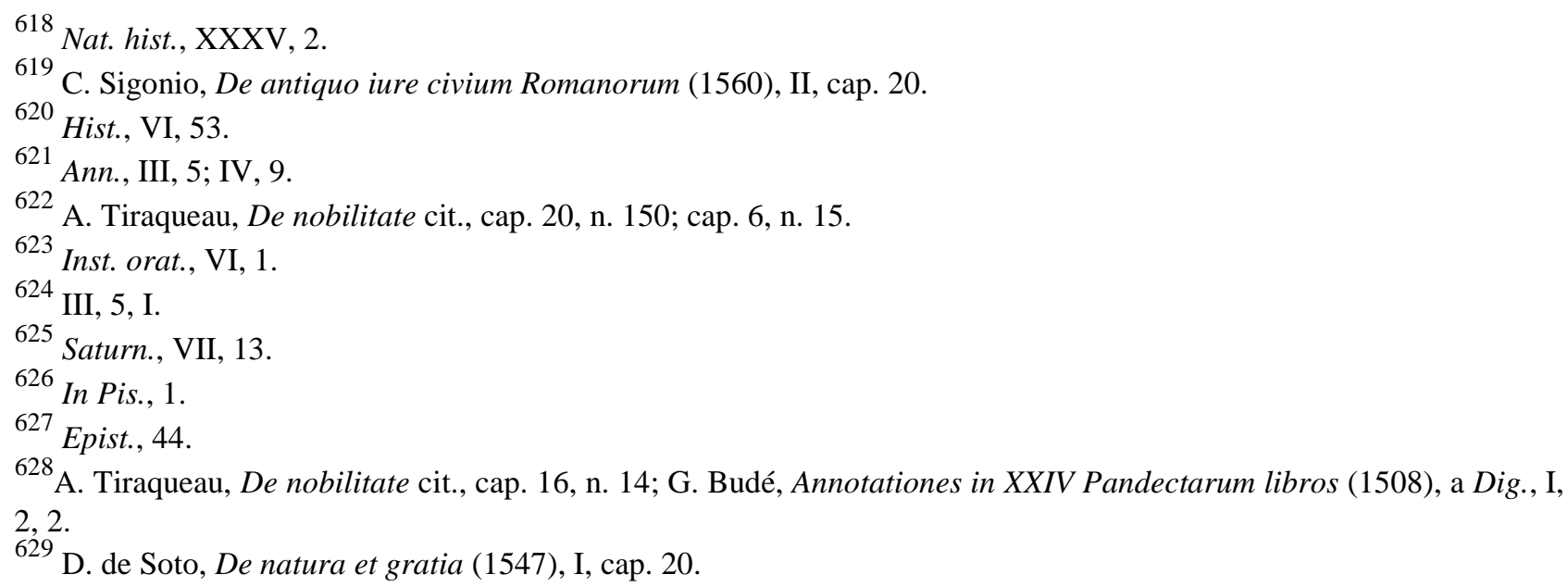


valore si deve aspettare da un petto cristiano armato di fede, [p. 317] cinto di grazia, fortificato de' sacramenti, guidato dagli angeli et erede del cielo. Che scusa dunque potrà egli trovare, contraponendo queste imagini a sé stesso e facendone giudice la sua propria conscienza e dimandandone conto a sé medesimo? Come non doverà egli confondersi con questo paragone, vedendo che si lascia vincere da persone tanto inferiori a sé in ogni parte? Viri Ninivitae, disse il signore Iddio, surgent in iudicio cum generatione ista et condemnabunt eam ${ }^{630}$, volendo avvertirci che nel giorno novissimo si scopriranno persone in faccia nostra, che averanno avuto molto minor occasione di operar bene, e nondimeno non seranno state così dedite a vizii come noi, riprendendo in ciò la debolezza e dapocaggine nostra.

Certo che giudicaressimo noi con questi simili discorsi potere ciascuno, come da' libri bene interpretati, cogliere non picciolo frutto per istruire sé stesso et i figliuoli, $i$ quali in quella tenera etade grandemente sogliono moversi et imprimersi da simili essempi, et eccitarsi al desiderio della vera gloria, quando gli fosse mostrata la strada sicura.

Questo basti per cognizione di quello che si può concedere intorno all'uso di queste imagini de' gentili, quando però nel resto siano senza lascivia alcuna e col suo decoro saggiamente espresse.

\section{CAP. XVII.}

Delle statue che dirizzano i popoli cristiani in onore de' suoi prencipi.

Le cose dette nel capo precedente potranno facilmente persuadere altrui, che tanto maggiormente debbono essere ricevute e commendate le statue de' prencipi fedeli, quanto che, oltre la virtù e valore loro, sono nati e vivuti sotto il glorioso [p. 318] stendardo di Cristo signore nostro. Il quale soggetto se ben non pare necessario all'instituto nostro, nientedimeno, poi che il contesto della materia ce ne dà occasione, soggiongeremo alcune considerazioni, che potriano generare varie difficoltà nella mente de molti, se non siano da noi, secondo quel lume che piacerà a Dio di concederci, dichiarate. Il che per meglio fare, tratteremo prima delle statue quanto al popolo che le dedica, di poi quanto al prencipe a chi elle sono dedicate.

Nel primo caso donque avviene talora che il popolo delibera di erigere una statua al suo prencipe non di propria volontà, ma sollecitato da' suoi magistrati, che la comandano o la procurano palesemente o secretamente. E perché in tal caso il popolo è più presto istrumento che principal causa, non facendo ciò per propria elezzione, ma solo spinto dal prencipe o suoi ministri, i cui prieghi hanno forza di commandamento, però, secondo la regola trita de' iureconsulti, che dicono: Qui per alium facit, per seipsum facere videtur, tocherà questo non la persona del popolo principalmente, ma più tosto quella del prencipe, del quale parleremo nel capo seguente.

Può ancor muoversi il popolo da sé stesso et esserne principale autore e porvi tutta la diligenza e spesa che occorre, e che il prencipe solo lo comporti overo gli acconsenta, non opponendosi ai desiderii de' suoi sudditi; nel qual caso, volendo noi conoscere se il popolo fa cosa lodevole o no, bisogneria sapere il fine a che egli si muove, perché, essendo la statua opera dell'arte e cosa inanimata, se bene fu ritrovata già a fine onorato, l'uso però di essa può esser buono e cattivo, secondo il fine et intenzione di coloro che ne sono autori. E però è riposto il tutto in investigar bene le cause perché si sia mosso il popolo a far questo.

Ora, quantonque noi parliamo solo rispetto a' cristiani e non a' gentili, è nondimeno a proposito nostro l'informarci bene di alcune cose usate dai gentili, da' quali ebbero da prima origine queste

${ }^{630}$ Matth., 12, 41. 
statue. Percioché chi va diligentemente [p. 319] osservando l'antichità, troverà che, quantonque il loro nascimento da radice lodevole procedesse per onorare la virtù, nientedimeno spesse volte dipoi andorono per la malizia degli uomini degenerando, applaudendosi con esse a chi non meritava et adulandosi alla potenza altrui ${ }^{631}$.

Viddero da principio gli uomini quanto beneficio riceveva il mondo da chi bene governava i popoli, difendendoli dalle ingiurie e procurandoli la pace, l'abondanzia e la giustizia; onde essi per molto degne e giuste cause a quelli posero le statue, primamente per onorare nel miglior modo che sapeano i loro signori e rendere testimonio publico della virtù e grandezza loro, dipoi per dimostrare gratitudine dei singolari beneficii ricevuti o che speravano di ricevere da quelli, desiderando mantenerli in tal maniera vivi nella memoria de' posteri, et ancora per eccitare gli altri alle azzioni onorate et a beneficare il mondo con la speranza di ottenere anch'essi onori simili dal publico.

Ma quest'uso fu di poi in molti luoghi pervertito e ridotto a manifestissima adulazione, dirizzandosi le statue a' prencipi di nessuna virtù e valore, anzi colmi di grandissime sceleragini, volendosi i popoli acquistare la grazia loro con questi mezzi, sapendo per esperienza, come disse quel savio ${ }^{632}$ : Quo apertior est adulatio, quo improbior, quo magis frontem suam perfricuit, hoc citius expugnat; onde le introdussero fino nei tempii et altri luoghi, con falso titolo di adorazione e di deificazione chiamata $\alpha \dot{\pi} \mathrm{o} \theta \dot{\varepsilon} \omega \sigma \iota \varsigma$, con esquisite illusioni e superstizioni, sì come scrive Erodiano et altri ${ }^{633}$.

Successe poi il tempo de' cristiani, nel quale non ricusarono i fedeli l'antica usanza di onorare con le statue i suoi prencipi; anzi, tanto maggiormente l'abbracciarono, quanto che da più alta causa si mossero, considerando che i prencipi erano posti in questo mondo da Dio come luogotenenti [p. 320] suoi, per essequire le sue santissime leggi in quello che apparteneva alla giurisdizzione loro, per difendere et accrescere la religione, per introdurre la disciplina, la innocenza e vera carità tra $\mathrm{i}$ popoli, per invigilare di continuo al commodo e salute universale, et imitare in somma, quanto più potevano, la divina providenza, che si dimostra larghissima e beneficentissima verso le sue creature. Laonde fino nei primi tempi di santa Chiesa ebbero instituto i cristiani, educati nella pietà e zelo dello onore divino, di pregare il signor Dio specialmente per la salute e prosperità de' prencipi $^{634}$, ancor che infedeli, facendo ciò tanto più ardentemente per li fedeli, onorandoli, riverendoli et osservandoli come padri, pastori e difensori loro, e dirizzandoli statue come a quelli che aveano ottenuta tal podestà da Dio, e per mostrare segno di gratitudine verso i benefattori loro, che con la vita e le operazioni gli avevano mirabilmente giovato.

Ebbero però avertenza che gli abusi già introdotti dalla gentilità e contrarii alla religione fossero emendati, e principalmente quello della falsa superstizione con che adoravano tali statue. E crescendo poi ogni giorno il zelo de' santi vescovi, cominciarono ancora a proibire che non si collocassero in luogo molto presso alle chiese, perché, solendo intorno ad esse fare il popolo giuochi, spettacoli e concorsi publici, venivano spesso dallo strepito et acclamazione popolare a sturbarsi grandemente gli officii divini che si celebravano nelle chiese. Per la qual causa leggiamo che S. Gioanni Crisostomo non volle tollerare la statua d'argento di Augusta Eudossia, posta sopra una colonna di porfido presso la chiesa di Santa Sofia ${ }^{635}$.

Un'altra prudente osservazione vi aggionsero molti, che fu l'indugiare di erigere le statue dopo la

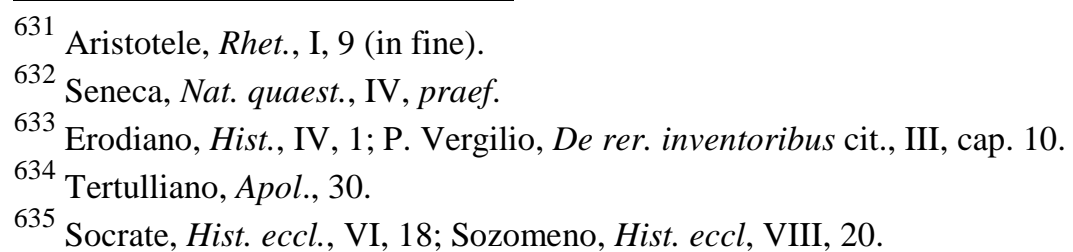


morte di quei che voleano onorare, per fuggire ogni vana sospizione, accompagnandole ancora con alcune note o gesti che dimostravano [p. 321] la preceduta vita loro, sì come degli antichi re di Francia si trova scritto ${ }^{636}$, e parimente ciò è stato osservato da molti gravi autori nel publicare le istorie de' viventi.

Ora, sì come si è detto de' gentili, che abusorono spesso l'instituto delle statue per varii loro disegni, così tra cristiani potria talora il simile essere accaduto. Ma perché questi sono pensieri occulti e conosciuti solo dall'altissimo Dio, a noi non tocca di essaminarli, parlandosi solo al presente delle statue come di operazione esteriore, la quale giustamente può essere difesa nella guisa che nel capo seguente meglio si dichiarerà.

\section{CAP. XVIII.}

Delle statue che i prencipi cristiani erigono a sé stessi.

Il capo presente pare a prima vista contener molta difficoltà, volendosi saper quello che cristianamente si debba giudicare, quando un prencipe pone a sé stesso la statua publicamente. Imperoché chi riguarda quello che talora ne hanno lasciato scritto gli autori, pare che più tosto a questo uso abbiano repugnato, scrivendo S. Crisostomo ${ }^{637}$ in proposito della statua di Nabuchodonosor alcune cose non solo in biasimo dell'idolatria, ma maggiormente contro la vanità che in essa si manifestava, dicendo: Nabuchodonosor statuam quandam erexit, a ligno et mortua corporis imagine magnam scilicet famam aucupaturus, vivus, si Deo placet, a rebus mortuis claritatem mutuaturus. O ingentem insaniam! Nam qui re mortua innixus magis quam seipso et mentis suae viribus, lignum supra se dignatur, qui non sit ille, obsecro, risu maxime dignus? Hunc itaque plurimi etiam imitantur: ut enim tunc de imagine aurea, [p. 322] sic modo alii de curribus, de amplitudine columnarum et picturis parietum opinantur se esse meliores, quia enim quod erant homines perdiderunt, solliciti huc illucque circumeunt, aliunde sibi gloriam colligentes omni sane irrisione dignissimam.

Il che da' savii antichi, se ben gentili, si trova approvato, dicendo Cicerone ${ }^{638}$ : Sed quanquam sapientibus conscientia ipsa factorum egregiorum amplissimum virtutis est praemium, tamen illa divina virtus non statuas plumbo inhaerentes nec triumphos arescentibus laureis, sed stabiliora quaedam et viridiora praemiorum genera desiderat; et in altro luogo ${ }^{639}$ dice ch'Agesilao niente però fu più oscuro, qui neque pictam, neque fictam imaginem suam passus est esse, e stimò più il lasciare la memoria delle operazioni virtuose celebrate da Senofonte, che qualonque sorte di imagine; e parimente è commendato l'atto di Catone, che col ricusare la statua volse più tosto che le persone si avessero a meravigliare perché egli non l'avesse voluta, che, vedendola, avessero a domandare la causa perché l'avesse ottenuta ${ }^{640}$. E quantunque questi essempii più tosto appartenghino a quelle statue che sono poste da altri, nientedimeno, vedendosi che essi non volsero ancor quelle, ci mostrarono chiaramente che tanto maggiormente avriano biasimate queste di che parliamo.

Ma oltre le sopradette cose vi aggionsero ancora varie ragioni per significarci che queste tali

${ }^{636}$ B. de Chasseneux, Catalogus gloriae mundi cit., I, n. 35.

${ }^{637}$ Hom. in Ev. S. Math., 4, a Matth., 8.

${ }^{638}$ De rep., VI, 8.

639 Epist. ad fam., V, 12, 7.

${ }^{640}$ Plutarco, Regum et imp. apophth,. Cato, 10, p. 198 f. 
imagini sono solamente de' lineamenti del corpo e non dell'animo, nella cui bellezza sta la dignità nostra, dicendo Plinio ${ }^{641}$ : Quoniam animorum imagines non sunt, negliguntur etiam corporum; e di più dissero i cristiani che, essendo l'uomo nato alla vera immortalità, e non a questa apparente, riposta nell'opinione degli uomini, non ha d'abbassarsi a cose fragili e caduche, come le statue sono, essendo massimamente la professione cristiana [p. 323] tutta fondata in umiltà, la quale aborrisce ogni segno di propria eccellenza e di umana gloria.

Dall'altro canto, chi rimira gli essempi de' passati e la consuetudine fra' cristiani, troverà che ancor dignissimi e segnalatissimi prencipi non si seranno guardati di publicare in vita loro le proprie statue, con molta lode di essi et universale commendazione, operando in ciò atti di onore e magnanimità, talché, se in questo cadesse di sua natura biasmo, non è da credere che i sommi pontefici, i sacri concilii e la disciplina de' santi padri non vi avesse per tanti secoli già proveduto.

Troviamo alcuni che, per levare queste difficoltà, hanno considerato varii casi, facendo differenza quando il prencipe pone per propria autorità la statua a sé stesso, overo procura che da altri gli sia dirizzata, il che da essi non vien lodato. Altrimente dicono essere, quando solamente tolera e non contradice al desiderio de' suoi sudditi o confederati, che vogliono in questa maniera onorarlo, perché questo non lodano né biasimano assolutamente, giudicando essi che ciò dipenda dalla verità conosciuta dei meriti o demeriti di quel signore. V'aggiongono di poi quando viene accompagnata quella statua da insegne di religione o d'altra virtù eroica, in modo che dimostri che quel prencipe riconosca da Dio le azzioni sue e niente attribuisca a proprii meriti; allora dicono questa potersi admettere, sì come di Constantino si legge che in Constantinopoli alla statua sua vi aggiunse una particola della croce santa, et a quella di Roma l'insegna della croce, volendo fare conoscere che il vero trofeo non a quella statua, come a persona dell'imperatore, ma al grande Iddio, signore dell'universo e conservatore di questi terreni imperii, si avea d'attribuire ${ }^{642}$. Di che scrisse Eusebio ${ }^{643}$ : Post multas victorias in urbem Romam introiens statuam suam in loco Romae celebri collocari noluit, nisi cum hastili ad formam crucis in manu propriae imaginis, et cum inscriptione 'Hoc salutari si [p. 324] gno, vero fortitudinis inditio, civitatem vestram tyrannidis iugo liberavi'.

Ma noi senz'altre distinzioni più tosto crediamo che chi vorrà con sano giudicio discorrere e bene esaminare il tutto non solo non biasimerà tal uso, ma insieme giudicherà che né anco gli autori di sopra addotti con le loro ragioni repugnano a questo, se non in uno o due casi, nei quali tutti sogliono convenire.

È cosa nota che i prencipi cristiani, posti da Dio in quel grado come leggi animate et istrumenti della divina giustizia e sapienza per il governo de' populi, sostengono insieme due persone, una publica e l'altra privata ${ }^{644}$. Alla publica appartengono tutte le cose che toccano la maestà del grado, la administrazione de' popoli e debita esecuzione della giustizia per conservazione della religione, della pace e della disciplina de' costumi, ad utilità commune, essendo ufficio di persona publica, come disse il Caietano $^{645}$, uti potestate publica, scientia publica et voluntate publica; e però per la altezza della dignità e per la preeminenza loro le si convengono cose sopra l'uso commune, come la corona, la purpura, lo scettro, la sala regale, il consesso, la corte regia, l'apparato splendidissimo, et altre cose dette da' Greci $\beta \alpha \sigma \imath \lambda ı \kappa \alpha ̀ ~ \sigma o ́ \mu \beta o \lambda \alpha$, che li fanno riguardevoli sopra gli altri, et insieme

\footnotetext{
${ }^{641}$ Nat. hist., XXXV, 2.

${ }^{642}$ Epifanio scolastico, Historia tripartita, II, 18.

${ }^{643}$ In vitam Constantini, I, 33.

644 A. Tiraqueau, De nobilitate cit., cap. 35, n. 22.

${ }^{645}$ T. De Vio a S. Tommaso, Sum. theol., II-II, q. 67, a. 2.
} 
essere più temuti et onorati: il che serve a migliore e più facile essecuzione della giustizia. Alla privata appartengono tutte l'altre cose che ad essi come uomini possono essere communi, o siano interne, come i pensieri, i desiderii e disegni loro, in quanto sono alieni dall'officio regale, o siano esterne, come sono le azzioni domestiche non dirizzate al governo universale. E di qui è che leggiamo $^{646}$ essere stati molti re e regine, non solo cristiani, ma ancor canonizzati per [p. 325] santi come S. Ludovico re di Francia, S. Radegunde moglie del re Clotario, S. Elisabeth regina di Ungaria et altri, i quali nella vita loro, quanto ricercava quella regia maestà, vestivano in publico di oro, aveano baroni attorno e fameglia onoratissima, palazzi richissimi et altri loro servizii magnifici e sontuosi; nientedimeno, quanto alla persona privata, portavano di sotto il cilicio, dormivano in aspro letto e spesso sopra la nuda terra, mangiavano parcissimamente, e con legummi et acqua celebravano i suoi domestici conviti. De' quali essempi sappiamo non essersi, per Dio grazia, anco nei nostri tempi perduto il seme in persone di gradi eminentissimi, le quali non potressimo ora nominare senza offesa della modestia loro.

Ora in proposito delle statue, parendo a noi che le azzioni degli uomini, e specialmente de' prencipi, il cui cuore è in mano d'Iddio ${ }^{647}$ si debbano interpretare più tosto in buona che in rea parte, giudicaressimo che si potesse dire che, tra l'insegne regie e che convengono alla sola persona del prencipe, una sia la statua, la quale a nissuno si pone in publico se non al solo prencipe, come dalle leggi communi è determinato ${ }^{648}$. Onde leggiamo che anticamente, quando uno era creato imperatore in oriente, si mandava il suo ritratto in occidente, et all'incontro da occidente in oriente, dove era con solennità ricevuto, e parimente nelle provincie dove esso non poteva andare ${ }^{649}$.

Per questo ancor fu ordinato che quelli, che a queste statue rifuggivano per certi delitti, fossero sicuri da ogni pena e violenza ${ }^{650}$; per questo parimente fu constituito che chi le violasse fosse reo di lesa maestà ${ }^{651}$. Di che ne leggiamo l'esempio di Teodosio contro il popolo Antiocheno, il quale [p. 326] essendosi mosso con furore popularesco a gittare a terra la statua di Placilla imperatrice, gli fu minacciato così atroce castigo dall'imperatore giustamente sdegnato, che si mosse quel santo vescovo Flaviano con ogni dimostrazione di affanno e supplicazione per mitigare l'animo alterato di Teodosio ${ }^{652}$; sopra di che medesmamente ne scrisse diverse omilie il facondissimo S. Giovanni Crisostomo $^{653}$, che da questo presero il nome di Andriande, come hanno alcuni voluto. E quello che si dice delle statue che representano la dignità imperiale, si afferma anco nelle imagini che si cugniano et imprimono nelle monete per segno di giurisdizzione, di che abbiamo il testimonio del Salvatore nostro, che, avendo veduto quel denaro con l'imagine di Cesare, disse: Reddite quae sunt Caesaris Caesari ${ }^{654}$; e di Constantino imperatore si legge ${ }^{655}$ : In aureis nummis imaginem ita insculpi curavit, ut, pansis manibus instar precantis, caelum intueri videretur.

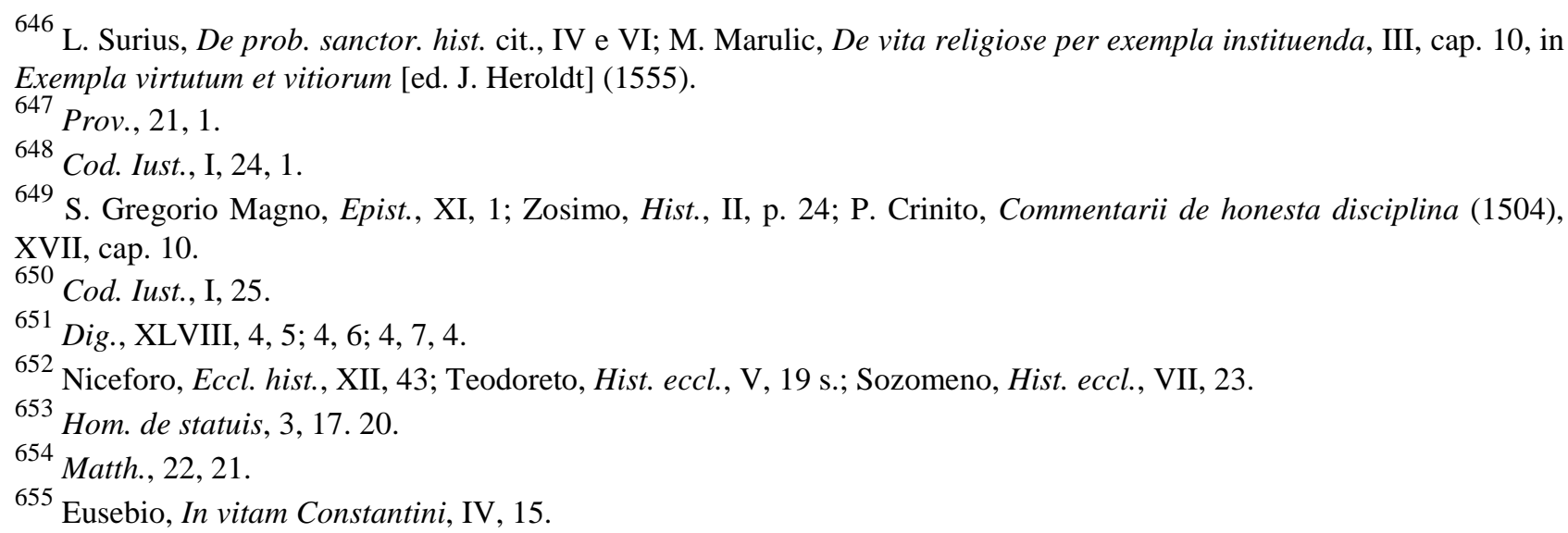


Sì che quegli antichi imperatori religiosissimi, se bene ordinorono che fosse levato ogni abuso di falsa superstizione con che si soleano adorare le statue, di che ne fecero publico decreto, volsero però che rimanesse l'uso che fossero dal popolo riverite alla presenza del giudice, come quelle che rappresentavano la maestà regale; di che si legge ancor oggi una constituzione con queste parole ${ }^{656}$ : Si quando nostrae statuae vel imagines eriguntur, sive diebus ut adsolet festis sive communibus, adsit iudex sine adorationis ambicioso fastigio, ut ornamentum diei et loco et nostrae recordationi sua probet accessisse praesentia.

E quantunque leggiamo che talor anco a persone private si concedessero, come di Gioseffo istorico fa menzione S. Ieronimo ${ }^{657}$, e di Vittorino scrive S. Agostino ${ }^{658}$, quod ob insi [p. 327] gne praeclari magisterii statuam in Romano foro meruit et accepit, il che de altri ancor si legge; nientedimeno è cosa nota che a' privati non si poteano dedicare senza licenza imperiale, anzi, che quando voleano i prencipi privileggiare notabilmente alcuno per meriti grandi et estraordinarii, li concedevano la statua come testimonio del prencipe e commendazione del valore et eccellenza di quel tale. Sì che questo arguisce più tosto la prerogativa grande di queste statue, ad essempio di quello che dicono i giurisconsulti delle facoltà amplissime reservate al solo prencipe, che essi chiamano regalia, quali può esso prencipe talora concedere ad alcuno, non privando però la propria $\operatorname{dignità~}^{659}$. Onde leggiamo nelle Sacre Lettere ${ }^{660}$ che Assuero, re grande che signoreggiava centoventisette provincie, si contentò che Mardocheo, uno della sua corte, portasse la veste sua e diadema regale per la fedeltà e valore ch'a' suoi servigi avea mostrato.

Da tutto questo vogliamo inferire che, servendo la statua al prencipe non solo per la sua propria insegna regale, che rappresenta la suprema maestà, ma ancor per essecuzione dell'ufficio regale, poiché produce effetto verso i sudditi simile a quello che fanno le imagini negli animi degli altri, rinovandoli la memoria dell'autorità regia e risvegliandoli l'affetto di onorare et obedire il suo prencipe; però si potrebbe dire che non si vede, quanto ad esso prencipe, perché possa più acquistare biasimo nell'eriggersi cotal statua, che nel portare il diadema, abitare il palazzo regale, avere il seggio sublime, tenere la guardia et allabardieri attorno, che tutti in certo modo servono per testimonio maggiore dell'autorità, giurisdizzione, grandezza e superiorità di esso prencipe, e conseguentemente ad inchinare maggiormente gli animi de' popoli all'obedienza.

Se dirà alcuno che, anzi, la natura et origine delle statue è stata per onorare la persona e dare testimonio de' meriti [p. 328] altrui, il che non conviene al prencipe né ad alcuno altro verso di sé stesso, acciò non parà che soni la tromba delle sue prodezze; si risponde che nell'onore che s'attribuisce alle persone poste in dignità concorrono due cose diverse: l'una è come causa, che è la dignità publica concessa da Dio, per la quale si onorano i prencipi buoni e cattivi ${ }^{661}$, l'altra è come termine, che è quella persona nella quale si rappresenta quella dignità; anzi, in un soggetto medemo potendo convenire diverse cause di eccellenza, se li devranno ancora diverse sorti d'onori, e potrà esser che alcuno si mova ad onorar con un rispetto che serà differente da quello per che si moveranno gli altri ${ }^{662}$. E però nel caso nostro con altro fine s'induce il suddito a porre la statua, e con altro il prencipe: il suddito per onorare la persona del prencipe, il prencipe per onorare non sé,

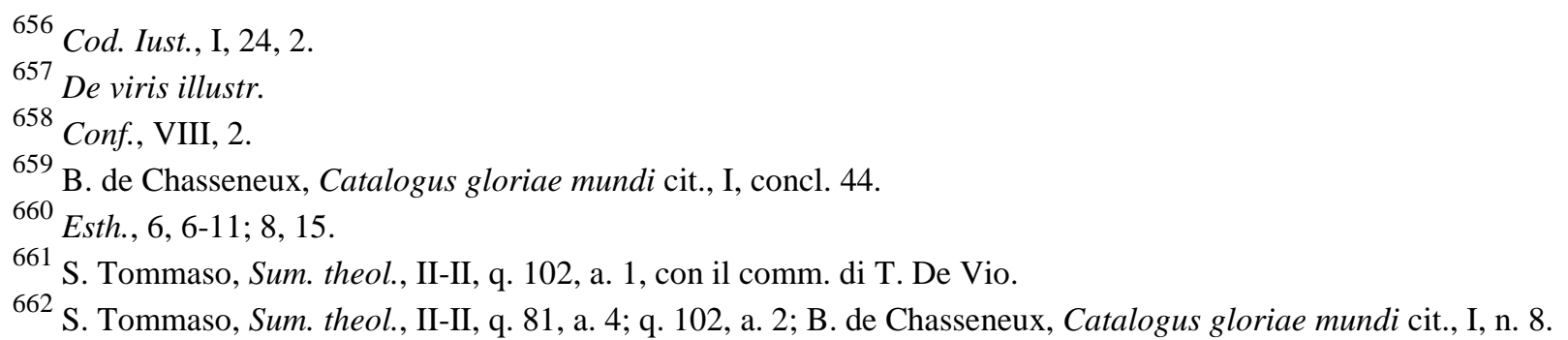


ma il principato, che è la prima ragione perché si debbono onorare i gradi e le dignità.

E se pure alcuno replicasse che l'onore non si deve tribuire se non alla virtù, risponde S. Tomaso $^{663}$ che questo ha luogo così nella virtù propria come nell'aliena e participata, sì come aviene nelle dignità publiche, che rappresentano in quella potestà Iddio o la republica e risplendono di quella eccellenza che gli è communicata, se bene le persone per sé stesse ne sono poco meritevoli.

Non intendiamo per questo che le statue siano di sostanza alla dignità regia, sapendosi che molti prencipi non l'hanno usate, sì come né anco tutte le insegne regie diciamo essere essenziali del re, poiché servono più tosto per segno e dimostrazione di quella potestà ${ }^{664}$, come disse Virgilio $^{665}: E t$ sellam regni trabeamque insignia nostri. Onde vediamo che, [p. 329] se bene le leggi civili ${ }^{666}$ ordinarono che solo l'imperatore abitasse nel palazzo regale, in ogni città separato dagli edificii privati per spacio di 15 piedi; che esso solo portasse la veste dorata e di tutto oro battuto; che esso portasse nei freni, selle et ornamenti di cavalli perle, iacinti e smeraldi; ch'ad esso solo convenisse lo scettro, la purpura, il diadema e l'altre insegne regie narrate da' dottori ${ }^{667}$ : nientedimeno non intesero imporli l'uso di queste cose in maniera che non potesse ancora tralasciarle, ma volsero solamente dare a lui l'autorità di usarle per ornamento et insegna regia, et a nessun altro ${ }^{668}$. Similmente dunque diciamo la statua publica essere cosa che appartiene a quella suprema dignità, et è come parte della magnificenza regale, che insieme può, secondo varii accidenti, mirabilmente servire all'ufficio publico.

E però concludiamo che, rispetto alla persona publica, è lecito al prencipe senza nota alcuna eriggere a sé stesso la statua, non essendo i meriti o demeriti suoi che lo rendano degno o indegno di quella, ma nudamente si ha riguardo all'autorità regia e publica potestà, alla quale si conviene tale prerogativa, come né anco il portare la veste di broccato non dipende dalla virtù o bontà del signore, ma dalla dignità o grado che tiene.

Venendo ora all'altro membro, che riguarda la persona del prencipe in quanto privato, non si può negare che molti prencipi già in diversi tempi non si movessero a desiderare le statue più per appetito di propria eccellenza, che per altro, perciò che, essendo ciascuno naturalmente cupido d'immortalità, né potendosi ella ottenere dalla natura, introrono già in opinione che col mezzo di conservare la memoria del nome loro potessero conseguire il medemo. Onde, per essere le statue, come a loro parve, cosa durabile, giudicarono che [p. 330] per mezzo di quelle dovessero perpetuarsi appresso gli altri, come dice la Scrittura sacra di Absalon ${ }^{669}$, quod erexerat sibi cum adhuc viveret titulum, dicens: Non habeo filium, et hoc erit monumentum nominis mei. E perciò, biasimando questi disegni così irragionevoli, et altri vanissimi ornamenti che, per esaltare più 1'opere loro, aggiongevano intorno a quelle statue, scrisse il Nazianzeno ${ }^{670}$ : Parum habent ipsi adorari, nisi idem quoque sibi in imaginibus picturisque praestetur, quo cumulatior sit ipsis perfectiorque veneratio; e dipoi dice: His porro imaginibus alii imperatores aliud quidpiam propterea appingi gaudent, quidam clarissimas urbes dona offerentes, alii victorias caput corona

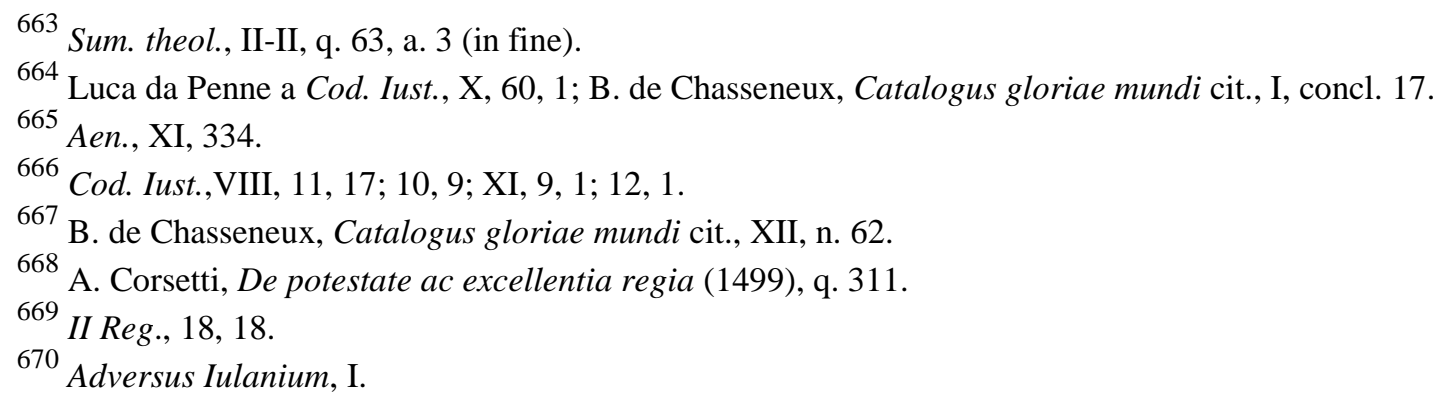


cingentes, nonnulli magistratus adornantes et praefecturarum tesseris exornatos; sunt qui ferarum iugulationes et eiaculationes, alii barbarorum domitorum atque ad pedes provolutorum vel trucidatorum varias multiplicesque figuras, neque enim rerum quibus magnopere gloriantur veritates solum amant, sed earum quoque simulacra.

Dal che si può dubitare che nel tempo ancor della vera religione alcuni de' prencipi cristiani abbiano potuto anch'essi essere aggirati da simili vanità et insidie sataniche; ma poiché questa è intenzione occulta, la quale medesmamente potria accadere nel portare il diadema in capo, stare sotto il baldachino, sedere sopra gli altri e simili cose, da noi, in dubbio, si ha da interpretare in bene, poiché, quanto all'estrinseco, è atto proporzionato e convenevole a quel grado, e, quanto all'intrinseco, è risservato al giudicio solo della eterna et infallibile sapienza: massimamente potendo anco il cuore del re, che suole essere guidato da $\mathrm{Dio}^{671}$, in tutta l'abondanza de' mondani onori essere retto da così candido spirito e moderato desiderio, che né statua, né somma d'oro che abbia attorno scemeria punto della grandezza della sua virtù.

Dalle quai cose restano abbattute le ragioni et autorità di sopra addotte in contrario, poi che toccano più tosto la [p. 331] persona privata che la publica, et alcune di esse, biasimando le statue, presuppongono che in esse si riponga il fine del perpetuare la gloria; il che non pensiamo che alcuno prencipe oggi si trovi così sciocco che se lo possa persuadere, vedendo che le monarchie dei re potentissimi in breve spazio hanno ceduto alla voracità et invidia del tempo, e che gli edificii che pareano dover essere perpetui e sicuri da tutte le ingiurie del mondo si sono anch'essi risoluti in polvere: onde disse Ezechiele: Statuae tuae nobiles in terram corruent ${ }^{672}$.

Agli altri ancora, che le hanno biasimate con dire che in esse si suol fare da molti maggior capitale assai che nelle operazioni virtuose, sì come scrisse Amiano Marcellino ${ }^{673}$, dicendo: Quidam aeternitati se commendare posse per statuas aestimantes, eas ardenter affectant, quasi plus praemii ex figuris aereis sensibus carentibus adepturi, quam ex conscientia honeste recteque factorum, eas auro curant imbracteari etc.; si risponde che noi non crediamo ch'oggi alcuno sia che loro contradica, sapendosi che le statue, senza gli aiuti della bontà, della giustizia e della sincera carità verso i popoli, niente possono giovare alla vera immortalità, onde disse quel Greco ${ }^{674}$ : Si quod opus bonum feci, hoc meum monumentum erit; sin nullum, ne omnes quidem statuae.

Ma queste e simili altre ragioni, che si potriano contro l'uso delle statue addurre, hanno regolarmente luogo in uno de' due casi dal nostro differenti. Perché o parlano quanto alla persona privata del prencipe, come di sopra si è detto, overo s'intendono nelle statue di persone particolari, che, non essendo prencipi, non le hanno per propria autorità, ma le sono state per grazia e privileggio da' suoi superiori concedute. Ne' quali casi avranno più tosto luogo le considerazioni che appresso si diranno nella materia dei ritratti, alla quale rimettiamo il lettore per più commodità.

[p. 332]

\section{CAP. XIX.}

Delle imagini cavate dal naturale, che si chiamano ritratti.

Sono molto differenti le statue publiche de' prencipi dalle imagini che per particolari persone

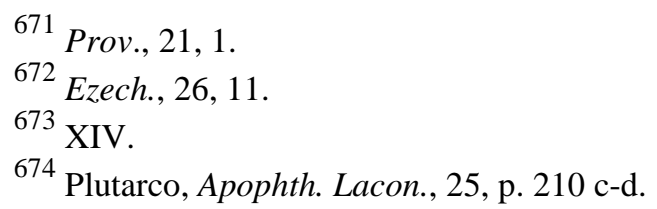


sogliono formarsi cavate dal naturale, communemente chiamate ritratti; e come di quelle a lungo abbiamo parlato, così ora di queste, che frequentemente si veggono usate da molti et in varii luoghi, intendiamo di trattare. Se dunque sia domandato se sono lodevoli simili ritratti, o no, diciamo che possono occorrere in ciò varie considerazioni: l'una è quando alcuno fa ritrarre sé stesso; l'altra è quando fa ritrarre un altro; la terza è quanto alla persona del pittore che fa il ritratto. Se parliamo dei ritratti proprii, cioè di quelle persone che procurano essere ritratte dal naturale e si compiacciono di tenere la loro imagine in casa o in altro luogo, si risponde che, o parliamo quanto al ritratto in sé, e rispetto alla specie esteriore ch'ei dimostra, overo quanto al fine che si può avere in esso. Nel primo caso non potiamo se non dire che, se bene il ritratto per sé, come imagine, non è cosa né buona né mala, ma indifferente, potendosi applicare a buono e mal uso, nientedimeno, perché tali cose che chiamamo indifferenti, redotte poi a' casi particolari dalla deliberazione ragionevole dell'uomo, non stanno più nella larghezza dell'indifferenza, ma si ristringono necessariamente e ricevono circostanze di persona, di luogo, di tempo e altre simili ${ }^{675}$, segue ancora che da queste particolarità elle, lasciando quella prima loro natura commune, cominciano a pigliare nuovo grado di cosa lodevole o biasmevole. [p. 333]

Tra l'altre circonstanze dunque una ne cade, in queste imagini di che ora parliamo, molto principale, che è della persona; percioché, essendo l'origine delle imagini stata principalmente instituita per onorare altri e conservarne degna memoria (come più volte si è discorso), seguita ch'ogni volta che vediamo l'imagine d'alcuno ritratta, insieme ci si appresenta non so che di onore e di riputazione, che per mezzo di quella imagine gli è attribuita; poiché, come scrive S. Crisostomo $^{676}$, nemo fugientis aut bellum detrectantis imaginem pinxit. Perciò, sì come quando uno loda sé stesso, allora si fa riputare per sciocco e vano, dovendo la vera laude non dalla propria, ma dall'altrui bocca uscire ${ }^{677}$; così, quando vediamo ch'uno ha fatto ritrarre sé stesso, pare che in conseguenza venghi a dare un tacito giudicio di sé medesmo, di essere persona onorata, virtuosa o bella, il che non gli accresce, ma gli sminuisce il credito, parendo sciochezza ridicola che uno presuma tanto di sé stesso, che si reputi degno, per servigio del mondo, di stare in prospettiva degli altri per essere veduto et ammirato. E perciò leggiamo ${ }^{678}$ che Acacio, patriarca Constantinopolitano, riputato prima persona molto veneranda per le religiose opere sue, avendo di poi fatta mettere l'imagine sua in varie chiese, subito s'acquistò il nome di vano et ambizioso; e per lo contrario è commendato assai Plotino ${ }^{679}$, che non volse mai lasciarsi ritrarre, dicendo che chi cerca con tal mezzo lasciare memoria di sé a' posteri suoi, mostra di conoscere poco la grandezza o bassezza delle cose, stimando ch'un dissegno fatto di così fragile materia sia bastante a conservare la fama sua longo tempo, e che a lui bastava pur troppo l'imagine che di continuo portava seco, accennando al corpo, nel quale, come troppo vile albergo, si vergognava che l'anima, cosa divina, stesse imprigionata. [p. 334]

Il simile si trova scritto da S. Paulino ${ }^{680}$ in una epistola a Sulpizio Severo, dal quale essendo stato con grande instanza ricercato che, poi che non potea goderlo di presenza, volesse mandarli il suo ritratto, egli cristianamente si scusa con varie ragioni, dicendo tra le altre: Quid tibi de illa, petitione respondeam, qua imagines nostras pingi, tibique mitti iussisti? Obsecro itaque te per viscera

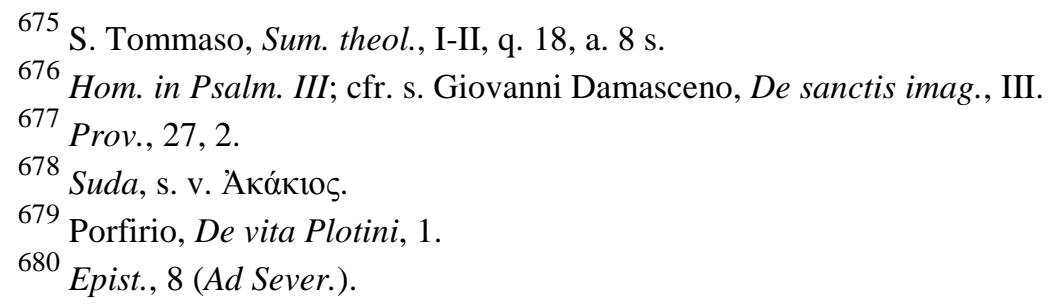


charitatis, quae amoris veri solatia de inanibus formis petis, qualem cupis ut mittamus imaginem tibi, terreni hominis an caelestis? Scio quia tu illam incorruptibilem speciem concupiscis, quam in te rex caelestis adamavit; sed pauper ego et dolens, quia adhuc terrenae imaginis squalore concretus sum, et plus de primo quam de secundo Adam carneis sensibus et terrenis artibus refero. Quomodo tibi audebo me pingere, cum caelestis imaginem inficiari prober corruptione terrena? Utrinque me conclusit pudor: erubesco pingere quod sum, non audeo pingere quod non sum; odi quod sum, non sum quod amo. E molte altre cose scrive in questo proposito, che desideriamo siano lette da quegli che sono così vogliosi di essere ritratti, acciò veggano quale è la vera loro imagine et il ritratto in che hanno a fare il loro fondamento. Il che tanto più dovrà moverli, sapendosi che, quantunque le altre cose, figurate nell'essere suo, se bene sono piene di orrore, però delettano gli occhi nostri per la imitazione del vero, nientedimeno il vedere noi stessi nella imagine propria deformi ci contrista; del che essempio n'abbiamo di quel greco, che non volse mai essere ritratto, né con colori né col scarpello, perché era brutto. Dal che comprendiamo che il procacciarsi il ritratto proprio ha naturalmente seco congionto certo desiderio di propria eccellenza, ch'arguisce non poca debolezza di mente, la quale tanto più apparisce considerandosi che quel tale non ha potuto stare meno di due o tre ore oziosamente in lasciarsi rimirare dal pittore, per fare ritrarre quella figura di corpo, che in poco spazio di tempo s'ha da risolvere in polvere per la morte. [p. 335]

Ma perché tutte queste cose abbiamo noi sinora discorse secondo la specie esteriore del ritratto, passaremo adesso all'altro membro esso, che è di considerarlo quanto al fine che in si può avere; perché, tra tutte le circonstanze essendo quella del fine la ragion formale, e causa principale che dà il vero peso alle azzioni umane ${ }^{681}$, non potiamo negare ch' alcuni ritratti potranno essere procurati dagli autori istessi con così retta intenzione, che non solo non seranno degni di riprensione, ma più tosto di lode e merito. E di qui è che molte persone ancor sante, che poco di sotto si diranno ${ }^{682}$, s'hanno lasciati ritrarre; e nelle età de' nostri maggiori e nostre ancora non mancano essempi assai di persone segnalate per grado et eccellenza di virtù, c'hanno fatto il medesimo, e si può giudicare che piamente si siano mossi, e da spirito buono e puro, conforme alle altre azzioni loro. Nientedimeno, perché questo fine è occulto ai sensi nostri, e così può dirizzarsi a cattiva come a buona parte, ufficio nostro è di ricordare che, per essere la natura nostra molto lubrica et arrendevole alla ostentazione, può ciascuno, in questi desiderii di essere ritratto, ragionevolmente sospettare di essere accecato dall'amor proprio, sì come anticamente favoleggiorno i poeti di Narciso, che, invaghito vanamente della sua faccia, estinse la propria vita col troppo amore di sé stesso; onde scrive Ovidio ${ }^{683}$ :

Visae correptus imagine formae,

Spem sine corpore amat; corpus putat esse, quod umbra est.

Se cupit imprudens, et qui probat, ipse probatur.

Quid videat nescit, sed quod videt, uritur illo

Atque oculos idem, qui decipit, incitat error.

Credule, quid frustra simulacra fugacia captas?

Al che s'aggiunge un'altra ragione, che, quando bene l'intenzione nell'autore fosse stata candidissima, però, quanto [p. 336] agli altri che non giudicano le cose se non dall'esteriore, non

\footnotetext{
${ }^{681}$ S. Tommaso, Sum. theol., I-II, q. 18, a. 4.

682 Cap. 23.

${ }^{683}$ Met., III, 416 ss.
} 
può apportare tal ritratto se non certa opinione di confidenza di sé stesso. A proposito di che serve l'essempio di sopra narrato d'Acacio, che puoté avere forsi buon fine nel fare porre le sue imagini, essendo nelle altre azzioni tanto lodato; nientedimeno non bastò questo a rimovere che nel popolo non nascesse subito un'opinione di lui molto contraria alla prima. E però in simili cose non ha l'uomo da riguardare tanto a sé stesso, quanto alla sospicione che ragionevolmente può nascere in altri.

E questo basti quanto ai ritratti da propria elezzione causati, perché di quelli che sono da altri e non dagli autori istessi procurati, se bene di poi vi concorre anco l'assenso del prencipale, ne tratteremo nel seguente capo.

\section{CAP. XX.}

Dei ritratti d'altri.

Nella materia proposta dei ritratti alieni possono occorrere varie cose da considerarsi. Imperò che sono alcune sorti de ritratti, che si avriano da fuggire per la qualità loro nociva al publico, come di eretici, idolatri, persecutori della fede santa, tiranni empii et abominevoli e simili altri mostri. Alcuni, per essere di persone di vita ignominiosa et odiosa alle buone leggi, se bene hanno titolo di cristiano, come meretrici, lenoni, ciurmatori, bagatteglieri, istrioni, mercenarii, buffoni, crapuloni, o altri che fossero tenuti per infami. Alcuni non per essere di natura sua viziosi, ma per qualche circonstanza che se gli aggiongesse, facendoli ritrarre per ischerno, o con abiti et insegne ridicole, o in altra maniera disdicevole. Alcuni per essere lascivi et alieni dalla onestà cristiana, et incitativi alla libidine, di che nel III libro largamente si tratterà. Alcuni ancora per lo fine occulto che in [p. 337] esso potesse essere, se bene la spezie del ritratto non fosse mala, come per vagheggiarsi in camera quella persona che non si può coi suoi perversi dissegni conseguire, o altrimente servendosene a fine non buono. I quali essempi et altri simili riponiamo nel numero di quei che chiaramente debbono essere ributtati.

Ma la difficoltà ora nasce negli altri, che, quantunque non siano di natura loro biasimevoli, ricevono però varia considerazione secondo la diversità de' soggetti et altre circonstanze che possono intervenirvi. Noi, non potendosi abbracciare tutti i casi, discorreremo ora di alcuni più frequenti, lasciando al lettore la strada in qualche parte aperta di giudicare il resto.

Ecco, avviene spesso che uno ricerca l'altro a fare copia di sé stesso e lasciarsi ritrarre. Qui s'ha da vedere quello che ragionevolmente si deve fare; e perché questo caso riguarda due persone, quello che è ricercato e quello che richiede, però parleremo dell'uno e l'altro distintamente.

Quanto al principale che è richieduto, ciò ha similitudine in molta parte con quello che nel capo precedente si è discorso; però rimettiamo il lettore alle cose già dette, in quanto servono a questo proposito. Solo raccordiamo che sogliono avenire talora varie cause assai oneste, che uno, così ricercato, potrebbe arrendersi di compiacere altrui: l'una serà quando il padre, la madre, la moglie, o altre persone strette di lecita benevolenza chiedessero altrui in grazia il suo ritratto, per potere con questo mezzo della presenza della pittura ristorare i danni dell'assenza di lui; altro sarà quando, per occasione de liti in parte lontana, bisognasse provare la somiglianza tra padre e figliuoli o fratelli o altri; overo quando, dovendosi prendere moglie absente, desiderasse lo sposo prima vedere la imagine di quella che gli ha da essere consorte, o la sposa l'imagine dello sposo; similmente se, per compiacere al publico o a qualche personaggio grande o ad altre persone mosse da degni e cristiani rispetti, si giudicasse ciò convenirsi. [p. 338]

Quando ancora, non per fare piacere alcuno al prencipale né ad altri, ma solo per giovamento del 
pittore, che per suo studio o essercitazione desiderasse figurare questo e quell'altro, per servirsene in suoi buoni propositi, crederessimo ch'alcuno potesse senza scropolo contentarsi, quando però, servata la debita onestà in ogni cosa, si procurasse d'aggiongere o levare quello che conviene, acciò non fossero conosciute le persone ritratte per quelle istesse.

A questi si possono aggiongere varie altre cause ancora, che renderiano la richiesta molto ragionevole e degna di essere admessa; quali lasciamo al discorso del prudente lettore da considerarsi, raccordando noi solo, per le ragioni et essempii nel capo di sopra addotti, che quando vengono simili richieste fatte, è bene andare molto circospetto e trattenuto, né così facilmente cedere alle domande et importunità altrui, se non per ragionevolissimi rispetti.

Soggiongiamo nondimeno che possono spesso farsi questi ritratti senza che gli autori ne siano punto consapevoli, perché, mentre un prelato o dottore o religioso si trova star attento alla predica o alli divini uffici, un pittore diligente, se bene più intento al suo interesse che alla parola del signor Dio, alle volte lo coglierà così dal naturale, come se lo avesse avuto in casa propria, e così dicono ch'avenne a Plotino, che fu ritratto da Carterio, pittore celebratissimo di quei tempi, ad instanza di Amelio, mentre esso Plotino leggeva nella scuola ${ }^{684}$.

Sogliono ancor alcuni per via d'impronto dopo' la morte formare le effigie e colorirle al vivo, o farne ancor ritratti molto al vero somiglianti. Altri si trovano, che alla sola relazione narratale della faccia, colore, aria, fatezze et altre proprietà della persona che non hanno mai veduta, apprendono con la felicità dell'ingegno talmente il tutto, e con l'arte così mirabilmente l'esprimono, come se l'avessero avuto longamente presente. [p. 339]

Ma noi non intendiamo ora di narrare i modi con che si possono formare i ritratti senza notizia dei padroni; solo vogliamo avvertire che, chi vede alcuno ritratto, se bene sia sacerdote o religioso o qualonque altro, non deve subito fare sinistro giudicio di quel tale, poiché può esser vano e senza alcuna colpa di lui. Ma se di poi accadesse che all'istesso autore, ritratto senza sua saputa, fosse donata la sua imagine, o in altro modo pervenesse alle mani sue, e che egli se la tenesse in camera o in altro luogo suo, passeria allora questo nell'essempio dei ritratti fatti per propria elezzione, poiché dal proprio autore viene approvato e ricevuto. Onde ancor noi lo rimettiamo alle regole dette di sopra in tal materia.

Resta ora che rispondiamo alla proposta fatta, di quello che deve osservarsi da chi richiede o desidera avere ritratti d'altri, nel che è necessario fare differenza tra l'atto del procurarli e tra il modo di usarli poi che si sono avuti.

Quanto al primo capo, diciamo che - oltre i casi eccettuati di sopra, ne' quali deve ciascuno astenersi da simili ritratti, e, di più, presupposto che il fine perché si ricercano non sia cattivo, et anco che per ottenerli s'usino i mezzi convenienti alla prudenza et onestà cristiana - pare a noi di mettere in considerazione che, dovendo le pitture servire a' costumi et utilità della vita, come di sopra più volte si è detto, non dovriano porsi in ritratto se non le persone le quali o con bontà morale o con santità cristiana potessero essere incitamento alle virtù. Onde anticamente si vede che non solo tra' gentili, de' quali scrive Plinio ${ }^{685}$ che, tra gli altri, Marco Varrone volse lasciare alla posterità settecento imagini d'uomini illustri, ma anco tra' cristiani si conservavano le figure degli antecessori nelle famiglie che erano di meriti celebri e famosi. Il che tanto più dovrà convenirsi a quegli che, avendo administrate le podestà spirituali o temporali con religione e giustizia, possono con l'essempio loro servire a beneficio publico; sì [p. 340] come noi con riverente vista riguardiamo volentieri i ritratti de' sommi pontefici, che con successione continuata hanno seduto nella catolica

\footnotetext{
684 Porfirio, De vita Plotini.

${ }^{685}$ Nat. hist., XXXV, 2.
} 
et apostolica catedra del Prencipe degli apostoli, e leggiamo che dei vescovi buoni e pii già si formavano l'effigie nel palazzo episcopale con longa schiera per ordine de' tempi. Né mancano oggi in molti regni e dominii de' cristiani espresse al vivo l'imagini de' loro prencipi e signori, che ancor si conservano nelle sale e loggie publiche ad essempio de' successori; e parimente si trovano le imagini d'altri segnalati uomini in varie professioni nelle camere e guardarobbe de' signori grandi e d'altre persone, raccolte con molta lode loro e beneficio degli altri, sì come dei pittori e scultori di che noi trattiamo piacque alla virtù e diligenza del Vasari ${ }^{686}$ che ne restassero ai descendenti le memorie loro non solo stese in scrittura, ma ancor formate in dissegno, quali oggi con molto onore del suo nome si vedono e si leggono.

Laonde diciamo che nel procurare questi ritratti si dovria usare gran discrezione nel sciegliere solamente quelli, i quali riconosciuti fossero di commune consenso degni di lode et onore. Di più, nei ritratti di persone di grado e dignità dovriano i patroni procurare che fossero espressi con la gravità e decoro che conviene alla condizione loro, e non con cagnuoli o fiori o ventarole in mano, non con uceletti o papagalli o bertuccie appresso, non con abiti poco lodevoli, massime le persone ecclesiastiche, non in atti di diporto, non in altre maniere poco degne di persone mature et essemplari.

E poiché si chiamano ritratti dal naturale, si dovria curare ancora che la faccia o altra parte del corpo non fosse fatta o più bella o più grave o punto alterata da quella che la natura in quella età gli ha conceduto, anzi, se vi fossero anco defetti, o naturali o accidentali, che molto la deformassero, né questi s'avriano da tralasciare, se non quando con l'arte si potessero realmente dissimulare, sì come è scritto del [p. 341] ritratto d'Antigono, che da Apelle fu fatto in profilo perché non apparesse ch'egli era losco e manco d'un occhio ${ }^{687}$.

Segue appresso l'altro capo, che è del modo dell'usare questi ritratti, quale stimiamo anco più importante, poiché questo è il fine per il quale essi si procurano, onde tanto più ricerca circonspezzione et avvertenza. E perché tra varie sorti di persone, che sogliono procurarsi di avere in ritratto, due sono nelle quali più frequentemente si incorre et in che spesso suole il cieco affetto nostro ingannarsi: l'una è de' nostri parenti et amici, l'altra delle persone grandi e di autorità, da quali speriamo commodo et onore; però di queste al presente parleremo, lasciando del resto il giudicio ad altri.

Dunque, quanto a' parenti, quando avvenga che siano state persone veramente dotate di meriti e virtù, talché se ne possa degnamente conservare nelle case onorata memoria per essempio a' descendenti e sprone de' figlioli all'imitazione delle virtù, diciamo che questi non si dovriano mettere in mostra né anco nelle case proprie, se non dopo la vita loro, non solo per allontanarsi da ogni ombra di vanità, ma ancora perché, dovendo servire questi ritratti solo per istimolo al bene operare, fuori di tempo è il volersene valere mentre che vive il proprio autore, la cui vita et azzioni ci sono il vero essemplare, onde non accade ricorrere al ritratto o dipinto. Anzi, dopo la vita sua ancora doveriano i parenti, a chi più che agli altri tocca, andare molto riservati di non porli facilmente in publico, per degni rispetti conosciuti dagli uomini savii, se non sono state persone segnalatissime.

Quanto poi agli altri ritratti di persone grandi e di grado, tanto più dovrà ciascuno usarli riservatamente, quanto maggiore è la dignità loro, acciò, in luogo di onorarli, non siano esposti alla censura del popolo e chi n'è stato autore non dia occasione di essere riputato persona che si muova più da assentazione che da giudicio.

\footnotetext{
${ }^{686}$ Vite, cit.

${ }^{687}$ Plinio, Nat. hist., XXXV, 10.
} 
Di più, doveriano avere questo avvertimento, di non farne [p. 342] spettacolo publico nei luoghi dove quei si trovano presenti, acciò non paiano di consentire o almeno dilettarsi di tal mostra, eccetto se siano persone di tanto valore, eccellenza e fama presso di ognuno, che siano armati e sicuri da' morsi del popolo.

Onde, per essere i ritratti per lo più sottoposti a scontri dubiosi, prudenza non picciola serà di chi n'è patrone, fuggendo li scogli e le tempeste del volgo, tenersi al porto discreto della solitudine e custodirli ad uso e beneficio solamente di quegli che ragionevolmente debbono con simile essempio muoversi et accendersi al vivere virtuosamente.

\section{CAP. XXI.}

Dei ritratti degli amanti, e come debbono governarsi i pittori intorno ad essi.

Veniamo ora a quello che riguarda la persona del pittore nel fare alcun ritratto, acciò sappia anco egli come in ciò regolarsi. Il che potrà esso in gran parte raccogliere dalle cose già discorse nei capi precedenti, imperoché, essendosi già fermato che non debbono procurarsi i ritratti di persone viziose o infami, chi dubita che tanto meno dovrà il pittore cristiano in ciò adoperarsi, per non essere ministro di cosa che repugni alla modestia e vera disciplina? Parimente, se tutte le altre opere sue deve sempre diricciare a quel fine buono e lodevole che da noi si è già dimostrato nel primo libro, et accompagnarle ancora con mezzi proporzionati alla vera onestà e religione, chi non vede che il medesimo dovrà aver inanzi gli occhi nel formare questi ritratti?

E perché queste cose presupponiamo noi ora come chiare e risolute, l'intendimento nostro al presente è di ragionare de alcuni casi più dubiosi che spesso sogliono avvenire, accioché il pittore timorato possa più che può assicurare la conscienza sua e non precipitare. [p. 343]

Vengono essi spesso ricercati di ritrarre alcune persone, e massime giovini, ne' quali possono errare così compiacendoli dei ritratti come negandogliene, quando o l'uno o l'altro facciano senza giudicio.

Già raccontammo alcune cause assai oneste, per le quali è lecito al padre, alla madre, allo sposo et ad altri ancora procurare il ritratto de giovini e giovane e d'altri a buono e lecito fine; nei quali casi dovrà essere parimente permesso al pittore di sodisfare a' loro onesti desiderii. Ma perché talora sotto simulati pretesti si viene a fare fraude alla pudicizia et onestà, però non potiamo noi prescrivere regola ferma e perpetua in ciò al pittore, ma solo li raccordiamo che, dove egli può probabilmente giudicare che tal ritratto si ricerchi per fine vizioso e disonesto, non ha da intromettersi punto, né adoperare ad uso vizioso et a ministerio diabolico quella arte et ingegno che Dio gli ha dato, perché chi communica nel peccato altrui, si fa partecipe di esso, oltre le altre ragioni che nel seguente libro si diranno.

Onde, lasciando noi da banda i ritratti delle meretrici et altre donne di vita impudica, che per le cose già dette debbono essere recusati; se un giovine che non appartiene ad una donna, e massimamente maritata, faccia la medema instanza, assai bene potrà discernere il pittore zelante, se questo sia fine cattivo o buono. Se altro lo pregarà che voglia rubbare il ritratto, come si dice, alla macchia, stando il pittore in una chiesa o altrove con un libretto in mano, mostrando di leggere et in effetto lavorando il ritratto, chi non dubitarà di fine cattivo e scelerato, e tanto più pernicioso, quanto che il mezzo di servirsi della chiesa a questo fine è tanto odioso a Dio? Ma chi ardisce, di più, di richiedere il ritratto di una vergine velata e consecrata a Dio, senza occasione di notabile santità di vita, che altro potrà il pittore giudicare che dissegno nefario e sacrilego? In somma, bisogna che il pittore prudente sappia in simili occasioni sospettare o temere, acciò per mezzo suo 
non venga offesa la divina bontà, mettendosi al sicuro col non pigliare simili im [p. 344] prese, se non vedesse ragioni molto buone e probabili in contrario. E perché non vorressimo che dall'altro canto si mettesse a fare sempre sinistro giudicio di essere ricercato a cattivo fine, nel qual caso, essequendo di poi egli l'opera, peccarebbe indubitatamente facendo contro la conscienza sua, se bene il suo pensiero fosse stato temerario e falso ${ }^{688}$; però cristianamente farà chi in tali casi di cuore si raccomandarà a Dio et insieme si consiglierà prima con persone spirituali e de intelligenza, seguendo il loro parere per non errare.

Non taceremo, in questo proposito, che a' tempi nostri uno già valente e molto pio pittore bolognese, non si potendo difendere da simili ritratti per la importunità di persone di condizione, dopo molte scuse e ragioni, non potendo achetare chi lo ricercava, si mosse, a conseglio de un religioso, quando era richiesto di tali ritratti, di dipingerli in iscambio una molto divota imagine di Cristo flagellato, o della Madonna, o d'altro santo o santa; la quale poi presentando al giovine lascivo, egli e gli altri, sì tosto che ciò vedevano, restavano stupefatti del santo inganno e sodisfattissimi del cambio, con molta edificazione della pietà e bontà dello artefice, e si astenevano per lo avenire dal chiederli cose simili.

Negli altri casi poi giudicati ragionevoli e non dubiosi raccordiamo al pittore che egli, nel fare ritratti, non si scosti punto dalla verità, servando in questo la regola dell'istorico, che narra il fatto come è stato, e non dell'oratore, che spesso amplifica et estenua le cose; peroché, oltre l'errore in che il pittore incorre mancando della dovuta imitazione, potrebbe causare talora col suo artificio molto pregiudicio ad alcuno, onde dovrà essere in ciò grandemente avvertito, né cedere a prieghi di chi che sia, essendo questo vizio de molti, e massime di alcune donnicciole, che ambiscono di essere ritratte con la faccia colorita e graziosa, credendosi pur troppo con questo mezzo di diventare più belle, che è cosa ridicola, come [p. 345] scrive Luciano ${ }^{689}$, eccetto se, mediante la sua arte veracemente essercitata, potesse occultare con bel giudicio alcuno della persona, come da noi di sopra è stato avvertito.

\section{CAP. XXII.}

Dei ritratti degli eretici.

Se bene dalle cose già discorse dei ritratti assai forsi si può raccogliere quello che sia di necessario avvertimento in essi, nientedimeno, sì come dai principii seguono le conclusioni e dopo' le teoriche si viene alla prattica, ci è parso di soggiongere questo capo et il seguente, affine che resti impresso nella mente del pittore quasi uno modello di due sorti de ritratti, che sono come capi di squadra degli altri, l'uno da essere aborrito, che si tratterà al presente, l'altro da abbracciarsi, che di poi si proponerà.

Pigliamo dunque ora per soggetto il ragionare dei ritratti degli eretici come capi nefandi dei viziosi, acciò che primamente si conosca che a nessuna ragione si debbono tolerare; di poi perché, se la necessità talora ricercasse che questi o simili s'avessero a rappresentare, si sappia insieme in che maniera s'avriano da proporsi al popolo.

Nel primo caso, se abbiamo giudicato non convenirsi ad un cristiano tenere le imagini de' gentili persecutori della santa fede, quanto più ciò si avrà da affermare in quelli che rappresentano la persona de' eretici, o antichi o moderni, che perfidamente da noi si son apostatati? È chiaro che con

${ }^{688}$ S. Tommaso, Sum. theol., I-II, q. 19, a. 3.

${ }^{689}$ De hist. conscrib.; Pro imaginibus. 
la pittura, sì come con i libri, pare che si conservi onorata memoria delle persone, la quale dagli eretici deve essere affatto cancellata, sì come fu già da diversi imperatori ordinato: leg [p. 346] gendosi nelle leggi di Arcadio et Onorio ${ }^{690}$ : Nemo Manichaeum nemo Donatistam, qui furere non desistunt, in memoriam revocet; e nel Codice di Giustiniano, che è constituzione greca di Teodosio e Valentiniano ${ }^{691}$ : Iubemus ut omnia quaecunque Porphyrius insania et furore suo impulsus, aut vero alius quisquam contra piam christianorum religionem conscripsit, apud quemcunque inventa fuerint, igni tradantur; nam quae scripta vel Deum accendunt ad iracundiam, vel animos hominum in perniciem et fraudem impellunt, ea scripta ne ad aures quidem cuiusquam pervenire volumus. $\mathrm{E}$ poi, parlando degli scritti di Nestorio eretico, dice: Iubemus ea quae sunt Nestorii flammis conflagrari, neque ad cuiusquam lectionem adhiberi; iis qui talia scripta ac tales libros, habere aut legere non dubitaverint, extremo supplicio condemnandis etc. E nelle leggi di altri imperatori ancora si trova parimente proibito ${ }^{692}$.

A che appartiene quello che Dio aveva ne[1] Testamento Vecchio ordinato degli idolatri con queste parole ${ }^{693}$ : Sculptilia eorum igne combures; non concupisces argentum et aurum de quibus facta sunt, neque assumes ex eis tibi quicquam, ne offendas, nec inferes quidpiam ex idolo in domum tuam, ne fias anathema, sicut et illud est. E leggiamo nelle istorie ecclesiastiche ${ }^{694}$ che Constantino papa primo ordinò che la memoria di Filippico, imperatore scismatico e fuori del gremio della santa Chiesa, fosse levata e cancellata da tutti i luoghi, come quello che per l'eresia si era fatto indegno di essere nominato tra cristiani. E molti altri essempi si trovano nelle antichità di quei di che era solito conservarsi e recitarsi la loro memoria nel canone della Messa, descritta in quelle tavole che chiamavano diptycha, che se di poi si scopriva che tali fossero eretici, subito si cancellava il nome loro e memoria da [p. 347] tali monumenti, come leggiamo in varii luoghi ${ }^{695}$. Né in ciò pare che sia necessario di stenderci più a longo per dimostrare questa verità; imperò che, se $\mathrm{i}$ libri degli eretici sono da' Canoni vietati, se la memoria loro, come dicevamo, dalle leggi è condannata $^{696}$, se le statue loro dal Santo Ufficio vengono abbruggiate, con che pretesto poi si potranno rappresentare le imagini delle persone, o memoria delle azzioni loro publicati e dannati per nemici di Dio, della santa Chiesa e di sé stessi? e massimamente che, come scrive S. Giovanni $^{697}$, non si debbono gli eretici, che si sono separati da noi, pur salutare, non che si abbia da servare con loro alcuna sorte di ufficio commune, se non per convertirli, quando si potesse, o per castigarli da chi abbia autorità nei casi dai Canoni descritti.

Né si inganni alcuno quando, tenendo simili imagini presso di sé, pensasse di escusare l'error suo col pretesto dell'artificiosa pittura o di altra sua trovata curiosità; perché, se non basta questa ragione a difendere le pitture dei gentili nei casi detti di sopra, quanto meno giovarà in queste? Anzi, potendo involgersi nelle censure ecclesiastiche, non senza sospetto di fede dannata e di eresia, chi ritenesse in casa senza licenza o autorità de' superiori i libri d'eretici, se bene non per seguire gli

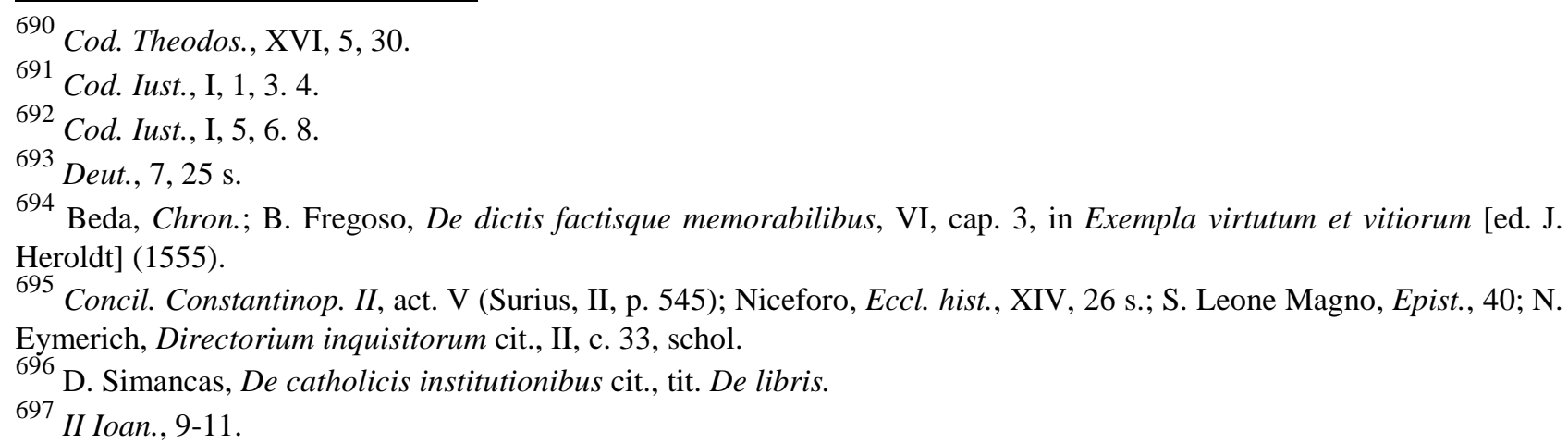


errori loro, ma solo per la eleganzia del dire o ancora per la bellezza della stampa o miniatura del libro ciò dicesse di fare; così di sospetto non mancaria chi tali imagini d'eretici custodisse.

Eccettuamo però quando tali ritratti fossero accompagnati con segni manifesti e giuste vendette della empietà loro, overo contenessero qualche accidente notabile contro la perfidia di essi e chiara dimostrazione del castigo datoli dal signor Dio, nel medesimo modo che si dipinge il Demonio scac [p. 348] ciato dal cielo e che arde nell'abisso dell'inferno, o Simon mago precipitato dal cielo per la rupe di Campidoglio e con ignominia confuso della superba temerità sua ${ }^{698}$; e sì come è narrato da alcuni eruditi che fu già usato nella imagine di Lutero, pingendolo in forma di lupo negro, vestito con la cocolla monachale et aggiontivi alcuni versi, che significavano la sua trasformata mostruosità. Altrimente, non servandosi questa circonstanza di far conoscere le sceleratezze loro con evidente castigo dei suoi falli, sarebbe pittura detestabile, perché faria in tutto contrario effetto a quello che deve; intendendosi però quando tali imagini non fossero meschiate con quelle de' santi, ma come accessorie a quelle, talché si vedesse che per necessità dell'istoria principale fossero state espresse, come quando Simone è convinto da S. Pietro, o Eutichio da S. Gregorio ${ }^{699}$, o gli Arriani in varii concilii, o simili altri essempi.

\section{CAP. XXIII.}

Dei ritratti de' santi.

Accioché ciascuno chiaramente conosca che noi non abbiamo pigliato per impresa il biasimare i ritratti affatto o bandirli dal commercio, ci è parso ora, se bene ragioniamo principalmente delle pitture profane, soggiongere nondimeno varii essempi de' ritratti de' santi, acciò che da questi, come capitanei maggiori di singulare bontà e religione, possa il pittore intendere che, sì come siamo stati sforzati per le ragioni già dette a recusare quei ritratti che possono eccitarci memoria viziosa, e conseguentemente nuocere a' costumi, così quelli soggetti, dove rilucono ornamenti di virtù ancor [p. 349] che morali, non potiamo non admettere, secondo i gradi però dei meriti loro degni di maggior e minor lode, e servate nel resto le circonstanze dette di sopra.

Dunque, tra questi riponiamo nel primo luogo i ritratti di quelli che chiamiamo santi, de' quali essendo stata la vita d'innocenza, di pietà, di religione tra tutte l'altre eminentissima, così non è dubbio che meritano le imagini loro, come trofei memorabili di virtù, essere rappresentati in tutti i luoghi publici e privati. Che se i medesimi si potessero non solo con li proprii lineamenti figurare, ma ancora della maniera che dice Aristotele ${ }^{700}$ di Polignoto, che col pennello esprimeva gli affetti intrinseci dell'animo, certo è che riempiriano ciascuno di riverenza e meraviglia, e commoveriano sino al cuore chi li riguardasse. Sì che di essi ora noi ricorderemo alcuni essempi, acciò si conosca quanto gli uomini di pietà hanno cercato d'averli più che puotero simili al vivo, per destare più efficacemente sé stessi con tali imagini ad imitare la strada che essi, vivendo, gli aveano mostrata di caminare al cielo.

Scrive il Damasceno ${ }^{701}$, seguito da molti altri, come altrove dicessimo ${ }^{702}$, se ben di ciò non vi è certezza autentica, che Abagaro re di Edessa procurò con grande instanza per via d'un pittore avere

\footnotetext{
698 S. Ambrogio, Serm., 66.

699 Giovanni Diacono, Vita S. Gregorii, I, 28.

${ }^{700}$ Poet., 4; cfr. Eliano, Var. hist., IV, 3.

701 De orthod. fide, IV, 17.

702 L. I, cap. 29.
} 
la imagine di Cristo signore nostro.

Si onora e riverisce da' fedeli il sudario di S. Veronica, chiamato il Volto Santo, che publicamente si mostra nella chiesa di S. Pietro in Roma, riputando noi per estrema felicità, non avendo potuto vedere quella faccia santissima nella propria forma, di vederne il ritratto miracolosamente espresso nel pannicello di quella santa donna ${ }^{703}$. [p. 350]

Si legge che S. Luca dipinse dal naturale la imagine della gloriosa Vergine mentre che ella vivea, che così scrive Niceforo ${ }^{704}$ dicendo: Pinxit $S$. Lucas imaginem Deiparae Virginis, illa adhuc vivente et tabulam ipsam vidente, gratiamque adeo illi formae suae immittente.

È scritto nella vita di Constantino imperatore che, sendoli mostrate le imagini di S. Pietro e S. Paolo, riconobbe dalla effigie loro che quelli che prima gli erano apparsi erano stati gli stessi apostoli, dal che comprendiamo che queste imagini erano state ritratte dal naturale ${ }^{705}$.

Di S. Gregorio scrive Gio. Diacono ${ }^{706}$ nella vita sua, che in un monasterio in Sassonia avea fatta dipingere la imagine di suo padre Gordiano e di sua madre Silvia con atti di divozione, e la sua propria con l'abito sacerdotale, imaginandosi quel sant'uomo che, riguardando i monachi nel suo ritratto, si dovessero muovere all'osservazione dei medesimi documenti religiosi, ch'esso, vivendo, continuamente si sforzava di imprimergli nel cuore; e però dice: Gregorius, dum adhuc viveret, suam similitudinem depingi salubriter voluit, in qua posset a suis monachis non pro elationis gloria, sed pro cognitae districtionis cautela frequentius intueri. E nella stessa vita si legge ${ }^{707}$ che, essendo apparso un vecchio ad un chierico, questo li domandò chi fosse; al quale il vecchio rispose che egli era quello che stava dipinto appresso il letto suo, dalla quale somiglianza riconobbe il chierico che quello che gli era apparso era stato S. Andrea apostolo.

Di S. Crisostomo si legge nella vita sua ${ }^{708}$ che anch'egli avea il ritratto dal vivo di S. Paolo apostolo, che tenea davanti agli occhi, et in esso, quando perlegebat illius epistolas, oculorum aciem intendebat, come dice il Damasceno ${ }^{709}$. [p. 351]

Del medesimo S. Paolo scrive S. Ambrosio: Tertia nocte apparuit persona mihi non dormienti sed stupenti, quae similis erat beato Paulo, cuius vultum me pictura docuerat ${ }^{710}$.

Narra Paolo Diacono ${ }^{711}$ che un duca di Spoleto gentile si vidde aiutare nella battaglia da un giovine che lo difese, e domandò chi fosse stato e non lo trovò; poi, ritornando a Spoleto entrò per ispasso nella chiesa, e guardando le pitture vidde la imagine di quello che lo avea difeso; e domandando chi era, gli fu detto che era S. Sabino, il che dimostra che era stato dipinto anch'egli dal naturale.

Del ritratto di S. Melezio, vescovo d'Antiochia, si scrive che si vedea negli anelli, nelle tazze, nei

\footnotetext{
703 J. de Torquemada, Super toto Decreto cit., a c. 28, D. III de cons., n. 4; J. Viguier, op. cit., cap. 5, § 5, vers. 12; P. Vergilio, De rer. inventoribus cit., VI, cap. 13; C. Braun, De imaginibus, cap. 18, in Opera tria nunc primum aedita... (1548).

${ }^{704}$ Eccl. hist., XV, 14.

705 Adriano I papa presso Surius, III, p. 65; Breviarium Romanum, 31 dic.

706 Vita. S. Gregorii, IV, 83 s.

${ }^{707}$ IV, 96.

708 Simeone Metafraste, Vita S. Chrys., presso L. Surius, De prob. sanctor. hist. cit., V; Giorgio patriarca di Alessandria, Vita S. Chrys.

${ }^{709}$ De sanctis imag., I.

${ }^{710}$ L. Surius, De prob. sanctor. hist. cit., III, p. 700 (Vita S. Gervasii).

${ }^{711}$ Hist. Langob., IV, 5.
} 
muri, per le piazze e per tutti i luoghi ${ }^{712}$.

Narra ancora Eusebio ${ }^{713}$ che al suo tempo si vedeano le imagini antiche del Salvatore e di S. Pietro e S. Paolo, che si servavano alla posterità con grande onore; le quali vogliono alcuni che fossero parimente esse ritratte dai vivi corpi.

E di S. Cosimo e Damiano si legge nella vita di S. Teodoro Archimandrita ${ }^{714}$, quod tales se per quietem conspicuos ei obtulerunt, quales in pictura quadam ibi exposita exprimebantur. E nella medesima vita si narra ${ }^{715}$ che, sendo $\mathrm{S}$. Teodoro andato in un monasterio, fu dai frati mandato a chiamare un pittore che ritraesse la sua imagine, e così fu fatto.

Si legge presso di Simeone Metafraste ${ }^{716}$ di S. Eutichio, patriarca Constantinopolitano, che fu ritratto da un pittore che per mezzo di lui avea ricevuto la sanità; e di un altro pittore, al quale essendo apparso S. Cornelio Centurione e mostratali la vera effigie sua, egli felicemente lo ritrasse $^{717}$. [p. 352]

Di molt'altri medemamente si trova che, essendo stati ritirati nei deserti, se bene vietorono agli altri e massimamente a donne l'aspetto loro, si compiacquero però di apparire in visione nelle sue proprie effigie, le quali, osservate da altri furono poi con colori rappresentate secondo l'occasioni.

E per non estenderci in ciò più a longo, passeremo ora a dare alcuni avvertimenti intorno a simili ritratti per memoria di ciascuno.

Primamente parrebbe a noi che s'avesse a porre gran cura nel sciegliere le persone di quelli che si hanno da ritrarre per santi, acciò siano santi veri et approvati dal consenso universale di santa Chiesa, e non immaginati a propria sodisfazzione o a relazione altrui; overo ch'almeno siano nel numero de' beati, e per tali publicamente da tutti tenuti et accettati, accompagnandoli con quelle note della loro beatitudine, che piamente suole usarsi nelle imagini di essi, di che altrove si parlerà. Di poi, che siano ritratti con l'effigie propria, se si può sapere, o verisimile, o almeno con quella che dai buoni et intelligenti suole essere figurata e che porta seco probabile apparenza che così fosse. Ma in nessun modo mai siano ritratti con faccie de particolari e di persone mondane e dagli altri conosciute; perché, oltre l'essere cosa vana et indignissima, verrebbe a rassomigliare un re posto nel trono della sua maestà con la maschera al viso d'un cerettano o d'altra persona ignobile e conosciuta dal volgo per privatissima, tal che chi la riguardasse, sùbito si movesse a riso ${ }^{718}$, oltre molt'altre inconvenienze, come al luogo suo si dirà più largamente ${ }^{719}$.

Oltre di ciò s'avrà riguardo alla qualità degli abiti con che si rappresenteranno, che siano convenienti a person sante, e che gli atti con che si dipingono, et altri ornamenti, tutti siano proporzionati alla professione, che essi fecero in questa vita, di sprezzare il mondo e conculcare il lusso e delizie terrene. Il che parimente servirà per documento di [p. 353] non collocare così fatte imagini di riverenza, se non in luoghi corrispondenti alla pietà e dignità loro, e non tra altre pitture profane o di favole o di altre cose poco gravi, acciò in nessuna parte sia detratto alla religione e grandezza di essi. Il che basti per ora, quanto a questo capo, però che il resto degli avvertimenti da osservarsi nelle imagini dei santi riserviamo di ragionarne a' suoi proprii luoghi.

\footnotetext{
712 S. Giovanni Damasceno, De sanctis imag., II.

${ }^{713}$ Hist. eccl., VII, 14.

714 L. Surius, De prob. sanctor. hist. cit., II, p. 739.

715 Ibid., II, p 767.

716 Ibid., II, p. 562.

717 Ibid., V, p. 195.

718 Luciano, Pro imaginibus, 2.

${ }^{719}$ L. III.
} 


\section{CAP. XXIIII.}

Delle pitture profane che rappresentano varie cose, come guerre, paesi, edificii, animali, arbori, piante e simili.

Ora veniamo all'altra parte delle pitture profane, che rappresentano varie cose della natura, overo dell'arte e dell'azzioni degli uomini. Nel che, universalmente parlando, non ci partiremo dalla regola detta di sopra delle imagini delle persone, cioè che quelle che non sogliono apportare giovamento alcuno non fanno a proposito nostro. Imperoché, sì come vediamo che i buoni artefici non vogliono nella lor bottega altro che quelle cose et instrumenti che servono all'arte loro, e gli altri come superflui si levano d'attorno; così un cristiano, nato all'essercizio delle virtù e trafico del ciclo, doverà tra quest'imagini appigliarsi solo alle virtuose et a quelle che si possono applicare ad utile della vita. Testimonio di che ne diede quel santo vescovo Epifanio, che nella settima Sinodo dice $^{720}$ : Omnes artes illiberales, quae a scopo mandatorum Dei declinant, interdictae sunt; quae vero in usum aliquem vitae proficiunt et non sunt indecorae, non sunt exclusae. Quod si quis picturae arte in aspectum turpitudinis usus fuerit, execrabili est, veluti si effigies meretricias, spectacula, molles saltandi flexus et equestrium certaminum formas, aut quid simile pingat, [p. 354] sane opus illud turpe et noxium censebitur, si autem honestorum virorum vitas et certamina martyrum et Christi magna mysteria repraesentat, tunc valde recte pictorum arte usus esse dicetur.

Ma per dichiarare meglio questa materia, che abbraccia assai, ci pare che in questo proposito si possano tali pitture ridurre tutte sotto quattro capi. L'uno è di quelle che chiaramente sono cattive o incitative al male, come sono le eretiche, le scandalose, le disoneste e le bugiarde. L'altro è di quelle che sono meramente vane e di nessun frutto, come sono tutte quelle che non sono dirizzate a fine alcun certo, ma si fanno, a capriccio del pittore, solo per empire qualche luogo et adornarlo di sue invenzioni, tra quali però alcune sono che non ributtiamo, come di sotto si dirà. Il terzo è di quelle che rappresentano cose, o naturali o artificiali, che per sé stesse non importano virtù, ma possono riferirsi ad essercizio di essa e servigio della vita umana, sì come sono pitture di paesi, di edificii, di animali, di guerre e di trionfi etc. Il quarto è di quelle che nel rimirarle scuoprono atto di

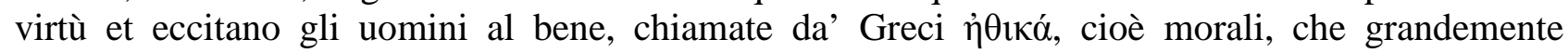
giovano alli costumi.

Chi dunque vuole valersi cristianamente delle pitture, doveria, quanto al primo capo, o sia il pittore o sia il padrone, stare molto avvertito che nissuna di quell'ordine fosse né formata, né ricevuta mai in luogo dove egli avesse podestà, figurandosela nel concetto suo come semenza che '1 Demonio va spargendo quanto più può per corrompere questa infelice natura nostra; onde chi è dotato di qualche lume, subito che la scuopre, doveria farseli incontro come a mostro infernale e cacciarla affatto dal comercio suo. Per tanto, oltre gli avvertimenti dati di sopra in varii capi di quelle pitture che s'hanno da schifare, ricordiamo ora, per regola generale, che, ad essempio dell'indice de' libri proibiti e degli editti in questa città più volte publicati, che si debbano rivedere tutti i libri per espurgarli da ogni menda che vi fosse, così doveria ciascuno rivedere minutamente la casa [p. 355] sua, dentro nella città e fuori, e levar via ogni pittura che potesse offendere gli occhi timorati d'Iddio, e per l'avenire caminar sempre con questa scorta, che non si introducesse mai in casa sua imagine alcuna pericolosa, rivedendo diligentemente le cose, ancor che piccole e che passano per le mani di giovanette, di fanciulli, di serve e di servi, come quegli che più facilmente si

\footnotetext{
${ }^{720}$ Surius, III, p. 147.
} 
possono corrompere e però sono degni di maggiore custodia e vigilanzia, sì come avviene in alcuni dissegni fatti nelle ventarole, coperte di libri, ornamenti di specchi, acconci di casse, di armarii e di molt'altre cose, alle quali dal publico s'averia da provedere, come al suo luogo meglio si dirà.

Alcune sono, che chiamiamo oziose et indeterminate, che non hanno né fine né regola alcuna certa, ma servono, come si dice, per passatempo. E queste, se si considera bene, poco fanno per un cristiano, perché, sì come non si contenta un padrone di aver un servitore che non sia cattivo, ma vuol che sia buono et industrioso, così il cristiano in luogo delle pitture oziose ha da procurare che ve ne siano delle fruttuose, non bastando per salvarsi il non far male, ma sendoli necessario l'operare bene; onde ha da procurare sempre ch'ogni sua cosa sia tale che gli possa portare qualche giovamento. E perché a questo si potrebbono forse opporre varie cose, noi, per fuggire la superfluità, ci riportiamo a quello che si discorrerà nei capitoli delle pitture vane e delle pitture ridicole, e negli altri delle grottesche ${ }^{721}$.

Delle pitture del secondo capo altre sono che, se bene paiono infruttuose, nondimeno non è così, e servono per ornamento, et imitando il vero terminato dalla ragione dell'arte, figurano compartimenti di broccati, ricami, fregi, marmi, porfidi, bronzi per abbellimento de pavimenti, di palchi, di muraglie et altri luoghi. E queste non riproviamo, né mettiamo propriamente in numero delle vane, purché siano fatte col suo decoro e proporzionate ai luoghi. [p. 356]

Delle pitture del terzo ordine non si può negare che quasi tutte le cose, naturali et artificiali, opportunamente dipinte non possino servire di qualche utile alla vita, come cose di speculazione, ad azzioni civili, ad operazioni mecaniche et ad altre cose necessarie al comercio umano, le quali, vedendosi espresse in pittura e potendosi con questo mezzo conservar meglio nella memoria ${ }^{722}$, sogliono riuscire di gran frutto, sì come sono tavole di geografia, navigazioni delle Indie, descrizzioni del ciclo e delle stelle, disegni di città e di paesi, espugnazioni di fortezze, vittorie massime contro infedeli, effigie d'animali, di piante, di pietre, cose di architettura, di edificii, disegni di fortificazioni, di essicazioni di valli e fiumi; et in somma tutte quelle cose che sono permesse che nelle academie publiche si leggano et insegnino agli altri e che S. Agostino ${ }^{723}$ vuole che ad un dottore ecclesiastico siano non solo non proibite, ma anco necessarie. Le quali, oltre il proprio loro uso, possono ancora servire alle volte ad altri effetti et utilità della vita, sì come, a proposito di geografia, si legge ${ }^{724}$ che Socrate, volendo reprimere l'alterezza di Alcibiade gonfio per le richezze e copia di possessioni ch'ei godeva, gli disse, mirando una tavola dove era tutto il circuito del mondo, che li mostrasse dove erano posti i suoi campi; i quali non ritrovando egli in alcuno luogo dissegnati, soggionse Socrate: «Dunque senza ragione t'inalzi di quello che non è parte alcuna, né pure apparisce nella terra». Intorno alle quali cose si potriano dare varii avvertimenti, se il desiderio di fuggire il tedio della longhezza e la sospizione di troppo minuta diligenza non ci ritenesse. Onde due cose solo toccaremo, una che appartiene alle pitture di astrologia, l'altra alle cose militari. Quanto a quelle, ricordiamo che non si entri in disegni o figure che possono dimostrare costellazioni di natività, o di segni celesti, [p. 357] o di pianeti, o d'altre cose simili, che significassero alcuna necessità all'azzioni umane o anco potessero dare probabile sospizione di ciò alli semplici et ignoranti ${ }^{725}$.

Della milizia diciamo che, se bene presso i gentili e barbari et altre nazioni infedeli è stato assai

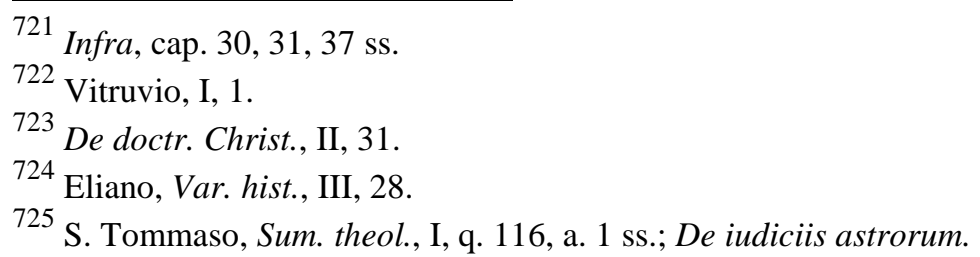


in uso il rappresentare spettacoli di fatti d'arme, di desolazioni di città, di ruine e cose sanguinose, percioché si legge che presso li Persi non si dipingevano altre cose che guerre et occisioni, come scrive Amiano ${ }^{726}$ : Apud Persas non pingitur vel fingitur aliud, praeter varias caedes et bella; nondimeno tra cristiani pare che s'avria da essere in ciò molto circonspetto, non perché non sia lecito, e spesse volte necessario e meritorio, il muovere guerra contro gli eretici, scismatici et infedeli, ma, parlandosi delle guerre accadute tra catolici, diciamo che, intervenendo in esse effusione di sangue, sacheggiamenti de luoghi, distruzzioni de popoli, violazioni de vergini, sacrilegii de' claustrali et altre calamità che apportano seco le guerre, pare che tra persone di una medesima fede, che abborrisce tanto questi eccessi, più tosto se ne dovesse cancellare la memoria che conservarla; eccetto che dove la causa fosse stata tanto iusta e notoria, che quasi necessariamente avesse ricercato tale essecuzione, overo che la necessità di rappresentare alcuno esquisito artificio, o nuova sorte di espugnazione, o altra simil cosa trovata nei conflitti tra prencipi cristiani, richiedesse di essere posta in notizia al resto del popolo per uso di altre guerre giuste. Meno dovrà esser luogo al rappresentare duelli proibiti dal sacro Concilio, o spettacoli sanguinosi d'uomini e di fiere, o torneamenti con pericolo di vita o di altre pruove inumane e spaventose, dette da' canoni purgazioni volgari ${ }^{727}$. E perché delle cose che cadono sotto questo terzo ordine molte ne sono che ricercariano discorso più amplo, noi riserviamo il parlarne altrove, secondo [p. 358] l'opportunità delle materie, massimamente vedendo che possono essere communi alle pitture sacre et alle profane. Per la qual ragione soprasediamo parimente ora di parlare di quelle del quarto ordine, che appartengono alle virtù e vizii dovendone parlare altrove più convenientemente.

\section{CAP. XXV.}

Abusi communi alle pitture sacre et alle profane. E prima delle pitture bugiarde e false.

Cominciaremo ora a discorrere degli abusi che possono essere communi alle pitture sacre e profane, non per astringerci ad abbracciare egualmente e queste e quelle, essendo il principale nostro proponimento rivolto alle sacre; ma, secondo che l'occasione richiederà et a noi parerà in proposito, non mancheremo d'inserire alcuni esempii ancora delle profane, e dove noi non lo faremo, potrà il lettore col giudicio suo applicare i difetti, che si noteranno delle sacre, proporzionatamente alle profane.

E per dare principio, parleremo al presente delle imagini bugiarde e false. Il qual sogetto potrà parere ad alcuno che sia stato da noi trattato ancor di sopra nel titolo delle erronee ${ }^{728}$; ma perché quelle comprendono solo cose pertinenti al Santo Officio in materia di fede e disciplina ecclesiastica, ora parleremo d'altri mancamenti che non sono di fede, ma però traviano assai dalla verità.

Dice S. Agostino ${ }^{729}$ che la falsità non è altro, quam significatio rei non ita se habentis ut significatur; il che appartenendo ad ogni sorte di rappresentazione che non conviene con la cosa rappresentata, o sia di voce, o d'altri segni, o ancor di similitudini, come sono le pitture delle quali parliamo, però intorno ad esse si può discorrere in tre modi: [p. 359] quanto al pittore, quanto alla

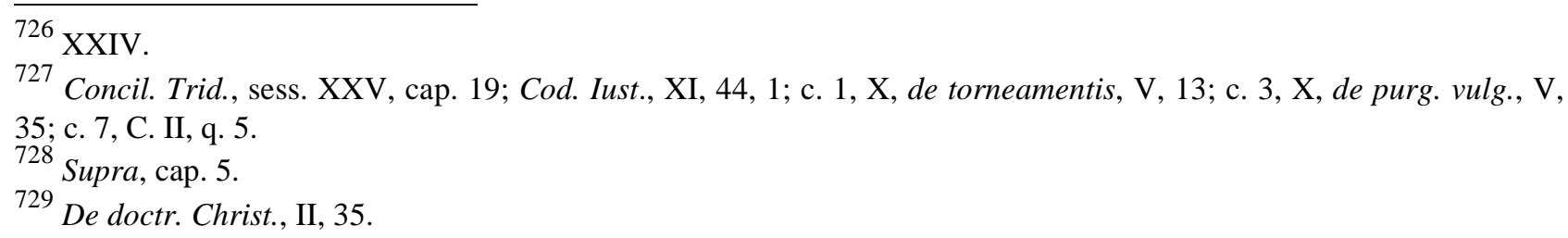


pittura e quanto a' riguardanti. Onde noi, se bene, seguendo tale descrizzione, potressimo largamente abbracciare ogni imperfezzione, per la quale in qualonque modo si tralascia la verità, ancor che sia per ignoranza, o per malizia, o per altri rispetti; nientedimeno non intendiamo di parlare altrimenti di quel difetto che procede dal pittore o dallo spettatore, né entreremo nelle dispute, trattate da' dottori, de errore, come essi dicono, in re vel intellectu, che non sono necessarie al caso nostro, ma solo ragioneremo di quella falsità che viene rappresentata agli occhi nostri dalla forma di alcuna imagine artificiata, senza che si abbia altro riguardo alla intenzione né del pittore né dello spettatore. Nel che chi volesse assotigliarsi potria forse dire che ogni pittura o scoltura regolarmente è falsa, però che mostra di essere quello che non è, essendo ella veramente una tavola disegnata o un sasso o un bronzo, e non un uomo vivo, come rassembra; onde diceva Platone ${ }^{730}$ che tutte queste arti erano più tosto cose di burla e di apparenza che opere sode, con queste parole: Ars quae imitatur, non id agit ut rei veritatem omnino repraesentet, sed imaginem tantum, et ideo pictor exiguum quoddam cuiusque rei attingit, nimirum simulacrum, quod procul abest a veritate. Nientedimeno, considerandosi che questa arte non è stata introdotta per rappresentarci la sostanzia delle cose, nelle quali consiste principalmente la verità, ma solamente la similitudine della verità, non potiamo dire che ella ne inganni, quando ci figura bene questa similitudine, facendo allora propriamente l'officio suo; ma solamente ci ingannerà quando non reppresenterà la similitudine che deve, e questo è che chiamiamo imagine falsa o bugiarda, perché manca dell'officio per lo quale ella è stata ritrovata.

Questa falsità dunque potrà considerarsi in due modi, o perché l'imagine rappresenterà uno oggetto falso, o perché, essendo l'oggetto vero, ella lo figurerà falsamente. [p. 360]

Si dirà anco l'oggetto falso in due modi: primo, se quello ch'è rappresentato non è mai stato né può essere, come chi dipingesse Augusto imperadore in un carro di fuoco volar per l'aria, o le Muse che nascessero da' tronchi di lauro o d'olivo, overo altre cose tutte finte et imaginate senza alcun fondamento di verità, di che si trovano molti esempii presso gli autori ${ }^{731}$ e noi in alcuni luoghi ne tocchiamo $^{732}$. E se alcuno dicesse che pur si leggono e dipingono simili favole degli antichi, e trasformazioni et altre cose, noi rispondiamo che ciò non toglie che la pittura non sia mendace secondo l'apparenza esteriore, poi che l'oggetto è falso, ma non per questo diciamo che tal falsità apporti difetto alla pittura, quando ella secondo l'arte rappresenti acconciamente quelli oggetti o favole, le quali furono anticamente admesse dagli autori per alcune similitudini di verità che rappresentavano, di che al suo luogo si ragionarà ${ }^{733}$.

Nell'altro modo si dirà l'oggetto falso, quando quel che si figura non è mai stato, ma avria però potuto essere, come chi rappresentasse il beato Polidoro da Castelfranco venire a Bologna et essere coronato re di tutta l'Italia; imperò che, se bene è chiaro che non è stato alcun beato Polidoro di quel luogo, che si sappia, e meno che sia stato coronato re, è però cosa che non è di sua natura impossibile e che avria potuto essere. Il simile si può dire di quella Giovanna ch'alcuni dipingono con la mitra et abito pontificale, e si ritrovano pittori tanto arditi, ch'anco ne tengono quadri venali di essa, il che è tutto menzogna et invenzione ridicola, la quale entreria nel numero delle pitture sospette o eretiche, quando s'avesse pensiero di significare che una donna fosse capace del sacerdozio. Ma perché si sa che non a questo effetto fu trovata, si ripone tra le bugiarde.

L'altro capo è quando l'oggetto è vero, ma si figura fal [p. 361] samente; il che accade quando

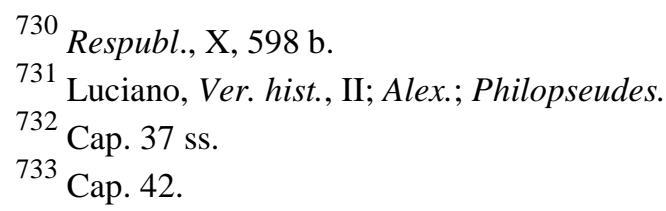


non si altera la sostanza o il fatto principale, ma solo si pervertiscono alcune particolarità e circonstanze di esso. E per meglio fare intendere il concetto nostro, diciamo che il termine actio, overo res, come parola che abbraccia tutta la sostanza del negozio, non numeramo noi tra le circonstanze, ancor che per altro rispetto alcuna parte dell'istesso negozio, chiamato dagli autori quid, vada posto tra le circonstanze ${ }^{734}$; ma noi presupponiamo ora tutta la azzione come fondamento delle circonstanze, essendo chiamate quelle $\pi \varepsilon \rho 1 \sigma \tau \alpha ́ \sigma \varepsilon ı \varsigma$, , cioè circumstantiae, quia circumstant rem, che è il fatto, talché il fatto è fondamento e circonstato, per dir così, e non circonstà. Avendo dunque noi di sopra parlato quando il fatto o fondamento è falso, parliamo ora quando, essendo vero quello, le circonstanze sue nondimeno sono false: imperoché, essendo necessario che ogni cosa naturale, o azzione umana o altro, sia stata prodotta in tempo, luoco e modo, da persona, da causa o con altre particolarità, secondo la condizione e soggetto di essa, e potendo il pittore errare, oltre le altre cose, in ciascuna di queste parti, o separate o unite insieme, poiché, secondo il detto volgare delle scuole, malum oritur ex singularibus defectibus ${ }^{735}$; però desiderando noi porgere qualche rimedio a schiera così grande di defetti che possono in ciò accadere, andaremo ora toccandone alcuni de' più principali e più frequenti, comprendendoli sotto nome di circonstanze o accidenti o proprietà, $\mathrm{o}$ in qualonque modo altri li chiamino ${ }^{736}$.

Perché, se bene sappiamo che la considerazione d'alcuni di essi in un modo appertiene al naturale, in altro al morale, in altro al retore o altre discipline, nientedimeno il punto nostro non consiste ora in distinguere dottrinalmente queste materie, ma in abbracciarle insieme, secondo che torna a proposito del pittore, la cui arte versa in sapere bene rap [p. 362] presentare tutte le cose imitabili, siano naturali o artificiali o morali o intellettuali, o di qualonque sorte. E perciò noi andaremo ora toccando alcune di quelle che possono essere materia del pittore, tralasciando l'altre che non possono da lui esprimersi, com'è la circonstanza del fine, del modo, del numero e simili altre, ch'eccedono talora la facoltà del pittore né si possono chiaramente rappresentare. E chiamiamo per ora false tutte quelle circonstanze o parti, che seranno dal pittore espresse contro la verità che sia apparente e notoria, o almeno così communemente tenuta e creduta dal commune consenso degl'intelligenti.

Comminciamo donque da quella che si chiama di quantità, nella quale errarà il pittore alterando la grandezza, picciolezza, longhezza, brevità, spazio o altra misura d'una cosa, come chi dipingisse il re Saul picciolo, dicendo la Scrittura ${ }^{737}$ che eminebat supra omnem populum ab humero sursum, o Zacheo grande, che dice S. Luca quod statura pusillus erat ${ }^{738}$; o Goliath di statura ordinaria, che pure si sa che era di forma gigantea ${ }^{739}$; o chi facesse Imola simile di circuito a Roma, come dicea quel pastore di Virgilio ${ }^{70}$ : Urbem quam dicunt Romam, Meliboee, putavi Stultus ego huic nostrae similem; overo, volendo rappresentare un essercito grande, come del popolo israelitico che esce d'Egitto, dove furono quasi seicentomilla uomini, senza le donne e putti ${ }^{741}$, e lo facesse di poco numero di persone; e in simil altri modi che occorrono nella considerazione della quantità.

Un altro errore si commetterà nel sito, come serìa facendosi gli antipodi stare sospesi in aria e col

\footnotetext{
734 Aristotele, Eth. Nic., III, 1.

735 Dionisio Areopagita, De div. nominibus, 4.

${ }^{736}$ S. Tommaso, Sum. theol., I-II, q. 7, a. 2.

${ }^{737}$ I Reg., 9, 2.

738 Luc., 19, 3.

${ }^{739}$ I Reg., 17, 4.

740 Buc., I, 19 s.

${ }^{741}$ Exod., 12, 35.
} 
capo verso il centro della terra; overo la beata Maddalena stare prostrata innanzi la faccia del Salvatore quando li lavava con le lacrime i piedi, leggendosi nell'Evangelio: stans retro secus pedes Domini $^{742}$; overo se a S. Clemente fosse legata l'ancora ai piedi, e non al collo, per sommergerlo. [p. 363]

Altro si dimandarà abuso di qualità, che riguarda varie circonstanze della persona, come quando si dipinge S. Giovanni Evangelista nel tempo che scrivea l'Evangelio, ch'era decrepito e di età presso a cento anni ${ }^{743}$, e nondimeno gli si farà la faccia da giovinetto senza barba; o quando si dipinge la madre de' figliuoli di Zebedeo, S. Giacomo e S. Giovanni, che s'accosta con essi loro al Salvatore per dimandarli la grazia che narra 1'Evangelio ${ }^{744}$, e si rappresentano questi figliuoli d'età fanciullesca, e pur erano già fatti apostoli.

Altro serà del luoco, come chi ponesse Roma in Asia, o Betlehem fuori della Giudea, o, dipingendo gli elementi, mettesse la terra sopra il fuoco e l'aere sotto l'acqua.

Altro si dirà di passione, come serìa dipingendosi S. Pietro decapitato, che pur si sa che fu crocifisso, overo S. Ignazio scorticato, che si sa che fu esposto preda a' leoni.

Altro si chiamarà di relazione, quando non si seguita il debito rispetto tra più cose, di che parlaremo nel titolo delle pitture sproporzionate, per essere materia che ricerca discorso separato.

Altro si dirà di azzione, attribuendo ad una persona quello che non ha fatto, come chi dipingesse S. Pietro in un fatto d'arme combattere, o S. Benedetto leggere in catedra in Salamanca, o S. Bernardo fabricare di sua mano la chiesa di Aracoeli, le quali cose sono affatto aliene da quello che si legge nelle vite e gesti loro. Potriasi ancor peccare in altro modo nell'azzione, attribuendo cosa che non conviene alla dignità della persona; ma di questo parlaremo nel capitolo delle pitture inette.

Altro serà del tempo, come chi dipingesse la guerra de' Filistei fornita da David ${ }^{745}$ farsi al tempo de' Macabei, o Moisè passare il Mar Rosso ${ }^{76}$ al tempo di Nabuchodonosor, o Numa Pompilio pigliare conseglio da Seneca filosofo.

Altro si chiamarà di abito, come seria di Elia, del quale [p. 364] dice la Scrittura, quod erat vir pilosus et accinctus renes zona pellicea ${ }^{747}$, e che il pittore lo formasse di corpo tutto delicato, e vestito di broccato; il che parimente si potria dire di S. Giovanni Battista ${ }^{748}$ e d'infiniti santi, de' quali restano le memorie autentiche che il loro abito era molto abbietto e vile.

A questi abusi se ne potriano aggiongere di molt'altri sotto varii nomi, ma, per fuggire il tedio della longhezza, ci basterà aver addotti questi per avertimento. Et avenga che alcuni d'essi potriano anco cadere sotto altri titoli più a basso, noi nondimeno li abbiamo ora compresi tutti sotto questo nome generale di falsità, poiché le pitture di essi sono contrarie al vero almeno in qualche parte, non volendo perciò lasciare di trattare d'alcuni più distesamente altrove, secondo che l'opportunità della materia lo ricchiederà.

\section{CAP. XXVI.}

Delle pitture non verisimili.

\footnotetext{
742 Luc., 7, 38.

${ }^{743}$ S. Girolamo, De viris illustr.

${ }^{744}$ Matth., 20, 20 ss.

745 I Reg., 17 s. 23.

${ }^{746}$ Exod., 14, 15 ss.

${ }^{747}$ IV Reg., 1, 8.

${ }^{748}$ Matth., 3, 4.
} 
Le pitture non verisimili sono differenti dalle false, in quanto che le false contradicono apertamente alla verità, queste non repugnano alle cose chiare e certe, ma a molta probabilità che occorre nel tutto o in alcuna circonstanzia di esso, onde si possono dire come di un grado inferiore a quelle.

E perché meglio si conosca la loro natura, è bene considerare che cosa noi chiamiamo verisimile, che per lo contrario s'intenderà quello che sia non verisimile.

Il verisimile non si può conoscere se non per notizia del vero. Il vero si piglia in più modi, come scrivono gli autori, [p. 365] ma noi, lasciando l'altre parti, pigliamo qui il vero prout est aequalitas signi ad rem significatam ${ }^{749}$, cioè quella pittura che si conforma intieramente con quello che si vuol rappresentare; perché ogni cosa, naturale o artificiale o morale, o di qualunque altra sorte, si presuppone fatta da certa persona et accaduta in certo tempo, certo luogo, con certa causa e certo modo, però ogni narrazione che vorrà spiegare una azzione o altra cosa vera e compita non doverà pretermettere alcuna di queste circonstanze. Onde il pittore, cui ufficio è d'imitare il vero, doverà precipuamente avere l'occhio a queste circonstanze, con le quali sta accompagnato il corpo della verità, procurando di chiarirsi bene di tutto il contenuto et ordine del fatto e secondo quello formare il disegno suo. Ma perché tutti i successi et ordini delle cose non si sanno, et infiniti sono tralasciati dagli autori, allora, volendosi esprimere quelle cose che non sono certe, si viene al verisimile ${ }^{750}$. Laonde narrazione verisimile si dirà quella, la quale spiegherà medesimamente tutte le circostanze dette di sopra, le quali accompagnano il vero; e perciò il verisimile è detto da' Greci cíkós, quasi $\tau \tilde{\varphi}$

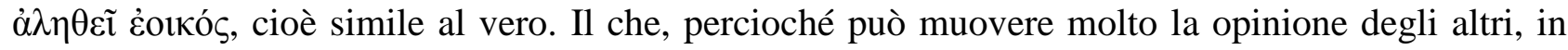

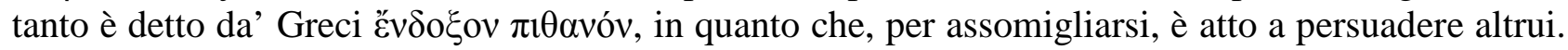
Né in questo intendiamo di stare su la distinzione minuta di probabile, opinabile, credibile e verisimile, perché, quanto al proposito nostro, ci basta il senso nel quale volgarmente suole essere da tutti inteso il nome di verisimile, essendo che ancora i retori chiamano verisimile quello che per lo più è tale, e si conviene alla natura, opinione e costume degli uomini ${ }^{751}$.

Dunque, essendo il verisimile quello che le cose, che non sono chiare e certe, porge così ragionevolmente e con le sue circostanze, che le rende persuasibili e quieta il commune [p. 366] intelletto delle persone, séguita perciò che non verisimile sarà quella pittura, la quale non contradirà già alla verità, perché quella saria falsa; né meno mancherà solo di alcune circostanze necessarie, perché questa saria più tosto imperfetta, come di poi si dirà; ma solo rappresentarà azzioni o cose contrarie ordinariamente alla natura, opinione, costumi e qualità degli uomini, degli animali, de' luoghi o di simile altra cosa. Né in questo ci restringemo noi solamente alle circonstanze dell'azzioni umane, ancor che sia solo proprio dell'uomo il considerare dette circonstanze nelle cose e paragonarle insieme; ma indistintamente l'applichiamo a tutte le cose, le quali, perché siano ragionevolmente rappresentate, ricercano necessariamente di essere accompagnate con alcune particolarità, o accidenti o proprietà che vogliamo dire: le quali, quando non si sappiano certe, né si dipingano secondo la probabilità che si ricerca, renderanno subito la pittura non verisimile.

E perché con gli esempii meglio si apprendono i concetti, potressimo, per esplicare questo, servirci delle medeme cose, dalle quali nel capo precedente abbiamo detto derivarsi le pitture false; perché, sì com'elle false si chiamano in quei casi, perché contradicono evidentemente alla verità, così, nei medesimi casi, non verisimili si diranno quelle che repugnano non alla certezza, che non si

\footnotetext{
${ }^{749}$ S. Tommaso, Sum. theol., II-II, q. 109, a. 1.

${ }^{750}$ Rhet. Ad Herenn., I, 9.

${ }^{751}$ Cicerone, De inv., I, 21.
} 
sa, ma alla credenza e commune opinione che si ha delle persone o delle cose di quei luoghi. Nientedimeno, per migliore esplicazione, toccaremo ancora alcuni capi principali, dai quali più chiaro si potrà conoscere quale intendiamo pittura non verisimile.

E prima diciamo che ciò può accadere o in cose universali, come nel dipingere battaglie, edificazioni di città, sedizioni de popoli, legazioni grandi, processioni publiche, entrate de prencipi, trionfi o simili atti, i quali non si esprimendo col numero convenevole delle persone e con la dignità e grandezza dell'azzione, si viene a causare la non verisimilitudine. Overo può accadere in cose particolari, le quali perché sono più frequenti, ne adduremo alcuni esempii specificati. Imperò che potria primamente derivare il non verisimile da [p. 367] tutto il corpo della persona ${ }^{752}$, come formandosi una donna di fattezza di corpo simile ad Ercole o Sansone, il che non conviene a quel sesso; overo da qualche qualità della persona come quando si figura il corpo di Nostro Signore in croce morbido e bianco, sì come communemente sogliono fare i pittori, senza alcun segno di livore o de flagelli: chi non s'accorgerà sùbito ciò essere non verisimile, essendo stato poco prima fierissimamente battuto e consumato ${ }^{753}$ ? Overo dall' abito e vestimenti, come accade nella pittura di santa Maddalena, piena di ricci e belletti e vanissimi acconci, dapoi che, ravedutasi dell'errore, si era prostrata a' piedi del Salvatore e facea professione di penitente ${ }^{754}$.

Potrà la non verisimilitudine ancora nascere dal luogo: come anticamente, in Gierusalemme, chi facesse gl'ippodromi, le terme, il Colliseo, il Pantheon et altre cose publiche a guisa di Roma, faria cose disdicevoli, perché gl'instituti della gentilità troppo erano diversi dagli ebraici; overo nella visitazione di S. Elisabetta ${ }^{755}$ dipingerla in un palazzo superbo con architravi e colonne di porfido, come fanno alcuni, molto difforme serìa alla condizione et instituto di sua vita; overo chi nell'alpi d'Italia dipingesse gli elefanti e camelli, e nelle valli di Chioggia gli abeti e i faggi.

Dal tempo ancor potrà causarsi: sì come nella passione del Salvatore nostro, quando afferma l'Evangelio che factae sunt tenebrae super universam terram ${ }^{756}$, chi figurasse nell'istesso tempo alcuno intento a leggere un libro o ritrarre qualche cosa o fare altro atto che ricerchi chiara luce, certo serìa non verisimile, essendo ottenebrato il cielo. Il simile accade quando nella medema passione, che era la stagione fredda ${ }^{757}$, si dipingono gli apostoli et altri mezzo nudi, senza vestimenti come se fosse stato di mezza estade.

Un altro esempio aggiongono alcuni, quando si dipingono varii santi congionti in un istesso quadro, i quali siano stati [p. 368] in diversi tempi: perché dicono che, dipingendosi questi santi non come beati in gloria, ma come ancor peregrini in questo mondo, non può esser verisimile, come serìa chi pingesse insieme S. Pietro, S. Silvestro, S. Ieronimo, S. Francesco e S. Antonino di Firenze, che furono in secoli molto diversi. A che noi consentiremo, quando si rappresentassero che parlassero insieme, o facessero tra di loro qualche azzione, perché senza interpretazione mistica malamente si potria difendere tal concerto. Ma quando tai santi si figurassero, come communemente si suole, con il trofeo in mezzo di essi del Signor nostro crocifisso, overo col Spirito Santo di sopra, o altro misterio celeste, non vediamo allora che repugni il rappresentare in una schiera diversi baroni principali della gloria del Signore, i quali tacitamente confessino, quasi uno a garra dell'altro, le grandezze di quel Dio, al quale essi già consecrarono la vita loro; sì come

\footnotetext{
752 Aristotele, Poet., 25.

${ }^{753}$ Matth., 27, 26 ss.

754 Luc., 7, 38.

755 Luc., 1, 39 ss.

${ }^{756}$ Matth., 27, 45.

${ }^{757}$ Ioan., 18, 18.
} 
non serìa da riprendere chi, volendo ridurre a memoria altrui uomini valorosi nell'armi, figurasse Alessandro Magno, Cesare, Temistocle, Scipione et altri simili raccolti in una istessa tavola, se ben furono in diversi secoli; o chi in una omilia, per invitar il popolo alla pacienza, raccontasse varii esempi de santi antichi e moderni. Che se ciò non si potria biasimare, perché non serà parimente lecito al pittore di fare il medemo col pennello, che a lui serve per penna o per favella? Anzi, si viene con simile pittura maggiormente a celebrare la perpetua provvidenza e cura che Dio conserva della Chiesa sua santa, poiché da quelli esempii, come da vivi raggi, si scuopre che giamai l'eterna misericordia non ha cessato di produrre al mondo in varii tempi molti suoi servi fedeli di diverse nazioni e di differenti professioni di vita, che hanno reso testimonio chiarissimo della potenzia e bontà sua.

$\grave{E}$ vero che, quando si dipingessero questi santi insieme senza la compagnia di altro misterio maggiore di quel Dio a cui servivano, talché non apparesse bene a che fine fossero stati posti insieme, potria allora causarsi dubitazione maggiore; la quale nondimeno facilmente si levaria con aggiungervi in [p. 369] luogo commodo alcune brevi parole, come serìa: Mirabilis Deus in sanctis suis $^{758}$; overo: Sancti et iusti gaudete in Domino; overo: Sancti qui in carne positi certamen habuistis etc. ${ }^{759}$, o altra cosa simile.

Dal modo ancor può causarsi il non verisimile; di che varii esempii si scorgono in molti atti dell'istessa passione, come nel coronarlo con le spine smisurate, nel batterlo alla colonna con flagelli inusitati, nell'inchiodarlo in croce con maniere stravaganti, nel deporlo di croce col capo in giù et i piedi in alto, et in molti altri atti poco conformi al vero, che nel IIII libro si diranno.

A questi si potriano aggiongere molti altri esempi di più circonstanze insieme non verisimili, come il dipingere gli apostoli con le berette in capo, o cavalcare gianetti, o che sonassero la citara; overo formare altre persone et azzioni con alcune sorti de vestimenti, insegne, bandiere et armi che non si adoperavano nel tempo che si figura, o con arbori a lato et animali che non nascono in quei paesi; con apparecchi di tavole, modo di mangiare, vivande et altri servigi introdotti solo ne' nostri tempi; con giuochi, balli, nozze, sacrificii, administrazione della giustizia, trionfi, assedii di città, fatti d'arme et altre molte simili cose, nelle quali spesso si scorgono grandi sconvenienze e conseguentemente fanno che si conosca se il pittore è, come doveria essere, perito delle istorie, poiché fa professione di dipingere ogni cosa. Onde doverà almeno stare grandemente avvertito nel pigliare le imprese e consigliarsi prima con persone prattiche e di intelligenza.

E per fine di questo capitolo vogliamo avvertire che, nel dare giudicio tra le cose false o vere o non verisimili, è molta prudenza l'andare riservato, prima perché alcune cose paiono non verisimili secondo la natura sua, che però sono verisimili per qualche accidente avvenuto: come si trova scritto anticamente ${ }^{760}$ della imagine di Ercole in Lidia, che era ve [p. 370] stito d'abito feminile con la rocca e la lana, la quale imagine, considerata la persona di Ercole, pareria lontanissima da ogni verità, ma chi intende poi dei lazzi di donne in che si trovò talora involto, non parerà più non verisimile. Di poi perché la imbecillità nostra è tale, che allo splendore della verità s'abbagliano gli occhi nostri, come di notturni uccelli, e talora ci parono le cose vere o verisimili, che sono manifestamente false, e talor ancor riputaremo essere falso quello che non solamente non è non verisimile, ma è forsi ancor vero. Onde disse quel savio ${ }^{761}$, che alcuna volta la bugia s'assomiglia

\footnotetext{
758 Psalm., 67, 36.

${ }^{759}$ Cfr. Matth., 5.

${ }^{760}$ Luciano, De hist. conscrib.

761 Aristotele, Top., VIII, 10.
} 
più alla verità, che la verità istessa; e scrive un orator greco ${ }^{762}$ d'uno che accompagnava le cose che diceva sempre con tante circonstanze e di luoghi e di tempi e di persone e di altre minuzie, che pareva la istessa verità, e pur era bugia. Et un altro autore ${ }^{763}$ scrive che sono alcuni di natura buoni, giusti, temperati e di molto sapere, i quali però nel suo parlare spesso dicono bugie, onde con l'opinione et autorità delle altre buone parti loro vengono ad ingannare le persone. Perciò per fare vero giudicio delle cose serà ottimo conseglio l'andare molto cauto e considerato.

\section{CAP. XXVII.}

Delle pitture inette et indecore.

Già dicemmo che può una pittura peccare in varii modi, e però soggiacerà a varii titoli d'abusi secondo diversi rispetti: imperò che potrà alcuna nominarsi falsa, in quanto ripugna alla verità, e non verisimile rispetto ad alcuna circonstanza, e sproporzionata per altra ragione, e per altra inetta.

Or donque siamo per parlare delle inette, le quali pec [p. 371] cano in una sorte di circonstanza, che, per essere molto principale, e che tira seco molt'altre imperfezzioni, ricerca da noi particolar discorso, massimamente che, nel dichiarare propriamente che cosa sia questo inetto e che sorte di abuso egli sia, non convengono tra loro intieramente li scrittori.

Approvano bene tutti ch'ogni operazione, perché riesca lodevole, deve avere la debita corrispondenza in tutte le circonstanze, a guisa di perfetta musica che rende la sua armonia proporzionata in tutte le $\operatorname{voci}^{764}$, e dicono che quella virtù ch'opera ciò da' Latini è chiamata decorum, e da' Greci $\pi \rho \varepsilon ́ \pi$ ov, la quale, quando per caso venghi in parte alcuna a mancare, lascia nel corpo dell'opera quella nota e quello sconcerto che communemente si chiama inetto.

Dicono anco che il sapersi valere bene di questo decoro è dono di singulare eccellenza, nascendo ciò dal trono regale della prudenza, virtù esquisitissima che modera tutte le cose; e che l'accommodare un'azzione sì che non offenda in parte alcuna né gli occhi, né l'orecchie, né il giudicioso conosciscimento [sic] delle persone, è impresa difficilissima sopra tutte l'altre operazioni, il che è da Cicerone ${ }^{765}$ affirmato ove dice: Ut in vita, sic in oratione nihil est difficilius, quam quod deceat, $\pi \rho \varepsilon \dot{\pi}$ ov appellant Graeci, nos dicamus sane decorum; huius ignoratione non modo in vita, sed saepissime et in poematis et in oratione peccatur; onde, parlando Platone ${ }^{766}$ appunto di un pittore, in questo proposito scrisse: Si quis figuram hominis pingentem vituperaret, quod pulcherrimis partibus non apponat pulcherrimos colores (oculi enim pulcherrimum membrum non purpura sed colore nigro pinguntur), decenter respondere videbimur, dicentes non oportere nos adeo pulchros oculos pingere, ut non videantur oculi, ac cetera membra similiter, sed considerandum esse si, singulis decorum suum tribuentes, totum pulchrum reddamus. [p. 372]

Ma quello in che si trova disparere tra essi è ch'alcuni hanno formato come due specie di decoro, l'una quanto all'affetto, l'altra quanto a' costumi. Altri hanno confuso il decoro col verisimile, pigliando indifferentemente l'uno per l'altro; altri ancor hanno preso questo nome generalmente per quella virtù che distribuisce o accompagna non solo l'azzioni degli uomini, ma tutte le cose, naturali o artificiali, sensibili o insensibili, con la debita ragione, tal che non metterà una tigre in compagnia

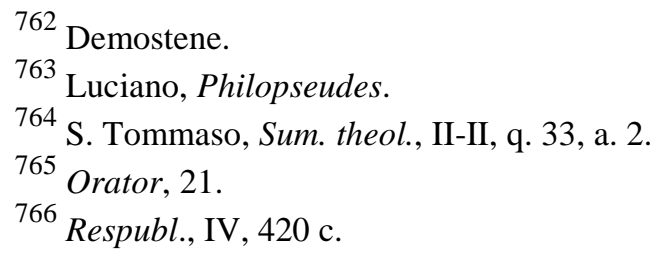


d'un agnello, né farà nascere il grano nel mese di gennaro, o produrre gli arbori in mezzo de' fiumi, o congregarsi gli augelli al suono d'una viola, o zapparsi la terra da un contadino con una lanza.

Ma noi, lasciando le contese ad altri, ci appigliamo al parere de' più savii, che attribuiscono il decoro propriamente alla dignità della persona, e per lo contrario chiamano inetto quello che pecca, attribuendoli azzione, costumi, affetto o altro che non conviene alla età, sesso, abito o grado di lui $^{767}$; il che da Cicerone ${ }^{768}$ pare che fosse assai ben significato, quando disse: Quem nos vocamus ineptum, is mihi videtur ab hoc nomen habere deductum, quod non sit aptus, idque in sermonis nostri consuetudine perlate patet; nam qui quod aut postulet tempus non videt, aut plura loquitur, aut se ostentat, aut eorum cum quibus est vel dignitatis, vel commodi rationem non habet, aut denique in aliquo genere inconcinnus aut multus est, is ineptus dicitur.

Noi donque in questo senso ora abbiamo intitolato questo capitolo «Delle pitture inette», non quanto all'arte del disegno rozzamente fatto, ché di questo non ragioniamo, ma intendiamo trattare di quello errore che si commette col non darsi alla condizione della persona quello che se li deve; il che può accadere quanto al tempo, al luoco, al modo, o ad altre molte circonstanze, ciascuna delle quali, mal usata, rende la figura come parto storpiato e che non abbia la perfezzione [p. 373] de' suoi membri, e fa conoscere l'artefice per inetto pittore. Imperò che la pittura, come ognuno sa, è arte imitatrice, e quello dipinge bene che ben imita; né mai imita bene chi non imita le cose o come furono, o come è ragionevole che fossero, massimamente quanto alla condizione della persona, che è la principale tra tutte le cose che si possono imitare.

E perché meglio s'intenda l'intenzione nostra, addurremo alcuni esempii di pitture che si conoscono peccare in ciò. Il che avressimo potuto fare con molto maggiore varietà de casi, che pur troppo frequenti si scorgono in varii luoghi, ma noi n'abbiamo per ora scelto solamente alcuni dei misterii della Madonna, come quei che sono più in uso e notizia del popolo, dalla cui somiglianza facilmente si potranno discernere gli errori ancora dell'altre pitture sacre e profane. Né manco in questo l'intenzione nostra è di abbracciare tutte le particolari circonstanze che possono causare l'inetto, di che si è trattato di sopra nel capitolo delle pitture false; ma per ora ne toccaremo solo alcuni de' più principali e che più chiaramente si veggono accadere nelle pitture proposte della Madonna.

Incominciando donque dalla qualità della persona, chiamano inetta ogni pittura di essa, che sia formata con faccia colorita, liscia, grassa e quasi lasciva, che è errore insopportabile.

Dall'abito poi, quando, sendo ella la vera idea dell'umiltà e modestia, vien rappresentata con ricci, vestimenti et ornamenti pomposi e vani, e fino con le perle e pendenti alle orecchie, che fa stomaco a vederla.

Dal luoco, quando si dipinge la stanza dove fu annonciata dall'angelo Gabriele, la quale si ha da credere che fosse conforme alla verginale sua semplicità, anzi, come ancor oggi chiaro si vede nella santa Casa di Loreto; e nientedimeno molti vi aggiongono fuori della stanza colonne alte, e dentro padiglioni ricchi, et altre superfluità molto lontane dalla professione sua. Overo quando altri la dipingono col capo scoperto trovarsi nel tempio di Ierusalem, cosa molto inde [p. 374] cente a quella somma onestà et alla venerazione che ella portava alle cose sacre.

Dal modo, come quando da alcuni si dipinge che, ascendendo ella per i gradi nel tempio, va filando; da altri che avendo smarito il figlio nel tempio, va scorrendo qua e là scapigliata per trovarlo; e da alcuni altri che, vedutolo su la croce, si straccia le vesti, lacera le guancie e si percuote il capo co' pugni: azzioni tutte e modi molto sconvenevoli alla vita e sapienza sua.

\footnotetext{
${ }^{767}$ Aristotele, Rhet., III, 7; Eth. Eud., III, 6.

768 De orat., II, 17.
} 
Dal tempo, come quando ella si dipinge, dopo la morte del suo unigenito figliuolo, andare con le Marie al santo sepolcro per ongere il suo sacratissimo corpo; pensandosi il pittore di favorirla con questo singolar atto di pietà, e non vede che ciò deroga alla grandezza della fede, che in lei non vacillò mai, della divinità del figliuolo: perché, essendo ella certa della resurrezzione, sciochezza serìa stata andare con gli unguenti alla sepoltura per preservare il corpo dalla putrefazzione.

Sono molt'altre simili cose, et anco maggiori, che si trovano espresse da pittori ignobili; le quali, quanto versano più intorno ad alcune circonstanze basse e certe minuzie troppo puerili, tanto più rendono la pittura sprezzabile et inetta, e causano che, chiunque la riguarda, non solo biasimi il giudicio, ma si rida insieme della sciochezza del pittore. Onde noi per degni rispetti le tralasciamo.

\section{CAP. XXVIII.}

Delle pitture sproporzionate.

Per trattare questa materia delle pitture sproporzionate, non pensiamo che sia necessario discorrere per via di dottrina quello che propriamente si chiami proporzione, sapendosi che secondo varie discipline diversamente è stato usato questo [p. 375] termine dagli autori, altrimente pigliandosi da geometri, altrimenti da aritmetici, altrimente da naturali et altrimente talora da teologi e da diversi altri ${ }^{769}$.

Ma noi, che serviamo più all'uso del mettere in prattica regulatamente le imagini, che a cose di speculazione, pigliando ora questa voce in quanto può convenirsi alla facoltà del pittore, acciò che schifi quelli errori che sogliono rendere una pittura sproporzionata, diciamo che in doi modi principalmente si può considerare la proporzione nelle imagini: l'uno è quanto alla convenevolezza e debita consonanza di due o più cose insieme; l'altro è considerando la corrispondenza delle parti col suo tutto. Et in amendue modi, quando si troveranno le figure servare buon concerto e ragionevole unione insieme, si dimanderanno pitture proporzionate; e, per lo contrario, sproporzionate seranno quelle che mancheranno di questa tacita intelligenzia tra loro.

Cominciamo donque dalla sproporzione di più cose insieme, la quale si può considerare in parti congionte o separate. Congionte seranno, come in un corpo formare un braccio longo et un corto, una gamba grossa e l'altra sottile, un occhio grande e l'altro picciolo, una guancia larga e l'altra

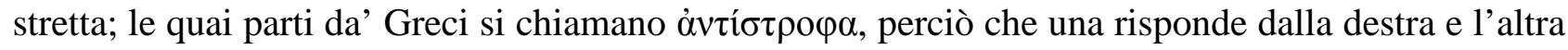
dalla sinistra, e sono e debbono essere eguali fra sé. Si possono nondimeno considerare ancora le parti altrimente sproporzionate, se bene non siano antistrofe, come formandosi in un corpo braccia carnute e grosse, e le gambe picciole e sottili, overo l'orecchie longhissime et il naso piccolissimo, che s'accosta al monstro. I quali però tutti chiamiamo errori di sproporzione, quando quello che si rappresenta non si trovi di quella maniera; an [p. 376] cora che, quando fosse così, serìa sproporzione non nella pittura, ma nella cosa.

Disgionti seranno, quando in uno stesso piano si figurassero varie cose, come uomini, animali, arbori, edificii, talmente che, paragonandosi insieme la grandezza, riuscessero gli edificii a guisa di montagne, e gli uccelli come elefanti e gli uomini meno che nani: il che perché appartiene propriamente all'arte del disegno, noi in ciò non ci estenderemo.

\footnotetext{
${ }^{769}$ Euclide, Elem., V; Aristotele, Eth. Nic., V, 3; Boezio, In Porph. Isag., II; S. Tommaso, Sum. theol., I, q. 12, a. 1, ad 4; II-II, q. 61, a. 2. 4; S. Bonaventura, In III Sent., d. 1, a. 1, q. 1; Nicola Cusano, De docta ignorantia, I, cap. 7; G. C. Scaligero, Exotericarum exercitationum liber quintus decimus, de subtilitate, ad Hieronymum Cardanum (1557), p. 895.
} 
Ci è un'altra sproporzione pur di cose disgiunte, che più tosto appartiene al discorso et intelletto, il quale subito penetra a considerare se quello che è figurato ha la sua debita ragione con l'altre cose accompagnate. E di questa sproporzione sono più specie, tra le quali una si chiama da alcuni di relazione, et è quando di due cose, che si riferiscono l'una all'altra et una è più antica dell'altra, come padre e figliuolo, si rappresenta nondimeno quello che è più vecchio con faccia di più giovine, come aviene quando si dipinge la beata Vergine che tiene in braccio il sacratissimo suo figlio già morto, e si figura la faccia della madre di aspetto giovenile a pena di 25 anni, e nondimeno il figlio già n'avea 33 .

Il simile accade quando alcuni formano S. Giovanni Battista in compagnia del Salvatore, et a quello fanno viso di giovinetto, e questo rappresentano con la barba longa, tra i quali nondimeno era differenzia di tempo solo di sei mesi ${ }^{770}$. L'istesso occorre in molt'altri esempii, che possono convenire ancor alle pitture false.

Un'altra sproporzione, largamente parlando, di più cose insieme suoi notarsi, quando elle non hanno alcuna convenienza insieme e paiono fatte a caso: come il dipingere in un quadro uno che suona la viola, altro che coglie fichi dall'arbore, altro che va correndo a cavallo, et un cingaro che numera denari, e simile altre cose.

L'altra sorte di sproporzione poi è quando le parti di [p. 377] scordano dal tutto: il che meglio si conoscerà, intendendosi che, quello che si chiama bellezza, fu detta da Platone $\sigma v \mu \mu \varepsilon \tau \rho i ́ \alpha \tau \tilde{\omega} v$ $\mu \varepsilon \lambda \tilde{\omega} v$, e da Cicerone ${ }^{771}$ apta membrorum compositio, volendoci significare che dalla proporzione nasce quel vago e grazioso che si chiama bello. Onde diciamo bella faccia e bella persona, che ha proporzionati tutti i suoi membri; dal che segue che sproporzionata e priva di bellezza si dirà quella pittura, dove le parti non corrisponderanno col tutto.

Queste parti donque si possono anch'elle considerare o congionte o disgionte: congionte seranno, come fare il capo di fanciullo ad un corpo grande e virile, overo porre la faccia d'un colosso ad un nano, e come anticamente descrissero i poeti quel suo chiamato Cupidine, che si vestiva i panni et armatura di Ercole; overo chi dipingendo un fanciullo, li ponesse in mano una spada nuda maggiore di tutto lui.

Parti disgionte seranno e sproporzionate col suo tutto, quando si troveranno in una tavola varie figure che non abbiano convenienza col luogo, col misterio o con quell'opera che si vuol rappresentare: perché allora si considera la tavola, o la facciata, o la capella, o la chiesa dov'è l'istoria, come il tutto, e le figure sono come parti d'esse. In questi casi adonque sproporzione rispetto al luogo serà quando quello che si figura non ha convenienza alcuna con il luogo che si piglia per il tutto: sì come il dipingere in una chiesa un convito o danza; o in una libraria un fatto d'arme o una cacciaggione; et in una infermaria il Concilio di Trento; o nella sala dei cavallieri Moisè o David che pasce le pecore; o nella stanza della dispensa di casa pingerli il corso del sole per il zodiaco, o quando si eclissa la luna.

Rispetto al luogo ancora un'altra sproporzione si potrà considerare, quando in un luogo piccolo s'inculcano senza necessità cose molte e grandi, che non compatiscono con quel sito, o secondo la proporzione non potriano ivi capire; sì come anticamente fu notato quel pittore che avea figurato a [p. 378] seder Giove di tal grandezza, che, se si fosse levato in piedi si romperla il capo nel tetto.

Si suol considerare da alcuni quella ancor per sproporzione di più cose insieme, quando non sono distribuite a' suoi proprii luoghi; non altrimente che faria un vasaio, mettendo il fondo dove va la bocca del vase. Così aviene quando il pittore non dà il luoco alle cose che figura, secondo la

\footnotetext{
${ }^{770}$ Luc., I, 25 s.

${ }^{771}$ De off., I, 28.
} 
condizione e dignità loro, e mette dai lati quello che dovria essere posto in mezzo; overo, pretermettendo quello che è lo scopo principale dell'istoria, pone maggior diligenza in quello che non importa tanto, facendolo apparire più agli occhii ${ }^{772}$ : sì come nella conversione di $\mathrm{S}$. Paolo si vedono molti pittori consummare tutta la sua cura in figurare un cavallo bello e gagliardo, e questo hanno per principale, né del resto si curano più che tanto; e nell'adorazione de' Maggi si affaticheranno per fare un camello meraviglioso, o un moro carico di presenti, et a quello danno il più bel luoco nel quadro, talmente che a pena si scorge dove sia il sacro fanciullo che si ha da adorare.

Un'altra sproporzione ancora rispetto al tutto pongono alcuni, quando con le imagini massimamente sacre, o di cose gravi, s'aggiongono altre che sono fuori di quello soggetto e che non hanno a fare punto con l'opera principale; le quali i Greci chiamano $\pi \alpha ́ \rho \varepsilon \rho \gamma \alpha$ : come serìa, dipingendosi il Signor nostro quando è crudelmente flagellato alla colonna, l'aggiongervi da un lato, se bene con disegno di lontana prospettiva, un putto che scherza con un cane, o una battaglia d'uccelli, o un contadino che pesca ranocchi, o altre simil cose che s'imaginano i pittori, non avendo risguardo se ciò risponde a quello che hanno per le mani.

Molt'altri esempii si potriano addurre, che ascrivono alcuni all'abuso di sproporzione; ma dalle cose già dette intorno a ciò si potrà raccogliere quanto è necessario.

[p. 379]

\section{CAP. XXIX.}

Delle pitture imperfette.

Si può chiamare una pittura imperfetta in varii modi. Primo, considerandola come opera d'uomo, che, essendo per lo peccato rimaso fiacco e debilitato, non può produrre se non azzioni molto difettose; e di questa imperfezzione noi non parliamo. Secondo, considerandola come cosa fatta da pittore, e questo ancora in più modi: o fatta da artefice che non sa e però manca nei precetti dell'arte del disegnare, adombrare, colorire e simili cose; overo che non vuole o non può compire l'opera, come aviene quando solamente è abbozzata e non postavi l'ultima mano: il che soleva significare Apelle, se bene ad altro fine, quando nelle sue pitture aggiungeva le parole Apelles faciebat ${ }^{773}$; ma né anco di questa imperfezzione ragioniamo. Overo si può considerare un'opera imperfetta, quanto alle cose che si averiano da rappresentare e quanto alla istoria che si è proposta di figurare; e di questa sorte d'imperfezzione al presente intendiamo.

Diciamo donque che si formano talora alcune opere che mancano o nelle parti sue integrali, o nel numero delle cose da isprimersi, o in altra circonstanza necessaria; tal che facilmente, da chi ha giudicio, si conosce che in essa non è stato compreso tutto quello che si conveniva, e conseguentemente che resta l'opera manca et imperfetta.

Per esempio, il dipingere un santo senza la diadema e corona, che è il segno della santità, si può dire imperfezzione. Così il dipingere li martiri o confessori senza le sue insegne solite et approvate dall'uso della santa Chiesa: come S. Lorenzo senza la graticola, santa Caterina senza la ruota e ra [p. 380] sori, santo Sebastiano senza le saette e santo Ambrosio senza il flagello in mano. Tutte queste cose arguiscono imperfezzione, perché a ciascuno d'essi è stata attribuita tale insegna non solo per discernerlo dagli altri santi, ma come istromento della gloria e trofeo onde egli ha vinto il

\footnotetext{
${ }^{772}$ Luciano, De hist. conscrib.

${ }^{773}$ Plinio, Nat. hist., praef., 26.
} 
mondo, e che però debbe sempre accompagnarlo. O vero chi dipingesse il tempio di Salomone senza le colonne, o senza l'atrio, o senza il santuario o altre parti sue ${ }^{774}$. Overo chi figurasse il sommo sacerdote con gli ornati e vestimenti suoi ${ }^{775}$, e vi lasciasse o il razionale, o il supernumerale, o il turibolo, o i tintinaboli, o simili parti, non è dubbio che tutte queste seriano imperfezzioni, che con infiniti altri esempii si potriano longamente narrare.

Nel numero ancora si scorgerebbe la medesima imperfezzione, quando, figurandosi la cena del Signore, dove mangia l'agnello pascale con gli apostoli ${ }^{776}$, non si dipingessero tutti i dodici apostoli, ma solamente sei, overo otto; et il medesimo facessero nel misterio della Pentecoste ${ }^{777}$, o altrove, dove è certo il numero. O chi dipingesse la lapidazione di santo Stefano con un solo che lo lapidasse $^{778}$; overo chi figurasse 1 'arca di Noè con poche specie solamente d'animali dentro ${ }^{779}$; overo l'essercito del re degli Assirii con poco numero di gente e de soldati ${ }^{780}$.

Serìa parimente imperfezzione il tralasciare alcuna circonstanza necessaria: sì come se, rappresentandosi il misterio della natività di nostro Signore, si tralasciasse il presepio, o il bue o l'asino ${ }^{781}$; o nei misteri della passione non apparisse la colonna o la corona di spine ${ }^{782}$; overo se, figurandosi alcuno dei sacramenti della santa Chiesa, sì come la collazione degli ordini che fa il vescovo, o la celebrazione d'un matrimonio fatta dal sacerdote, non si esprimessero quelle cose e riti che sono di necessità secondo l'uso di santa Chiesa, e che ci insegna il Pontificale e Sacerdotale e sacro Concilio. [p. 381]

Ma perché questa sorte d'imperfezzioni, potendosi stendere in tutte le sorti di pitture, forse potria indurre alcuno in errore contrario a quello che noi intendiamo, però, per più chiarezza del sentimento nostro et avertimento di chi leggerà, soggiungeremo le infrascritte cose.

Prima, che, se bene biasimiamo le pitture di questa maniera imperfette, non intendiamo però volere con questo ubligare un pittore a fare minutamente ogni particella che pertenga a quella imagine o azzione o misterio che rappresenta; ma intendiamo solo delle cose che sono sostanziali dell'opera, overo accidentali necessarie. Onde, peroché questo ricerca giudizio e perizia, saggio sarà quel pittore che, dovendo dipingere cose ecclesiastiche, se ne consiglierà prima con persone perite et intendenti di quelle.

Secondo, si ha d'avertire che alle volte in un medesimo misterio si comprendono due o più azzioni diverse, le quali non è tenuto il pittore di abbracciare tutte; e lasciandone alcune, non però si dirà la pittura imperfetta: sì come nella cena ultima del Signore sappiamo tutti che altro fu il mangiare l'agnello, altro la instituzione del sacramento ${ }^{783}$, altro il lavare de' piedi agli apostoli ${ }^{784}$. Onde non sarà difettoso il pittore, se, volendo rappresentare l'atto del mangiare alla mensa, tralascierà la abluzione dei piedi o la Eucaristia, perché sono azzioni diverse.

Terzo, ricordiamo che ci è una sorte d'imperfezzione, per dir così, perfetta, et una diminuzione

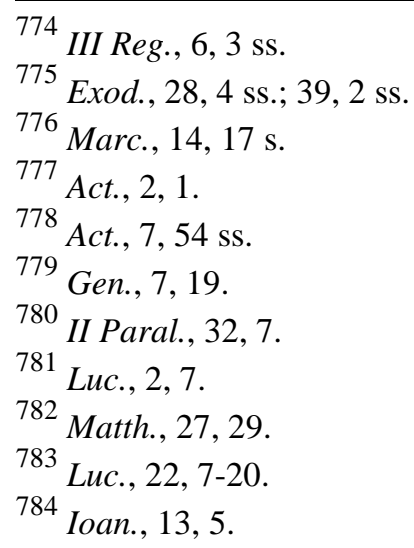


con augumento, a guisa di quella figura de' retori chiamata $\dot{\alpha} \pi 0 \sigma i \omega ́ \pi \eta \sigma \iota \varsigma$, che col tacere significa cose maggiori $^{785}$. Così nella pittura si possono e si devono spesso dipingere le cose in tal maniera, che, col tralasciarne alcuna e solo accennarla destramente, s'imagini lo spettatore cose maggiori tra sé medemo; la qual fu lode di gran meraviglia principalmente attribuita a Parasio, come scrisse Plinio $^{786}$, soggiongendo queste parole: Extrema corpo [p. 382] rum facere, et desinentis picturae modum includere rarum in successu artis invenitur; ambire enim debet se extremitas ipsa et sic desinere, ut promittat alia post se, ostendatque etiam quae occultat. Ond'è celebre l'atto che fece quel pittore detto Timante, del quale scrive l'istesso Plinio ${ }^{787}$ che, avendo dipinta Ifigenia che stava per essere sacrificata in presenzia de molti e tra gli altri di un suo zio e di suo padre, non li dando animo di esprimere pienamente la mestizia del padre, li coperse la faccia con un velo: Cum maestos, dice egli, pinxisset omnes, praecipue patruum, et tristitiae omnem imaginem consumpsisset, patris ipsius vultum velavit, quem digne non poterat ostendere; dal cui esempio veggiamo alcuna volta molto giudiziosamente farsi da valenti pittori, che, nel rappresentare le Marie a' piedi del Signore nostro crocifisso ${ }^{788}$, volendo esprimere la grandezza della amaritudine loro, sogliono figurarne alcune col capo chinato in seno, e con le mani e manto coprirsi la faccia, per dare segno di maggior cordoglio e di acerbità inesplicabile. Questo però, se bene più tosto appertiene all' arte del disegno, ci è parso nondimeno di non tralasciarlo, potendo anco servire alla tessitura delle cose istoriche, dove alle volte lo usare simile arte serve ad isprimere più efficacemente quello che si intende.

\section{CAP. XXX.}

Delle pitture vane et oziose.

Siegue ora il ragionare di quelle pitture che si chiamano vane; il qual nome potria rendere forsi dubitazione, essendo che ogni pittura in certo modo si può dire vana, per essere come ombra e figura della verità, onde va per le bocche de molti il verso di Virgilio ${ }^{789}$ :

\section{[p. 383]}

\section{Atque animum pictura pascit inani.}

Nientedimeno, avendo la pittura il proprio suo ufficio, che già abbiamo dichiarato ${ }^{790}$, chiamiamo in questo proposito vane quelle pitture che si scostano da tale ufficio, né mirano cosa relevante, ma solo a pascere gli occhi senza sodo frutto. In questo numero però non comprendiamo quelle che, fatte con certa ragione, servono a coprire la bruttezza de' legni, de' mattoni, de' tavolati, ad ornamento de' muri, e simili altre cose, come di sopra abbiamo discorso ${ }^{791}$. Parliamo al presente d'altre sorti di pitture, che rappresentano varietà di cose, o favole, o altre invenzioni, né hanno alcun fine certo, se non di stendere col disegno e colore quello che al pittore sia venuto in fantasia per dare trattenimento a chi lo riguarda. E perché tale materia suole variamente essere intesa da molti, abbiamo giudicato conveniente di mettere in considerazione alcune cose, accioché, avvertitone, il

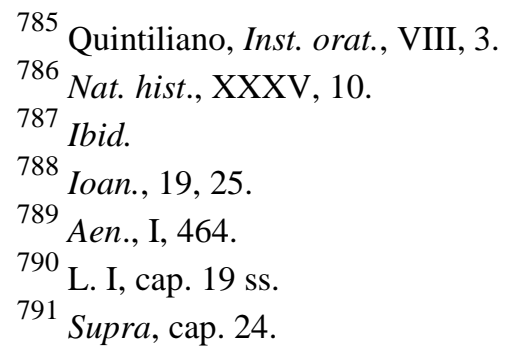


lettore possa per l'avenire aggiongere qualche maggior industria a simili invenzioni, riservandoci di trattare a parte delle grottesche, se bene hanno qualche similitudine insieme.

Mostrassimo altre volte con varie ragioni, che le imagini tra cristiani devono avere principale riguardo al giovare. Or v'aggiungiamo che è stata opinione accettata da' dotti ${ }^{792}$ che gli atti degli uomini si possono secondo la sua specie considerare di tre sorti: l'una, di quei che sono buoni, perché conformi alla ragione; l'altra, de' cattivi, perché sono difformi dalla ragione; e la terza, di altri che sono come mezzani, perché necessariamente non includono né questo né quello, come è l'andare in piazza, leggere una carta, levare da terra una pietra e simili, che possono applicarsi a bene et a male, e Però sono stati domandati atti indifferenti. E secondo questa opinione pareria che tali pitture chiamate vane non si avessero da sprezzare, essendo cose mezzane, che si possono riferire a buono uso. Ma si ha d'avertire che quella opinione è stata ancora dichiarata in questo modo $^{793}$, cioè che tali atti, [p. 384] considerati di poi, come dicono, in particolare nella persona di questo o di quello che gli opera, non sono più indifferenti, ma necessariamente riescono dell'uno dei primi due ordini, cioè o buoni o cattivi; poiché, dovendo l'uomo operare secondo la natura sua, ch'è ragionevole, ha da fare ancora le cose sue sempre deliberatamente, dirizzandole a qualche fine, e però non si deve più chiamare atto indifferente. Che se pur alcuno farà talora qualche cosa senza deliberazione o considerarvi sopra, allora questa azzione potrà chiamarsi actio hominis, ma non già actio humana, per usare il termine loro ${ }^{794}$.

Da questo vogliamo inferire che noi applichiamo questo nome di vano alle pitture, benché siano dilettevoli all'occhio e quantunque ancor siano di sua natura indifferenti. La ragione è perché il fine della pittura cristiana non è solo di dilettare, ma di giovare insieme; onde si chiama vana, quando non conseguisce tutto questo. Non basta ancor l'essere indifferente, perché non fa per un cristiano lo stare in questo pendente, ma ha da ricercare che ogni cosa gli sia istrumento di operar bene, essendo esso nato alla virtù, né si ha da contentare di astenersi dal far male, ma deve sempre crescere nel bene. Veggiamo ch'Iddio ha creato tutte le cose buone, e niuna cattiva o superflua; parimente diciamo che l'uomo, creato all'imagine e similitudine sua, e la pittura, che è una imitazione delle cose, non deve stare in questo mezzo di oziosità, ma essere sempre dirizzata ad uso buono: perché, se di una parola sola momentanea e fuggitiva, purché sia oziosa, siamo in obligo di renderne conto a Dio ${ }^{795}$, quanto più d'una opera durevole e fatta con deliberazione. Sappiamo bene che di molte cose che paiono indifferenti uno ne potrà cavare utile, dove forse l'altro non ritrarà se non danno, per la disposizione di chi l'usa e diversità dei fini che si propongono; e che però non si può dire assolutamente che tutte queste sorti di pitture a tutte le sorti di persone siano inutili [p. 385] o causino danno, perché chi è dotato di spirito e di giudicio può e dalli uccelli e dai pesci e dai fiori e dalle citare e dai sassi cavare gran filosofia; anzi, a questo fine stanno esposte agli occhi nostri tutte le cose create di questo mondo, acciocché, medianti quelle che si veggono, entriamo in cognizione e desiderio delle eterne, che non si veggono.

Tuttavia, perché pochi sono quelli che ascendono a questa speculazione, noi, parlando per l'ordinario, chiamiamo pitture buone e convenevoli quelle che di natura sua e proprietà ci rappresentano cose lodevoli et utili da sapersi per uso della vita umana; e pitture cattive, quelle che causano contrario effetto negli animi nostri; e l'altre di poi oziose e vane, che di sua natura non mirano né a questo né all'altro fine, e però, come corpo senza anima, pare che debbano essere da un

\footnotetext{
792 S. Tommaso, Sum. theol., I-II, q. 18, a. 8.

${ }^{793}$ Ibid., a. 9.

794 Ibid., q. 1.

${ }^{795}$ Matth., 12, 36.
} 
vero cristiano tralasciate. Il quale, come mercante industrioso, che cerca di tutte le cose trarre guadagno, né patisce che luogo o tempo, danari o merci, né altra cosa veruna gli stia senza frutto, così deve egli sempre versare in questa sollicitudine santa, che ragionando, caminando, negoziando, riguardando, et in somma di tutte le cose di questo mondo riporti guadagno per la salute sua. E di questo sentimento pare che sia stato espressamente S. Agostino ${ }^{796}$, che, parlando delle statue e pitture, dice: Hoc totum genus inter superflua hominum instituta numerandum est, nisi cum interest, quid eorum, qua de causa, et ubi, et quando, et cuius auctoritate fiat; e nelle Confessioni ${ }^{797}$ dice: $^{2}$ Quam innumerabilia variis artibus et opificiis, in vestibus, calceamentis, vasis et huiusmodi fabricationibus, picturis etiam diversisque figmentis, atque his usum necessarium atque moderatum, et piam significationem longe transgredientibus, addiderunt homines ad illecebras oculorum! foras sequentes quod faciunt, intus relinquentes a quo facti sunt, et exterminantes quod facti sunt; e nel capitolo seguente dice ${ }^{798}$ : In quam multis minutissimis rebus curiositas [p. 386] quotidie nostra tentatur? Et quam saepe labitur? Canem currentem post leporem conspiciens in agro, si casu transeam, avertit me fortassis ab aliqua magna cogitatione, et ad se convertit illa venatio. Quid cum me domi sedentem stellio muscas captans, vel aranea retibus suis irruentes implicans, saepe intentum facit? Et nisi iam mihi demonstrata infirmitate mea cito admoneas, vanus hebesco; e S. Tomaso $^{799}$ per le istesse ragioni dice, quod cognitio sensitiva tunc est vitiosa cum non ordinatur in aliquid utile, sed potius avertit hominem ab aliqua utili consideratione. Al che serve quello che sino al tempo de' Romani leggiamo esser accaduto a Marcello, il quale avendo condotto da Siracusa a Roma varie statue deliziose e che grandemente allettavano gli occhi de' riguardanti, ma inutilmente, narra Plutarco ${ }^{800}$ che, se bene con questo spettacolo si acquistò molto la grazia della plebe, fu però biasimato dalla città, quod assuetum bello ac rebus rusticis populum, necdum delitias expertum aut desidiam, otio, nugisque refersisset, qui dum circa artis artificumque oblectamenta versabatur, diei plurimum mirando terebat.

Noi donque, seguendo il medesimo, non siamo però così indiscreti e rigorosi, che vogliamo escludere dal cristiano la dilettazione del senso, che si piglia dalle cose, ma diciamo che deve insieme dilettarci e con ragione inviarci alla virtù, che è il fine di tutte le azzioni, essendo quella vera e cristiana ricreazione, che serve all'uno e l'altro, e dilettando giova, e giovando diletta; sì come parimente non vietamo al pittore o scultore qualunque disegno, ben che non sia di istoria sacra, anzi molte ne accettiamo delle etniche, molte delle moderne, che non si contengono nei libri sacri, pur che da quelle ne possa uscire probabilmente giovamento, come più chiaramente altrove si è esplicato ${ }^{801}$. Altrimenti come vane meglio serìa il tralasciarle ${ }^{802}$; peroché qual utile renderà a chi [p. 387] mirerà una facciata piena di grottesche? che utile la trasfigurazione di Dafne? che utile Acteone convertito in cervo? che utile una danza? che utile quei mascheroni et animali contrafatti? E di qui scrisse Filone ${ }^{803}$ che, per solere i pittori dipingere spesso cose inutili e favolose, ideo Moyses laudatas elegantesque artes, picturam atque statuariam, e sua republica eiecit, quod veritatem mendaciis vicient, illudentes per oculos animabus facilibus et credulis.

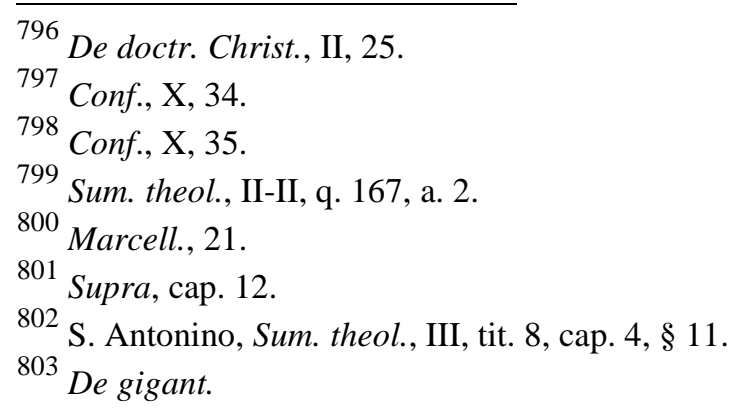


Se direte che sotto vi stanno spesso allegorie e sensi morali ascosi, si risponderà che questi sono noti a pochissimi e per la imbecillità nostra non causano i dovuti effetti, anzi mantengono gli animi bassi in quella sola apparenza colorita, sì come di sotto meglio si dirà; onde scrisse un savio ${ }^{804}$ : Pictae tabulae delectatio, si consilio regeremur, ad amorem caelestem erigere et originis nos deberet admonere. At vos humi affixi caelum aspicere non audetis, et obliti opificem illum solis ac lunae, tanta cum voluptate tenuissimas picturas aspicitis, atque unde ad altiora erat trans eundum, illic metam figitis intellectus. E però chi volesse pure dipingere qualche favola d'Esopo o de' poeti, dovria insieme aggiongervi la medolla espressa con parole significanti il concetto interiore dirizzato alla disciplina della vita, accioché si conoscesse che non ci contentiamo di quel diletto col quale non sia principalmente congionto il giovamento.

Se direte che anticamente s'usavano pure simili pitture per sola ricreazione e vaghezza agli occhi, sì come oggi ancor si veggono nei fragmenti sontuosi degli edificii romani (e scrive Plinio ${ }^{805}$ esser stato al tempo di Augusto un pittore chiamato Ludio, qui primus instituit amoenissimam parietum picturam, villas et porticus, ac topiaria opera, lucos, nemora, colles, piscinas, euripos, tum varias obambulantium species aut navigantium terraque villas adeuntium asellis aut vehiculis, plurimas praeterea tales argutias, facetissimos sales, tum maritimas urbes [p. 388] blandissimo aspectu minimoque inpendio, etc.); si risponde che anco in quei tempi molti uomini savii le hanno biasimate per infruttuose, come di sopra si è detto. Ma, sia stato presso di loro quel che si voglia, oggi, poi che, scacciata la caligine degli errori, è illustrato il mondo dallo splendore evangelico, non è dubbio che altri concetti, altri pensieri, altri mezzi, altri fini debbono movere un petto cristiano e dirizzarlo in tutte le cose alla virtù, tenendo sempre viva memoria che sino d'una paroluccia si ha da stare al sindicato.

E se replicarete che le ville, le fontane et i palazzi si dipingono per mero diletto degli occhi, noi responderemo, come di già abbiamo detto, che l'occhio del cristiano deve penetrare più oltre, talmente che col diletto sia congionto il giovamento presente o subsequente.

Se di nuovo direte che nel tempio di Salomone vi erano pure e le palme et i leoni e bovi e pomi granati e molte altre simili cose ritratte ${ }^{806}$, noi rispondiamo che tutte quelle aveano i suoi sensi assai noti in quei tempi et erano piene de misterii dichiarati da' dottori ${ }^{807}$, e che però non vanno nel numero delle cose vane, sì come ancora si legge ${ }^{808}$ essere stato dalli Egizzii osservato, che con note

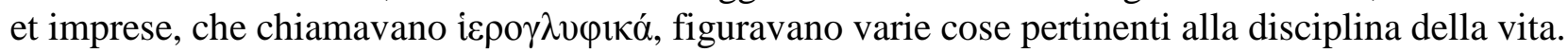

Ma ultimamente aggiongiamo che almeno nelle chiese si fugga ad ogni modo tale oziosità che non abbia misterio, del che ne abbiamo esempio notabile di Nilo vescovo antichissimo, referito nella settima Sinodo ${ }^{809}$, che ben dimostra quanto li dispiacessero simili pitture vane et oziose; però che avea Nilo inteso che Olimpiodoro proconsole in una chiesa de martiri voleva dipingere varii animali, e gli rescrive di questa maniera: Scribis mihi num decorum putem, cum in animo [p. 389] habeas fani aedificationem in honorem sanctorum martyrum, eiusque qui per eorum testata certamina, labores et sudores praedicatus est Christus, ut imagines in sacro loco omnigenarum animantium in parietibus undique fieri cures: has quidem a dextera parte, illas vero a sinistris, quo

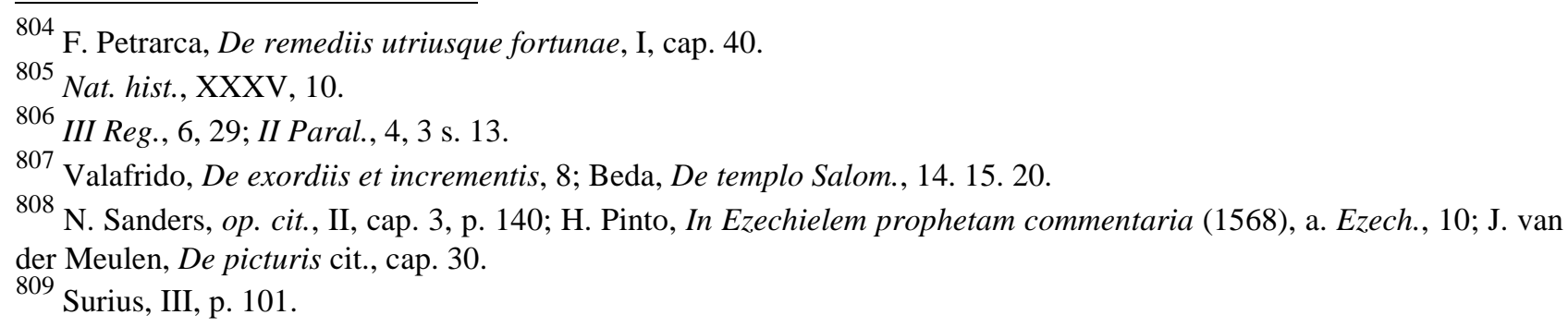


spectatores per terram casses, apud eosque lepores et capreas circumcursantes, venatoresque fugientia animalia velociter cum canibus insequentes videant; in mari vero emissa retia, omneque genus piscium captum, in terramque piscatorum manibus eductum; praeterea, e gypso omne id quod oculos pascere potest effectum, idque in domo Domini contemplentur. Nequaquam. E più basso dice: Ego vero ad scripta sic respondeo, puerile plane esse et stultum huiusmodi rebus fidelium oculos fascinare; e più giù: Verum novi et veteris testamenti historiis hinc inde parietes templi doctissimi operis pictas velim; et in vulgari domo mille cruces figi, quam historiam animalium malim. Sopra che S. Bernardo ${ }^{810}$ fa un longo discorso e tra l'altre cose dice: Quid faciunt ibi immundae simiae? quid feri leones? quid monstruosi centauri? quid semihomines? quid maculosae tigrides? quid venatores tubicinantes? Laonde pare in effetto che quelli che più s'approssimeranno a questa osservazione nel fare le pitture o scolture, più mostreranno di imitare le vere orme della virtù. Il che tanto più doverla essere in considerazione a' prelati, religiosi, sacerdoti e persone ecclesiastiche, che debbono essere guida agli altri in tutte le perfezzioni.

Ma acciò che nissuno ci abbia per tanto rigorosi, che sbandiamo da tutti i luoghi quelle pitture che principalmente si fanno per refocillazione delli spiriti e ristoro della imbecillità umana, ci rimettiamo alle considerazioni poste nel capitolo seguente.

[p. 390]

\section{CAP. XXXI.}

Delle pitture ridicole.

Sono altre pitture che chiamiamo ridicole, perché muovono il riso a chi le riguarda; il che potendo nascere da varie cause, e per lo più viziose, è necessario andarvi molto considerato. Non parliamo ora di quelle che, per rozzezza del disegno o lineamenti storti, o altra inezzia del pittore, eccitano il riso a chi ha qualche giudicio; imperoché questo non è veramente riso, ma deriso, essendo che il riso, onde deriva 'ridicolo', nasce da una diformità sì, ma fatta non diformemente, dicendo Cicerone ${ }^{811}$ : Locus et regio ridiculi deformitate quadam continetur, quae designat turpitudinem non turpiter. Il che non aviene in queste pitture di che parliamo, che sono tutte piene di sproporzioni e sciochezze causate dal solo diffetto dell'autore, che le fa passare in stoltizia, secondo Quintiliano ${ }^{812}$, che disse: Anceps ridiculi ratio est, quod a derisu non procul abest risus, cuius sedes cum sit in deformitate aliqua et turpitudine, cum in aliis demonstratur, urbanitas, cum in dicentem ipsum recidit, stultitia vocatur. Sopra di che fu anticamente motteggiato con quel detto: Homo facie magis quam facetiis ridiculus; e di un pittore narra Eliano ${ }^{813}$ ch'era sì sciocco et imperito nell' arte sua, che, non dipingendo cosa che s'assomigliasse, era sforzato di aggionger il nome alle cose, dicendo: «questo è un cavallo, questo è un arbore, questo è un libro», onde ognuno se ne ridea.

A queste pitture donque, che peccano nei principii e fondamento dell'arte, talché non solo sono sconvenevoli, ma ancora causano deriso, si avrà da provedere dai capi dell'arte e deputati dal publico, come al suo luogo si dirà.

Quanto poi a quel ridicolo di che ora parliamo, che nasce [p. 391] dalla cosa che si figura, noi

\footnotetext{
${ }^{810}$ Apol. ad Guilelm.

${ }^{811}$ De orat., II, 58.

812 Inst. orat., VI, 3.

${ }^{813}$ Var. hist., X, 10.
} 
facciamo necessariamente differenza tra le imagini sacre e le profane; perché, quanto alle sacre, essendosi per lo Concilio Tridentino ${ }^{814}$ dichiarato che non sia lecito ad alcuno di valersi delle parole della Scrittura sacra in alcun modo per burla o scherzi, così non doverà alcuno ardire di formare pittura sacra ad altro fine che di gravità, venerazione e santità, conforme al detto di Salomone: Audite, quoniam de rebus magnis locutura sum $^{815}$; e di S. Ambrosio ${ }^{816}$ : Licet interdum honesta ioca ac suavia sint, tamen ab ecclesiastica abhorrent regula; quoniam quae in scripturis sacris non reperimus, ea quemadmodum usurpare possumus? Il che dagli altri dottori santi parimente è confirmato $^{817}$.

Quanto alle profane, due obiezzioni ci vengono in mente, che pare che abbattino affatto et escludano ogni uso delle pitture ridicole, onde è necessario di ragionarvi sopra: una nasce dalla natura della cosa, l'altra dal modo di usarla. Intorno alla prima dicono alcuni che, essendo necessario, per causare il ridicolo, che quel che si dice o fa abbia seco una certa novità, la quale, cogliendo l'uomo all'improviso, gli eccita admirazione ${ }^{818}$; et essendo che le cose meravigliose secondo Aristotele ${ }^{819}$ porgono diletto: di qui è che tal novità lo fa prorompere in certa allegrezza. Però soggiongono che questo malamente potrà succedere in una imagine durevole, mostrandoci la sperienza che quelle cose che più volte abbiamo o vedute o intese non ci muovono più a riso. Talché potria questa imagine ben fatta muovere forse a riso un forestiero che più non l'avesse veduta, ma non già il padrone e posseditore, al quale non è mai nuova né improvisa tale figura.

A questa obiezzione rispondiamo che, potendo il ridicolo nascere da più cause, potrà una pittura con tal maniera et [p. 392] artificio esser fatta, che per varii accidenti estrinseci potrà eccitare nuove cagioni di riso alla giornata; sì come scrive Cicerone ${ }^{820}$ della imagine di quello scudo di Mario, che, se bene era stata veduta già longo tempo, nientedimeno con un motto all'improviso fece ridere ogni uomo, scrivendo egli così: Valde ridentur etiam imagines, quae fere in deformitatem aut in aliquod vitium corporis ducuntur cum similitudine turpioris; ut illud 'ostendam cuiusmodi sis', et digito demonstravit pictum gallum in Mariano scuto cimbrico sub nodis distortum, eiecta lingua, buccis fluentibus: risus est commotus, nihil illi tam simile visum est.

Potriano ancora tenersi queste pitture in luoghi tali, o mostrarsi in tale congiontura di tempo, o in ragionamento così a proposito, o scoprirsi così di raro, che, maestrevolmente fatte e mostrate, causeriano almeno in buona parte il ridicolo di che si parla.

Ma l'altra obiezzione è di molto maggiore importanza, perché è stata sentenza di gravissimi dottori e santissimi, che niuna sorte di facezie o burle convenga alla professione cristiana, scrivendo S. Ambrosio ${ }^{821}$ : Non solum profusos, sed omnes etiam iocos declinandos arbitror, plenum tamen suavitatis et gratiae sermonem esse non indecorum; perché dicono essi che noi siamo stati banditi dal cielo e confinati da Dio in questo mondo come in un carcere per penitenza e non per solazzo ${ }^{822}$; che il principio della vita nostra cominciando da' pianti et il fine riuscendo in dolori, assai ci mostra

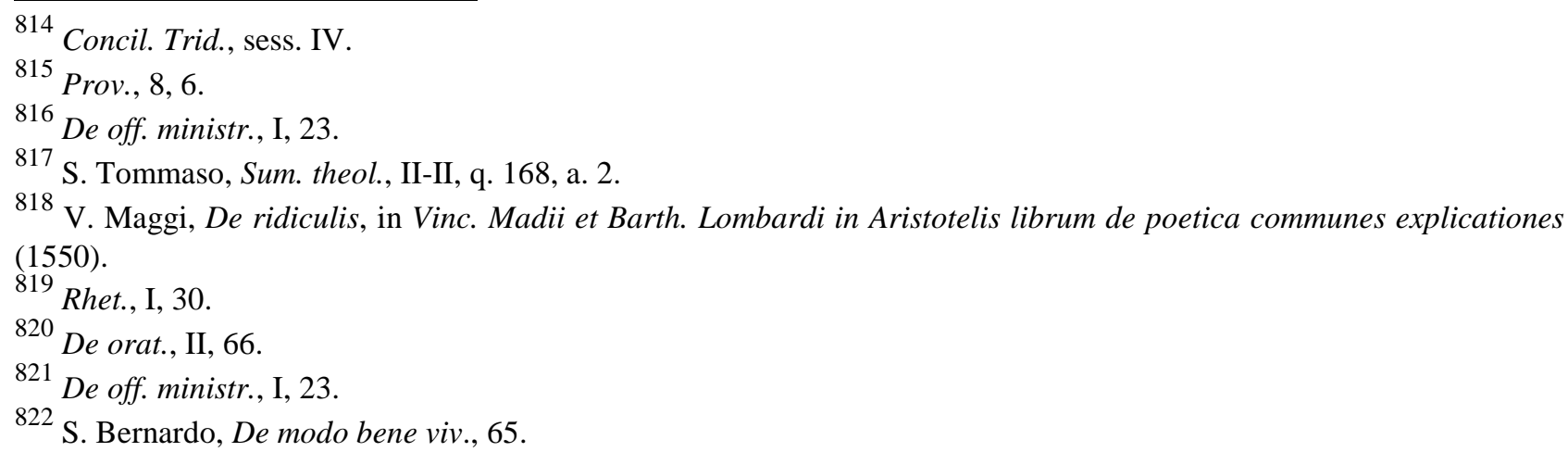


quale debbia essere anco tutto il tempo di mezzo; che siamo pellegrini in questa vita, i quali debbiamo attendere a non ismarire il viaggio e giongere sicuri alla patria e non trattenerci per la strada ad ascoltare le burle; che contra di noi tuttavia si fa il processo e si registrano i testimonii, e noi a guisa di fanciulli stiamo su li scherzi e giuochi; che ci serà domandato conto d'ogni paroluccia disutile e vana ${ }^{823}$, non che de' [p. 393] maneggi tanto infruttuosi; che nella vita del Salvatore nostro non leggiamo mai ch'egli ridesse, ma sì bene che piangesse ${ }^{824}$; che il medesimo egli ci ha lasciato scritto per li suoi evangelisti, dicendoci: Vae vobis qui ridetis, quia flebitis ${ }^{825}$; che in somma la fede nostra, la legge cristiana e tutta la Scrittura sacra non dice, non predica e non intona altro nelle orecchie nostre, che lagrime, penitenza, travagli, tribulazioni e croci, essendo questi i sentieri e le porte maestre per entrare nel regno del cielo: onde Salomone conclude: Risum reputavi errorem et gaudio dixi: Cur frustra deciperis ${ }^{826}$.

Ma per aprire meglio ancora il concetto c'hanno avuto questi santi, narraremo le parole stesse ch'usa tra gli altri S. Crisostomo in alcuni luoghi ${ }^{827}$. Scrive dunque così: Praesens tempus non effundendi gaudii, sed luctus est et tribulationis et lamentationis, tu vero urbanis facetiis iocularis? Qui athletarum, stadium ingressus, relicta solicitudine cum adversario certandi, facetiis utitur? Instat diabolus, circuit rugiens ut rapiat animam, movet, tentat, ac omnia adversus caput tuum invertit, extraque nidum ejicere te molitur; dentibus stridet ac fremit, ignem spirat adversus salutem tuam, et tu sedes, facetias effundens et quae stulta sunt et ad rem non faciunt effutiens? Observa apostolum dicentem $^{828}$ : Triennium noctes ac dies non destiti cum lachrymis admonere unum quemque vestrum etc. Non vides facies belligerantium quomodo sint tristes, contractae, superciliis terribiles et horrore plenae? Non vides aciem oculorum austeram, cor excitatum saliens et palpitans? animum collectum, trementem ac trepidantem? Tu vero, qui cum visibilibus et invisibilibus hostibus certamen habes, haec non advertis? malorum tuorum gratia crucifixus est Christus, et tu rides? alapis percussus est, tantaque ne tu patiaris passus est, et tu deliciaris?

Il medesimo S. Crisostomo in un altro luogo ${ }^{829}$ pur dice: Tu qui rides, dic quaeso, ubi Christus hoc fecit? audisti hoc [p. 394] alicubi? Nusquam. Sed contristatum quidem saepius legisti, tu autem rides? Si is, qui propter aliorum peccata non dolet, accusatione dignus est, qui in suis sine dolore existit et ridet, qua venia dignus erit? Tempus est luctus et tribulationis, sub afflictione et servitute certaminum et sub doloribus res agitur, et tu rides? Tu ante tribunal Christi terribile futurus et summa cum examinatione rationem pro cunctis actibus redditurus, securus sedes miserabili risu lugendisque facetiis? Quod si conspectui regis terreni consistens nec subridere quidem audes, ipsum angelorum Dominum cum habeas ubique praesentem, quomodo non ei cum tremore assistis? Ille quotidie minatur et tu adhuc rides? Immo eo irascente nihil curas, nihil vereris, nec vides, quod amplius hinc eum commoveas, quam peccando commoveras? Non audis dicentem et singulis diebus clamantem: Discedite, maledicti, in ignem aeternum paratum diabolo et angelis eius? Nec de Paulo apostolo, nec de ullo sanctorum ioci aut facetiae narrantur; de sola Sara legimus eam risisse, sed Dei voce correpta fuit; et filius Noe propter risum ex libero factus est servus.

Queste insomma sono le grida et avertimenti lasciatici dai dottori santi; i quali però non

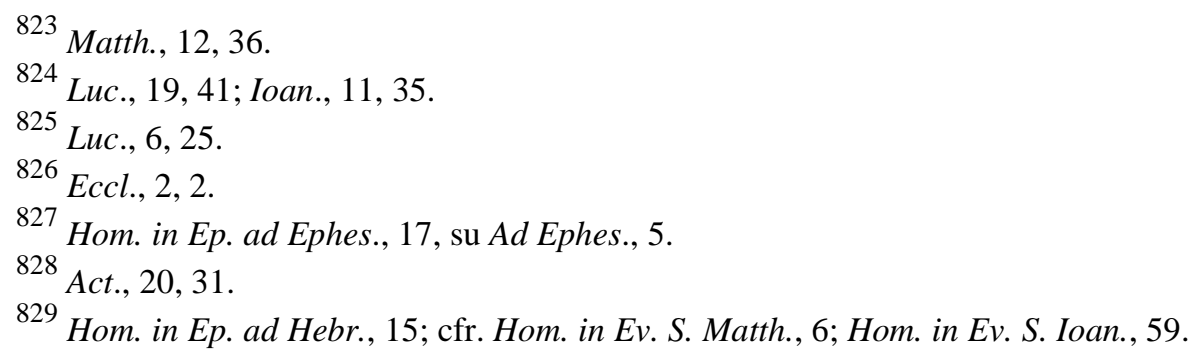


intendiamo noi rigorosamente, per modo che in questa fragile e calamitosa vita ci debba essere interdetta ogni sorte di giocondità e ricreazione, ma sì bene che ogni azzione nostra sia regolatamente ordinata e temperata con le debite misure, che non cada né in melanconia, né in soverchio solazzo. Imperoché è sentenzia approvata dai dottori sacri ${ }^{830}$ che, sì come la natura nostra corporale, per essere di facoltà finita, non può continuamente soggiacere alle fatiche, ma ha bisogno di riposo, così alla intellettuale, per essere anch'essa limitata, è necessaria alcuna intermissione, a guisa dell'arco che sempre teso si snerveria; sì come si legge nelle vite de' santi Padri essere stato detto da S. Giovanni Evangelista ${ }^{831}$. Sì che, dovendo l'operazioni [p. 395] e del corpo e dell'anima essere proporzionate alla condizione dell'uno e dell'altro, necessariamente si ha da concedere ad amendue opportuna quiete e ristoro. Il che consiste in alcune cose che, secondo la inclinazione naturale di ciascuno, sogliono apportare dilettazione alla mente nostra senza travaglio o fatica. E perché queste maniere di dilettare sono di varie sorti, e quando sono usate come si deve, giovano grandemente alla vita umana, è stata da' savii descritta una virtù che serve a tutte queste cose, chiamata $\varepsilon \dot{\tau} \tau \rho \alpha \pi \varepsilon \lambda i \alpha^{832}$, la quale con debita ragione rivolta i detti o fatti in solazzo e ricreazione onesta.

E perché tra i varii modi, onde suole uscire tale ricreazione, uno principalmente si causa dalle pitture non solo vagamente fatte, ma con questo di più, che eccitino il cuore in un sùbito a fare festa, che diciamo ridicolo; però di questo noi al presente parlando, mettiamo in considerazione alcune cose.

Prima, cominciando dal fine, che è la principale circonstanza in tutte le azzioni per renderle virtuose, diciamo che, essendo permessa la ricreazione nell'umana vita solamente a questo effetto, per ristorare gli spiriti e rendergli più svegliati e forti a potere di poi operare (dicendo Aristotele ${ }^{833}$ quod quies et delectatio non quaeritur propter se in humana vita, sed propter operationem), parimente di queste pitture si avrà da servire il cristiano come di mezzo et aiuto per essercitarsi più virtuosamente; sì come chi vuol fare un gran salto, spesso si tira indietro per farlo maggiore. E però saperà che poca dilettazione e trattenimento basta a ciò, sì come basta poco sale per condimento di molte vivande; altrimenti, chi si trattiene troppo in esse o non le applica a questo uso, pervertisce il fine della virtù ${ }^{834}$. Onde prima deve dare luogo alle cose gravi, dipoi, s'è necessario, divertire un poco in questo, [p. 396] come scrive Cicerone ${ }^{835}$ : Ludo et loco uti quidem licet, sed sicut somno et quietibus ceteris, tunc cum gravibus seriisque rebus satisfecerimus.

Oltre di ciò si ha d'avertire che tale dilettazione si procuri da pitture oneste, non lascive o immodeste, perché, dovendosi ciò fuggire in tutte le sorti di ricreazione, acciò ricreino l'animo e non lo corrompano, tanto più si avrà da schifare nelle pitture obscene, che fanno maggiore impressione nei sensi. Il che intendiamo ancora di altre pitture che rappresentano cose di gola, ubbriachezza e dissoluzione di vita, se ben paresse che movessero i riguardanti a riso: perché sempre si ha d'avertire che con esse non si scioglia il contento buono delle virtù, dicendo S. Ambrosio $^{836}$ : Caveamus ne, dum animum relaxare volumus, solvamus omnem armoniam quasi concentum bonorum operum.

\footnotetext{
${ }^{830}$ S. Tommaso, Summ. theol., II-II, q. 168, a. 2 s.

831 B. Fregoso, De dictis factisque memorabilibus cit., VIII, cap. 8.

${ }^{832}$ Aristotele, Eth. Nic., IV, 8 (e relativo comm. di Eustrazio).

${ }^{833}$ Eth. Nic., X, 6.

${ }^{834}$ S. Tommaso, Sum. theol., II-II, q. 168, a. 3 s.

${ }^{835}$ De off., 1, 29.

${ }^{836}$ De off. ministr., I, 20.
} 
Di più, tali debbono essere queste pitture e collocate in modo che convengano al luogo, al tempo et alla condizione di chi vuole ricrearsi ${ }^{837}$; onde gran riguardo si dovrà avere, che non siano poste simili cose di facezie nelle sale publiche, non nei luoghi delle audienze, non nelle stanze di consiglio, non presso i tribunali, non nelle librarie, né in alcun luogo di gravità, ma in altro appartato e ritirato.

Ma, quello che più importa, si avertisca bene ai gradi delle persone che possono usarle; perché agli ecclesiastici che militano espressamente sotto lo stendardo di Dio e con l'abito danno segno di essere ritirati dalle cose del secolo, massime prelati, sacerdoti e religiosi, non pare se li convengano per la gravità loro cose di burla. Perché, sì come veggiamo che la musica de voci e degli organi, se bene si frequenta dalla santa Chiesa nei tempii e celebrazioni dei divini ufficii, nientedimeno non è admessa da molte religioni più ristrette, come sono i Camaldolensi, Certosini, Capuccini et altri molti, dei quali l'instituto presuppone che quegli del suo ordine siano penetrati tanto oltre con lo spirito, che non abbiano bisogno [p. 397] di simili eccitamenti; così questi passatempi e facezie, se bene in molte altre persone potranno commodamente cadere, a quegli però, che per lo grado o abito si dimostrano come superiori alla vita commune et essere giunti a certa perfezzione, o almeno essere nello essercizio di essa, pare che sia cosa disdicevole e repugnante l'avere ancora bisogno di questi aiuti volgari e come fanciulli non potere vivere senza latte, perché, come dice S. Bernardo ${ }^{838}$, inter saeculares nugae, nugae sunt, in ore sacerdotis blasphemiae; e S. Ambrosio ${ }^{839}$ : Quidam solent stultiloquiis iocum movere, quasi non sit peccatum; hoc prohibet apostolus, quia Dei servi semper sobrii et modesti debent videri. Il che similmente doverà esser considerato da' magistrati, senatori, dottori, consiglieri et altri di provetta età, che, per essere posti, o per l'ufficio o per la maturità, in ordine differente dagli altri, debbono ancora seguire instituto diverso dal resto del popolo, massime scrivendo Cicerone ${ }^{840}$ : Non ita generati a natura sumus, ut ad ludum et iocum facti esse videamur, sed ad severitatem potius et ad quaedam studia graviora atque maiora.

Ultimamente diciamo che alle pitture ridicole non si può prescrivere certa legge, perché, secondo le nature o costumi o ammaestramenti delle persone, variamente si moverà il riso ${ }^{841}$, a chi d'una cosa, a chi d'un'altra, a chi più, a chi meno, anzi, per l'ordinario si suole causare fuori del pensiero di chi ride, essendo questo un moto dell'animo praeter electionem ${ }^{842}$, perché, come scrive Cicerone $^{843}$ e la sperienza lo dimostra, ita repente risus erumpit, ut eum cupientes tenere nequeamus. Al che basti l'essempio di Crasso, che, sendo giunto a grave età senza aver mai riso, onde fu detto $\alpha \gamma \varepsilon \dot{\lambda} \lambda \alpha \sigma \tau \varsigma \zeta$, un giorno, vedendo un somaro che mangiava i cardi selvatici spinosi, si diede fortemente a ridere; e di qui nacque il proverbio: Similes habent labra lactucas ${ }^{844}$.

[p. 398]

CAP. XXXII.

Delle pitture che apportano novità e sono insolite.

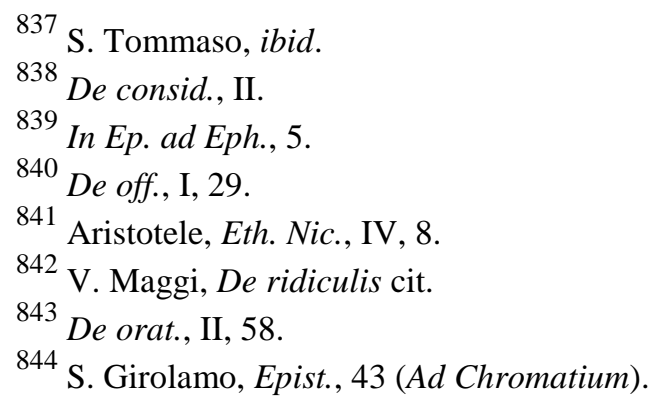


Volendo noi trattare il presento soggetto, serìa forsi stato conveniente dichiarare prima che cosa s'intenda per questa voce 'novo', attesa la molta varietà che si trova fra gli autori della origine delle cose nuove secondo le loro professioni. Imperoché, quanto alle cose naturali, volsero molti che le specie tutte fossero eterne e conseguentemente nissuna di esse si potesse dire nuova quanto alla prima origine, ma solo quanto ad alcuno particolare secolo, nel quale doppo una longa oblivione fossero un'altra volta venute a notizia. Quanto alle artificiali, dissero che non solamente si poteano creare nove forme, ma ancora trovare nuove arti, avendo lasciato scritto Aristotele ${ }^{845}$, quod nondum compertae erant omnes artes.

Altri, imaginandosi un longhissimo spazio di tempo, che da essi fu chiamato annus vertens sive annus magnus $^{846}$, dissero che nel girare di trentasei millia anni solari, rivolgendosi tutti i cieli a quel medesimo punto nel quale erano stati prima, ritornavano ancora tutte le cose, e naturali et artificiali, al medemo segno; e chi oggi scrive o canta parimente in quel punto si ritrovarà ancora esso fare il medesimo $^{847}$. Li iureconsulti, servendo più tosto che altro alla pratica delle cose, pare che abbiano domandato nuova qualonque cosa aggionta, scemata o alterata da un'altra cosa anteriore. Li teologi, maestri della verità, quantunque abbino detto con Salomone nihil sub sole novum ${ }^{848}$ non hanno però inteso questo [p. 399] quanto alle opere artificiali, ma quanto alle specie delle cose, per essere state al principio da Dio prodotte nella creazione del mondo.

Ma noi non entriamo ora in queste dispute e differenze troppo sottili, anzi seguitiamo, per dire così, il senso popolare che chiama le cose nuove non rispetto al loro nascimento, ma solo quanto al tempo che elle sono venute in luce e lasciatesi vedere e conoscere in quel luogo; e però si dice comedia nuova quella che mai più non fu udita da quel popolo, e foggia nuova di vestire che mai più tra loro non si è usata. Onde e noi chiamiamo quella pittura nuova, che scopre una invenzione che più non è stata da quel popolo riguardata.

Sappiamo ancora molto bene che questo nome 'nuovo' e 'vecchio' per sé non significa cosa esistente, ma che è uno accidente solo, che importa relazione fondata nel tempo: onde, quando si pecca in simili pitture, se bene il difetto è proprio della invenzione, che non figura la imagine come deve, si dimanda nondimeno errore dal tempo che si publica al popolo, perché inanzi non era conosciuto, e però si chiama peccato di novità rispetto agli occhi del popolo. E quantunque tal errore possa essere commune alle sacre et alle profane, nientedimeno, perché in queste non può apportare molto detrimento, ci stenderemo noi principalmente nella novità delle figure sacre.

Nel che avertiamo prima il lettore, che qui non intendiamo parlare di quelle novità che ripugnano a cose del Santo Officio, di che di sopra si è ragionato; né manco trattiamo di quella novità che contradice direttamente al senso della Scrittura sacra o tradizione ecclesiastica, se bene non è in cosa di fede, perché questo cade sotto il nome delle pitture false, delle quali si è discorso di sopra; né meno abbracciamo l'altre che hanno i suoi proprii difetti e particolari nomi sparsi nel trattato nostro; ma sotto questo capo generale di novità comprendiamo un'altra sorte d'errori non contenuti in quelli, sì come fanno li iureconsulti, che, avendo assignato [p. 400] i suoi proprii nomi a varii contratti, come di vendita, di locazione, di deposito, di compagnia e simili, vi sogliono aggiungere alcune altre convenzioni sotto questa voce di contratto innominato ${ }^{849}$.

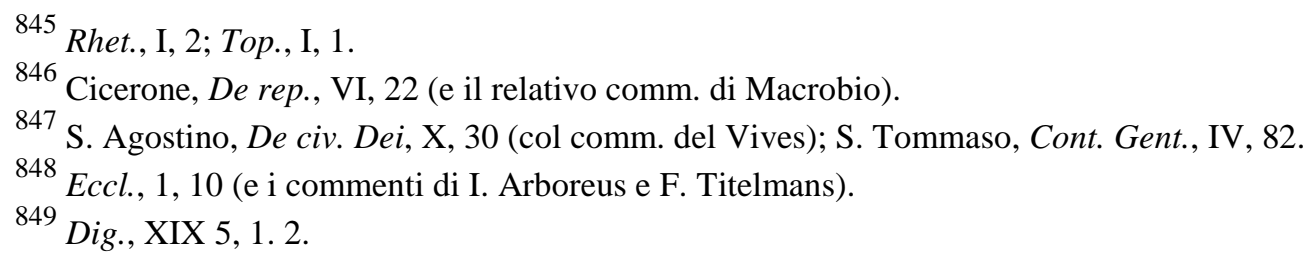


Vogliamo donque primieramente ricordare al lettore, che ogni novità, se bene di cose profane, deve essere avuta molto sospetta, né accettarsi se non opportunissimamente ${ }^{850}$, come ci ammaestrano ancor quelli che insegnano l'arte del parlare e scrivere acconciamente ${ }^{851}$. Intorno a che si narra uno esempio molto a proposito di quel famoso pittore chiamato Zeusi, che, avendo dipinta con grande artificio la figura d'un Ippocentauro femina ch'allattava due figliuolini gemelli, et avendola accompagnata con molte particolarità nuove, insolite e meravigliose, pensandosi egli per tal via di fare stupire ogni uomo della eccellenza dell'arte sua, nientedimeno, scoperta che l'ebbe al popolo, si racconta che ciascuno, rivolto a considerare la invenzione e la novità di quella, non applicò punto il pensiero alla bellezza dell'arte, né alla industria del disegno o del compartimento di tutta l'opera o d'altre cose, dove fondava Zeusi principalmente la lode sua, talché egli, sdegnatosi di questo giudicio popularesco e, come dice Luciano ${ }^{852}$, quod argumenti novitas vinceret operis diligentiam, si risolse di portarsi a casa la pittura e per l'avvenire lasciare queste invenzioni così peregrine et inusitate.

Un altro esempio narra essere accaduto al re Tolomeo, che con fare spettacolo agli Egizzii di un camelo insolito e di un uomo di due colori, la metà bianco e l'altra negro, pensò con questa novità guadagnarsi gli animi loro, ma gli successe molto diversamente e conobbe, come dice il medemo Luciano $^{853}$, non novitatem apud Aegyptios in admiratione esse, sed quod concinnum, compositum iustaque forma praeditum erat ab illis probari. [p. 401]

Non vorressimo però che alcuno, sbigottito da questa tal proposta, ci giudicasse troppo rigidi e severi in volere restringere l'invenzione ingegnosa de' pittori, anzi ci riputasse contrarii al detto del poeta $^{854}$, che va per le boche d'ognuno: Pictoribus atque poetis Quidlibet audendi semper fuit aequa potestas etc., parendoli che questo autore non voglia inferire altro, se non che alla professione della poesia e pittura è data ampiissima facoltà, con la penna e col pennello, di rappresentare quello che viene loro in fantasia. Imperoché, oltre la dichiarazione che soggionge il medemo poeta, dicendo:

\section{Sed non ut placidis coeant immitia, non ut Serpentes avibus geminentur, tigribus agni,}

noi, per non causare in altri questo sinistro giudicio, gli facciamo sapere che non siamo di quelli che si pigliano per impresa di biasimare tutte le cose nuove e lodare solamente le vecchie; né manco di quelli che vogliono innalzare sempre i soggetti moderni et abbassare l'opere antiche: imperoché in questo modo si verria a dare come una tacita sentenza contra il Testamento Vecchio o contra il Nuovo, e spesso si trovano cose dell'uno e dell'altro modo ora commendate, ora riprovate, secondo i varii soggetti loro ${ }^{855}$.

La novità donque per sé stessa o la antichità non fanno una cosa commendabile o biasimevole, nascendo il merito non dagli anni, ma dalle $\operatorname{cose}^{856}$; le quali, se sono buone, tanto più per la longa osservanza vengono lodate, e se sono cattive, tanto più il loro abuso, per essere invecchiato, è

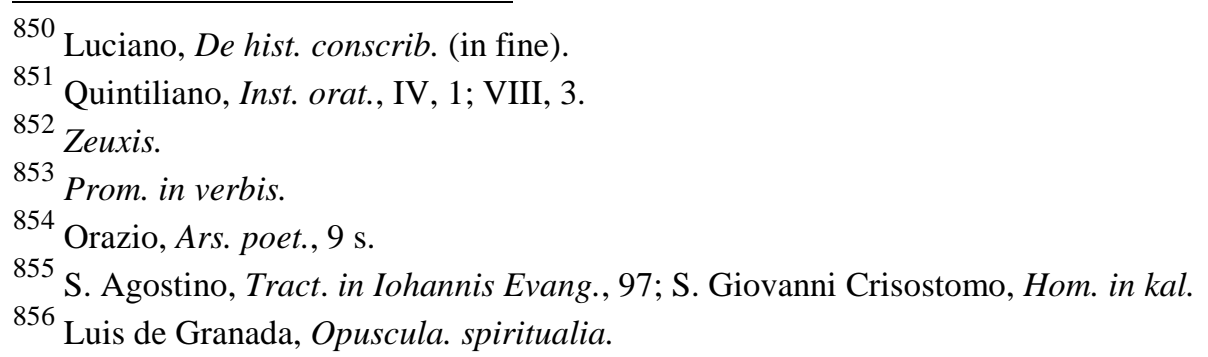


biasimevole. Parimente la novità, quando sia da salda ragione accompagnata, tanto più merita pregio quanto meno è stata per l'adietro avertita; e secondo questo senso intendiamo noi che sia lecito a poeti e pittori di formarsi nuove invenzioni, [p. 402] non a sbalzi e capricci senza ordine e legge, ma regolate dal fine proposto alle loro facoltà, che è principalmente di giovare, dilettando insieme, sì come altre volte si è detto.

Ora, venendo al proposito nostro, se parliamo delle pitture profane, non potiamo non ricordare quello che altrove e poco dianzi abbiamo detto, cioè che in tutti i concetti invenzioni nuove che si appresentino abbia il pittore l'occhio sempre al fine di giovare, e da quello pigli la misura di ciascuna sua opera. E perché nel discernere questo talora ci inganniamo e l'amore de' proprii parti spesso ci abbaglia, però, sendo il proprio della pittura l'imitare, cautamente farà chi, lasciando le sue proprie imaginazioni, aderirà alle istorie sicure e materie approvate e come stabilite dal consenso universale de' buoni et intendenti. Al che fa molto a proposito quello che scrive Platone ${ }^{857}$ essersi osservato dagli Egizzii, ch'aveano per legge che i pittori et altri formatori d'imagini non potessero alterare né introdurre cosa nuova, talmente che le pitture di quel tempo, quanto alla figura e forma, erano in tutto simili alle passate di molti secoli, scrivendo così: Si observes quae decem annorum milibus retro depicta formatave quomodocunque fuerunt, invenies ea nec pulchriora, nec turpiora his quae hodie depinguntur, sed eadem arte confecta.

Quanto alle sacre poi, tanto più avrà d'avertire in esse, quanto che il Concilio Tridentino espressamente commanda, nemini licere ullam insolitam ponere imaginem ${ }^{858}$ e la materia loro è tale che non patisce né alterazione né innovazione da chi non ha legitima autorità. E perché in questo soggetto si può facilmente errare in più maniere, noi per maggior chiarezza anderemo raccordando varii avertimenti, che debbono essere principalmente considerati.

Il primo serà, che non solo non si rappresenti cosa nuova sostanziale in materia di fede, di che già abbiamo parlato, ma né alcuna altra circonstanza nuova, che ripugni al modo o [p. 403] costume ecclesiastico. Il che quantunque possa parere che appartenga più tosto alla materia delle cose del Santo Officio già da noi trattata ${ }^{859}$, nientedimeno, perché tali circonstanze potriano essere di natura tale che non toccariano cosa di fede ci è parso non disconvenire il ponerle sotto questo titolo generale, acciò che nell'uno o nell'altro modo possano essere fuggite. Abbiamo nella istoria ecclesiastica ${ }^{860}$ l'esempio di quel santo vescovo Spiridione, che non puoté tollerare che fosse detto da un altro vescovo: Tolle lectum tuum et ambula, ma volse che dicesse grabatum tuum, per non innovare quella parola. E leggiamo appresso S. Ieronimo ${ }^{861}$ della perturbazione grande che nacque nel popolo congregato in una chiesa per essersi solo alterata una parola di Iona profeta, che si leggeva publicamente. Quanto donque maggiormente si dovrà schifare ciò in una pittura, che rappresenta non una parola sola, ma tutta un'azzione? Onde S. Paolo, scrivendo a Timoteo, l'ammonisce che schifi profanas vocum novitates ${ }^{862}$, le quali parole, oltre le cose di religione potendo abbracciare ancor altre sorti di deformità, tanto più dovranno osservarsi nelle pitture, che sono non semplici voci che passano, ma come libri e tavole publiche permanenti.

Ci è di poi un'altra sorte di novità, la quale non si sa che contradica alla verità, ma né essa ancora ha fondamento di autorità certa e versa intorno ad alcune cose c'hanno alquanto del basso o

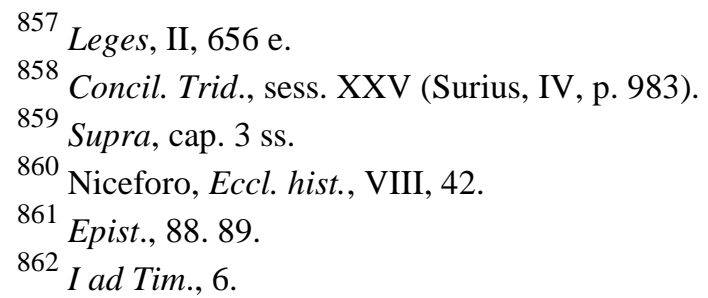


dell'affettato, vedendosi che si parte dal più commun uso de' buoni; e però suole essere biasimevole più e meno, secondo la qualità delle cose e la maniera con che si alterano. Il che può accadere in molti modi toccati da noi di sopra in varii luoghi, ma ora v'aggiungiamo per esempio quello che da alcuni si dipinge nel sacro Bambino, che giuoca da fanciullo con S. Giovanni Battista overo scherza da sé con un rondenino in mano, cose che rendono più tosto bassezza che divozione; overo quando si figura il misterio della [p. 404] Madonna allora che fuggì in Egitto, che con un vaso in mano piglia l'acqua del fiume per darne al figliuolo, e S. Gioseffo che piglia anch'egli un ramo carico de frutti da un arbore e lo porge al figliuolo, e molti altri esempii simili, ne' quali l'accorto pittore dovrà avere cura di non lasciarsi trapportare dalla curiosità né dal desiderio di sodisfare all'appetito di ogni uomo, ma star saldo nella gravità et antichità de' santi padri e maggiori nostri. Nel che tanto è più pericoloso alle volte d'inciampare, quanto che sono alcune materie di sua natura non conosciute e poco distintamente narrate nelle Scritture, nelle quali pare a molti d'avere per ciò largo campo da poterle rappresentare a modo e capriccio suo; sì come aviene nel figurare il tremendo giudicio e la persona di Lucifero, l'anime dannate, la gloria celeste o il cielo empireo e le sedie de' beati. Nelle quali cose molti si fingono invenzioni meramente di suo capo, senza appoggio o fondamento alcuno di dottrina di santi padri o d'altri approvati da santa Chiesa; intorno alle quali diremo noi in altro luogo quello che serìa di parere nostro ${ }^{863}$.

Un'altra novità è, la quale non ripugna punto a cosa di religione, anzi è conforme quasi necessariamente alla verità, nondimeno l'uso non l'ha mai introdotta, e però turba la vista nostra non mediocremente. Il che può accadere in due modi principalmente: l'uno de' quali è quando si figurassero cose di santi che non giovano né rilevano punto, come serìa chi dipingesse $\mathrm{S}$. Filippo in letto che dorme, o S. Andrea a tavola che mangia, o S. Petronio che si veste, o S. Agnese che si scalza; perché, se bene non si può negare che queste cose non siano state vere, nientedimeno è novità infruttuosa il rappresentarle, se non siano accompagnate da altra cosa notabile. L'altro è quando ancora quell'atto che si rappresenta possa avere qualche esempio di umiltà, di pietà, d'industria o di fatica, ma che però non sia in uso di essere dipinto, essendovi altre cose molto più segnalate et esemplari di quel [p. 405] santo da publicare al popolo; sì come serìa chi figurasse Cristo salvator nostro ch' andasse battendo alle case per chiedere elemosina, il che vogliono i sacri teologi che facesse, massimamente nei tre giorni della fanciullezza che stette smarito ai suoi, che poi lo trovarono nel tempio ${ }^{864}$.

Chi dipingesse ancora la gloriosa Madonna con la rocca a lato, che andasse filando, overo sedendo con un cussino in grembio che lavorasse d'ago, non è dubio che, per non essere l'uso di vedersi simili pitture, dispiacerebbono a chi le mirasse, se bene si legge ch'ella fece simili lavori et essercizii ${ }^{865}$.

Chi dipingesse S. Pietro capo degli apostoli con la suocera e la figliuola a canto, o quando le visita che sono inferme, $\mathrm{o}$ in altro atto, se bene di carità, però insolito di essere veduto, non è dubbio che tal pittura daria più tosto da fantasticare alla mente, che divozione ${ }^{866}$.

Chi figurasse S. Paolo in una bottega, che lavorasse pelle et andasse cucendo insieme lana e lino

${ }^{863}$ L. IV.

${ }^{864}$ S. Tommaso, Sum. theol., II-II, q. 187, a. 5, con il comm. di T. De Vio; Alessandro di Hales, Summa, IV, q, 31, m. 2, a. 2; S. Bonaventura, Apolog. paup., resp. 3, p. 1, a. 1; De Christi paupertate; S. Lorenzo Giustiniani, Synodicon, tit. De paupertate, cap. 4; D. de Estella, In Evangelium secundum Lucam enarrationum tomus primus (1595), a Luc., 2.

${ }^{865}$ Sabellico, Exempla, II, cap. 4. 9, in Exempla virtutum et vitiorum [ed. J. Heroldt] (1555); S. Pietro Canisio, De Maria virgine incomparabili (1577), I, cap. 13.

${ }^{866}$ S. Girolamo, Adv. Iovinianum, I. 
o altra materia per far padiglioni, ancor che sia chiaro ch'era scenofactoriae artis e che spesso lavorava giorno e notte, abbassarebbe nondimeno forse quel sant' uomo ${ }^{867}$.

Similmente chi dipingesse S. Giovanni Evangelista con una perdice in mano, qual egli accarezzasse dolcemente e con essa s'andasse trattenendo, come scrive il Cassiano ${ }^{868}$, certo che anco questo, per essere insolito, daria grandemente da maravigliare.

Il medesimo si potria dire quasi in tutte le vite de' santi, quando uno curiosamente volesse andare scegliendo alcune [p. 406] particolari azzioni, le quali, se bene sono state vere, non sono però così notabili e conosciute dal popolo, che non induchino novità; eccettuando nondimeno noi da questo, quando alcuno distesamente facesse dipingere tutta la vita di quel santo, divisa, come s'usa lodevolmente in molte chiese, in più quadri e compartimenti, perché allora non disdice il rappresentare alcune azzioni particolari, che da sé stesse non converriano così; overo ancor quando tale azzione, che si figura, fosse appropriata a qualch'altra cosa che si volesse fare, o che convenisse a quel luogo che si deve ornare di figure.

Avertiamo, oltre ciò, che non intendiamo noi di volere ligare affatto le mani al pittore, che non possa talora stenderle fuor di quello che si trova scritto, o di quello che nel suo paese sia posto in uso; ma solo ricordiamo che la libertà de' pittori nelle cose sacre deve essere accompagnata sempre da probabilità, decoro e giovamento, come poco di sopra in altro proposito s'è detto.

Sappiamo ancora che alcuni pittori scusano talora le loro novità col senso allegorico, e di qui nasce che dipingeranno il Salvator nostro in mezzo de' suoi apostoli con l'abito regale, o con l'abito episcopale, overo col vestimento di religioso professo d'alcuna religione. Altri dipingeranno la Madonna col fanciullo in braccio risplendente tutta di luce e riccamente adorna, con vestimenti di broccato e corona di gemme in capo; et altri altre cose che s'hanno imaginate. Onde ancora è nato, secondo alcuni, che S. Giovanni Evangelista, mentre che scrive l'Evangelio nell'età già decrepita, si dipinge con la faccia giovinile.

Ma noi, lasciando questo di S. Giovanni al luogo suo, diciamo che, essendo l'officio del pittore l'imitare le cose nel naturale suo essere e puramente come si sono mostrate agli occhi de' mortali, non ha egli da trapassare i suoi confini, ma lasciare a' teologi e sacri dottori il dilatarle ad altri sentimenti più alti e più nascosti. Altrimente serìa un confondere ogni cosa e passare tumultuariamente dallo stato della natura a quello della grazia o della gloria; il che ognun vede che si [p. 407] potria fare medesimamente in tutti i santi, che, essendo stati ripieni de' celesti doni in questa vita, godevano insieme di mirabile luce e gioia interna: ma poiché le scritture autentiche non dicono che da alcuno siano mai stati veduti in tale trasfigurazione, non pare che convenga al pittore ora d'introdurla, eccetto in quei casi dove le vite loro approvate facessero fede che fossero stati talora veduti in quella forma, come di alcuni santi si legge. E ci sovviene quel che si trova scritto d'un pittore in tal proposito, che, avendo voluto figurare il Salvator nostro in abito e forma di Giove, subito se li seccò la mano ${ }^{869}$.

Ricordiamo ancora, che è cosa molto da savio l'andare riservato in determinare s'alcuna sia invenzione nuova o vecchia; imperoché spesso ci inganniamo, e l'ignoranza e poca esperienza nostra è sempre maggiore di quello che per lo corrotto giudicio nostro ci pare, sì come accade talora in varii disegni che si veggono, e varietà d'abiti, et instrumenti de martiri, e maniere di croci, e figure de beati, e simil altre cose di che parleremo nel quarto libro: le quali agl'imperiti e che poco sono andati attorno paiono spesso nuove, e non sono. Sì come per lo contrario sapranno i pittori che

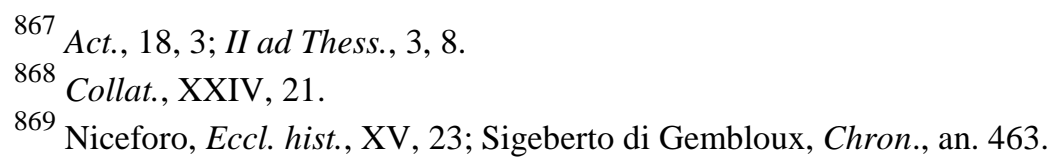


ad essi non gioverà quello che suole essere rifugio alla sterilità de molti, i quali, per avere veduta una pittura in qualche luogo, sùbito la pigliano ad imitare senza scegliere il grano dal loglio; percioché, essendo tutti gli abusi derivati da qualche autore, non basta questo a scusare il pittore, ma deve egli nell'opere sue assicurarsi bene col consenso universale dei dotti e con le imagini approvate da' santi vescovi nelle loro chiese: il che ricerca consiglio maturo, esperienza molta e giudicio fondato.

[p. 408]

\section{CAP. XXXIII.}

Delle pitture oscure e difficili da intendersi.

Una delle principali laudi che sogliono darsi ad uno autore o professore di qualche scienza, è ch'egli sappia chiaramente esplicare i suoi concetti, e le materie, se bene alte e difficili, renderle col suo facil modo di parlare intelligibili a tutti e piane. Il medesimo possiamo affermare in universale del pittore, e tanto più, quanto l'opere sue servono principalmente per libro degli idioti, alli quali bisogna sempre parlare aperto e chiaro. A che non avertendosi da diversi, accade che ogni giorno si veggono in varii luoghi, e massimamente nelle chiese, pitture così oscure et ambigue, ch'ove doveriano, illuminando l'intelletto, eccitare insieme la divozione e pungere il cuore, elle con la loro oscurità confondono per modo la mente, che la distraeno in mille parti e la tengono occupata in disputare tra sé stessa quale sia quella figura, non senza perdita della divozione. Onde ne fugge quel poco di buon pensiero, che si era portato alla chiesa, e spesse volte si piglia una cosa per un'altra; talmente che, in luogo di essere ammaestrato, si resta confuso o ingannato.

Per provedere dunque a tal disordine, ch'è grande, bisogna cercare bene la radice di questo errore, la quale conosceremo nascere dall'uno de' tre capi: cioè, o che il pittore, overo padrone che comanda, non vuole, o che non sa, o che non può; e pigliamo in ciò l'esempio dagli scrittori, in quello però in che convengono in questo caso insieme. Quanto al non volere, dovria parere strano che si truovino persone, le quali amino l'essere oscure e di non essere intese, e pur è così; onde anticamente fu nominato Eraclito $\sigma \kappa o \tau \varepsilon v$ ó dalla oscurità $^{870}$, e narra Quintiliano ${ }^{871}$ che fu già un retore, il [p. 409] quale non insegnava altro a' suoi discepoli ch'oscurare il parlare, dicendo:

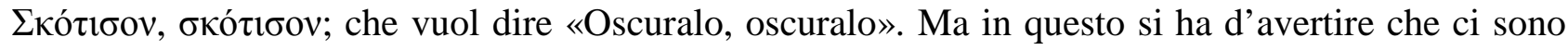
due sorti di questa oscurità che nasce da volontà, l'una lodevole, l'altra biasimevole: la prima si truova essere stata osservata fino dagli Ebrei, dagli Egizzii, da' filosofi e da altri, quando volevano parlare delle cose sacre, che per ciò chiamarono misterii per il senso che ha la parola greca, che è di 'occultare', giudicando essi che gli alti secreti di Dio non si avessero da scoprire alla profana moltitudine ${ }^{872}$, ma più tosto con enigmi e sensi parabolici da trattarsi, il che e da' santi dottori nostri è stato admesso nei misterii maggiori della religione nostra ${ }^{873}$; volendo che, sì come inanzi le reliquie sacre si pone qualche sottile velo o trasparente cristallo, così i gran segreti delle cose eterne si avessero a conservare nella sua maiestà, e che insieme con questa via si contenesse maggiormente

\footnotetext{
${ }^{870}$ Cicerone, De fin., II, 5.

871 Inst. orat., VIII, 2.

872 A. Fiocchi, Lucii Fenestellae De Romanorum magistratibus liber (1561), cap. 13; Clemente Alessandrino, Strom., V; Eusebio, Praep. evang., XII, 4; Valerio Massimo, I, 1, 13.

${ }^{873}$ Dionisio Areopagita, De eccl. hier., I, 1; Clemente Alessandrino, Strom., VI; Gregorio Nazianzeno, Hom., 27 (De theol. I); Beda, In Luc., 4; Origene, Hom. in Num., 5; S. Basilio, De Spiritu Sancto, 27. 29.
} 
il popolo nella dovuta reverenzia.

Ma questa ragione de' teologi non può aver molto luoco nei pittori, i quali nelle cose sacre solamente rappresentano quello che si truova essere proposto dai santi dottori et accetato dal commune consenso della Chiesa, non aggiongendo, né minuendo, né alterando punto quello che da essi è stato approvato, né quanto alla sostanza, né quanto al modo o altre sue circonstanzie.

Però passaremo all'altra sorte di oscurità procurata, la quale viene biasimata perché nasce alle volte da una occulta superbia et affettata vanità di esser tenuto grande e meraviglioso, poi che non parla o non dipinge cose triviali, ma concetti sublimi e cavati come dal terzo cielo; la quale è una stolidità sciochissima, non solo perché non ha per fine se non [p. 410] la propria e vana riputazione, ma ancor perché pervertisce il modo di quella scienza o arte che tratta, dicendo S. Agostino ${ }^{874}$ : Loquendi omnino nulla est causa, si quod loquimur homines non intelligunt. Onde a questi conviensi quello che fu detto verso quel'autore ributtato per la oscurità: Si non vis intelligi, nec intelligaris.

Alle volte ancora ciò avviene perché si vuol mostrare di avere cognizione delle cose naturali et essere praticato in varie parti del mondo; onde si figurano senza occasione animali o piante o artificii usati solo in paesi alieni e non conosciuti in questa regione. Da che nasce l'oscurità.

Altre volte perché si vuol essere breve, e con poche parole o spazio abbracciare molto; onde ne segue quel detto volgare: Brevis esse laboro, obscurus fio ${ }^{875}$. Però, per fuggire l'uno e l'altro, doverà il buon pittore avere proponimento nell'animo di volere giovare principalmente agli altri, e tenere ancora modo a ciò fare conveniente, esprimendo le circonstanze necessarie e fuggendo l'equivocazioni, o altre figure ambigue, più che si potrà.

Nasce ancora l'oscurità dal non sapere; ma non intendiamo ora di trattare della perizia dell'arte, perché, come in più luoghi s'è detto, trattiamo noi delle cose e non della ragione del disegno, presuponendo che di quella il pittore ne sia instrutto quanto si conviene; altrimente non è dubbio che, non possedendo bene l'arte che sta ne l'assomigliare, l'opere sue riusciranno oscurissime e non conoscibili da chi le guarderà, sì come altre volte abbiamo raccontato d'uno ch'era forzato di aggiongere all'imagini che faceva: «Questo è un leone, questo è un cane, questa è una torre, questa è una fontana» ${ }^{876}$. Ma noi parliamo di quella oscurità che nasce per non sapere bene il pittore quella materia che vuol fare; perché, come dicea Socrate ${ }^{877}$, quelle cose che l'uomo sa bene e le possiede compitamente, le esprime ancora, quando vuole, commodata [p. 411] mente; e per lo contrario, chi non è ben sicuro della cognizione di una cosa, ne parla spesse volte confusamente e senza ordine e molto imperfettamente. Così nella pittura, chi possederà bene e fondatamente quello che è per ritrarre, e saperà il fine a che è ordinato quel misterio, o a che mira quella figura, non è dubbio che lo porgerà molto più chiaramente, e con maggiore espressione per le particolarità che vi inserirà, che non farà un altro poco intendente. E sì come, a volere sciogliere bene una questione di alcuna scienza, chi va distinguendo e considerando varii capi riesce molto meglio e con quelle distinzioni quieta affatto l'intelletto ch'è sospeso; così sono molte istorie sacre e misteri, i quali se il pittore averà questo giudicio di andarli compartendo con ordine e distinguerle in varii quadri o spazii, e si astenerà più che potrà di ammassare et inculcare una moltitudine di figure e di azzioni, le quali confondono la vista e l'intelletto, senza dubbio più sodisfarà a tutti e darà maggiore segno di giudicio e di perizia. A che gioverà principalmente l'aggiungervi in luogo conveniente il nome del

\footnotetext{
${ }^{874}$ De doctr. Christ., IV, 10.

875 Orazio, Ars poet., $25 \mathrm{~s}$.

876 Eliano, Var. hist., X, 10.

${ }^{877}$ Cicerone, De orat., I, 14.
} 
misterio o del santo, quando non sia figura notissima (sì come anticamente veggiamo essersi usato, secondo che afferma S. Paolino ${ }^{878}$ dicendo: Martyribus mediam pictis pia nomina signant); overo notarvi il luogo dello autore della istoria sacra che si rappresenta, overo ancora alcune brevi parole e significanti, tolte dal medesimo libro dell'autore, a proposito di quello che si fa.

Nasce ultimamente questa oscurità dal non potere; perché alle volte si cercano di esprimere cose di sua natura non fattibili, tanto recondite e difficili, che non si può commodamente renderne capace il popolo, sì come sono l'operazioni delle intelligenze, i secreti della providenza divina, i misteri della predestinazione, e simili: dai quali il rimedio più sicuro è l'astenersene più che si può, acconsentendoli però interiornente con la vera fede, sì come ammonisce S. Agostino ${ }^{879}$ [p. 412] con queste parole: Sunt quaedam quae sua vi non intelliguntur, aut vix intelliguntur, quantumvis plenissime dicentis versentur eloquio, quae in populi audientiam, vel raro si aliquid urget, vel nunquam omnino mittenda sunt. Talora ancor si vogliono rappresentare cose che, per la gran somiglianza che tengono con altre, non si possono ben col dissegno distinguere, come sono molte sorti di piante, di ucelli, di pesci e di animali.

Ma quest'oscurità può ancor nascere o maggiormente accrescersi dall'angustia del luogo dove sia collocata la pittura, che in effetto non capisca la moltitudine delle cose che si vorriano rappresentare, se non mescolate et ammassate insieme; overo perché restringa il disegno, che di sua natura richiederia maggior campo, sì come è narrato di un pittore che, avendo in una picciola tavoletta ritratto un cavallo corrente con il freno in bocca, e sdegnatosi il patrone, a cui instanzia era fatta l'opera, che gli avesse aggionto il freno, rispose egli che in così picciol spazio era stato necessario di mettere il morso alla bestia, perché non traboccasse.

Non neghiamo però che in picciol luogo non possa un eccellente artefice esprimere efficacemente quello che si vuole, come si legge di colui, qui Alexandrum ex equo venantem et beluam ferientem finxerat, cuius magnitudo unguem digiti non superabat et tamen terrorem vultu incutiebat, et equus ipse consistere recusans arte moveri videbatur ${ }^{880}$. Et altri esempii meravigliosi racconta Plinio ${ }^{881}$. Ma si dice per avertenza, perché questa non è impresa da ogn'uomo, e che il luogo proporzionato fa meglio riuscire le cose.

[p. 413]

\section{CAP. XXXIIII.}

Delle pitture indifferenti et incerte.

Si trovano anco pitture che per altra ragione rendono confusione a molti, e ciò nasce perché si veggono diversamente fatte in varii luochi, onde lo spettatore, trovando questa diversità, sta sospeso tra sé se sia il medemo soggetto, o se questo o quello sia falso. Onde abbiamo giudicato che in ciò sia grandemente d'avertire, perché non si inciampi dove è la via piana, o si condanni d'ignoranzia o d'errore il pittore che non lo merita. E perciò è bene che il prudente lettore sappia che sono alcuni soggetti che nel rappresentarli ricevono varii modi, forme et invenzioni, essendo che nissuno d'essi contradice alla notizia che se n'ha, anzi ciascuno di loro pare appoggiato a qualche ragione, se bene noi non sappiamo precisamente il vero. Onde, vedendosi che ne l'una e l'altra maniera i buoni e

\footnotetext{
${ }^{878}$ Nat., 10.

${ }^{879}$ De doctr. Christ., IV, 9.

${ }^{880}$ Giuliano, Epist. ad Georg.

${ }^{881}$ Nat. hist., VII, 21.
} 
gravi autori hanno consentito ${ }^{882}$, e communemente i pittori non si sono obligati più all'una che all'altra parte, però chiamiamo tali pitture indifferenti et incerte, poiché per anco non è data la sentenza del modo preciso con che si debbano formare e, tra varie maniere che si sogliono usare, quale di loro debba prevalere. Potressimo addurre in ciò varii esempii di cose profane e sacre; ma poi che le profane non importano più che tanto, narreremo alcuni esempii delle sacre.

Li pastori donque ai quali fu annonciata dall'angelo la natività di N. S. ${ }^{883}$ non si dice quanti fossero, né se erano giovani o vecchi, né come vestiti, e però in ciò ciascuno segue quello che giudica fosse più conveniente. [p. 414]

I Maggi che andarono ad adorare il Signore ${ }^{884}$, altri vogliono che fossero vecchi e gioveni, e venessero di Egitto et avessero in compagnia mori e dromedarii e cameli; altri vogliono che fossero altramente e venissero di Persia senza tanta comitiva ${ }^{885}$.

I ladroni che furono crucifissi in compagnia di nostro Signore ${ }^{886}$, altri vogliono che fossero confitti con chiodi, altri che fossero ligati con le funi.

La croce che dicono gli evangelisti che fu data a portare a Simone Cireneo ${ }^{887}$, non è chiaro, secondo alcuni ${ }^{888}$, se Simone la portasse solo e levata affatto dalle spalle di nostro Signore, overo se la portasse in compagnia di lui, sollevandolo da quel sì gran peso et aiutandolo a portarla.

Ci sono che dipingono il Salvatore nostro in croce con quattro chiodi, altri con tre solamente, e noi in questa diocese di Bologna ne abbiamo veduto ne l'uno e l'altro modo, se bene è più frequente quello delli tre chiodi.

L'abito della beata Vergine si fa più communemente di colore turchino e ceruleo; altri nondimeno lo fanno diversamente.

Similmente negli apostoli sogliono i pittori distinguere gli abiti loro con particolari colori, sì come al luogo suo si dirà; ma però né questa è cosa tanto certa o necessaria, che chi fa altrimenti abbia ad essere reietto. Così aviene in infinite altre istorie del Vecchio e Nuovo Testamento, delle quali non si trovando espresso se non la sostanza del fatto, il modo poi e le circonstanze, overo il numero delle persone o le maniere loro si sogliono rappresentare variamente: sì come la captività delli Ebrei fatta da Nabuchodonosor ${ }^{889}$, l'andata della regina Sabba a Salomone, il convito che Assuero fece a quelli [p. 415] del suo regno ${ }^{890}$, le guerre di David contro i Filistei ${ }^{891}$, la turba che seguiva il Signor nostro quando ascese sul monte ${ }^{892}$, l'entrata sua gloriosa in Ierusalem ${ }^{893}$, le cose di S. Paolo in Atene ${ }^{894}$, o quando fu carcerato in Roma ${ }^{895}$, e molte altre simili istorie, che noi domandiamo incerte non quanto in sé stesse, ma in quanto non sono particolarmente ben chiare a

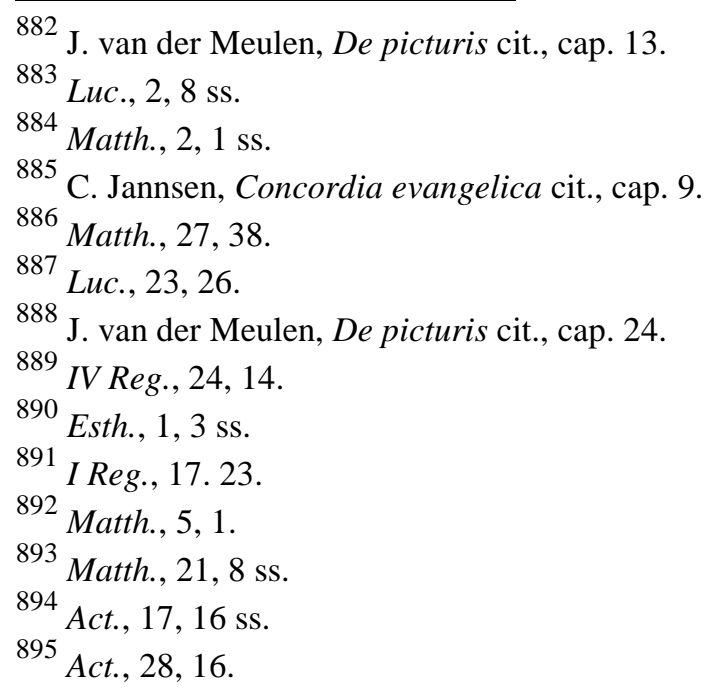


noi intorno a molte circonstanze, come fossero. Hanno nondimeno tacitamente la sua verisimilitudine, la quale non si ha mai da abbandonare, come in altro luogo si è detto.

Laonde, se bene ora chiamiamo tali pitture indifferenti e quasi arbitrarie, intendiamo però che tale arbitrio sia probabile nell'una e nell'altra parte et usato dalli antecessori nostri nell'uno et altro modo senza riprensione; avertendosi però che non l'uso di ogni pittore, né anco di molti insieme, se bene antico e frequentato, ci ha da dare regola o da assicurarci, ma solo l'uso di quelli, l'opere de' quali consentino con la ragione et abbino l'approbazione delle persone dotte et intelligenti delle cose ecclesiastiche: sì come, per esempio, il dipingere nostro Signore quando dà le chiavi a $S$. Pietro, non diremo che sia arbitrario perché alcuni lo faccino in Ierusalem, altri sotto alcune loggie con colonne et architravi, altri appresso il mare dove si pescava, perché tutto repugna alla istoria del Vangelio, chi bene lo considera dove dice ${ }^{896}$ : Venit Iesus in partes Caesareae Philippi et interrogabat discipulos suos dicens etc., e dipoi: Et tibi dabo claves regni caelorum. E però deve il pittore considerato non subito attaccarsi a sue invenzioni o alli esempii d'altri, pensando che siano cose indifferenti, ma deve veder bene e consigliarsi, in ciascuna istoria, del luogo, del tempo che è descritto, et a quello poi, secondo la capacità dell'opera accompagnata da qualche circonstanze, dovrà accommodare i luoghi veri e vicini, o fiumi [p. 416] o città o fonti che siano, secondo la vera descrizzione di quei paesi; che così caminerà giudiciosamente e fondatamente in tutto quello che gli occorrerà.

\section{CAP. XXXV.}

Delle pitture fiere et orrende.

Altre volte abbiamo dimostrato che le pitture principalmente sono state introdotte per giovare con dilettazione; dal che si argomenta che quelle che mancano o dell'una o dell'altra parte sono imperfette rispetto al fine. Ma quelle che di amendue sono prive, tanto più si allontanano dallo scopo loro, sì come aviene in quelle che chiamiamo orrende, perché esprimono senza alcun fine virtuoso certi atti che la natura degli uomini aborrisce: sì come il dipingere che il padre sia sbranato dal figliuolo, o che la madre mangi le proprie figlie, o alcuni che bevano il sangue dalle vene degli uomini vivi, o altri che arrostiscano i corpi umani e ne facciano un convito, distribuendo i membri intieri per vivanda a ciascuno. Tutte queste simili cose non solo sono disutili, ma attristano grandemente il senso umano, come ferine e fuori d'ogni ragione ${ }^{897}$. Che se i poeti antichi, o chi ha scritto dell'arte loro ${ }^{898}$, ha giudicato che nelle tragedie, se bene il proprio loro è di versare in azzioni molto turbulente e calamitose de personaggi grandi et illustri, non sia però lecito farne di quelle spettacolo e rappresentarle agli occhi, essendo che la natura umana troppo di esse si turba; quanto più converrà ad un costumato pittore il schifarle, come lontane dalla pietà cristiana? [p. 417]

E se alcuni degli autori dell'arte di medicina hanno giudicato non convenirsi che le anatomie de' corpi umani, tanto necessarie per curare bene la sanità degli uomini, si facciano nei corpi de' viventi, se bene siano, come rei nocenti, condennati agli ultimi supplicii ${ }^{899}$; perché non dovrà parimente un giudizioso pittore astenersi dall'imitare quelle cose che dalle leggi e dai sensi si vedono aborrire? Certo che ancora i gladiatori furono anticamente levati dalli teatri per questa

\footnotetext{
${ }^{896}$ Matth., 16, 13. 19.

897 S. Tommaso, Sum. theol., II-II, q. 159, a. 2.

898 Orazio, Ars poet., 182 ss.

${ }^{899}$ Celso, De med., prooem.
} 
causa, come si trova scritto, perché apportavano quei sanguinosi spettacoli molto travaglio et orrore alla natura nostra ${ }^{900}$.

Crediamo però che da questa regola si debbano eccettuare due casi assai frequenti e segnalati. L'uno è quando queste imagini si facessero in commendazione et amplificazione della virtù; l'altro è quando si facessero in odio e detestazione del vizio e peccato. Imperò che, quanto al primo, noi veggiamo giornalmente figurarsi i cruciati atrocissimi de' santi e minutamente esprimersi e le ruote et $\mathrm{i}$ rasoi e le cataste ferrate e le capanne di fuoco e le graticole e gli eculei e le croci et infinite altre sorti de crudelissimi tormenti; i quali ha approvato la Chiesa catolica che si rappresentino agli occhi del popolo cristiano come insegne eroiche della pazienza, della magnanimità de' santi martiri e trofei della invitta fede e gloria loro, volendo la zelante madre nostra che da questi esempii piglino cuore i suoi figli et imparino a sprezzare la vita, se così accada, per servigio divino, et a stabilirsi nella constanza in tutti gli accidenti di questo mondo, e perché anco, considerandosi quanto incomparabilmente sono stati maggiori i dolori e l'afflizzioni dei martiri, che quegli che noi sentiamo nelle infirmità e miserie di questa vita, impariamo di sopportare e sprezzare virilmente ciò che ci suole perturbare, crescendoci la fiducia in Dio e desiderio della gloria sua. Ma di questa materia e di varii esempii notabili de martirii ne parleremo più a longo al luogo suo. [p. 418]

L'altro capo appartiene al biasimo de' vizii et in ciò si potranno con orrore utilmente figurare quelle cose che più siano atte a commovere i sensi, per farci aborrire tanto maggiormente alcuna sorte di peccato; sì come, nel dipingere la ribellione di Lucifero e suoi seguaci, chi potrà mai a bastanza esprimere la severità del castigo giustamente datoli dalla divina potenza? nel dipingere la spaventosa faccia dello inferno e le pene de' dannati alle fiamme eterne e la ferocia de' crudelissimi demonii, chi sarà mai bastevole pienamente al rappresentarla? Or qui si può dare campo franco al pittore in quante maniere vuole, pur che verisimilmente, di stender e le tenebre e lo squalore, $\mathrm{i}$ tormenti e le angoscie, gli odii e le strida, le desperazioni e le fiamme e la eternità di tutti i tormenti; però che questa non sarà mai amplificazione, non potendosi né con inchiostro, né con colori, né anco col pensiero agguagliare la grandezza e la infinità di tanto male. Chi anco volesse dipingere alcun vizio, come l'impietà, l'eresia, la perfidia, il sacrilegio e l'ipocrisia, avendo per fine di mostrare la bruttezza loro per metterlo in odio alle persone, potrà, con l'esempio degli oratori che fanno le invettive gagliarde contra i rei colpevoli, calcandoli la mano a dosso con essagerazione anch'esso usare qualche artificio giudiziosamente, acciò dall' aspetto di quella imagine così deforme si ecciti negli animi più forte abominazione di quel delitto.

Accaderà ancora di figurare talora atti di giustizia essercitati contra malfattori scelerati, come contro eretici empii et ostinati condennati al fuoco, o altri perversi publicamente castigati da' magistrati; o esempii de' atroci supplicii permessi da Dio contra l'impietà de' tiranni. Il che perché abbraccia e la esaltazione della giustizia administrata da' giudici et il biasimo della iniquità aborrita dalle sante leggi e l'ira divina contro le sceleratezze, potrassi utilmente rappresentare il tutto con grandezza di orrore, se nel resto la materia et il luogo opportunamente lo comporteranno.

[p. 419]

CAP. XXXVI.

Delle pitture monstruose e prodigiose.

900 Cod. Iust., XI, 44. 1; Teodoreto, Hist. eccl., V, 26; C. Sigonio, Historiarum de occidentali Imperio libri XX (1578), an. 397. 
La pittura monstruosa de' Greci è stata detta $\tau \varepsilon \rho \alpha \tau o \gamma \rho \alpha \varphi i ́ \alpha$, ch'abbraccia tutte le sorti de' mostri, potendo quelli essere o dalla natura o dalla imaginazione, o tenere della qualità dell'uno e l'altro, o non essere propriamente né l'uno né l'altro. I mostri dalla natura sono, come gl'intelligenti, quei corpi i quali sono contro l'ordine della natura, siano d'uomini o d'animali bruti. Il che suole accadere principalmente in due modi: primo, rispetto alli membri e parti del corpo in sé stesso; secondo, rispetto all'abitudine che debbono avere fra loro.

Nel primo modo può accadere la mostruosità o per la quantità o per la qualità ${ }^{901}$. Se parliamo della quantità, può ella considerarsi o continoa o discreta: continoa serà o di grandezza (quali sono alcuni corpi de' giganti, di che si legge nel libro de' Numeri ${ }^{902}$ : Populus quem aspeximus procerae staturae est, ibi vidimus monstra quaedam filiorum Enac de genere giganteo, quibus comparati, quasi locustae videbamur etc.), o di picciolezza, come sono quelli chiamati da' Greci e dal parlare nostro commune nani et altrimente pigmei, dal nome di cubito; discreta serà la monstruosità che risguarda il numero o per eccesso, come avendo doi capi, tre braccia e quattro gambe, overo in defetto, non avendo mani o piedi, overo un occhio solo et una orecchia.

Quanto alla qualità, potrà parimente considerarsi la mostruosità o nella figura o nel colore: nella figura, o perché non [p. 420] abbia la figura naturale semplicemente della sua specie perché rappresenti membro di altra specie, come un uomo ch'abbia la bocca di cinghiale, l'orecchie di cavallo, li piedi di capra; o quanto al colore, facendo un uomo di colore verde, o mezzo negro e mezzo rosso, o in altra simile maniera.

Quanto all'abitudine poi, può anco la mostruosità occorrere o per il luoco o per il tempo o per l'uso dei membri: nel luoco avendo gli occhi in mezzo la fronte, il naso ove è il mento, o le braccia dopo' le spalle; nel tempo, come un fanciullo che nasca con li denti longhi, o un puttino che abbia la barba; nell'uso de' membri, come adoprando le mani per caminare, o portando le gambe in spalla, o in molt'altri modi che si potriano più dilatare, se accadesse ${ }^{903}$.

Questi mostri dalla natura diciamo che si possono dipingere, però con occasione quando ricerchi così il soggetto che s'ha per le mani; et allora non solo non averanno deformità, ma più tosto commendazione, per rappresentare la verità di quello che è stato: sì come, chi figurasse la vita di $S$. Antonio potrà molto bene isprimere quello che scrive S. Girolamo ${ }^{904}$ di lui, dicendo: Vidit homunculum aduncis naribus et fronte cornibus aspera, cui extrema corporis in caprarum pedes desinebant; e dipoi soggiunge: Hoc ne cuiquam ob incredulitatem scrupulum moveat, sub rege Constantino universo mundo teste defenditur; nam Alexandriam istius modi homo vivus perductus magnum populo spectaculum praebuit, et postea, cadaver exanime, ne calore aestatis dissiparetur, sale infuso Antiochiam, ut ab imperatore videretur, allatum est. Così chi figurasse le cose di Africa o de' paesi nuovamente trovati, potria senza biasimo pingere varii mostri et umani e ferini, narrati dagli scrittori autentici di quei luoghi.

Mostri imaginati si possono pigliare in due modi, cioè o che sono falsamente finti dalla pura nostra imaginazione, [p. 421] overo che sono formati dalla imaginazione nostra, mossa però da cause superiori e divina revelazione. Nel primo modo si comprendono quelli che si hanno finti i poeti, come sono sirene, sfingi, arpie, pegasi e dette da Omero chimere ${ }^{905}$, e quelli che chiamarono

\footnotetext{
901 S. Agostino, De civ. Dei, XVI, 8; Alessandro di Hales, Summa, II, q. 80, m. 3.

902 Num., 13, 33 s.

903 Dig., L, 16, 38; 16, 135 (col comm. di A. Alciati); Plinio, Nat. hist., VI, 30; VII, 2.

904 Vita Pauli.

905 P. Valeriano, Hieroglyphica cit., XXXII, XXXIX.
} 
ciclopi, uno de' quali narra Plinio ${ }^{906}$ che fu dipinto con vaga invenzione, dicendo: Pictor Timanthes pinxit in parvula tabella Cyclopem dormientem et iuxta Satyros metientes thyrso pollicem eius etc.; overo altri che ciascuno si va fabricando di sua imaginazione, come raconta Platone ${ }^{907}$ che fino al suo tempo s'usava da' pittori, scrivendo: veluti cum pictores tragelaphos et cetera huiusmodi multiplicia figmenta depingunt; e quelli che narra Luciano ${ }^{908}$ in varii luoghi, e simili se ne vedono nelle grottesche, de' quali parlaremo nei capi seguenti più diffusamente.

$\mathrm{Nel}$ secondo modo intendiamo quelli che non nascono da finzione vana d'uomini, ma si trovano narrati nelli sacri volumi, o dai dottori santi, a' quali per divina grazia, come cose sopranaturali e piene di gran misterii, sono state revelate, onde li chiamiamo allegorici e misteriosi, perché figurano cose diverse da quelle che dimostrano, sì come era la statua di Nabuchodonosor, che avea il capo d'oro, le braccia e petto d'argento, il ventre di metallo, le gambe di ferro et i piedi di terra: il che significava la varia condizione de' tempi che dovea seguire, sì come fu interpretato sapientissimamente da Daniello ${ }^{909}$. Tali ancora sono state molte visioni de' patriarchi e profeti narrate nella Scrittura sacra e principalmente nell'Apocalisse, piene di sensi mistici, che tutte utilmente si potranno rappresentare, aggiongendovi il luoco della Scrittura onde sono cavate, acciò gli occhi di chi le vede non restino confusi.

Altri mostri sono, che possono tenere della qualità del [p. 422] l'uno e dell'altro, il che aviene quando alla mostruosità di natura il pittore ve n'aggiunge un'altra per la sua imaginazione, facendo la cosa più mostruosa; il che può accadere in più modi, che si possono cogliere dalle cose dette di sopra. Includiamo ancora in questo membro quando quello che si vuol dipingere non è stato vero secondo la natura, o ancor, se è stato vero in qualche parte, nondimeno il modo di rappresentarlo è mera imaginazione del pittore, tanto trascendente il ragionevole, che causa molta mostruosità nella cosa che si figura; sì come narra il Cedreno ${ }^{910}$ di un pittore siropersa, condotto da Anastasio imperatore, che, pingendo certe cosaccie aliene dal rito ecclesiastico, fu per essere dal popolo maltrattato: Adduxit, dice egli, Anastasius pictorem quendam Syropersam habitu presbyteri, qui in regia iussu imperatoris (nam is manichaicis nugis delectabatur) quaedam monstruosa et ab imaginibus ecclesiasticis aliena pingeret: ob id magna populi est coorta seditio.

$\mathrm{Al}$ che per essempio aggiongono alcuni quelle figure dove, volendosi isprimere la santissima Trinità, hanno dipinta una figura con tre capi: cosa che muove più tosto nausea che divozione. Alcuni, volendo dipingere il diluvio al tempo di Noè, hanno rappresentato certi corpacci gonfiati e stravagantemente formati. Altri per esprimere la grandezza di S. Cristoforo hanno fatto non un gigante, ma un colosso di altezza e grossezza smisurata.

In questo tale errore parimente caddero già anticamente gli Egizzii, aggiongendo errore ad errore, ché, volendo rappresentare un loro falso dio chiamato Serapis, lo fecero di tanta mole e grandezza, che al primo incontro sbigottiva le persone, avendo essi trovata quest'arte per acquistarli maggiore credito e venerazione dal popolo. La cui menzogna narra l'istoria ecclesiastica che fu molto bene scoperta da quel santo e zelantissimo vescovo Teofilo Alessandrino, il quale commandò che con una secure fosse buttato a terra; e dice ${ }^{911}$ : [p. 423] Serapis, plaga accepta, neque dolere neque vocem emittere visus est, sed capite detruncato gregatim mures prorupere; inde frustulatim

\footnotetext{
906 Nat. hist., XXXV, 10.

907 Respubl., VI, 488 a.

908 Ver. hist., I, II; Alex.; Philopseudes.

909 Dan., 2, 31 ss.

910 Compend. hist., p. 295 (Xyl.).

${ }^{911}$ Teodoreto, Hist., eccl, V, 22.
} 
dissecto signo, alias quidem partes concremarunt, caput vero per totam traxerunt urbem, aspectantibus iis qui quondam adorarunt, et infirmitatem ipsius iocis insectantibus.

Ultimamente sono altre pitture che, se bene potriano capire sotto alcuno dei capi detti di sopra, per contenere anch' esse cose oltre il solito della natura, talora vere e talora false, nientedimeno pare che a queste tali si soglia assegnare il suo particolare nome, che è di cose prodigiose: sì come l'apparire due soli, piovere dal cielo pietre o sangue, ardere la terra, volare per l'aria i sassi, et altre simili assai. Le quali doveranno ricevere la sua ragionevole considerazione nel rappresentarle in pittura, perché né anco queste si debbono fare a capriccio, di propria invenzione, né meno si doverà assicurare alcuno sùbito di farle, se bene altri l'avesse o riferite o scritte; però che, per essere materie molto estraordinarie et insolite, tanto più ricercano e giudicio per isprimerle opportunamente, e verità, acciò nessuno resti ingannato.

Tra queste molto notabile è quella scritta nei libri de' Macabei con queste parole ${ }^{912}$ : Contigit autem per universam Hierosolymorum civitatem videri diebus quadraginta per aera equites discurrentes auratas stolas habentes et hastas, quasi cohortes armatas, et cursus equorum per ordines digestos, et congressiones fieri cominus, et scutorum motus, et galeatorum multitudinem gladiis districtis, et telorum iactus, et aureorum armorum splendorem omnisque generis loricarum. Vi sono ancora quelle accadute al tempo di Moisè e Faraone ${ }^{913}$, e quando Iddio piové dal cielo pietre contro i Gabaoniti ${ }^{914}$, et altre narrate non solo nella Legge sacra, ma ancora da diversi autori ecclesiastici, come quella che scrive Gioseffo ${ }^{915}$ essere accaduta innanzi la distruzzione di Ierusalem, e quella narrata da Nicefforo ${ }^{916}$ innanzi che Alarico re de' Gotti sacheggiasse [p. 424] Roma; e quella che successe al tempo d'Antonino imperatore, quando in favore de' soldati cristiani scesero moltitudini di saette dal cielo contro i nemici, onde fu chiamata fulminea legio ${ }^{917}$; e se ne ritrovano molte altre, che si potranno rappresentare nel modo che di sopra si è detto. Et appresso $i$ gentili ve ne sono infinite nell'istorie loro, delle quali Giulio Obsequente ne raccolse un libro ${ }^{918}$; e da altri dipoi et anco da' moderni ${ }^{919}$ ne sono state narrate molte con grande attestazione.

Ma perché i falsi demoni con vane apparenze spesso cercano ingannarci, onde è scritto: Surgent pseudochristi et pseudoprophetae et dabunt signa magna et prodigia, ita ut in errorem inducantur, si fieri potest, etiam electi ${ }^{920}$; e sappiamo che con varie strade e fallaci ogni giorno tentano insidiarci; però vogliamo avvertire che molto gioverà lo stare riservato, né credere facilmente al detto o rivelazione d'ognuno, ché spesso sono cose apparenti o illusioni diaboliche ${ }^{921}$ : sì come $\mathrm{S}$. Clemente $^{922}$ scrive di Simone mago, che si vantava dicendo: Statuas animatas reddam, ita ut putentur, ab iis qui vident, homines esse.

E così molti altri essempii di cose scoperte vane et ingannevoli, che mostravano faccia

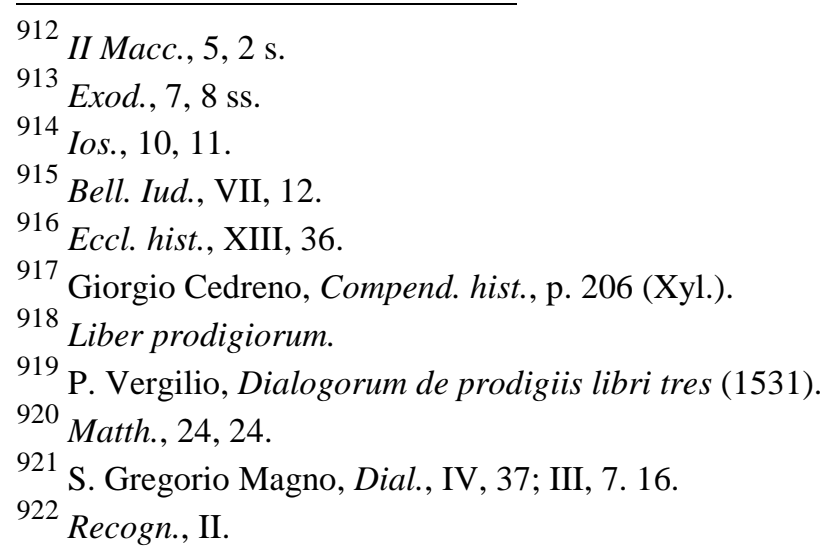


miracolosa, se ne leggono presso a varii autori ${ }^{923}$, alle quali non è da dare fede, e molto meno s'avranno da ridurre in pittura, acciò da esse non resti la posterità fallacemente delusa.

[p. 425]

\section{CAP. XXXVII.}

Delle pitture dette grottesche; e se anticamente si usavano nei luoghi solamente sotterranei, overo ancora negli edificii sopra terra.

Nella divisione fatta di sopra delle pitture mostruose dicessimo alcune essere imaginarie, che non sono né possono essere secondo la natura, ma le persone se le hanno fabricate nella mente, sì come il capriccio gli ha portato; delle quali tante si possono dire essere le sorti e le maniere, quanto varii sono i cervelli delle persone, fingendosene ognuno qualcuna a suo modo, come gli viene in fantasia.

E perché in ciò si commette spesso non picciolo errore, poi che tali pitture paiono fatte a caso senza regola alcuna di ragione, però, parendo a noi cosa degna di molto avvertimento, ci siamo mossi al presente a ragionare di quelle che volgarmente si chiamano grottesche; ché da quello che ci occorrerà di raccordare intorno ad esse si potrà comprendere quel che giudichiamo convenirsi in altre ancor simili materie.

E per levare ogni equivocazione che potesse nascere, diciamo che sotto questo nome di grottesche non intendiamo quei lavori de fogliami, tronchi, festoni o altre varietà di cose che talora si pingono e possono essere secondo la natura; né quelle invenzioni degli artefici, che nei fregi, nei tavolati, nelle opere dette arabesche, nei recami et altri ornamenti proporzionati alla ragione sogliono con vaghezza rappresentarsi; né manco intendiamo di quei mostri, o marini, o terrestri, o altri che siano, che dalla natura talora, se bene fuori dell'ordine suo, sono stati prodotti. Ma solo comprendiamo sotto questa voce quelle forme d'uomini o d'animali o d'altre cose, che mai non sono state, né possono essere in quella maniera che vengono rappresentate, e sono capricci puri de' pittori e fantasmi vani e loro irragionevoli imaginazioni; le quali perché ormai si sono intruse in tutti i luoghi, e tal [p. 426] mente si trovano sparse negli edificii publici e privati, che sono penetrate fino nei tempii venerandi et accompagnatesi con gli altari e coi vasi e vestimenti sacri, facendo mostra di sé per tutto, perciò tanto più ci è parso necessario di ragionarne alquanto copiosamente, acciò meglio dagli altri si possa deliberare quello che si convenga.

Cominciaremo donque dall'origine di questo nome, perché siano state chiamate grottesche; il che dall'un canto pare assai chiaro, dall'altro è molto oscuro. Pare chiaro, in quanto si vede che le grottesche sono dette da grotte, alterato alquanto il nome greco che dice $\kappa \rho v \pi \tau \eta$, che significa luogo occulto, ascoso e segreto, derivato dal verbo крv́ $\tau \omega$, come ognuno sa. È di poi oscuro, perché, secondo la sopradetta etimologia, pareria che tal nome non convenisse all'istesse pitture, che si fanno nei luoghi aperti e luminosi, che pure sono dette anch'esse grottesche.

E però da questo sono venute in campo a' tempi passati, e durano ancor oggi, due opinioni molto contrarie tra di loro: l'una vuole che queste pitture non s'usassero se non nei luoghi cavernosi e sotterranei, onde presero et hanno conservato il nome di grottesche; l'altra contende l'opposito e dice che queste si usavano solo nei luoghi che communemente s'abitavano e che quasi s'aveano per delizie, non essendo verisimile che nei luoghi tenebrosi e che non si possono godere senza lume volessero gli antichi gettare via tant'opera, tanta industria e tanta spesa. Dice anco che il nome di grottesche è stato causato da accidente, perché, sopragionte le ruine degli edificii di Roma et

\footnotetext{
923 Luciano, De Syria dea; Alex.
} 
alzatosi il terreno, rimasero le abitazioni antiche come a fondo, onde è stato creduto dal vulgo ch'elle fossero già fabricate per grotte.

Noi non vogliamo entrare a decidere simili questioni, né manco intendiamo di pigliare briga o contesa alcuna con antiquarii, architetti o altri di questa professione, lasciando ciascuno nel suo parere; ma solo diremo quel tanto che ci occorre per occasione della materia che trattiamo, che necessariamente ci ha divertiti a questo, volendo noi sempre cedere a chi sentisse meglio. [p. 427]

Diciamo donque che a noi paiono queste due opinioni come estreme, e che l'una e l'altra abbia parte del vero e parte del falso; e però che la migliore sentenza sia quella che sta nel mezzo, anzi che le abbraccia e congionge ambedue insieme, concludendo che tali pitture si facessero nell'una e l'altra maniera, cioè e nelli luoghi sotterranei et anco nelli sopra terra.

Per provare questo ci basterà di confutare ciascuna delle dette opinioni nei suoi termini, che così ne risulterà assai chiaro quello che noi pretendiamo. Quegli c'hanno detto non essersi usate le grottesche se non nei luoghi cavernosi della terra, mossi dalla forza della parola greca, non è dubio che si sono ingannati, come si prova dalla evidenza del fatto, la quale ci fa vedere oggi ancora in varii luoghi di Roma e del Lazio e di Campagna et altrove sale spaziose eminenti e loggie magnifiche, piene di queste pitture, che è come impossibile, o almeno lontano da ogni verisimilitudine, che fossero ascose da principio sotto terra, sì come sappiamo così essere tenuto da diversi ch'oggi sono stimati peritissimi delle antichità, che di più affermano che nelle sale, nell'anticamere, nei cenacoli, nelle loggie, nei criptoportici, nei luoghi de' bagni e quasi in ogni parte della casa indifferentemente si usavano tali pitture. Ma oltre di ciò abbiamo l'autorità di Vitruvio $^{924}$, che parlandone a longo, come diremo di sotto, non vediamo che le restringa sotto terra, ma ne ragiona come di cose che si usassero nelle abitazioni communi; e se bene egli non usa la voce di 'grottesche', si vede però chiaramente che la descrizzione sua tutta conviene ad esse, e gli espositori che hanno commentato quel luogo ${ }^{925}$ in lingua latina e volgare l'hanno in questo modo inteso. Né fa caso che il nome di grottesca, cavato dal greco, significhi luogo recondito et occulto e però non s'applichi bene alle pitture fatte al chiaro lume, perché di sotto si dichiarerà onde si sia causato questo. [p. 428]

L'altra opinione, che vuole che queste pitture non si usassero ne' luoghi tenebrosi, ma solo nelle abitazioni aperte communi della casa, manifestamente anch'ella si convince dalla istessa evidenzia del fatto, poiché oggi se ne truovano molte, che da principio veramente furono fabricate sotto terra, e se ne vedono ancor alcune con le fenestre su alto nelle volte, il che, secondo gli antiquarii, dimostra che non erano fatte sopra terra, perché avriano avuti i lumi più bassi: come dicono vedersi nelle grotte di S. Pietro in Vincula e nelle Diocliziane, Antoniane, Villa Adriana et altre assai, che dai vestigii chiaramente dimostrano la prima loro positura essere stata sotterranea.

Ma l'errore di questi pensiamo che forsi sia nato perché hanno preso questo nome crypta all'estremo, per un luogo profondo nelle viscere della terra, quali oggi sono le sepolture antiche de' martiri, dette catacombe e volgarmente le grotte di S. Sebastiano, di S. Lorenzo e d'altri, delle quali scrive S. Ieronimo ${ }^{926}$ : Dum essem Romae puer et liberalibus studiis erudirer, solebam cum ceteris eiusdem aetatis et propositi diebus dominicis sepulcra apostolorum et martyrum circuire crebroque cryptas ingredi, quae in terrarum profundo defossae ex utraque parte ingredientium per parietes habent corpora sepultorum; et ita obscura sunt omnia, ut propemodum illud propheticum compleatur, descendant in infernum viventes, et raro desuper lumen admissum horrorem temperet

\footnotetext{
924 VII, 5.

925 D. Barbaro e G. Philandrier.

${ }^{926}$ In Ezech., 40.
} 
tenebrarum, ut non tam fenestram quam foramen demissi luminis putes, rursusque pedetentim acceditur et caeca nocte circundatis illud Virgilianum proponitur: 'Horror ubique animos simul ipsa silentia terrent'. Donque da questa significazione mossi alcuni, hanno creduto che nei luoghi così profondi e tenebrosi non sia verisimile che vi sia stato lavorato con tanto artificio e spesa, come queste pitture sogliono dimostrare. Ma noi diciamo che questo nome è assai generale e che conviene ad ogni luogo scavato, o perforato, o altrimente fabricato nelle caverne della [p. 429] terra per qualonque uso ancor che immondo, come si vede da quel verso ${ }^{927}$ : Et solitus mediae cryptam penetrare Suburae; e s'applica ancor alle sepolture, come dimostra l'epitaffio antico già ritrovato nel colle Quirinale in Roma, che dice: Crypta Flavi Sabini privata cum anacrypta, LAT. P. XIIII. E Brocardo, parlando del santo sepolcro di nostro Signore, lo chiama parimente crypta $^{928}$. Ma di più, abbraccia ogni luogo, se ben poco sotto alla superficie della terra, pur che sia alquanto retirato e separato dal commune uso, sì come sono i luoghi che si sogliono fare per riporre frutti, vini, grani, legna, oglio e per altri servizii di casa; di che fa menzione Vitruvio ${ }^{929}$, dicendo: In aedibus cryptae, horrea, apothecae ceteraque, quae ad fructus servandos magis, quam ad elegantiae decorem esse possunt, le quali furono ancora chiamate hypogea, come ne rende testimonio Budeo ${ }^{930}$, dicendo: Hypogeorum appellatio complectitur cellas vinarias, carnaceas, olearias, poenarias, promptuarias; e ne fa menzione ancor Vitruvio ${ }^{931}$, dicendo: Sin autem hypogea concamerationesque instituentur, fundationes eorum fieri debent crassiores, quam quae in superioribus aedificiis etc. Dove gl'interpreti dicono ${ }^{932}$, quod erant aedificia subterranea, arcuato opere extructa, e che ancora si faceano ambulationes hypogeae, cioè luoghi sotto terra per passeggiare, simili ai criptoportici; dal che si racoglie che questo nome di crypta o grotta conviene ancora ad alcuni luoghi sopra terra, quando sono rinchiusi e riserati, sì come sono questi chiamati criptoportici, de' quali scrisse Plinio $^{933}$ : Subest cryptoporticus subterraneae similis, aestate incluso frigore riget contentaque aere suo nec desiderat auras, nec admittit. E questi si legge ch'erano tali, che si potevano tenere [p. 430] aperti e chiusi con varie sorti di fenestre, come l'istesso Plinio ${ }^{934}$, descrivendo la villa sua, dice: Hinc cryptoporticus, utrinque fenestrae a mari plures, ab horto singulae et altius pauciores. Hae cum serenus dies et immotus, omnes; cum hinc vel inde ventus inquietus, qua venti quiescunt sine iniuria patent; e servivano per luoghi freschi e di ricreazione nel tempo dell'estate, soggiongendo Plinio: Ipsa cryptoporticus tunc maxime caret sole, cum ardentissimus culmini eius insistit, e lo chiama amores mei, ché servivano per delizie. E però hanno voluto molti che in essi si facessero pitture et ornamenti straordinarii, di che al suo luogo si parlerà.

Laonde concludiamo che, essendo questo nome di grotta commune ai luoghi sopradetti e trovandosi oggi molti vestigii e fragmenti di simili pitture in diverse fabriche, più e meno profondi et anco superficiali, non s'ha da dubitare che in varie etadi non si siano le persone indifferentemente servite dell'uso loro, ora sotto, ora sopra la terra, sì come ad esse veniva a proposito.

\footnotetext{
927 Giovenale, V, 106.

928 C. Jannsen, Concordia evangelica cit., cap. 145.

${ }^{929}$ VI, 5.

${ }^{930}$ Annotationes cit., a Dig., XVII, 2, 52, 12.

931 VI, 8.

932 G. Philandrier a Vitruvio, VI, 8; V, 9 (in fine).

933 Epist., V, 6.

934 Epist., II, 17.
} 


\section{CAP. XXXVIII.}

Onde abbiano avuta origine le pitture grottesche secondo diverse opinioni.

Con tutto che si veggia chiaro, et il senso senz'altro lo dimostri, che queste pitture si usavano in luoghi sotterranei e non sotterranei, resta però ingombrata alquanto la mente, perché abbiano preso il loro nome dalle grotte, che ordinariamente sono tenebrose. E però, per chiarir bene questo, è necessario di discorrere alquanto intorno all'origine loro e vedere che cosa desse occasione già a' pittori di formare figure [p. 431] così contrafatte e fuori dell'uso ordinario; da che insieme si coglierà perché siano state di poi chiamate grottesche.

Troviamo varie esser state le opinioni intorno a questo, il che tanto più arguisce maggiore l'oscurità di questa materia, poi che non si legge ragione che intieramente appaghi l'intelletto. Scrive il maestro delle arti Vitruvio ${ }^{935}$, dove parla di simili figure mostruose, che questa è stata invenzione de pittori poco eccellenti, per coprire con varietà di forme e di colori il mancamento della loro arte, dicendo così: Quod antiqui, insumentes laborem et industriam, probare contendebant artibus, id nunc coloribus et eorum eleganti specie consequuntur, et quam subtilitas artificis adjiciebat operibus authoritatem, nunc dominicus sumptus efficit ne desideretur; la qual ragione se bene per l'autorità di chi l'ha scritta e per reverenzia che portiamo all'antichità non deve essere biasmata, nientedimeno, per avertimento solo, si dice che tal ragione non è più appropriata a questa sorte di pitture che all'altre, dove i pittori con la vaghezza dei colori et ornamenti che vi aggiongono cercano supplire al difetto dell'arte e del dissegno.

Altri hanno detto che, quando i Romani tornavano vittoriosi a casa, sì come pigliavano diversi nomi d'Affricano, Ispanico, Macedonico e simili, così soleano dipingere nelle loro case varie sorti d'animali peregrini o mostri che si trovavano nei paesi vinti da loro, i quali ancora dopo' la morte soleano scolpirsi nelle pile delle loro sepolture, con varie sorti d'armi et instrumenti di guerra adoprati in quelle imprese; dalla qual varietà cominciorono i pittori, con la solita loro libertà, estendersi a molt' altre cose inusitate.

Altri scrivono che nelle cene degli antichi, che si faceano nelle vigne e luoghi boscarezzi, soleano i ministri del convito servire in abito di ninfe, fauni, satiri e d'altri abitatori de' boschi; e che nel mezzo del servizio meschiavano rappresentazioni, comedie e diversi ragionamenti satirici, onde dicono esser state denominate le satire de' poeti; e da questo vogliono [p. 432] che cominciassero poi alcuni per recreazione a dipingere varie forme d'uomini e d'animali, con fiumi, rupi, boschi e maniere disusate e stravaganti.

Altri le derivano dalle guglie egizziace ripiene di figure ieroglifice, ch'aveano sensi alti nella loro lingua; e dicono che i pittori poi, vedendo che quella varietà portava vaghezza e meraviglia, si valsero di quelle forme, poco curandosi del significato, attendendo solo al dilettare, e le stesero et amplificarono con altre loro varie invenzioni.

Altri hanno referita l'origine loro all'uso de' poeti, che con varii significati degli accidenti delle cose umane introdussero nei suoi poemi molte favole, con trasformazioni di uomini, animali, piante e varie misture di cose insieme, le quali aveano gran sensi ascosi, per instruzzione della vita degli uomini, per dilettare e giovare insieme; sì come, tra gli altri, di Crate e Proteo filosofi si legge che attesero grandemente a questo, i quali furono poi seguitati et ampliati ancora da' pittori ${ }^{936}$.

Altri hanno attribuito il tutto principalmente alle opinioni vane de' Pitagorici ${ }^{937}$, che volsero che

\footnotetext{
935 VII, 5.

936 N. Conti, Mythologiae sive Explicationum fabularum libri decem (I568), VIII, cap. 8.

${ }^{937}$ Diogene Laerzio, Vitae, VIII, 1 ss.
} 
l'anime passassero d'uno in altro, ora uomo, ora animale, ora arbore, ora pianta, o sasso ancora della terra; e che però negli spettacoli si rappresentavano talora simili trasmutazioni fuori del naturale, che di poi i pittori andarono imitando et accrescendo.

Ma tutte queste ragioni et altre simili, se bene potessero dimostrare in qualche parte l'origine di queste pitture, non però levano la difficoltà perché siano state chiamate grottesche, essendo che le pitture ora narrate non ricercavano necessariamente di essere collocate nelle grotte. È vero che alcuni dicono che questo nome è stato per accidente, perché nei tempi passati, quando si cominciorono a scoprire queste pitture, elle si trovarono nelle reliquie delle rovine, che pareano [p. 433] sotterranee; talché vogliono che il nome sia moderno, ma il modo di dipingerle sia stato antico. Noi respondiamo che questo pare un rifugio, non dovendosi tribuire ad accidente quello che può convenire secondo la propria natura; e però la prudenzia ricerca che prima si investighi bene, se ci è ragione con che si possa salvare l'uno e l'altro e che convenga insieme alla forma di queste pitture et al nome che già tanti secoli si hanno conservato, non essendo verisimile che i nostri maggiori fossero sì sciocchi che tutto quello che trovavano nelle rovine rimaste degli edificii antichi pensassero che anticamente ancora fosse stato fabricato sotto terra. E però bisogna meglio esaminare tutto questo negocio, per trovarne, se si può, la verità.

\section{CAP. XXXIX.}

Altre ragioni della origine delle grottesche, e perché abbiano preso questo nome.

Volendo noi dire alcuna ragione vera et approvata della origine delle grottesche, confessiamo chiaramente che non ci assicuriamo, in materia così poco trattata dagli autori, potere sodisfare a quello che si desideraria. Nientedimeno, poi che siamo in questo soggetto, non vogliamo anco mancare di raccordare altrui per via di discorso quel che ci sovviene. E la difficoltà al parer nostro consiste in questo, che bisogna accoppiare quattro cose insieme che convengano tra loro: la prima è il dimostrare che anticamente vi fossero luoghi sotterranei di questa maniera; seconda, che fossero depinti; terza, che fossero d'imagini mostruose; quarta, che fossero instituiti a tale uso, che ragionevolmente admettesse simili pitture. Imperò che si troverà bene varietà de' luoghi sotto terra chiamati grotte, per riporre grano, vino, legna e per altri communi servizii della casa, come di sopra dicessimo, ma forsi non si proverà che fossero dipinti, né meno è verisimile. [p. 434]

Si troveranno ancora altri dipinti, ma non di fantasmi; e quando si trovassero ancor de fantasmi, non si vedrà la necessità che ciò richiedesse. Potrassi ancor trovare qualche ragione probabile perché si dipingessero simili mostruosità, come si è detto nel capo precedente; ma non si saprà la causa perché s'avessero a fare sotto terra e perché la loro origine uscisse dalle caverne: come per esempio si legge di Augusto, che talmente temeva i tuoni, i lampi e le minaccie del cielo tempestoso quando freme, che si ritirava in luogo rinchiuso e concamerato, come scrive Svetonio ${ }^{938}$; ma questo non ha che fare con le pitture. Scrive il Nazianzeno ${ }^{939}$ di Iuliano Apostata, che, per essercitare la magia, entrava in un luogo sotto terra, dicendo: Descendit in quoddam adytum plerisque inaccessum et horrendum cum comite mago; e racconta Luciano ${ }^{940}$ d'un sacerdote egizzio, che abitava sotto terra per imparare la medema arte magica, il quale per questo è chiamato da lui

\footnotetext{
${ }^{938}$ Div. Aug., 90.

${ }^{939}$ Adv. Iulianum, I.

${ }^{940}$ Philopseudes, 34.
} 


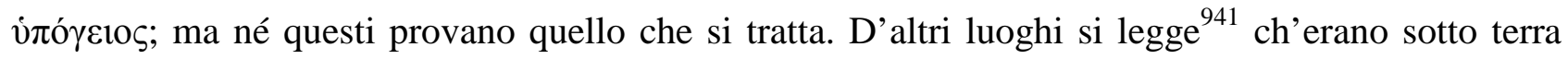
escavati per fare ridutti di cose oscene e disoneste; altri per parlare occultamente e con maggior libertà contro i prencipi o persone grandi, di che temevano; altri per bagni, delizie e passatempi, massimamamente nel tempo estivo, per essere luoghi opaci e riposti; altri per nascondervi dentro le cose preziose, come scrive Ioseffo istorico ${ }^{942}$ del sepolcro di David, nel quale erano alcuni repostigli per occultarvi dentro i tesori della eredità regia, fatti con sì grande artificio che non poteva alcuno accorgersene; altri per far più insidiosamente furti et inganni, come dei falsi sacerdoti si legge, scoperti da Daniele ${ }^{943}$; altri per occultarvi cose secrete, come avenne a Ieremia per commandamento di Dio, onde scrive ${ }^{944}$ : Et factus est sermo Domini ad Hieremiam [p. 435] in Taphnis dicens: Sume tibi lapides grandes in manu tua, et abscondes eos in crypta, quae est sub muro latericio in porta domus Pharaonis; altri per altri privati rispetti di ciascuno. Ma né questi ancora concludono cosa di momento.

Noi donque dicemo che, tra varii luoghi sotterranei instituiti dagli antichi a diversi fini, uno vi era molto principale, fabricato al nome e culto de' dèi infernali; percioché è cosa nota che avevano gli antichi più sorti di dei ${ }^{945}$, come i celesti, aerei, marini, terreni, e questi chiamati infernali, de' quali se ne trova frequentissima memoria non solo nei libri, ma ancor nelle medaglie e nei marmi delle sepolture col nome diis manibus. Donque a questi dèi deputava l'antichità i proprii luoghi insieme, e riti e tempii, con che a ciascuno di loro si dovea prestare il culto; e però a questi infernali aveano assignati i luoghi sotterranei, che servivano parte per raccogliere il sangue delle vittime che si gli offerivano, parte per dare le loro risposte e parte per edificarli i tempii, ne' quali si sacrificava loro: di che ne fanno menzione gli autori greci e latini, e tra gli altri Eusebio ${ }^{946}$, che recita i versi dell'oracolo d'Apolline, che diceva: Porro et capiuntur apertis Terrestres aris, foveas cum numina contra Exposcunt atro imbutas inferna cruore etc., e soggionge che Porfirio, esplicando questo oracolo, dice: Modus offerendi hostias diis differt, nam terrestribus super aras, infernis autem in foveis mactandas esse hostias oraculum praecipit etc.; e Sesto Pompeo ${ }^{947}$ scrive, antiquos diis superis in aedificiis a terra exaltatis sacra fecisse, diis terrestribus in terra, infernis autem in effossa terra; oltre quello che si legge della spelonca Sibillina e d'altre simili caverne, nelle quali quei falsi dèi davano le loro risposte ${ }^{948}$. E questi tempii perché alcune volte erano grandi e

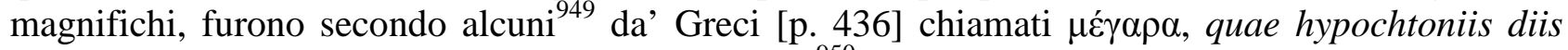
dedicabantur, del quale uso è stato scritto da diversi ${ }^{950}$.

Vogliamo ora inferire che, sì come i tempii degli altri dèi si solcano ornare e dipingere di cose convenienti al culto loro, come in più luoghi ne ammaestra Vitruvio ${ }^{951}$, così è molto verisimile che questi che si dedicavano a dèi infernali si adornassero di imagini e forme appropriate alla

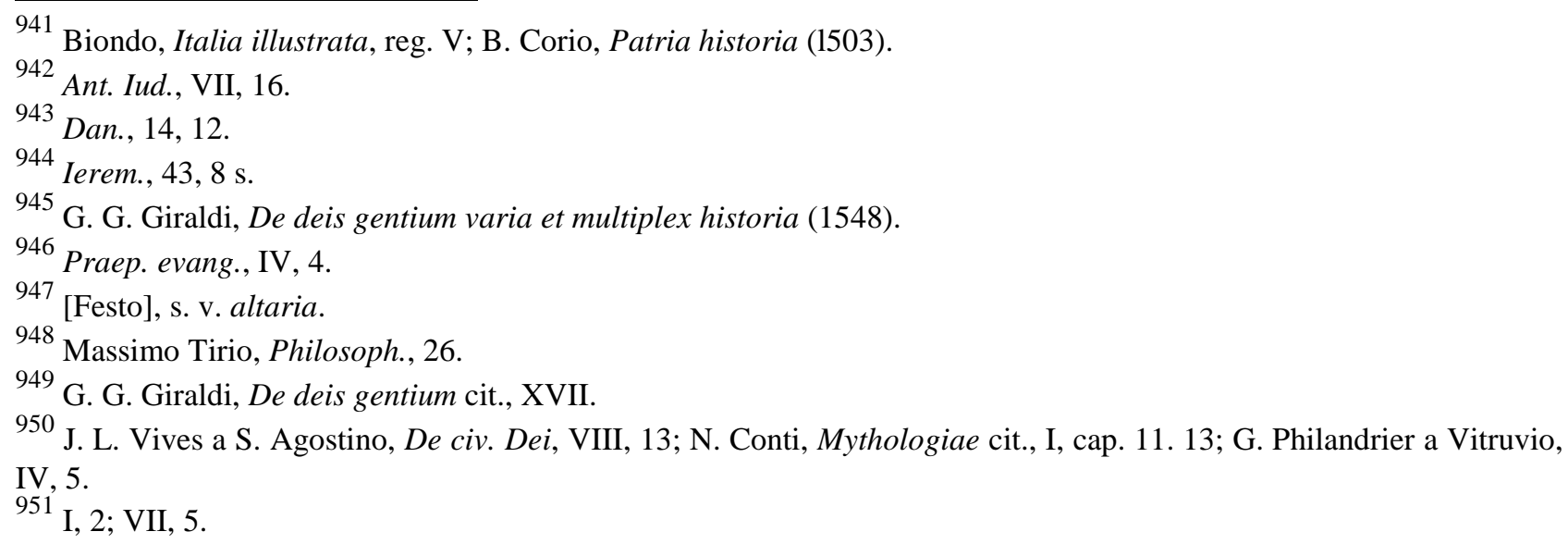


condizione d'essi. E questo è che la gentilità, aiutata dalle favole de' poeti, persuasasi che quei luoghi sotterranei fossero la propria stanza dei dèi infernali, credette insieme che, sì come questi luoghi erano esclusi dallo splendore del sole, dalla luce del giorno, dal canto degli ucelli, dal comercio degli animali terrestri e dall'abitazione degli uomini, così ancora fossero sotto il governo di questi dèi, differenti dai dèi celesti; e che nelle tenebre di questa regione vi fossero altri corpi et altre forme molto dissimili da quelle che noi veggiamo sopra la faccia della terra; e che insomma queste caverne, prive di lume e piene di orrore, abbondassero anco di fantasmi, mostri e cose contrafatte, anzi, che questi dèi medemi si transformassero ora in fiere, ora in serpi, ora in altri mostri. E di qui figurarono quei dèi che chiamarono lemures seu larvae, che con volti inusitati mettevano terrore agli altri. Di qui finsero quel dio Sumano con li fulmini notturni ${ }^{952}$, del quale scrive S. Agostino ${ }^{953}$ : Romani veteres nescio quem Sumanum, cui nocturna fulmina tribuerunt, coluerunt magis quam Iovem, ad quem diurna fulmina pertinebant; sed postquam etc. Di qui ancora scrissero i Platonici che, tra varie sorti di demoni che essi si imaginarono, un ordine vi era sotterraneo, quod habitabat sub terra, et invadebat eos qui puteos effodiunt, et suscitabat flammivomos ventos $^{954}$; et un antico filosofo, chia [p. 437] mato Ferecide Siro, scrive che questi demoni aveano i piedi serpentini.

I pittori adonque, considerata la natura del luogo e con questi principii avuti dagli autori, cercarono accommodare l'arte loro a queste favolosità, aggiungendovi poi ciascuno altre cose di suo capriccio, secondo che l'ingegno suo gli porgeva, e così introdussero questi fantasmi e mostruosità grottesche; la qual cosa, oltre le ragioni sopradette, pare a noi che si possa molto corroborare dall'essempio della Scrittura santa posto da Ezechiele profeta, nel quale si vedono le quattro cose che di sopra abbiamo detto: imperò che, scrivendo egli degli Ebrei del suo tempo, dice che alcuni, e massime donne, si aveano elette certe spelonche sotto terra, dove adoravano gl'idoli e piangevano quello che S. Ieronimo chiama Tammutz; e non solo gli offerivano sacrificii, ma ancor aveano dipinto nel muro in tutte le parti le imagini di quegli animali e reptili et altre abominazioni, di che giudicavano si dilettassero quegli idoli, dicendo Ezechiele ${ }^{955}$ : Et ingressus vidi, et ecce omnis similitudo reptilium, et animalium abominatio, et universa idola domus Israel depicta erant in pariete in circuitu per totum. Per la qual causa fu dimandata questa setta di gente, che entrava in tali spelonche, setta di Trogloditi ${ }^{956}$, pigliandosi questo nome a similitudine de' popoli di Etiopia, che abitavano nelle caverne ${ }^{957}$. Non ci astrengiamo però noi a dire che le grottesche, di che parliamo, siano discese dalla Palestina o che abbiano avuta origine dagli Ebrei, ma solo adduciamo ciò per similitudine che, sì come era questo modo in uso presso di loro, così puoté essere presso ad altri popoli, variati solamente i sacrificii e gl'idoli e le diverse sorti di superstizioni.

Onde non repugna a ciò chi dicesse che nelle vestigie [p. 438] delle grottesche antiche di Roma nissun segno si discerne che quei luoghi fossero fabricati a dèi: perché noi parliamo ora quanto alla origine e primo instituto di esse, quale dicemo aver potuto nascere da questo falso culto che si tribuiva ai dèi infernali, se bene i pittori hanno di poi allargata la mano e stese queste pitture ad altre fabriche ancora, come di sotto si mostrerà.

Vediamo oggi che nei luoghi sotterranei delle chiese cristiane, chiamati in Bologna confessii,

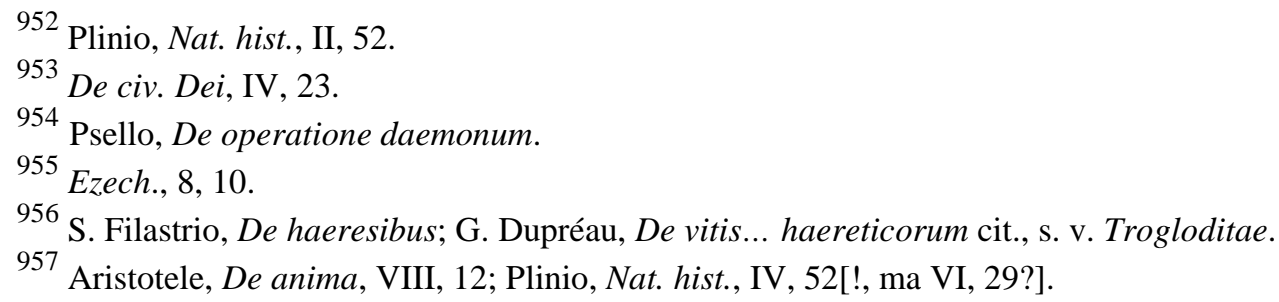


altrove scuruoli et anticamente martirii o confessionali, che sono sorti di grotte, usano i cristiani e giudiziosi pittori, dove il luogo comporta, d'accompagnarli con misterii appartenenti alle pene sostenute da quelli gloriosi martiri e coi trionfi che le sacre verginelle riportorno da quei crudelissimi tiranni, per essere queste cose accommodate a tali soggetti; e che in altri luoghi ancor cercano con la loro arte esprimere più che possono quelle cose che siano più appropriate alla materia principale. Così è molto verisimile che i pittori gentili anch'essi volessero onorare i suoi falsi dèi d'invenzioni che imitassero la loro natura, valendosi delle cose narrate nei notturni sacrificii di Bacco, di Proserpina e d'altri ${ }^{958}$. Al che si puotero muovere ancor per altra ragione, considerando essi che queste grotte per la loro opacità rappresentano a certo modo la notte et il luogo del sonno coi parti suoi, che sono aggiramenti in aria, chimere, fantasmi e bizzarie molto stravaganti ${ }^{959}$; onde finsero quella esser figlia del Chaos e moglie d'Erebo, e questo, tra una gran schiera de figli, averne tre principali, de' quali ciascuno si mutasse in varie forme, chi d'uomini, chi di fiere, d'ucelli, di serpenti, di sassi, di tronchi, et altre loro fantasie, come lasciò scritto Ovidio ${ }^{960}$ dicendo:

\author{
At pater e populo natorum mille suorum \\ Excitat artificem, simulatoremque figurae [p. 439] \\ Morphea, sed solos homines imitatur, at alter \\ Fit fera, fit volucris, fit longo corpore serpens: \\ Hunc Icelon superi, mortale Phobetora vulgus \\ Nominat; est etiam diversae tertius artis \\ Phantasos: ille in humum saxumque undamque trabemque \\ Quaeque vacant anima, fallaciter omnia transit. \\ Regibus hi ducibusque suos estendere vultus \\ Nocte solent, populos alii plebemque pererrant.
}

E quando pure al lettore non sodisfacesse intieramente alcuna di queste considerazioni, noi crederessimo che per ultimo si potesse acquietare, ricordandosi che, sì come già furono alcuni poeti che s'ingegnarono di fare studiosamente certi versi senza significato, ma solamente per dare occasione alle persone oziose di fantasticarli sopra senza frutto e, come essi dicevano, ut figerent crucem grammaticis; così i pittori, emuli dei poeti, mossi dalla qualità del luogo, pensarono anch'essi di oscurare affatto l'intelligenza delle loro pitture con levarli ogni sorte di verità, per lasciare ai posteri materia abondante d'assotigliarsi e travagliarsi disutilmente, sì come gli è riuscito ancor davantaggio, poiché non solo si contende di quello che essi non hanno voluto che s'intenda, ma ancora s'imitano per tutti i luoghi le loro fizzioni e sogni, senza avvertire et essaminare quello che si ha per le mani.

\title{
CAP. XXXX.
}

Per che causa dagli antichi e da' moderni siano state tanto abbracciate le grottesche, conservandoli questo nome.

\footnotetext{
958 Livio, XXXIX, 9 ss.

959 Artemidoro, De soma, interpr.; Luciano, Ver. hist., II, 4.

960 Met., XI, 633 ss.
} 
Ma, qualonque sia stata l'origine delle grottesche, chiaro è che, vedendo gli uomini tale invenzione riuscire graziosa ancora all'aspetto per la novità delle forme che più non si erano vedute, cominciorono con poca circonspezzione invaghirsi in maniera di esse, che le dilatarono et usarono ancor [p. 440] fuori delle grotte. Nel che pare a noi che sia avenuto ad esse come ad alcune piante appropriate solo a certa sorte di terreno, che, volendole gli uomini traspiantare fuori del naturale loro sito e regione del cielo, restano di poi languide e quasi morte, senza umore e vivacità; così queste pitture, che per certa convenienzia potevano passare in quelle caverne delle grotte, ora, trasportate in altri luoghi, s'infiachiscono, come peregrini nodriti nell'aere grosso delle valli, che non possono patire poi l'aria sottile delle montagne. Laonde ben furono avertiti da Orazio ${ }^{961}$ i poeti e pittori, che osservassero di porre le cose ai suoi proprii luoghi, dicendo: Sed nunc non erat his locus. Et fortasse cupressum Scis simulare: quid hoc, si fractis etc. Sì che anco queste grottesche, prima nate nelle tenebre, perdono la sua forza nei luoghi aperti, sì come gli ucelli di notte, che si smariscono alla luce del sole. Crediamo però che tale origine disordinata sia stata molto accresciuta, parte dalla debolezza de' pittori e parte dalla scarsezza de' padroni.

Dal lato de' pittori non è dubio che simili pitture, che non ricercano molto essatta imitazione e forza di dissegno, sono più facili da essere messe in opera da un mediocre ingegno, che quelle che vanno continuate e ricercano necessariamente la connessione o dipendenza l'una dall'altra, perché in queste, dovendo l'ingegno per forza stare raccolto e reggersi con la briglia dell'arte, non dà luogo al pittore di andare vagando a capriccio, e conseguentemente l'astringe a maggiore diligenza, vigilanza, pazienza e fatica, sì come aviene negli scrittori che, non pigliando un soggetto particolare né trattando con metodo fermo l'opere loro, se la passano con digressioni, saltando or qua or là senza ordine; il che è manco fatica assai, ma rende insieme ancora l'opera meno illustre, non se gli scorgendo continuazione alcuna, né come le cose ultime convengano con le prime, né vedendosi da tutto il corpo risultare quel totum che, dice Aristotele ${ }^{962}$, deve avere il principio, [p. 441] mezzo e fine, simile ad una forma animata che ha il capo, le braccia et i piedi ai suoi luoghi.

Sì che, per essere il numero degli artefici mediocri o imperiti molto maggiore senza paragone che degli eccellenti e perfetti, non è meraviglia se questa pittura prevale, come quella che è manco bisognosa d'industria e più conforme all'imbecillità loro, avendo ancora di più essi ritrovato modo di fare queste grottesche con lo spolvero, dove poco si ricerca industria et eccellenza di arte.

Quanto alla parte dei padroni, è tornato ad essi ancora bene di valersi de simili lavori, perché portano minore spesa, facendosi con manco quantità de colori e con più brevità di tempo, e porgono al primo aspetto una certa ammirazione a chi le guarda et a chi non penetra più oltre, come sono la maggior parte degli uomini, che si pascono d'apparenza; alla quale aggiongendovisi la varietà e la vaghezza de' colori, di che scrive Vitruvio ${ }^{963}$, con alcuni ornamenti attrativi che hanno ritrovati, pare che si possa concludere che, congionte tutte queste cose insieme, si vegga la causa assai chiara della introduzzione di queste pitture e del possesso che indirettamente vanno mantenendo in tanti luoghi, et insieme ancora si possa conoscere la ragione perché oggi ritenghino il loro nome antico di grottesche, quantonque si faccino fuori delle grotte. Il che secondo noi avviene perché elle veramente nacquero nelle grotte, come di sopra s'è detto, et ivi s'acquistorono questo nome dalle fascie; onde, se bene gli si è poi mutato allogiamento, non è stato però necessario di mutarli il nome, sì come vediamo essersi osservato ancor nel nome delle nozze, che gli antichi chiamorno

\footnotetext{
961 Ars. poet., 19 ss.

962 De caelo, I, 1.

963 VII, 7 ss.
} 
nuptiae perché allora coniuges nubebant caput ${ }^{964}$, onde, ancor che poi quel'uso si sia mutato, il nome però istesso gli si è conservato. Per la qual ragione sogliono i iureconsulti ${ }^{965}$ chiamare molte cose non da quello [p. 442] ch'oggi sono, ma da quello che già erano, sì come domandano isola, che già era isola, e la quarta legitima, ch'oggi è la terza, e molti altri essempii che possono servire al proposito nostro.

\section{CAP. XXXXI.}

Che le grottesche poco oggi convengono altrove, ma nelle chiese in nissun modo

Abbiamo detto che la propria sede delle grottesche anticamente fu constituita nelle caverne, e però, sì come gli animali sotterranei non vivono alla luce del sole, così elle ragionevolmente, secondo la gentilità ancora, non possono capire negli edificii sopra terra.

Ora passiamo ad altre ragioni, per mostrare più chiaramente che simili pitture malamente si possono oggi da persone giudiziose tolerare.

Se l'officio del pittore è l'imitare cose vere o verisimili, chi dubita che il pingere un uomo ch'abbia le membra superiori di gigante, e che poi riesca nelle inferiori in tronco o sasso; overo il formare candelieri con faccie d'uomini che dal capo mandino fiamme; overo conchili che gettino fiumi d'acque; o arbori prodotti da serpenti; o faccie, busti, gambe ora d'uomini, ora di leoni, ora di pesci complicati insieme, o accompagnati con arbori, con sassi, senz'ordine e ragione di natura; chi dubita, dico, che tal pittura non solo è repugnante all'officio del pittore, ma ancora alla natura, alla ragione et a quanti libri hanno mai scritto gli autori di qualonque facoltà? Se l'arte imita la natura, dunque le grottesche non sono secondo l'arte; se le pitture hanno da servire per libri agl'idioti, ch'altro potranno essi imparare da queste, che bugie, menzogne, inganni e cose che non sono? L'anima della pittura è il giovare, e dove non è questo fine [p. 443] è come un corpo morto, che diremo di queste, che non solo non giovano, ma possono intricare le menti de' semplici in mille errori? Se ciascuno dei difetti discorsi in questo trattrato in varii capi deprime assai la dignità di quest'arte, che avverrà in questa sorte d'opera, dove tutti insieme o la maggiore parte d'essi concorrono, non potendosi chiamare simili pitture se non bugiarde, inette, vane, imperfette, inverisimili, sproporzionate, oscure e stravaganti? Per tal causa scrive Filone, come altrove abbiamo detto, che Moisè scacciò dalla sua republica li artefici di statue e pitture che con bugie corrompessero la verità ${ }^{966}$.

È stato detto da alcuni ${ }^{967}$ che, sì come il dialettico cerca di sodisfare con la ragione et il sofista attende col falso a contrafare il vero, così i pittori delle grottesche, lasciando il vero et appigliandosi al falso, non cercano altro, a guisa de' sofisti, che ingannare chiunque gli s'accosta, o più tosto a similitudine de ebrii vaneggiando, per non dire de stolti che fanno le cose sue a caso, senza pensare quello che fanno, vanno errando senza proporsi fine certo o altro lodevole consiglio. Per lo che, volendo Orazio nella sua Poetica mostrare le cose che principalmente dovea un poeta fuggire, cominciò da questo capo, come importantissimo, pigliando a punto l'essempio di un pittore che facesse male l'arte sua, e però scrisse quei versi ch'oggi sono volgati ${ }^{968}$ :

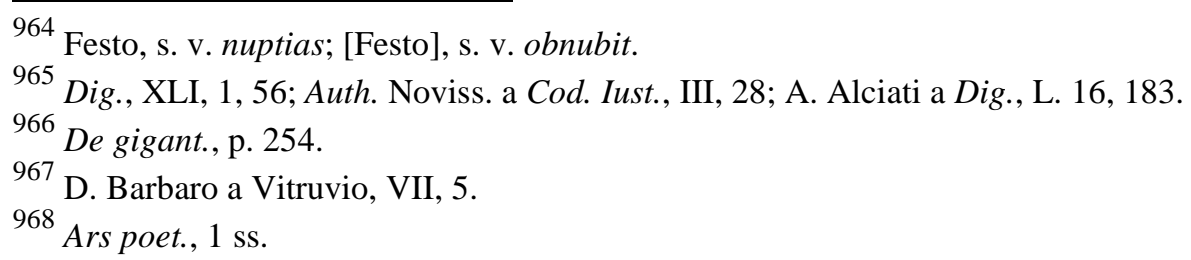




\section{Humano capiti cervicem pictor equinam \\ Iungere si velit, et varias inducere plumas \\ Undique collatis membris, ut turpiter atrum \\ Desinat in piscem mulier formosa superne, \\ Spectatum admissi risum teneatis, amici?}

E seguita di poi, paragonando simile poema over pittura, poi che vanno al pari, ai sogni d'un amalato, nel quale tro [p. 444] vandosi sconcertati tutti gli umori, si vanno generando nella fantasia varie confusioni di cose, le quali in sogno essa rappresenta avvilupate insieme al capo debole dell'infermo; onde scrive: Velut aegri somnia vanae Fingentur species, ut nec pes, nec caput uni Reddatur formae. Talché, sì come le cose fatte con ordine e ragione sùbito si fanno conoscere ch'escono da persona vigilante et accorta, così l'altre, confusamente poste e senza regola alcuna di virtù, portano seco il soprascritto che sono manifatture di persone sonnacchiose et addormentate; per la qual cosa simili grottesche sono chiamate da alcuni, ad imitazione di Orazio, sogni de pittori.

Ma a che ci stendiamo noi in discorrere di queste invenzioni ? poi che Vitruvio, tanto celebre presso a tutti nell'architettura e nella ragione del formare gli edificii e di ornarli e colorirli con pitture, ne ha scritto così largamente e declamato con tanta efficacia contro questo abuso o inavertenza de pittori, che questo solo dovria bastare a chi è capace di correzzione.

Sappiamo ben noi aver ciò spesso recato non poca meraviglia agli uomini di giudicio, poi che hanno veduto che quegli che fanno professione, nelle loro fabriche et edificii, di caminare con la guida di questo autore e di reggersi affatto sotto la sua disciplina, hanno peccato chiaramente in questa parte contro i suoi decreti, e si può dire contro i suoi principii, scrivendo egli in questo modo $^{969}$ : Constitutae sunt ab antiquis ex certis rebus certae rationes picturarum; namque pictura imago fit eius quod est, seu potest esse, uti hominis, aedificii, navis, reliquarumque rerum, $e$ quarum formis certisque corporum finibus figurata similitudine sumuntur exempla. Sed haec quae a veteribus ex veris rebus sumebantur, nunc iniquis moribus improbantur: nam pinguntur tectoriis monstra potius, quam ex rebus finitis imagines certae etc. E di poi séguita longamente essagerando questo abuso e mostrando con [p. 445] varii essempi che ciò è contro l'arte, la ragione, la verità e la natura istessa.

Ma quello che più a noi importa è che, se questi lavori si fossero contenuti solamente nei luoghi profani, dove la libertà degli uomini può avere alquanto più campo, si saria potuto con minore avertimento tolerare. Ma il vedere che questa indignità passi ancora nei luoghi sacrati di Dio et occupi ormai i più preziosi e reverendi apparati che siano per lo culto e tremendo sacrificio suo, certo non è cosa che dagli animi pii si possa dissimulare; perché se, come più volte s'è detto, le pitture sacre sono state dall'antica Chiesa instituite per certa instruzzione del popolo et eccitazione dell'affetto alla pietà, e per raccogliere la memoria delle cose divine ${ }^{970}$, dicami per grazia chi si compiace tanto di queste grottesche, se elle possono servire ad alcuno di questi usi, o pure se più tosto sono atte a distruggere tutto l'instituto della Chiesa; e se corrisponde alla maestà di un tempio, o gravità de' misterii che ivi si celebrano, il vedersi attorno pitture da burla, ghiribizzi di sogni, mascheroni de pazzi, chimere di vanità e giuochi da fanciulli.

Onde non è meraviglia, se il glorioso $\mathrm{S}$. Bernardo con tanta veemenzia si mostrò sdegnato contra

\footnotetext{
969 Vitruvio, VII, 5.

${ }^{970}$ S. Tommaso, In III Sent., d. 9, q. 1, a. 2; q. 2, ad 3.
} 
queste pitture, dicendo ${ }^{971}$ : Quid facit illa ridicula monstruositas? quid Centauri? quid semihomines? Videas sub uno capite multa corpora, et rursus in uno corpore capita multa; cernitur hinc in quadrupede cauda serpentis, illinc in pisce caput quadrupedis; ibi bestia praefert equum, capram trahens retro dimidiam; hic cornutum animal equum gestat posterius. Tam multa denique tanquam mira diversarum formarum ubique varietas apparet, ut magis libeat etc. Pro Deo, si non pudet ineptiarum, cur vel non piget expensarum? E così vediamo che altri sacri autori ancora hanno biasimato queste pitture mostruose ${ }^{972}$. [p. 446]

Ma almeno i nostri, c'hanno il lume della vera religione, non si lasciassero vincere dagli architetti o pittori che viveano nelle tenebre della falsa religione, in quella parte che serve al decoro e riverenza che si deve avere negli edificii sacri, poi che noi ritroviamo presso lo stesso Vitruvio ${ }^{973}$ et altri antichi essere stato con tanta diligenza et osservazione lasciata memoria nei loro libri della differenza dei tempii e maniera dell'architettura che a ciascuno dio secondo la sua proprietà si doveva edificare, e delle varietà parimente dei luoghi dove si avevano a collocare i tempii; giudicando essi ad alcuni convenirsi d'essere posti nelle città, ad altri fuori, ad altri nelle piazze, ad altri in altri luoghi ${ }^{974}$.

La simile diligenza servarono negli altari, come dovessero essere posti, verso qual parte del cielo riguardare, se alti o bassi; e della differenza da farsi presso i fiumi, o le vie publiche, o altre parti; delle porte dei tempii, degli ornamenti e di altre cose, come dovessero essere distribuite ${ }^{975}$.

Et in somma, oltra l'avere scritto Vitruvio due libri interi di cose pertinenti alla struttura degli edificii sacri, e anco in altri luoghi averne secondo l'opportunità parlato nell'opera sua, dice nel terzo libro questo, che desideriamo grandemente sia avertito dai nostri pittori, acciò sappiano quanto maggiore diligenza et industria debbono porre nelle pitture sacre che in qual si voglia opera profana, scrivendo così: Cum causa constituisse videntur antiqui, ut etiam in operum perfectionibus singulorum membrorum ad universam figurae speciem habeant commensam exactionem. Igitur cum in omnibus operibus ordines traderent, id maxime in aedibus deorum, in quibus operum laudes et culpae aeternae solent permanere ${ }^{976}$.

Ma perché in diffesa di queste grottesche sogliono addursi varie ragioni da alcuni, che potriano forse ingombrare gli animi deboli, abbiamo pensato di parlarne a parte nel capitolo seguente, acciò resti questa materia, ch'è assai frequente, pienamente dichiarata.

[p. 447]

\section{CAP. XXXXII.}

Si risponde ad alcune obiezzioni, che sogliono addursi in diffesa delle grottesche.

Molti, vedendo che queste grottesche si trovano nei vestigli degli antichi edificii di Roma, del Lazio, di Puzzuolo, et altri luoghi fatti sontuosissimamente e con molto artificio, non si possono persuadere che tale opera non sia molto esquisita e nobile, massimamente essendo di poi stata accettata dal commune uso del mondo nei luoghi più celebri et onorati che si trovino. Noi altre volte

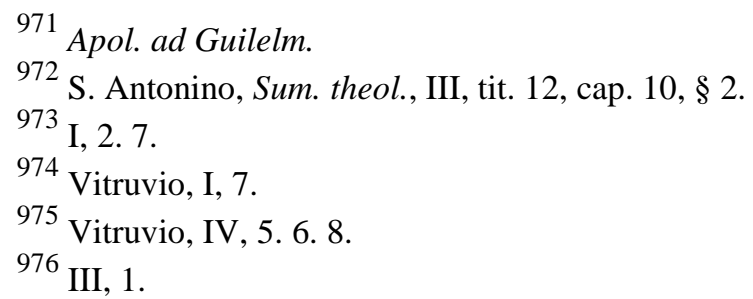


abbiamo risposto ad una simile ragione, dove si parlava delle pitture antiche e moderne ${ }^{977}$, dicendo che le cose s'hanno da misurare da sé stesse, e col sesto della ragione, e non dall'abuso e condizione del tempo, la quale sola non basta a giustificare veramente una cosa, quando vi ripugna la ragione; imperoché i più enormi e principali vizii, che oggi regnano nel mondo, si trovano avere discendenza sino dall'origine de' secoli, né però sono meno, anzi tanto più biasmevoli, quanto che sempre nell'età precedenti sono stati dai cattivi seguiti e dai buoni condennati. Sì come parimente aviene in queste grottesche di che parliamo, vedendosi che sino al tempo di Vitruvio erano da lui severamente biasimate, dicendo ${ }^{978}$ : Haec nec sunt, nec fieri possunt, nec fuerunt, sed ita novi mores coegerunt, uti inertia mali iudices conniveant artium virtutes; talché in questo caso la longhezza del tempo non è altro che una vecchiezza del vizio, degna d'essere perpetuamente bandita.

Altri si vagliono dell'autorità del medesimo Vitruvio ${ }^{979}$, che rende la ragione perché nelle colonne si figurassero quelle donne di marmo con la veste longa, chiamate cariatidi delle quali ancora è fatta menzione da Ateneo ${ }^{980}$, Plinio ${ }^{981}$ [p. 448] et altri; e parimente perché quelle statue persiane fossero formate in atto di sostenere gli architravi e tutto l'edificio delle quali se ne trovano oggi ancora molte in diversi luoghi; ad imitazione delle quali pare che i nostri abbiano figurati quelli che chiamano termini et altri simili nelle grottesche.

Ma a questo si risponde ${ }^{982}$ che l'istoria delle donne cariatidi è narrata per vera da Vitruvio, et il figurarle in quella maniera fu ritrovato come per insegna di trofeo: Ut aeterno dice egli ${ }^{983}$, servitutis exemplo gravi contumelia pressae, poenas pendere viderentur pro civitate, et posteris nota poena peccati Caryatium memoriae traderetur. Et il medesimo dice delle statue persiane, scrivendo: Captivorum simulacra barbarico vestis ornatu sustinentia tectum posteris pro tropaeo constituerunt, uti hostes horrescerent, timore eorum fortitudinis affecti, et cives id exemplum virtutis aspicientes gloria erecti ad defendendam libertatem essent parati. Per lo che si vede che queste ebbero origine da principio vero e furono instituite ad eccitamento di virtù; la qual ragione da ogni parte manca in queste grottesche, dove né la verità, né l'essempio può rispondere. Onde l'istesso Vitruvio in un altro luogo ${ }^{984}$ si lamenta, dicendo: Neque enim picturae probari debent, quae non sunt similes veritati, nec, si factae sunt elegantes ab arte, ideo de his statim debet 〈recte> iudicari, nisi etc.

Dicono altri che la libertà conceduta a' poeti e pittori può molto bene diffendere questa invenzione nata da fecondità d'ingegno, sì come col testimonio di Orazio ${ }^{985}$ s'afferma in quei versi volgati: Pictoribus atque poetis Quidlibet audendi semper fuit aequa potestas. A questo basti la risposta che soggionge lo stesso Orazio, dicendo: Scimus, et hanc veniam petimusque damusque vicissim; Sed non ut placidis coeant immitia, non ut Serpentes avibus geminentur, tigribus agni etc., talché l'istesso poeta viene a biasimare questa mostruosità.

Pare ad altri che non s'abbia così sottilmente e con tanto [p. 449] rigore a procedere contra queste pitture, poi ch'elle servono a pura dilettazione e trattenimento; né si trova alcuno così

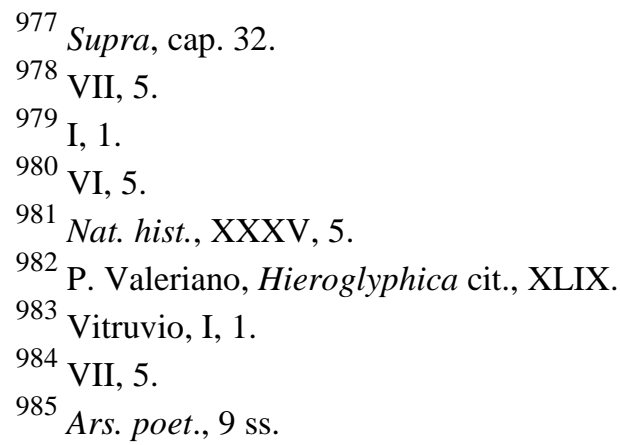


sciocco che non conosca chiaramente che tutte sono girandole, figurate così per ricreazione della mente d'alcuno, che più si compiace nel riguardare simili fantasie, che non farà un altro nel vedere la pittura di un prato fiorito o di qual si voglia altra cosa naturale; anzi, di più dicono che il pittore merita maggiore commendazione, poi che col fare simili figure quasi nel frontispicio si dichiara che non vuole figurare cosa vera, né vuole ingannare alcuno, ma solo per passatempo rappresentare cose capricciose, al contrario di molti che, promettendo di narrare o di pingere la verità, accumulano gran bugie et ingannano le persone ${ }^{986}$.

Ma la risposta è che non mancano modi onesti e ragionevoli per ricreazione dell'animo e dilettazione, ai quali deve attenersi il cristiano; e perché di questa materia abbiamo parlato di sopra largamente ${ }^{987}$, rimettiamo il lettore ai suoi capi, per fuggire l'inutile ripetizione.

E se pure alcuno replicasse che questo volere tanto fermarsi nella verità delle cose, tal che non si possa dipingere altro al mondo, verrà a distrugere tutte le favole de' poeti e gran parte delle comedie e tragedie che sono state scritte, et ancora verrà ad indebolire l'ufficio del poeta, quale essendo di scrivere le cose vere o verisimili, chiaro è che nelle verisimili non segue la verità, ma va accomodando il poema secondo che il decoro delle persone e la condizione delle cose che possono essere ragionevolmente hanno ricercato (il che parimente è parte propria del pittore); noi rispondiamo che non si esclude dal pittore, né anco come cristiano, questo verisimile di che di sopra abbiamo trattato, ma ciò è molto differente dalle grottesche di che parliamo, le quali non hanno parte alcuna né di vero né di verisimile, come ciascuno vede: perché altro è il riferire una cosa che non si sa certamente come sia stata in molti particolari, ma è verisimile che po [p. 450] tesse stare nel tale o nel tal modo - e questo non disconviene né al poeta né al pittore -, altro è il volere narrare una cosa che non solo ripugna alla verità del fatto, ma ancora alla possibilità della natura, e questa non ha luogo né tra poeti buoni, né tra pittori.

Ora, s'alcuno dicesse che pure i poeti hanno figurato e Cerbero con li tre capi, e Tizio co l'avoltore che sempre col becco gli straccia il fegato, e la barca di Caronte, e le Ninfe, e Dafne trasmutata in lauro, e Giove col fulmine ${ }^{988}$, e tant'altre cose che non sono né possono essere vere secondo la natura, e nientedimeno si scrivono e pingono per tutto; si risponde che il verisimile conceduto a pittori e poeti, sì come dichiara Aristotele ${ }^{989}$, si intende secondo il senso populare e certa capacità del vulgo; e però dice egli che il sapere fingere accommodatamente non è impresa di ciascuno, ma ricerca gran perizia, giudicio et intelletto, e per questo effetto egli propone Omero da imitarsi, come quello che ha servato grandemente il decoro et accommodatosi graziosamente al verisimile. Laonde, parlandosi in queste materie di cose pertinenti a dèi, ch'erano tenuti avere suprema potestà sopra le cose create dalla natura, parve a' poeti che non fosse fuori del verisimile che essi gli attribuissero cose che superavano le forze umane, e però andorno fingendo e colorando le loro invenzioni con molta probabilità popularesca. Sotto la quale nondimeno molti vi aveano ascosa ancora l'intelligenza morale, giovevole alla disciplina della vita, sì come narra Vitruvio ${ }^{990}$ di quei chiamati Telamoni e da' Greci Atlanti, che sostenevano gli edificii, e leggiamo parimente di molt'altre favole de' Greci ${ }^{991}$, che secondo alcuni aveano dentro allegoria et erano appropriate all'instruzzione de' costumi, del che copiosamente e largamente ne è stato scritto da diversi autori

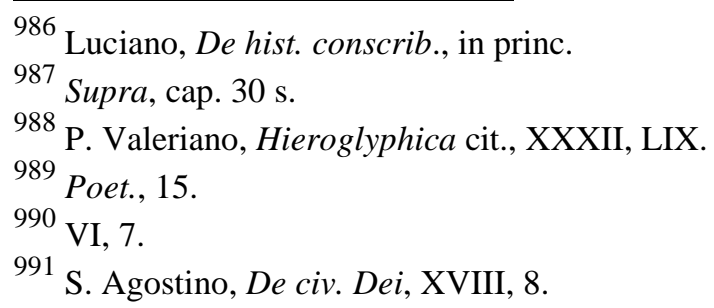


greci e latini ${ }^{992}$. Per la quale ragione potrà parere forsi ad [p. 451] alcuno ch' anco queste grottesche si possano defendere col senso della moralità et allegoria che dentro vi è posta.

Ma noi, lasciando per ora scrittori grandi, che simili favole hanno giudicato non dovere essere tolerate sotto pretesto d'alcuna allegoria ${ }^{993}$, et altri c'hanno scritto chiaramente che questo è stato un modo di colore o di velame imaginato da alcuni per coprire in qualche modo la bruttezza o sciochezza di quelle favole ${ }^{994}$, e che i Romani non volsero mai admettere simili allegorie; noi, quanto al proposito delle grottesche, diciamo che esse ordinariamente, come ognuno sa, non hanno ascoso alcuno senso giovevole, ma sono fatte a salti et a capriccii; e quando pure ve ne fosse alcuno, viene ad essere tanto recondito et abstruso, che serve per pochissimi et inganna moltissimi, e però si ha da tralasciare. Del che varie ragioni ne rende Dionisio Alicarnaseo ${ }^{995}$, che, parlando delle favole de' Greci, scrisse così: In Graecorum fabulis pauca bona insunt, nec multis prosunt, nisi qui scopum earum intelligunt, quae quidem sapientia paucis contigit; ceterum vulgaris turba et rudis philosophiae tales sermones in deteriorem partem accipit, et duplex hinc capit incommodum, aut deos contemnens tanquam multis involutos infortuniis, aut a nulla iniquitate turpitudineve abstinens, cum videat deos quoque his obnoxios. Quanto più dunque oggi dovranno simili invenzioni da noi tralasciarsi, che, sendosi già diffusa la luce della verità evangelica, non abbiamo bisogno più di tali favole o invenzioni, non mancando ottimi soggetti e dilettevoli nelle istorie sacre et ecclesiastiche e nelle vite de' santi?

Sì che concludiamo che, se bene gli antichi, involti nelle tenebre, ebbero qualche probabile ragione di figurare in quei luoghi sotterranei queste grottesche, a noi però, ai quali è apparso il sole della verità, più non convengono simili invenzioni; le quali maggiormente disdicevole sarà di fare nei [p. 452] luoghi publici et aperti, per le ragioni già dette, perché, quanto alle chiese, pensiamo che non sarà alcuno così privo di ragione che non confessi che, adorando noi in esse quella suprema maestà, per participazione della quale tutte le cose hanno l'essere e sono vere, nissuna cosa più le è repugnante che rappresentare in esse cose de sogni e de falsità.

\section{CAP. XXXXIII.}

Delle pitture delle virtù e dei vizii, e della molta difficoltà in poterle rappresentare.

Non veggiamo in che cosa possa il pittore cristiano essercitare l'arte sua più splendidamente o con maggior frutto, dopo le pitture sacre e religiose, che nel rappresentare con ogni vivacità la bellezza e la eccellenza delle virtù, come gioie preziosissime della casa di Dio; e parimente nel figurare la orribiltà et abominazione de' vizii contrarii e nemici capitali delle virtù e per conseguenza odiatissimi da Dio: percioché dal seguire quelle e fuggire questi dipende la perfezzione della vita cristiana ${ }^{996}$.

Leggiamo di quel famoso anacorita nel Climaco $^{997}$, che, desiderando acquistare la vera umiltà e perfetta mansuetudine, fece distintamente scrivere nel muro della sua cella diverse proprietà e condizioni di molte altissime virtù e, come si sentiva tocco da stimolo alcuno di vanagloria,

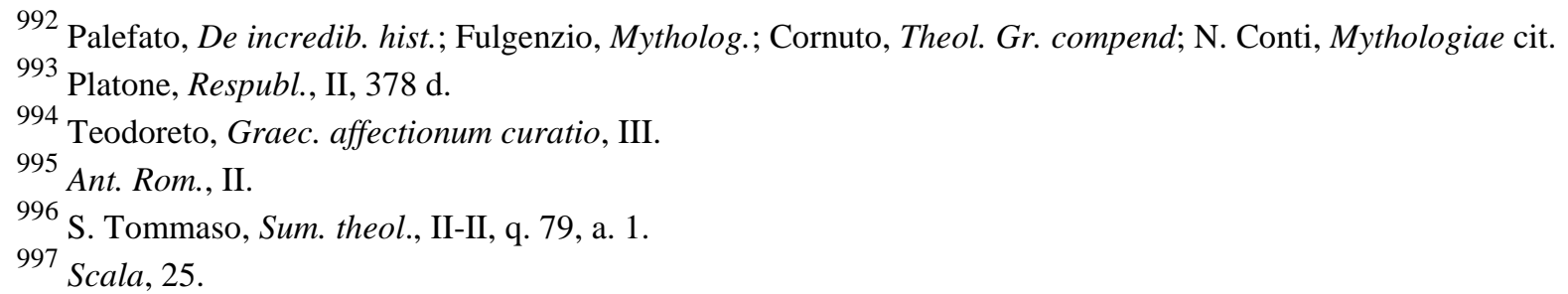


ricorreva subito a quel luogo; e rivedendo la scrittura, confondeva sé stesso, narrando il detto autore così: Cum cogitationes eius eum laudare incipiebant, eis dicebat: Eamus ad lapidem et ad reprehensionem. Veniebat ergo, et definitiones legebat, et contra se ipsum clamabat: Quando ista possederis, tunc cognosce quia adhuc longe es a Deo: quoniam si possides, servus inutilis es, fecisti quod facere debuisti; si vero non possides, longe distas [p. 453] ab observatione mandatorum Dei. Che se tanto giovamento sentiva egli da quelle poche linee dissegnate in un muro per raffrenare la propria confidenza e destarsi a maggior vigilanza, quanto più efficace dobbiamo giudicare il profitto che sia per uscire da tavole colorite e giudiziosamente formate, che ne' sensi nostri imprimono le cose che debbono essere da noi desiderate o aborrite! Veggiamo certo che anticamente ebbero questa mira alcuni pittori, sì come si legge presso Severiano: Frequenter fieri vidimus, ubi regum vel fratrum tabulae pinguntur, ut in utrisque unanimitatis declarentur insignia: artifex pictor femineo habitu post tergum utriusque Concordiam statuit brachiis suis utrumque complectentem, indicans quod ii qui corpore videntur separati, sententiis et voluntate conveniunt ${ }^{998}$. Onde che desidereressimo noi grandemente che i pittori nostri, ad essempio delle tavole di quel santo anacorita e di questo altro autore, con le loro pitture e dissegni formassero simili ritratti et apportassero questo beneficio o utile così notabile al mondo; perché non è dubbio, come già scrisse Platone $^{999}$, che chi potesse con gli occhi rimirare la faccia della virtù et onestà, si accenderebbe di meraviglioso desiderio di quella. Il che parimente fu affermato da Cicerone ${ }^{1000}$, così dicendo: Facies honesti si oculis cerneretur, mirabiles amores excitaret sui.

Ma l'importanza è che non si vedono dissegni antichi né moderni, che in parte alcuna agguaglino la grandezza et eccellenza loro, perché, da certe poche imagini in poi, molto ordinarie e trite, della Giustizia, Fortezza, Temperanza o simili, la schiera gloriosa di tante altre virtù resta come derelitta, parendo quasi smarrita la strada di rappresentarle, vedendosi che rari oggi si mettono o più tosto riescono in questa impresa.

Laonde, per trovare la radice di questa difficoltà, è necessario prima discorrere che cosa s'intenda per virtù cristiana, di cui contrario è il vizio. [p. 454]

Diciamo noi dunque che il nome di virtù, al detto de' savii, non è altro che un abito operativo secondo la norma della ragione, imperò che, essendo l'uomo di natura sua ragionevole, debbonsi regolare le azzioni sue secondo la ragione, onde allora si giudicano buone, quando a quella sono conformi; e perché sola è la virtù che fa vivere l'uomo secondo la rettitudine della ragione, di qui è che sola è essa ancora che rende l'uomo veramente buono ${ }^{1001}$. Per lo contrario, si chiama vizio quel'abito con che si opera diversamente dalla ragione, e però si dice essere contra la natura dell'uomo in quanto è uomo, perché, sendo egli di natura ragionevole, l'operare virtuosamente, se bene non nasce dalla natura del genere, è però secondo la natura della specie dell'uomo; onde l'operare fuori dell'ordine della ragione sarà un deviare dalla natura dell'uomo: il che si domanda vizio e peccato $^{1002}$.

Ma questo ancor non bastando alla virtù cristiana, però è da avvertire che, se bene $\mathrm{i}$ gentili et $\mathrm{i}$ filosofi nell'uso di questo nome di virtù pare che convengano con li fedeli, pigliandola gli uni e gli altri per l'abito di operare secondo la ragione, sì come si è detto di sopra; nientedimeno vi è gran differenza tra di loro, percioché la vera e perfetta virtù propriamente e legitimamente non conviene

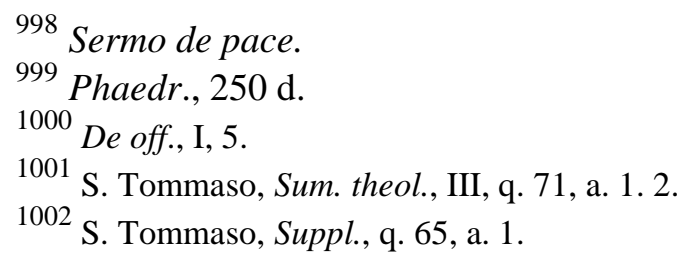


se non al nome cristiano ${ }^{1003}$, e se ai gentili talora ella si attribuisce, è stata in quelli però molto imperfetta e di gran lunga inferiore a quella del cristiano.

La causa di questa differenza nasce che, essendo il fine quello che principalmente dà la forma alla virtù ${ }^{1004}$, et essendo che da' soli cristiani per divina rivelazione è conosciuto il vero e supremo fine, al quale essi indrizzano le sue azzioni mediante la carità ${ }^{1005}$; ne segue ch'essi, con questa cognizione communicatali dalla divina grazia, danno la reale [p. 455] forma a qual si voglia virtù e di quelle acquistano il vero possesso. Ma i gentili, che, non avendo il lume della fede, non hanno potuto inalzarsi tanto, né scoprire quel'ultimo fine al quale ogni bene et ogni opera nostra deve essere indirizzata, sono per questo restati privi del godimento di questo tesoro, non avendo avuto la vera chiave per aprire la porta et entrare dove è riposto; percioché, se bene conobbero Dio, non però, secondo che dice l'A Apostolo ${ }^{1006}$, lo glorificarono come Dio.

Non diciamo per questo già che tutte le azzioni loro fossero vizii o peccati, perché, quantunque mancassero della grazia, non però mancarono de' beni di natura, i quali, usandosi da loro rettamente et a fini veramente buoni ${ }^{1007}$, come per salvezza della republica, per conservazione della giustizia, per difesa della onestà o altri simili, non si può negare che in tali casi non si potessero chiamare virtuosi e buoni moralmente, ma non perfettamente buoni né virtuosi, perché non furono questi atti dirizzati e ordinati da loro al finale e perfetto buono ${ }^{1008}$; ma l'altre operazioni essercitate da quelli, se bene a fine di onesto o di forte o di giusto, nelle quali però essi principalmente pretendeano l'onore proprio o gloria umana o altri disegni loro privati, non puotero a nissun modo numerarsi tra le vere virtù. Laonde Aristotele ${ }^{1009}$ istesso, parlando di Ettore, nega che a lui si convenga la laude della vera fortezza, percioché le battaglie e vittorie che di lui sono narrate non erano elette per zelo dell'onesto, né ordinate a fine di virtù, ma per fuggire vergogna e forsi per conservarsi in buon credito presso i Troiani; e di qui ancora scrive S. Agostino che molte azzioni de' Romani, che spesso sogliono tanto essere dagli uomini admirate, come la liberalità, la continenza, la fortezza, la fedeltà, la magnani [p. 456] mità, et altre simili di quegli imperatori e senatori antichi, non furono nella classe della vera virtù, né meritano questo nome, ma più tosto titolo di cupidità e di ambizione $^{1010}$. E perché altri distinguono altrimente, noi a quelli ci rimettiamo, non essendo proprio soggetto nostro.

Da tutte queste cose discorse diciamo dunque che, potendosi considerare la virtù et il vizio nel suo genere, che semplicemente si dimanda con l'istesso nome, cioè virtù o vizio; overo in alcuna sua specie, come giustizia, temperanza, gola e lussuria: si vede che in tutti due i modi è molto difficile impresa il figurarli, perciò che, essendo il genere e la specie cose universali, che s'intendono solamente in astratto, e sono operazioni dell'intelletto, non potiamo noi così vestirle che le facciamo venire obietto del senso, né possiamo sottoporre agli occhi del corpo quello ch'è proprio della mente. Laonde si vede per esperienza che quelli che sinora hanno voluto rappresentare alcuna di queste virtù sono ordinariamente incorsi in uno de' due errori, che sono tra sé come estremi: l'uno è stato di quegli che hanno cercato di esprimerle con alti concetti et isquisite

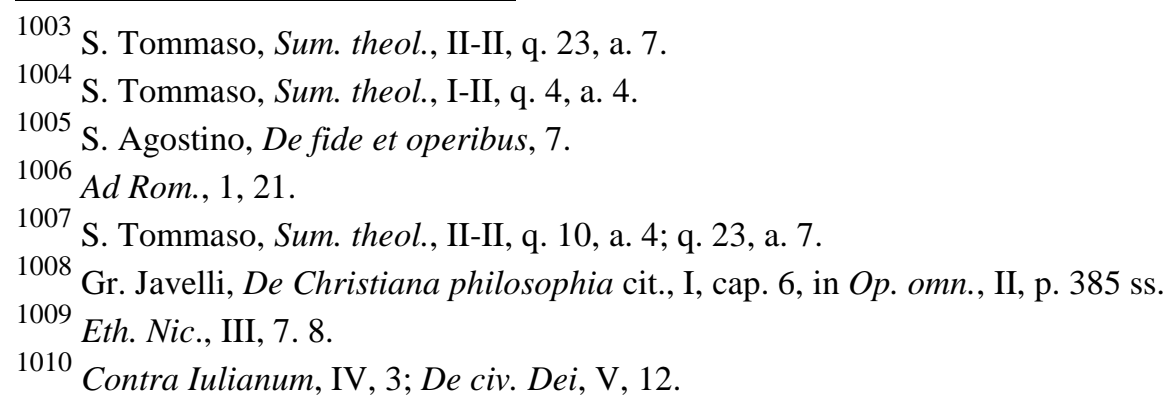


invenzioni, per partirsi dalle cose volgari; e questi hanno partorito opera tanto oscura et intricata, che senza l'aiuto appresso d'alcun valente filosofo o teologo non se ne può cavare i piedi, e resta il concetto loro incomprensibile. L'altro è stato di quegli che, volendo farle conoscere al popolo, le hanno figurate, come volgarmente si usa, in forma di donna con gli abiti et insegne che le si danno; il che viene tanto ad abbassare et avilire la grandezza loro, che perdono tutta la dignità e splendore della virtù, talché, dove dovriano queste imagini rapir l'animo per meraviglia et infiammarlo d'ardore di bontade, rendono più tosto negligente il pensiero, parendoli rimirare cosa commune e triviale, come sono le donne che si veggono ogni giorno. A proposito di che fa quello che leggiamo anticamente di Policleto, che, essendo nel resto così celebre arti [p. 457] fice, nel formare però l'imagini de' dèi fu giudicato che l'opere sue mancassero in rappresentare quella grandezza e maestà che si li conveniva ${ }^{1011}$; il che medemamente diciamo del figurare il vizio con la sua orribilità, alla quale con niuna sorte di descrizzione si può aggiungere.

Sì che per queste o simili ragioni pensiamo noi che i più valenti et aveduti pittori, conoscendo l'ardua difficoltà del negozio, volentieri si siano ritirati, non altrimente di quello ch'è accaduto agli antichi nel diffinire o descrivere l'essenza d'Iddio, che, non potendo attribuirli cosa alcuna, quantunque degna tra noi, senza imperfezzione o dipendenza, presero partito di dichiararla con parole negative, perché con le affirmative era un avilirla, abbassarla e quasi annichilarla ${ }^{1012}$; et il medemo aviene alla virtù, che, essendo la più eccellente cosa che sia tra noi, e come divina, non potiamo trovar cosa per significarla, che non le tolga grandissima parte della sua eccellenza.

Intorno a che avendone voluto noi udire il parere di persone segnalate, non n'abbiamo riportato altro che il testimonio loro, di non aver sinora veduto disegno alcuno di cosa che risponda a gran pezzo alla vera dignità d'una sola virtù, o bruttezza d'un sol vizio.

Nientedimeno non vogliamo noi restare di non soggiungere, secondo la debolezza nostra, alcuni avvertimenti, da' quali possano i pittori ricevere qualche maggior lume, per potere più commodamente et utilmente adoprarsi in soggetto così necessario et importante, di che nel capo seguente ragioneremo.

[p. 458]

\section{CAP. XXXXIIII.}

Alcuni avvertimenti per rappresentare le imagini delle virtù e vizii.

Serìa certo cosa sopramodo giovevole alla vita umana il potere esprimere le vere imagini delle virtù e vizii, acciò che ne' sensi nostri più efficacemente s'imprimesse la bellezza di quelle e la diformità di questi. Ma, come digià dicessimo non si è trovato sinora concetto che possa degnamente rappresentare la grandezza loro; e però ricordiamo noi alle persone essercitate nelle lettere e studii, ch' ad essi toccaria per beneficio publico di aiutare la industria de' pittori col ritrovare la vera ragione e modo di figurare acconciamente questi due esserciti numerosi delle virtù e vizii, l'uno prodotto dal padre dei lumi e l'altro dal prencipe delle tenebre.

Intanto diciamo che, sì come ci sforziamo di rappresentare con alcuna cosa sensibile tutte le altre cose intelligibili et invisibili, che hanno veramente il loro essere reale, ma non però sottoposto al senso; così, per significare e figurare le virtù et i vizii, potiamo valerci d'alcune cose delle più atte ad esprimere la sostanza e condizione loro. Talché, sì come gli angeli et i demoni si dipingono nella

${ }^{1011}$ F. Patrizi, De institutione rei publicae (1518), I, cap. 10.

1012 Dionisio Areopagita, De myst. theol. 
maniera che ognuno sa, poi che non si è trovato cosa megliore e più proporzionata al senso nostro; così, volendosi rappresentare alcuna delle virtù o vizii, s'avria da applicarli alcuna invenzione conveniente al grado loro: la quale perché desideraressimo più tosto intendere da altri, che proporla noi, però tochiamo solo al presente alcune cose per semplice avvertimento.

Prima, che, quanto al corpo della virtù, è stato parere d'alcuni che s'avria da formare, potendosi, la imagine rilucente di quel lume e splendore che i teologi per translazione hanno chiamato nitore, proprio, come essi dicono, dell'ani [p. 459] ma virtuosa ${ }^{1013}$. E, quanto al vizio, hanno detto che s'avria da circondare di quella bruttezza che si chiama macola, che priva l'anima del lume che prima l'illustrava.

Dipoi, perché, oltre ciò, sono necessarie altre particolarità per fare conoscere che sia questa o quella virtù, dicono che s'avria di più a descendere ad alcuni propri atti più notabili e propri obietti di ciascuna di loro, servendosi di quelle cose che sogliono precedere e seguire essa virtù e vizio, $o$ vogliamo dire che sono antecedenti e conseguenti.

E perché è pericoloso spesso il fondarsi in proprie invenzioni, prudentemente crediamo farà quel pittore che si diletterà seguire gli autori gravi et approvati, che di queste cose hanno ragionato, e vedere come da quelli sono state descritte, valendosi del modo, in dipingerle col pennello, che quelli con la penna hanno tenuto: sì come della umiltà e della fucata bellezza appresso il Nazianzeno ${ }^{1014}$; dell'iracondia et invidia appresso il Nisseno ${ }^{1015}$; dell'avarizia appresso S. Basilio ${ }^{1016}$; della eloquenza e della calunnia presso Luciano ${ }^{1017}$; della giustizia, della discordia, della emulazione, del silenzio e di molte altre appresso altri autori ${ }^{1018}$, che ne hanno parlato giudiziosamente e molto a proposito per poter fare un ritratto de' detti loro e rappresentarlo al popolo: sì come Tertulliano ${ }^{1019}$ dipinge la imagine della pazienza nella orazione dove raccommanda questa virtù a tutti i buoni; e parimente S. Crisostomo ${ }^{1020}$ descrive diligentemente l'avarizia e le sue parti, che per essere egregiamente da lui toccate, riferiremo l'istesse parole: dice dunque: Fingite videre tetrum hominem quendam, [p. 460] qui ab oculis ignem emittat, cui ex utroque humero dracones pro manibus dependeant, cuius os cavernae instar magnitudine sit, in quo pro dentibus acuti enses stent; ex lingua fons venenosus scaturiat; venter omni fornace sit ardentior, cuncta quae immittuntur subito consumens; pedes alati ventis quoque ipsis velociores; facies canis, ac lupi simul faciem ostendat, nec hominis vocem emittat, sed insuave quiddam atque terribile mugiat; is ad haec omnia faces ardentes in manibus teneat. Mira haec forsan vobis videntur, sed nondum digne ipsum descripsimus; sequi etiam debent horum instrumentorum effectus. Itaque imaginemur eum obviam factos ingulare, carnes eorum lacerare et devorare. Sed quid facio? nam et hoc descripto multo truculentior est avarus, in omnes ut mors insiliens, omnes ut infernus deglutiens, communis generis hominum hostis.

Ma di più: per fare queste pitture delle virtù, potrà talora l'accorto pittore valersi delle imagini di

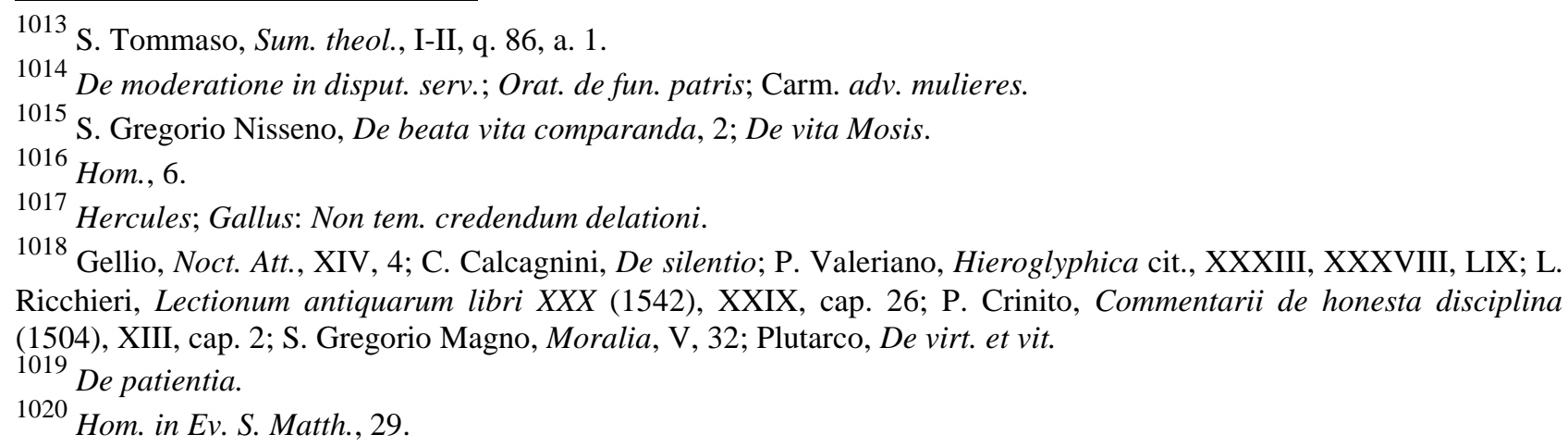


persone onorate, massime de' santi, cavandone sensi buoni et accommodandole al proposito suo: sì come della pittura di S. Georgio e di S. Cristoforo e di molti altri è stato mostrato da alcuni ${ }^{1021}$. Potrassi parimente da alcuni poeti cristiani e gentili sciegliere materia non volgare a questo effetto: poi che con l'ingegno suo hanno mirabilmente espresse alcune cose, sì come, presso Prudenzio ${ }^{1022}$, della fede et idolatria, della castità e libidine, e di molte altre virtù e vizii; presso il Carmelitano ${ }^{1023}$, dei sette vizii capitali; presso Ovidio ${ }^{1024}$, della invidia e sua casa; presso Lucano ${ }^{1025}$, del lusso e della parsimonia; presso Silio Italico ${ }^{1026}$, della virtù e della voluptà; e presso Claudiano ${ }^{1027}$, della eternità; e così presso molti altri.

Troviamo ancora essere commendato assai a questo proposito il dipingere alcuna persona che sia stata eccellente in [p. 461] quella virtù che vogliamo significare, o che sia stata vittoriosa di quel vizio che si vuole biasimare, scrivendosi $\operatorname{così~}^{1028}$ : Cum ex avaritia et habendi studio aliquis rapitur, sancta Ecclesia Mathaeum ex telonio apostolum illi indicat, qui, relicta avaritiae insania, Christum sequutus est. Si quis autem amore meretricio detinetur, casti Ioseph imaginem proponit, qui adulterium execratus, et temperantia illud vicit. Rursus alibi beatam Susannam continentia exornatam exhibet, extensis manibus auxilium ex alto invocantem, Danielemque praesidentem iudicem eruentem eam e manibus impiorum presbyterorum. Rursus luxurioso mollibusque vestimentis induto, et non eroganti in pauperes quae posset ab istis preciosis vestibus sumere, exhibet Ioannem pilis camelorum indutum, sive Basilium magnum, et cum eo solitariorum ieiunantiumque corporibus in terram stratis multitudinem, etc. E così, per impugnare l'avarizia, celebrare la liberalità, et inalzare la pacienza, la verità, la onestà e simili altre virtù, si potranno molto bene figurare le imagini di persone note e segnalate in quelle virtù, le quali tanto più averanno forza, quanto che seranno state persone della istessa professione: come ai soldati, ai mercanti, ai dottori, ai cortigiani, a' scolari, agli agricoltori et ad altri tornerà molto a proposito, secondo i gradi et instituti di ciascuno, mettergli davanti agli occhi quegli che nei medemi essercizii, come specchi di quella virtù, possono maggiormente moverli per la similitudine; e massime quando seranno di persone già passate all'altra vita, acciò sia senza sospetto d'adulazione.

E sopra tutto, per maggiore distinzione e chiarezza, lodaressimo assai alcuno breve e significante motto, che venisse a dar anima e vita alla imagine; poi che, essendo formata di cose forsi non molte note, viene a restare come corpo morto, se non è vivificato da alcune parole o dal luogo dello autore approvato, come di sopra in altro proposito si è discorso ${ }^{1029}$.

\footnotetext{
1021 Lorenzo da Villavicencio, De recte formando studio theologico (1575), III.

1022 Psych.

1023 Battista Mantovano, De calamitatibus temporum, I.

1024 Met., II.

1025 Phars., IV.

${ }^{1026}$ Pun., XV.

1027 De bello Goth., V, VI.

1028 Concil. Nic. II, act. VI (Surius, III, p. 177).

${ }^{1029}$ Supra, cap. 33.
} 
[p. 462]

\section{CAP. XXXXV.}

Delle pitture dei simboli.

Abbiamo un altro modo d'esprimere le virtù e gli atti virtuosi, col rappresentare alcune cose naturali et artificiali, come arbori, piante, fiumi, metalli, stelle, uomini, animali, edificii, torri, machine et altre simili cose, nelle quali riluce qualche vestigio del sommo creatore e stanovi riposti non piccioli semi per essercizio della virtù. Onde, congionte che siano alcune di quelle insieme con certa ragione, secondo la proprietà di esse, et applicate le loro operazioni al vivere nostro, formiamo corpi di figure tali, che rendono non solo vaghezza all'aspetto per la varietà delle cose che sono figurate, ma apportano anco mirabile giovamento all'animo per la similitudine misteriosa che ci rappresentano, o vogliamo dire per la medolla della virtù che in esse è contenuta.

Questi sono stati chiamati anticamente simboli ${ }^{1030}$, perché, tra i varii significati che porta seco questa voce, l'uno serve principalmente per certa nota e contrasegno di un'altra cosa maggiore; tal che, nel proposito nostro, simbolo vorrà dire una o più figure insieme, o adunanza di varie altre cose, che, oltre quella somiglianza esteriore che rappresenta, significa ancora un altro concetto più alto e sensato, appartenente alla vita nostra. Sappiamo bene noi esser state da alcuni non indottamente assignate varie differenze tra i simboli, note ieroglifice, emblemi, imprese, insegne, ziffre, armi e simili altre figure; ma non intendiamo di entrare ora in queste difficoltà e solamente ci pare di toccare alcune cose in generale, che servono a tre sorti di pitture che più frequentemente sogliono usarsi in questo genere, che sono i simboli, le imprese e [p. 463] l'armi delle famiglie; non già estendendoci a tutte le loro particolarità, ma solo dando un poco di lume di esse, quanto ci pare essere necessario per lo contesto del trattato nostro.

I simboli dunque vogliono alcuni ${ }^{1031}$ che abbiano avuta origine dalle note ieroglifice degli Egizzii, dei quali è stato scritto ampiamente da' Greci e da' Latini. Altri dicono che le ieroglifice erano di due sorti, l'una detta simplicemente ieroglifica, l'altra simbolica; e che della simbolica vi erano parimente tre specie tra sé diverse, una, come dice Clemente Alessandrino ${ }^{1032}$, per imitationem, altera per tropos, tertia per aenigmata.

Ma a noi non importa di fermarci in questo, e bastici solo di sapere che, secondo il parere degli eruditi, questo ch'oggi chiamiamo simbolo consiste ordinariamente di più e varie imagini unite insieme, che fanno un certo corpo di figure, siano d'uomini o d'animali, di piante o d'altre cose dette di sopra, le quali rappresentano alcun atto vero, o verisimile che sia stato, o altro che sia finto, dal quale ne risulta interiormente un altro senso buono e morale. Talmente che il simbolo propriamente cava da cose particolari un precetto universale, che serve al vivere morale e mostra la via d'abbracciare la virtù e fuggire il vizio.

E di qui è che, nel formare i simboli, alcuni si vagliono delle cose accadute, che sono state vere, et altri delle finte, come di favole di poeti, applicate però queste e quelle all'uso universale della vita; e nell'una e l'altra maniera non mancano uomini che gli hanno usati con molta lode. E tra gli altri, allargando assai questa invenzione, si sono in ciò serviti grandemente alcuni degli apologi di Esopo, commendati molto dagli autori per essere vaghi, onesti e molto efficaci per fare con diletto impressione negli animi, massime de' fanciulli, applicando i modi e maniere degli animali [p. 464] ai costumi e nature degli uomini; a imitazione del quale altri di poi hanno da sé stessi composto et

\footnotetext{
1030 S. Cirillo, Apol., IX.

1031 Orapollo, Hieroglyphica; P. Valeriano, Hieroglyphica cit.; I. Sambucus, Emblemata (1564).

1032 Strom., V.
} 
imaginatosi altre favole e ragionamenti d'animali, tutte però dirizzate al vivere virtuoso, sì come tuttavia si leggono non senza frutto e dilettazione ${ }^{1033}$.

Non lascieremo di dire che intorno alle figure di questi simboli troviamo ancor varii pareri di persone non volgari essendo che alcuni in essi non admettono motto alcuno, ma separatamente dalle figure vi aggiongono versi, che sono come interpretazione di quel corpo figurato; altri inseriscono nelli stessi simboli, cioè nella tavola delle figure, alcun motto o verso, che dicono ravivare e dare come l'anima a tutto il disegno; altri sono che congiongono l'uno e l'altro insieme, inserendo il motto nelle figure e di poi aggiongendovi più stesa la parafrase sotto; altri pare che ricusino le figure dei corpi umani; altri non vi admettono se non azzioni umane; et altri indifferentemente si servono dell'uno e dell'altro, sì come torna più loro a proposito.

Noi dunque, sì come non pretendiamo di volere determinare queste differenze né biasimare il parere altrui, così giudicheressimo che, quanto appartiene al fine nostro, che è di dare quei ricordi che possono essere giovevoli, non si avesse questa materia da ridurre a bilancia, così uguale et a pesi così minuti, ma universalmente fossero accettati questi simboli, in qualunque modo fossero espressi, purché col suo decoro e con la corrispondenza delle parti; e che, oltre la vaghezza e dilettazione, avessero seco la medolla, che è di giovare alla vita onesta. Il che però non fosse tanto oscuro e difficile, che avesse bisogno sempre di sottile interprete, né manco tanto triviale e volgare, che non apportasse né meraviglia, né novità, né trattenimento alcuno all'intelletto; il quale tanto più suole eccitarsi et apprendere le cose, quanto più sono state da lui apprezzate per la loro dignità. [p. 465]

Laonde, per qualche maggior agevolezza di chi vorrà servirsene, ci pare di ammonire il lettore che, oltre il fuggire alcuni abusi assai noti, come il dipingere cose lascive, o monstruose, o di falsi dèi, o di altro da noi di sopra notato, avertisca ancora, quando vorrà valersi degli essempii posti da altri, di fare buona scielta e di non attaccarsi subito a ciascuna istoria, o favola, o apologo, o altro che sia, perché sia stata scritta o stampata; ma consideri bene, prima, se corrisponde interamente a quello che egli pretende, dipoi, se vi è aggiunta chiarezza conveniente a quello che vuol significare: il che grandemente suol riuscire mediante alcun motto breve, grazioso e significante. Ma quello che principalmente si avrà da avertire è che il simbolo porti seco instruzzione et utilità al ben vivere; onde, per assicurarsi da questi scogli e caminare senza intoppo, lodiamo noi grandemente quei che sogliono valersi delle parabole evangeliche riferite dal Salvatore nostro, aggiongendovi alcune parole brevi e sostanziali della Scrittura sacra, le quali come gioie preziose ornano, arrichiscono et illustrano tutto il disegno. Sì come serìa, dipingendosi la parabola del frumento congregato nell'aia, da noi detta ara, dove si batte il grano e si separa dalla paglia (il che figura l'estremo giudizio), aggiongervi le parole dell'istesso Evangelio per motto: Paleas comburet igni inextinguibili ${ }^{1034}$. Overo la parabola di quelli che edificano la casa, l'uno sopra la pietra e l'altro sopra l'arena, onde vengono $\mathrm{i}$ fiumi et $\mathrm{i}$ venti che rovinano questa e non nuociono a quella ${ }^{1035}$, col motto dicendo: Domus super petram, stat; non super petram, cadit. Overo la parabola del grano di senape, che, sendo minutissimo, cresce nondimeno in tale altezza, che diventa arbore dove gli augelli si riposano $^{1036}$, col motto: Exaltavit humiles. Overo la parabola della rete buttata in mare, che

\footnotetext{
1033 A. Alciati, Emblemata (1550); A. Bocchi, Symbolicarum quaestionum de universo genere... libri quinque (1555); Fedro, Fabulae Aesopiae; H. Iunius, Emblemata (1565).

1034 Matth., 3, 12.

1035 Matth., 7, 24-27.

${ }^{1036}$ Matth., 13, 31 s.
} 
raccogliendo ogni sorte di pesce, vi si sciegliono poi i buoni da' cattivi ${ }^{1037}$, col motto: Boni electi, mali eiecti. [p. 466]

Le quali parabole noi ora adduciamo per esempio, intendendo di ricordare a tutti, e principalmente alle persone ecclesiastiche, che vogliano valersi di simili invenzioni buone, secure, vaghe e di grandissimo giovamento alla vita umana; delle quali gran copia ne potranno raccorre non solo dai libri evangelici, ma ancora dai sacri volumi della Legge antica, e dalla istoria eclesiastica, e dalle vite de' santi; le quali, scielte con giudicio, seranno per apportare meravigliosa vaghezza, utilità, esempio e grandezza, con riputazione di chi le usarà e del luogo dove si troveranno rappresentate.

\section{CAP. XXXXVI.}

Delle pitture delle imprese.

Ancor che le figure, che volgarmente si chiamano imprese, paiano avere molta conformità e similitudine con li simboli di che abbiamo ragionato, talmente che alcuni ancora hanno confusi questi nomi e preso l'uno per l'altro; nientedimeno, chi bene considera, vi è tanta differenza fra loro, che, sì come i simboli, fatti con debita ragione, sono lodevoli et apportano non picciolo giovamento alla vita umana, così l'imprese, fatte come oggi più universalmente si costuma, patiscono non per la natura loro, ma per l'abuso, gran contradizzione presso i buoni e savii, e non mancano di molte obiezzioni.

Noi lasciamo ora l'etimologia di questa voce 'impresa', che non è necessario il disputarla, e parimente l'origine, il tempo, l'autore; lasciamo ancor le cose che dicono necessariamente dover concorrere in formar il corpo d'una impresa, e quelle di che deve mancare ${ }^{1038}$; e seguiamo il più commun [p. 467] parere degli autori, che l'impresa sia un componimento di figura e di motto, che rappresenti alcun concetto et operazione, che abbia fatto o disegni di fare qualche persona particolare, di cosa che sia nobile e magnanima, o dal volgo così reputata.

Nel che diciamo primamente che, oltre molte differenze che sono tra i simboli e le imprese, questa si scuopre principale, che i simboli, avendo per soggetto una azzione particolare, da quella inferiscono un precetto universale virtuoso e giovevole alla disciplina della vita commune; ma l'imprese, per lo contrario, da cose atte a riferirsi universalmente inducono un concetto particolare applicato alla propria persona dell'autore dell'impresa, il qual concetto ordinariamente altro non fa che magnificare qualche azzione o pensiero di sé stesso. Talmente che, sì come i simboli ci rappresentano quella maestà e liberalità regia, che ad altro non è intenta che al servizio commune et al far bene ad altri, così nelle imprese, per il contrario, pare che si scuopra quasi che un certo tirannico instinto di dirizzare ogni cosa a commodo proprio e valersi dell'altrui per interesse particolare.

Et in questo avertiamo anco il lettore che, potendosi le imprese considerare in due modi: o per sé stesse e secondo la faccia sua esteriore, overo quanto al fine che in esse vi può avere l'autore; noi, lasciando per ora la intenzione occulta, che non appartiene a noi di giudicare, e può essere buona $\mathrm{e}$ rea, trattiamo solo del corpo esteriore dell'impresa, per quello che la figura sua, accompagnata col

\footnotetext{
1037 Matth., 13, 47 s.

${ }^{1038}$ P. Giovio, Ragionamento... sopra i motti e disegni d'arme et d'amore, che comunemente chiamano imprese, con un discorso di Girolamo Ruscelli intorno allo stesso soggetto (1566); L. Contile, Ragionamento sopra la proprietà delle imprese (1574).
} 
motto, estrinsecamente dimostra e communemente da tutti viene interpretata; sì come anco nel discorso delle statue, dei ritratti, dell'armi delle fameglie e di altre cose simili abbiamo significato.

Ora, perché in questo campo fecondissimo hanno passeggiato molti nobili ingegni d'Europa, non è al presente intenzione nostra di detraere in parte alcuna a' suoi onorati pensieri, ma solo di porre in considerazione a questo populo alcune cose intorno a questa materia, acciò per l'avenire [p. 468] possa ciascuno con cristiana prudenza et edificazione degli altri valersi di simili invenzioni. Imperoché a chi bene riguarda appare assai chiaramente che alcune di esse si travagliano intorno a soggetti poco gravi, anzi molto giovinili e sensuali, come di cose d'amore, di dame, di danze, di mascherate, di scene e di cose simili, delle quali non è necessario il discorrere altrimente perché da sé stesse scuoprono la loro qualità, e quanto poco convengano a persona grave o di alcun grado in qualonque città o republica, non che ad una persona cristiana che faccia professione di credere e di osservare quello che la legge nostra, nemica capitale dell'ozio e della lascivia, ne commanda.

Altre imprese sono dirizzate a cose di onore, di prodezza e di virtù; ma in queste ancora caggiono varie considerazioni, però che la maggior parte di esse paiono studiosamente fatte solo per onorare le proprie persone et inalzare sé stessi, come poco fa dicessimo; il che non pare altro, in sostanza, che una mera ostentazione et iattanza. Imperoché vedansi, di grazia, l'imprese che si trovano stampate, e quelle che vanno attorno per l'academie e per le corti; e cerchisi di cavare il succo di esse secondo il proprio loro significato, con le parole che vi sono accompagnate: certo che, non già tutte, ma gran parte di esse altro non pare che inferiscano che un lodare sé medesimo, perché una dirà in questo o simile senso: Ecco, io son quello che non mi metto ad azzione alcuna, che non ne cavi i piedi; un'altra: Ecco, io son quello che son inespugnabile dai colpi del mondo; et un'altra: Ecco, io son quello che col mio valore mi faccio la strada aperta; overo: Ecco che da lontano e d'appresso mi faccio sentire; overo: Ecco che, vivo e morto, serò trionfatore. I quali concetti, solamente a sentirli narrare, pare che muovano lo stomaco ad ogni modesto e ben creato uomo. Imperoché, lasciamo stare che spesse volte l'uomo s'attribuisce cose bugiarde e falsissime, che egli non ha mai fatte né pensate; non potrà già almeno negare alcuno che, quando bene tutte fossero vere, questo non sia un imitare quella enfiatura [p. 469] farisaica che tanto dispiacque al Salvatore nostro: perché, dicendo egli: Ieiuno bis in sabbato, decimas omnium do ${ }^{1039}$, diceva quello che forsi avea fatto e che era vero; nientedimanco, perché questo non inferiva altro che un sonare la tromba delle cose sue, manifestando l'appetito della propria eccellenza e superbo pensiero, contrario affatto alla dottrina della umiltà, radice d'ogni vera virtù ${ }^{1040}$, per ciò condannò il Signore nostro questa arroganza del fariseo et inalzò l'umiltà del publicano e soggionse quella memorabile sentenza, da seguirsi da tutti: Omnis qui se exaltat, humiliabitur; et qui se humiliat, exaltabitur ${ }^{1041}$.

E se alcuno dicesse che è pur lecito, secondo i teologi ${ }^{1042}$, in alcuni casi di commendare sé stesso, e massime quando col suo esempio si possono accendere gli altri ad abbracciare azzioni onorate; e che perciò le imprese potranno servire e giovare a questo effetto; si risponde che non si nega che non possano esser fatte alcune imprese con sì prudente circonspezzione, che dovranno giustamente tenere il suo luogo nel seggio della virtù. Ma soggiongiamo che, per lo più, parlandosi di quello che ordinariamente si vede con gli occhi, si ritroverà che la maggior parte di esse sono molto differenti dai casi de' teologi. E però avertiamo il lettore che sia ben cauto, né si lasci sotto

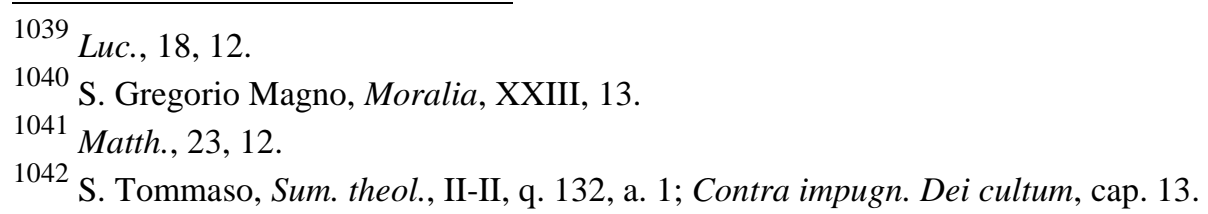


velame di virtù prendere dall'esca della vana gloria, figliuola primogenita della superbia ${ }^{1043}$; e massime che non basta che una cosa sia vestita di umiltà e di onestà, se parimente non sia fatta con debito ordine e convenienza ${ }^{1044}$, la quale nel presente caso apparisce in contrario, poiché la faccia dell'impresa istessa confonde l'autore di vana riputazione. [p. 470]

E se si replicasse che, anzi, tali imprese vengono a mettere in obligo l'autore di esse di vivere virtuosamente e conforme al sentimento che detta impresa dimostra, poi che per tale si è publicato al popolo; noi rispondiamo che questa è burla, poi che non ci è magistrato che faccia esequire tali obligazioni, anzi si è veduto per isperienza che la vita seguente di molti spesso è stata di gran lunga differente da quello che con l'impresa aveano dimostrato.

E se di nuovo si replicasse che con l'impresa si vuole esprimere un concetto virtuoso fatto o da farsi, per mostrare che ciò non è nato a caso o da fortuna, come volsero i gentili, ma per deliberazione e certo giudicio; si risponde che un cristiano ha già questo per legge, di non tribuire le azzioni umane al fato o alla fortuna, ma alla previdenza d'Iddio e libertà dello arbitrio ${ }^{1045}$. Onde, essendo questo uno dei primi principii e fondamenti della sacra religione nostra, non ci è bisogno d'impresa a questo effetto, poi che ciò porta scritto nel cuore perpetuamente.

Se si dicesse che si ritrovano pure varie imprese che non mirano punto a lodare sé stessi, ma più tosto ad eccitare sé medesimi al desiderio della virtù e disciplina della vita; si risponde a questo come ancora di sopra già abbiamo detto, cioè che non si biasimano queste, che sono con cristiana modestia congionte, ma l'altre, che sono ripiene di fasto e spirano non so che di vanità, come è la maggior parte di quelle che vanno attorno.

Avertiamo però che anco in queste, che paiono così vestite di modestia, si può peccare in più modi. L'uno, perché siano troppo vili et abiette, che non conviene alla natura delle imprese. L'altro è che, nel mostrare tanta umiltà, si può recadere per contraria strada in altra suspizione di troppa affettazione. Il terzo è perché forsi non convengono al luogo, al tempo et al soggetto. Il quarto, perché siano troppo communi e triviali, overo abbino concetti troppo alti et oscuri. [p. 471] Il quinto, perché siano cavati da animali o piante o pietre di che non s'ha notizia, o da proprietà loro troppo recondite se bene uno o due autori l'avessero narrate, che spesso ancora non sono vere. Ma di più si erra spesso in farne publico spettacolo e multiplicarle senza occasione, il che mostra troppo voglia di essere commendato per bello ingegno e tenuto per molto saputo.

Ora, nel genere delle imprese che biasimiamo, abbracciamo quelle ancora che fossero fatte da terza persona in lode di un altro; perché, essendo di poi accettate e come ratificate dalla persona principale, vengono, secondo la regola dei iureconsulti, a diventare sue proprie e consequentemente a soggiacere alle condizioni e rispetti di che si è ragionato di sopra.

Restano altre imprese, che si riferiscono ad alcuna virtù non propria, ma generale, come di continenza, di giustizia, di liberalità; overo contengono qualche atto notabile, come la destruzzione di Ierusalem, l'avertimento che ebbe il re David da Nathan profeta ${ }^{1046}$, o altre cose de' Greci e de' Latini, che sogliono figurarsi nelle facciate dei palazzi, nei camini delle sale et in capo delle loggie. Ma queste, perché non toccano al particolare di persona, non si chiamano propriamente imprese, ma emblemi o simboli o riversi di medaglie o ziffre figurate, o con altri nomi, secondo che piace a ciascuno di chiamarle, se bene le nominasse ancor imprese, ma seranno però di specie diversa dalle communi e da quelle di che noi ora trattiamo; e però di esse non diremo altro, bastando le cose dette

\footnotetext{
1043 S. Gregorio Magno, Moralia, XXXI, 31.

1044 S. Tommaso, Sum. theol., I-II, q. 7.

1045 S. Tommaso, Sum. theol., I, q. 186, a. 1; I-II, q. 1.

${ }^{1046}$ II Reg., 12, 1 ss.
} 
nel capitolo precedente.

Ora, da quello che si è discorso, potrà restare chiaro che noi non destruggiamo tutto l'ordine delle imprese, né condanniamo quelle che servano il suo decoro e danno segno di modesta gravità, come se ne veggono alcune di uomini grandi e di sommo valore. Ma solo diamo avertimento al lettore di alcuni abusi, che schiffandosi nel formarle, restarà la dignità loro con maggiore grazia, splendore et utilitade.

[p. 472]

\section{CAP. XXXXVII.}

Delle pitture delle arme delle famiglie.

Quelle che volgarmente si chiamano arme delle fameglie onde abbiano avuto origine e chi ne sia stato l'inventore è varietà tra gli scrittori. Imperò che presso alcuni traono l'origine loro fino dal tempo de' Romani ${ }^{1047}$; o, per dir meglio vogliono quelli, ch'elle succedessero al luogo delle imagini che i Romani tenevano de' loro maggiori, in segno di nobiltà, ne' palazzi e portavano nelle pompe funerali, et a guisa d'arbori le estendevano secondo le descendenze, di che altre volte parlassimo $^{1048}$. Dicono dunque che in luogo loro sono poi state admesse queste arme, che si conservano nelle fameglie per memoria della loro antichità e nobiltà; e però in alcuni luoghi già fu osservato che tali arme non passassero agl'illegittimi, se non col segno d'una linea transversale ${ }^{1049}$, ma oggi quest'uso quasi communemente si trova alterato.

Altri dicono che questi sono stati doni militari, cioè alcuni segni di onoranza che gl'imperadori concedevano ad alcuni in foggia di scuti militari, ne' quali era figurata alcuna imagine, come argomento di virtù operata in cose di guerra ${ }^{1050}$; di che scrisse Plinio ${ }^{1051}$ : Scutis, qualibus apud Troiam pugnatum est, continebantur imagines, unde et nomen habuere clypeorum; origo plena virtutis, faciem reddi in scuto cuiusque, qui fuerit usus illo. Oggi hanno preso il nome d'arme; le quali cominciandosi di poi a donar ad alcuni benemeriti, ben [p. 473] ché non in cose militari, e col progresso del tempo essendo concedute ancor solo per favore e per fare ad alcuno questo onore - se bene in esso non era grado alcuno di autorità, di lettere, di nobiltà o di sufficienza, che meritasse tal prerogativa, - perciò degenerò molto la prima loro dignità, vedendosi adulterata in soggetti poco proporzionati al dono. Dal che non è alieno quello che si trova scritto presso Svetonio ${ }^{1052}$, che Claudio Cesare instituit imaginariae militiae genus, quo absentes et titulo tenus fruerentur.

Altri vogliono che esse non abbiano avuto il loro principio prima che da Carlo Magno, perché, se bene si trova che anticamente i Romani portassero l'aquila, i Sciti il fulmine, i Persiani l'arco, gli Egizzii il bue, e molt'altre provincie o città avessero alcune sue proprie insegne, con le quali si discernevano dalle altre ${ }^{1053}$ (sì come ancor si legge nelli Atti degli Apostoli della nave alessandrina che condusse S. Paolo, S. Luca et altri, alla quale dice che insigne erat Castorum) ${ }^{1054}$, nondimeno

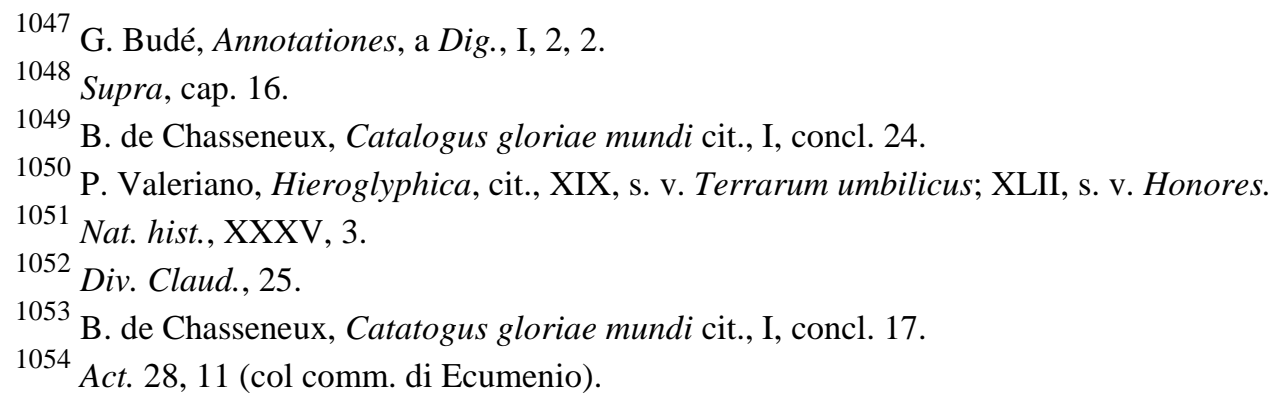


dicono che queste erano insegne publiche di nazioni, o provincie, o regni, ma che queste arme sono di famiglie private e domestiche, introdotte al tempo quando scorsero nell'Italia i Vandali, i Gotti, Ongari, Saraceni, Longobardi et altre nazioni, dalla violenzia de' quali avendo cominciata ella ad essere come divisa in più parti, furono donate da quei che signoreggiavano in alcun luogo queste insegne a diversi, per riconoscere meglio ciascuno i suoi confederati; e che di poi elle si sono andate moltiplicando, secondo la varietà de' tempi et ambizione delle persone.

Altri le danno il nascimento più basso e vogliono che cominciassero solo al tempo di Federico Barbarossa, da quattrocento anni in qua, o circa, quando ancora uscirono in campo quelle fazzioni nominate Guelfi e Ghibellini.

Ma noi lasciamo ora tutte queste contese non necessarie [p. 474] al caso nostro, sì come anco il discorrere della forma de' colori, de' corpi, delle figure o similitudini che rappresentano, e delle altre cose che in esse sogliono vedersi; perché, essendo la maggior parte d'esse, come dicono, arbitrarie spesse volte fatte a voglia di questo e di quello, senza altra ragione e come a caso, non vogliamo al presente occuparci in questo, bastando a noi, tralasciata la varietà delle opinioni circa la loro origine, di supporre che, come i nomi sono posti per distinzione di molti contenuti sotto questo commune di uomo, così l'arme, significando la diversità del cognome, sono poste per differenza di quei che possono participar il medesimo nome, e per distinguere con questo segno alcune sorti de' beni dell'uno da quelli dell'altro. Sì che l'intenzione nostra è solo di discorrere al presente di alcuni abusi che si sono attaccati a quest'arme, non per escluderle affatto, né tassar quelli che le hanno usate et oggi le adoprano, ma perché, vedendo noi che da molti s'usano indifferentemente con poca considerazione, desideraressimo poter mostrare quanto più sicura cosa fosse, e lodevole, il ridurle alla maniera che si dirà. E perché si possono tal arme considerare in due modi, sì come dei ritratti ancor si è detto: l'uno, quanto alla forma loro esteriore, l'altro, quanto all'intenzione che in esse si può avere; però parleremo dell'uno e l'altro separatamente.

Quanto, dunque, all'arma esteriormente considerata, diciamo che, se bene ella è cosa indifferente, si può nondimeno errare in varii modi nell' usarla, cioè nell' affetto, nel modo, nel luogo e nella persona.

Nell'affetto s'ingannano gran parte degli uomini, perché abbracciano queste arme con tanto ardore, e vi fanno tanto capitale sopra, che pare che in quelle ripongano la somma della loro riputazione; e si lasciano intendere che, quando non potessero accompagnare le operazioni, che fanno nella vita sua, con le loro arme, più tosto eleggeriano di non farle, come che li paia che, senza l'arme, fossero poco appariscenti: e non s'aveggono i meschini, primamente, che la figura di [p. 475] quell'arme può essere commune ad infiniti altri ch'essi non conoscono, o forsi anco li vogliono poco bene; percioché è opinione de' iureconsulti ${ }^{1055}$ che è lecito a ciascuno di formarsi di nuovo un'arma a suo gusto, o valersi delle fatte da altri, secondo che a lui piace, purché ciò non sia in pregiudicio o fraude altrui. Talmente che da questo solo principio può ciascuno comprendere che fondamento debbe fare in cosa che sia tanto esposta a tutto il volgo, e spesse volte non abbia né ordine, né ragione, né fondamento alcuno di verità. Ma quello che più importa è che, disegnando gli uomini che questo sia un mezzo da perpetuare il nome della casa o famiglia loro e renderli come immortali al mondo, non s'accorgono che questi sono accidenti appoggiati ad una sostanza fragilissima, che subito cade et in consequenza tira seco in ruina tutti gli accidenti.

Vogliamo dire che, se gli edificii, gli archi, le colonne et i palazzi, ancor che di marmi e bronzi, col tempo finiscono e si risolvono in polvere, quanto maggiormente ciò accaderà a questi titoli et

1055 Bartolo, Tractatus de insigniis et armis, 4, 5; Abbas antiquus a c. 14, X, de excess. praelat., V, 13; B. de Chasseneux, Catalogus gloriae mundi cit., I, concl. 28. 
arme, aderenti loro et assai più deboli e fragili che quelli non sono? Né veggiamo, in effetto, che a patroni e signori, che tant'hanno premuto e faticato in questo, altro abbia da restare di perpetuità, che forse la soma del peccato che in ciò hanno fatto, et il render conto della vanità e speranza falsa posta in cose così basse; sì come, oltre David profeta, che ne' suoi salmi ne avvertisce, dicendo tra l'altre cose: Vocaverunt nomina sua in terris suis ${ }^{1056}$, ancora S. Giovanni Crisostomo spesso lo ricorda in varii luoghi, e tra gli altri quando dice ${ }^{1057}$ : Multi sunt, qui splendidas domos aedificant, et lavacra, et porticus, et deambulacra; quorum si aliquem rogaveris, quare ita laboret et tantos faciat sumptus eosque inutiles, nihil aliud audies, quam haec [p. 476] verba: ut immortalem servet memoriam, et audiat quod illius est haec domus, hic ager, et sui memores sint posteri. Verum aliter evenit, quoniam res ab uno in alium, et ab illo iterum in alium transeunt, et hodie quidem domus dicitur huius, cras vero alterius, interimque sponte nos ipsos decipimus. Il che se è vero in queste cose da lui narrate, che sono di sua natura più durevoli et apportano utilità alla vita umana, quanto maggiormente si avrà ciò da affirmare in una pittura o intaglio d'arma momentanea, che non è di frutto alcuno? Et altrove dice il medesimo autore ${ }^{1058}$ : Malorum omnium causa est vana gloria, quia vult quisque apud se nomen aliquod manere, agrorum, balneorum, domuum. Quae tibi utilitas, homo? cum non multo post, febricula te invadente, anima subito evolans nudum et vacuum te relinquet, nudatum quidem virtute, vestitum autem iniustitia, mendaciis et vanitate. Vana enim haec ideo dicuntur, quoniam evanescunt, et nihil habent stabile neque firmum, sed solum est oculorum deceptio, et priusquam appareat, avolat.

Et il medesimo in altro luogo ${ }^{1059}$, mostrando che questi nostri titoli et insegne, che tanto stimiamo al mondo, sono vane e fabricate in aria e da farne poco conto, dice, quod nomina hominum fere omnia et tituli relinquuntur in nudo aëris sonitu, ab omni re destituto, quod cognoscent in illa die homines, quando omnia detegentur; il che appartiene in consequenza generalmente ad ogni sorte di segno, o sia in voce, o in scrittura, o colori, o marmi, o in altro modo.

E perché è cosa che facilmente si può comprendere da chi vuole aprire gli occhi, vedendosi per isperienza che ogni dì mancano queste arme, e che spesso in luogo di una ne sottoentra un'altra, e di poi, mutatasi quella, se ne forma un'altra, e spesso di persone o case [sic] contrarie alle prime; però, non ci estendendo noi più oltre, lascieremo considerare più attentamente alle persone giudiziose, se conviene porre [p. 477] l'animo con tanta ansietà e sforzo in materia così leggiera, lasciando spesso ancora per obligo di testamento a' posteri il dover portare quest'arme in perpetuo: il che arguisce non solo peccato, quando si riponga in ciò il suo fine, ma ancora mostra a tutti certi pensieri poco sodi e molto ingannevoli.

Diciamo di poi che si può errare nel modo di usare quest'arme, il che aviene quando l'uomo se ne serve con molta ostentazione e troppa affettazione, cercando di moltiplicarle per ogni luogo et in ogni cosa, se bene non vi si veda bisogno alcuno, e spesse volte mettendone più insieme, dove una sola serìa bastata e forsi nessuna serìa stata meglio, o distribuendole di sopra, di sotto e dai lati, dove un luogo solo avria supplito. Che se appresso i gentili fu reputata sciocca vanità quella di Traiano imperatore, che pingeva il nome suo et insegne per tutti i muri, tal che per questo fu chiamato da alcuni erba parietaria ${ }^{1060}$; quanto meno ciò converrà a' cristiani, professori di gravità e sprezzatori di cose apparenti?

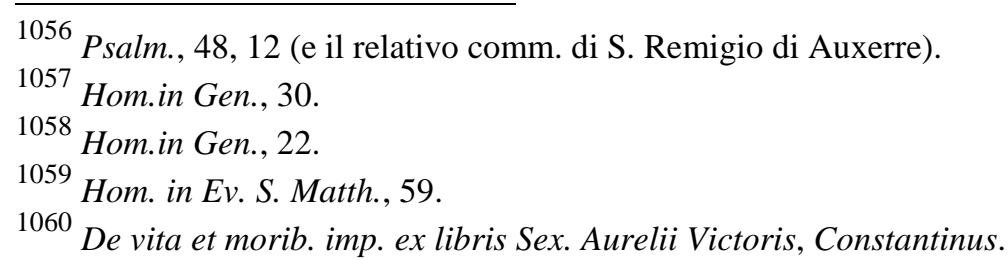


Si può ancora errare grandemente nel luogo, volendo affigere quest'arme nelle chiese, o congiongerle con cose sacre e dedicate al culto divino, che rende molta indignità e sproporzione, sì come nel seguente capitolo si dimostrerà.

Ultimamente, quando ancor tutte le sopradette circonstanze cessassero nelle persone laiche, mettiamo in considerazione a chi leggerà, essere parere d'uomini dotti e pii, che saria cosa degna di persone ecclesiastiche, e segno di molto spirito e prudenza, ch'essi tralasciassero queste arme; perché, facendo i chierici aperta professione col carattere, con l'abito, con l'entrate di chiesa che godono, con gli officii che administrano, e con tutta l'ordinazione sacra, di vivere sequestrati dal secolo e di essere veramente dedicati a Dio, converria ancora che in queste arme delle famiglie e titoli di parentadi si dimostrassero differenti dagli altri, e che in [p. 478] luogo di esse pigliassero quelle delle chiese proprie, se ne hanno, o dell'officio ecclesiastico a che sono obligati, o ne sciegliessero altre appropriate alla professione et instituto loro, acciò in effetto venessero a dimostrare quasi l'opposito di quello che sogliono fare le arme. Imperoché, significando queste che le cose, dove è posta tale insegna, sono proprie, quelle dovriano dimostrare che quello che si possiede è della chiesa e della dignità o officio in che si trovano; overo dovriano contenere qualche altro senso conveniente alla vita ecclesiastica, sì come Clemente Alessandrino ${ }^{1061}$ ci insegna, dicendo: Sint nobis signacula columba, vel piscis, vel navis quae celeri cursu a vento fertur, vel lyra musica, vel ancora nautica, vel piscans aliquis pueros qui ex aqua extrahuntur, memor apostoli; neque enim idolorum sunt imprimendae facies, quibus vel solum attendere prohibitum est, sed nec ensis vel arcus iis qui pacem persequuntur, nec pocula his qui sunt moderati ac temperantes; e S. Agostino $^{1062}$ scrive di sé stesso queste parole: Hanc epistolam signatam misi anulo, qui exprimit faciem hominis attendentis in latus; e di S. Francesco narra S. Bonaventura ${ }^{1063}$ che per suo segno usava quello T misterioso. E si sa che l'usanza, che oggidì va attorno tra prelati, di ritenere l'arme et i titoli delle famiglie loro è cosa assai moderna e non usata da' Padri antichi. Il che ci fa dall'un canto escusar quelli che, vedendo la consuetudine già introdotta, et osservata quasi universalmente dai prelati di santa Chiesa, di portare queste arme, hanno anch'essi seguito tal costume e tuttavia lo ritengono. Dall'altro ci muove a ricordare di nuovo che, poi che questo è uso di non molto tempo, e che il sacro concilio desidera che si restituisca la disciplina antica, non potrà essere se non degno di molta lode chi cominciarà in casa sua a retirarsene.

Leggiamo di Costantino Magno che, poi che fu da Dio illuminato mediante quel segno ch'ei vidde in cielo meravi [p. 479] glioso, mutò la sua insegna militare di labaro nella sacratissima croce $^{1064}$, usando di poi sempre quella per sua impresa e lasciando a noi altri esempio di scordarci queste nostre terrene et appigliarci a quelle che ci ricordano l'obligo nostro e la strada sicura di caminare al cielo.

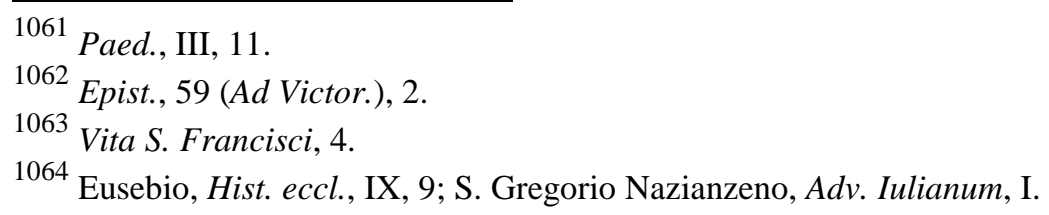




\section{CAP. XXXXVIII.}

Che le arme delle famiglie non convengono nelle chiese.

Tra gli avertimenti che debbono osservarsi nell'uso delle arme, abbiamo detto l'uno essere grandemente da considerarsi, che s'appartiene al luogo; non parendo molto dicevole che simil arme, che col nome solo mostrano la loro origine militare et in effetto sono cose profane, si inseriscano nelle chiese consecrate al riverire il nome divino. Intorno a che, se bene doveriano bastare le ragioni altre volte da noi addotte per mostrare che nelle chiese non capiscono altre cose che ecclesiastiche, nientedimeno, perché in favore di queste arme si sogliono addurre altre particolar ragioni, perciò siamo stati mossi ancor noi a ragionarne particolarmente.

Pare ad alcuni che si possano diffendere benissimo l'arme delle famiglie nelle chiese: prima, per la conservazione de' patronati, i quali, quando vi interviene antichità di tempo, sogliono da simili insegne essere corroborati. L'altra, perché più facilmente si inducono gli uomini ad essere benefattori delle chiese et ornarle ora d'altari, ora di pitture, ora de paramenti e di altre cose sontuose, quando sanno potere lasciare in esse la loro memoria. Di più dicono che questo serve per un eccitamento ancor agli altri, i quali, vedendo il nome altrui restare così onorato in quelle insegne, si ac [p. 480] cendono di desiderio de imitarli: onde le chiese ne divengono ognora più ampliate et ornate.

Ma noi diciamo che, sendo le chiese case d'Iddio e consecrate solo al culto suo, non pare ragionevole che noi introduciamo nella casa de altri l'insegne nostre, le quali mostrano certo segno di dominio ${ }^{1065}$. Imperoché, se vediamo che alienata che sia una casa o un podere, non può il primo possessore astringere il secondo a ritenervi l'arme antiche ma è lecito al nuovo subito levare quelle e riporvi le proprie; come vorrà, chi ha dedicata liberamente una chiesa o altra cosa a Dio, ingerirvi più l'arma sua, poi che già ne ha fatto grazioso dono a Dio, e da sé ha transferito totalmente il dominio? Non volse Salomone nel tempio suo cosa che non fosse coperta di oro puro ${ }^{1066}$; il che figurava la perfezzione del culto che si deve a Dio, che non ha da essere mischiato con affetto alcuno delle cose terrene. E se alle chiese si va per rendere obedienza a Dio e chiederli perdono degli errori, per il che si figurano in esse i misterii della santa Passione; che convenienza dipoi sarà, in luogo di croce, rappresentarci agli occhi le insegne ora de' Guelfi, ora de' Ghibellini, che forsi possono eccitare il cuore alla vendetta e distraere l'animo da ogni buon pensiero?

Ma quello che più si dovrebbe considerare è che non solo nelli muri, ma ancora ne' pallii d'altari, nelle pianete, ne' piviali, ne' candelieri, ne' lampadarii, nelle croci, ne' reliquiarii, e spesso fino ne' calici sacrati e tabernacoli del santissimo Sacramento si scolpiscono con molto artificio queste arme mondane, non avertendosi alla religiosa antichità, che non figurava in essi se non cose sacre: sì come nel calice scrive Tertulliano ${ }^{1067}$ che vi era il pastore che porta su le spalle la pecora smarrita. Et è talmente scorso innanzi et accettato quasi universalmente questo abuso, che non sì tosto viene in pensiero ad alcuno di fabricare una chiesa o di or [p. 481] narla di qualche cosa celebre, che subito comincia a disegnare il più conspicuo luogo dove abbia a riporvisi l'arma sua, forsi, per onorare sé stesso, cercando farla più acconcia e riguardevole che si possa. Dice gentilmente un dottore, servendosi d'un proverbio che si suol dire, che non si fa chiesa dove il Demonio non vi voglia una capella, né si fa predica dove non vi voglia una banca, né si mette partito dove non abbia i suoi voti. Così dice egli che, quando in una pianeta di sacerdote, o pallio, o

\footnotetext{
1065 Cod. Iust., I, 8, 1; Bartolo, Tractatus de insigniti cit., 4.

${ }^{1066}$ III Reg., 6, 22.

${ }^{1067}$ De pudic., p. 748 (ed. De La Barre, 1580).
} 
candeliere d'altare, o simili altre cose sacre, si fanno le arme dello autore, pare di vedere il Demonio che si faccia alla fenestra e dica al popolo: "Vedete che io son qui; eccomi, che ci ho la parte mia; ecco la insegna della vanità». E se sarebbe tenuto poco giudicioso chi, donando al prencipe alcun libro, medaglia o altro, accompagnasse l'insegna propria con quella del prencipe; molto più giusto serà che, in quello che si dedica a Dio, altra arma o segno non apparisca, che quello della maestà sua, massimamente che non ha bisogno Iddio di arma nostra per sua memoria, sì come suol essere spesso necessario agli uomini del mondo, che non sanno o non si ricordano le cose ${ }^{1068}$. Onde resta che tale arma non serve punto a Dio, ma tutto è instrumento per dar noi stessi a conoscer ad altri.

E però è stato avertito fino da' dottori non teologi, che quegli che pongono l'arme sue nelle chiese che fabricano e nei paramenti che donano, portano pericolo di perdere tutto il merito ${ }^{1069}$; il che però noi intenderessimo secondo la intenzione con che si sono mossi, come nel seguente capitolo si dirà. Vediamo che nelle leggi secolari gli imperatori hanno constituito che ne' suoi pallazzi regii non sia lecito ad alcun privato d'inserire la imagine sua, come troppo sproporzionata alla reale maestà ${ }^{1070}$; e parimente, che nessuno ardisca [p. 482] ne' luoghi dove sono consecrate le imagini imperiali aggiongervi appresso pitture di cose ignobili e sordide ${ }^{1071}$. Quanto meno donque pare che convenga nel santuario di Dio, dove per riverenza tremono gli angioli e le podestà del cielo, ingerire la bassezza nostra? E come tra le perle e l'oro mischiare il fango et i carboni?

Ora, da questi fondamenti non è difficile il confutare le ragioni in contrario; perché, quanto ai patronati, dicono i medesimi dottori che questi sono stati tolerati da' sacri canoni per certa indulgenzia, sapendo essi molto bene che meglio serìa stato il fondare le chiese per mera liberalità cristiana e pura intenzione di piacere a Dio ${ }^{1072}$, sì come anticamente facevano quei santi Padri, che solo la mira aveano a dilatare il nome divino ${ }^{1073}$. Ma essendo degenerato tanto da quello antico ardore lo spirito de' successori, e così raffredata la pietà cristiana, presero questo partito i sapientissimi padri nostri, di condescendere alla infirmità umana; e per invitare gli uomini a fondare, edificare e dotare le chiese, deliberarono di interessarli con questo mezzo di conservarsi il patronato nelle famiglie. Il che gli fu concesso per pura grazia, non essendo i laici capaci di cosa spirituale. E però diciamo che, quando alcuno pure voglia ritenersi il patronato, in tal caso doveranno collocarsi queste arme in luoco così ritirato et in maniera sì dimessa, che si conosca che non per ostentazione, ma per questo solo effetto della conservazione delle ragioni, vi siano state aggiunte quelle insegne.

Quanto poi alle altre cause, non neghiamo potere essere ciò talora fatto con così pura e retta intenzione, che niente nocerebbe all'autore, anzi li potria essere di merito, come di sotto si dirà. Ricordiamo nondimeno essere così inclinata e [p. 483] sottile la natura nostra in procurare il proprio interesse, che, come bene ci ammonì il Salvatore nostro, in queste materie di pietà sarebbe meglio che l'una mano non sapesse dell'altra ${ }^{1074}$. Il che maggiormente s'avria da osservare in opere così fatte, dove, facendo noi professione di magnanimità, veniamo con queste arme, che sono come

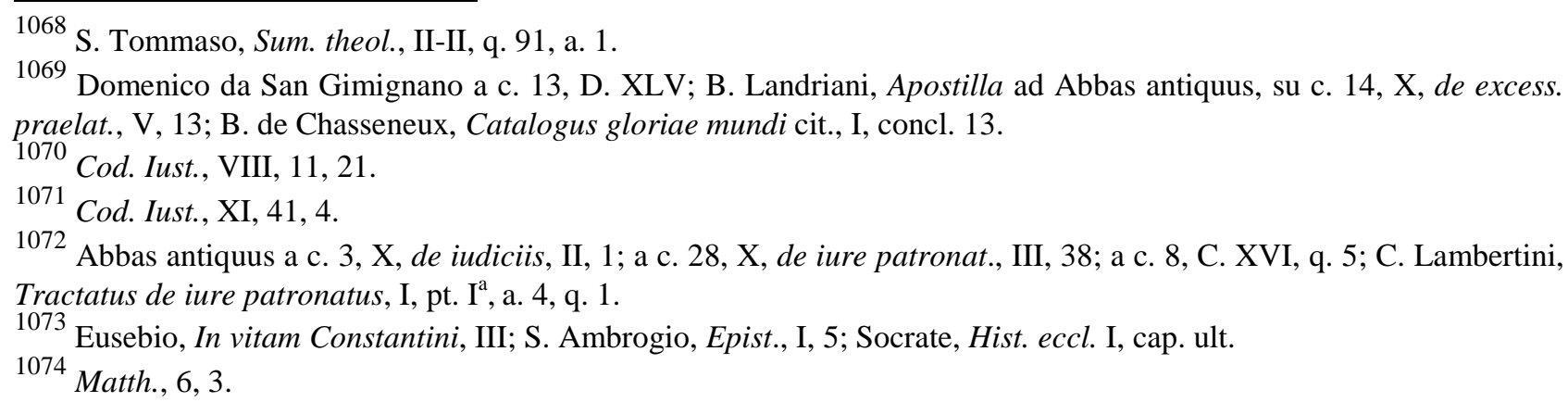


insegne dell'amor proprio, a distruggere quasi il resto che vi era di buono. Al che tanto più doveranno avertire i prelati, i curati et i rettori delle chiese, acciò che, dovendo con lo esempio loro fare la strada ad altri, non siano essi i primi ad affigere le loro arme ne' più bei luoghi e prospetti che siano nella chiesa; avertendo ciò maggiormente ne' pallii degli altari, pianete, pluviali, missali, calici et altri vasi sacri detti disopra, perché, se bene può essere da loro ciò fatto con molta simplicità e senza offesa d'Iddio, non resta però che ciò non dia ad altri molto da sospettare altrimente, e che agli occhi amici di umiltà non apparisca certa ostentazione che gli offende. Per il che si doveria parimente aver riguardo di non affiggere, né dentro né alle facciate delle chiese, le arme de altri, se bene siano signori e prencipi grandi; prima perché, come si è detto, essendo queste nel numero delle cose profane, non convengono a luoco sacro; di poi perché, dovendo le facciate ancora rappresentare cose misteriose al popolo, non si conviene che queste armi occupino il luogo loro e le scaccino dal proprio possesso. Oltre che pare una imitazione della gentilità, che con esquisita assentazione poneva nei tempii istessi le imagini di quegli che volevano deificare; ad esempio de' quali noi più copertamente in luogo delle imagini riponiamo queste arme, che a punto dicono essere succedute in vece delle imagini antiche de' Romani ${ }^{1075}$; e cerhiamo con queste insegne, di persone che chiamamo illustri, di celebrarle quasi al pari de' santi, circondandole ancora d'intorno di angeli alati che le sostentano. E non s'avedono gli [p. 484] uomini che, in luogo d'ornare le chiese, le rendono quasi a somiglianza delle osterie, con tali spettacoli e prospetti.

E se alcuno giudicasse che almeno si potessero convenientemente porre queste arme nelle sepolture che si fanno in chiesa, dove si sogliono affigere gli epitafii e le insegne de' defonti, noi di ciò ci reserviamo a parlare al suo luogo proprio ${ }^{1076}$, del modo di dipingere $\mathrm{i}$ monumenti cristianamente. Ma perché intorno a questa materia restano ancora alcune dubitazioni da solvere, però per maggiore chiarezza ne parleremo nel capitolo seguente più distesamente.

\section{CAP. XXXXIX.}

Perché nei libri spirituali ponendosi i nomi degli autori, nelle pitture sacre non convenghino l'arme delle famiglie. E si risponde ad alcune altre dubitazioni intorno a queste arme nelle cose sacre.

Alle cose dette di sopra restano alcune obbiezzioni non picciole, che ricercano particolare considerazione. Imperò che, se è lecito a ciascuno che componga e stampi un libro, ancor che di cose sacre e teologali, di mettervi il nome suo, anzi, secondo l'Indice romano, oggi è necessario che vi sia posto, se ha da essere publicato; perché non parimente nelle pitture, che sono libri per lo popolo, come spesse volte si è detto, non dovrà essere conceduto che vi si affiga l'arma, la quale serve per nome dell' autore? E se uno, dopo avere fabricata una chiesa o ornato una capella, può dire senza peccato: «Questa chiesa o capella è stata fatta da me»; perché non lo può parimente scrivere? E se lo può scrivere mettendovi il nome suo, perché non lo può significare ancora, affigendovi la sua arma? essendo che la scrittura conterrà il nome, [p. 485] cognome e tutta l'istoria dell'opera fatta, e l'arma significherà solamente di che famiglia fu l'autore di essa.

Per rispondere a questi motivi, si ha da considerare il fine perché si fanno i libri et il fine delle pitture. I libri ordinariamente si compongono non per servizio dell'autore, ma per altri, cioè per insegnare: il che si fa in due modi, o con ragione, o con autorità. Serve adunque il nome del compositore per autorità, essendo che serà ricevuto dal popolo con molto maggior credito una cosa

1075 G. Budé, Annotationes, a Dig., I, 2, 2.

${ }^{1076}$ L. V, cap. 8 [ma 7]. 
scritta da una persona di riputazione, che scritta da un altro; e molte cose, per non sapersi l'autore, non si prezzano, che, quando si sapesse, cresceriano di credito e seriano tenute in stima: come $\mathrm{i}$ iuresconsulti fanno, che sottoscrivono i loro consigli, però che, senza quel testimonio, avriano poca autorità. Ma perché spesso gli uomini pervertiscono questo fine, e dove, scrivendosi i libri, si deve avere mira principale agli altri, essi, riflettendo tutto questo fine verso di sé, hanno per principale intento la propria eccellenza e manifestazione di sé stessi; di qui è che quei che anticamente scrissero de contemnenda gloria ponendovi il loro nome, possono essere escusati se lo fecero per dare maggiore autorità al libro, e possono essere ripresi se, scrivendo del dispregio della gloria, pensarono d'immortalare sé stessi ${ }^{1077}$.

Ma il fine delle pitture, di che noi ragioniamo, è molto diverso, perché, essendo esse sacre e poste nelle chiese per istruire e movere il popolo alla devozione, elle non ricevono l'autorità e persuasione sua estrinsecamente da alcuno, ma dal misterio sacro che in esse si rappresenta; talmente che lo accompagnare con quelle l'arma della famiglia non porta, quanto alla pittura, utile alcuno al popolo, ma solo ha rispetto allo autore et ad un certo modo di magnificare l'opera di quello. E quando il pittore vi aggiongesse anch'egli il nome o insegna sua, non gioveria ciò in accrescere la religione, ma solo potria dare qualche più credito al disegno, se fosse [p. 486] di persona celebre e segnalata; il che è cosa diversa da quello che noi pretendiamo.

L'altra opposizione è stata che, se è lecito ad uno il dire d'aver fatto una capella, può anco metterlo in iscritto et esprimerlo con la pittura. Al che respondiamo, che anco nella voce e nella scrittura giudichiamo noi essere necessaria molta considerazione, per fuggire il vizio della iattanzia, dovendo essere gli uomini molto parchi in parlare di sé stessi e delle cose sue, fuor che dove l'ufficio della persona o debito di giustizia e di carità gli astringe. Altrimente il raccontare alle persone, senza proposito, di avere fabricato la capella, o fondato la tal chiesa, serìa un suonar la tromba e mettere in mostra la supellettile di casa sua, che facilmente li potrà esser rubata dal ladro della vanità. Il porre anco queste cose in iscrittura corre il medesimo pericolo, e tanto maggiore, quanto che la scrittura, come cosa publica e permanente, sta esposta a tutti e vien notata da' giudicii più rigorosamente. Ma, oltre di questo, l'esempio opposto non è simile, perché le voci che parliamo e scritture che componiamo sono cose private, che dipendono dalla volontà di ciascuno e si compongono, si mutano, si revocano come piace a noi. Ma le pitture, di che ragionamo, come si dedicano a Dìo escono dalla podestà nostra e mutano la sua natura, non si potendo più transferire ad uso privato, poi che già sono sacre, sono nelle chiese, sono per ammaestramento del popolo e servono alla gloria divina. Onde per l'oggetto, misterio, luoco e fine non hanno da regolarsi con la misura dell' altre cose.

Altri dicono: se è lecito, anzi talora necessario, ne' sedili e banche o scabelli delle chiese porre l'arma sua, acciò non siano mosse da luogo overo adoperate da altri, perché non si potrà fare il medesimo in una pianeta o pallio dell'altare? A questi si risponde che le sedie e panche si fanno da' privati nelle chiese per servizio loro, onde si levano ancora a volontà de' padroni; ma gli ornamenti dell'altare e de' vasi sacri non hanno da servire se non a ministerio sacro e sono già dedicati a Dio. Né in essi è necessario altro segno de' [p. 487] benefattori, poiché chi dona una cosa, aliena da sé totalmente il dominio.

E se replicheranno che, anzi, nel donare le cose può ciascuno aggiongervi la legge e condizione che vuole, e però nel donare una pianeta può proibire che non si adopri in altro luoco et ordinare che si usi con quell'arma e si riconosca sempre per sua; si risponde che non si nega che ciò non possa essere permesso talora, ma, sì come ne' patronati abbiamo detto che maggiore atto di pietà e

1077 Cicerone, Pro Archia, 11. 
beneficenza mostra chi dona puramente alla chiesa, che chi si riserva il patronato, così diciamo, in tutti questi ornamenti o mobili di chiesa quello mostrarsi più liberale, che ne fa dono più libero e puro a Dio. A proposito di che serve quello che si legge anticamente de' sacrificii, de' quali il più perfetto e segnalato era il chiamato olocausto, che tutto si abbruciava in onor di Dio e niente si riservava per il sacerdote né per l'offerente, come in alcuni altri sacrificii si usava ${ }^{1078}$; così nel donare la pianeta, essendo questa una sorte d'oblazione, chi vuole che ella si accosti più all'olocausto debbe offerirla puramente et intieramente, ma chi vuole ritenersi l'arma, imita l'altro sacrificio, del quale vuol godere anch'egli qualche parte.

Aggiongono alcuni che questo sarebbe un biasimare e dare nota grande ad infiniti prelati e signori molto pii e divoti, che nell'edificare le chiese o donarli varii ornamenti hanno servato quest'istesso stile di porvi le loro arme. Si risponde che questo appartiene a quello di che ragioneremo nel capo seguente; oltre che non intendiamo noi di biasimare alcuno, ma sì bene tra varii usi e costumi, che possono essere in ciò, dirizzare il popolo a quello che pare più lodevole, e come col dito mostrarli il termine dove s'avria a giongere e che dà segno di maggiore perfezzione.

Dicono altri che il Signore nell'Evangelio vuole che le opere nostre siano note alle persone ${ }^{1079}$ per loro esempio et [p. 488] edificazione. Rispondiamo che, appunto, il Salvatore dice che si vedano le opere, ma non gli autori delle opere, il che è diverso dalle arme o titoli, che non servono se non a mostrare la persona, essendo che l'opera da sé stessa si manifesta senz'altr'arma. Di più aggionge il medemo Salvatore la causa perché ricerca questo, dicendo: Et glorificent patrem vestrum qui in caelis est.

Di nuovo pare che premano alcuni, dicendo che, vedendosi quell' arma nella pianeta o altare, si muove il cuore di chi la riguarda, per la memoria dello autore, ad imitarlo in atto così virtuoso et anco a pregar Dio per lui. Ma si dice che o consideramo l'arma rispetto all'autore, o rispetto a chi la rimira; nel primo caso si ha da vedere con che intenzione ella sia stata posta da lui, come poco appresso diremo; nel secondo può essere che lo spettatore abbia nel mirarla concetto molto diverso dall'autore. Onde, potendo in tutto questo occorrere varie considerazioni, ci reserviamo nel capitolo seguente a discorrere dell'uno e dell'altro più largamente.

CAP. L.

Delle arme delle fameglie che si pongono nelle chiese, quanto alla intenzione dell'autore che ve le affigge e quanto alla opinione che possono concepire quelli che le riguardano.

Abbiamo finora parlato delle arme quanto alla specie loro esteriore; ora tratteremo quanto al fine che in esse si può avere, il che, se bene riguarda principalmente la persona dello autore, in conseguenza però tira seco la persona ancor di quello che le riguarda, imperoché non si affiggono ordinariamente l'arme in alcun luogo, se non perché in qualche tempo siano conosciute da altri. Dunque parleremo prima dell'autore, poi dello spettatore.

Ci è parso necessario di trattare alquanto distesamente al [p. 489] presente questa materia, perché non vorressimo che dalle cose già dette alcuni interpretassero troppo duramente il senso nostro, come che notassimo di peccato tutti quelli che mettessero le loro arme nelle chiese e conseguentemente li dessimo bando affatto dai luochi sacri, tal che per questa falsa credenza si ritraessero le persone, contro il desiderio nostro, da ornare le chiese et elle ne ricevessero questo

1078 S. Tommaso, Sum. theol., I-II, q. 102, a. 3, ad 8.

${ }^{1079}$ Matth., 5, 16. 
danno. Perciò noi, per maggiore dichiarazione di quello che sentiamo, soggiongeremo alcune cose che serviranno a dare più piena istruzzione al popolo di tutta questa materia. Imperoché, sì come chi traffica pietre preziose deve avere molta notizia del valore di ciascuna per dare il luoco suo a tutte secondo lo pregio loro, così il cristiano, che ha da mercantare il cielo in questa vita, deve avere perfetta cognizione di tutte le cose nelle quali versa, e sapere quale sia buona e quale migliore e quale ottima, per appigliarsi alla suprema più che può.

In questo proposito dunque, quanto appartiene all'autore, diciamo che il dipingere l'arma della famiglia essendo cosa per sé stessa indifferente, può essere alcuna volta meritoria, altra peccato mortale, altra veniale et altra solamente imperfezzione. Questa diversità nasce dalla intenzione che l'uomo tiene in fare le cose sue, perché essa sola è principale e dà il tratto alla bilancia, non considerando Dio tanto il corpo dell'opera, quanto il fine a chi è dirizzata ${ }^{1080}$; onde spesso quello che agli occhi degli uomini parerà gran cosa, nel teatro del cielo serà niente, come significò Aggeo profeta, dicendo ${ }^{1081}$ : Respexisti ad maius et ecce factum est minus etc.; e Daniele ${ }^{1082}$ : Appensus es in statera et inventus es minus habens. Da questo si vede che noi assolutamente non riprendiamo tutte l'arme nelle chiese, perché possono talora essere fatte con sì pura e zelante intenzione, che seranno accette a Dio e meritorie; ma perché possono anco peccare nell'altra parte et implicarsi in maggiore e minore difetto, però vo [p. 490] gliamo che il popolo sia avertito di tutti questi gradi, acciò, intendendo che tutto il negozio dipende principalmente dal fine e proponimento nostro, cerchi sempre di darli il primo luogo e piantare questo stendardo in cima della rocca.

E perché la materia è assai lubrica e spesso l'affetto nostro ci inganna, è proprio ufficio di cristiano ricordare a ciascuno che, per non cadere nel fosso, non si accosti tanto alla riva, ma si tenga più che può alla terra ferma per meglio assicurarsi; sì come simigliantemente fanno anco quei che hanno scritto della imitazione, lodando che sempre ci proponiamo le cose ottime et eccellentissime da imitare ${ }^{1083}$, poi che, non conseguendo noi per ordinario il fine che disignamo, veniamo almeno per questa strada ad avanzarci assai. Dunque molto utilmente crediamo noi che farà ciascuno, quanto più si allontanerà da simili pitture dell'arme nelle chiese; delle quali, se bene la natura loro è indifferente, però la esperienza mostra che ordinariamente se ne servono le persone a fine mondano. Sì che, per via di teorica, si potranno forsi defendere l'arme nelle chiese cessante pompa, come dice il Biel ${ }^{1084}$; ma, a considerare la pratica, averrà il contrario; e però ben disse $\mathrm{S}$. Crisostomo $^{1085}$, quod Diaboli opus est facere ut indifferentia contemnantur, perché si usano troppo spesso in male.

Però noi consiglieressimo chi ha in animo di fare queste arme, che prima si mettesse la mano al petto e vedesse che fine principalmente lo muove: se è per incitare gli altri con l'esempio suo ad ornare le chiese, o per raccomandarsi a quel santo e pigliarselo per protettore; overo per destare sé e gli altri ad imitare quel martire nella fortezza, nella pazienza e simili atti eroici; overo per desiderio che ha l'autore, che ciascuno a garra si muova ad onorare Dio con pitture et ornamenti; o se è per ricordare alle persone che preghino [p. 491] Dio per l'anima di chi ha fatta fare quella figura; overo se è pure per altro rispetto mondano. E così da questi motivi spirituali o sensuali, o altri che forse sentirà dentro sé stesso, potrà regolare l'appetito suo, facendo differenza, se sono luoghi dove si

\footnotetext{
1080 S. Tommaso, Sum. theol., I-II, q. 7, a. 4.

1081 Aggaeus, I, 9.

1082 Dan., 5, 27.

1083 Quintiliano, Inst. orat., X, 2.

${ }^{1084}$ In IV Sent., d. 45. q. 2.

${ }^{1085}$ Hom. in Ep. ad Eph., 17.
} 
abbia a conservare il patronato, ne' quali è più ragionevole l'arma per pruova del titolo, in parte però alquanto retirata; o se sono fabriche e pitture d'altra maniera; o se sono ornamenti sacri, come pianete di sacerdote, palii d'altare, pluviali, candelieri, calici e simili cose non così proporzionate a ricevere queste insegne. E considerato bene il tutto dentro di sé, e pigliatone anco parere da persone pie et intelligenti, meglio potrà deliberare quello che lo spirito buono gli inspirerà.

Ragioneremo ora della persona che le ha da riguardare, perché, come dicemo di sopra, serìano indarno queste insegne, se non fossero vedute da altri. Occorre dunque da considerare se la intenzione che ha avuto l'autore è atta, mediante queste arme, a produrre l'effetto nello spettatore che egli si ha proposto, nel che certamente non potiamo noi se non dubitarne assai. Imperoché, presupposto che alcuno veramente si muova da tutte quelle buone e cristiane ragioni nel lasciare queste memorie che si sono dette di sopra; nondimeno, essendo queste arme segni equivoci e communi a più cose, a più persone et a più concetti degli uomini, possono negli animi altrui partorire varie interpretazioni.

E però chi vuole delle opere che ha fatto in onor di Dio lasciare qualche dichiarazione a' posteri della intenzione sua, e piglia quest'arme come istrumento per dichiararla, pare che s'inganni di longo, tralasciando i mezzi certi e securi di che si potea valere et appigliandosi a quello che di sua natura è incerto e che può servire e deservire, anzi, che più facilnente può essere preso in sinistro che in buono senso.

Percioché altre volte dicessimo che la propria natura di queste arme pare che altro non sia che un segno per differenziare le cose e distinguere i padroni dell'une da quelli dell'altre, dando ancor con tal segno non so che di riputazione [p. 492] alle cose o persone loro. Laonde veggiamo che tal arme si usano solo da quelli che siano in qualche notizia e non dalli ignobili affatto et oscuri; e parimente s'adoprano nelle cose di qualche credito e non nelle volgari e communi. Talché, essendo la natura propria dell'uso di queste arme dirizzata al distinguere e dare non so che di stima ai soggetti, si ha grandemente da dubitare che, con tutta la buona intenzione dello autore, vedendosi queste insegne poste nelle cose sacre, riteneranno facilmente la sua propria natura e daranno ad intendere al popolo credulo, che, sì come si suole nelle cose profane, così in queste abbia voluto l'autore far celebre la sua mercanzia.

Né in ciò, come ognuno vede, basta il buon proponimento di esso, perché in così fatte cose che in certo modo si riferiscono ad altri, come sono queste arme, che si fanno perché siano vedute e conosciute dalla moltitudine, non basta l'occulta intenzione, se non è manifestata con segni convenevoli et appropriati a loro. Anzi, pare che manchi in ciò l'autore dei termini debiti della prudenza, la quale, per conseguire il desiderato fine di una cosa, vuole che tra molti mezzi s'eleggano i più sicuri e proporzionati, lasciando gli altri fallaci e dubiosi ${ }^{1086}$; onde, essendo queste arme indirizzate e communemente interpretate nel modo che di sopra si è detto, verranno per le ragioni addotte a partorire più tosto effetto contrario a quello che si pretende.

Il che tutto sia detto da noi per semplice discorso, sperando che agli animi pii non debba essere inutile affatto tale avvertimento, se non a rivocarli totalmente da quest'uso, nel quale possono essere perseverati sinora molti, forsi per inconsiderazione; almeno per renderli più cauti per l'avvenire, acciò che, volendo depingere le sue insegne, lo facciano con altra intenzione e con qualche meglior modo che per lo passato fatto non hanno, onde ancor conseguiscano dal Signore quel maggior frutto per l'anime che noi le preghiamo.

\footnotetext{
1086 Aristotele, Eth. Nic., III, 3.
} 
[p. 493]

CAP. LI.

Di alcuni avertimenti generali posti dagli autori, da osservarsi in ciascuna pittura perché sodisfaccia universalmente.

Potrà parere ad alcuno quasi superfluo il presente discorso, perché, essendosi di sopra longamente trattato degli abusi da schifarsi nelle pitture, si può giudicare che, mancando di quelli una imagine, ella sia posta come in sicuro di non patire più giusta contradizzione. Con tutto ciò, chi meglio considera troverà che questo non basta, essendo cose molto diverse, come ognuno sa, l'allontanarsi dal male e l'abbracciar il bene; onde, quantunque una pittura manchi dei difetti già sopranominati, non però dirassi ella intieramente bella e perfetta, come si ricerca in un'opera a fine che da tutti sia commendata. A che s'aggionge una difficultà maggiore, perché, essendo molto diversi e come infiniti i giudicii e pareri delle persone, o sia per naturale disposizione, o per debolezza di arte, o per lo instituto degli uomini disordinato, o per qualunque altro rispetto, pare come impossibile il ritrovare cosa che universalmente piaccia.

Et in vero così serìa, se intendessimo che il pittore avesse da pigliarsi per impresa di volere sodisfare a tutti indifferentemente. Ma noi diciamo che non conviene ad uomo savio, e tanto meno ad un cristiano, l'affannarsi in ciò, poi che, non regolando molti il giudicio loro col lume della ragione, bisogneria, volendoli acquetare, condescendere a' suoi appetiti spesso irragionevoli. Laonde questa difficultà ha altre ragioni, percioché, se bene intendiamo di parlare con uomini capaci del vero secondo la loro professione, nientedimeno, per essere non solo le nature, ma anco gl'instituti loro molto tra sé diversi, se bene tutti lodevoli, come al presente presupponiamo, pareria a noi che la pittura, la quale ha da servire ad uomini, donne, nobili, ignobili, ricchi, poveri, dotti, indotti, et [p. 494] ad ognuno in qualche parte, essendo ella il libro popolare, dovesse ancor essere formata in modo che proporzionatamente potesse saziare il gusto di tutti. Et in questo riputiamo riposta l'eccellenza dell'artefice et a ciò tende la difficultà che ora abbiamo alle mani, la quale in vero è grandissima.

Dunque, per dare qualche indirizzo al pittore intorno a ciò, andremo ricordando varii modi e maniere proposte da diversi; le quali nondimeno perché forsi non sodisfaranno intieramente a quello che si richiede, non mancheremo noi di soggiongere il parer nostro, qualunque si sia, rimettendoci, come nell'altre cose, a chi più fondatamente ne discorra.

Il primo modo fu significato da Vitruvio nel principio de' suoi libri ${ }^{1087}$, dove, parlando delle qualità che si richiedono ad un compito architetto perché l'opere sue riescano perfette, numera molta varietà di scienze, come geometria, aritmetica, filosofia, musica, astrologia et altre cognizioni di cose che a questo reputa necessarie, come si leggono presso di lui. E perché l'architettura è come base di queste altre facoltà del formare le imagini, poi che queste sono come per servizio et ornamento di quella, però pare conseguentemente che nel pittore, scultore et altri simili debbano concorrere l'istesse cose, e forsi altre ancora, oltre quelle che da lui sono racconte. Ma noi dubitiamo assai che il mettere oggi in campo tal concetto et intonare all'orecchie de' nostri artefici questo suono serìa quasi porli poco meno che tutti in disperazione; poiché o la povertà, o la corrotta disciplina del mondo, o la qualità de' tempi, o altro che sia, ci mostra per esperienza che nissuno o pochissimi pervengono per questi gradi a tale professione, talmente che non ci par ora a proposito il gravarli di così fatta soma.

${ }^{1087} \mathrm{I}, 1$. 
Il secondo modo si racconta essere stato osservato da Zeusi ${ }^{1088}$, pittore celebratissimo nell'antichità, che, volendo formare l'imagine d'una donna compita d'ogni bellezza, si [p. 495] elesse per imitazione la forma di diverse verginelle, ch'erano tenute singolari, chi in una parte e chi in un'altra; e sciegliendo da ciascuna d'esse quello che giudicò più a proposito, formò da tutte insieme un corpo di donna leggiadrissimo e di somma eccellenza. Ma questo esempio, oltre che patisce molta difficoltà nell'essercitarlo, rispetto all'onestà che si deve principalmente osservare, non pare ancora che possa commodamente riuscire nel dipingere cose d'istorie, o altre opere dove cadono molte diversità di figure animate et inanimate; perché, essendo il numero come infinito di queste, serìa impresa troppo eccedente le forze nostre il potere pigliare le forme di ciascuna così esquisitamente, o avere presso di sé i modelli compiti di tutte le cose grandi e piccole, con tutti i moti et atti che s'hanno da rappresentare.

Il terzo modo è posto da quelli c'hanno scritto di questa arte, volendo che tre cose facciano perfetta una pittura, che è circonscrizzione, composizione e ricevimento di lumi. Altri si sono stesi in prescrivere le regole a lineamenti, misure, quantità, contorni, ombre, lumi et a varii altri suoi concetti copiosamente da loro descritti. Altri in altra maniera hanno di ciò discorso ${ }^{1089}$. Ma noi diciamo che tutti questi e simili altri modi stanno posti nella sola maestria dell'arte e forza del disegno, la quale se bene reputiamo principale, affermiamo però che sola non basta a rendere una opera generalmente lodevole. Di più, chi considererà la gran varietà delle cose che possono cadere nella pittura, come quella ch'è capace di rappresentare l'infinita moltitudine di tutte le opere visibili di questo mondo, insieme ancora giudicherà che ci è numero grande di cose e di soggetti che non può dependere propriamente da alcuna delle regole sopra dette, ma ch'è necessario d'accumulare più aiuti e remedii insieme. [p. 496]

Il quarto modo è quello che da noi nel primo libro fu esposto, mentre parlammo dell'ufficio e fine del pittore ${ }^{1090}$, dicendo che, sì come gli oratori hanno per ufficio di dilettare, insegnare e muovere, così i pittori delle imagini sacre, che sono come teologi mutoli, debbono operare il medesimo, e che quella pittura sarà più e meno perfetta, che più presso o lontano s'accosterà a questo segno. Ma qui ancora avertiamo che puoté questo allora servire a quel proposito di che si trattava, che ora non converria così; perché pretendiamo di presente noi, partendoci da' termini in astratto e matematici, venire a regole particolari, che mostrino in prattica più che si può la via che s'ha da tenere, acciò le pitture che si fanno meritino la grazia universale. Il che se bene conosciamo essere grandemente difficile, nientedimeno, per dare compimento al presente libro e mostrare da lungi almeno la meta principale, alla quale giudichiamo che si debba indirizzare il corso, accenneremo alcune cose che serviranno almeno di segno o di guida a' migliori ingegni per trovare il vado nel fiume e condurre in porto chi dissegna fare l'opere sue in maniera che ricevano per lo più laude dalle persone; il che nel seguente capitolo si dichiarerà.

\footnotetext{
1088 Cicerone, De inv., II, 1.

1089 L. B. Alberti, Della pittura, II; A. Dürer, De varietate figurarum et flexuris partium ac gestib. imaginum (1534); De symmetria partium in rectis formis humanorum corporum (1532); G. Philandrier a Vitruvio, VI, 2; G. Vasari, Vite, I, introd.

1090 L. I, cap. 21 ss.
} 


\section{CAP. LII.}

Conclusione di quello che principalmente si giudica necessario, affine che le cose che si dipingono sieno da tutti commendate.

Scrivendo S. Paolo apostolo ai Corinzii, diceva ch'egli si era accommodato a Giudei, a gentili, a quelli ch'aveano la legge et a quelli che non l'aveano, et in somma a tutte le sorti di persone, per guadagnarli tutti ${ }^{1091}$; et altrove ${ }^{1092}$ si confessava debitore di giovare a' Greci, barbari, a sapienti, insipienti, a perfetti et imperfetti. Questo esempio pare a noi [p. 497] che debba movere molto i pittori dell'imagini sacre, che sono taciti predicatori del popolo, come più volte si è detto, ad affaticarsi con ogn'industria per conquistare più che potranno l'animo di ciascuno et apportare utilità universale a tutti; imitando in questo l'esempio di quelli che compongono le imagini, nell'Indie occidentali, di piume d'ucelli, che, sapendo essi che secondo la diversità de' lumi esse piume rappresentano diversi colori, non si contentano che riescano solamente al sole della matina, ma vogliono che rispondano ancora a quel del mezzo giorno, dell'occidente et anco al lume della lucerna nella notte.

Ma perché, come già dicemmo, pare questa impresa oltra modo difficile e sopra le forze umane, per essere nei popoli gli essercizii et instituti molto differenti et in varie maniere numerosi; però, volendosi trovare rimedio, per lo quale possiamo almeno in qualche modo accostarci al segno, si andava considerando che, avendo ciascuno due principali potenze, dalla perfezzione delle quali dipende la vera dignità et eccellenza dell'uomo, che sono l'intelletto e la volontà, ogni volta che le pitture fossero formate in modo che, come libri o maestri, giovassero all'uno et all'altro nella maniera che si dirà, certo che allora si potrebbe pensare che elle fossero su la strada di acquistare la grazia di ciascuno.

Il che per dichiarare meglio e venire più al particolare nella pratica, diciamo che, quanto all'intelletto, si avria da ricercare che elle fossero ben fondate prima nel disegno secondo l'arte, di poi nella vera cognizione delle cose che si hanno da imitare. E, quanto all'affetto, che elle fossero figurate in maniera che operassero due cose, l'una nel muovere il senso, l'altra nell'eccitare lo spirito e la divozione.

E da queste quattro cose giudicheressimo noi che si venessero ad abbracciare quattro gradi o professioni di persone, che sono i pittori, i letterati, gl'idioti e gli spirituali, come appresso si dichiarerà; a' quali quando le pitture sodisfacessero, si potria dire che avessero insieme in certo modo il consenso universale del popolo. [p. 498]

Et a questo concetto è stato parere d'alcuni che si possa assai commodamente applicare, secondo il senso morale, il versicolo di David profeta ne' suoi salmi, dove, ammaestrando il popolo di quello che si deve osservare nel culto d'Iddio numera appunto quattro cose principali, che sono: confessio et pulchritudo in conspectu eius, sanctimonia et magnificentia in sanctificatione eius ${ }^{1093}$. Dalle quali hanno voluto dire questi che simigliantemente la pittura sacra, instituita principalmente per onorare e riverire la maestà divina, allora sarà degna di lode, quando starà appoggiata a questi quattro capi, come colonne principali dell'edificio.

Il primo è confessio, la qual voce, sì come nel suo proprio e litterale senso significa quell'atto esteriore che con parole riconosce e manifesta la providenzia e grandezza d'Iddio signor nostro ${ }^{1094}$,

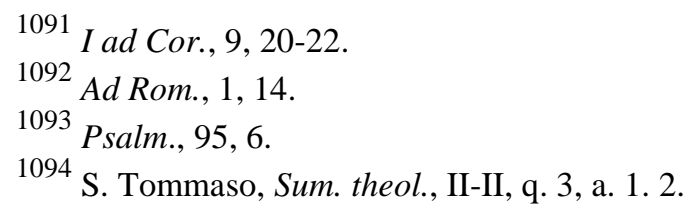


dal qual principio depende tutto il rimanente della religione; così dicono che la principale parte della pittura sta posta nel rappresentare, co' lineamenti, ombre, colori et altri, alcuno misterio d'Iddio o de' santi suoi, il che appartiene all'arte del disegno, che è base e fondamento delle altre cose.

Poi, dicendo pulchritudo, dicono che questo conviene alla vaghezza de' colori et alla grazia overo bellezza; parti che per lo più quasi sogliono sodisfare agli idioti. Sanctimonia vogliono che abbracci quello che si ricerca per gli spirituali; e magnificentia, la parte che tocca a' letterati et alle persone d'alto intelletto nella cognizione delle cose che si hanno da figurare, come ora meglio con gli esempi dichiareremo.

Cominciandosi dunque dal primo, diciamo che, essendo la pittura arte d'imitazione e che sta tutta nel rassomigliare le cose naturali o artificiali o imaginarie al vivo o al vero, come altrove si è detto, è necessario, a chi vuole onoratamente essercitarla, possedere intieramente l'arte chiamata del disegno, che da alcuni è detta l'anima della pittura e fondamento prin [p. 499] cipale di quest'arte. Laonde chi per lungo tempo in ciò non serà essercitato e non avrà perseverato sotto la disciplina di buoni maestri, a quelli prestando fede e volentieri admettendo le loro correzzioni, né avrà in teorica e pratica conseguito quanto è di mestiero, indarno s'affaticarà in leggere questo nostro trattato, né con l'osservanza intiera di ciascuno degli abusi già detti, e di tutte l'altre cose che negli altri libri s'aggiongeranno, si persuada già mai di poter giongere a grado alcuno d'eccellenza. Sotto il qual nome di disegno comprendiamo tutte le cose che i periti dell' arte sogliono intendere, la prospettiva, i scurci, l'ombre, le superficie, i lineamenti, la ragione de' siti, le lontananze, i moti, i contorni, i rilievi, le proporzioni, le varietà de' corpi, il colorire, il fare modelli di cera e di terra, et altri loro ammaestramenti, necessarii da sapersi in tutti i soggetti che possono occorrerli, di uomini, d'animali, piante, città, paesi, chiese, vestimenti, artificii et altri. E però ricordiamo che primamente procuri il pittore che l'opera sua in questa parte non abbia opposizione alcuna e che da quei dell'arte ne venga affatto commendata.

Dopo' questo dovrà aver l'occhio il pittore di sodisfare alle persone erudite in quella professione di che serà il soggetto suo, o sia di materie ecclesiastiche, o istorie profane, o cose naturali, o artificiali, o altre; perché si ritrovano alcuni eccellenti nel disegno e nel colorire, che, per essere imperiti di lettere, né consigliandosi nell'opere sue con persone ben versate negli studii di quella professione, fanno errori notabili ora nell'istoria, talora ne' siti dei luoghi, talora negli abitanti, nei tempi, nella specie d'animali et in diverse altre cose di sopra da noi raccontate, che diligentemente si avranno da osservare; perché, essendo veduta simile pittura da persone letterate e di giudicio, de' quali principalmente si ha da tenere conto, essendo quelli ch'insegnano ad altri, non possono fare che non le biasimino, il che leva il credito a quell'opera e resta il pittore in concetto di non sapere se non copiare, e non essere abile da sé stesso a cose che siano ben fondate; non altrimente che si faccia l'imperito nocchiero, che col pe [p. 500] doto guida sicuramente la nave, ma da sé stesso, non avendo cognoscimento né del golfo, né de' scogli ascosi, né del paese dove si trova, al fine fa naufragio e si sommerge.

La terza sorte di persone, a chi necessariamente si ha da sodisfare, sono gl'idioti, che è la maggior parte del popolo, per servizio de' quali principalmente furono introdotte le pitture sacre; onde, se essi ancora non restano, quanto comporta la capacità loro, appagati, non si conseguisce in gran parte quello che si dovria. Peroché sappiamo noi bene ch'essi, riguardando le pitture non minutamente ciascuna da sé, ma tutte amassate insieme, come scrisse Plutarco ${ }^{1095}$, spesse volte sogliono lodare più un'opera mediocre o rozzamente fatta, che un'altra di eccellente mano; né per

\footnotetext{
1095 De gen. Socr., p. 575 b.
} 
questo intendiamo che il pittore debba rimettere punto della dovuta industria e diligenza, né essere meno compito nelle cose sue, ma diciamo che desideraressimo ch'accompagnasse l'uno e l'altro e che con l'artificio et accuratezza del disegno, e col fare l'opere sue ben finite, aggiungesse ancor quella grazia tanto commendata da Apelle ${ }^{1096}$; onde con la vaghezza e varietà de' colori, or chiari, or scuri, or delicati, or rozzi, secondo la qualità de' soggetti, e con la diversità d'ornamenti, leggiadria de' paesi, dove il luogo comporta, et altre belle invenzioni traesse gli occhi degl'imperiti a rimirarle.

Non diciamo però che, per piacere a simil sorte di persone, s'abbia da lasciare indurre a rappresentare danze lascive, devoratori o ebrii, o altre sorti d'intemperanze; ma più tosto che, stando sempre col decoro e dignità del soggetto, cerchi di accompagnare l'opera sua con quelle cose che più sogliono dilettare agli occhi popolari, e tra l'altre procuri che quello che vuole rappresentare imiti vivamente il vero, talché, se è possibile, resti ingannata la vista loro con la somiglianza, sì come, oltre varii esempii che si leggono anti [p. 501] camente $^{1097}$, parlando quel poeta ${ }^{1098}$ di una cagnuola dipinta e paragonata con la vera, disse:

\section{Pictam Publius exprimit tabella, \\ In qua tam similem videbis Issam, \\ Ut sit tam similis sibi nec ipsa. \\ Issam denique pone cum tabella: \\ Aut utramque putabis esse veram, \\ Aut utramque putabis esse pictam.}

Dipoi, che la pittura abbia seco quella maggior chiarezza che si può e, dove accade, sia distintamente compartita, talmente che chi la riguarda, sùbito con poca fatica riconosca quello che si vuol rappresentare; e quando pure la materia sia tale, che non sia così volgare e nota ad ogni uomo, almeno sia talmente espressa e compartita, che quegli di maggior intelligenza ne possano commodamente instruire gli idioti.

Resta l'ultima qualità di persone, che noi chiamano spirituali, il qual nome dovria abbracciare universalmente tutti i cristiani, che, privilegiati del sacro battesimo et illuminati per la fede, dovriano in tutte le cose avere un sentimento interno che gli stimolasse al cielo. Ma il peso di questa carne e la corruzzione umana è così grande, che molti non mirano altro che quello che agli occhi apparisce e col pensiero non penetrano più oltre, né cercano imitare gli animali chiamati nella Legge sacra mondi ${ }^{1099}$, di che era proprio il ruminare i cibi.

Sì che, essendo gli uomini composti di due sostanze, carne e spirito, chiamiamo quelli spirituali, che più si danno all'impresa dello spirito et applicano le cose esteriori all'interiori, e diciamo sensuali quelli che principalmente abbracciano le cose del senso et in quello si fermano.

Essendo dunque le pitture sacre principalmente per lo spirito, necessariamente conviene ch'aggradischino quello, o, [p. 502] per dire meglio, che siano formate con tali segni di religione e santità, che quegli che già hanno fatto l'abito nello spirito e si chiamano spirituali, vedendole, se ne compiacciano come di cosa a loro proporzionata; e gli altri, mirandole et accorgendosi di essere loro dissimili, si compungano e si destino a qualche principio di devozione.

\footnotetext{
1096 Plinio, Nat. hist., XXXV, 10.

1097 Plinio, ibid.

1098 Marziale, I, 109, 18 ss.

1099 Levit., 11, 3.
} 
Laonde è grandemente da deplorare l'abuso che corre così gagliardamente per l'opere della maggior parte dei pittori, che, intenti solo al magnificare sé stessi et al desiderio della propria eccellenza, pigliano nelle imagini sacre tutte le occasioni che possono di mostrare l'industria et artificio suo, non si curando punto di pensare se ciò fa a proposito di colui c'ha da riguardare essa imagine, o al luogo dove ella va posta, che è tempio d'Iddio, o al fine per che fu instituito il formare le imagini sacre. E nientedimeno Vitruvio, maestro loro, lasciò pur scritto ad essi per memoria in varii luoghi ${ }^{1100}$, che gli edificii, gli ornamenti e le pitture doveano essere accomodate ai luoghi et a' soggetti delle cose; e Platone ${ }^{1101}$, parlando de' pittori, antepone quegli agli altri, che, oltre la perizia del rappresentare, avranno riguardo al fine, alla natura et all'uso della cosa che vogliono figurare. Ma da questa loro ingordigia di laude propria e desiderio di farsi celebri al mondo scorrono in un altro errore grandissimo e totalmente contrario alla professione dell'arte, peccando notabilmente nella imitazione; imperoché, dipingendo imagini de' santi, che furono astinentissimi e macerati da digiuni e lacrime, dove dovriano formarli con faccie macilenti et estenuate, essi li rappresentano con viso morbido et altiero; e dove quelli furono sempre onestissimi e che mai non si lasciorono vedere scoperta parte alcuna del corpo che non convenisse, essi li formano con le gambe e spalle ignude, e peggio; e dove i medesimi santi, pieni di modestia et umiltà, appena ardivano alzar gli occhi da terra, essi li figurano con aspetti e gesti e moti più che licenziosi, dicendo che così meglio fanno cono [p. 503] scere l'arte et ingegno loro nell'imitare l'antichità: non si avedendo essi che altro è il pingere una Venere, un Marte, una Cleopatra, un Tiberio, rappresentati ad atti mondani, et altro è il dipingere i santi e sante, tutti intenti ad atti religiosi. Et è da credere che, se gli antichi avessero avuto a dipingere col fine che a noi è proposto, avrebbono fatto pitture di modestia veneranda e piene di mirabile divozione. In somma, si trova oggi questa parte tanto abusata ancor da molti, che sono stimati valentissimi, che non potiamo non incaricarne loro la conscienza e ricordarli l'esempio d'un devotissimo pittore dei nostri tempi, che inanzi si mettesse a formare l'imagine d'alcun santo, leggeva diligentemente la sua vita e dal concetto appreso delle virtù sue cercava poi di rappresentarlo tale, che, vedendolo, si movea a compunzione e gli altri eccitava a divozione. Intorno a che avendo noi in altro luogo da ragionare più a lungo della vita et obligo del pittore ${ }^{1102}$, ora soprasederemo, aggiungendo solo che, per assicurarsi meglio il pittore delle opere sue, che riescano conformi agli avertimenti già detti, prudentemente farà rivedendole con interposti tempi, innanzi che vi ponga l'estrema mano, secondo che Plutarco ne ammaestra ${ }^{1103}$. Et anco, con l'esempio d'Apelle, che, in esse sottoscrivendo Apelles faciebat, le esponeva al giudicio del popolo, ascoltando quel che ne diceva ${ }^{1104}$, così dovrà esso farle prima considerare da diversi giudiciosi $\mathrm{e}$ privi d'adulazione, acciò ne riporti il dovuto premio da Dio e dagli uomini. Il che serà il fine di questo capitolo e del presente libro.

\footnotetext{
${ }^{1100}$ I, 2. 7; IV, 5; VI, 1. 5; VII. 5.

1101 Respubl., X.

1102 L. V.

1103 De cohib. ira, p. 452 e.

1104 Plinio, Nat. hist., praef.
} 
[p. 504]

Restano tre altri libri, che si daranno fuori poi al suo tempo; imperoché ancora questi, che al presente si sono stampati, si desiderava che, inanzi si publicassero, fossero per degni rispetti riveduti da altri, oltre la diligenza usatavi da chi ne ha avuto il carico. Si è nondimeno dipoi tollerato che di questi primi dui libri se ne stampino ora alcuni pochi pezzi, non per publicarli, ma per maggior commodità, acciò servano per copia a quegli che avranno da rivederli. Laonde, imposta che sarà l'ultima mano a tutta l'opera, si divulgaranno intieramente insieme; e per ora basterà l'indice generale posto di sopra nel principio del trattato per informazione dei lettori.

\section{TAVOLA DEL TERZO LIBRO.}

CAP. I. Delle pitture lascive e non convenevoli all'onestà, che è il soggetto del presente libro.

CAP. II. Della grande inclinazione che tiene la natura nostra nei vizii della carne, et onde nasca questo.

CAP. III. In che cosa consista la disonestà e che regola abbiamo per conoscerla.

CAP. IIII. Quanto la disonestà sia dalla natura, dalle leggi e da Dio aborrita.

CAP. V. Dei danni che seguono dalla brutezza e lascivia.

CAP. VI. Di varie cause onde deriva questo vizio di lussuria e di che si nudrisce. [p. 505]

CAP. VII. Che uno de' principali mezzi, onde s'introduce dentro di noi la lascivia, si è il senso dell'occhio.

CAP. VIII. Quanta ruina all' anima abbia talora apportato uno incauto aspetto.

CAP. VIIII. Come la miseria universale del mondo ebbe la principale origine dal vedere e riguardare.

CAP. X. Della forte impressione che dentro di noi si causa dalle cose che si rimirano con gli occhi.

CAP. XI. Come le statue et imagini d'uomini e di donne hanno sopra le altre grande efficacia per muovere i sensi nostri.

CAP. XII. Della custodia da tenersi assiduamente agli occhi, perché non mirino cosa lasciva.

CAP. XIII. Autorità de' gentili, i quali hanno biasimato le disoneste imagini.

CAP. XIIII. Autorità de' santi Padri, che hanno biasimato l'istesso.

CAP. XV. Autorità de' concilii, che hanno dannato il medesimo.

CAP. XVI. Delle figure ignude, e quanto dagli occhi casti debbono essere schifate.

CAP. XVII. Varie ragioni perché non si convengano le figure ignude.

CAP. XVIII. Autorità et essempi contro l'abuso del formare imagini ignude.

CAP. XVIIII. Quai santi et in che maniera si possano in alcuna parte rappresentare nudi.

CAP. XX. Che non si deve, per imitare li corpi al vivo, spogliarli ignudi.

CAP. XXI. Che in niun modo sotto forme de' santi si dipingano faccie de' giovini o giovine lascive, né anco d'altre persone particolari.

CAP. XXII. Opposizioni de' pittori per iscusarsi dal dipingere imagini ignude o lascive o con atti poco onesti.

CAP. XXIII. Risposta alle obiezzioni de' pittori.

CAP. XXIIII. Altre risposte per dimostrare che nessuna ragione può scusare i pittori nel dipingere cose disoneste e lascive.

CAP. XXV. Che l'artificio del pittore bene si può mostrare nelle figure vestite, e secondo alcuni meglio che nelle ignude. 
CAP. XXVI. Effetti perniciosissimi, narrati dagli autori, che sono seguiti dalle imagini lascive. [p. 506]

CAP. XXVII. Per che causa si tolerano le meretrici e non si permettino le pitture disoneste.

CAP. XXVIII. Quanto bene et utile può causare al mondo un pittore amico dell'onestà e della divozione.

CAP. XXVIIII. Quanto danno derivi da un pittore licenzioso e poco amico della onestà.

CAP. XXX. Conclusione delle cose sopradette, con laude dei pittori onesti e biasimo de' disonesti.

\section{TAVOLA DEL QUARTO LIBRO.}

CAP. I. Delle pitture particolari di tutti i santi, secondo l'ordine delle litanie.

CAP. II. Della pittura di Dio Padre.

CAP. III. Della pittura di Dio Figliuolo, ch'è Cristo salvator nostro. - D'alcuni suoi santi misteri, e prima della natività del Signore. - Della circoncisione et imposizione del nome Iesus, e come questo nome di [sic] debba formare o dipingere. - Della adorazione dei Magi. - Della presentazione nel tempio. - Della fuga in Egitto. - Della disputa nel tempio, quando fu smarrito dal padre e dalla madre. - Dell'infanzia del Salvatore, e resto dell'età fino alli 33 anni. - Della figura e faccia di nostro Signore. - Delle nozze in Canna di Galilea. - De' varii miracoli fatti dal Salvatore. - Dell'entrata in Ierusalem e solennità delle palme. - Della cena del Signore. - Della Maddalena, quando bagnò con le lagrime i piedi al Signore. - Del lavare i piedi agli Apostoli. Delle battiture e della corona di spine. - Della crucifissione del Signore. - De li ladroni e Calvario. - Del sepolcro e custodia. - Della unzione delle Marie. - Del sudario o sindone, in che fu involto il corpo del Signore. - Della resurrezzione et apparizione del Signore. Dell'ascensione. - Della Pentecoste.

CAP. IIII. Della pittura d'Iddio Spirito Santo.

CAP. V. Della pittura della santissima Trinità.

CAP. VI. Della pittura della gloriosa Vergine madre d'Iddio. - Della sua concezzione e natività. Della annonciazione. - Della visitazione. - Della forma, abito e statura della beata Vergine. Dello spasmo presso la croce. - Della morte, assonzione e coronazione della Madonna. - Delle imagini che oggi si tengono fatte [p. 507] da S. Luca. - Della miracolosa e sacratissima casa della Madonna di Loreto.

CAP. VII. Delle pitture degli Angeli, e loro abito et insegne. - Dell'angelo Michele. - Dell'angelo Gabriele. - Dell' angelo Rafaele.

CAP. VIII. Delle pitture dei Patriarchi e Profeti. - Di Adamo et Eva. - Di Abraamo, Moisè e David. - Di S. Giovanni Battista.

CAP. VIIII. Delle pitture degli Apostoli, e loro abito et insegne. - Di S. Pietro. - Di S. Paolo. - Di S. Andrea. - Di S. Giacomo. - Di S. Giovanni. - Di S. Tomaso. - Di S. Giacomo minore. - Di S. Filippo. - Di S. Bartolomeo. - Di S. Matteo. - Di S. Simone. - Di S. Tadeo. - Di S. Mattia.

CAP. X. Delle pitture degli Evangelisti, e loro abito et insegne. - Di S. Matteo. - Di S. Marco. Di S. Luca. - Di S. Giovanni.

CAP. XI. Delle pitture dei santi Innocenti.

CAP. XII. Delle pitture dei Martiri, e loro insegne e varii martirii. - Di S. Steffano. - Di S. Lorenzo. - Di S. Vicenzo. - De' SS. Fabiano e Sebastiano. - De' SS. Gioanni e Paolo. - De' SS. Cosimo e Damiano. - De' SS. Gervasio e Protasio. - De' SS. Vitale et Agricola. - Di S. Proculo, 
uno de' protettori di Bologna.

CAP. XIII. Delle piture dei Confessori, e loro abito et insegne. - Dei Confessori pontefici. - Di S. Silvestro. - Di S. Gregorio. - Di S. Petronio vescovo e protettore di Bologna. - Di S. Ambrosio. Di S. Agostino. - Di S. Ieronimo. - Di S. Martino. - Di S. Nicolò.

CAP. XIIII. Delle pitture dei Confessori non pontefici. - Di S. Benedetto. - Di S. Antonio. - Di S. Bernardo. - Di S. Domenico, uno dei protettori di Bologna. - Di S. Francesco, uno de' protettori di Bologna.

CAP. XV. Delle pitture delle Vergini et altre sante. - Di S. Maria Maddalena. - Di S. Agata. - Di S. Lucia. - Di S. Agnese. - Di S. Cecilia. - Di S. Caterina. - Di S. Anastasia.

CAP. XVI. Della imagine del Paradiso.

CAP. XVII. Del Limbo, Purgatorio et Inferno.

CAP. XVIII. Della imagine del Demonio.

CAP. XVIIII. Della imagine del giudicio estremo.

[p. 508]

\section{TAVOLA DEL QUINTO LIBRO.}

CAP. I. Alcuni avertimenti alli curati nel fare dipingere le loro chiese, oratorii o capelle.

CAP. II. Che nelle pitture sacre vi convengono ornamenti d'oro e preziosi et altre cose per maggiore venerazione.

CAP. III. Essempii degli antichi, che ornavano le chiese de imagini sacre di pittura, di scultura, mosaico et altri preziosi artificii.

CAP. IIII. Dei luoghi dove si conviene o non conviene mettere imagini sacre, e dello inganno degli eretici intorno a ciò.

CAP. V. Dei voti che si offeriscono nelle chiese, e quello che intorno a ciò si dovria servare.

CAP. VI. Dell'altre cose, come armature, insegne militari, galere, crocodrilli, corna de' cervi, onocrotali, ova de struzzi, animali stranieri, et cose simili, se si convengono nelle chiese.

CAP. VII. Delle sepolture de' morti e pitture loro.

CAP. VIII. Degli oratorii, capellette, croci, et altre pitture sacre che si fanno fuori delle chiese maggiori, nelle strade o altri luoghi publici, dentro e fuori delle città.

CAP. VIIII. Delle canoniche et abitazioni de' curati.

CAP. X. Dei monasterii de' religiosi, claustri, refettorii, luoghi dei capitoli e celle private.

CAP. XI. Del modo di dipingersi gli ospitali, le confraternità et altri luoghi pii, e dei loro stendardi et insegne.

CAP. XII. Come i palazzi de' magistrati, le sale publiche delle audienze et i luoghi de' consigli si avriano da ornare.

CAP. XIII. Del modo di dipingere le academie publiche, librarie e luoghi de' studii.

CAP. XIIII. Degli ornamenti di pitture intorno agli archi, trofei et altri apparati per onorare prencipi, per trionfi et allegrezze publiche.

CAP. XV. Avertimenti nel figurare piante, arbori, ucelli, pesci, animali e cose simili.

CAP. XVI. Come si avriano da ornare di pitture le osterie dentro le città e fuori.

CAP. XVII. Le case particolari di ciascuno, come acconciamente si potriano dipingere. [p. 509]

CAP. XVIII. Che ogni casa capace, così nelle città come nelle ville, devria avere alcuno oratorio o capella per servizio della famiglia.

CAP. XVIIII. Delle imagini antiche, cancellate dal tempo et oscurate, quello che intorno ad esse 
si dovria osservare.

CAP. XX. Della pena di quei che fanno ingiuria alle imagini, et a qual giudice questa cognizione appartenga.

CAP. XXI. Avertimenti generali alli pittori per fare le pitture sue cristianamente e giudiciosamente.

CAP. XXII. Se è lecito il giorno di festa dipingere alcuna imagine sacra per servigio delle chiese.

CAP. XXIII. Di quello che dovrebbe fare un pittore cristiano per lo avenire, volendo essercitare come si deve l'arte sua.

CAP. XXIIII. Degli errori molti e gravissimi, in che incorrono i mali pittori.

CAP. XXV. Modo di confessarsi per li pittori, con alcune interrogazioni, acciò meglio sappiano conoscere i falli et iscaricare le conscienze loro.

CAP. XXVI. Quello che dovrebbono fare i superiori, così spirituali come temporali, i padri di famiglia, i capi dell'arti, e ciascuno in quanto può, per svellere gli abusi delle imagini.

CAP. XXVII. Della diligenza da usarsi in varie sorti d'artefici che si servono dell'uso delle figure, come stampatori, vetrari, orefici, intagliatori, vasai, e quei che fanno scattole, specchi, ventarole, spalliere di cuoio, panni di razzo, ricamatori, tessitori et altri artefici, acciò si levino infiniti abusi loro.

CAP. XXVIII. Ordine da tenersi per lo avenire nella città e diocese di Bologna intorno a tutte le sorti di figure, così nelle chiese come negli altri luoghi.

CAP. XXVIIII. Autori che hanno scritto delle imagini e delle pitture e sculture, secondo varie professioni.

CAP. XXX. Conclusione di tutta la presente opera, con alcuni avertimenti ai lettori. 
[p. 511]

\title{
AVVERTIMENTI DEL DOTTORE ALDROVANDI
}

\author{
ALL'IlL.MO E R.MO CARDINAL PALEOTTI \\ SOPRA ALCUNI CAPITOLI DELLA PITTURA.
}

Ill.mo e R.mo Monsignore e Principe mio colendissimo.

Ho letto gli altri capitoli sopra la pittura mandatimi e sono dell'opinione di V. S. Ill.ma, che l'origine della pittura sia antichissima, vedendo che non ci è quasi cosa veruna al mondo, che del disegno, vero fondamento della pittura, non abbia bisogno, essendo ella il fiore di tutte l'altre arti. Ma che sia anteriore ai libri si potria molto dubbitare, attentoché Plinio dice che le lettere assirie sono state sempre ${ }^{1105}$. Oltra di questo, per testimonio di Epigene, autore gravissimo, testifica il medesimo che appresso i Babilonii furono scritte in mattoni cotti l'osservazioni delle stelle di settecento anni; ancorché Beroso e Critodemo dicano solamente di quattrocento ottanta anni. Laonde si vede che sempre fu l'uso delle lettere, né così potiamo dire della pittura.

Scrivono alcuni istorici che Seth, figliuolo di Adamo, scrisse la scienza dell'astrologia in due colonne: una delle quali, essendo presago che il mondo avea a perire, era construtta di mattoni, accioché dal fuoco non fosse danneggiata; l'altra fece di pietra soda, acciò dall'acqua non fosse rovinata. E tutto questo fece a fine che in tutti i modi la scienza de l'astrologia restasse perpetua. Io sono di parere che questi mattoni, de' quali fa qui menzione Plinio, altro non sia che la colonna di Seth, che parimente di mattoni fu fabricata; la qual per testimonio di Gioseffo si [p. 512] trovava, ancora al suo tempo, in Soria, quantunque il Cedreno ${ }^{106}$, citando il medesimo autore, dica 'nel

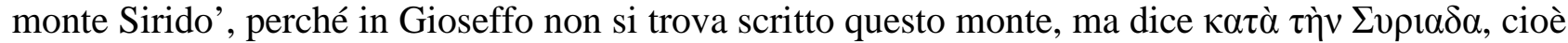
'in Soria'. Et è facil cosa che Cedreno per Syriada abbia scritto Sirido, tanto più che cita il medesimo autore. Questo medesimo Seth fu quello che prima trovò e scrisse lettere ebraiche; a cui, essendo rapito dall'angiolo, fu rivelata la futura impietà de' suoi posteri e l'avenimento del Salvatore dell'universo ${ }^{1107}$.

L'arti conservative della memoria che si può lasciare a' posteri sono lo scrivere, il dipingere, lo scolpire, il fondere; fra' quali essendo lo scrivere et i libri più conservativi della memoria e più universali di tutte l'altre arti che la memoria delle cose conservano, è adunque verisimile che siano più antichi che il depingere, e che devono esser più lodati, attentoché per la memoria in longhezza di tempi si conserva ogni sorte di scienza e sapienza nella mente degli uomini. E questo, come ho detto, molto meglio sì fa per i libri e lo scrivere, che per pitture o altre arti, sì come copiosamente ho trattato nel primo libro della mia Biblologia, scritta ora all'ill.mo sig. Camillo, fratello di V. S. Ill.ma, parlando dell'antichità delle lettere avanti si scrivesse e si ritrovasse l'uso della carta del papiro, pianta nobilissima del Nilo in Egitto.

Vengo ora al decimoquinto capitolo della Pittura, dove V. S. Ill.ma con belle ragioni mostra l'utilità grande che le pitture al mondo apportano. E dico, in conformazione di questo, che non ci è

\footnotetext{
1105 Nat. hist., VII, 56.

1106 Giorgio Cedreno, Compend. hist., p. 6 (Xyl.).

1107 Ibid., p. 7.
} 
cosa al mondo che meglio possa rappresentare tutte le cose dal grande Iddio prodotte, che la pittura istessa per mezzo della varietà de' colori, i quali dalla varia mistione di quattro elementi in tutti i corpi misti si veggono, essendo il colore oggetto proprio del vedere, come dice il Filosofo, non si potendo vedere cosa alcuna, se non in quanto è colorata. Il colore veramente è un accidente nelle cose, che dà gran giovamento a intendere le sostanze. Diceva Aristotile, quod accidentia maxime conferunt ad quod quid erat esse. Questo colore è un accidente inseparabile dalla sostanza, senza la cui notizia non si può venire alla [p. 513] cognizione di quel misto, essendo scala e mezzo, insieme con gli altri accidenti, in conseguire la cognizione perfetta di ciascuna specie; le quali per mezzo delle prime sostanze, chiamate individui, si conoscono, e sono dette sostanze seconde, che sono oggetto dell'intelletto; e le prime sono oggetto del senso del vedere, come colorate, non altrimenti. Quanto sia necessario accidente il colore quindi è manifesto, che non ci è cosa in questo mondo basso, che non abbia bisogno di esser descritta e depinta mediante i colori, avanti si possa conseguire la cognizion d'essa.

Per isperienza si vede quanto giovamento alli studiosi apportano le pitture di varii animali, come d'occelli, pesci, ceti, serpenti; animali quadrupedi, ovipari e vivipari. Sì come anco veggiamo nella pittura degli animali essangui, come sono gli insetti, crustacei, testacei et altri chiamati dal Filosofo malachia; e parimenti i zoofiti, nominati piantanimali, sì come si può vedere nelle mie istorie e nelle mie figure, dove ho depinti al vivo insino a tre mila animali diversi. Per mezzo di queste pitture, insieme con l'istorie, ponno li studiosi venire in piena cognizione, quali fossero appresso gli antichi. La qual utilità è tanto grande, che non si può imaginar maggiore, perché, se gli antichi avessero fatto ritrare e depingere tutte le cose che hanno descritte, non si trovarebbe tanti dubii et errori infiniti appresso i scrittori. Dove lasciarò le piante, depinte parimente al vivo, che tanta utilità apportano agli medici, conoscendo per mezzo della pittura le piante istesse dalla natura all'umano beneficio prodotte? Dalle cui parti (o siano fiori, frutti, semi, radici o foglie; legni, scorze, lacrime, come resina e gomma, o sughi e liquori) si pigliano tanti varii rimedii per indurre la sanità perduta, come ancora per conservarla. Sapendo Euace, re degli Arabi, quanto giovamento portava la pittura delle piante, fu il primo che dipinse in un libro varie piante e per cosa regia lo mandò a donare a Nerone imperatore.

Dio volesse che gli antichi prìncipi e monarchi, come fu Alessandro Magno, e tanti altri scrittori, come Aristotele, Teofrasto e Cratina, tanto amico del nostro divino Ippocrate, avessero fatto dipingere le piante et animali che da loro descritti furono! Ché certo non ci saria oggi tanta difficoltà in conoscerli. Però è di gran laude degno il serenissimo Gran Duca di Toscana, il quale tiene appresso di sé un eccellentissimo pittore, che giorni [p. 514] e notti non attende ad altro che a depingere piante et animali di varie sorti e particolarmente delli peregrini, come se ne può vedere appresso di me alcune figure d'uccelli venuti dall'Indie, donatemi da S. A. Serenissima insieme con li ritratti nati di duoi serpenti apportati d'Africa; li quali animali sì leggiadramente con mirabile artificio sono formati e depinti, che altro non li manca che lo spirito, tanto sono fatti dal naturale. Grand'obligo certamente hanno d'avere i studiosi a S. A., che in questa e mille altre maniere illustra le cose naturali. Piacesse a Dio che il Re Catolico, per la gran commodità che ha dell'Indie Orientali et Occidentali (avendo ora impero sopra l'amendue per la vittoria conseguita), facesse dipingere in quei regni, agli antichi scognosciuti, tutte le cose naturali che ivi si trovano, mandando per questo effetto varii uomini dotti insieme con pittori perfettissimi, per poter dipingere ciascuna cosa secondo il suo esser naturale. Guaynacapa, re del Cusco, fu di tanto grand'animo e tanto si dilettò delle cose di natura, che nella sua guardarobba, tra infinite statue grandissime d'oro, che parevano giganti, avea ancora le figure, fatte con la grandezza naturale, di tutti gli animali quadrupedi de' quali avea notizia, e parimente di tutti gli uccelli, sì come ancora degli arbori e piante che la terra 
produceva; similmente di quanti pesci erano nel mare, fiumi et altre acque de' suoi regni; e tutte queste cose erano fatte e formate d'oro e d'argento. Se un prencipe barbaro avea tanto grand'animo, che volse far formare tutte le cose naturali, dal grand'Iddio a l'uso umano prodotte, d'oro e d'argento; quanto maggiormente i prìncipi cristiani, che sanno quel detto di S. Paulo che invisibilia Dei per ea quae visibilia facta sunt cognoscuntur, doveriano far dipingere tutte le cose che ne' suoi regni dalla natura continuamente sono prodotte! che sarebbe molto minor spesa di quella che fece il sudetto prencipe barbaro in simil impresa. E certamente, si questo facessero, non solo ne nascerebbe grand'utilità al genere umano, ma anco per questo verrebbesi a conoscere maggiormente la grandezza di Dio creatore di tutte le cose, e conseguentemente ne resultarebbe onore a la bontà divina per le debite grazie renduteli, che tante cose varie et infinite per le sue creature abbia prodotte, e di continuo produce, non cessando mai di operare, per esser atto puro et infinito.

Doppo aver discorso forse troppo a longo sopra il decimo [p. 515] sesto capitolo, vengo parimente al 26, dove molto dottamente mostra V. S. Ill.ma i varii e diversi effetti che dalle pie e divote imagini causar si possano. A questo proposito adunque non restarò di dirle di quella statua di Venere Gnidia, di marmo palio formata, la qual fu collocata nel suo tempio, sì come testifica Luciano $^{1108}$, e fu tanto bella che fece quasi impazzire Caricle, vedendo che egli, quando la vidde, disse: «O fortunatissime deorum Mars, qui propter hanc victus fuisti!»; et accorrendo la baciò a piene labia, stendendo quanto più gli era possibile il suo collo. E dalla bellezza di questa statua impazzito, stando tutto il giorno in quel tempio, subito levato correva a quella et ogni ora più s'accendeva il suo amore verso tanto bella e graziosa statua. E se una statua di marmo scolorita faceva questo effetto, che dovranno poi fare le colorite e dipinte al vivo?

Ho cercato con grandissima diligenza i duoi luochi cittati da S. Girolamo, dove dice: Venerabantur etc., e parimente quel verso di Virgilio: Sic pater etc.; ma mai ho potuto trovare alcune di queste autorità, ancorché S. Girolamo citi questo poeta in più di venti luoghi, che ho voluto vedere tutti per trovare questi duoi, ma mi sono affaticato in ciò indarno. Circa il terzo luoco, dove desidera sapere V. S. Ill.ma qual autore faccia menzione di Pausone pittore, che aveva depinto in una tavoletta un cavallo corrente col freno, per il che essendosi sdegnato il patrone che l'avea fatto fare e dimandando perché ci avesse aggionto il freno, rispose che in sì angusto spazio era stato necessario di metter il morso alla bestia, perché non traboccasse; non mi ricordo aver mai letto appresso antichi né moderni (fra' quali è stato Georgio Vassario, che parla delle vite di pittori, sì come anco l'Ariosto nel XXXIII canto ne descrive molti, antichi e moderni, ma di questo non fa menzione) che sia stato alcun pittore che si chiamasse Pausone. Vo pensando se per sorte fosse Arrigo di Pannone, conte di Verafio e duca di Buoiano, il qual in molte parti delle sue rocche fece dipingere dal vivo i più belli et aggraditi cavalli che da le sue razze gli uscivano. Potrebbe essere che questo nome di Pannone fosse corretto in Pausone, ancorché io sia d'opinione che più presto voglia dire Pausia che [p. 516] Pannone o Pausone, attento che Plinio ${ }^{1109}$ fa menzione di molti eccellenti pittori, fra li quali parla di Pausia Sicionio, chiamato così dalla patria, che per lungo tempo, come il medesimo Plinio testifica, fu chiamata patria di pittura; e tanto più lo credo, sapendo che Pausia si dilettava di depingere in tavolette, sì come nel portico di Pompeo dipinse i sacrifici de' bovi. Scrisse parimente fra l'altre opere sue una battaglia a cavallo, fece medesimamente un'altra figura in Efeso, nella qual era un Ulisse che finse d'esser pazzo mettendo ad un giogo un bue et un cavallo. Che questo Pausia si dilettasse di dipingere tavole lo testifica il medesimo Plinio ${ }^{110}$

\footnotetext{
1108 Amores.

1109 Nat. hist., XXXV, $10 \mathrm{~s}$.

${ }^{1110}$ Nat. hist., XXI, 2.
} 
parlando delle ghirlande, così dicendo: «Quando si facevano di fiori, percioché quelli erano intrecciati, allora si chiamavano serv[i]e; ma ciò non è molto antico appresso de' Greci, i quali usorono prima far ghirlande di rami d'arbori ne' giuochi sacri, poi cominciorono a variare con misture di fiori, e la città di Sicione cominciò ad accendere i colori e gli odori de' fiori, e ciò nacque dall'ingegno di Pausia pittore e di Glicera facitrice di ghirlande, alla quale egli volle grandissimo bene, percioché egli nell'opera e componimenti delle sue ghirlande con la pittura l'imitava, et ella, provocandolo, si ingegnava di variare; così veniva a esser un contrasto dell'arte e della natura. Però ci sono ancora sue tavole di tal pittura e massimamente quella che è chiamata Stefanoploco, nella quale egli ritrasse Glicera, e ciò fu doppo la centesima olimpiade». Potria adunque esser stato questo Pausia, che avesse ritratto nella picciola tavoletta quel cavallo corrente con il freno in bocca; perché si vede che era molto ingegnoso e capriccioso, come da alcune delle sudette sue pitture si può comprendere. E se non è questo, non saprei dire chi fosse questo Pausone.

Non restarò di dire a V. S. Ill.ma, per compimento del capitolo delle grotesche, sopra le quali alli giorni passati dimandò il mio parere, che pare che Platone avesse notizia al suo tempo di queste grotesche e figure stravaganti, quando nel sesto libro della sua Republica, parlando de' governi,

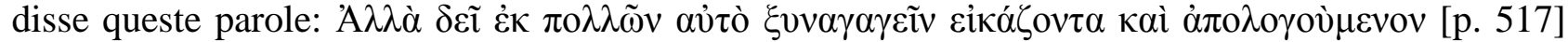

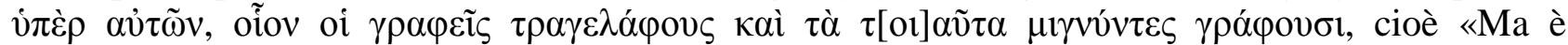
necessario che chi assomiglia et esplica la ragion d'esse, raccoglia questo da molte, a guisa de' pittori, quando dipingono i tragelafi e molti altri simili figmenti». Dalle qual parole di Platone si vede che insino allora si dilettavano i pittori di fare molte pitture a fantasia e per suo capriccio, che in natura non si trovano, sì come sono le grotesche di questi nostri pittori moderni.

Altro per i presenti capitoli non m'occorrendo ora a dire, farò fine. Però con questo, basciando con ogni riverenza le mani a V. S. Ill.ma e R.ma, Le desidero dal sig. Iddio ogni felicissimo successo de' suoi santi desiderii.

Di casa, alli 5 Gen. 1581.

Di V. S. Ill.ma e R.ma umilissimo e divotissimo servitore

ULISSE ALDROVANDI. 